Raphael Carvalho de Vasconcelos

\title{
Teoria Geral do Estado Aplicada à Unidade Sistêmica do Direito Internacional
}

Orientador: Professor Titular Paulo Borba Casella

Faculdade de Direito da Universidade de São Paulo

São Paulo

2014 
Raphael Carvalho de Vasconcelos

\section{Teoria Geral do Estado Aplicada à Unidade Sistêmica do Direito Internacional}

Tese apresentada ao Programa de PósGraduação da Faculdade de Direito da Universidade de São Paulo como requisito parcial para obtenção do título de Doutor. Área de concentração: Direito Internacional. 
Autorizo, apenas para fins acadêmicos e científicos, a reprodução total ou parcial desta tese, desde que citada a fonte. 


\section{Teoria Geral do Estado Aplicada à Unidade Sistêmica do Direito Internacional}

Tese apresentada ao Programa de PósGraduação da Faculdade de Direito da Universidade de São Paulo como requisito parcial para obtenção do título de Doutor. Área de concentração: Direito Internacional.

Tese aprovada em:

Banca examinadora:

Prof. Dr. Paulo Borba Casella (Orientador)

Faculdade de Direito da Universidade de São Paulo

Prof. Dr. Wagner Menezes

Faculdade de Direito da Universidade de São Paulo

Prof. Dra. Mônica Herman Salem Caggiano

Faculdade de Direito da Universidade de São Paulo

Prof. Dra. Carmen Beatriz de Lemos Tiburcio Rodrigues

Faculdade de Direito da Universidade do Estado do Rio de Janeiro

Prof. Dr. Jorge Luiz Fontoura Nogueira

Instituto Rio Branco

Prof. Dra. Nina Beatriz Stocco Ranieri (Suplente)

Faculdade de Direito da Universidade de São Paulo

Prof. Dra. Eunice Aparecida de Jesus Prudente (Suplente)

Faculdade de Direito da Universidade de São Paulo

Prof. Dr. Eduardo Carlos Bianca Bittar (Suplente)

Faculdade de Direito da Universidade de São Paulo

Prof. Dr. Sedi Hirano (Suplente Externo)

Faculdade de Filosofia Letras e Ciências Humanas da Universidade de São Paulo

Prof. Dr. Modesto Florenzano (Suplente Externo)

Faculdade de Filosofia Letras e Ciências Humanas da Universidade de São Paulo 

Ao professor Casella. Já uma lenda do direito internacional. 
À minha mãe, Leia, à Tia Teca e à Tia Tony: sem elas, não seria o que sou.

Ao meu pai, Vital, e à minha avó, Dolores: por estarem sempre presentes de alguma forma.

À Ana Paula: pela paciência. E pela falta dela também.

Às Tias Cema e Iolanda: pelo carinho.

Aos funcionários do Tribunal Permanente de Revisão do MERCOSUL: por tornarem minha vida possível em meio a tantas adversidades.

Aos meus alunos e colegas da Universidade Federal Rural do Rio de Janeiro: pelo apoio, compreensão e entusiasmo.

Aos professores Casella, Carmen, Jacob, Wagner e Fontoura: meus mentores. 
"The trick usually lies in not thinking too hard about whatever you want to do, but just allowing it to happen as if it was going to anyway." 


\section{RESUMO}

VASCONCELOS, Raphael Carvalho de. Teoria geral do estado aplicada à unidade sistêmica do direito internacional. 2014. N $^{\circ}$ f. 316. Tese (Doutorado em Direito) - Faculdade de Direito, Universidade de São Paulo, 2014.

Ultrapassado o debate em torno de seu caráter jurídico, impõem-se ao direito das gentes, na atualidade, perspectivas desafiadoras de seus contornos sistêmicos. Como ponto de partida teórico deste estudo, adotou-se a verificação da natureza dos conceitos utilizados pelas teorias fragmentárias do direito internacional que tendem a desestabilizar sua característica de unicidade. Política e direito conformam preceitos que não apenas interagem, mas muitas vezes se identificam. Propõe-se investigar, para tanto, em que medida o resgate de estruturas jurídico-políticas tradicionais como aquelas da teoria geral do estado poderia contribuir à institucionalização da ordem mundial. O trabalho se realiza sob o método dedutivo-indutivo de pesquisa. A partir das referências teóricas estabelecidas pela teoria geral do estado e de sua aplicação ao direito internacional e às propostas doutrinárias fragmentárias, estabelecem-se marcos particulares, os quais são analisados na busca de constatações mais abrangentes e gerais quanto à relação existente entre política e direito. $\mathrm{O}$ trabalho divide-se em três partes distintas. Na seção inicial, apresentam-se os elementos teóricos que embasam a pesquisa. Busca-se fixar na primeira parte do capítulo inaugural a perspectiva do direito como um sistema e, em seguida, apresentam-se as premissas iniciais da relação existente entre o político e o jurídico. Logo, procede-se à delimitação de conteúdos a conceitos fundamentais ao estudo. No capítulo segundo, concentram-se os esforços no delineamento das idéias de estado e de soberania e em sua importância para o direito das gentes. Propõe-se, no capítulo seguinte, a aplicação das teorias estudadas à compreensão do direito internacional. No mesmo capítulo terceiro, inicia-se a vinculação das teorias da organização do estado à idéia de poder. A questão do poder pauta a parte seguinte do trabalho, que desenvolve o conceito à luz dos exercícios de concreção e de extração de normatividade para, logo, estabelecer paralelos com as funções exercidas pelo estado internamente e, então, aplicar os mesmos conceitos ao contexto internacional. A função jurisdicional merece, finalmente, atenção especial na última parte do capítulo. A pesquisa segue, em sua quinta divisão, à análise das organizações internacionais. A personalidade e a capacidade dos atores da ordem internacional são, então, estudadas e, em uma segunda parte, a importância dos sistemas de solução de controvérsias no exercício de poder por tais estruturas orienta a investigação. Apresenta-se, finalmente, uma nova proposta de classificação para as organizações internacionais no sexto capítulo com base na existência de sistema institucionalizado de solução de litígios. Inaugurando a segunda seção do trabalho, estabelecem-se, no capítulo sétimo, as linhas gerais da relação existente entre as teorizações fragmentárias do direito das gentes e a política para, em seguida, buscarse, no capítulo oitavo, elementos empíricos que comprovem o que se defende em experiências regionais, das quais o Brasil faz parte. A nona parte do trabalho se dedica à análise de como a teoria geral do estado se aplicaria à compreensão do direito das gentes de forma propositiva e, em seguida, de como a função jurisdicional identificada na ordem mundial poderia servir à preservação da unidade do direito internacional. No décimo e último capítulo, apresentam-se argumentos já de caráter conclusivo que sustentam ser a percepção fragmentada do direito internacional mero retrato estático de um processo evolutivo.

Palavras-chave: Direito Internacional Público; Teoria Geral do Estado; Política; Unidade Sistêmica; Fragmentação. 


\begin{abstract}
Considering the debate on its legal character overcome, international law is nowadays confronted with perspectives challenging its systemic character. The examination of the nature of concepts used by the fragmentary theories of international law which tend to destabilize its unity was adopted as a theoretical starting point of this study. Politics and law conform concepts that not only interact, but often equal themselves. It is proposed to investigate to what extent traditional legal structures as those of the general theory of the state could contribute to the institutionalization of international law. The work is performed under the deductive-inductive method of research. From the theoretical frameworks established by the general theory of the state and its use on international law and on the fragmentary doctrinal proposals, particular landmarks are settled, which are analyzed in search of more comprehensive and general conclusions about the relationship between politics and law. The work is divided into three distinct parts. In the initial section, the theoretical elements that outline the research are presented. In the first part of the opening chapter the perspective of law as a system is established and the preliminarily assumptions about the relationship between politics and law are presented. Afterwards, the fundamental contents of important concepts for the study are assigned. In the second chapter, the efforts are concentrated in the concepts of state and sovereignty and its importance to the law of nations. In the following section, the application of the theories studied is proposed to the comprehension of international law. At the same third chapter, the theories concerned with the organization of the state are connected to the idea of power. The questions related to the power compose the main issue of the following part of the work, which develops the concept in light of the legislative and judiciary functions to draw, than, parallels with the functions performed by the state internally and internationally. Jurisdiction deserves, finally, special attention in the last part of the chapter. In the fifth chapter, the research is concentrated on the analysis of international organizations. The personality and the capacity of the actors of the international order are then analyzed, and in a second part, the importance of dispute settlement systems in the exercise of power by such structures is researched. Finally, in the sixth chapter, a new classification of international organizations is proposed based on the existence of institutionalized systems of dispute resolution. Opening the second section of the work, the general lines of the relationship between the fragmentary theories of international law and politics are settled in the seventh chapter and then, in the eighth chapter, evidences of the conclusions established are searched in empirical evidences of regional experiences, of which Brazil is part. The ninth part of the work is dedicated to the analysis of how the general theory of the state applies to the understanding of international law and how the judicial function identified in the world order could preserve the unity of international law. In the tenth and final chapter, arguments already of conclusive character sustain that the fragmented perception of international law conforms a mere static picture of an evolutionary process.
\end{abstract}

Keywords: International Law; General Theory of the State; Politics; Systemic Unity; Fragmentation. 


\section{SUMÁRIO}

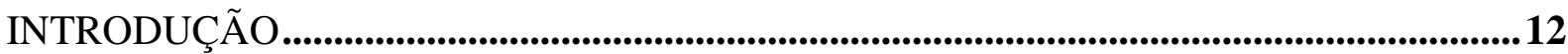

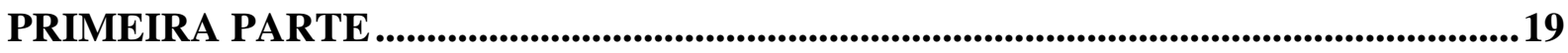

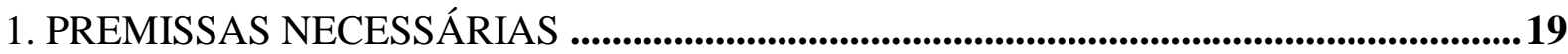

1.1. Direito Internacional e Direito Interno: Direito...............................................................................19

1.2. Direito, Política e Direito Internacional .......................................................................40

1.3. Nomenclaturas: Estabilizando Conceitos ......................................................................48

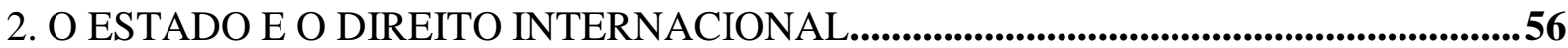

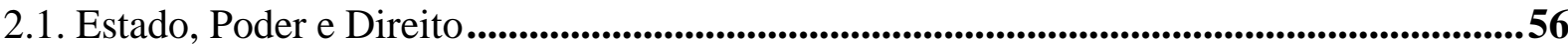

2.2. Soberania, Poder e Direito Internacional..................................................................66

2.3. A Superação da Soberania, a Teoria Geral do Estado e o Direito Internacional..................80

3. A TEORIA GERAL DO ESTADO E O DIREITO INTERNACIONAL .............................87

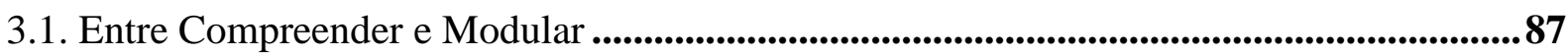

3.2. Poder, Teoria Geral do Estado e Direito Internacional .....................................................999

4. DIREITO INTERNACIONAL, POLÍTICA, TEORIA GERAL DO ESTADO E PODER

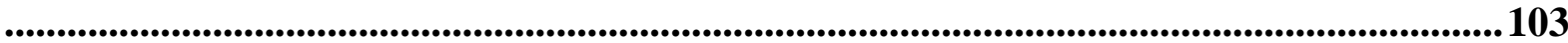

4.1. Concreção, Normatividade e Direito Internacional ..........................................................103

4.2. As Funções do Estado e o Direito Internacional ..............................................................114

4.3. A Organização do Poder Global e os Sujeitos de Direito Internacional ............................123

4.4. Direito e Função Jurisdicional ...........................................................................................138

5. ORGANIZAÇÕES INTERNACIONAIS E TRATADOS ASSOCIATIVOS: PERSONALIDADE JURÍDICA E SOLUÇÃO DE CONTROVÉRSIAS .................................146

5.1. Personalidade, Capacidade e Organizações Internacionais ....................................................146

5.2. A Ordem Internacional, Solução de Controvérsias e Organizações Internacionais .........164

6. ORGANIZAÇÕES INTERNACIONAIS, PERSONALIDADE JURÍDICA E SOLUÇÃO DE CONTROVÉRSIAS: UMA PROPOSTA DE CLASSIFICAÇÃO ......................................170

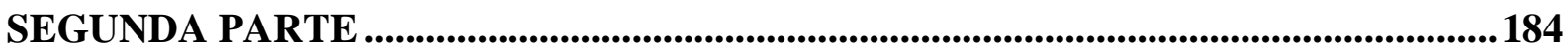

7. A FRAGMENTAÇÃO DO DIREITO INTERNACIONAL E A POLÍTICA .....................184

8. ORGANIZAÇÕES INTERNACIONAIS, O BRASIL E O MERCOSUL ...........................210

9. A TEORIA GERAL DO ESTADO E A COMPREENSÃO DA ORDEM GLOBAL ......223

10. A FUNÇÃO JURISDICIONAL COMO FERRAMENTA DA UNIDADE DO DIREITO INTERNACIONAL ..................................................................................................................248

11. A UNIDADE DO DIREITO INTERNACIONAL, A FOTO E O FILME.......................277 


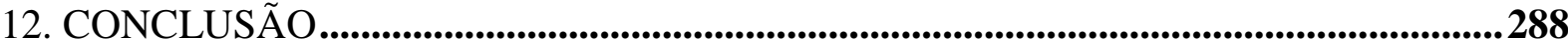
12.1. A Teoria Geral do Estado como Ferramenta à Compreensão do Direito Internacional 292 12.2. A Teoria Geral do Estado e a Unidade Sistêmica do Direito Internacional ....................296 12.3. Considerações Finais ........................................................................................................299

13. BIBLIOGRAFIA …....................................................................................................................302 
"Desse modo, a compreensão se põe como necessidade para qualquer profissional do direito, para caminhar entre os dados técnicos do sistema legal, sem nestes se perder, nem tampouco esquecer o que é, como é, e como deve operar o direito. A compreensão pressupõe que se possa captar o que os outros exprimem e que possamos nos fazer compreender pelos demais. A compreensão, no direito, é indispensável para entender o que se formou e chegou até nós, enquanto conjunto de princípios e regras, com os indispensáveis mecanismos de implementação, bem como para que possamos nos fazer entender, no que cada um diz."

\section{INTRODUÇÃO}

$\mathrm{O}$ direito internacional e seus desafios. O ofício do internacionalista apresenta e sempre apresentou desafios. Questionam-se seus marcos originários, vislumbram-se incertezas relacionadas à sua coerência normativa e mesmo sua condição de direito é colocada freqüentemente à prova. Restaria como grande certeza, talvez, a falta de monotonia da doutrina que se dedica a seu estudo.

Nos dias atuais, ultrapassado o debate em torno de seu caráter jurídico, impõem-se ao direito das gentes perspectivas desafiadoras de seus contornos sistêmicos. Busca-se constantemente fixar parâmetros de ordenação e unidade em uma miríade de sistemas normativos. O direito internacional cresceu em quantidade e densidade, especializou-se e dividiu sua normativa em setores: categorizou-se.

A universalidade jusnaturalista de outrora não se vê mais confrontada apenas com a perspectiva positivista das ordens estatais. Agora, a especialização temática ameaça os dogmas positivistas com a fragmentação e nem mesmo o discurso aberto e fluído dos direitos humanos mostra-se consistente o suficiente para liquidar o debate.

Haveria alternativa teórica hábil a auxiliar o direito das gentes a preservar sua unidade? Se a pluralidade constitui hoje premissa de qualquer estudo que se desenvolva acerca do direito internacional, quais instrumentais teóricos se encontrariam disponíveis para racionalizar sua estrutura dotando-a de coerência e previsibilidade?

Em nenhum momento pretende-se neste trabalho refutar a complexidade da organização do poder e as conseqüências disso para o direito. Elegeu-se, assim, como ponto de partida teórico, a verificação da natureza dos conceitos utilizados pelas teorias

\footnotetext{
${ }^{1}$ CASELLA, Paulo Borba. ABZ - ensaios didáticos. São Paulo: Imprensa Oficial do Estado, 2009. p. 159.
} 
fragmentárias do direito internacional que tendem a desestabilizar sua característica de unicidade.

Política e direito conformam preceitos que não apenas interagem, mas muitas vezes se identificam. A política, como escolha social, está na criação e - hoje definitivamente - na aplicação do direito. Sob perspectiva estrita, contudo, enquanto a política se referiria ao exercício do poder, o direito cuidaria de sua organização.

Busca-se nesta pesquisa demonstrar, em síntese apertada, que a aparente fragmentação do direito das gentes não constituiria alternativa às teorias sistêmicas unitárias e representaria mero traslado equivocado de percepções estritamente políticas ao direito. Propõe-se investigar, para tanto, em que medida o resgate de estruturas jurídico-políticas tradicionais tais como os esquemas publicistas da teoria geral do estado - poderia contribuir à institucionalização do direito internacional.

A proposta estima, ainda, as possibilidades apresentadas, por exemplo, pela utilização de instrumentais teóricos tradicionais à compreensão do desenvolvimento dos sistemas jurisdicionais internacionais de solução de controvérsias. Especificamente, observa-se de que maneira a separação de funções do estado poderia servir de modelo aplicável às organizações internacionais.

Quanto ao debate fragmentário, questiona-se se a repartição sistêmica reconhecida por parte importante da doutrina do direito internacional atual representaria situação jurídica consolidada, a qual, portanto, exigiria verdadeiro abandono do paradigma unitarista moderno ou se consubstanciaria arranjo transitório compatível com algum tipo de construção una ainda que diversa daquela concebida pelo positivismo tradicional.

No que se refere à relevância acadêmica, faz-se necessário, inicialmente, ressaltar que não se pretende em nenhum momento esgotar o tema, mas, na verdade, investigar como fundamentos teóricos da teoria geral do direito e, especificamente, da teoria geral do estado poderiam auxiliar a compreensão do direito das gentes na atualidade.

$\mathrm{O}$ estudo tem como objetivo, desse modo e em um primeiro momento, abordar os aspectos políticos da ordem global envolvidos na discussão entre unidade e fragmentação do direito internacional para diagnosticar até que ponto as teorias estritamente políticas fundamentam posições nesse debate. A partir das conclusões parciais obtidas, estabelece-se como meta verificar se existiriam elementos da teoria do direito hábeis a orientar a percepção da ordem jurídica mundial atual como um sistema de direito, no qual as características de ordenação e unidade estariam preservadas. 
A relevância para a academia estaria no resgate dos instrumentais da teoria do estado e sua aplicação sistemática ao direito das gentes para demonstrar sua unidade. Busca-se comprovar, nessa seara, que as teorias fragmentárias não seriam genuinamente jurídicas e serviriam exclusivamente a abordagens teóricas da organização do poder relacionadas, por exemplo, às relações internacionais.

$\mathrm{Na}$ aplicação de pontos específicos da teoria geral do estado ao direito internacional residiria o elemento inovador da pesquisa. Estruturas comumente úteis apenas à compreensão do direito interno dos estados são utilizadas no estudo do direito das gentes para fundamentar propostas à sua compreensão e evolução institucional.

A novidade não estaria, assim, no tema abordado, já que a aplicação da teoria do estado ao direito internacional não constitui incomum doutrina. Inovador seria, portanto, o resgate da sinergia entre as teorias do direito interno dos estados e as de direito internacional análise que parece ter caído em desuso nas últimas décadas.

Nova seria, por exemplo, a tentativa de se aplicar pontos específicos das teorias jurídicas clássicas estudadas à institucionalização das organizações internacionais e a conseqüente proposta de que tal dinâmica contribuiria ao desenvolvimento do direito internacional e ao fortalecimento de suas matrizes jurídicas - reveladoras da preservação de sua unidade.

Diversos são os questionamentos que se apresentam ao panorama investigativo proposto. Seriam os esquemas doutrinários tradicionais incapazes de explicar a multiplicação de organizações internacionais com capacidade legiferante e a complexa trama normativa que se forma a partir da sobreposição de suas competências? Seria essa inabilidade a causa de sua substituição por teorias que sustentam a fragmentação do direito internacional? Exigiria o atual momento de transição entre o modelo de relação entre estados centrado no conceito clássico de soberania e seu arrefecimento ainda tempo e esforços para sua consolidação? Estaria a visão eminentemente política das relações internacionais por essa razão tomando espaços antes ocupados pelo direito na descrição dos fenômenos organizacionais humanos? Seria esta uma das causas ou conseqüência do distanciamento da doutrina do direito internacional da teoria geral do estado? Poderia estar a chave da compreensão do direito internacional atual no resgate do instrumental teórico interno da teoria do estado e do direito constitucional? Conformariam a concretude e a normatividade variáveis essenciais às garantias de previsibilidade, segurança jurídica e coercibilidade inerentes à idéia sistêmica do direito que promoveriam sua independência da discricionariedade característica da política? Teria o direito internacional se estagnado ou retrocedido em meio à aparente prevalência da 
política nos últimos anos ou sua evolução teria se tornado apenas mais lenta e seus entraves seriam maiores? Poderia a rejeição de toda a teoria do estado como instrumental hábil a explicar fenômenos organizacionais do direito internacional prosperar? Representaria o abandono do plano teórico da teoria do estado e sua substituição por propostas que defendam a fragmentação e contradigam preceitos fundamentais da teoria do direito o abandono do próprio direito? Seria a produção acadêmica resultante desse processo investigativo não jurídica? Poderia o poder interno do estado servir de parâmetro aplicável à sociedade internacional ao menos como ponto de partida de estudo jurídico? Surgiriam os sistemas de solução de controvérsias instituídos internacionalmente como expressões incipientes da função judiciária apresentada pela teoria do estado? Favoreceria o descolamento da ordem internacional da lógica da teoria do estado o uso desmedido da força por sujeitos de direito internacional, mormente estados? Poderia o aperfeiçoamento institucional dos sistemas de solução de controvérsias conformar instrumento fundamental de estabilização jurídica e de manutenção da unidade do direito internacional? Surgiria o desenvolvimento de sistemas de solução de controvérsias estabelecidos para garantir a preservação de marcos acordados em tratados como condição fundamental à prevalência do jurídico na esfera internacional da atualidade?

Para atingir os objetivos estabelecidos, apresenta-se o seguinte problema:

Seria possível afirmar, a partir do prisma da relação entre política e direito, que as teorias fragmentárias resultariam de premissas alheias ao direito, tais como aquelas adotadas pelas relações internacionais, e que o resgate da aplicação da teoria geral do estado ao direito internacional se apresentaria como alternativa viável à preservação de suas características sistêmicas de ordenação e unidade e, ainda, que o traslado da perspectiva da separação de funções do estado - separação de poderes - à institucionalização dos sistemas de solução de controvérsias internacionais poderia servir de instrumento promotor da referida unidade?

Ao problema teórico, propõe-se a seguinte hipótese:

Considerando a aplicação das premissas da teoria geral do estado ao direito internacional a partir do prisma da relação entre política e direito, afirma-se que a fragmentação resultaria de premissas alheias ao direito, tais como aquelas adotadas pelas relações internacionais, e que o resgate da aplicação da teoria geral do estado ao direito 
internacional se apresentaria como alternativa viável à preservação de suas características sistêmicas de ordenação e unidade e, ainda, que o traslado da perspectiva da separação de funções do estado - separação de poderes - à institucionalização dos sistemas de solução de controvérsias internacionais poderia servir de instrumento promotor da referida unidade.

O trabalho se realiza sob o método dedutivo-indutivo de pesquisa. A partir das referências teóricas estabelecidas pela teoria geral do estado e de sua aplicação ao direito internacional e às propostas doutrinárias fragmentárias, estabelecem-se marcos particulares, os quais são analisados na busca de constatações mais abrangentes e gerais quanto à relação existente entre política e direito.

Pretende-se, na verdade, derivar a aplicação das referências teóricas escolhidas à compreensão da relação entre a política e o direito sob a perspectiva do debate entre as teorias unitaristas e fragmentárias do direito das gentes fazendo uso, principalmente, dos sistemas internacionais de solução de controvérsias como parâmetro empírico de investigação. Para a realização do projeto faz-se necessária, também, a utilização de ampla documentação indireta através de uma pesquisa bibliográfica tanto jurídica quanto histórica e política, dado o caráter interdisciplinar com o qual se buscou abordar o tema.

Durante a elaboração do trabalho, observam-se elementos internos do direito público envolvido na compreensão do estado e a possibilidade desses serem derivados às relações interestatais, mormente no que se refere à institucionalização da ordem jurídica global. Tal proposta, compatível com o método jurídico-dogmático de pesquisa, tem como objetivo a verificação de como - e se - o direito internacional atual poderia ser harmonizado com as premissas de ordenação e unidade tradicionalmente identificáveis em conjuntos coerentes de normas.

Em alguns momentos mostram-se necessárias, ainda, pesquisas projetivas, por exemplo, para inferir, a partir da análise proposta, as possibilidades que se apresentam à evolução dos sistemas jurídicos internacionais e, especificamente, de seus mecanismos de solução de litígios.

A pesquisa apresenta, também, características transdisciplinares por não envolver apenas questões jurídicas, referentes principalmente às teorias do estado e ao debate entre fragmentação e unidade do direito global, mas também a análise política da ordem mundial a partir, por exemplo, de abordagens da teoria das relações internacionais.

Em termos estruturais, optou-se por uma divisão lógica do trabalho em três partes distintas, mas interdependentes. Na seção inicial, apresentam-se os elementos teóricos que 
embasam a pesquisa desenvolvida. Assim sendo, busca-se fixar na primeira parte do capítulo inaugural a perspectiva do direito como um sistema, no qual o interno e o internacional conformariam partes de um todo. Em seguida, apresentam-se as premissas iniciais da relação existente entre política e direito e, logo, procede-se à delimitação de conteúdos a termos fundamentais ao estudo.

No capítulo segundo, concentram-se os esforços no delineamento dos conceitos de estado e de soberania para sugerir, então, a importância dos mesmos para o direito das gentes. As conclusões iniciais são aprofundadas no capítulo seguinte, quando se explica a aplicação das teorias estudadas à compreensão e, portanto, não necessariamente à formatação do direito internacional. No mesmo capítulo terceiro, inicia-se a vinculação das teorias da organização do estado à idéia de poder.

A questão do poder pauta a parte seguinte do trabalho, que inicialmente desenvolve o conceito à luz dos exercícios de concreção e de extração de normatividade para, logo, estabelecer paralelos com as funções exercidas pelo estado internamente. No mesmo capítulo, inicia-se a aplicação dos mesmos conceitos à organização do poder no contexto internacional a partir da figura dos sujeitos dotados de capacidade para seu exercício. A função jurisdicional merece, finalmente, atenção especial na última parte do capítulo, na qual se busca introduzir seu exercício na esfera global.

A pesquisa segue no capítulo quinto à análise das organizações internacionais a partir dos parâmetros previamente estabelecidos. Para tanto, a personalidade e a capacidade dos atores da ordem internacional, principalmente das organizações internacionais, são analisadas e, em uma segunda parte, a importância dos sistemas de solução de controvérsias no exercício de poder por tais estruturas pauta a investigação.

Nesse sentido, uma nova classificação para as organizações internacionais é apresentada no sexto capítulo estabelecendo como paradigma fundamental à sua caracterização a existência de sistema institucionalizado de solução de litígios entre seus membros.

Estabelecidas as premissas teóricas mais importantes da pesquisa na primeira seção do trabalho, parte-se para o desenvolvimento da proposta apresentada. Estabelecem-se, para tanto, no capítulo sétimo do estudo as linhas gerais da relação existente entre as teorizações fragmentárias do direito das gentes e a política para, em seguida, buscarem-se, no capítulo oitavo, elementos empíricos que comprovassem o que se defende em experiências regionais, das quais o Brasil faz parte. 
$\mathrm{Na}$ nona parte do trabalho, pretende-se demonstrar como a teoria geral do estado se aplicaria à compreensão do direito das gentes de forma propositiva e, em seguida, como a função jurisdicional identificada na ordem mundial poderia servir à preservação da unidade do direito internacional. No décimo e último capítulo, apresentam-se argumentos já de caráter conclusivo que sustentam ser a percepção fragmentada do direito internacional mero retrato estático de um processo evolutivo. 


\section{PRIMEIRA PARTE}

\section{PREMISSAS NECESSÁRIAS}

\subsection{Direito Internacional e Direito Interno: Direito}

A concepção do direito internacional como algo primitivo ou incompleto, apesar de bastante pessimista, não é incomum ${ }^{2}$. Toda a construção teórica positivista, em sua busca pela racionalização e pela mecanização de estruturas, questionou em determinado momento a institucionalidade do direito das gentes. A ordem global não atendia, sob as premissas estritas fixadas, aos padrões de validade e hierarquia que se estabeleciam ao direito.

A modernidade no direito se viu marcada pelo pensamento constitucionalista e isso repercutiu também na concepção do direito internacional e na organização do poder mundial. Aquilo que se costuma referir como pós-modernidade refletiria no direito, nesse contexto, tentativa de superação dos fracassos do projeto moderno e de consolidação de perspectivas como, por exemplo, a da centralidade do ser humano ${ }^{3}$.

Ainda que o direito internacional, outrora vislumbrado de maneira desagregada prisma que persiste hoje equivocadamente sob novas roupagens como será demonstrado adiante, aparentasse distanciamento de perspectivas valorativas, possível se faz observar identidade entre a solidariedade e a coexistência na ordem global. Desse panorama,

\footnotetext{
${ }^{2}$ CASELLA, Paulo Borba. Evolução institucional do direito internacional: à luz do cinqüentenário do conceito de direito de Hart (1961). In: Revista Brasileira de Filosofia. Ano 60, Vol. 236, janeiro-junho, 2011. pp. 313329. p. 315. "In verbis": "A concepção de Hart a respeito do direito internacional parece não somente bastante limitada e mesmo pessimista. Este não deixa de ser fenômeno recorrente."

${ }^{3}$ BARROSO, Luís Roberto. Temas de direito constitucional - Tomo II. Rio: Renovar, 2003. p. 12. "In verbis": "A crença na Constituição e no constitucionalismo não deixa de ser uma espécie de fé: exige que se acredite em coisas que não são direta e imediatamente apreendidas pelos sentidos. Como nas religiões semíticas judaísmo, cristianismo e islamismo -, tem seu marco zero, seus profetas e acena com o paraíso: vida civilizada, justiça e talvez até felicidade. Como se percebe, o projeto da modernidade não se consumou. Por isso não pode ceder passagem. Não no direito constitucional. A pós-modernidade, na porção em que apreendida pelo pensamento neoliberal, é descrente do constitucionalismo em geral, e o vê como um entrave ao desmonte do Estado social."
} 
características cooperativas capazes de promover, mesmo indiretamente, o caráter sistêmico do direito podem ser extraídas ${ }^{4}$.

Assim sendo, qualquer dúvida que se imponha ao tema deve considerar, ao menos, que o direito internacional nasceu e busca se desenvolver de maneira organizada para garantir a coexistência entre os estados e para permitir que os mesmos entre si cooperem ${ }^{5}$.

O período medieval costuma ser apontado como exemplo de coexistência entre as nações. Ressalva necessária deve ser feita, contudo, quanto ao referido marco temporal. Nesse sentido, acepções teóricas identificadas como medievais não significariam mera delimitação histórica temporal, mas também geográfica. Aquilo que se costuma tratar por "idade média" se refere territorialmente, em regra, à região mediterrânea e à Europa ocidental. Não se trataria, portanto, de um fenômeno temporal em escala global, mas eminentemente europeu ${ }^{6}$.

$\mathrm{Na}$ evolução histórica da disciplina, podem-se reconhecer ao menos dois momentos teóricos importantes anteriores ao debate positivista e ao período de institucionalização posterior à primeira guerra mundial. No primeiro, os autores modernos considerados clássicos contribuíram ao distanciamento do direito das gentes do poder espiritual, isto é, à sua laicidade. Mais tarde, o conceito de pessoa moral, pela atribuição de personalidade jurídica aos estados, consubstanciou importante ferramenta que - sem alterar fundamentalmente a

\footnotetext{
${ }^{4}$ WEIL, Prosper. Le droit international en quete de son identité: cours général de droit international public. In: Recueil des Cours. Academie de Droit International de la Haye, Volume 237, 1992-VI, pp. 09-370. p. 38. "In verbis": "Même si le droit de la coopération n'a pas remplacé le droit de la coexistence, comme certains l'avaient présagé, la fonction solidariste du droit international demeure, aujourd'hui comme hier - aujourd'hui plus encore qu'hier - la soeur jumelle de la fonction de coexistence."

${ }^{5}$ WEIL, Prosper. Le droit international en quete de son identité: cours général de droit international public. In: Recueil des Cours. Academie de Droit International de la Haye, Volume 237, 1992-VI, pp. 09-370. p. 50. "In verbis“: "Bien qu'il n'y ait pas de gouvernement international, il existe une société de vivre dans un cadre ordonné et stable permettant des rapports mutuels et des activités communes. Le vouloir-vivre ensemble - le devoir-vivre ensemble, dirais-je volontiers -, qui est une nécessité sociale autant que morale, exige une règle du jeu et mérite quelques sacrifices. On retrouve ainsi, sous une autre forme [...] : le droit international est né et s'est développé afin d'assurer la coexistence des Etats et de rendre possible leur coopération.“
}

${ }^{6}$ CASELLA, Paulo Borba. Direito internacional no tempo medieval e moderno até vitoria. São Paulo: Atlas, 2012. pp. 84-85. "In verbis": "O terceiro aspecto é o da determinação da extensão espacial do conceito de Idade média. É importante determinar em quais áreas do mundo cabe falar em ocorrência de Idade média. Pois esse conceito difere consideravelmente, conforme a civilização que se esteja a considerar. Justamente se constata que a Idade média será antes dado cultural que meramente geográfico. Nesse sentido, oportuna a delimitação feita por E. GEBHART (1901) ao examinar 'os contistas florentinos medievais' - primeiro suscitando o espaço cultural, lingüístico e social, no qual se inscreve o mundo medieval. Simplesmente não faz sentido, ao menos, não fará o mesmo sentido falar em Idade média, ao se considerar espaços, nesses mesmos séculos, além das áreas normalmente caracterizadas como o Mediterrâneo e a Europa ocidental. E mesmo assim, somente em relação a parte destas. E com variações da extensão geográfica, em função da época a respeito da qual se fala." 
idéia de soberania externa - auxiliou a transferência de sua titularidade dos governantes para o estado ${ }^{7}$.

Contemporaneamente, o direito internacional não comporta mais as definições que lhe atribuem caráter primitivo ou reducionismos que se atenham a aspectos aparentemente políticos de sua estrutura. A normatização mundial apresenta hoje uma série de preocupações substantivas que conduzem sua doutrina e estrutura claramente à consolidação de um conteúdo material para a comunidade internacional ${ }^{8}$.

Em termos formais, importante se faz ressaltar que o direito das gentes não se confunde com os sistemas jurídicos globais. Nesse sentido, percebe-se que sistemas jurídicos internacionais podem ser radicalmente alterados e até deixar de existir, mas o direito internacional, como estrutura, não ${ }^{9}$.

O estudo do direito das gentes permite ao menos três abordagens distintas: a histórica, a política e propriamente jurídica ${ }^{10}$. O reconhecimento do status de direito ao direito

\footnotetext{
${ }^{7}$ GUGGENHEIM, Paul. Contribution à l'histoire des sources du droit des gens. In: Recueil des Cours. Academie de Droit International de la Haye, Volume 94, 1958-II, pp. 01-84. p. 80. "In verbis“": "Le point crucial de cette conquête se situe à l'époque de la divisio regnorum. C'est aussi à cette époque que commence à se développer la doctrine humaniste du droit des gens. Déjà avant Grotius, Vasquez et Suarez, s'inspirant de la pensée rationaliste de saint Thomas d'Aquin, avaient jeté les bases d'une conception laïque du droit des gens. Mais Grotius fait un pas décisif en reconnaissant pratiquement la primauté du droit des gens sur le droit naturel dont l'application est souvent écartée par avance et reléguée au forum internum. Hobbes et Pufendorf perfectionnent ensuite le système en incorporant au droit naturel et au droit des gens la notion de personne morale. Wolff met le point final à l'évolution en comprenant que l'autonomie du droit des gens implique que ses règles sont différentes dans leur substance de celles du droit national.“
}

${ }^{8}$ CASELLA, Paulo Borba. Evolução institucional do direito internacional: à luz do cinqüentenário do conceito de direito de Hart (1961). In: Revista Brasileira de Filosofia. Ano 60, Vol. 236, janeiro-junho, 2011. pp. 313329. p. 328. "In verbis": "A compreensão do sentido e do papel específico do direito internacional, sobretudo em nosso contexto pós-moderno se faz útil porquanto este é ferramenta indispensável para a ordenação do mundo e da interação entre os estados e demais agentes, no plano internacional. Este não mais é o sistema 'primitivo', como ainda o via Hart, nem tampouco pode ser reduzido a concepções reducionistas de 'direito e política', mas reintegra a busca de valores comuns e sentidos compartilhados. Nessa busca de valores comuns e de sentidos compartilhados se constrói, progressivamente, o sentido e o conteúdo de "comunidade internacional',"

${ }^{9}$ KUNZ, Josef L. La crise et les transformations du droit des gens. In: Recueil des Cours. Academie de Droit International de la Haye, Volume 88, 1955-II, pp. 01-104. pp. 60-61. "In verbis“: "L'ordre juridique des Natios Unies ne couvre nullement le droit des gens entier. Le droit international particulier d'une organisation internationale à vocation universelle peut disparaître, comme dans de cas de Societé des Nations, mais le droit des gens général continue.“

${ }^{10}$ ROUSSEAU, Charles. Principes de droit international public. In: Recueil des Cours. Academie de Droit International de la Haye, Volume 93, 1958-I, pp. 369-550. p. 374. "In verbis": "Pour étudier le droit international public on peut se placer à différents points de vue. On peut adopter par exemple le point de vue historique : le droit des gens se présentera alors comme une science descriptive qui retrace, dans leur développement chronologique, l'évolution des rapports internationaux. On peut également se placer au point de vue politique : cette méthode, qui amène inévitablement l'interprète à formuler des jugements de valeur, consiste à envisager le droit des gens comme le produit d'un milieu social donné, comme la résultante des besoins, des aspirations et des croyances d'une société et d'une époque déterininées. Enfin on peut adopter le 
internacional implica necessariamente assumir, gize-se de plano, que a existência de um poder legislativo central e de meios coercitivos para garantir o cumprimento de normas não seriam requisitos fundamentais à caracterização de um sistema normativo ${ }^{11}$.

Pode-se afirmar, em rasa análise, que a revolução francesa não representou em si um marco relevante para o direito internacional, mas que as liberdades - humanas e dos povos consagradas nos documentos dali surgidos repercutiram em todo o direito produzido a partir do fim do século XVIII ${ }^{12}$.

$\mathrm{O}$ século $\mathrm{XX}$ e os eventos históricos globais principalmente de sua primeira metade foram também determinantes no desenvolvimento da disciplina. A perspectiva doutrinária passou da completa negação de sua condição de direito - pelo não reconhecimento de suas características de fundamentação e validade - às teorias que sustentam sua primazia em relação às ordens internas dos estados ${ }^{13}$.

Cumpre observar, contudo, que os questionamentos - em voga na primeira metade do século passado - relacionados à condição de direito do direito internacional exigem que se superem, primeiro, os limites do próprio conceito de direito. Nesse sentido, é de se perceber que direito pode ser entendido sob o prisma normativo, é dizer, como um conjunto de prescrições que regulamentam a ação humana em sociedade, ou, diferentemente, apenas como uma forma particular de expressão da conduta humana em suas relações sociais ${ }^{14}$.

point de vue juridique, le droit des gens étant alors conçu comme l'ememble des règles applicables à la communauté intemationale $[\ldots]^{\text {“ }}$

${ }^{11}$ MARYAN GREEN, N.A. International law: law of peace. London: Macdonald and Evans, 1982. p. 01. "In verbis": "International law appears to differ in at least two significant respects from law as it is reflected in municipal legal systems. There is no legislature or law-making authority; and there is no police force or army to enforce obedience to the law or sanction breaches of it. To affirm the legal nature of international law, it is thus necessary to establish that neither of these elements is indispensable to the existence of a legal system."

${ }^{12}$ DUPUY, René-Jean. La révolution française et le droit international actuel : conférence prononcée le 25 juillet 1989. In: Recueil des Cours. Academie de Droit International de la Haye, Volume 214, 1989-II, pp. 09-29. p. 28. "In verbis“: "La Révolution française n'a pas multiplié les innovations dans l'ordre formel du droit international, mise à part l'éviction de l'Etat dynastique au profit de l'Etat-nation, entité qui se généralisera tout au long des deux sigles suivants, après s'être aussi implantée dans les monarchies parlementaires. Son effet majeur s'est manifesté dans la diffusion de principes politiques exaltant la liberté de l'homme, dans l'esprit de 1789 , et la libération des peuples, dans celui de 1793 .“

${ }^{13}$ BEREZOWSKI, Cezary. Les sujets non souverains du droit international. In: Recueil des Cours. Academie de Droit International de la Haye, Volume 65, 1938-III, pp. 01-85. p. 05. "In verbis“: "Il est évident à tous que le développement de cette science, pour ne prendre que les cinquante dernières années, a fait un progrès immense : depuis la négation complète de l'existence d'un droit international, on en est arrivé, dans l'après-guerre, à prendre, à tort ou à raison, la primauté du droit des gens pour base de la doctrine.“

${ }^{14}$ KELSEN, Hans. Théorie du droit international public. In: Recueil des Cours. Academie de Droit International de la Haye, Volume 110, 1953-III, pp. 01-203. p. 09. "In verbis": "Ce qu'on appelle le droit international est-il un droit au sens spécifique du mot ? La réponse à cette question dépend de la définition que l'on donne de la notion de droit. Pour établir une telle définition il faut d'abord choisir le concept de base auquel on croit 
Se, por um lado e sob a ótica normativa, a questão da existência do direito das gentes como direito já se encontra superada, o mesmo não se pode afirmar quanto às dúvidas relacionadas às razões de seu caráter obrigatório e aos meios para garantir sua eficácia ${ }^{15}$.

A noção de obrigatoriedade se embasa comumente em concepção jusnaturalista de fundamentação teórica. Bastante complicado se faz, entretanto, determinar com exatidão no que consistiria o direito natural. A concepção de existência de valores intrínsecos e préconcebidos se mostra mais claramente quando contrastada com o positivismo jurídico, isto é, com a justificativa de validade estabelecida pela expressão da vontade dos sujeitos que se submetem às normas ${ }^{16}$.

Entre o direito natural e o direito positivo algumas diferenças se mostram determinantes. Jusnaturalistas defendem a existência de critérios jurídicos universais, imutáveis. Com ressalvas doutrinárias específicas, esses critérios seriam inerentes à natureza, baseados na razão e em um cartesianismo inato focado no que seria o "bem". Já o direito positivo, por outro lado, seria particular, absolutamente mutável e formado pela vontade social baseada em justificativas mormente de utilidade ${ }^{17}$. Jusnaturalismo constituiria, assim, a

pouvoir rattacher les phénomènes désignés sous le nom de droit. A cet égard nous sommes en présence de deux thèses opposées. Pour l'une le droit a un caractère normatif. Il est un ensemble de normes réglant par des prescriptions ou des permissions la conduite des hommes ou les relations des hommes entre eux. Le droit serait donc un ordre normatif au même titre que la morale. Pour l'autre thèse le droit est un mode particulier de la conduite des hommes ou des relations des hommes entre eux."

${ }^{15}$ RIVAROLA PAOLI, Juan Bautista. Derecho internacional público. Asunción: Ediciones y Arte, 2013. p. 31. "In verbis": "El problema de la existencia del Derecho Internacional Público es un asunto actualmente superado, que jurídicamente sólo tiene un interés histórico, aunque su discusión podría ser muy interesante desde el punto de vista filosófico. En cambio, mantiene su vigencia la necesidad de exponer la razón de su obligatoriedad y acatamiento, intentando así explicar de dónde extraen su fuerza las reglas que pretenden-y logran obligar a entes que, por ser soberanos o estar íntimamente vinculados a ese atributo, no reconocen poder material que les someta, ni fuerza ajena que les condicione, aunque si están dispuestos a someterse a un tipo especial de reglas jurídicas. Las del Derecho Internacional Público, que ellos mismos crean, pero que luego de entrar en vigor, por el principio de la buena fe-y la necesidad de mantener su soberanía-no pueden desconocer caprichosamente, ni pueden pretender eludir las consecuencias de sus violaciones."

${ }^{16}$ QUADRI, Rolando. Le fondement du caractère obligatoire du droit international public. In: Recueil des Cours. Academie de Droit International de la Haye, Volume 80, 1952-I, pp. 579-633. p. 585. "In verbis“: "Parmi les théories qui ont essayé de donner une solution au probléme concernant la force obligatoire des règles du droit international, la première en ordre de temps et, sans doute, la plus résistante est celle qui dans les formes les plus différentes, consciemment u inconsciemment, se rattache au droit naturel. Il est très difficile de donner une idée exacte de ce qu'il faut entendre par droit naturel (jus naturae), comme il est difficile, sinon impossible, de classifier les autres qui doivent être rangés parmi les jusnaturalistes. [...] On peut dire, d'une manière approximative, que l'idée du droit naturel s'oppose historiquement à l'idée du droit positif et que l'idée du droit positif évoque celle de source formelle, c'est-à-dire d'un acte de production juridique.“

${ }^{17}$ BOBBIO, Norberto. O positivismo jurídico: lições de filosofia do direito. São Paulo: Ícone, 1995. pp. 22-23. "In verbis": "Critérios de distinção entre direito natural e direito positivo. Tratemos, agora, de extrair das várias definições anteriormente examinadas um rol, tanto quanto possível completo, das características distintivas dos dois direitos. Podemos destacar seis critérios de distinção: a) o primeiro se baseia na antítese universalidade/particularidade e contrapõe o direito natural, que vale em toda parte, ao positivo, que vale 
concepção de um direito pressuposto, inerente à vontade dos atores políticos da sociedade estatal ou internacional ${ }^{18}$.

Importa demarcar, nesse momento, que ao mesmo tempo em que a consagração do estado liberal representou a vitória dos ideais jusnaturalistas, a ordenação do poder marcou sua superação pelo positivismo, a partir do momento em que valores e princípios passaram a ser reduzidos a termo em processo de intensa produção normativa ${ }^{19}$. Atualmente, a superação do jusnaturalismo e o êxito limitado do positivismo, como expressão da modernidade no direito, abririam espaço à pós-modernidade jurídica, isto é, ao pós-positivismo ${ }^{20}$.

apenas em alguns lugares (Aristóteles, Inst. - $1^{\text {a }}$ definição); b) o segundo se baseia na antítese imutabilidade/mutabilidade: o direito natural é imutável no tempo, o positivo muda. (Inst. - $2^{\mathrm{a}}$ definição -, Paulo): esta característica nem sempre foi reconhecida: Aristóteles, por exemplo, sublinha a universalidade no espaço, mas não acolhe a imutabilidade no tempo, sustentando que também o direito natural pode mudar no tempo; C) o terceiro critério de distinção, um dos mais importantes, refere-se à fonte do direito e funda-se na antítese natura-potestas populus (Inst. - $1^{\text {a }}$ definição -, Grócio); d) o quarto critério se refere ao modo pelo qual o direito é conhecido, o modo pelo qual chega a nós (isto é, os destinatários), e lastreia-se na antítese ratiovoluntas (Glück): o direito natural é aquele que conhecemos através de nossa razão. (Este critério liga-se a uma concepção racionalista da ética, segundo a qual os deveres morais podem ser conhecidos racionalmente, e, de um modo mais geral, por uma concepção racionalista da filosofia.) O direito positivo, ao contrário, é conhecido através de uma declaração de vontade alheia (promulgação); e) o quinto critério concerne ao objeto dos dois direitos, isto é, aos comportamentos regulados por estes: os comportamentos regulados pelo direito natural são bons ou maus por si mesmos, enquanto aqueles regulados pelo direito positivo são por si mesmos indiferentes e assumem uma certa qualificação apenas porque (e depois que) foram disciplinados de um certo modo pelo direito positivo (é justo aquilo que é ordenado, injusto o que é vetado) (Aristóteles, Grócio); f) a última distinção refere-se ao critério de valoração das ações e é enunciado por Paulo: o direito natural estabelece aquilo que é bom, o direito positivo estabelece aquilo que é útil."

${ }^{18}$ BARROSO, Luís Roberto. Temas de direito constitucional - Tomo II. Rio: Renovar, 2003. pp. 19-20. "In verbis": "O termo jusnaturalismo identifica uma das principais correntes filosóficas que tem acompanhado o Direito ao longo dos séculos, fundada na existência de um direito natural. Sua idéia básica consiste no reconhecimento de que há, na sociedade, um conjunto de valores e de pretensões humanas legítimas que não decorrem de uma norma jurídica emanada do Estado, isto é, independem do direito positivo. Esse direito natural tem validade em si, legitimado por uma ética superior, e estabelece limites à própria norma estatal."

${ }^{19}$ BARROSO, Luís Roberto. Temas de direito constitucional - Tomo III. Rio: Renovar, 2005. pp. 10-11. "In verbis": "O advento do Estado liberal, a consolidação dos ideais constitucionais em textos escritos e o êxito do movimento de codificação simbolizaram a vitória do direito natural, o seu apogeu. Paradoxalmente, representaram, também, a sua superação histórica. No início do século XIX, os direitos naturais, cultivados e desenvolvidos ao longo de mais de dois milênios, haviam se incorporado de forma generalizada aos ordenamentos positivos. Já não traziam a revolução, mas a conservação. Considerado metafísico e anticientífico, o direito natural é empurrado para a margem da história pela onipotência positivista do século XIX."

${ }^{20}$ Importante se faz ressaltar que muitos doutrinadores, dos quais aqui se discorda, não estabelecem paralelos entre o positivismo e a modernidade e entre o pós-positivismo e a pós-modernidade. Sobre a superação do positivismo, BARROSO, Luís Roberto. Temas de direito constitucional - Tomo II. Rio: Renovar, 2003. p. 27. "In verbis": "A superação histórica do jusnaturalismo e o fracasso político do positivismo abriram caminho para um conjunto amplo e ainda inacabado de reflexões acerca do Direito, sua função social e sua interpretação. O pós-positivismo é a designação provisória e genérica de um ideário difuso, no qual se incluem a definição das relações entre valores, princípios e regras, aspectos da chamada nova hermenêutica e a teoria dos direitos fundamentais." 
Nesse ambiente de superação, percebe-se que a coerência do sistema normativo deve assumir, definitivamente, a perspectiva positivista de validade que inadmite a percepção das ordens locais e da ordem internacional como sistemas distintos ${ }^{21}$. O ingresso na perspectiva pós-positivista exigiria, portanto, a prévia consolidação de algumas premissas da teorização que se pretende superar.

De volta à modernidade, a concepção do direito como ciência, como técnica, teve eminentemente nos parâmetros positivistas seu campo mais fértil. O direito internacional não se constituiria, sob tais teorias, de princípios apriorísticos, mas da estruturação criativa de normas a partir da expressão da vontade dos sujeitos de direito reconhecidos na ordem do direito das gentes ${ }^{22}$.

A doutrina, em seu momento, discutiu amplamente a possibilidade de se exigir de forma coercitiva o cumprimento de uma norma - a sanção - como condição ao reconhecimento do sistema internacional como direito ${ }^{23}$. Percebe-se hoje, claramente, a superação dessa discussão não apenas pela identificação da coerção na guerra e na retaliação,

${ }^{21}$ KELSEN, Hans. Reine Rechtslehre - Einleitung in die rechtswissenschaftliche Problematik. Leipzig und Wien: Franz Deuticke, 1934. p. 135. "In verbis“ : "Diese dualistische - oder mit Rücksicht auf die Vielheit der einzelstaatlichen Rechtsordnungen besser als <<pluralistisch〉> zu bezeichnende - Konstruktion ist jedoch schon rein logisch unhaltbar, wenn sowohl die Normen des Völkerrechts als auch die der einzelstaatlichen Rechtsordnungen als gleichzeitig gültige Normen, und zwar gleicherweise als Rechtsnormen angesehen werden sollen. In dieser auch von der dualistischen Doktrin geteilten Anschauung liegt schon die erkenntnis theoretische Forderung: alles Recht in einem System, das heißt von einem und demselben Standpunkt aus als ein in sich geschlossenes Ganzes zu betrachten. Indem die juristische Erkenntnis das als Völkerrecht charakterisierte ganz ebenso wie das als einzelstaatliches Recht sich darbietende Material als Recht, das heißt unter der Kategorie der gültigen Rechtsnorm erfassen will, stellt sie sich - ganz ebenso wie die Wissenschaft von der Natur - die Aufgabe: ihren Gegenstand als Einheit darzustellen."

${ }^{22}$ EHRLICH, Ludwik. The development of international law as a science. In: Recueil des Cours. Academie de Droit International de la Haye, Volume 105, 1962-I, pp. 173-265. p. 177. "In verbis“: "The science of international law is a positive science, and by that is meant that it deals with facts and not with deductions drawn from abstract principles accepted a priori. The phenomena with which the science of international law deals are the facts of establishing and applying rules of international law. The science of international law must, by using sources of international law, find what rules exist, must explain them by finding on what Principles they are based and what conditions have caused the application of those principles to bring about those rules. The science of international law analyses the rules, points out to what consequences they lead, and verifies whether the reasoning which points to those consequences is confirmed in practice, that is, whether the practice of relations between states as evidenced by sources of international law confirms the acceptance of such consequences by states.”

${ }^{23}$ WEIL, Prosper. Le droit international en quete de son identité : cours général de droit international public. In: Recueil des Cours. Academie de Droit International de la Haye, Volume 237, 1992-VI, pp. 09-370. p. 56. "In verbis": "Ce n'est donc pas parce que le systme international ne comporte pas les mêmes mécanismes de sanction judiciaire que les systmes nationaux qu'il doit être regardé comme insuffisamment développé au point de ne pas atteindre le seuil minimal de la juridicité. Et ce n'est pas parce que les normes internationales sont potentiellement justiciables qu'elles accèdent de ce fait la juridicité. Le problème, tout simplement, n'est pas là.“ 
mas, principalmente, na acepção de que a judicialização não dependeria da execução de uma decisão e sim da possibilidade de apreciação jurisdicional de questão específica ${ }^{24}$.

Em perspectiva histórica, a própria codificação era observada no início do século $\mathrm{XX}$ por parte da doutrina - em momento ainda bastante hostil e incerto, mas de grande entusiasmo com a normatização comum da ordem internacional e sem mencionar diretamente conceitos como uniformização e harmonização - como instrumento e parâmetro da universalização de um núcleo de normas comuns, isto é, internacionais ${ }^{25}$.

Os grandes nomes do positivismo, contudo e por considerarem inexistirem elementos essenciais à sistematização normativa da esfera internacional, chegavam a negar o status de direito ao conjunto de regras comuns, mormente costumeiro, que - de certo ainda rudimentarmente - surgia para regular a relação entre os estados; então os únicos sujeitos reconhecidos na comunidade mundial.

Ao abordar o direito internacional, Hart, por exemplo, partiu da perspectiva interna do participante e procurou racionalizar a obrigatoriedade das regras em meio à inexistência de um sistema organizado de sanções ${ }^{26}$. Essa sistematização do direito das gentes sugeriria o reconhecimento de um conjunto de regras primárias obrigatórias para os atores internacionais a ele submetido, apesar de, entretanto, não identificar regras secundárias que regulassem sua aplicação dessas regras primárias. Da ausência de regras secundárias decorreria, ainda e admitida a existência de jurisdição, a falta de obrigatoriedade das decisões emanadas por sistemas jurisdicionais de solução de controvérsias ${ }^{27}$.

\footnotetext{
${ }^{24}$ WEIL, Prosper. Le droit international en quete de son identité : cours général de droit international public. In: Recueil des Cours. Academie de Droit International de la Haye, Volume 237, 1992-VI, pp. 09-370. p. 54. "In verbis": "L'idée que, si un ordre juridique peut à la rigueur se passer du législateur, il ne saurait se dispenser d'un mécanisme de sanction judiciaire sous peine de perdre sa juridicité est ce point ancrée dans l'esprit de nombreux juristes, notamment occidentaux, que la suggestion a été émise, pour sauver la juridicité du système international, qu'il suffit, pour qu'un ordre juridique mérite ce nom, que les règles soient justiciables au moins potentiellement, même si elles ne le sont pas effectivement.“
}

${ }^{25}$ DE VISSCHER, Charles. La codification du droit international. In: Recueil des Cours. Academie de Droit International de la Haye, Volume 6, 1925-I, pp. 325-455. p. 449. "In verbis": "Les relations juridiques entre États dont la réglementation est l'objet de la codification tendent à revêtir un caractère d'universalité de plus en plus accentué; leur développement toujours croissant tend à multiplier dans tous les domaines les points de contact entre l'activité internationale de tous les États. L'évolution du droit doit correspondre à cette évolution des faits : comme les relations qu'il est appelé à régir, le droit international tend à l'universalité.“

${ }^{26}$ HART, H.L.A. The concept of law. Oxford: Clarendon Press, 1961, passim.

${ }^{27}$ CASELLA, Paulo Borba. Evolução institucional do direito internacional: à luz do cinqüentenário do conceito de direito de Hart (1961). In: Revista Brasileira de Filosofia. Ano 60, Vol. 236, janeiro-junho, 2011. pp. 313329. p. 316. "In verbis": "A alegada 'primitividade' do sistema internacional decorreria não da ausência total de normas, porquanto estas existem, mesmo na visão dos mais acerbos detratores do direito internacional, mas seriam estas tão somente normas primárias (primary rules), no sentido de estipular conteúdos, sim, mas o sistema internacional careceria de normas secundárias (secondary rules), justamente aquelas destinadas a 
Sem encontrar um elemento normativo que estabelecesse critérios de validade para a ordem jurídica internacional, o autor inglês não a percebia como um sistema jurídico, mas tão somente como um mero conjunto de preceitos legais ainda não organizado de maneira sistemática e coerente. Diante disso, muito embora sua teoria reconhecesse a obrigatoriedade da normativa internacional, Hart não considerava a ordem jurídica comum dos estados como um sistema vinculante e, portanto, de direito ${ }^{28}$

A negação do caráter sistêmico do direito internacional comprometia, sob tal teorização, qualquer concepção unitarista de seu corpo normativo. A perspectiva da unidade decorreria naturalmente, portanto, do reconhecimento do conjunto de normas internacionais como direito, ou seja, como um sistema jurídico organizado.

A doutrina de Kelsen, por outro lado, fundava-se no protagonismo da sanção, é dizer, na possibilidade de coerção decorrente do descumprimento da norma válida ${ }^{29}$. O direito consubstanciaria, assim, um sistema que regularia as ações individuais mediante a prescrição de condutas sob a ameaça de sanção.

Nesse sentido, mesmo reconhecendo seu estado primitivo, o autor austríaco emprestava ao direito internacional o status de direito propriamente dito capaz, portanto, de regular as ações individuais ao prescrever condutas e estabelecer sanções ao seu descumprimento. Cumpre ressaltar que o reconhecimento das normas de direito das gentes como jurídicas não excluiria sua caracterização como primitivo em razão de sua conformação desorganizada e da inexistência de órgãos centrais investidos da função concretiva ${ }^{30}$.

Mais que isso. O positivismo sozinho encontrou, conforme se ressaltou, grande dificuldade para explicar a natureza obrigatória da normativa do direito das gentes. A doutrina - historicamente e na atualidade ainda - acaba recorrendo atualmente à fundamentação jusnaturalista para justificar conceitos como o de "anuência tácita" e a presunção de uma

determinar a executoriedade das normas, os seus procedimentos de implementação e regular as conseqüências do descumprimento das normas primárias. Mesmo se existe jurisdição, no sistema internacional, esta não se revestiria de obrigatoriedade, nem de compulsoriedade."

${ }^{28}$ HART, H.L.A. The concept of law. Oxford: Clarendon Press, 1961. pp. 230-231. "In verbis": "[...] there is no basic rule providing general criteria of validity for the rules of international Law, and that rules which are in fact operative constitute not a system but a set of rules, among which are the rules providing for the binding force of treaties"

${ }^{29}$ KELSEN, Hans. Reine Rechtslehre - Einleitung in die rechtswissenschaftliche Problematik. Leipzig und Wien: Franz Deuticke, 1934, passim.

${ }^{30}$ KELSEN, Hans. Reine Rechtslehre - Einleitung in die rechtswissenschaftliche Problematik. Leipzig und Wien: Franz Deuticke, 1934. pp. 129-132. 
"regra fundamental" para a ordem legal internacional ${ }^{31}$. Nesse contexto, a codificação - como redução do costume internacional a termo ou como mera expressão inovadora da vontade dos estados na elaboração de preceitos gerais - costumava ser apontada como manifestação do caráter tecnicista do, então considerado primitivo, direito internacional ${ }^{32}$.

A coerção como elemento basilar à caracterização de um sistema jurídico exigiria a identificação de uma estrutura de sanções para que o direito internacional pudesse ser definitivamente reconhecido como direito. A guerra e as represálias conformariam, nesse contexto, as típicas sanções à disposição na esfera internacional e habilitariam, portanto, a compatibilização do sistema aparentemente primitivo de regras com a concepção de direito proposta.

Também a questão hierárquica se apresentava - e ainda hoje se apresenta - como desafio. Nesse sentido, ainda que organizações internacionais como as Nações Unidas possuam importante papel no estabelecimento de instrumentais normativos comuns aos sujeitos de direito internacional, não seria possível identificar, ainda, um órgão central dotado de atribuições concretivas e coercitivas e esse conforma grande entrave à estabilização do sistema normativo global $^{33}$.

\footnotetext{
${ }^{31}$ QUADRI, Rolando. Le fondement du caractère obligatoire du droit international public. In: Recueil des Cours. Academie de Droit International de la Haye, Volume 80, 1952-I, pp. 579-633. pp. 613-617. "In verbis“: "L'impossibilité pour la doctrine positiviste traditionelle, en tant que doctrine volontariste-contractualiste, d'expliquer le caractère obligatoire du droit international se manifeste en outre en ce qui concerne les sources. A part les fictions qui se rattachent à la construction de la coutume comme tacita conventio, construction qui implique des présomptions sans base aucune (théorie du consentement présumé), le problème que Grotius avait résolu par l'intervention du droit naturel n'a trouvé, malgré les efforts déployés, aucune solution satisfaisante jusqu'à présent. Pourquoi les règles posées par convention sont-elles obligatoires ? D'où vient leur force obligatoire ? [...] Au reste Kelsen lui-même qui représent peut-.être la personnalité la pius intéressante du monde juridique contemporain derniérement a reconnue le caractére coutumier de la règle fondamentale. Non seulement. Par l'élimination de la Science du droit de tout contenutisme, soit de nature morale, soit de nature sociale, etc., il a rendu un service éminent dont les fruts ne se laisseront pas attendre longtemps. D'autre part le recours qu'il fait à l'effectivité, la définition qu'il donne de l'ordre juridique comme d'un ordre de contrainte (Zwangsordnung) et la considération qu'il développe qu'il n'est pas nécessaire à la notion du droit que la contrainte soit entre les mains d'organes spécialisés, révèlent un esprit profondément réaliste malgré toute apparence."
}

${ }^{32}$ DE VISSCHER, Charles. La codification du droit international. In: Recueil des Cours. Academie de Droit International de la Haye, Volume 6, 1925-I, pp. 325-455. p. 451. "In verbis": "Et ainsi nous nous trouvons amenés, une fois de plus, à reconnaître le concours que se prêtent mutuellement les trois grands facteurs que nous avons vu intervenir sans cesse dans l'élaboration du droit. Et tout d'abord, les normes juridiques fondamentales, données immédiates de la conscience humaine, qui peu à peu se dégagent et se précisent; qui, inspirant et dominant toute oeuvre législative, éclairent et guident la marche du droit inter-national positif. C'est ensuite l'action consciente et volontaire de la technique qui cherche à mettre en ceuvre ces données et dont la codification nous est apparue comme la manifestation la plus accentuée.“

33 KELSEN, Hans. Reine Rechtslehre - Einleitung in die rechtswissenschaftliche Problematik. Leipzig und Wien: Franz Deuticke, 1934. p. 131. "In verbis": "Aber das Völkerrecht ist noch eine primitive Rechtsordnung. Es steht erst am Anfang einer Entwicklung, die die einzelstaatliche Rechtsordnung bereits zurückgelegt hat. Es zeigt zumindest im Bereich des allgemeinen Völkerrechts und sohin für die ganze 
Desde que tais discussões surgiram o mundo passou, entretanto, por mudanças importantes e tudo aquilo que se conhecia, as verdades que se buscavam eternizar, foi sendo, aos poucos, transformado. A técnica, tão valorizada pela modernidade, avança hoje muito rapidamente e bastante difícil se faz qualquer estabilização normativa. Nada parece definitivo. A velocidade não se atém às mudanças e se incorpora aos meios de comunicação e de transporte. O planeta diminuiu de tamanho e o desconhecido é desvendado. O local cada vez menos se encerra e busca cada vez mais interagir globalmente com o plural.

O direito natural pode servir igualmente à fundamentação da lei interna dos estados e tal perspectiva deve afastar a percepção de que o jusnaturalismo apenas encontraria no direito das gentes maior aceitação em razão da impossibilidade de se definir um poder centralizado e organizado dotado da atribuição de concretizar o direito, é dizer, de produzir regras jurídicas vinculantes para os sujeitos a ele submetidos ${ }^{34}$.

Mas foi o positivismo jurídico que, de fato, estabeleceu as bases para a concepção atual do direito das gentes ao transportar ao direito a perspectiva filosófica do positivismo, baseada na objetividade científica e na separação entre a moral e a norma jurídica. A identidade entre direito e norma, a completude e o formalismo são algumas características marcantes que podem ser apontadas ao direito - interno e internacional - ao longo do século $\mathrm{XX}$, no auge dessa doutrina ${ }^{35}$.

Völkerrechtsgemeinschaft noch weitgehende Dezentralisation. Es gibt hier noch keine arbeitsteilig funktionierenden Organe zur Erzeugung und Vollziehung der Rechtsnormen. Die Bildung der generellen Normen erfolgt im Wege der Gewohnheit oder durch Vertrag, das bedeutet: durch die Glieder der Rechtsgemeinschaft selbst und nicht durch ein besonderes Gesetzgebungsorgan.“

${ }^{34}$ QUADRI, Rolando. Le fondement du caractère obligatoire du droit international public. In: Recueil des Cours. Academie de Droit International de la Haye, Volume 80, 1952-I, pp. 579-633. p. 590. "In verbis“: "On peut [...] dire que le jusnaturalisme s'est manifesté au sein de la Science du droit international comme application à un domaine particulier d'une idée générale qui embraissait également le droit interne. C'est une erreur que de dire, comme on le dit très souvent, que le reconus au droit naturel par les pères de la Science du droit international fut nécessité ou au moins sollicité par l'absence dans la communauté internationale d'un supérieur politique."

${ }^{35}$ BARROSO, Luís Roberto. Temas de direito constitucional - Tomo II. Rio: Renovar, 2003. pp. 25-26. "In verbis": "O positivismo jurídico foi a importação do positivismo filosófico para o mundo do Direito, na pretensão de criar-se uma ciência jurídica, com características análogas às ciências exatas e naturais. A busca de objetividade científica, com ênfase na realidade observável e não na especulação filosófica, apartou o Direito da moral e dos valores transcendentes. Direito é norma, ato emanado do Estado com caráter imperativo e força coativa. A ciência do Direito, como todas as demais. Deve fundar-se em juízos de fato, que visam ao conhecimento da realidade, e não em juízos de valor, que representam uma tomada de posição diante da realidade. Não é no âmbito do Direito que se deve travar a discussão acerca de questões como legitimidade e justiça. O positivismo comportou algumas variações e teve seu ponto culminante no normativismo de Hans Kelsen. Correndo o risco das simplificações redutoras, é possível apontar algumas características essenciais do positivismo jurídico: (i) a aproximação quase plena entre Direito e norma; (ii) a afirmação da estatalidade do Direito: a ordem jurídica é una e emana do Estado; (iii) a completude do ordenamento jurídico, que contém conceitos e instrumentos suficientes e adequados para a solução de qualquer caso, inexistindo lacunas ; (iv) o 
O positivismo tem na idéia de contrato entre estados independentes - na pacta sunt servanda - sua base no direito internacional. Interessante se faz perceber que, para tanto, exige-se a aceitação da concepção jusnaturalista de um "estado natural das coisas", o qual se daria no direito das gentes na percepção da existência de estados soberanos e de seu convívio como um fato ${ }^{36}$. Mais que isso, a força cogente do direito é constantemente confrontada pela doutrina da soberania, a qual desvia a obrigatoriedade de um parâmetro abstrato de validade para a expressão da vontade dos sujeitos que exercem a concreção política do sistema ${ }^{37}$.

A esse respeito, é de se perceber que um dos maiores legados do positivismo estrito teria sido a própria transformação do conceito de "jurídico", o qual passou da metafísica a algo puramente reflexivo - relacionado à assunção de que as regras de direito têm origem determinada e são produto de um processo criativo. Internamente, o direito constituiria principalmente, assim, expressão da vontade do estado e, internacionalmente, dos sujeitos de direito internacional em seu conjunto. A vontade como elemento concretizador do direito consubstanciaria, portanto, o cerne da perspectiva positivista ${ }^{38}$.

formalismo: a validade da norma decorre do procedimento seguido para a sua criação, independendo do conteúdo. Também aqui se insere o dogma da subsunção, herdado do formalismo alemão."

${ }^{36}$ QUADRI, Rolando. Le fondement du caractère obligatoire du droit international public. In: Recueil des Cours. Academie de Droit International de la Haye, Volume 80, 1952-I, pp. 579-633. p. 609. "In verbis“: "En effet le positivisme débute, dans le domaine du droit international, par le dogme rationaliste de l'état de nature qui constitue l'un des traits essentiels du jusnaturalisme. La communauté internationale est représentée comme une simple somme ou juxtaposition de membres indépendants ou souverains, Indépendants non seulement par rapport aux autres membres individuellement considérés, mais aussi par rapport à leur ensemble. [...] Etant donné cette idée absolue de la souveraineté, le positivisme accepte nécessairement, malgré l'idée de l'autonomie du droit positif, avec la construction contractualiste du consentement, l'origine contractuelle du droit positive en ce qui concerne le droit interne. Les sources du droit international sont conçues d'une façon uniforme, comme des variétés d'une seule catégorie : le contrat, étant donné que même la coutume est représentée, d'après la terminologie de Grotius, comme une tacita conventio.“

${ }^{37}$ LAUTERPACHT, H. La théorie des différends non justiciables en droit international. In: Recueil des Cours. Academie de Droit International de la Haye, Volume 34, 1930-IV, pp. 493-654. p. 499. "In verbis": "La fonction du droit est de régler la conduite des hommes par référence aux règles dont la source formelle de validité se trouve dans un précepte imposé du dehors. Dans la communauté internationale, cet aspect formel, mais essentiel, du droit est constamment mis en doute par la doctrine de la souveraineté internationale des États, qui fait dériver la force obligatoire du droit des gens de la voloté propre de chaque membre individuel de cette communauté."

${ }^{38}$ AGO, Roberto. Science juridique et droit international. In: Recueil des Cours. Academie de Droit International de la Haye, Volume 90, 1956-II, pp. 851-958. p. 884. "In verbis": "Le positivisme juridique a eu finalement comme effet de transformer la notion même du «juridique », en en faisant un caractère purement réfléchi, une simple conséquence du fait que certaines règles proviennent d'une origine déterminée, qu'elles sont le produit d'un processus créatif donné, Le droit cesse ainsi d'être un phénomène qui puisse se caractériser par les aspects qui lui sont propres et par les effets auxquels il donne lieu : dans le cadre de l'Etat, le droit est la «Staatswille», ce que le Etat veut; dans le cadre international, il est ce que plusieurs Etats ont collectivement voulu et statué. Le caractère propre du droit ne provient donc plus que de son origine historique reposant sur certaines sources, sur certaines faits créateurs.“ 
A discussão da natureza de direito ou não do direito internacional não pertence à ordem internacional. Trata-se de questão levantada sob a perspectiva limitada ao campo de atuação dos estados individualmente que apresentou por muitos anos fragilidade ao direito das gentes $^{39}$. Apesar de sua importância histórica, o tema se encontra hoje definitivamente superado pela doutrina e irrelevante para o desenvolvimento deste estudo.

Ultrapassada a discussão acerca da existência do direito internacional, é dizer, de seu reconhecimento como direito, questões de fato relacionadas, por exemplo, à existência de múltiplos atores da ordem global levam à conclusão de que, caso o direito internacional não existisse, teria necessariamente que ser inventado ${ }^{40}$.

No que se refere à validade temporal, as regras de direito das gentes - como qualquer outra regra jurídica - possuem validade indeterminada e devem ser compreendidas como obrigatórias para os sujeitos de direito internacional. Entender de forma distinta, seria transformá-lo em um sistema meramente informativo, de normas de cortesia ${ }^{41}$.

Entre as perspectivas positivista e jusnaturalista de fundamentação teórica do direito internacional, justificativas filosóficas relacionadas à realização do bem comum, da busca do bem-estar da comunidade internacional, acabam consubstanciando fator axiológico importante a ser considerado como parâmetro ${ }^{42}$.

\footnotetext{
${ }^{39}$ FENWICK, Charles G.. The progress of international law during the past forty years. In: Recueil des Cours. Academie de Droit International de la Haye, Volume 79, 1951-II, pp. 01-71. p. 11. "In verbis“: "How futile it was under such conditions to discuss, as many writers whether international law was or was not "law" in the proper sense of that term. It was not the nature of international law which was at fault in the limited fields in which it had application. It was the restricted scope of the law, or, more strictly speaking, the wide area left to the free decision of the individual state, that constituted its essential weakness, -a weakness, indeed, which we have not as yet entirely overcome."
}

${ }^{40}$ WEIL, Prosper. Le droit international en quete de son identité: cours général de droit international public. In: Recueil des Cours. Academie de Droit International de la Haye, Volume 237, 1992-VI, pp. 09-370. p. 36. "In verbis": "Pour certains auteurs l'existence d'un corpus juris régissant une société décentralisée et horizontale relève du miracle. Je dirais plutôt qu'elle relève de la nécessité. Ce n'est pas en dépit, mais à cause de l'hétérogénéité des Etats dans une société de juxtaposition que droit international a été créé et s'est développé. Si le droit international n'existait pas, il faudrait l'inventer “.

${ }^{41}$ GIRAUD, Emile. Le droit international public et la politique. In: Recueil des Cours. Academie de Droit International de la Haye, Volume 110, 1963-III, pp. 419-809. p. 423. "In verbis“: "Comme tout autre droit, le droit international public est constitué par un ensamble de règles, règles générales et impersonnelles susceptibles d'une application indéfinie dans le temps. Ces règles ont pour les sujets du droit, qui en l'espèce sont les Etats ou les institutions internationales formées d'Etats, un caractère obligatoire ; autrement, elles seraient des règles de politesse, de courtoisie, de convenance internationale et non des règles de droit.“

${ }^{42}$ CASTBERG, Frede. La méthodologie du droit international public. In: Recueil des Cours. Academie de Droit International de la Haye, Volume 43, 1933-I, pp. 309-383. p. 379. "In verbis": "La science du droit international doit, somme toute, servir la vie, ce qu'elle fait en formulant et en appliquant les principes du droit international de manière à servir le bien de la communauté internationale.“ 
Fundamentações filosóficas atemporais como a apontada possibilitam que se reconheçam como rasas as análises da evolução do direito internacional público contaminadas quem sabe pelo protagonismo dos direitos humanos na atualidade sob a perspectiva da novidade - que indiquem ser o reconhecimento da principiologia do direito das gentes como jus cogens algo recente e que apenas a submissão ao pactuado era aventado pela doutrina tradicional ${ }^{43}$.

A busca por justificativas para as normas tem nos valores importante aliado. Pode-se, nesse sentido, reconhecer a especial relevância de determinados princípios para o direito das gentes, os quais - como, por exemplo, a pacta sunt servanda - tendem a ser posicionados entre os fundamentos da regulamentação da ordem global ${ }^{44}$.

Na esfera interna, a concepção dos princípios gerais do direito como vinculantes per se pela doutrina não encontrou, por muito tempo, respaldo nas decisões emanadas pelos tribunais, os quais entre o direito positivo e as teorias jusnaturalistas preferiam claramente o primeiro. Aplicado aos princípios gerais do direito das gentes, esse contexto interno poderia, em grande medida, explicar o dilema monista e dualista tão em voga no direito internacional na primeira metade do século $\mathrm{XX}^{45}$.

${ }^{43}$ KELSEN, Hans. Reine Rechtslehre - Einleitung in die rechtswissenschaftliche Problematik. Leipzig und Wien: Franz Deuticke, 1934. p. 129. "In verbis“" "Das Völkerrecht besteht aus Normen, die ursprünglich durch Akte von Staaten - das heißt von den nach den einzelstaatlichen Rechtsordnungen hierzu zuständigen Organen - zur Regelung der zwischenstaatlichen Beziehungen erzeugt wurden, und zwar im Wege der Gewohnheit. Das sind die Normen des allgemeinen, weil alle Staaten verpflichtenden und berechtigenden Völkerrechts. Unter ihnen ist von besonderer Bedeutung die Norm, die man gewöhnlich mit der Formel <<pacta sunt servanda〉> kennzeichnet. Sie ermächtigt die Subjekte der Völkerrechtsgemeinschaft, ihr Verhalten, das heißt das Verhalten ihrer Organe und Untertanen durch Verträge zu regeln."

${ }^{44}$ SCHWARZENBERGER, Georg. The fundamental principles of international law. In: Recueil des Cours. Academie de Droit International de la Haye, Volume 87, 1955-I, pp. 191-385. p. 204. "In verbis“: "In order to decide whether any individual principle of international law may be regarded as fundamental, it is propose to apply three tests: (1) The principle must be especially significant for international law. Opinion on this matter is bound to be greatly influenced by anybody's pictures of international law in perspective. (2) The principle must stand out from others by covering a relatively wide range of rules of international law which appear to fall naturally under its heading. (3) The principle must be one which is either so typical of international law that it is an essential part of any known system of international law or so characteristic of existing international law that if it were ignored, we would be in danger of losing sight of an essential feature of modem international law."

${ }^{45}$ FINCH, George A.. Les sources modernes du droit international. In: Recueil des Cours. Academie de Droit International de la Haye, Volume 53, 1935-III, pp. 531-629. p. 616. "In verbis“: "La conception d'un seul système de droit dans lequel le droit international occupe une situation supérieure et le droit national une situation inférieure paraît une réssurection des théories de droit naturel en vogue avant la naissance de l'école positive. Nous avons vu par les jugements des tribunaux nationaux oi-dessus mentionnés qu'en cas de conflit entre les théories du droit naturel et du droit positif dans la pratique actuelle des nations, c'est le droit positif qui préveut. Par contre, la conception d'une incorporation positive du droit international dans le droit municipal va trop loin dans ses prétentions., parce qu'il existe des restrictions à la conduite des Etats dits souverains à l'égard des individus, qui permettent de contrôler leur action - qu'ils le veuillent ou non." 
Observa-se, a título de exemplo, que parâmetros como o de justiça e equidade, dotados de extrema instabilidade e textura aberta, encontram-se inseridos no conceito de "leis da natureza" ${ }^{" 46}$. Constituem padrões indeterminados que dependem de referenciais para serem definidos. Sua aplicação em conjunto com outros conceitos pode transformar seus conteúdos - tal qual se percebe, por exemplo, no binômio igualdade-desigualdade ${ }^{47}$.

Possível se faz afirmar, ainda, que a importância dos princípios para o direito internacional foi consagrada e reduzida a termo antes mesmo de ser sedimentada internamente. $\mathrm{O}$ estatuto da Corte Permanente de Justiça, nesse sentido, já elencava em seu artigo 38 - vigente na atualidade para a Corte Internacional de Justiça - os princípios gerais de direito como fonte do direito das gentes. A proposta do reconhecimento amplo de valores gerais de direito internacional consagrados e a vinculação dos estados pelo mandato outorgado ao sistema jurisdicional multilateral não são novos e - ainda que reforçados atualmente pelas teorias de proteção dos direitos humanos - não devem ser reduzidos a essas conquistas $^{48}$.

${ }^{46}$ HOBBES, Thomas. Leviathan. Cambridge: hackett Publishing Company, 1994. p. 106. "In verbis": "For the laws of nature (as justice, equity, modesty, mercy, and (in sum) doing to others as we would be done to) of themselves, without the terror of some power to cause them to be observed, are contrary to our natural passions, that carry us to partiality, pride, revenge, and the like."

47 BOBBIO, Norberto; MATTEUCCI, Nicola; PASQUINO, Gianfranco. Dicionário de política - Vol. 1. Brasília: Editora Universidade de Brasília, 2010. p. 661. "In verbis": "Se a Justiça é um conceito normativo, surge agora o problema da possibilidade de a definir em termos descritivos. A Justiça foi equiparada à legalidade, à imparcialidade, ao igualitarismo e à retribuição do indivíduo segundo seu grau, sua habilidade ou sua necessidade, etc. Ora, se estas definições fossem aceitáveis, poderíamos partir de premissas baseadas em fatos para chegar a conclusões normativas. Por exemplo, se 'justo' tiver o mesmo significado de 'igual' e, portanto, se uma determinada norma for igualitária, concluiremos logicamente que ela também é justa. Logicamente seria por isso incoerente para qualquer um considerar injustas tanto as normas igualitárias como as normas não-igualitárias. Evidentemente que estas definições não são aceitáveis. Evidentemente que não podemos ir do 'ser' para o 'dever ser' e dos fatos para os valores. Todas as definições de Justiça aqui apresentadas não são, de fato, definições e sim juízos normativos, sob a capa verbal de definições, tendo como finalidade geral uma eficácia retórica. Por esse motivo, afirmações como 'a Justiça significa igualitarismo' devem ser interpretadas, não como uma definição do conceito de Justiça, mas como expressão do princípio normativo de que as normas igualitárias de distribuição são justas e as não igualitárias injustas, de onde se concluiria que apenas as normas do primeiro tipo deveriam ser aprovadas e aplicadas. A melhor coisa é considerar a Justiça como noção ética fundamental e não determinada.”

${ }^{48}$ VERDROSS, Alfred von. Les principes généraux du droit dans la jurisprudence internationale. In: Recueil des Cours. Academie de Droit International de la Haye, Volume 52, 1935-II, pp. 191-251. p. 249. "In verbis“: "Une analyse - bien qu'incomplète - de la jurisprudenee de la Cour permanente de Justice internationale nous montre donc que celle-ci n'applique pas seulement des règles coutumières et conventionnelles, mais également des principes du droit découlant d'une autre source, et que l'article $38, \mathrm{n}^{\circ} 3$, appelle - comme nous le savons «principes génraux du droit reconnus par les naitions civilisées ». A y regarder de plus près pourtant, ces principes n'ont pas tous le mêrne caractère.“ 
Percebe-se, na verdade, que, já na primeira metade do século passado, a limitação genérica dos poderes soberanos dos estados na ordem internacional por princípios gerais encontrava defesa e adesão expressa ${ }^{49}$.

O reconhecimento definitivo da importância dos indivíduos para o direito constitui hoje elemento que costuma ser apontado na caracterização das teorias pós-positivistas. Em linhas gerais, essa reformulação das teorias positivistas conformaria um conjunto difuso de ideais permeados pela distinção qualitativa entre regras e princípios e pelo posicionamento da ética e dos direitos fundamentais no centro do direito ${ }^{50}$.

As teorias jurídicas atuais se encontram bastante marcadas, em síntese, pelos princípios, os quais não conformam regras, mas, na verdade, servem para explicá-las e, principalmente, como nexo de sua fundamentação. Tanto no sistema estatal quanto no internacional, as regras se refeririam, portanto, ao "o quê" enquanto os princípios ao "porquê" das soluções jurídicas apresentadas ${ }^{51}$.

Outro dado importante do papel atual da principiologia para o direito diz respeito à textura aberta dos preceitos reconhecidos como axiológicos nos ordenamentos. A amplitude conceitual acaba reduzindo a normatividade tão almejada pelo positivismo na modernidade e

\footnotetext{
${ }^{49}$ VERDROSS, Alfred von. Les principes généraux du droit dans la jurisprudence internationale. In: Recueil des Cours. Academie de Droit International de la Haye, Volume 52, 1935-II, pp. 191-251. pp. 205-206. "In verbis": "[...] il est facile de reconnaître que les principes généraux du droit ont la précellence sur le droit international positif. En effet, s'ils se trouvent à la base du droit positf, il ne peut y être dérogé par les règles de celui-ci. Pourtant l'existence d'un principe général n'empêche en général pas l'application du droit positif valable en la matière. Car d'ordinaire les règles du droit positif ne sont que la cristallisation et la concrétisation des principes généraux. Dans ces cas, il ne sera donc pas nécessaire de recourir aux principes généraux euxmêmes, il suffira d'appliquer les règles positives. D'ordinaire, l'application directe des principes géneraux suppose ainsi la carence d'une règle positive. $\mathrm{Si}$, par contre, une règle positive se trouve en opposition avec un principe général du jus cogens, il est clair qu'elle doit céder au principe général régissant la matière. C'est ainsi qu'une disposition d'un traité, contraire aux bonnes moeurs, n'est pas valable par la raison que cette règle positive a étè dictée en violation d'un principe général s'imposant à toute convention, interne ou internationale."
}

${ }^{50}$ BARROSO, Luís Roberto. Temas de direito constitucional - Tomo III. Rio: Renovar, 2005. p. 57. "In verbis": "Pós-positvismo é a designação provisória e genérica de um ideário difuso, no qual se incluem o resgate dos valores, a distinção qualitativa entre princípios e regras, a centralidade dos direitos fundamentais e a reaproximação entre o Direito e a Ética. A estes elementos devem-se agregar, em um país como o Brasil, uma perspectiva do Direito que permita a superação da ideologia da desigualdade e a incorporação à cidadania da parcela da população deixada à margem da civilização e do consumo. E preciso transpor a fronteira da reflexão filosófica, ingressar na prática jurisprudencial e produzir efeitos positivos sobre a realidade."

${ }^{51}$ FITZMAURICE, Gerald. The general principles of international law considered from the standpoint of the rule of law. In: Recueil des Cours. Academie de Droit International de la Haye, Volume 92, 1957-II, pp. 01227. p. 07. "In verbis": "By a principle, or general principle, as opposed to a rule, even a general rule, of law is meant chiefly something which is not itself a rule, but which underlies a rule, and explains or provides the reason for it. A rule answers the question 'what': a principle in effect answers the question 'why'. In the event of any dispute as to what the correct rule is, the solution will often depend on what principle is regarded as underlying the rule." 
abre espaço para a atuação política concretiva no momento da aplicação do direito. O direito atual, pós-positivista, perdeu sua característica de neutralidade e viu as possibilidades hermenêuticas serem potencializadas.

Tal qual sistematizado na teoria jurídica interna, os princípios do direito internacional podem ser classificados em estratos, ou seja, em níveis de importância ${ }^{52}$. Essa característica, apontada por parte da doutrina aos valores não pertenceria, na verdade, ao direito local ou ao geral com exclusividade, mas à teoria do direito como um todo ${ }^{53}$.

$\mathrm{Na}$ estrutura de direito internacional, o costume muitas vezes se identifica com a principiologia e chega a ser reconhecido no mesmo patamar das normas reduzidas a termo por tratado. Podem, inclusive, ter sua força derrogatória de acordos escritos reconhecida. Tais características não se reproduzem, entretanto e em regra, no direito positivo interno de um estado $^{54}$.

Do exposto, ressalta-se, portanto, que a doutrina internacionalista chega a aceitar o costume internacional como vinculante. Nesse sentido, além do clássico exemplo do princípio da pacta sunt servanda, o próprio reconhecimento dos estados como sujeitos de direito internacional se dá com base no costume e uma vez mais se torna bastante clara a analogia

\footnotetext{
${ }^{52}$ SCHWARZENBERGER, Georg. The fundamental principles of international law. In: Recueil des Cours. Academie de Droit International de la Haye, Volume 87, 1955-I, pp. 191-385. p. 195. "In verbis“: "The principles of International Law may, however, also be understood in a narrower sense. The task is then to elaborate the fundamental, as distinct from more subordinate, principles of international law. [...] Experience with any of the systems of municipal law teaches that all of them take for granted a stratification of legal principles. Thus, prima facie, it may be assumed that the same is true of international law."
}

${ }^{53}$ SCHWARZENBERGER, Georg. The fundamental principles of international law. In: Recueil des Cours. Academie de Droit International de la Haye, Volume 87, 1955-I, pp. 191-385. p. 200. "In verbis“: "In order to deal fairly with this argument, we must attempt to clarify the nature and purpose of legal principles. Every lawyer who has received his basic training in one or the other mature system of municipal law is so steeped in thinking in terms of legal principles that, subconsciously, he primarily tends to look to relevant principles for the solution of any particular problem and to apply these to the concrete issue before him. Even in CommonLaw systems this is unavoidable; for legal principles are the only means of creating order in a gradually unwieldy mass of case law. Moreover, an increasing number of consolidating and codifying statutes has transformed a growing number of there legal principles into actual rules of law.”

${ }^{54}$ HEILBORN, Paul. Les sources du droit international. In: Recueil des Cours. Academie de Droit International de la Haye, Volume 11, 1926-I, pp. 01-63. p. 29. "In verbis“: "Les deux sources ont la même force : une règle du droit coutumier peut être abolie par un accord, mais le droit coutumier a aussi force dérogatoire vis-à-vis de l'accord. Chaque règle peut être ou bien révoquée par simple « desuetudo » ou bien remplacée par une nouvelle règle inconciliable avec l'ancienne. La force égale des deux sources va de soi pour quiconque regarde le droit coutumier comme un accord tacite, c'est-à-dire les deux sources comme émanations de la même volonté. Mais encore à notre point de vue l'égalité des deux sources ne saurait être mise en doute. Dans le droit interne, la discussion de la force dérogatoire du droit coutumier vis-à-vis de la loi n'est pas dénuée de fondement." 
com o direito local e com a maneira como a personalidade dos indivíduos é reconhecida internamente pelas ordens jurídicas ${ }^{55}$.

Percebe-se, assim, que o costume sempre foi reconhecido como ponto fundamental do direito das gentes. Mais intensamente, na verdade, do que nos outros ramos do direito, os quais historicamente passaram por processos legislativos formais. Essa característica diversa tampouco pode servir de argumento para que não se reconheça a obrigatoriedade das regras de direito das gentes, as quais - ainda que muitas vezes sem força executória - mostram-se cogentes ${ }^{56}$.

Muito dessa obrigatoriedade pode se dever, observa-se, à política, isto é, à distribuição da força no plano internacional, a qual pode exigir o cumprimento de uma tradição - de um costume reconhecido como princípio - para que um estado participe da comunidade internacional.

Fundamental se faz ressaltar, ainda, o valor das normativas internas dos estados para o direito das gentes. Nesse sentido, à norma de direito interno - constitucional, mormente pode ser reconhecido efeito internacional. Isso se dá, por exemplo, nos dispositivos constitucionais que proíbem a guerra de conquista. Esse tipo de vedação de direito local possui claros efeitos que ultrapassam os limites do território do estado ${ }^{57}$.

Ainda no que se refere à relação da ordem local com a geral, alguns estudiosos observam a prática do common law inglês como tendo sido a primeira ordem estatal a adotar um sistema monista - com prevalência do direito internacional. Tal perspectiva interpreta, via

\footnotetext{
${ }^{55}$ MORELLI, Gaetano. Cours général de droit international public. In: Recueil des Cours. Academie de Droit International de la Haye, Volume 89, 1956-I, pp. 437-604. p. 517. "In verbis“: "La conclusion à laquelle il faut aboutir, sur la base des considérations exposes jusqu'ici, est que les règles internationales ayant le caractère de règles coutumières générales s'adressent d'une façon immédiate à tous les Etats existants de fait. Cela revient à dire que les Etats acquièrent la personalité par un procédé analogue à celui par lequel la personnalité est attribuée dans les ordres étatiques aux individus humains.“
}

${ }^{56}$ HEILBORN, Paul. Les sources du droit international. In: Recueil des Cours. Academie de Droit International de la Haye, Volume 11, 1926-I, pp. 01-63. pp. 20-21. "In verbis“: "Le droit des gens, comme tout droit, naquit d'abord dans la forme du droit coutumier. Mais tandis qu'avec les progrès de la civilisation les autres branches du droit furent réglées en plus eu plus par voie de législation, aujourd'hui encore le droit des gens est en grande partie un droit coutumier. La jurísprudence générale nous présente la notion du droit coutumier. C'est le droit qu'une société applique effectivement et d'une manière permanente dans la conviction de sa force obligatoire."

${ }^{57}$ MIRKINE-GUETZEVITCH, Boris. Le droit constitutionnel et l'organisation de la paix (droit constitutionnel de la paix). In: Recueil des Cours. Academie de Droit International de la Haye, Volume 45, 1933-III, pp. $667-$ 773. p. 767. "In verbis“: "Et si, à côté des pactes du droit international, on peut aboutir ainsi à un certain jus gentium de la paix, à des règles parallèles dans toutes les Constitutions, bien que la source de cette renonciation à la guerre soit constitutionnelle, l'effet en sera toujours international. L'effet international peut être réalisé par une règle du droit international. La législation parallèle, si elle ne remplace pas un traité, peut cependant avoir les mêmes effets internationaux qu'un traité. Or, en ce qui concerne la paix, c'est l'effet, l'effet international qui compte et non les bases philosophiques ou théoriques." 
de regra, de maneira equivocada a premissa de que o direito das gentes deve ser considerado pelo aplicador do direito como direito local. Não se trata de um reconhecimento de preferência de um pelo outro, mas, na verdade, de uma autorização para que o juiz nacional aplique normativa internacional na solução de casos $\operatorname{concretos}^{58}$.

Também as experiências da ordem interna relacionadas à organização do estado podem servir de parâmetro à ordem internacional, mas essas não devem ser, conforme se demonstrará adiante, meramente reproduzidas. A construção jurídica interna relacionada ao poder deve servir apenas à compreensão da dinâmica global em razão de não existir absoluta identidade entre os princípios gerais de direito das gentes e de direito estatal interno. A identidade entre princípios orientadores pode, de fato, ocorrer, mas essas questões devem ser verificada caso a caso ${ }^{59}$.

Nesse sentido, se, por um lado, constituições ou o costume freqüentemente permitem a aplicação do direito das gentes pelo juiz nacional, poucos são os sistemas que reconhecem nas regras externas primazia em relação às internas. Trata-se de mera autorização, a qual não raramente permite emprego reverso, é dizer, a aplicação da norma local em desfavor da normativa internacional ${ }^{60}$.

\footnotetext{
${ }^{58}$ VISSCHER, Paul De. Les tendances internationales des constitutions modernes. In: Recueil des Cours. Academie de Droit International de la Haye, Volume 80, 1952-I, pp. 511-578. pp. 522-524. "In verbis“": "C'est dans le système juridique anglais que nous trouvons l'application la plus ancienne de ce procédé de l'adoption automatique qui s'énonce dans l'adage : 'International law is part of the law of the land'. Les juristes d'Europe continentale, peu familiarisées avec la pratique du common law, ont parfois tendance à voir dans cet adage, l'énoncé de la théorie moniste de la supériorité automatique du droit international sur le droit interne. [...] Ainsi entendue dans sa nature de règle du droit interne, ainsi limitée dans son objet, la règle 'International law is part of the law of the land' a pour effet d'autoriser le juge interne à considérer comme faisant partie du common law les régles impératives et certaines du droit international commun, alors même que ces règles n'auraient fait l'objet d'aucune reconnaissance ou réception formelle de la part du législateur naturel. [...] Ce bref rappel de la pratique anglais nous permet d'affirmer que l'adage 'International law is part of the law of the land' ne consacre en aucune façon la supériorité du droit international coutumier sur le droit interne.“
}

${ }^{59}$ VERDROSS, Alfred von. Les principes généraux du droit dans la jurisprudence internationale. In: Recueil des Cours. Academie de Droit International de la Haye, Volume 52, 1935-II, pp. 191-251. p. 219. "In verbis": "[...] un principe du droit interne commun aux nations civilisées n'est valable pour les relations internationales que s'il est applicable à celles-ci. Mais il n'existe pas de critère général pour savoir si un principe du droit interne est applicable, par analogie, aux relations internationales : il faut décider dans chaque cas d'après la nature du principe invoqué.“

${ }^{60}$ VISSCHER, Paul De. Les tendances internationales des constitutions modernes. In: Recueil des Cours. Academie de Droit International de la Haye, Volume 80, 1952-I, pp. 511-578. pp. 530-531. "In verbis": "Si, expressément ou tacitement, la plupart des régimes constitutionnels consacrent au profit du juge interne le pouvoir d'appliquer le droit intemational commun, rares sont ceux qui conférent aux règles internationales ainsi globalement adoptées une suprématie quelconquc sur les règles de droit interne. Au contraire, nous avons vu que le juge qui, statutairement, est un organe de la souveraineté nationale, doit appliquer les lois qui sont manifestement, en opposition avec le droit international commun." 
A concepção do direito como um todo, isto é, o abandono das estruturas que repartem ordens jurídicas e ramos do direito e criam categorias estanques tem na percepção atual do direito constitucional como horizontal seu maior exemplo na ordem interna de países como o Brasil $^{61}$. Não raramente, essa característica do direito interno é entendida pela doutrina como reflexo de conquistas globais relacionadas aos direitos humanos ${ }^{62}$. A definitiva centralidade do ser humano é, de fato, uma das razões do paulatino abandono da visão compartimentada do direito $^{63}$.

O corpo normativo do direito é uno e a divisão entre ordens internas e internacional faz sentido apenas para fins de organização sistêmica, mas isso não quer dizer, contudo, que as regras aplicáveis não variam conforme as circunstâncias e as aspirações dos sujeitos envolvidos $^{64}$. Dividir o direito entre local e global esbarra em sua própria concepção

${ }^{61}$ BARROSO, Luís Roberto. Temas de direito constitucional - Tomo III. Rio: Renovar, 2005. p. 509. "In verbis": "Perda da centralidade do Código Civil e atenuação da dualidade público e privado. Simultaneamente, verificou-se a perda da centralidade do direito civil, do Código Civil e, no caso de países como o Brasil, dos múltiplos microssistemas que se formaram em torno dele. A própria dualidade extrema entre público e privado, entre direito público e direito privado, foi atenuada, deixou se ser qualitativa e passou a ser quantitativa: a Constituição, o direito público passou a permear as relações jurídicas em geral, em maior ou menor intensidade."

${ }^{62}$ TIBURCIO, Carmen; BARROSO, Luís Roberto. Direito constitucional internacional. Rio: Renovar, 2013. pp. 20-21. "In verbis": "O legislador constituinte, assim, traz para o plano interno tendência já consolidada no plano internacional. Nessa seara, os direitos humanos ingressaram de maneira definitiva no rol de preocupações do legislador convencional a partir da Carta da ONU de 1945 e, posteriormente, com a Declaração Universal dos Direitos Humanos e a Carta da OEA, ambos os textos de 1948, a Convenção Americana sobre Direitos Humanos de 1969 e os Pactos das Nações Unidas (Direitos Civis e Políticos e Direitos Econômicos Sociais e Culturais) de 1966. Mais recentemente, tem-se como exemplo de instrumento internacional inserido no tema, O Estatuto de Roma de 1998, instituidor do Tribunal Penal Internaciona1. O respeito aos direitos humanos constitui hoje um padrão para aferir a legitimidade do Estado perante a comunidade internacional. Tal postura é considerada como dever do Estado na Declaração de Direitos e Deveres dos Estados (1949), artigo $6^{\circ}[\ldots] "$

${ }^{63}$ TIBURCIO, Carmen; BARROSO, Luís Roberto. Direito constitucional internacional. Rio: Renovar, 2013. p. 15. "In verbis": "Como já visto, a convergência temática entre as preocupações constitucionalistas e internacionalistas recai na dignidade humana e nos direitos humanos - ou direitos fundamentais. O final da década de 1980 traz consigo dois importantes acontecimentos para esse fenômeno. No plano internacional, a eminência do fim da Guerra Fria fez com que as violações dos direitos humanos deixassem de ser encaradas como mera guerra de propaganda para constituir temática das mais relevantes no cenário internacional. Simultaneamente, no Brasil, a intensa participação da sociedade civil no processo de redemocratização e na elaboração da Constituição de 1988 trouxe à tona a temática dos direitos fundamentais."

${ }^{64}$ ROBERTSON, Arthur Henry. Legal problems of European integration. In: Recueil des Cours. Academie de Droit International de la Haye, Volume 91, 1957-I, pp. 105-211. p. 109. "In verbis": "If international law is the body of rules binding on states in their relations with one another, then the rules themselves must vary according to the relations being considered. If these relations amount to a state of war, obviously different rules will apply from those applicable in time of peace. But even in time of peace, international relations conducted between two states for the achievement in cooperation of a common objective will differ (as regards the rules which apply) from negotiations between states which are each seeking to obtain some advantage at the expense of the other." 
sistêmica ${ }^{65}$. Não cabe mais hoje falar em monismo ou dualismo - interno ou internacional. Trata-se de questão superada ou - para os mais resistentes - que urge ser superada.

Assim, a questão da existência de um direito das gentes, ou seja, do reconhecimento da ordem internacional como uma estrutura jurídica normativa não está contida atualmente na teorização internacionalista. Direito internacional é direito.

A urgência moderna da proteção do ser humano amadureceu e a pós-modernidade aprofundou a percepção da centralidade do indivíduo para o direito. Mais que significar uma conquista, a valorização da pessoa representou uma nova percepção do jurídico que, indiretamente, devolveu ao direito das gentes a pretensão de universalidade que lhe coube em período anterior à formação das ordens normativas estatais autônomas na modernidade. Dessa forma, o direito se fundamentaria hoje não apenas nas regras de validade positivistas, mas também definitivamente em princípios e valores.

As premissas apontadas são válidas atualmente, ressalte-se, para o direito como um todo. Ainda que sejam reconhecidas ordens normativas locais autônomas, essas convivem como partes de um sistema jurídico global comum. Marcos legais consensuados e princípios reconhecidos como inerentes trabalham em conjunto promovendo a unicidade sistêmica do direito.

Superada a questão existencial, a superação da dicotomia entre interno e internacional impõe-se aos juristas. A percepção sistêmica do direito exigirá em algum momento o abandono do estudo do local e do geral como estruturas independentes. Nesse contexto, da escolha entre o interno e o internacional restará, portanto, apenas o direito.

\footnotetext{
${ }^{65}$ KELSEN, Hans. Les rapports de système entre le droit interne et le droit international public. In: Recueil des Cours. Academie de Droit International de la Haye, Volume 14, 1926-IV, pp. 227-331. pp. 231-232. "In verbis": "Nous aurons ainsi frayé la voie à cette idée que les rapports entre État et communauté internationale, ou encore entre droit interne et droit international, sont des rapports systématiques c'est-à-dire que ce sont deux éléments d'un seul et même système juridique. De la sorte, nous aurons établi l'unité du droit en tant que système de toutes les règles juridiques en vigueur, tant des regles de droit interne que de celles de droit international. Mais cette unité n'est en somme que l'expression de l'unité de la connaissance juridique. La science du droit, comme toute science, se propose en dernèire analyse de saisir son objet dans son unité. Aussi faut-il admettre, avant tout et sans rèserve, qu'elle a pour seul et unique objet des règles de droit positif. Si l'on considère le problème de l'unité dernière de la connaissance comme un problème philosophique, et par suite l'unification du système du droit, comme une tâche propre de la philosophie du droit, la philosophie du droit, que nous exposons ici, n'est pas autre chose qu'une théorie du droit positif, et une véritable science du droit n'est possible qu'autant que la philosophie du droit y est immanente.“
} 


\subsection{Direito, Política e Direito Internacional}

\section{O conceito de política se encontra hoje intimamente ligado ao da organização do}

poder, mais especificamente ao governo e a sua técnica de exercício do poder em sociedade. Do conceito genérico original que se referia a tudo que dizia respeito à vida social, houve ao longo da história sua restrição semântica à estruturação do poder ${ }^{66}$. Política consiste, portanto, basicamente no próprio poder, em sua organização e nas formas como se estrutura seu exercício $^{67}$.

${ }^{66}$ BOBBIO, Norberto; MATTEUCCI, Nicola; PASQUINO, Gianfranco. Dicionário de política - Vol. 1. Brasília: Editora Universidade de Brasília, 2010. p. 954. "In verbis": "Derivado do adjetivo originado de pólis (politikós), que significa tudo o que se refere à cidade e, conseqüentemente, o que é urbano, civil, público, e até mesmo sociável e social, o termo Política se expandiu graças à influência da grande obra de Aristóteles, intitulada Política, que deve ser considerada como o primeiro tratado sobre a natureza, funções e divisão do Estado, e sobre as várias formas de Governo, com a significação mais comum de arte ou ciência do governo, isto é, de reflexão, não importa se com intenções meramente descritivas ou também normativas, dois aspectos dificilmente discrimináveis, sobre as coisas da cidade. Ocorreu assim desde a origem uma transposição de significado, do conjunto das coisas qualificadas de um certo modo pelo adjetivo 'político', para a forma de saber mais ou menos organizado sobre esse mesmo conjunto de coisas: uma transposição não diversa daquela que deu origem a termos como física, estética, ética e, por último, cibernética. O termo Política foi usado durante séculos para designar principalmente obras dedicadas ao estudo daquela esfera de atividades humanas que se refere de algum modo as coisas do Estado: Politica methodice digesta, só para apresentar um exemplo célebre, é o titulo da obra com que Johannes Althusius (1603) expôs uma das teorias da consociatio publica (o Estado no sentido moderno da palavra), abrangente em seu seio várias formas de consociationes menores. $\mathrm{Na}$ época moderna, o termo perdeu seu significado original, substituído pouco a pouco por outras expressões como 'ciência do estado', 'doutrina do estado', 'ciência política', 'filosofia política', etc., passando a ser comumente usado para indicar a atividade ou conjunto de atividades que, de alguma maneira, têm como termo de referência a polis, ou seja, o estado. Dessa atividade a pólis é, por vezes, o sujeito, quando referidos à esfera da Política atos como o ordenar ou proibir alguma coisa com efeitos vinculadores para todos os membros de um determinado grupo social, o exercício de um domínio exclusivo sobre um determinado território, o legislar através de normas validas erga omnes, o tirar e transferir recursos de um setor da sociedade para outros, etc.; outras vezes ela é objeto, quando são referidas à esfera da Política ações como a conquista, a manutenção, a defesa, a ampliação, o robustecimento, a derrubada, a destruição do poder estatal, etc. Prova disso é que obras que continuam a tradição do tratado aristotélico se intitulam no século xix filosofia do direito (Hegek, 1821). Sistema da ciência do Estado (Lorenz von Stein, 1852-1856), Elementos de ciência politica (Mosca, 1896), Doutrina geral do Estado (Georg Jellinek, 1900). Conserva parcialmente a significação tradicional a pequena obra de Croce, Elementos de política (1925), onde política mantém o significado de reflexão sobre a atividade política, equivalendo, por isso, a 'elementos de filosofia política'. Uma prova mais recente é a que se pode deduzir do uso enraizado nas línguas mais difundidas de chamar história das doutrinas ou das idéias políticas ou, mais genericamente, história do pensamento político à história que, se houvesse permanecido invariável o significado transmitido pelos clássicos, teria de se chamar história da Política, por analogia com outras expressões, como história da física, ou da estética, ou da ética: uso também aceito por Croce que, na pequena obra citada, intitula Para a história da filosofia da política o capitulo dedicado a um breve excursus histórico pelas políticas modernas."

${ }^{67}$ WEBER, Max. Politik als Beruf. Stuttgart: Reclam, 2008. p. 07. "In verbis“: "Das entspricht im wesentlichen ja auch dem Sprachgebrauch. Wenn man von einer Frage sagt: sie sei eine $>>$ politische $<<$ Frage, vor einem Minister oder Beamten: er sei ein $>>$ politischer $<<$ Beamter, von einem Entschluß: er sei $>>$ politisch $<<$ bedingt, so ist damit immer gemeint: Machtverteilungs-, Machterhaltungs- oder Machtverschiebungsinteressen sind maßgebend für die Antwort auf jene Frage oder bedingen diesen Entschluß oder bestimmen die Tätigkeitssphäre des betreffenden Beamten. - Wer Politik treibt, erstrebt Macht, - Macht entweder als Mittel 
Outra relação importante diz respeito à política e ao direito. Direito e política, na verdade, não apenas se relacionam, mas dependem reciprocamente um do outro. Particularmente quanto ao direito, sua estrutura depende claramente da política, mas, ao mesmo tempo, conserva em relação a ela alguma autonomia ${ }^{68}$. Tratam-se de categorias distintas que, em certa medida, competem na regulação do poder social ${ }^{69}$.

Mais que isso, constituem fenômenos inter-relacionados, pontas de uma mesma trama social. Em perspectiva eminentemente positivista, a política criaria o direito: internamente como expressão da vontade do estado e internacionalmente como expressão dos anseios de um coletivo de estados. Assim, a política estaria no direito e o direito, uma vez criado, estabeleceria limites e regulamentaria a atividade política. Uma ordem social - interna ou internacional - pode ser regulamentada e legitimada por mais direito e menos política ou ao contrário, mas nunca apenas por direito ou apenas por política.

Concebida a política como sinônimo de força, por exemplo, é de se observar que sua relação com o direito muitas vezes significa, na ordem internacional, a tensão entre direito e força $^{70}$. Internamente, a titularidade da soberania como poder absoluto que concentraria o monopólio da força foi inicialmente percebida de maneira pessoal e autárquica pela doutrina e apenas em um segundo momento, principalmente no século XIX ainda que identificáveis posicionamentos anteriores nesse sentido, como prerrogativa da sociedade, é dizer, do elemento subjetivo que compõe o estado ${ }^{71}$.

im Dienst anderer Ziele - idealer oder egoisticher - oder Macht >>um ihrer selbst willen<<: um das Prestigegefühl, das sie gibt, zu genießen.“

${ }^{68}$ GIRAUD, Emile. Le droit international public et la politique. In: Recueil des Cours. Academie de Droit International de la Haye, Volume 110, 1963-III, pp. 419-809. p. 427. "In verbis“: "Le droit en général et pas seulement le droit international a avec la politique des rapports très étroits et non point des relations plus ou moins lâches comme il en existe entre toutes les activités sociales et entre les diverses sciences qui étudient ces activités. Le droit est dans la dépendance de la politique qui le domine. Toutefois, malgré cette dépendance, le droit conserve une certaine autonomie vis-à-vis de la politique.“

${ }^{69}$ GIRAUD, Emile. Le droit international public et la politique. In: Recueil des Cours. Academie de Droit International de la Haye, Volume 110, 1963-III, pp. 419-809. p. 431. "In verbis": "Si la politique est la source du droit, à la fois du droit interne qui est l'expression de la volonté du pouvoir politique de l'Etat et du droit international qui est l'expression de la volonté des Etats, c'est-à-dire de leurs gouvernements, il reste que le droit, une fois qu'il a été crée ne se confond pas avec la politique. La créature a une vie distincte de celle de son créateur.“"

${ }^{70}$ TUNKIN, Grigory. Politics, law and force in the interstate system. In: Recueil des Cours. Academie de Droit International de la Haye, Volume 219, 1989-VII, pp. 227-395. p. 372. "In verbis“: "[...] politics is omnipresent: it stands behind the law as well as behind power or force. According to what outweighs in politics - law or force - one may speak of two conceptual models of the interstate system: the balance-of-power model and the rule of law, or as I would prefer, the primacy of international law model."

${ }^{71}$ JELLINEK, Georg. Das Recht des modernen Staates. Berlin: Verlag von O. Häring, 1900. pp. 424-425. "In verbis": "Nachdem der Versucht, das Problem der souveränetät mit der Annahme einer doppelten Hoheit, der 
De início, contudo, essa alteração de paradigmas não significou diminuição da submissão dos indivíduos à força soberana. Essa apenas se deslocou do monarca, pessoa, para o governo, como conjunto de detentores da exclusividade do exercício do poder. O marco histórico definitivo do arrefecimento da submissão arbitrária da sociedade ao governo soberano pode ser estabelecido na revolução francesa, a partir da qual se desenvolveu o constitucionalismo limitador da soberania interna - instrumentalizado por e para o ser humano $^{72}$.

$\mathrm{Na}$ esfera interna, o constitucionalismo substituiu, portanto, o absolutismo organizando o poder do estado com base e nos limites do direito ${ }^{73}$. Constitucionalismo possui

maiestas realis und personalis zu lösen, sowie auch die Andeutungen des Grotius nicht Erkenntniss der Staatssouveränetät zu führen vermochten, vielmehr in der so einflussreichen Lehre des Hobbes die fürstliche Souveränetät die des staatlichen Corpus völlig absorbirte, wird in der Folge lange Zeit hindurch die persönliche Souveränetät als die alleinige betrachtet, und auch sie ruht fernerhin im letzten Grunde auf der Volkssouveränetät. Nicht nur der absolute Herrscher des Hobbes, auch das mit despotischer Gewalt ausgerüstete Parlament Blockstones und endlich das mit unveräusserlicher Gewalt begabte Volk Rousseaus führen auf dieselbe Gedankenkette zurück. Nicht minder steht aber die in Englaud mit Thomas Smith und Hooker beginnende, in Locke und Montesquieu zur Blüte gedeihende constitutionelle Theorie bis auf Sieyès und B. Constant herab auf dem Boden der Lehre von der denknotwendigen ursprünglichen Volkssouveränetät. Hatte doch vor Rousseau bereits Montsquieu in der gesetzgebenden Gewalt die volonté générale erblickt. Damit dringt die Souveränetätslehre von neuem erobernd vor. Die konstitutionelle Doktrin und die Lehre des contrat social erheben nicht minderen Anspruch auf Gestaltung des staatlichen Lebens nach ihren Principien, wie es in den zwei vorangehenden Jahrhunderten im Westen Europas die Theorie der Fürstensouveränetät getan hatte. Die Verfassungen der Vereinigten Staaten im Gliedstaat und in der Union, die konstitutionellen Experimente der frenzösischen Revolution, die Theorie vom unveräusserlichen, dem Volke zustehenden pouvoir constituant, die bis in die Bewegung der Jahre 1848 hinein eine so grosse Rolle spielt, die Konstruirung der belgischen Monarchie auf der Basis der Nationalsouveränetät sind Beispiele von der praktisch-politischen Bedeutung dieser Wendung der Souveränetätslehre.”

${ }^{72}$ A afirmação feita não ignora a importância da Revolução Inglesa e da Independência dos Estados Unidos da América nesse processo. Cumpre reconhecer, ainda, a percepção continental européia que exprime. BONAVIDES, Paulo. Teoria geral do estado. São Paulo: Malheiros Editores, 2012. p. 40. "In verbis": "O Absolutismo pré-1789 expirava, para nunca mais erguer-se com a rigidez do ancien régime. Das Constituições Francesas da Revolução derivava, assim, o primeiro Estado constitucional. De sua feição, de seus traços mais característicos, de sua importância para a História e para a evolução das sociedades livres, que o perfilharam, haveremos de tratar em seguida. Começa então o capítulo da limitação do poder; do Homem-povo, do Homem-cidadão, do Homem-político, do Homem que faz a lei, que governa, ou se deixa governar, que cria a representação, que toma consciência da legitimidade, que é poder constituinte e poder constituído.”

${ }^{73}$ BONAVIDES, Paulo. Teoria geral do estado. São Paulo: Malheiros Editores, 2012. pp. 42-43. "In verbis": "Se a Idade Média enquanto expressão de poder fora obra de uma teologia jusnaturalista, a mesma base filosófica - a saber, o direito natural, desvinculado, porém, da divindade e articulado com a razão, donde emana - reaparece e escreve o segundo capítulo dessa novela de poder que é o Constitucionalismo, em substituição do Absolutismo. [...] Verifica-se, portanto, que a premissa capital do Estado Moderno é a conversão do Estado absoluto em Estado constitucional; o poder já não é de pessoas, mas de leis. São as leis, e não as personalidades, que governam o ordenamento social e político. A legalidade é a máxima de valor supremo e se traduz com toda energia no texto dos Códigos e das Constituições." 
estreita vinculação com as liberdades individuais e com as garantias a elas relacionadas. A liberdade individual se encontraria, assim, estruturada e limitada pelo direito ${ }^{74}$.

No que se refere ao prisma funcionalista, a diferença entre as perspectivas objetiva e subjetiva de poder pode ser considerada presente na teoria do estado em seus primórdios desde os primeiros escritos que buscavam explicar a organização de seu exercício. Nesse contexto, a separação das funções, por exemplo, não significa, em nenhuma das perspectivas teóricas destacadas de maneira mais recorrente, que um órgão pode exercer mais de uma delas ou, até mesmo, que apenas um centro de poder exerceria todas ${ }^{75}$.

Internamente, essa peculiaridade pode se refletir em diferenças entre os modelos de estado disponíveis na atualidade e, internacionalmente, pode respaldar a possibilidade de aplicação destas teorias para auxiliar a compreensão da organização do poder na esfera global $^{76}$.

${ }^{74}$ MONTESQUIEU, Charles de Secondat Baron de. De l'esprit des lois - Vol 2. Paris: Garnier-Flammarion, 1979. p. 198. "In verbis“: "La liberté consiste, principalement, à ne pouvoir être force à faire une chose que la loi n'ordonne pas; et on n'est dans cet état, que parce qu'on est gouverné par des lois civiles: nous sommes donc libres, parce que nous vivons sous des lois civiles.". Também em pp. 321-322, "In verbis“": "Il faut remarquer que les trois pouvoirs peuvent être bien distribués par rapport à la liberté de la constitution, quoiqu'ils ne le soient pas si bien dans le rapport avec la liberté du citoyen. A Rome, le peuple ayant la plus grande partie de la puissance législative, une partie de la puissance de juger, c'était un grand pouvoir qu'il fallait balancer par un autre. Le sénat avait bien une partie de la puissance exécutrice; il avait quelque branche de la puissance législative: mais cela ne suffisait pas pour contrebalancer le peuple. Il fallait qu'il eût part à la puissance de juger; et il y avait part, lorsque les juges étaient choisis parmi les sénateurs. Quand les Gracques privèrent les sénateurs de la puissance de juger, le sénat ne put plus résister au peuple. Ils choquèrent donc la liberté de la constitution, pour favoriser la liberté du citoyen; mais celle-ci se perdit avec celle-là.“

${ }^{75}$ JELLINEK, Georg. Das Recht des modernen Staates. Berlin: Verlag von O. Häring, 1900. p. 553. "In verbis": "Prüft man die Lehre Montesquieus unter dem Gesichtspunkte der Funktionentheorie, so ergiebt sich, dass er gleich allen seinen Vorgängern aus der Verschiedenheit der Subjekte den Rückschluss auf eine Verschiedenheit der von diesen versehenen objektiven Tätigkeiten gemacht hat. Der bedeutende Unterschied aber zwischen ihm und all seinen Vorgängern besteht darin, dass in seinem Idealbilde des Staates der subjektive und der objektive Unterschied sich durchweg decken sollen, während von Aristoteles bis auf Montesquieu zwar auf den Unterschied der Subjekte die Erkenntniss objektiver Unterschiede gegründet, jedoch nicht der geringste Anstoss daran genommen wird, dass dieselben Personen an der Ausübung mehrerer oder aller Funktionen beteiligt sind. Dieselben Personen können nach Aristoteles im Rat, in der Regierung, im Gericht sitzen, während bei Locke der Monarch an allen Staatstätigkeiten teilnimmt."

${ }^{76}$ JELLINEK, Georg. Das Recht des modernen Staates. Berlin: Verlag von O. Häring, 1900. p. 562. "In verbis": "Deckt sich somit der materielle (objektive) Gegensatz von Gesetzgebung, Verwaltung, Rechtsprechung keineswegs mit dem formellen (subjektiven) der Tätigkeiten der gesetzgebenden, verwaltenden und Justizorgane, so ist dennoch auf Grund der Erkenntniss des Unterschiedes der materiellen Funktionen auch ihre fortschreitende Aufteilung an die entsprechenden Organe gefordert und in steigendem Masse durchgeführt worden. Unter diesem Gesichtspunkte hat man die Superiorität der Gesetzgebung über die Verordnungsgewalt, die Unzulässigkeit dispensatorischer Akte der Regierung ohne gesetzliche Ermächtigung aus der schärferen Erkenntniss des Wesens der materiellen Gesetzgebung abgeleitet. Die Auseinandersetzung zwischen Verwaltung und Rechtsprechung ist in stetem Fortschreiten begriffen. Die Verwaltungsgerichtsbarkeit nimmt immer mehr an Umfang zu, und obwohl dort, wo bereits ein geregelter Instanzenzug vorhanden ist, die Vereinigung von Gerichts- und Beschlussbehörde in der unteren und mittleren Instanz noch statt hat, so sind doch auch hier Ansätze zu einer organisatorischen Sonderung der verschiedenen Funktionen dieser Behörden durchgeführt worden." 
De certo, o estado de direito vem desde o século XVIII, ao lado dos princípios liberais do iluminismo, sendo utilizado pelos juristas como paradigma conceitual aplicável à sociedade internacional, a qual - não raramente antes, mas agora menos - tende a ser percebida de forma análoga ao domínio jurídico interno de um país ${ }^{77}$. A referida analogia estrutura e justifica a ordem jurídica internacional como una, isto é, dotada de objetividade não constatável em idéias, preferências e visões políticas. O esforço comparativo habilita o direito das gentes, portanto, a produzir normas gerais, abstratas e pretensamente universais ${ }^{78}$.

Os críticos à mencionada objetividade normativa - de característica moderna, positivista e genuinamente apartada da política - sustentam que essa não se verificaria na prática por desatender, sob o prisma legislativo, o pressuposto liberal da concretude, segundo o qual o direito deveria se basear em algo palpável, como um comportamento social, para que

${ }^{77}$ BOBBIO, Norberto. Estado, governo, sociedade; por uma teoria geral da política. Rio : Paz e Terra, 1987. pp. 101-104. "In verbis“: "A soberania tem duas faces, uma voltada para o interior, outra para o exterior. Correspondentemente, vai ao encontro de dois tipos de limites : os que derivam das relações entre governantes e governados, e são os limites internos, e os que derivam da relação entre os Estados, e são os limites externos. [...] A formação de Estados independentes e nacionais do século passado a hoje, primeiro nos Estados Unidos da América, depois na América Latina, depois na Europa e finalmente nos países do Terceiro Mundo através do processo de descolonização, ocorre ora por decomposição de Estados maiores ora pela recomposição de Estados pequenos. Mas sempre a recomposição tende a reforçar os limites internos e a decomposição a afrouxar os limites externos. A tendência atual para a formação de Estados ou de constelações de Estados cada vez maiores (as assim chamadas super-potências) comporta um aumento dos limites externos dos Estados que são absorvidos na área maior (os Estados satélites) e uma diminuição dos limites externos do super-estado. No caso em que se chegasse à formação do Estado universal, este teria apenas limites internos e não mais externos.“. Ressaltam-se, ainda, os conceitos de estado apresentados por ROUSSEAU, Jean-jacques. $D u$ contrat social. Paris: Union Générale d'Éditions, 1973. p. 74. "In verbis": “A l'instant, au lieu de la personne particulière de chaque contractant, cet acte de association produit un corps moral et collectif, compose d'autant de members que l'assemblée a de voix, lequel reçoit de ce meme acte son unite, son moi commun, sa vie et sa volonté. Cette personne publique, qui se forme ainsi par l'union de toutes les autres, prenoit autrefois le nom cité (a), et prend maintenant celui de république ou de corps politique, lequel est appelé par ses membres État quand il est passif, souverain quand il est actif, puissance en le comparant à ses semblabes." e as diferenças entre o plano interno e o internacional apontadas por GIRAUD, Emile. Le droit international public et la politique. In: Recueil des Cours. Academie de Droit International de la Haye, Volume 110, 1963-III, pp. 419809. pp. 432-433. "In verbis“: "Sur le plan international, la situation est assez différente [du national]. L'autonomie du droit est moindre du fait que la politique joue constamment un rôle dans le processus d'application du droit. Comme il n'y a pas de super-Etat et d'exécutif international, ce sont les gouvernements nationaux qui ont la charge d'appliquer le droit international. Si l'on se borne à considerér les choses d'un point de vue formel, il en est de même pour l'application de la règle de droit national et de la règle de droit international. Dans les deux cas, c'est le gouvernement qui exerce la fonction exécutive et qui prend les initiatives nécessaires pour assurer l'application de la règle de droit national ou international. Mais dans la réalité, les situations diffèrent profondément. Quand le pouvoir exécutif d'un Etat applique le droit national, il applique un droit qui a été créé par les pouvoirs politiques de l'Etat et qui, à tout moment, peut être changé par la seule volonté de ces pouvoirs.“.

78 MIRKINE-GUETZEVITCH, Boris. Droit international et droit constitutionnel. In: Recueil des Cours. Academie de Droit International de la Haye, Volume 38, 1931-IV, pp. 307-465. p. 315. "In verbis": "Ici, la construction élégante et logique de M. Kelsen est violée poar l'auteur lui-même, qui, à la fin de son exposé, propose, malgrétout, un choix, puisqu'il indique l'existence de deux morales, de deux théories étiques, le « subjectivisme » et l' « objectivisme ». Le subjectivisme, dit-il, conduit au nationalisme, à l'impéralisme. L’objectivisme est une foi pacifiste qui aboutrait à la construction future de l'Etat universel [...]“ 
subjetivismos políticos e constrangimentos ilegais pudessem ser evitados ${ }^{79}$. Nesse sentido, a transcendência normativa quase metajurídica atribuída atualmente por parte da doutrina aos direitos humanos poderia constituir exemplo argumentativo desses críticos ${ }^{80}$.

A importância da questão dos direitos humanos deve ser destacada, na verdade, em todos esses fenômenos descritos. A textura aberta e a ausência de reconhecimento de conteúdo firme para suas premissas permitem que o discurso principiológico desses preceitos sirva tanto à esfera jurídica quanto à política como fundamento argumentativo. Assim, enquanto utilizados em conformidade com a teoria do direito, o indivíduo se fortaleceria. Quando capturados pela política, haveria falseamento da verdade teórica e os direitos humanos perderiam seu caráter normativo. Aplicados à política, os direitos humanos passam, na verdade, a fundamentar a concretude, isto é, o exercício das escolhas legislativas, mas não a aplicação do direito ${ }^{81}$.

Na esfera global, o fim da segunda guerra mundial - além de marcar a consolidação da busca pela paz e das garantias aos direitos humanos - pode ser reconhecido também como arauto da definitiva prevalência do direito sobre a força no contexto político internacional ${ }^{82}$. Prevalência, contudo, não absolutamente consolidada na atualidade, gize-se.

${ }^{79}$ KOSKENNIEMI, Martti. From apology to utopia: the structure of international legal argument. Nova Iorque: Cambridge University Press, 2005. pp. 17-18. "In verbis": "Like international politics, it [international law] is assumed to emerge from the subjective, politically motivated State wills or interests. Law creation is a matter of subjective, political choice. But while law emerges from politics and diplomacy, it is assumed to remain separable from them. It is assumed to be binding regardless of the interests or opinions of the State against which it is invoked. If such separation were not maintained, then we could only concede the critic's point and admit the laws political nature."

${ }^{80}$ TRINDADE, Antônio Augusto Cançado. International law for humankind : towards a new jus gentium (I): general course on public international law. In: Recueil des Cours. Academie de Droit International de la Haye, Volume 316, 2005, pp. 09-439. p. 335. "In verbis“: "The new jus gentium of our days, the International Law for humankind, already counts on some conceptual achievements. The fact that the concepts both of the jus cogens and of the obligations (and rights) erga omnes already integrate the conceptual universe of International Law discloses the reassuring and necessary opening of this latter, in the last decades, to certain superior and fundamental values. This significant evolution of the recognition and assertion of norms of $j u s$ cogens and obligations erga omnes of protection is to be fostered, seeking to secure their full practical application, to the benefit of all human beings."

${ }^{81}$ KOSKENNIEMI, Martti. From apology to utopia: the structure of international legal argument. Nova Iorque: Cambridge University Press, 2005. p. 17. "In verbis": "To prevent international law from losing its independence vis-à-vis international politics the legal mind fights a battle on two fronts. On the one hand, it attempts to ensure the normativity of the law by creating distance between it and State behaviour, will and interest. On the other hand, it attempts to ensure the law's concreteness by distancing it from a natural morality."

82 TUNKIN, Grigory. Politics, law and force in the interstate system. In: Recueil des Cours. Academie de Droit International de la Haye, Volume 219, 1989-VII, pp. 227-395. p. 392. "In verbis“: "Then after the horrible Second World War it was the Charter of the United Nations that embodied common goals which will live for a long time. These goals may be summarized as follows: (1) Elimination of war. (2) Primacy of common human 
Nesse sentido, importante se faz perceber - ainda sob padrões subjetivistas - que parte da doutrina entende que o direito das gentes, ainda que aplicável mormente a entes abstratos, estrutura-se de maneira orientada aos indivíduos responsáveis pela expressão da vontade desses atores dotados de atribuição de atuação internacional ${ }^{83}$. Construções teóricas nesse sentido não se sustentam, contudo, quando os responsáveis pela expressão da vontade dos entes são percebidos como partes da sociedade política que representam, é dizer, como o conjunto de indivíduos de uma sociedade ${ }^{84}$.

Identificada a política com a força, observa-se que seu extremo na esfera global seria a guerra. A relação entre a guerra e o desenvolvimento do direito internacional não deve surpreender, portanto, quando compreendida a vinculação teórica existente entre o direito e a política $^{85}$.

Conforme já mencionado, a tensão entre direito e política se encontra mais nítida no direito das gentes que em qualquer outro ramo jurídico e as preocupações com a identificação de traços de institucionalidade na ordem internacional como elemento tendente a reforçar seu reconhecimento como direito constituiria, assim, fenômeno muito anterior às construções teóricas propostas por Kelsen e Hart pouco antes e pouco depois da segunda grande guerra ${ }^{86}$.

values and problems. (3) Respect for human rights. (4) Primacy of international law in politics. (5) Promotion of social progress and better standards of life in larger freedom."

${ }^{83}$ ROSENNE, Shabtai. The perplexities of modern international law: general course on public international law. In: Recueil des Cours. Academie de Droit International de la Haye, Volume 291, 2001, pp. 09-471. p. 46. "In verbis": "Finally, let me recall that international law, like all law, is ultimately addressed to human beings: not to abstract entities such as States but to the men and women responsible for the conduct of their affairs. Regulating human conduct — that is what brings international law squarely into the general discipline of the law."

${ }^{84}$ LOCKE, John. Two treatises of government. London: Guernsey Press, 1986. pp. 154-155. "In verbis“": "God, having made man such a creature that, in His own judgment, it was not good for him to be alone, put him under strong obligations of necessity, convenience, and inclination, to drive him into society, as well as fitted him with understanding and language to continue and enjoy it. The first society was between man and wife, which gave beginning to that between parents and children, to which, in time, that between master and servant came to be added. And though all these might, and commonly did, meet together, and make up but one family, wherein the master or mistress of it had some sort of rule proper to a family, each of these, or all together, came short of 'political society', as we shall see if we consider the different ends, ties, and bounds of each of these."

${ }^{85}$ TUNKIN, Grigory. Politics, law and force in the interstate system. In: Recueil des Cours. Academie de Droit International de la Haye, Volume 219, 1989-VII, pp. 227-395. p. 374. "In verbis": "The balance-of-power system has been probed by mankind for centuries. It has always brought about an arms race and wars. War is an essential element of the balance-of-power system because there force remains the main regulatory means. This model is in crying contradiction with contemporary international law. It suffices to say that the balanceof-power system is based on the threat or use of force, whereas both are prohibited by contemporary international law."

86 BENOIST, Charles. L'influence des idées de Machiavel. In: Recueil des Cours. Academie de Droit International de la Haye, Volume 9, 1925-IV, pp. 127-306. p. 301. "In verbis“: "L'écueil sur lequel a été 
A construção do direito - interno e internacional - se confunde com o desenrolar da história política. Os mesmos atores que exercem a concreção internamente ao legislar expressam a vontade por meio do estado externamente nos processos legislativos internacionais ${ }^{87}$.

De todo o panorama descrito, resta que política e direito não apenas se relacionam. São partes de uma mesma estrutura na organização da vida em sociedade. Nessa toada, a política é encontrada, por exemplo, na decisão tomada na formação do direito positivo ou no reconhecimento de valores axiológicos. Esses, por sua vez e uma vez estabelecidos ou reconhecidos, orientam e delimitam seu campo de atuação que retorna quando da extração da normatividade exercida no momento da interpretação do direito.

A organização das relações sociais pela dinâmica descrita decorre diretamente da necessidade de se estabelecerem parâmetros de regulamentação e controle ao exercício do poder na convivência humana. É de se perceber, finalmente e a partir das premissas apontadas, que o estado constituiria a mais bem-sucedida forma de organização social fundada em estruturas políticas e jurídicas. Nesse sentido, a estabilidade social é garantida no plano interno dos países pelo controle do poder por meio do uso de instrumentos de política e de direito.

Internacionalmente, entretanto, o panorama não se mostra tão simples. Percebe-se na ordem global verdadeiro descompasso - atualmente bem menos extremo, adianta-se - entre a política e o direito. Os excessos da política no plano sobreestatal mais que demonstrar a fragilidade normativa denunciam a urgência da definitiva organização da ordem global pelo direito.

longtemps menacée de venir se briser la barque, encoré fragile, qui nous apporte peut-être plus de paix, sinon la paix, c'est l'idéologie. Malgré sa désastreuse et cruelle faillite de 1914, l'organisation pratique du droit des gens a fait depuis vingt ans plus de chemin qu'elle n'en eût fait jamais auparavant, parce qu'au cours de ces vingt années, les institutions et les formes juridiques sont passèes au premier plan.“

${ }^{87}$ MIRKINE-GUETZEVITCH, B.. Droit international et droit constitutionnel. In: Recueil des Cours. Academie de Droit International de la Haye, Volume 38, 1931-IV, pp. 307-465. p. 322. "In verbis": "Le droit public est, comme nous 1'avons exposé ailleurs, intimement lié à l'histoire politique. Le droit public international et le droit public interne sont les produits du même milieu historique. Ce sont les mêmes hommes, les mêmes groupes qui créent les règles du droit international et les règles du droit interne.“ 


\subsection{Nomenclaturas: Estabilizando Conceitos}

Muito mais que instrumento de sedimentação das decisões políticas da convivência humana e de sistematização dos valores reconhecidos como fundamentais à vida em sociedade, direito constitui uma técnica: uma linguagem. Um idioma que estabelece os contornos e organiza as relações sociais. A redução de idéias a conceitos exige muito cuidado com os termos. $\mathrm{O}$ mais criterioso jurista acaba fazendo sempre, em algum momento, uso de palavras em sentido não técnico, mas o cuidado deve persistir.

No estudo da ordem internacional, "estado", por exemplo, constitui hoje termo consolidado em referência à organização política da sociedade que atua de forma concretiva ou extraindo normatividade no plano global. Seu conceito se confundiria, assim, com o de poder e se identifica, em perspectiva histórica, com expressões como nação e povo, as quais ainda que atualmente dotadas de significados específicos - chegaram a indicar agrupamentos de indivíduos em suas relações como conjunto.

Nesse sentido, críticas podem ser encontradas na doutrina quanto ao uso da expressão "direito internacional", em razão de se tratar mais propriamente de normativa que regulamenta a relação entre estados, ou seja, de um direito "interestatal" e não de um sistema jurídico entre nações. $\mathrm{Na}$ atualidade, o reconhecimento de outros atores que expressam vontade na comunidade mundial colocaria em dúvida também a opção referida e exemplificaria muito bem as dificuldades de estabilização terminológica pelo direito ${ }^{88}$.

Quanto ao emprego do termo "direito das gentes", observa-se que no século XVIII, esse era aplicado de forma análoga ao que hoje se entende por direito internacional e apontava tanto à conduta dos estados quanto àquela dos soberanos, isto é, dos governantes que exerciam com exclusividade o poder interna e externamente nos estados ${ }^{89}$.

\footnotetext{
${ }^{88}$ JELLINEK, Georg. Das Recht des modernen Staates. Berlin: Verlag von O. Häring, 1900. p. 120. "In verbis": "Neben, „Staat” sind auch heute noch andere Bezeichnungen für das politische Gemeinwesen gebräuchlich. Der nach Aussen gewendete Staat heisst Macht, puissance, potenza, power, welche Ausdrücke der diplomatischen Sprache geläufig sind. Ebenso wird auch Volk, nation, nazione, in Nachwirkung antiker Ausdrucksweise - namentlich durch ius gentium vermittelt - für den Staat gebraucht. Unser „Völkerrecht” und der von Bentham erfundene Terminus ,internationales Recht” meinen das Recht zwischen den Staaten. Besonders die letztere Bezeichnung aber ist vieldeutig und daher verwirrend. Besser wäre es, statt von ius inter gentes oder nationes von zwischenstaatlichem Recht zu sprechen. Die Terminologie folgt aber nicht immer der Logik. Wissenschaftlich ist aber kein Terminus so brauchbar wie der des Staates, der schliesslich so abgeblasst ist, dass sich keine Nebenvorstellung mit ihm mehr verbindet, die eine störende Zweideutigkeit hervorrufen könnte."

89 GUGGENHEIM, Paul. Contribution à l'histoire des sources du droit des gens. In: Recueil des Cours. Academie de Droit International de la Haye, Volume 94, 1958-II, pp. 01-84. p. 05. "In verbis“: "La notion du
} 
No presente estudo, "direito internacional", "direito das gentes" e "direito interestatal" serão, portanto, utilizados de forma indiscriminada como sinônimos por opção mais relacionada a estilo que a padrões lógicos de uso. Não serão feitas em relação a nenhum deles, portanto, referências históricas ou conceituais específicas não expressamente indicadas.

Também as expressões "comunidade internacional" e "sociedade internacional" oferecem dúvidas semânticas. A doutrina costuma estabelecer diferenciação que dá à primeira caráter natural - entendido como alusão à característica da participação inata na ordem internacional como ator - e, ao segundo, o significado de vontade de fazer parte de grupo específico. Assim, o sujeito seria membro da comunidade internacional e poderia decidir voluntariamente ingressar em determinado grupo e fazer parte de uma sociedade internacional $^{90}$.

No que se refere aos entes que atuam internacionalmente, não se mostra incomum o incômodo com o a uso de "sujeito" para caracterizá-los. A origem de sua popularização estaria na transposição de vocabulário utilizado para institutos de direito interno ao direito das

droit des gens, du jus gentium, est celle dont, jusqu'à la fin du 18ème siècle, s'est servie la doctrine juridique pour désigner l'ensemble des règles se rapportant à la conduite des Nations et aux affaires des souverains.“

${ }^{90}$ VELASCO, Manuel Diez de. Instituciones de derecho internacional público - Tomo I. Madrid: Editorial Tecnos, 1978. p. 44. "In verbis": "La cuestión, en base a la existencia de un diverso grado de solidaridad en una o en otra, ha dado origen, al aplicarse a la esfera internacional, a una amplia controversia doctrinal Schwarzemberger, Poch, Wirth, Corbett, Miaja, etcétera-. Nosotros no vamos a entrar en dicha polémica con detalle. No obstante, tomaremos posición en favor de la utilización del término <<Comunidad > internacional para referimos a la formada por el conjunto de todos los sujetos internacionales que operan en el ámbito internacional. En este sentido, consideramos que la Comunidad tiene un ámbito universal. Por el contrario, reservamos el término <<Sociedad>> para aquellas otras Organizaciones internacionales cuya creación obedece a la voluntad común de los Estados, que les dan vida por medio de un Tratado. Preferimos utilizar el término Comunidad en el estado de evolución actual de la vida internacional, pues, como ha sido puesto de relieve por Freyer, <<las estructuras Comunidad y Sociedad se suceden en ésta y sólo en ésta ordenación del tiempo. La Comunidad sólo puede convertirse en Sociedad, la Sociedad viene de la Comunidad; jamás se invierte el proceso real. No son dos simples posibilidades, sino dos etapas de la realidad social >> (FREYER: La Sociología..., PP. 209-210). En efecto, la actual Comunidad internacional, en la que los vínculos que unen a sus miembros son muy tenues y está carente de una estructura autoritaria centralizada, va dando origen en determinados sectores de la misma a la creación de sociedades internacionales u Organizaciones internacionales que palian las imperfecciones de la Comunidad. Por otro lado, la actividad de estas últimas van, insensible y paradójicamente, perfeccionando la Comunidad internacional general. Ello permitirá, salvo regresiones motivadas por conflictos de intereses entre sus miembros, el paso de la actual Comunidad a una Sociedad internacional de ámbito universal, de la que tenemos un ensayo, aunque imperfecto, en la Organización de Naciones Unidas.”. No mesmo sentido, MELLO, Celso Duvivier de Albuquerque. Curso de direito internacional público - v 1. Rio: Renovar, 1994. p. 45. "In verbis": "A comunidade apresentaria as seguintes características: formação natural; vontade orgânica (energia própria ao organismo, manifestando-se no prazer, no hábito e na memória); e os indivíduos participariam de maneira mais profunda na vida em comum. A comunidade é uma criação de cooperação natural 'anterior a uma escolha consciente de seus membros' [...] A sociedade já possuiria caracteres diferentes: formação voluntária, vontade refletida (seria produto do pensamento, dominada pela idéia de finalidade e tendo como fim supremo a felicidade); e os indivíduos participariam de maneira menos profunda na vida em comum. A comunidade estaria regida pelo direito natural, enquanto a sociedade se encontraria sob o contrato." 
gentes $^{91}$. A prática, contudo, impõe seu uso sem grandes ressalvas, ainda que alguns doutrinadores prefiram os termos "participantes" ou "atores"

O termo "sistema" será utilizado aqui em diversas ocasiões como sinônimo de "ordem jurídica" ou de "conjunto normativo" como forma de se ressaltarem as características de ordenação e unidade que correspondem ao direito ${ }^{93}$. As dificuldades de sua equiparação a "ordenamento jurídico" - mormente em razão de nem todo sistema de normas, como o moral, constituir propriamente um ordenamento - são reconhecidas, mas entende-se que tais dúvidas não chegam a comprometer seu uso indiscriminado ${ }^{94}$.

91 ARÉCHAGA, Eduardo Jiménez; ARBUET-VIGNALI, Heber; PUCEIRO ROPOLL; Roberto. Derecho internacional público - Tomo I. Montevideo: Fundación de Cultura Universitaria, 2005. p. 179. "In verbis": "Es posible que la expresión 'sujetos' no sea la más correcta para señalar esta realidad y que hubiera sido preferible recurrir a otra, como por ejemplo 'actores'; o a una expresión nueva que destacara la característica principal de la participación directa del 'sujeto' en el manejo del sistema de normas que lo regula. Esto no fue así. Se tomó la expresión del derecho interno, dónde etimológicamente es correcta, y se la llevó al Derecho Internacional Público, dónde indica otra realidad. En el ámbito de este último, la expresión fue aceptada y ahora es de uso corriente, razón por la cual no parece conveniente sustituirla por otra, aunque si resulta necesario aclarar su alcance en este sistema."

${ }^{92}$ HIGGINS, Rosalyn. Problems and process: international law and how we use it. Oxford: Clarendon Press, 1994. p. 50, "in verbis": "There are no 'subjects' and 'objects', but only participants. Individuals are participants, along with States, international organizations, [...] multinational corporations, and indeed private non-governmental groups."

${ }^{93}$ Uma definição que se propõe ao termo "sistema" seria a apresentada por CANARIS, Claus-Wilhelm. Pensamento Sistemático e Conceito de Sistema na Ciência do Direito. Introdução e tradução de António Menezes Cordeiro. $3^{a}$. ed. Lisboa: Fundação Calouste Gulbenkian, 2002. pp.10-13. que ressalta a ordenação e a unidade como conformadoras de suas principais características, "in verbis": "As definiç̧ões que se encontram na literatura jurídica correspondem-lhe, também, largamente. Assim, por exemplo, segundo Savigny, o sistema é a <<concatenação interior que liga todos os institutos jurídicos e as regras de Direito numa grande unidade〉>, segundo Stammler <<uma unidade totalmente coordenada〉>, segundo Binder, <<um conjunto de conceitos jurídicos ordenado segundo pontos de vista unitários >, segundo Hegler, <<a representação de um âmbito do saber numa estrutura significativa que se apresenta a si própria como ordenação unitária e concatenada〉>, segundo Stoll um <<conjunto unitário ordenado〉> e segundo Coing uma <ordenação de conhecimentos segundo um ponto de vista unitário〉>. Há duas características que emergiram em todas as definições: a da ordenação e a da unidade; elas estão, uma para com a outra, na mais estreita relação de intercâmbio, mas são, no fundo, de separar. No que respeita, em primeiro lugar, à ordenação, pretende-se, com ela - quando se recorra a uma formulação muito geral, para evitar qualquer restrição precipitada - exprimir um estado de coisas intrínseco racionalmente apreensível, isto é, fundado na realidade. No que toca à unidade, verifica-se que este factor modifica o que resulta já da ordenação, por não permitir uma dispersão numa multitude de singularidades desconexas, antes devendo deixá-las reconduzir-se a uns quantos princípios fundamentais." Grifo nosso.

${ }^{94}$ Sobre o termo "ordenamento jurídico", BOBBIO, Norberto. O positivismo jurídico: lições de filosofia do direito. São Paulo: Ícone, 1995. pp. 197-198. "In verbis": "Não sabemos dizer como e quando a expressão "ordenamento jurídico" entrou no uso corrente e este é um problema que mereceria ser estudado; somos, entretanto, da opinião que seja a tradução italiana do termo alemão Rechtsordnung. A difusão e, podemos dizer, a vulgarização de tal expressão na Itália (já que ela também passou da linguagem técnico-jurídica para a comum) coube a Santi Romano, que em 1917 publicou um estudo (agora clássico no pensamento jurídico italiano deste século) intitulado precisamente $\mathrm{O}$ ordenamento jurídico (embora as teses nele sustentadas não sejam propriamente as do juspositivismo). Que a origem do termo em questão seja procurada no filão alemão e italiano do pensamento jurídico é demonstrado pelo fato de que tal termo não é encontrado nem na língua francesa nem na inglesa (porque nas culturas jurídicas correspondentes a dogmática e a sistemática tiveram um menor desenvolvimento). Os franceses, para exprimirem o conceito de ordenamento jurídico, recorreram à 
Especificamente quanto à atividade jurisdicional internacional, a clara opção pela expressão "competência" em detrimento de "jurisdição" merece ser salientada. Sob a perspectiva interna do direito das gentes, tratar o campo material de atuação de um sistema de solução de controvérsias como abrangência jurisdicional apontaria à existência de uma multiplicidade de jurisdições, ou seja, ao reconhecimento de que cada ordem legal internacional constituiria formação independente.

O debate acerca do conteúdo de tais expressões não é novo ${ }^{95}$. Seria possível reconhecer, de fato, a existência das jurisdições internas dos estados, submetidas às soberanias particulares, e a jurisdição internacional, a qual se repartiria nas diversas competências dos sistemas de solução de controvérsias que se apresentam.

Ocorre que "jurisdição" significaria um sistema fechado de normas e o reconhecimento de internas e a internacional redargüiria a concepção unitarista do direito ${ }^{96}$. Nesse sentido, é de se entender competência como termo correto a ser aplicado - nas esferas interna, internacional ou de sistemas específicos. Autores que tratam tais espécies como jurisdições independentes imprimem uma concepção eminente política a estruturas de direito. Sob o prisma da unidade, esse constituiria erro grosseiro ${ }^{97}$.

expressão ordre juridique (que é, contudo, pouco satisfatória porque o termo ordre é demasiado genérico), ou ainda ao termo ordonnancement (que, todavia, foi acolhido pouco favoravelmente, tratando-se de um neologismo). Os ingleses se inclinam para o termo system, mas este pode dar lugar a confusões, porque o ordenamento jurídico pode ser considerado um sistema de normas, mas nem todo sistema de normas (como, por exemplo, o sistema normativo moral) pode ser considerado igual, em sua estrutura, ao ordenamento jurídico."

${ }^{95}$ MENEZES, Wagner. Tribunais internacionais: jurisdição e competência. São Paulo: Saraiva, 2013. p. 331. "In verbis": "A discussão sobre a distinção entre 'jurisdição' e 'competência' no Direito Internacional, como termos que possuem significados diferentes, não é nova."

${ }^{96}$ Como sinônimo de Geltungsbereich - âmbito de validade - ou de Gesetzgebungsgewalt - poder concretivo seu uso pode ser aceito. Combate-se, nesse ponto, a idéia de total independência e separação de ordens normativas. Uso preciso em MANN, F.A.P.. The doctrine of jurisdiction in international law. In: Recueil des Cours. Academie de Droit International de la Haye, Volume 111, 1964, pp. 01-162. p. 15. "In verbis“: "Jurisdiction, it thus appears, is concerned with what has been described as one of the fundamental functions of public international law, viz. the function of regulating and delimiting the respective competences of States, 'de conférer, de repartir et de réglementer des compétences'. The same idea is expressed, when in German reference is made to the 'Geltungsbereich' of laws, or the 'Gesetzgebungsgewalt' of States."

${ }^{97}$ Exemplo desse equívoco em MANN, F.A.P.. The doctrine of jurisdiction in international law. In: Recueil des Cours. Academie de Droit International de la Haye, Volume 111, 1964, pp. 01-162. p. 09. "In verbis": "The problem of international jurisdiction relates to the activities of a State, though it can arise also in the case of an international organization which, by the treaty creating it, usually is empowered to act within a limited sphere and which, by exceeding it, would be acting ultra vires. But jurisdiction in international law has nothing to do with the question of municipal taw whether certain State organs have jurisdiction in a given case, whether, for instance, a Court has jurisdiction to entertain certain proceedings, or whether an Inspector of Taxes has jurisdiction to set aside an assessment. These are matters of internal organization in which international law does not ordinarily have any interest." 
O mundo testemunhou alteração terminológica que descreve importante mudança de parâmetro do direito internacional na segunda metade do século XX. A independência - como sinônimo de soberania externa ${ }^{98}$, ainda que fundamental para a maior parte da formação das regras de direito das gentes, deu lugar à perspectiva da integração, a qual distancia claramente a linguagem do direito internacional da esfera dos estados para aquela que traduz sua verdadeira essência ${ }^{99}$. Na década de 80 do século XX, mesmo antes da queda do muro de Berlin, a doutrina internacionalista já apontava à necessidade de construção de uma nova ordem mundial e a referida alteração de linguagem participou de maneira bastante ativa desse processo tanto como ferramenta quanto como sintoma ${ }^{100}$.

O entusiasmo que marcou a evolução cooperativa do direito das gentes na última década do século XX que promoveu, por exemplo, a proliferação de organizações internacionais e de tratados associativos ${ }^{101}$, não se sustentou a partir dos primeiros anos do século XXI. Em pouco tempo, a disposição internacional de controlar o exercício do poder na ordem global por instrumentos jurídicos se dissipou e a política voltou ao protagonismo.

\footnotetext{
${ }^{98}$ VIRALLY, Michel. Panorama du droit international contemporain: cours général de droit international public. In: Recueil des Cours. Academie de Droit International de la Haye, Volume 183, 1983, pp. 09-382. p. 76. "In verbis“: "La souveraineté est une notion à la fois maudite et exaltée : maudite par ceux qui voient en elle la cause de toutes les faiblesses du droit international et le rempart de l'égoïsme des Etats ; exaltée par ceux pour qui elle est le plus solide rempart de l'indépendance des peuples. Ces sentiments sont excessifs. Ils sont provoqués l'un et l'autre par une même conception hyperbolique et absolutiste de la souveraineté, qui paraît mythique et presque mystique, et doit certainement être réformée.“
}

${ }^{99}$ SCHWARZENBERGER, Georg. The fundamental principles of international law. In: Recueil des Cours. Academie de Droit International de la Haye, Volume 87, 1955-I, pp. 191-385. p. 214. "In verbis“": "Current fashion in the fields of international law and organization tends to put the emphasis on the growing integration of international society and interdependence rather than independence. Superficially, this view is attractive. For many purposes, world society is objectively a unit and, corresponding to the trend towards bipolarization, earlier loyalty areas tend to widen within each of the world's two halves. This explains the paradox that, within each of the two world camps, undeniable evidence of growing interdependence is easy to produce. International law, however, is universal and, on the vital level of the overall relations between West and East, the principle of sovereignty appears as much as ever the appropriate starting point of any systematic exposition of the fundamental principles of international law."

${ }^{100}$ CALDERA, Rafael. The juridical basis of a new international order : conference held on 8 July 1986. In: Recueil des Cours. Academie de Droit International de la Haye, Volume 196, 1986-I, pp. 385-400. p. 391. "In verbis“: "[...] a new international order is needed, not only in economic relations, but also in juridical and political relations that are daily demanding a structural change to strengthen institutionality among communities."

101 MENEZES, Wagner. Direito internacional: legislação \& textos básicos. Curitiba: Juruá, 2003. p 19. "In verbis": "Esta nova realidade internacional foi desencadeada, mais nitidamente, a partir da queda do muro de Berlim que representou o fim do modelo estatal socialista e decretou o sepultamento da guerra fria e de um mundo bipolar. A partir de então, a humanidade tem convivido com novos fatores que estão a compor um novo cenário internacional tais como a) o surgimento de novos atores do plano internacional antes apenas reservado aos Estados soberanos, como as organizações internacionais e as ONGs; b) à revolução tecnológica, indo do computador à 'internet', a dinamização das informações e telefonia; C) a transnacionalização dos capitais e empresas com o conseqüente 'deslocamento da soberania' do setor publico estatal para o privado; d) a tendência de os estados buscarem a integração regional e se organizarem em blocos econômicos ou organizações internacionais. Além dos fatores escalados acima, a humanidade imprime, aos poucos, uma nova pauta de discussöes internacionais; sai de cena a guerra como foco principal, e entram em discussão os direitos humanos, o comércio internacional, a preocupação com o meio ambiente e com o desenvolvimento sustentável das nações." 
O apontado deslocamento da percepção da ordem internacional do direito para a política pode muito bem ser ilustrado por análise semiótica da linguagem jurídicointernacionalista nas últimas décadas. No período imediatamente posterior à guerra fria, observou-se claro adensamento normativo e institucional internacional e expressões como cooperação, integração e harmonização orientavam os diálogos jurídicos. Na primeira década do século XXI, em dinâmica absolutamente diversa, o direito internacional passou a evoluir em compasso mais lento e permeado, não coincidentemente, por termos como coalizão, intervenção e protecionismo.

Questão paralela - mas diretamente atada ao diálogo político-jurídico - se refere à recente arquitetura da normativa internacional sob vocabulários específicos, técnicos, cujas interpretações tornaram-se essencialmente dependentes de especialistas para o preenchimento, por exemplo, de lacunas legislativas. A aplicação do direito cada vez mais parece não se pautar estritamente no comprometimento com a equidade e a justiça, mas, por exemplo, no pragmatismo técnico.

Para dirimir quaisquer dúvidas ortográficas, ressalta-se a opção pelo uso da inicial minúscula no termo "estado" em linha com pensamento internacionalista que, sem negar a importância desse ator da ordem internacional, relativiza sua centralidade ${ }^{102}$. Ainda em referência aos estados, cumpre consignar que esses devem ser compreendidos como partes de tratados e membros de organizações internacionais. Distinta combinação não atenderia à técnica.

Quanto às organizações internacionais, doutrinadores sustentam que os entes desprovidas de estrutura com processo decisório supranacional deveriam ser referidos como “interestatais" e não "internacionais". Tendo ciência das referidas ressalvas, uma vez mais optou-se ao longo dessa investigação por fazer uso do termo "intergovernamental" também

\footnotetext{
${ }^{102}$ Nesse sentido, CASELLA, Paulo Borba. BRIC: Uma perspectiva de cooperação internacional. São Paulo: Atlas, 2011. pp. 01-02. "In verbis": "De tudo quanto se fez e se escreveu, antes do final do período da guerra fria (1949-1989) pouco sobreviveu, sem parecer história antiga, no sentido de tratar de mundo que não mais existe, este se conhece pela experiência vivida no passado, ou a partir de leituras, mas trata-se de contexto desligado de nossa realidade presente. $\mathrm{E}$, no entanto, somente se passaram vinte anos desde a queda do muro de Berlim, do final da União Soviética e do término do período de confrontação, latente ou aberta, como alternadamente se fez, entre os blocos ideológicos, que tiveram a pretensão de alinhar o mundo durante as quatro décadas que se seguiram ao fim da segunda guerra mundial. Guerra se grafa em minúsculas, porquanto não se podem admitir como os marcos principais ordenadores do mundo e dos períodos de análise e de exame deste. Como tendo a escrever 'estado' em minúsculas, para tormento dos revisores das editoras, que tendem a querer corrigir. Aliás, estaria em tempo de se economizarem maiúsculas no português contemporâneo do Brasil."
} 
em referência à interestatalidade sem apego extremo ao seu conteúdo, tal como se observa amplamente na doutrina internacionalista atual ${ }^{103}$.

O uso do termo "intergovernamental" merece, igualmente, ressalvas. A descrição de uma organização internacional como intergovernamental significaria, em apego literal, restringir a vinculação à mesma aos governos e não necessariamente aos estados. A doutrina chega a apontar exemplos isolados de organizações que teriam tal característica e é de se perceber que a adesão às estruturas internacionais comuns é feita pelo estado e não apenas pelo governo, um de seus elementos.

Ainda quanto às organizações internacionais, na América Latina autores têm sido ultimamente mais cuidadosos em suas análises comparativas. Especificamente quanto ao MERCOSUL, estudos têm evitado, com melhor técnica, o uso do termo "comunitário" para fazer referência à sua normativa. A terminologia "comunitário" surgiu das então "Comunidades Européias" e se refere a um mercado comum com liberdades de circulação consolidadas $^{104}$.

Quanto aos termos, importante se faz ressaltar as resistências que se apresentam ao termo "bloco" para indicar experiências regionais de direito. Recomendável seria banir o termo da doutrina jurídica. Trata-se de expressão não técnica - eminentemente jornalística utilizada de maneira inaceitável pelos aplicadores do direito.

Pensar o direito constitui ofício teórico que se opera com base em conceitos. O cuidado com a delimitação de conteúdos aos termos utilizados mostra-se, portanto, fundamental a qualquer ponto de partida lógico que se pretenda adotar. Com base em tais premissas, entendeu-se necessário concentrar neste capítulo grande parte das considerações terminológicas que se fazem importantes no presente estudo.

\footnotetext{
${ }^{103}$ MARYAN GREEN, N.A. International law: law of peace. London: Macdonald and Evans, 1982. p. 45. "In verbis": "An 'international organisation' is an organisation established by a treaty to which three or more states are parties. An 'organisation' is an entity legally distinct from any other and composed of one or more organs. An 'organ' has been described as a 'collectivity of powers grouped under one name'. Strictly speaking, it is inaccurate to incorporate the expression 'intergovernmental' in this definition, for the parties to the treaty by which an organisation is created are necessarily states and not governments. The latter merely act on behalf of the former. However, by becoming a party to a treaty constituting an international organisation a state may accept obligations the performance of which falls exclusively upon its government and not upon the state as a whole. This is the case, for example, of the 'Intergovernmental Maritime Consultative Organisation', one of the specialised agencies of the United Nations."

${ }^{104}$ Em outras iniciativas regionais latino-americanas - como o Sistema de Integração Centro-americano - SICA e $a$ Comunidade Andina - CAN - observa-se com frequiência o uso do termo e as mesmas reservas se fazem aplicáveis.
} 
Não se pretendeu, ressalte-se, esgotar as questões semânticas que possam surgir no trabalho, mas apenas reduzir a termo determinados padrões sobre parte das expressões utilizadas no decorrer dos próximos capítulos. 


\section{O ESTADO E O DIREITO INTERNACIONAL}

\subsection{Estado, Poder e Direito}

A percepção da organização da vida em sociedade como um contrato, um contrato social, implica admitir que, em determinado momento, os indivíduos teriam substituído a liberdade natural pela liberdade convencional ${ }^{105}$. O consentimento contratual legitimaria, dessa forma, a construção de uma unidade social que serviria, inclusive, para defender uma associação de pessoas específica de eventuais ameaças promovidas por outros grupos sociais unificados $^{106}$.

Os seres humanos se reuniriam em corpos unificados, de acordo com tais teorias e conforme ressaltado, por meio do consentimento - pela vontade, expressa ou tácita, de se associar e de permanecer associado. Nos últimos dois séculos, ao menos, a instituição associativa por excelência resultante desse processo seria o estado ${ }^{107}$.

Regras se fazem necessárias para dar viabilidade à vida em sociedade, mas também à relação entre as sociedades humanas. O estado, assim, consubstanciaria a institucionalização

\footnotetext{
${ }^{105}$ ROUSSEAU, Jean-jacques. Du contrat social. Paris: Union Générale d’Éditions, 1973. p. 73. "In verbis": "Les clauses de ce contrat [social] sont tellement déterminées par la nature de l'acte, que la moindre modification les rendroit vaines et de nul effet; en sorte que, bien qu'elles n'aient peut-être jamais été formellement énoncées, elles sont partout les mêmes, partout tacitement admises et reconnues, jusqu'à ce que, le pacte social étant violé, chacun rentre alors dans ses premiers droits, et reprenne sa liberté naturelle, en pendant la liberté conventionnelle pour laquelle il y renonça."
}

${ }^{106}$ LOCKE, John. Two treatises of government. London: Guernsey Press, 1986. p. 164. "In verbis“: "MEN being, as has been said, by nature all free, equal, and independent, no one can be put out of this estate and subjected to the political power of another without his own consent, which is done by agreeing with other men, to join and unite into a community for their comfortable, safe, and peaceable living, one amongst another, in a secure enjoyment of their properties, and a greater security against any that are not of it."

${ }^{107}$ LOCKE, John. Two treatises of government. London: Guernsey Press, 1986. p. 165. "In verbis“: "For, when any number of men have, by the consent of every individual, made a community, they have thereby made that community one body, with a power to act as one body, which is only by the will and determination of the majority. For that which acts any community, being only the consent of the individuals of it, and it being one body, must move one way, it is necessary the body should move that way whither the greater force carries it, which is the consent of the majority, or else it is impossible it should act or continue one body, one community, which the consent of every individual that united into it agreed that it should; and so every one is bound by that consent to be concluded by the majority. And therefore we see that in assemblies empowered to act by positive law which empowers them, the act of the majority passes for the act of the whole, and of course determines as having, by the law of Nature and reason, the power of the whole." 
dessa necessidade em um centro de poder, o qual tem suas normas de convivência com as outras estruturas sociais análogas fixadas pelo direito internacional ${ }^{108}$.

No contexto local, a concentração do poder no estado representa a superação da situação individual de combate - do estado da natureza - pela união, isto é, pela agregação, pela ação em conjunto ${ }^{109}$. Os seres humanos encontram-se regidos pelas leis a partir do momento em que se inserem na sociedade. Observada a comunidade internacional sob o prisma da descentralização do poder e o estado como o exemplo mais latente de corpo social formado por conjuntos de seres humanos na atualidade, possível se faz perceber a relação entre esses entes associativos como análoga ao estado de natureza, no qual os indivíduos se encontravam em momento anterior à regulamentação da vida em sociedade pelo direito ${ }^{110}$.

Ainda que os princípios de direito possam ser concebidos por parte da doutrina como universais e inatos, a estrutura estatal depende claramente da participação dos indivíduos em sua institucionalidade e não se sustentaria apenas em conceitos pressupostos. Estados se estruturariam, assim, com base na soma das forças dos distintos indivíduos da sociedade -

108 ARÉCHAGA, Eduardo Jiménez; ARBUET-VIGNALI, Heber; PUCEIRO ROPOLL; Roberto. Derecho internacional público - Tomo I. Montevideo: Fundación de Cultura Universitaria, 2005. p. 24. "In verbis": "El ser humano, gregario y conflictivo, para convivir en sociedad sin destruirse necesita de reglas. Con el correr de los tiempos creó el derecho positivo, instrumento mediante el cual procura lograr la armónica convivencia en grupos; pero este no es el único instrumento, ni fue el primero, aunque sea el más extendido e importante. Los Centros de Poder independientes, entre ellos los mas desarrollados, los Estados, como los seres humanos que les constituyen y vivifican, persiguen en sus relaciones mutuas determinados fines y requieren de reglas para convivir. A lo largo del tiempo las estructuras políticas en que se integraron los Centros de Poder independientes al relacionarse, fueron diferentes y distintos fueron los conjuntos de reglas que enmarcaron esas relaciones."

${ }^{109}$ ROUSSEAU, Jean-jacques. Du contrat social. Paris: Union Générale d’Éditions, 1973. p. 72. “In verbis”: “Je suppose les hommes parvenus à ce point où les obstacles qui nuisent à leur conservation dans l'état de nature l'emportent, par leur résistance, sur les forces que chaque individu peut employer pour se maintenir dans cette état. Alors cet état primitif ne peut pas subsistier; et le genre humain périroit s'il ne changeoit de maniére d'être. Or, comme les hommes ne peuvent engendrer de nouvelles forces, mais seulement unit et diriger celles qui existent, ils n'ont plus d'autre moyen, pour se conserver, que de former par agrégation une somme de forces qui puisse l'emporter sur la résistance, de les mettre en jeu par un seul mobile et de les faire agir de concert."

${ }^{110}$ LOCKE, John. Two treatises of government. London: Guernsey Press, 1986. p. 191. "In verbis“": "There is another power in every commonwealth which one may call natural, because it is that which answers to the power every man naturally had before he entered into society. For though in a commonwealth the members of it are distinct persons, still, in reference to one another, and, as such, are governed by the laws of the society, yet, in reference to the rest of the mankind, they make one body, which is, as every member of it before was, still in the state of Nature with the rest of the mankind, so that the controversies that happen between any man of the society with those that are out of it are managed by the public, and an injury done to a member of their body engages the whole in the reparation of it. So that under this consideration the whole community is one body in the state of Nature in respect of all other states or persons out of this community. This, therefore, contains the power of war and peace, leagues and alliances, and all the transactions with all persons and communities without the commonwealth, and may be called federative if anyone pleases. So the thing be understood, I am indifferent as to the name." 
estado político - e em suas vontades - estado civil ${ }^{111}$. A divisão feita pela doutrina entre duas expressões da fundamentação da estrutura de estado não significa uma dicotomia. Trata-se de forma de se revelar que o ente que se sobrepõe aos indivíduos e estabiliza a sociedade seria formado pelo poder e pela maneira como esse se expressa. E, além disso, de que ambos os elementos não se identificariam necessariamente ${ }^{112}$.

A unidade social resultante do poder exercido pela expressão da vontade seria hoje, conforme mencionado, o estado, mas a idéia atual de estado teria apenas algumas poucas centenas de anos. Atribui-se a Maquiavel o primeiro uso do termo "estado" no século XVI, mas isso não significa que os indivíduos antes não organizavam o poder e seu exercício em estruturas institucionalizadas $^{113}$. O estado constituiria, portanto, apenas o aperfeiçoamento dessa organização.

A institucionalização da vida no estado, o qual apaziguaria os conflitos sociais que seriam inerentes às relações humanas, pode ser também concebida como autocrática. $\mathrm{O}$ mitológico "Leviatã", por exemplo, quando utilizado em referência ao estado, denuncia a perspectiva de Thomas Hobbes e reforça o conceito de centralização do poder em um governo

\footnotetext{
${ }^{111}$ MONTESQUIEU, Charles de Secondat Baron de. De l'esprit des lois - Vol 1. Paris: Garnier-Flammarion, 1979. pp. 127-128. "In verbis“": "Le droit des gens est naturellement fondé sur ce principe, que les diverses nations doivent se faire dans la paix le plus de bien, et dans la guerre de moins de mal q'il est possible, sans nuire à leurs véritables interest. L'objet de la guerre, c'est la victoire; celui de la victoire, la conquête; celui de la conquête, la conservation. De ce principe et du précédent, doivent dériver toutes les lois qui forment le droit des gens. Toutes les nations ont un droit de gens. [...] Outre le droit des gens qui regarde toutes les sociétés, il y a un droit politique pour chacune. Une société ne saurait subsister sans un gouvernement. La reunión de toutes les forces particulares, dit très bien Gravina, forme ce qu'on appelle l'ÉTAT POLITIQUE. [...] Il vaut Vieux dire que le gouvernement le plus conforme à la nature est celui dont la disposition particulère se rapporte vieux à la disposition du peuple pour lequel i lest établi. Les forces particulares ne peuvent sa réunir, sans que toutes les volontés se réunissent. La reunión de ces volontés, dit encore très bien Gravina, est ce qu'on appelle l'ÉTAT CIVIL.“
}

112 MONTESQUIEU, Charles de Secondat Baron de. De l'esprit des lois - Vol 1. Paris: Garnier-Flammarion, 1979. p. 129. "In verbis“: "Je n'ai point séparé les lois politiques des civiles. Car, comme je ne traite point des lois, mais de l'esprit des lois; et que cet spirit consiste dans les divers rapports que les lois peuvent avoir avec diverses choses; j'ai dû moins suivre l'ordre naturel des lois, que celui de ces rapports et de ces choses.“

${ }^{113}$ BONAVIDES, Paulo. Teoria geral do estado. São Paulo: Malheiros Editores, 2012. pp. 36-37. "In verbis": "Aliás, a expressão "Estado" foi, segundo a versão mais aceita, criada por Maquiavel, que a introduziu nas primeiras linhas de sua célebre obra intitulada O Príncipe. Mas seu uso só ficou consagrado muito tempo depois, porquanto faltava o dado estabilizador e legitimante do conceito que unicamente a face jurídica lhe havia de ministrar para associá-lo, em definitivo, à instituição nascente, ou seja, O Estado, definido já em seus elementos constitutivos e positivado num sistema de organização permanente e duradoura.". MAQUIAVEL, Nicolau. O príncipe. Rio: Paz e Terra, 1996. p. 13. "In verbis": "Todos os Estados, todos os governos que tiveram e têm autoridade sobre os homens são Estados e são ou repúblicas ou principados. Os principados, por sua vez, ou são hereditários, neste caso o príncipe é tal por descendência antiga, ou são novos.” 
autoritário $^{114}$. O contraponto a tal concepção extremada seria, a partir da consolidação da percepção da centralidade do homem, o direito e as limitações ao poder por ele estabelecidas.

O estado não só pode como deve ser abordado por múltiplas perspectivas teóricas. $\mathrm{O}$ uso do direito como parâmetro exclusivo dificultaria bastante o processo de justificação normativa e a sociologia, por exemplo, poderia auxiliar a compreensão do monopólio da força pela estrutura artificialmente criada em sociedade. A própria concepção de estado apenas poderia ser realmente visualizada a partir da observação histórica dos fatos que levaram a humanidade à adoção desse tipo de estrutura como modelo de organização do poder ${ }^{115}$.

Essa transdiciplinariedade se faz exigível em razão da impossibilidade de o direito, sozinho, fundamentar e justificar todas as questões envolvidas na idéia de poder organizado. Uma ordem normativa local não possui meios para impor limites à sua própria existência ou se apresentar como condição hábil a determinar o nascimento ou o fim do corpo político que regulamenta. Nada impediria, de fato, que o direito reconhecesse e se referisse a momento fundacional específico ou - como hipótese - estabelecesse o término do estado pela absorção por outra estrutura política de poder, mas nada disso servia para condicionar o reconhecimento de sua existência institucional ou para fixar um marco ao seu exaurimento ${ }^{116}$.

\footnotetext{
${ }^{114}$ HOBBES, Thomas. Leviathan. Cambridge: hackett Publishing Company, 1994. p. 03. "In verbis": "For by art is created that great LEVIATHAN called a Commonwealth, or State (in Latin Civitas), which is but an artificial man, though of greather stature and strength than the natural, for whose protection and defence it was intended; and in which the souvereignty is an artificial soul, as giving life and motion to the whole body; the magistrates and oter officers of judicature and execution, artificial joints; reward and punishment (by which fastened to the seat of the souvereignty every joint and member is moved to perform his duty) are the nerves, that do the same in the body natural; the wealth and riches of all particular members are the strength [...]".
}

115 Citando Hegel, JELLINEK, Georg. Das Recht des modernen Staates. Berlin: Verlag von O. Häring, 1900. p. 111. "In verbis": "Damit stellt sich die sociale Betrachtungsweise des Staates als notwendiges Korrektiv der juristischen dar. Die Rechtslehre behauptet, dass der souveräne Staat jeder anderen organisirten Gewalt überlegen, keiner untertan sei. Aber den gewaltigen Mächten des socialen Lebens, die nicht in der Form bewusster Wiliensmacht wirken, ist der Herrscher selbst untertan. Möge der Jurist sich daher hüten, seine Normenwelt, die das Staatsleben beherrschen soll, mit diesem Leben selbst zu verwechseln. All die formaljuristischen Vorstellungen von Staatsallmacht, die, hypothetisch aufgestellt, ihre gute Berechtigung haben, verschwinden wenn man von der Welt der juristischen Möglichkeiten in die Wirklichkeit der Gesellschaft blickt. Da wogen die historischen Kräfte, die das An-sich der Staaten bilden und zerstören, das jenseits aller juristischen Konstruktion besteht. Von diesem An-sich gilt, was mit genialem Worte der vielverlästerte deutsche Denker ausgesprochen hat: Für Werden, Sein und Vergehen der Staaten giebt es kein anderes Forum als die Weltgeschichte, die das Weltgericht bildet. Seine Normen sind aber sicherlich nicht die des Juristen.”

${ }^{116}$ KELSEN, Hans. Théorie générale du droit international public : problèmes choisis. In: Recueil des Cours. Academie de Droit International de la Haye, Volume 42, 1932-IV, pp. 117-351. p. 260. "In verbis“": "Le droit étatique ne pose pas de limites à sa propre validité dans le temps. Il prétend valoir éternellement ; sa validité ne doit pas trouver de fin dans le temps; en employant une personnification, l'Etat ne veut pas sa propre fin. La doctrine du droit naturel, obéissant au dogme de la souveraineté, a aussi affirmé que l'éternité est, avec la toute-puissance et avec la justice, une qualité essentielle de l'Etat divinisé, c'est-à-dire transformé en un absolu, dans le dogme de la souveraineté. Mais un, regard sur la réalité - de l'histoire comme du droit - montre que le temps pendant lequel les Etats existent est limité comme l'espace dans lequel ils font sentir leur action. Des Etats naissent et disparaissent. Dans l'espace qui formait le domaine de l'Empire romain s'appliquent 
Os elementos povo e território são considerados hoje fundamentais ao reconhecimento de um estado. Sem a presença de ambos, não haveria, assim, o ente político - soberano ou não. Referidos pressupostos existenciais não delimitariam, contudo, o campo de ação da soberania estatal, é dizer, ainda que consubstanciem elementos fundamentais ao reconhecimento de um estado soberano, o povo e o território não constituem, necessariamente, limites absolutos à soberania ${ }^{117}$.

O conjunto de indivíduos de uma sociedade estatal conforma o povo. Quando referidos como cidadãos, tem-se alusão ao sentido político da atuação das pessoas em sociedade, ou seja, à participação política na formação da vontade soberana. Quando referidos como sujeitos, percebe-se perspectiva relacionada à submissão dos indivíduos ao estado e, portanto, ao poder a ele trasladado e nele concentrado ${ }^{118}$. Essa terminologia é, entretanto, comumente confundida e utilizada sem conteúdo técnico preciso ${ }^{119}$.

Quanto ao território, o outro elemento reconhecido como necessário ao reconhecimento de uma estrutura de poder como estado, sua importância ultrapassa claramente os limites das ordens particulares e faz do mesmo o mais transcendente dos elementos dessas estruturas políticas. O conceito de território possui, assim, relevância também para o direito internacional porque fixa os limites espaciais do exercício da soberania $^{120}$.

aujourd'hui les droits d'Etats tout au tres. Mais une détermination juridique - du moins du début de la validité du droit étatique, c'est-à-dire de la naissance de l'Etat - ne peut pas résulter de son propre droit. La détermination du terme de cette validité par le droit interne serait peut-être théoriquement possible, mais, en fait, il n'arrive pas que le droit étatique restreigne lui-meme dans le temps sa propre validité en tant que système, qu'il ordonne qu'il cessera de valoir à un moment déterminé, bien qu'il doive nécessairement contenir certaines prescriptions sur le début et la fin de la validité des différentes normes particulières qui le composent."

117 KLEFFENS, Eelco Nicolaas van. Sovereignty in international law : five lectures. In: Recueil des Cours. Academie de Droit International de la Haye, Volume 82, 1953-I, pp. 01-131. p. 94. "In verbis“: "No state, sovereign or non-sovereign, is conceivable without a population or without a territory. But whilst a sovereign state must have a population and a territory, its authority is by no means confined to that territory and to its permanent population."

${ }^{118}$ ROUSSEAU, Jean-jacques. Du contrat social. Paris: Union Générale d'Éditions, 1973. p. 74. "In verbis": “A l'égard des associés, ils prennent collectivement le nom peuple, et s'appellent en particulair citoyens, comme participant à l'autorité souveraine, et sujets, comme soumis aux lois de l'État."

${ }^{119}$ ROUSSEAU, Jean-jacques. Du contrat social. Paris: Union Générale d'Éditions, 1973. p. 74. "In verbis": "Mais ces termes se confondent souvent et se prennent l'un pour l'autre; il suffit de les savoir distinguer quand ils sont employés dans toute leur precision."

${ }^{120}$ WEIL, Prosper. Le droit international en quete de son identité: cours général de droit international public. In: Recueil des Cours. Academie de Droit International de la Haye, Volume 237, 1992-VI, pp. 09-370. p. 35. "In verbis": "A ces deux fonctions centrales du droit international que sont la coexistence et la coopération il convient d'en d'ajouter une troisième, qui les précède et les présuppose : la fonction territoriale, qui assure à chaque Etat le respect de sa souveraineté à intérieur de ses frontières. En effet, selon le modèle qui s'est forgé 
O terceiro elemento reconhecido como essencial ao reconhecimento de uma estrutura estatal seria o governo, o qual pode ser concebido - em concepção ideal - como expressão, em menor escala, da soberania, ou seja, da vontade do conjunto social ${ }^{121}$.

Dos três elementos apontados, tem-se na idéia de governo aquele que mais dependeria hoje das estruturas de direito. A consagração teórica do exercício do poder pela democracia como verdadeiro requisito à proteção dos seres humanos - em perspectiva, admite-se, eminentemente ocidental - implica assumir que um governo que tenha por base a lei apenas poderia ser legitimado pela expressão da vontade dos indivíduos que compõem a sociedade ${ }^{122}$. No que se refere à legitimação, especificamente, a prevalência do direito na organização social estaria no cerne da idéia republicana e, nesse sentido, todo governo legitimado pelo direito poderia ser, portanto, considerado republicano ${ }^{123}$.

O estado pode ser percebido tanto como produtor de direito, quanto como ente a ele submetido. Na ótica da submissão, a organização personificada poderia ser considerada sujeito ou objeto de direito, conforme a situação. Na prática, contudo, tem-se que o estado é,

en Europe à la fin du Moyen Age et qui s'est depuis lors étendu au monde enteier, la société internationale este construite autour de la notion de territoire. Le paysage international est caractérisé par la juxtaposition d'aléoles territoriales, dont chacune relève d'un Etat qui y exerce ce que l'on appelle, de manière significative, la souveraineté territoriale. Territoire et souveraineté sont, en queleque sorte, consubstantiels.“

${ }^{121}$ ROUSSEAU, Jean-jacques. Du contrat social. Paris: Union Générale d'Éditions, 1973. p. 125. "In verbis": "Le gouvernement est un petit ce que le corps politique qui le renferme est en grand. C'est une personne morale douée de cartaines facultés, active, comme le souverain, passive comme l'État, et qu'on peut décomposer en d'autres rapports semblables; d'où naît par conséquent une nouvelle proportion; une autre encore dans celle-ci, selon l'ordre des tribunaux, jusqu'à ce qu'on arrive à un moyen terme indivisible, c'est-àdire à un seul chef ou magistrat suprême, qu'on peut se représenter, au millieu de cette progression, comme l'unité entre la série des fractions de celles des nombres."

${ }^{122}$ LOCKE, John. Two treatises of government. London: Guernsey Press, 1986. p. 166. "In verbis“: "Whosoever, therefore, out of a state of Nature unite into a community, must be understood to give up all the power necessary to the ends for which they unite into society to the majority of the community, unless they expressly agreed in any number greater that the majority. And this is done by barely agreeing to unite into one political society, which is all the compact that is, or needs be, between the individuals that enter into or make up a commonwealth. And thus, that which begins and actually constitutes any political society is nothing but the consent of any number of freemen capable of majority, to unite and incorporate into such a society. And this is that, and that only, which did or could give beginning to any lawful government in the world."

123 Observa-se, nesse sentido, que a concepção de república estabelecida por Rousseau não se referia, necessariamente, à forma de governo adotada e que uma monarquia, devidamente regida e legitimada pelo direito poderia ser concebida como republicana. ROUSSEAU, Jean-jacques. Du contrat social. Paris: Union Générale d'Éditions, 1973. p. 99. "In verbis": “J'appelle donc république tout État régi par des lois, sous quelque forme d'administration que ce puisse être: car alors seulement l'intérêt public gouverne, et la chose publique est quelque chose. Tout gouvernement légitime est républicain [...]" 
mormente, concebido sob três perspectivas possíveis: a do direito de família - patriarcal, a dos direitos reais - patrimonial - ou a do direito contratual - contratualista ${ }^{124}$.

Ainda no que se refere às referências terminológicas, observa-se que a expressão "estado de direito" se relacionaria com o ideal moderno de estado. Mais precisamente à idéia de poder e a seu exercício e regulamentação ${ }^{125}$. A alusão a "estado de direito" poderia indicar, na verdade, dois momentos distintos: o da produção da norma - função legislativa - e o de sua aplicação - função judiciária ${ }^{126}$. No plano interno de alguns países como o Brasil, entretanto, o momento prescritivo acaba se confundindo hoje, muito freqüentemente, com o de extração da normatividade e esse contexto poderia dar à expressão conteúdo ainda mais genérico.

Também "estado moderno" não significaria apenas a forma centralizada de organização do poder fulcrada no direito. Sua concepção deve abranger a perspectiva histórica da modernidade como marco da transformação da estrutura de poder nas sociedades européias da difusão à centralização ${ }^{127}$.

${ }^{124}$ JELLINEK, Georg. Das Recht des modernen Staates. Berlin: Verlag von O. Häring, 1900. pp. 174-175. "In verbis": "Unter Rechtstheorien verstehe ich diejenige Gruppe von Lehren welche den Staat auf einem Satz der Rechtsordnung stützen, ihn selbst also als Produkt des Rechtes ansehen. Sie gehen alle, ausdrücklich oder unausgesprochen, von der Anschauung aus, dass es eine dem Staate vorangehende und über ihm stehende Rechtsordnung gebe, aus der er selbst abzuleiten sei. Sie treten geschichtlich in drei Formen auf. Entweder wird der Staat als ein familienrechtliches, oder als ein sachenrechtliches oder als ein vertragsreclttliches Institut aufgefasst. Es sind die Patriarchal-, die Patrimonial- und die Vertragstheorie, die hier zur Sprache kommen."

${ }^{125}$ SALEM CAGGIANO, Monica Herman. Oposição na política. São Paulo: Angelotti, 1995. p. 28. "In verbis": "Com efeito, do mais perfunctório exame do processo politico, emerge flagrante o continuo questionamento acerca do melhor sistema, isto é, do mecanismo mais adequado a preordenar, no âmbito da comunidade social, o modo pelo qual se operam a aquisição, o exercício e o controle do poder politico."

${ }^{126}$ KRABBE, H.. L'idée moderne de l'état. In: Recueil des Cours. Academie de Droit International de la Haye, Volume 13, 1926-III, pp. 509-583. p. 567. "In verbis“: "L'idée moderne de l'État a son point de départ dans la doctrine de l'État de droit. Cette expression peut avoir une double signification. On l'emploie pour désigner la tâche de l'État pour indiquer ainsi la conception kantienne de l'État, de sorte que la fonction de l'État réside dans la réalisation du droit. L'expression « réalisation du droit » est donc prise ici dans le double sens de maintien et de formation du droit. Je fais remarquer, en passant, que cette détermination du but de l'État peut conduire à un formidable développement de la tâche de l'État, car l'aptitude, pure et simple, à former le droit, comprend la tâche de déterminer la valeur juridique d'un nombre illimité d'intérêts.“

${ }^{127}$ BONAVIDES, Paulo. Teoria geral do estado. São Paulo: Malheiros Editores, 2012. pp. 33-34. "In verbis": "Esta locução política "Estado Moderno" só se faz inteligível na sua realidade contemporânea se houver primeiro remissão a elementos históricos que ilustram a natureza governativa da sociedade ocidental, já na Antiguidade, já na Idade Média. Por via desse cotejo ou paralelo se percebe quanto o Estado Moderno em verdade significa uma nova representação de poder grandemente distinta daquela que prevaleceu em passado mais remoto ou até mesmo mais próximo, como foi o largo período medievo. [...] Eis ai a que se reduzia, pois, o Estado Antigo: numa extremidade, a força bruta das tiranias imperiais típicas do Oriente; noutra, a onipotência consuetudinária do Direito ao fazer suprema, em certa maneira, a vontade do corpo social, qualitativamente cifrado na ética teológica da pólis grega ou no zelo sagrado da coisa pública, a res publica da civitas romana. [...] Em verdade, toda a Idade Média, com sua organização feudal levantada sobre as ruínas do Império Romano, vira em certa maneira arrefecer a concepção de Estado. Pelo menos do Estado no sentido de 
Especificamente quanto à soberania, é de se ressaltar, inicialmente, que a rejeição de determinados conteúdos dados à sua expressão externa e de sua aplicação à relação entre os sujeitos de direito internacional constituiria posicionamento doutrinário compreensível e harmônico com o pensamento jurídico. Nesse caso, não se rejeitaria o direito, mas se perceberia tão somente a inaplicabilidade de determinada premissa jurídica a contexto fático diverso $^{128}$.

Sem que se adrente - ainda e entretanto - na questão soberana como conceito, ao reconhecimento do estado bastaria que o poder exercido pelo governo não se submetesse a nenhum outro que não ao seu próprio ${ }^{129}$. As relações com outros estados se encontram compreendidas, na verdade, no próprio conceito de soberania como uma de suas funções ${ }^{130}$.

Em todo esse contexto, percebe-se que a igualdade entre os entes políticos independentes - decorrente da mencionada concepção de soberania - poderia ser observada como um obstáculo à evolução do direito internacional. Isso porque, mesmo sem que o tamanho ou o nível de desenvolvimento importe, os estados devem ser tratados como iguais no plano internacional ${ }^{131}$.

instituição materialmente concentradora de coerção, apta a estampar a unidade de um sistema de plenitude normativa e eficácia absoluta."

${ }^{128}$ MIRKINE-GUETZEVITCH, Boris. Droit international et droit constitutionnel. In: Recueil des Cours. Academie de Droit International de la Haye, Volume 38, 1931-IV, pp. 307-465. p. 320. "In verbis": "Nous avons déja dit que la théorie de M. Triepel était en 1899 une théorie progressive. Mais cette théorie ne correspond plus à la réalité actuelle, cette doctrine ne peut expliquer tous les phénomènes de la vie internationale de nos jours. D'autre part, le plan théorique de M. Verdoss, par example, ne correspond pas non plus à toute la réalité internationale contemporaine, parce qu'il reste encore divers phénomènes de la vie internationale n'ayant point à l'heure actuelle subi une évolution suffisante. Le parallélisme de M. Triepel ne peut plus expliquer toute la vie internationale, mais la primauté du droit international de M. Versross n'existe pas en pratique dans tous les rapports du droit international et du droit interne."

${ }^{129}$ GUGGENHEIM, Paul. Les principes de droit international public. In: Recueil des Cours. Academie de Droit International de la Haye, Volume 80, 1952-I, pp. 01-189. p. 96. "In verbis": "Pour qu'il y ait donc Etat au sens du droit international, une seule chose est nécessaire : c'est que le gouvernement instituéexerce son pouvoir sur les destinataires de l'ordre juridique dans un espace determiné, sans que ce pouvoir soit limité par un autre ordre juridique étatique.“

${ }^{130}$ HOBBES, Thomas. Leviathan. Cambridge: hackett Publishing Company, 1994. p. 114. "In verbis": “[...] is annexed to the souvereignty the right of making war and peace with other nations and commonwealths, that is to say, of judging when it is for the public good, and how great forces are to be assembled, armed, and paid for that end, and to levy money upon the subjects to defray the expenses thereof. For the power by which the people are to be defended consistenth in their armies; and the strength of an army, in the union of their strength under one command; which command the sovereign instituted therefore hath, because the command of the militia, without other institution, maketh him that hath is sovereign. And therefore, whosoever is made general of an army, he that hath the sovereign power is always generalissimo."

131 GARNER, James W.. Le développement et les tendances récentes du droit international. In: Recueil des Cours. Academie de Droit International de la Haye, Volume 35, 1931-I, pp. 605-720. pp. 704-705. "In verbis“" “Le principe de l'égalité des États n'implique, ou ne devrait pas impliquer, autre chose que l'égalité devant le droit international, c'est-à-dire le droit de tout les États, grands ou petits, à la même protection du droit et à 
A abstração cientificista permitida pelo positivismo puramente técnico na modernidade serviu muito bem ao direito internacional e permitiu que se reconhecessem na estrutura da ordem internacional padrões que puderam, aos poucos, afastar sua fundamentação da vontade soberana como motriz exclusiva ${ }^{132}$. Assim, mesmo a guerra poderia ser afastada da idéia de estado e concebida em contexto não necessariamente que o envolva. Guerras são historicamente anteriores à atual concepção de ente soberano e esse não poderia ser entendido, portanto, como única estrutura passível de se relacionar de forma beligerante ${ }^{133}$.

Mesmo textos supostamente técnicos como a Carta das Nações Unidas tampouco eliminam as dúvidas relacionadas às estruturas organizadas de poder. Verifica-se, dessa forma, que o referido tratado faz referência a estado, nação e povo de forma assistemática, isto é, sem adotar conceito jurídico determinado e preciso para cada um dos termos. Estabeleceu-se de maneira clara, contudo, que apenas estados - como estruturas soberanas de poder - poderiam ser admitidos como membros da organização ${ }^{134}$.

l'égalité de traitement quand ils se présentent devant les juridictions internationales comme demandeurs ou défendeurs. [...] Manifestement il ne peut pas signifier égalité de capacité en ce qui concerne les droits, égalité de voix dans les conférences internationales, égalité de représentation dans les organisations internationales, égalité de participation à la formation du droit international, particulièrement pour formuler des règles (règles du droit maritime, par example) qui n'affectent que certaines États et n'intéressent en aucune façon les autres États. Comme le dogme de la souveraineté de l'État, celui de l'égalité des États a été un sérieux obstacle aux progrés du droit international et de l'organisation internationale, et sa persistance est encore un obstacle. Mais il a perdu, heureusement, beaucoup de sa sacro-sainteté, et en pratique on l'a fréquemment écarté ces dernières années."

132 BRIERLY, J.-L.. Le fondement du caractère obligatoire du droit international. In: Recueil des Cours. Academie de Droit International de la Haye, Volume 23, 1928-III, pp. 463-552. p. 488. "In verbis": "La vérité est que le positivisme a rendu un service bien nécessaire au droit international en insistant clairement sur deux points : le que ce qu'est le droit et ce qu'il devrait être ne sont pas toujours et nécessairement même chose, et o que l'on peut découvrir le premier point en examinant la pratique internationale et en s'efforcant de noter les principes sur lesquels cette pratique est fondée, et qu'on ne le peut pas autrement. Mais le positivisme trahit sa propre profession de foi quand il implique que le droit puisse être réduit à une serie de propositions formulées, car il omet d'observer que la pratique internationale admet habituellement le recours au droit naturel ou à la raison, et il outrepasse sa fonction lorsqu'il se considère comme un système de philosophie du droit, en enseignant que l'obligation peut trouver sa source ultime dans les volontés consentantes de ceux qu'assujettit le droit."

${ }^{133}$ MONTESQUIEU, Charles de Secondat Baron de. De l'esprit des lois - Vol 2. Paris: Garnier-Flammarion, 1979. p. 262. Usando os conflitos surgidos a partir dos laços de suserania e vassalagem medievais e comparando-os com os de sua época, "in verbis“: "L'usage du combat judiciaire s'étendent de plus em plus, Il y eut dês lieux, des cãs, dês temps, ou par conséquent on negligea de rendre la justice. L'appel de défaute de droit s'introduisit; et ces sortes d'appels ont été souvent des points remarquables de notre histoire, parce que la plupart des guerres de ces temps-là avaient pour motif la violation du droit politique, comme nos guerres d'aujourd'hui ont ordinairement pour cause, ou pour pretexte, celle du droit des gens.“

${ }^{134}$ FLEINER-GERSTER, Thomas. Teoria geral do estado. São Paulo: Martins Fontes, 2006. p. 183. "In verbis": "No preâmbulo da Carta das Nações Unidas, os povos destas nações se obrigam, para o futuro, a impedir a guerra e a preservar a paz. Mas quem são pois os povos das Nações Unidas? Para nossa surpresa, constatamos que, segundo o artigo 3 e seguintes da Carta, somente "Estados", mas não povos ou nem mesmo "nações" podem ser membros das Nações Unidas. A Carta emprega portanto os conceitos de povo, Estado e nação, sem definir a significação particular de cada um destes diferentes termos. Na declaração solene do preâmbulo não 
No que se refere à diferenciação dos estados federais das confederações, essa pode ser empreendida no marco jurídico fundamental das próprias ordens legais dos entes. Enquanto o primeiro estruturaria seu ordenamento sob uma constituição, as organizações confederativas possuiriam como base um tratado. Entre essas duas formas de estruturação do poder se encontraria a característica restrita aos entes genuinamente independentes de submissão exclusiva à sua própria vontade, é dizer, a soberania ${ }^{135}$.

Há que se pontuar, nesse momento, que a afirmação de diminuição de importância do estado como sujeito de direito internacional merece ressalvas e aprofundamento teórico. $\mathrm{O}$ estado segue constituindo sujeito central da ordem jurídica mundial e assertivas nesse sentido apenas podem servir para apontar o fim de sua exclusividade como sujeito de direitos e a ascendência cada vez maior de seus deveres em relação aos seus pares, às organizações internacionais e, até mesmo, aos indivíduos ${ }^{136}$.

Conforme já ressaltado anteriormente quando do estudo da relação existente entre política e direito, o estado constitui forma de organização do poder. Nesse sentido, é de se perceber que os indivíduos esquematizam a vida comum sob a estrutura estatal em razão da necessidade de se organizar o uso da força na sociedade.

consta o conceito abstrato, inanimado e racional de "Estado"; são antes os povos que juram solenemente preservar a paz. Por outro lado, não falamos nem dos "Povos Unidos" nem dos "Estados Unidos", mas sim das "Nações Unidas", e referimo-nos, desse modo, tanto aos Estados-membros quanto aos povos que neles vivem. Esta confusão conceitual (consultar a esse respeito especialmente a declaração de Argel de 1976, bem como A. Cassese e E. Jouve) mostra claramente quão difícil e problemático é o conceito moderno de Estado. Não está claro a qual território e a qual povo cabe a condição de "Estado", quer dizer, quando o Estado e o povo são idênticos e quando não o são. Quem pode, por exemplo, invocar o direito de autodeterminação? Os Estadosmembros ou os povos, que são em parte submissos aos Estados-membros das Nações Unidas?"

${ }^{135}$ GUGGENHEIM, Paul. Les principes de droit international public. In: Recueil des Cours. Academie de Droit International de la Haye, Volume 80, 1952-I, pp. 01-189. p. 97. "In verbis“: "On prétend souvent cependant que la différence entre l'Etat fedéral et la Confédération d'Etats réside dans le fait que le premier reposerait sur une constitution, tandis que la seconde reposerait sur une convention internationale, l'Etat fédéral ne pouvant être basé sur un traité interétatique. La fédération internationale se distingue de l'Etat par le fait que son pouvoir législatif et exécutif est limité à certains objets. Contrairement à l'Etat, elle ne prétend pas à une réglementation totale, délimitée uniquement par le droit iles gens."

${ }^{136}$ ACCIOLY, Hildebrando; NASCIMENTO E SILVA, G.E. do; CASELLA, Paulo Borba. Manual de direito internacional público. São Paulo: Saraiva, 2011. p. 249. "In verbis“" "No direito internacional clássico, o sujeito por excelência do direito internacional, embora não mais se possa sustentar ser o único, era o estado, tal como se definia a partir de seu ordenamento interno. São também sujeitos de direito internacional as organizações internacionais enquanto associações de estados, ao lado do reconhecimento progressivo da condição internacional do ser humano. Participam das relações internacionais e atuam no contexto internacional, além dos estados e das organizações intergovernamentais, também as organizações não governamentais, as sociedades transnacionais, os rebeldes, os beligerantes, os povos, os moviimentos de liberação nacional e mesmo os seres humanos, estejam de um modo ou de outro organizados, como expressão do que se vem a chamar de sociedade civil internacional." 
As instituições jurídicas se mostram, nesse contexto, extremamente hábeis a garantir a paz social. Especificamente no que se refere ao estado, sua doutrina jurídica dispõe de sistematizações teóricas relacionadas à organização do poder desenvolvidas ao longo pelo menos dos últimos trezentos anos e não se pode negar que esse ente moral abstrato presta - há tantos séculos e com sucesso - serviços à preservação da paz social.

Seria razoável o direito internacional abandonar completamente essa perspectiva? Teria a aparente aversão consolidada ao menos em parte dos internacionalistas, que observam a soberania como entrave ao desenvolvimento do direito das gentes, desenvolvido repulsa à própria teoria do estado como um todo?

Estado e teoria geral do estado são coisas distintas. Ainda que o ente tivesse sua importância reduzida ou relativizada, o mesmo não se aplicaria necessariamente às estruturas de poder teorizadas e esquematizadas pelo direito para seu funcionamento como estabilizador da vida em sociedade.

\subsection{Soberania, Poder e Direito Internacional}

O poder soberano do estado tem no monopólio do uso da força sua expressão mais nítida e reconhecível. Soberania e força, contudo, não se confundem. O estado possui, em regra e de fato, o monopólio da força, mas não a exclusividade do poder ${ }^{137}$. Soberania, como conceito, depende, portanto, de submissão, mas pouca importância resta à forma de obtenção dessa obediência para que se reconheça a titularidade e a investidura no exercício do poder em uma estrutura estatal ${ }^{138}$.

\footnotetext{
${ }^{137}$ FLEINER-GERSTER, Thomas. Teoria geral do estado. São Paulo: Martins Fontes, 2006. p. 245. "In verbis": "O poder do Estado subdivide-se pois em força do Estado, de um lado, e autoridade do Estado, de outro. Examinemos primeiramente a força do Estado. A força é a utilização de meios de coerção física. Somente os órgãos do Estado podem recorrer a meios tais como a privação da liberdade ou da execução judicial. O Estado não tem o monopólio do poder, mas certamente o da força. Este monopólio da força diferencia o Estado moderno dos Estados precedentes. O antigo direito do senhor de, por exemplo, castigar os seus criados está abolido. O uso da força está exclusivamente reservado aos órgãos do Estado.”

${ }^{138}$ FLEINER-GERSTER, Thomas. Teoria geral do estado. São Paulo: Martins Fontes, 2006. p. 239. "In verbis": "A soberania se determina pois pela obediência ou pela submissão de um povo a um governo. A maneira pela qual se obtém a obediência, como seja, alternando-se belevolência e severidade, ou então pelo convencimento e pela informação, não é determinante. O que importa é o fato de que o povo seja submisso (oboedientia facit imperantem)."
} 
Nos parâmetros fixados pelo direito das gentes tradicional, a idéia de soberania revela aspectos positivos, como aquele da obrigatoriedade interna das diretivas emanadas, e negativos, relacionados aos limites estabelecidos exclusivamente pela vontade do titular exercente do poder - e a nenhum outro, portanto $^{139}$.

Em outras palavras, a concepção tradicional de estado soberano se refere basicamente ao gozo de duas características essenciais: de não submissão ao poder de outro ente soberano e de plenitude do exercício desse poder internamente ${ }^{140}$. Costuma-se fazer referência à primeira como "soberania externa" - que, para grande parte da doutrina, corresponderia a um sinônimo de independência - e à segunda como "soberania interna". Cumpre ressaltar de plano, no entanto, que ambas as expressões do poder soberano se encontram há algum tempo em claro processo de relativização.

Ainda que concebida genericamente como expressão do poder, a soberania se confundiria, com base nas teorias apontadas, internamente com o conceito de subordinação e externamente com a idéia de coordenação ${ }^{141}$. A adoção de percepções tradicionais mais extremas, as quais reconheciam ao estado a plenitude da vontade nos planos interno e internacional, consubstanciaria, contudo, verdadeira negação do próprio direito internacional $^{142}$. Esse entendimento expansivo da soberania resultaria no exercício da função

\footnotetext{
${ }^{139}$ ROUSSEAU, Charles. L'indépendance de l'Etat dans l'ordre international. In: Recueil des Cours. Academie de Droit International de la Haye, Volume 73, 1948-II, pp. 167-253. pp. 184-185. "In verbis“: "Telle qu'elle se présente dans la théorie classique du droit des gens, la notion de souveraineté revêt, comme en droit interne, un aspect positif et un aspect négatif. Au point de vue positif, elle se caractéerise par le pouvoir de donner des ordres inconditionnés; au point de vue négatif, elle se définit par le droit, de n'en recevoir d'aucune autre autorité humaine. En bref, elle apparaît comme le pouvoir abslolu et incontrôtable pour l' Etat de se comporter, dans les affaires extérieures connme dans les affaires domestiques, selon son bon plaisir, sans autres restrictions que celles qu'il aurait volontairement acceptées.“
}

${ }^{140}$ KLEFFENS, Eelco Nicolaas van. Sovereignty in international law : five lectures. In: Recueil des Cours. Academie de Droit International de la Haye, Volume 82, 1953-I, pp. 01-131. p. 13. "In verbis“: "A sovereign state is a state subject to no other state, and having full and exclusive authority within its jurisdiction, without prejudice to the limits set by applicable law."

${ }^{141}$ PODESTÁ COSTA, L.A. Derecho internacional público - tomo I. Buenos Aires, Tipográfica Editora Argentina, 1955. p. 71. "In verbis": "En el siglo xix, como consecuencia de la transformación de las monarquías absolutas en monarquías constitucionales, la soberanía se ha despersonalizado hasta el punto de convertirse en una idea abstracta; y además, como resultado de la existencia de Estados confederados y de Estados federales, se afirmó el concepto de que la soberanía admite restricciones y por lo tanto no es indivisible ni absoluta. La soberanía, si bien se concentra en el poder público que rige al Estado sin subordinación a otro poder, no es indivisible: en lo interno, su ejercicio se distribuye en las funciones concurrentes de los diversos Órganos que integran al gobierno; y no es tampoco absoluta, porque cuando trasciende al exterior su ejercicio debe ser coordinado con la soberanía de los demás Estados. Por esto la doctrina contemporánea afirma que 'e1 derecho internacional es un derecho de coordinación, mientras que el derecho interno es un derecho, de subordinación'; esto último, porque el derecho interno se caracteriza por la presencia de autoridades con fuerza coercitiva."

142 ANDRASSY, Georges. La souveraineté et la Société des Nations. In: Recueil des Cours. Academie de Droit International de la Haye, Volume 61, 1937-III, pp. 637-762. p. 653. "In verbis“: "Dans le même ordre d'idées, 
legislativa por um estado produzindo regras aplicáveis e exigíveis fora de seus limites territoriais vinculantes para indivíduos não integrantes de seu povo ${ }^{143}$.

No mesmo sentido, por outro lado, a soberania do estado, isto é, de uma comunidade de indivíduos capaz de expressar vontade de maneira conjunta na ordem internacional constituiria verdadeira condição de existência de uma ordem jurídica extraestatal ${ }^{144}$. Mais que uma característica dos estados, tratar-se-ia, portanto, de um pressuposto de sua interação e daí seu reconhecimento como requisito ao direito internacional, o qual apenas se concretizaria na medida em que os entes morais soberanamente expressassem sua vontade de fazê-lo ${ }^{145}$.

A relação entre estados e direito internacional conviveu desde sempre com os dilemas da dualidade apontada ${ }^{146}$. Autores chegam a criticar o uso das expressões soberania interna e externa para fazer referência ao exercício do poder nos planos local e global ${ }^{147}$. Optou-se,

on rencontre l'argument inverse, selon lequel la souveraineté comporte la négation du droit international. On conclut donc, en combinant les deux arguments, à l'inconapatibilité absolue entre le droit international et la souveraineté des Etats. Celle-ci serait une « antitèse de l'idée d'un droit international ».“

${ }^{143}$ KLEFFENS, Eelco Nicolaas van. Sovereignty in international law : five lectures. In: Recueil des Cours. Academie de Droit International de la Haye, Volume 82, 1953-I, pp. 01-131. pp. 99-100. "In verbis“: "LLegislation," said the Permanent Court of International Justice in the Eastern Greenland-case, is one "of the most obvious forms of the exercise of sovereign power", and since any sovereign state may make laws on anything so long as it does not thereby contravene international law, the range of matters which a sovereign state may deal with by way of legislation is enormous. When discussing territory, we have already noted that the effect of the national legislation of a sovereign state may extend well beyond the borders of its own territory, and apply, e. g., to ships flying its flag or to its nationals elsewhere. International law sets the limits to which this power is subject."

${ }^{144}$ ANDRASSY, Georges. La souveraineté et la Société des Nations. In: Recueil des Cours. Academie de Droit International de la Haye, Volume 61, 1937-III, pp. 637-762. p. 657. "In verbis“: "Non seulement la souveraineté n'est pas incompatible avec le droit internationral, mais elle doit même être considérée comme un élément indispensable de la notion et de l'existence du droit international. Le droit international est, par définition, l'ensemble des regles sur les rapports entre Etats coordonnés. Nous pouvons affirmier, avec Kant et tant d'autres, que le droit international présuppose l'existence d'un certain nombre d'Etats inidépendants. Il n'est pas concevable sans cela. Une civitas maxima, si elle venait jamais à se réaliser, entraînerait la disparition du droit international et son remplacement par le droit constitutionnel de 1'Etat mondial.“

${ }^{145}$ KOROWICZ, Marek Stanislaw. Some present aspects of sovereignty in international law. In: Recueil des Cours. Academie de Droit International de la Haye, Volume 102, 1961-I, pp. 01-120. p. 29. "In verbis": "It is thus clear that the defenders of sovereignty are not confined to one State or a block of States, since publicists of all countries believe that the existence of international law is tied up with sovereign States, and that without sovereignty there are neither States subjects of international law, nor this law itself."

${ }^{146}$ ANDRASSY, Georges. La souveraineté et la Société des Nations. In: Recueil des Cours. Academie de Droit International de la Haye, Volume 61, 1937-III, pp. 637-762. pp. 663-664. "In verbis“: "Dans les deux sens, il existe certaines bornes qu'on ne peut dépasser sans toucher à l'essence même de la souveraineté. Trop de liberté signilierait la destruction de l'ordre international, et par là la disparition de la notion de souveraineté elle-même. Inversement, si les restrictions sont excessives, la souveraineté est supprimée. Ceci se produit quand les restrictions arrivent à interposer entre l'entité, jusqu'alors souveraine, et l'ordre international, une nouvelle entité à laquelle la première se trouve subordonne.“

${ }^{147}$ KOROWICZ, Marek Stanislaw. Some present aspects of sovereignty in international law. In: Recueil des Cours. Academie de Droit International de la Haye, Volume 102, 1961-I, pp. 01-120. p. 13. "In verbis": "In a 
neste estudo, pela adoção da referida divisão terminológica apenas para fins didáticos e de estilo. Assim sendo, compreende-se o poder do estado como uno e indivisível, mas faz-se uso de interno e externo para indicar o contexto do exercício a que pontualmente se está referindo.

As críticas ao uso do termo "soberania" pelo direito internacional aduzem, por exemplo, as confusões causadas por seu emprego e a carga semântica que a história lhe conferiu. Chega-se a atacar sua concepção como teoria ou como princípio e termos como “autoridade" são apresentados como alternativa ${ }^{148}$.

A soberania, como poder, é amplamente reconhecida como una e indivisível ${ }^{149}$. Ainda que não possa ser, em princípio e entretanto, dividida, essa pode ver seu objeto, isto é, seu exercício, repartido em funções - ou, de forma não técnica, poderes. Nesse caso, a terminologia comumente utilizada se refere a "soberania" como poder indivisível e a "poderes" como funções desse poder soberano ${ }^{150}$.

number of treatises on international law, and even in some international judgments or opinions, the expression 'internal and external sovereignty' is used, but it should be rejected without hesitation. Sovereignty, meaning supreme power, may only exist with independent States inside but not outside the State and, therefore, may not be external. The external facet of sovereignty is called independence, unless by external sovereignty we mean 'personal sovereignty' that is the power of the State over its citizens abroad, which matter belongs, however, to municipal law."

148 BRIERLY, J.-L.. Le fondement du caractère obligatoire du droit international. In: Recueil des Cours. Academie de Droit International de la Haye, Volume 23, 1928-III, pp. 463-552. p. 523. "In verbis“: "Un récent théoricien de la souveraineté, après avoir remarqué que l'emploi du terme a cessé de faciliter la discussion contemporaine des problèmes politiques, et est devenu une simple source de confusión parce que c'est une notion qui a été transplantée hors de son milieu historique, émet l'opinion que le terme « autorité » est entièrement adéquat, et ne présente aucune des implications historiques embarrassantes qui sont attachées à « souveraineté. » Cela me semble parfaitement juste. L'autorité ou le pouvoir des États est un fait très réel; quelque nécessaire qu'il soit, c'est quelque chose dont on peut abuser et dont on abuse souvent; c'est quelque chose qui ne s'est jusqu'á présent montré qu'imparfaitement maniable par la loi. La souveraineté est une tentative d'expression de ces faits, et tout critique de la souveraineté ne devrait jamáis oublier qu'ils existent, ou se permettre de négliger leur importance; il doit au contraire essayer de montrer que le terme exagère même ces faits formidables et, de plus, qu'il implique qu'ils sont nécessaires et inaltérables. « On veut d'abord le résultat,» dit M. Saleilles, « on trouve le principe après; telle est la genèse de toute construction juridique. » II y a encoré trop de gens dans tous les pays qui veulent maintenir en fait tout ce que la souveraineté implique en théorie; il serait deplorable que la science du droit international dût continuer à faciliter ce dessein."

${ }^{149}$ Após listar doze direitos contidos na idéia de soberania, o reconhecimento de sua unidade e indivisibilidade: HOBBES, Thomas. Leviathan. Cambridge: hackett Publishing Company, 1994. p. 115. "In verbis": "These are the rights which make the essence of sovereignty, and which are the marks whereby a man may discern in what man, or assembly of men, the sovereign power is placed and resideth. For these are incommunicable and inseparable. [...] And so if we consider any one of the said rights, we shall presently see, that the holding of all the rest will produce no effect, in the conservation of peace and justice, the end for which all commonwealths are instituted. And this division is it, whereof it is said a kingdom divided in itself cannot stand."

${ }^{150}$ ROUSSEAU, Jean-jacques. Du contrat social. Paris: Union Générale d'Éditions, 1973. pp. 84-85. “In verbis": "Par la même raison que la souveraineté est inaliénable, elle est indivisible; car la volonté est générale (a), ou elle n'est pas; elle est celle du corps du peuple, ou seulement d'une partie. Dans le premier cas, cette volonté déclarée est un acte de souveraineté et fait loi; dans le second, ce n'est qu'une volonté particuliére, ou un acte de magistrature; c'est un décret tout au plus. Mais nos politiques ne pouvant diviser la souverainité dans son principe, la divisant dans son objet: ils la divisent en force et en volonté, en puissance législative et en puissance exécutive; en droits d'impôt, de justice et de guerre; en administration intérieure et en pouvoir de 
A soberania, contudo, nem sempre foi concebida pela doutrina como um elemento fundamental hábil a condicionar o reconhecimento de um estado. Nessa toada, surgiria a idéia de estado não-soberano como possibilidade, mas - mesmo nesses casos - a capacidade de auto-organização e a autonomia, normalmente ligadas ao conceito, resistiriam como premissas teóricas de reconhecimento ${ }^{151}$. Trata-se, na verdade, da relativização da soberania como um valor dado e pré-estabelecido, mas não de uma relativização de todas as características materiais que lhe são atribuídas.

A soberania popular já era identificada pelas teorias de poder antes mesmo da consolidação da noção de estado nos contornos verificados atualmente. Locke, por exemplo, não apenas conferia ao povo a titularidade absoluta do poder, mas também reconhecia a concreção como a mais importante das funções da maneira como esse povo se organizaria politicamente $^{152}$.

traiter avec l'étranger: tantôt ils confondant toutes ces parties, et tantôt ils les séparent. Ils font du souverain un être fantastique et formé de pièces rapportées; c'est comme s'ils composoient l'homme de plusieurs corps, dont l'un auroit des yeux, l'autre des bras, l'autre des pieds, et rien de plus."

${ }^{151}$ JELLINEK, Georg. Das Recht des modernen Staates. Berlin: Verlag von O. Häring, 1900. p. 445. "In verbis": "Ist demnach Souveränetät kein wesentliches Merkmal sowohl der mittelalterlichen als der Staaten aus der Blütezeit des naturrechtlichen Dogmas von der Identität der Staats- mit der souveränen Gewalt gewesen, so kann auch für die Gegenwart diese Gleichstellung nicht aus der Betrachtung der realen Staatenwelt dargetan werden. Auch die heutige Staatenwelt weist Gebilde auf, die staatliche Aufgaben mit selbständiger Organisation und staatlichen Mitteln erfüllen, aber nicht souverän sind. An diese historisch-politische Tatsache haben auch alle wissenschaftlichen Vorstellungen vom Staate anzuknüpfen, die ja das Gegebene erklären, aber nicht meistern sollen. Es giebt demnach zwei Gattungen von Staaten: souveräne uud nichtsouveräne. Da erhebt sich aber die Frage, welches Merkmal den nichtsouveränen vom souveränen Staat einerseits, vom nichtstaatlichen, dem Staate ganz untergeordneten Verband andererseits scheidet. Sie wird beantwortet durch Untersuchung der folgenden Eigenschaft der Staatsgewalt, der Fähigkeit zur Selbstorganisation und Autonomie."

${ }^{152}$ LOCKE, John. Two treatises of government. London: Guernsey Press, 1986. pp. 192-193. "In verbis": "Though in a constituted commonwealth standing upon its own basis and acting according to its own nature that is, acting for the preservation of the community, there can be but one supreme power, which is the legislative, to which all the rest are and must be subordinate, yet the legislative being only a fiduciary power to act for certain ends, there remains still in the people a supreme power to remove or alter the legislative, when they find the legislative act contrary to the trust reposed in them. For all power given with trust for the attaining an end being limited by that end, whenever that end is manifestly neglected or opposed, the trust must necessarily be forfeited, and the power devolve into the hands of those that gave it, who may place it anew where they shall think best for their safety and security. And thus the community perpetually retains a supreme power of saving themselves from the attempts and designs of anybody, even of their legislators, whenever they shall be so foolish or so wicked as to lay and carry on designs against the liberties and properties of the subject. For no man or society of men having a power to deliver up their preservation, or consequently the means of it, to the absolute will and arbitrary dominion of another, whenever any one shall go about to bring them into such a slavish condition, they will always have a right to preserve what they have not a power to part with, and to rid themselves of those who invade this fundamental, sacred, and unalterable law of self-preservation for which they entered into society. And thus the community may be said in this respect to be always the supreme power, but not as considered under any form of government, because this power of the people can never take place till the government be dissolved." 
Em conteúdo pessoal, soberania se referiria ao titular do poder em um estado. Em um regime autocrático, por exemplo, o termo pode indicar o monarca ou o ditador. Em regimes democráticos, o titular seria o próprio povo que exerceria esse poder concretivo indivisível por meio de seus representantes ${ }^{153}$.

Necessárias se fazem ressalvas, entretanto, a tais concepções ideais da organização do poder. Isso se deve ao fato de, mesmo em democracias exemplares, nem sempre a vontade expressada pelo governo na concreção de normas - nas esferas interna e internacional corresponder à vontade do povo representado ${ }^{154}$.

O estudo da soberania exigiria, ainda, leitura histórica de seu surgimento e das restrições que cada vez mais lhe são impostas. Em sua gênese, o poder se encontrava concentrado nas mãos de imperadores, reis ou do papa e a idéia de soberania veio apenas revestir essa dinâmica organizativa com características de não limitação a qualquer outro poder - interno ou externo - e, portanto, de independência em relação às outras estruturas análogas.

Não se pode negar, em todo esse contexto, o papel da soberania não apenas na estruturação do estado moderno, mas, na verdade, como nexo central promotor da organização de poder que persiste, ainda que em suave declínio, na atualidade ${ }^{155}$. Também a autodeterminação dos povos, por exemplo, manteve-se como importante princípio do direito das gentes e foi se consolidando até integrar definitivamente as cartas internacionais - e nacionais também - de direito.

Ressalvas, todavia, subsistem em relação àqueles capazes de exercer essa autodeterminação estabelecida como premissa pelo direito das gentes. Que seria povo? Quem

\footnotetext{
${ }^{153}$ GIRAUD, Emile. Le droit international public et la politique. In: Recueil des Cours. Academie de Droit International de la Haye, Volume 110, 1963-III, pp. 419-809. p. 425. "In verbis": "C'est l'action du gouvernement qui, en qualité de pouvoir souverain, dirige l'Etat. Le « gouvernement » est pris au sens large du mot. Il désigne l'ensemble des gouvernants. Il peut y avoir un seul homme disposant de tous les pouvoirs comme c'est le cas dans un régime de monarchie absolue ou de franche dictature. Il peut y avoir des centaines de gouvernemants comme c'est le cas en France et en Grande-Bretagne où la liste des gouvernants comprend le chef de l'Etat, les ministres et secrétaires d'Etat et les membres des Assemblées.“

${ }^{154}$ GIRAUD, Emile. Le droit international public et la politique. In: Recueil des Cours. Academie de Droit International de la Haye, Volume 110, 1963-III, pp. 419-809. p. 427. "In verbis“: "Mais, même dans Ies pays de démocratie authentique, le peuple ne s'identifie jamais complètement avec le gouvernement issu de l'élection qui serait censé représenter sa volonté. Le gouvernement a assez souvent la possibilité d'orienter la politique de la nation dans des directions diverses sans que le pays se rende compte de ce qui se passe et qu'il s'émeuve."

${ }^{155}$ BONAVIDES, Paulo. Teoria geral do estado. São Paulo: Malheiros Editores, 2012. p. 35. "In verbis": "Mas nunca deslembrar que foi a soberania, por sem dúvida, o grande principio que inaugurou o Estado Moderno, impossível de constituir-se se lhe falecesse a sólida doutrina de um poder inabalável e inexpugnável, teorizado e concretizado na qualidade superlativa de autoridade central, unitária, monopolizadora de coerção.”
} 
seria o titular de seu exercício interna e, especificamente em relação ao que aqui se propõe, internacionalmente ${ }^{156}$

Aspecto interessante da bilateralidade das teorias relacionadas ao estado em seus prismas interno e internacional mostra-se bastante claro no reconhecimento do direito à autodeterminação dos povos quando da declaração da independência dos Estados Unidos. A noção de que o povo seria senhor do próprio povo - e apenas ele - serviria para justificar e orientar a soberania interna e, por muitos anos, orientou a visão tradicional de sua expressão externa adotada pela doutrina internacionalista ${ }^{157}$. Soberania e autodeterminação constituiriam, portanto, conceitos que interagem, mas que não necessariamente se identificam $^{158}$.

De volta à concepção da soberania externa como algo pleno, irrestrito, percebe-se que essa consubstancia, na verdade, mera vertente doutrinária e não um núcleo conceitual. Os escritos do final do século XIV, reconhecidos como precursores da noção atual de poder soberano, imaginavam claramente a possibilidade de restrições estabelecidas por tratado. A idéia de soberania estatal externa absoluta possuiria, na verdade, estreitas ligações com o absolutismo pessoal dos governantes da modernidade ${ }^{159}$.

\footnotetext{
${ }^{156}$ FENWICK, Charles G.. The progress of international law during the past forty years. In: Recueil des Cours. Academie de Droit International de la Haye, Volume 79, 1951-II, pp. 01-71. p. 25. "In verbis“": "Let us now look at some particular aspects of the principle of self-determination and see what constructive solutions we may find for some of the problems it presents. The Charter speaks of the "self-determination of peoples'. But what is a 'people'? When can we say that a particular group living in a specific area of territory constitutes a 'people'?"
}

${ }^{157}$ FENWICK, Charles G.. The progress of international law during the past forty years. In: Recueil des Cours. Academie de Droit International de la Haye, Volume 79, 1951-II, pp. 01-71. p. 21. "In verbis": "The Declaration of Independence put forth by the United States in 1776 proclaimed a new principle, which we at this date may describe as 'the right of self-determination'. The United States appealed to the fundamental and inherent rights of man, to the principle that governments derived their just powers from the consent of the governed. The principle was a broad one, involving not only the relations of citizens to their immediate colonial rulers but the relations of the colony itself to the mother-country."

${ }^{158}$ CHAUMONT, Charles. Cours général de droit international public. In: Recueil des Cours. Academie de Droit International de la Haye, Volume 129, 1970-I, pp. 333-527. p. 396. "In verbis": "En bref et en définitive, la souveraineté et l'autodétermination n'ont pas le même contenu pour les situations coloniales, pour les situations néo-coloniales, pour les relations entre pays développés de type capitaliste, pour les relations entre pays développés de type socialiste. Il est impossible de donner une formule unique du droit des peuples à disposer d'eux-mêmes pour toutes ces situations, et par consiauent d'élaborer un corps unique de règles pour l'application de ce droit. Mais il n'est pas possible non plus de méconnaître l'importance singulière de chacune de ces situations."

${ }^{159}$ KOROWICZ, Marek Stanislaw. Some present aspects of sovereignty in international law. In: Recueil des Cours. Academie de Droit International de la Haye, Volume 102, 1961-I, pp. 01-120. p. 09. "In verbis“: "The more we study the reasonings of Bodin, the more we are convinced that the presently dominant doctrine of sovereignty has been definitely formulated in 1576. Indeed, apart from the supra-national Divine or Natural law, still professed today by the believers in the Natural law with changing content, we see in Bodin's theory the limitations imposed upon sovereignty by international agreements to which the State is a party, that is 
Em análise panorâmica, a soberania externa teria passado por, ao menos, duas transformações históricas fundamentais à compreensão de seus contornos atuais. Em um primeiro momento, ela deixou de ser um atributo pessoal para fundamentar um exercício de poder territorial e, logo, evoluiu da perspectiva política para a do direito, onde foi confrontada nitidamente com a relativização ${ }^{160}$.

A soberania externa garantida ao estado pode hoje, portanto, ser restringida e negociada. Um ente estatal poderia, nesse contexto, voluntariamente compartilhar sua independência com outro - por meio de uma fusão, incorporar-se a outra estrutura ou, ainda, limitar seu exercício de poder pela participação em uma organização internacional ${ }^{161}$. Na realidade, caso a soberania - em sua faceta externa - fosse considerada absoluta e ilimitada, o direito internacional não passaria, na atualidade, de uma ilusão ${ }^{162}$.

Em relação a seu conteúdo, a identidade entre soberania - externa - e independência não raramente é apontada pela doutrina. De fato, tanto um termo quanto o outro se referem classicamente, ainda que hoje de maneira mais rarefeita - ao exercício de um poder de forma plena, isto é, sem submissão a qualquer outro ${ }^{163}$. Nenhum dos elementos reconhecidos ao

which it co-created. In this way, the concept of an absolute sovereignty unrestrained by law is rejected, while the concept of relative sovereignty, of a sovereignty limited by international law, is born and continues to thrive."

${ }^{160}$ SCHWARZENBERGER, Georg. The fundamental principles of international law. In: Recueil des Cours. Academie de Droit International de la Haye, Volume 87, 1955-I, pp. 191-385. p. 220. "In verbis“: "On the level of international law, the principle of sovereignty underwent two essential transformations in the course of its evolution: change in emphasis from personal sovereignty to territorial sovereignty and from political sovereignty to legal sovereignty."

${ }^{161}$ GUGGENHEIM, Paul. Les principes de droit international public. In: Recueil des Cours. Academie de Droit International de la Haye, Volume 80, 1952-I, pp. 01-189. p. 90. "In verbis“: "D'autre part, il n'est pas douteux qu'un Etat souverain est autorisé par le droit international coutumier à renoncer à son indépendance, soit par fusion avec un autre Etat, soit par incorporation. [...] Mais l'abandon de la souveraineté, c'est-à-dire de l'indépendance, peut être intérdit par le droit conventionnel, ou être subordonné par lui au consentement d'autres Etats ou de l'organe d'une union d'Etats.“

${ }^{162}$ CLAPHAM, Andrew. Brierly's law of nations. Oxford: Oxford University Press, 2012. p. 15. "In verbis": "International lawyers have cried to escape from the difficulty in various ways, which we shall have to consider later, but, if these premises about sovereignty are correct, there is no escape from the conclusion that international law is nothing but a delusion."

${ }^{163}$ KOROWICZ, Marek Stanislaw. Some present aspects of sovereignty in international law. In: Recueil des Cours. Academie de Droit International de la Haye, Volume 102, 1961-I, pp. 01-120. pp. 11-12. "In verbis": "The duality of terminology sovereign and independent applied in treaties, diplomatic correspondence and writings of publicists could lead one to the conclusion that these expressions cover two different and separate legal phenomena. However, such a conclusion would be wrong; both notions are inseparable. Sovereignty means independence, and independence implies sovereignty. A State which is legally deprived of the supreme power over its territory and inhabitants, depends on a higher power, and, ipso iure is not independent; on the other hand, a State which is legally independent of any foreign State or authority, is ipso iure sovereign, since no superior authority exists above it, and it has the suprema potestas in internal matters." 
estado possui conteúdo fixo ou estável. Assim como povo e território, a soberania, como conceito, vivenciou ao longo da história e se submete nos dias atuais a constantes mutações $^{164}$.

Ressalvadas as variações de conteúdo, a identificação entre soberania e independência e seu reconhecimento como elemento fundamental ao reconhecimento de um estado excluiria dessa classificação, por outro lado, toda e qualquer forma de organização social que - mesmo apresentado os elementos povo, território e governo - não fosse senhora de sua própria vontade $^{165}$. Esse conceito sociológico de soberania, identificável com a idéia de independência, mostra-se anterior ao seu conceito jurídico e prévio, portanto, à própria noção moderna de estado que se mantém na atualidade ${ }^{166}$.

O estabelecimento de esferas de atuação exclusiva dos estados negativamente, ou seja, de limites àquilo que não se submeteria ao arbítrio de outro poder independente conformaria a principal função do conceito mais freqüente outorgado à soberania externa ${ }^{167}$. A plena adoção da independência como reflexo exterior do poder soberano criaria, contudo, dúvida não

${ }^{164}$ CHAUMONT, Charles. Cours général de droit international public. In: Recueil des Cours. Academie de Droit International de la Haye, Volume 129, 1970-I, pp. 333-527. p. 384. "In verbis“: "Il n'est pas nécessaire de fournir des définitions de l'Etat, de la nation et du peuple pour expliquer l'importance de la souveraineté. Ce ne sont pas des notions statiques. Les nations, comune les Etats, se forment et passent. Des facteurs subjectifs et objectifs sont sans cesse en mouvement : la nation algérienne a repris conscience par le refus français initial d'intégration, et la diversité des régimes fera peut-être des deux Allemagnes deux nations.“

${ }^{165}$ GUGGENHEIM, Paul. Les principes de droit international public. In: Recueil des Cours. Academie de Droit International de la Haye, Volume 80, 1952-I, pp. 01-189. pp. 85-86. "In verbis“": "La notion d'indépendance est donc identique à celle de «souveraineté étatique ». Elle permet toutefois de donner à cette dernière une interprétation dogmatique plus rigide. La pratique judiciaire internationale emploie souvent aussi la notion de « souveraineté extérieure » qui correspond à celle d'indépendance au sens technique, en ce qu'elle admet que l'Etat souverain est soumis à l'ordre juridique international. [...] Si l'on accepte cette thèse, il faut exclure de la catégorie des Etats au sens du droit internanonal toutes les entités qui présentent également les caractéristiques que nous venons de mentionner comme étant propres à l'Etat (centralisation du pouvoir, prétention à être la seule source de réglementation juridique sous réserve des règles du droit des gens coutumier ou conventionnel), mais qui ne répondent pas à ce critère.“

${ }^{166}$ KOROWICZ, Marek Stanislaw. Some present aspects of sovereignty in international law. In: Recueil des Cours. Academie de Droit International de la Haye, Volume 102, 1961-I, pp. 01-120. p. 07. "In verbis“": "The sociological concept of sovereignty existed a long time before the legal one was created. The awareness of the rulers of a State that they are the supreme power over the State's territory and its inhabitants and independent of any other power can be traced in history from the beginning of States living in the neighborhood of other States. Ancient rulers of States realized clearly the meaning of independence and dependence, and the Romans elaborated a precise legal concept of independence which is as valid today as it was then. "That nation is free which is not subject to any government of any other nation' was the famous definition of Proculus."

${ }^{167}$ SCHWARZENBERGER, Georg. The fundamental principles of international law. In: Recueil des Cours. Academie de Droit International de la Haye, Volume 87, 1955-I, pp. 191-385. p. 225. "In verbis": "The primary purpose of the rules underlying the principle of sovereignty is to establish spheres of exclusive jurisdiction for au subjects of international law. Whether these rules are formulated in positive or negative terms, they are, in substance, of a prohibitory character. [...] The emphasis in independence is on the negation of any superior worldly authority and on exclusion of the jurisdiction of any sovereign State from the reserved domain of every sovereign State. In this sense, the principle of sovereignty is negative." 
apenas quanto à natureza jurídica da comunidade formada por estados, mas principalmente quanto à fundamentação teórico-material do direito das gentes. Desse panorama, resultaria a inconsistência anárquica por vezes detectada pela doutrina na ordem global ${ }^{168}$.

A pacta sunt servanda como princípio jurídico aplicável ao direito internacional não constitui exceção ou situação estranha à lógica jurídica geral. A submissão ao pactuado conforma mandamento amplamente reconhecido e basilar que orienta - e sempre orientou direta ou indiretamente - a regulamentação do poder pelo direito ${ }^{169}$. O princípio pode muito bem representar, por um lado, saída engenhosa à fundamentação do direito das gentes, mas a adoção dessa doutrina de maneira extrema impõe ao direito os limites da expressão da vontade soberana e as questões decorrentes da possibilidade de se estabelecerem reservas ao exercício da soberania estatal ${ }^{170}$.

Fundamental se faz ressaltar que a pacta sunt servanda não seria um comando de engessamento das relações entre os estados e tampouco encontraria espaço em contexto de instabilidade. A vontade de pactuar e de cumprir o desejo expressado depende - nesse contexto de limitações ao princípio - tanto da possibilidade de as partes soberanas poderem promover o rearranjo dos termos estabelecidos quando situação superveniente exigir e, principalmente, da previsibilidade no momento em que se firma o tratado ${ }^{171}$.

\footnotetext{
${ }^{168}$ BILFINGER, Carl. Les bases fondamentales de la communauté des états. In: Recueil des Cours. Academie de Droit International de la Haye, Volume 63, 1938-I, pp. 129-241. pp. 137-138. "In verbis": "La question se pose maintenant de savoir si cette structure, en plus de la base résultant de l'existence d'Etats indépendants, exige encore une autre base matérielle, afin que la communauté des Etats puisse, en fait, exister. Qu'on compare à cette question la question concernant le siège de la puissance effective de l'Etat, par exemple l'armée, la police, les finances, etc., en un mot, tout ce qui concerne le pouvoir de l'Etat. La communauté des Etats n'est, en soi, ni un Etat, ni un Etat fédéral, ni une confédération d'Etats. Mais peut-elle exister sous forme d'une simple juxtaposition d'Etats indépendants? La structure de cette communauté est évidemment relêchée et de peu de consistance. Et par suite du principe de lindépendance des Etats elle renferme justement un facteur négatif centrifuge et anarchique. Néanmoins, elle offre toujours une organisation qui lui est propre, quoique primitive, une association sui generis, capable de créer empiriquement des onganisations s'étendant au monde entier, comme par exemple l'Union postale universelle."
}

${ }^{169}$ WHITTON, John B.. La règle 'Pacta sunt servanda'. In: Recueil des Cours. Academie de Droit International de la Haye, Volume 49, 1934-III, pp. 147-276. p. 151. "In verbis“: "Aucune société, aucun régime juridique ne sont possibles sans la certitude que la parole donnée sera respectée. Cette vérité a été reconnue de tout temps. A toutes les époques, l'homme - inconsciemment dans la tribu primitive, consciemment dans tout système de droit organisé, ancien ou moderne - a manifesté son approbation pour le principe pacta sunt sernanda.“

170 VERDROSS, Alfred. Le fondement du droit international. In: Recueil des Cours. Academie de Droit International de la Haye, Volume 16, 1927-I, pp. 247-323. p. 308. "In verbis“: "Les États sont, d'après une doctrine très répandue, des personnes souveraines qui ne sont soumises à l'empire du droit que dans la mesure où ils veulent le reconnaître. La souveraineté de l'État, il est vrai, n'est pas, d'après cette doctrine, le pouvoir sans limite, il n'est que la capacité de se déterminer lui-même. Mais les limites juridiques tracées par la volonté souveraine, ne sont pas absolues. L'État peut s'affranchir de toute obligation juidique qu'il s'est imposée luimême."

${ }^{171}$ WHITTON, John B.. La règle 'Pacta sunt servanda'. In: Recueil des Cours. Academie de Droit International de la Haye, Volume 49, 1934-III, pp. 147-276. pp. 251-252. "In verbis“: "Ici nous touchons au point 
Especificamente quanto à vinculação dos estados ao direito das gentes, ainda que não fosse possível admitir a possibilidade de reconhecimento de princípios gerais como jus cogens, isto é, como obrigatórios aos sujeitos de direito internacional, o mesmo não se poderia afirmar, contudo, quanto às regras sedimentadas em tratado e decorrentes, portanto, da expressão de sua vontade. Ironicamente, nesse ponto, o princípio geral da pacta sunt servanda se converteria em exceção e, ainda que não reduzido a termo, serviria de limitação inerente à soberania que sustentaria a obrigatoriedade das normativas aderidas expressamente pelos estados $^{172}$.

A Corte Internacional de Justiça tem sido cautelosa no reconhecimento da possibilidade de um estado abrir mão definitivamente de sua soberania externa ${ }^{173}$. Compreensível se faz tal acepção no caso de manutenção do reconhecimento da independência de um sujeito de direito internacional que tenha limitado o exercício externo do poder de maneira autônoma por completo e a mesma também se coaduna com a possibilidade de estabelecimento de limitações transitórias ou revogáveis ${ }^{174}$.

névralgique du progrès du droit des gens. C'est un problème fondamental issu de deux préoccupations primordiales : la nécessité simultanée de stabilité et d'évolution. Comment, avec les moyens primitifs actuellement à notre disposition, arriver à'assurer au monde troublé la sécurité dont il a si impérieusement besoin, ce qui est largement une question d'inviolabilité des traités, et en même temps pourvoir au sine qua non de tout progrès humain : la possibilité de s'adapter, de changer, d'évoluer, ce qui est un problème portant encore une fois sur les traités, puisqu'il comprend la question de révision ? Et quand on réfléchit, on voit que si on réussit à faire quelque progrès dans la solution de l'un ou de l'autre de ces grands problèmes, on ne fera que renforcer le princpe : pacta sunt servanda. Ce principe ne sera jamais solidement établi, d'ailleurs, avant que ces deux grands buts - la sécurité et évolution - soient atteints.“

${ }^{172}$ VERDROSS, Alfred von. Les principes généraux du droit dans la jurisprudence internationale. In: Recueil des Cours. Academie de Droit International de la Haye, Volume 52, 1935-II, pp. 191-251. p. 203. "In verbis“: "La thèse que les Etats ne sont liés que par le droit des gens est donc juste à condition de prendre le terme «droit des gens », dans un sens large qui embrasse également les principes supposés par le droit positif. Si, par contre, on veut réserver ce terme aux règles conventionnelles et coutumières, c'est-à-dire au droit international positif, on doit reconnaitre que les Etats sont encore obligés par les principes généraux du droit“

${ }^{173}$ KLEFFENS, Eelco Nicolaas van. Sovereignty in international law : five lectures. In: Recueil des Cours. Academie de Droit International de la Haye, Volume 82, 1953-I, pp. 01-131. p. 88. mencionando o Wimbledon Case de 1923.

${ }^{174}$ KLEFFENS, Eelco Nicolaas van. Sovereignty in international law : five lectures. In: Recueil des Cours. Academie de Droit International de la Haye, Volume 82, 1953-I, pp. 01-131. pp. 87-88. "In verbis“: "Treaties by their nature very often constitute a voluntary limitation of the exercise of sovereignty, and the limitation may go very far. Yet, the Permanent Court of International Justice declined 'to see in the conclusion of any treaty by which a state' undertakes to perform or refrain from performing a particular 'act an abandonment of sovereignty'. Whether this is not too sweeping a statement inasmuch as it also seems to cover irrevocable acts whereby sovereignty may be seriously and permanently impaired, seems to us a legitimate question. Yet, for revocable acts or acts of a temporary character, the dictum seems unassailable. The same high tribunal ruled that encroachments on sovereignty cannot be inferred or presumed; and that in case of doubt a limitation of sovereignty must be construed restrictively." 
A igualdade entre os estados, como exigência da aplicação do conceito de soberania externa às relações entre países, tem como resultado a adoção de parâmetros democráticos no funcionamento da ordem internacional ${ }^{175}$. As atuais concepções da soberania se afastam da idéia de poder absoluto e adotam perspectivas claramente funcionais relacionadas ao exercício de funções derivadas tanto do interesse individual dos estados quanto daquele do conjunto da comunidade internacional ${ }^{176}$.

A relativização da soberania externa, como forma de se admitir a subordinação dos sujeitos de direito das gentes ao corpo normativo global - primeiro expressamente, mas atualmente com tendência também à admissão tácita - constitui evolução necessária do direito internacional, a qual poderá - projetivamente, gize-se - resultar na centralização do poder também na esfera geral - ou seja, de maneira análoga ao que ocorre no plano interno estatal $^{177}$.

As iniciativas regionais de integração são apontadas pela doutrina como exemplos mais representativos da relativização do conceito de soberania e algumas análises chegam a cogitar a possibilidade mesmo de total supressão da independência dos estados. A menos que um grau de integração pleno fosse atingido com o surgimento de novo estado - ou sujeito de direito internacional de qualquer conformação dotado de plena soberania externa - vários são

175 TENEKIDES, Georges. Régimes internes et organisation internationale. In: Recueil des Cours. Academie de Droit International de la Haye, Volume 110, 1963-III, pp. 271-418. p. 404. “In verbis“: “D’une manière plus concrète, le principe démocratique a imprégné les Organisations internationales en revalorisant la règle de l'égalité des Etats. L'égalité de traitement juridique des Etats est une règle inhérente à la notion de service public laquelle se trouve à la base de toute Organisation internationale.“

176 Apesar de não ter sido encontrada a citação feita do professor Virally na obra mencionada, a ilustração da soberania apresentada complementa de forma bastante interessante a explicação de CARRILLO-SALCEDO, Juan-Antonio. Droit international et souveraineté des états: cours général de droit international public. In: Recueil des Cours. Academie de Droit International de la Haye, Volume 257, 1996, pp. 35-221. pp. $215-216$. "In verbis": "Il est certain que la souveraineté n'est plus perçue aujourd'hui comme un pouvoir absolu et inconditionné mais, au contraire, comme un faisceau de compétences exercées dans l'intérêt de l'Etat, mais aussi, quoique dans une bien moindre mesure, dans le sens des intérêts généraux de la communauté internationale dans son ensemble. C'est à cette conception fonctionnelle de la souveraineté que se référait, dans une formule heureuse, le professeur Michel Virally lorsqu'il évoquait la façon dont le développement progressif du droit international avait remodelé le visage de la souveraineté."

${ }^{177}$ KELSEN, Hans. Théorie du droit international public. In: Recueil des Cours. Academie de Droit International de la Haye, Volume 110, 1953-III, pp. 01-203. p. 200. "In verbis“": "De cette façon notre théorie du droit international enlève à l'Etat le caractère absolu que le dogme de la souveraineté lui confère. Elle le relativise en le considérant comme un stade intermédiaire dans la série de formes juridiques qui va de la communauté universelle du droit international aux diverses communautés juridiques subordonnées à l'Etat. En éliminant le dogme que la souveraineté est une qualité essentielle de tous les Etats cette théorie écarte en efiet un obstacle, qui a pu paraître insurmontable, à tout développement technique du droit international, à toute tentative de le centraliser davantage." 
os argumentos hábeis a sustentar, nesse contexto, subsistência de autonomia de exercício de poder pelas partes que integram acordos do gênero ${ }^{178}$.

Nos dias atuais, nenhuma iniciativa local de integração estabelecida por tratado limitou, entretanto, a soberania de um estado ao ponto de suprimi-la ${ }^{179}$. Restam como variável de controle referências meramente históricas que remontam, por exemplo, aos processos de formação dos estados nacionais alemão e italiano, mas os tratados que lhe deram origem não possuem identidade estrutural e institucional com as iniciativas surgidas no decorrer do século $\mathrm{XX}$.

Relativizar os contornos da soberania não significa banir o conceito ao ostracismo da história, mas sua adaptação a uma realidade da comunidade internacional completamente diversa daquela de seus primeiros teorizadores. O contexto político interno dos estados mudou e isso se refletiu também na ordem internacional, a qual admite atualmente sem grandes esforços teóricos criativos a existência de estruturas sobrepostas aos estados, hábeis a exigir-lhes, inclusive, coordenação ${ }^{180}$.

${ }^{178}$ KLEFFENS, Eelco Nicolaas van. Sovereignty in international law : five lectures. In: Recueil des Cours. Academie de Droit International de la Haye, Volume 82, 1953-I, pp. 01-131. p. 120. "In verbis“: "But, when exactly does integration result in the extinction of sovereignty? It seems to me that, when it state desires to take part in an integration of sovereign rights, ceding some of its own, and especially if it does so of its own free will, there cannot be said to be extinction of sovereignty so long as the integration is either partial, or stipulated for a given period of time, or conditional, in the sense that, from the beginning of the integration, sovereignty is meant to revive at the end of the term stipulated, or when the condition laid down materializes. In other words, there can only be said to be extinction of sovereignty if the integration is (a) total, or at least so extensive that such sovereign rights as the participants retain amount to very little ; (b) irrevocable ; (C) unconditional. In all other cases, integration necessarily has a decreasing effect on sovereignty, but not that of extinguishing it: according to the larger or smaller degree of integration, the sovereignty of the participating states may become wholly dormant for a specified or unspecified time, or it may merely be reduced to a greater or lesser extent and for a definite or indefinite period.“

${ }^{179}$ KLEFFENS, Eelco Nicolaas van. Sovereignty in international law : five lectures. In: Recueil des Cours. Academie de Droit International de la Haye, Volume 82, 1953-I, pp. 01-131. p. 126. "In verbis“: "Our conclusion, then, must be that such organizations in the realm of international law other than unitary or federal states, as the world has hitherto seen, have not destroyed the sovereignty of their members. The supra-national communities of recent origin are new only in the sense that they are entities other than states, having what may be called sovereign rights in a strictly limited field; as a recent writer has expressed it, they 'stand midway between inter-national and federal organs'. We are reminded here of what was said earlier about integration and the very variable degrees in which it may manifest itself. And let us remember above all that, as follows clearly from all that has been said, integration may (at least theoretically) be of such intensity that it destroys the sovereignty of the integrated elements, but that this need not at all be so, and that hitherto, except in the case of a new unitary or federal state absorbing a number of states which previously had an individual sovereign existence, there is no example on record of so vast a degree of integration that the sovereignty of the integrated parts is destroyed thereby. In other words: integration and continued sovereignty of the parties thereto are not necessarily mutually exclusive. Far from it.“"

${ }^{180}$ ROLIN, Henri. Les principes de droit international public. In: Recueil des Cours. Academie de Droit International de la Haye, Volume 77, 1950-II, pp. 305-479. p. 325. "In verbis“: "D'autre part, la notion de souveraineté s'implante dans le droit des gens à une époque où les seuls candidats à l'autorité supraétatique sont, ou des empereurs qui se prétendent continuateurs de Rome, ou des papes, ou des rois auxquels a souri la fortune des armes. Nul n'envisage à cette époque les formes d'organisation internationale crées par les Etats 
Soberania constitui, assim, tema atual e presente em cada ato, iniciativa ou tratado internacionalmente celebrado e os internacionalistas não podem - agora e durante muito tempo ainda - cogitar seu desaparecimento ou completa irrelevância ${ }^{181}$. Resta ao direito internacional conviver com essa forma de expressão de poder, mas não necessariamente buscar nela sempre a fundamentação de sua existência.

Soberania e direito internacional se encontrariam, assim, ao mesmo tempo em sincronia e oposição. Enquanto, para grande parte dos internacionalistas, a expressão da vontade soberana fundamentaria a produção das normas internacionais, essas, por sua vez, regulamentariam não apenas a forma dessa expressão volitiva, mas também o reconhecimento da independência dos estados nos contornos que se estabelecem ao poder soberano ${ }^{182}$.

O papel da soberania no contexto geral pode ser comparado ao do conceito de liberdade no plano local dos estados ${ }^{183}$. Nesse sentido e tal qual perceptível nas construções teóricas atuais acerca da liberdade individual nas ordens normativas estatais, a doutrina, muitas vezes fazendo referência expressa a acordos associativos regionais, admite as limitações à soberania como verdadeira condição ao fortalecimento do direito na comunidade internacional. Em nenhum momento, contudo, ela deixa de ser reconhecida como característica inerente aos estados ${ }^{184}$.

eux-mêmes au cours des dernières années. Ce n'est donc pas rétrécir la portée historique de la souveraineté que d'y voir l'exclusion de tout lien de dépendance à l'égard d'un État étranger, sans préjuice à l'institution d'autorités supraétatiques par la communauté des Etats.“"

${ }^{181}$ KLEFFENS, Eelco Nicolaas van. Sovereignty in international law : five lectures. In: Recueil des Cours. Academie de Droit International de la Haye, Volume 82, 1953-I, pp. 01-131. p. 130. "In verbis": "In other words: the notion of sovereignty continues to be a dominating element in the treasure-house of our heart and mind; we are strongly affected by it, and it is part of nearly everybody's being. To ignore this fact would be silly. One has to take the human race as it is, and not as we should like it to be. If, then, for our own salvation, we of Western Europe try to federate or integrate, we do so because with our mind (not always in our heart) we recognize that this is necessary for our survival. For most people it is a cerebral rather than an emotional process. That is one of the reasons why it is so difficult. But what will always remain in the world, are one or more sovereign states. That is why international lawyers will always have to gain an understanding of the notion of sovereignty."

${ }^{182}$ KOROWICZ, Marek Stanislaw. Some present aspects of sovereignty in international law. In: Recueil des Cours. Academie de Droit International de la Haye, Volume 102, 1961-I, pp. 01-120. p. 107. "In verbis": "Sovereignty and international law are at the same time symbiotic and antagonistic; sovereignty creates international law, and that law recognizes sovereignty as its foundation and basic principle."

${ }^{183}$ KOSKENNIEMI, Martti. From apology to utopia: the structure of international legal argument. Nova Iorque: Cambridge University Press, 2005. p. 300. "In verbis": "In modern international law 'sovereignty' plays a role analogous to that played by 'liberty' in domestic liberal discourse. It works as a description and a norm. It characterizes the critical property an entity must process in order to qualify a State. And it involves a set of rights and duties which are understood to constitute the normative basis of international relations."

${ }^{184}$ KOROWICZ, Marek Stanislaw. Some present aspects of sovereignty in international law. In: Recueil des Cours. Academie de Droit International de la Haye, Volume 102, 1961-I, pp. 01-120. p. 17. "In verbis": "International lawyers emphasize, above all, the necessity of increasing limitations of State sovereignty for the 
Soberania se vincula diretamente a poder. Seu conceito justifica, na verdade, a própria existência de uma autoridade superior às pessoas na sociedade, responsável por organizar e coordenar a interação social.

A figura do estado consolida atualmente os parâmetros institucionais que ao mesmo tempo exigem e instrumentalizam a idéia de soberania. Na esfera interna, o poder do ente moral sobre os sujeitos, antes considerado absoluto e sustentado em concepções extremas de autodeterminação, já se encontra sujeito a limitações, por exemplo, decorrentes das teorias universalistas dos direitos humanos.

No plano internacional, a expressão externa do poder das coletividades determinadas se confunde com a idéia de independência e, além de se submeter historicamente à dinâmica natural da força na relação com as outras soberanias e, mais recentemente, a valores axiológicos assumidos como cogentes, mais que nunca se mostra relativizada pelos compromissos assumidos, ou seja, pelo princípio da pacta sunt servanda, um dos fundamentos elementares do direito.

Poucos são os resquícios do caráter ilimitado e absoluto da soberania estatal observáveis na atualidade. $\mathrm{O}$ direito das gentes não apenas provoca, mas também exige tal relativização, a qual pode se dar de forma voluntária, como no caso da adesão a organizações internacionais supranacionais, ou, involuntariamente, como no reconhecimento de regras de jus cogens internacional.

\subsection{A Superação da Soberania, a Teoria Geral do Estado e o Direito Internacional}

A estruturação da ordem internacional pela teoria moderna exclusivamente com base na vontade dos estados somada ao conceito clássico de soberania teria como consequiência lógica a possibilidade de uma norma ser ou deixar de ser obrigatória para um sujeito de direito das gentes na medida de sua conveniência ${ }^{185}$. A conciliação da vontade estatal com a força cogente do direito internacional constitui o maior desafio da adoção de tal perspectiva.

benefit of the international community. They believe, nevertheless, in the inescapability of the concept of sovereignty as a quality of the State under present-day international law. They like to invoke international treaties and draft conventions furthering close international cooperation, as for instance those, undoubtedly inspiring, agreements which promote 'European integration'."

185 VERDROSS, Alfred. Le fondement du droit international. In: Recueil des Cours. Academie de Droit International de la Haye, Volume 16, 1927-I, pp. 247-323. p. 266. "In verbis“: "La théorie moderne de 
A visão centrada no estado moderno chega a estabelecer o Congresso de Viena de 1814-1815 como símbolo definitivo do reconhecimento de uma ordem normativa global, de um direito internacional ${ }^{186}$. De fato, a partir da segunda década do século XIX inúmeras foram as conferências e os congressos que construíram os primeiros documentos jurídicos de concreção com características definitivamente mundiais ${ }^{187}$.

Ponto importante de diferenciação entre as percepções tradicional e contemporânea de soberania residiria na definição teórica de poder. Soberania era classicamente conceituada como algo externo ao direito e, de maneira paulatina, evoluiu até a definitiva inserção na teorização normativa tanto no que se refere à sua regulamentação quanto à sua fundamentação. Esse deslocamento teórico representou, principalmente, o estabelecimento de limitações ao conceito absoluto outrora amplamente adotado ${ }^{188}$

Autores do início do século XX não raramente observavam a ordem internacional como projeção da estrutura interna de um estado, isto é, reconhecendo identidade entre seu papel de organização da conduta dos sujeitos de direito internacional e aquele exercido pelas leis de ordem jurídica determinada em relação aos indivíduos que compõem uma

l'autolimitation soutient la thèse d'après laquelle le droit international trouve son fondement dans la volonté de l'État isolé, mais reste malgré tout obligatoire, parce que l'État est capable de se lier lui-même. Elle adopte donc, le même point de départ que Spinoza et Hegel, mais elle n'a pas le courage d'entirer les mêmes conséquences logiques, à savoir qu'un droit international basé uniquement sur la volonté de l'État cesse d'être obligatoire par un simple changement de cette volonté. Cette doctrine veut ainsi concilier déux thèses inconciliables : la souveraineté absolue de l'État d'une part et l'obligation des États par le droit des gens d'autre part. Mais ces eftorts sont vains, car toute obligation d'une volonté suppose, comme nous le développerons plus tard, l'existence d'une règle supérieure à cette volonté.“

186 LIANG, Yuen-Li. Le développement et la codification du droit international. In: Recueil des Cours. Academie de Droit International de la Haye, Volume 73, 1948-II, pp. 407-532. p. 421. "In verbis“: "On peut dire que l'histoire de la « législation international », c'est-a-dire le développement du droit international par les efforts conscients et concertés des gouvernements, commence au Congrès de Vienne en 1814-1815. En effet, ce Congrès a adopté des règlements relatifs à l'ordre de préséance des envoyés diplomatiques, ainsi que des déclarations concernant l'abolition de la traite des esclaves, et la navigation sur les fleuves internationaux."

187 LIANG, Yuen-Li. Le développement et la codification du droit international. In: Recueil des Cours. Academie de Droit International de la Haye, Volume 73, 1948-II, pp. 422-423. p. 421. "In verbis“: "Dans la seconde moitié du xix'e siècle, une nouvelle phase a commencé. De 1864 à 1914, plus de cent conférences et congrès internationaux ont été tenus, et plus de deux cent cinquante instrumients inernationaux ont été rédigés. Une proportion notable de ces derniers concernait la prévention, la réglementation et le soulagement des maux causés par la guerre. On peut dire que cette procédure législative internationale, orientéee peut-être trop exclusivement contre le fléau de la guerre, avait déjà commencé dans la Déclaration de Paris, et qu'elle atteint son maximum aux Conventions de La Haye de 1899 et 1907.“

${ }^{188}$ ROUSSEAU, Charles. L'indépendance de l'Etat dans l'ordre international. In: Recueil des Cours. Academie de Droit International de la Haye, Volume 73, 1948-II, pp. 167-253. p. 192. "In verbis“: "La conception de la souveraineté admise par la doctrine contemporaine, spécialement par la doctrine positiviste, est très différente de la théorie traditionnelle. Au lieu de voir dans la souveraineté une notion extra ou supra-juridique, la doctrine actuelle dominante s'est efforcée de présenter celle-ci comme un notion strictement juridique, s'analysant en un pouvoir limité par le droit.“ 
sociedade $^{189}$. A partir de tal analogia, a doutrina da teoria geral do estado chegava a descrever o contexto internacional como anárquico quanto à organização do poder e apontava essa característica como justificativa principal de suas imperfeições e deficiências ${ }^{190}$.

Necessário se faz ressaltar que sob "teoria geral do estado" compreende-se para fins da pesquisa aqui proposta não apenas as teorias jurídico-políticas que buscam estruturar logicamente a relação existente entre os elementos que compõem o poder e seu exercício em ordens específicas, mas também toda a doutrina sociológica - e política! - que possa servir - e que há séculos serve - de ponto de partida ao entendimento dos fenômenos envolvidos com a convivência humana em sociedade ${ }^{191}$.

Nesse sentido, é de se admitir que a fundamentação do direito internacional na soberania estatal corresponderia à fundamentação do direito interno na liberdade individual concebida de maneira inalienável e ilimitada. Sob a perspectiva interna, tal acepção extremada resultaria em anarquia incompatível com qualquer organização social regulamentada pelo direito. $\mathrm{O}$ uso de conceitos como o de justiça e de outros fundamentos

${ }^{189}$ HEILBORN, Paul. Les sources du droit international. In: Recueil des Cours. Academie de Droit International de la Haye, Volume 11, 1926-I, pp. 01-63. p. 19. "In verbis“: "On appelle droit l'ensemble des règles qui régissent les relations entre les hommes. Le droit international public ou droit des gens est l'ensemble des règles qui gouvernent les relations entre les États. Les États, en leur qualité de personnes morales, sont les sujets de droits. Comme le droit assimile les personnes morales aux personnes physiques, c'est-à-dire aux hommes, quant à la capacité d'étre sujets de droits, il peut y avoir un ensemble de règles applicables à la conduite des personnes morales seules. Tel est le droit des gens applicable aux États seuls. II détermine les droits et les devoirs respectifs des États dans leurs relations mutuelles. Les États sont les sujets du droit des gens ou, ce qui revient au même, les sujets des droits internationaux.“

${ }^{190}$ JELLINEK, Georg. Das Recht des modernen Staates. Berlin: Verlag von O. Häring, 1900. pp. 340-341. "In verbis": "Wenn nun aber auch das Völkerrecht formell auf dem Willen der Einzelstaaten ruht und von ihm seine rechtliche Sanktion erhält, so entspricht es doch materiell einem Etwas, das über den Einzelstaat hinaus geht. An diesem Punkte zeigt sich die Verbindung von Gesellschaftslehre und Völkerrecht. Da, wie oben näher ausgeführt, die gesellschaftlichen Interessen vielfach weit über den Einzelstaat hinausreichen und die Staaten selbst als sociale Bildungen Gesellschaftsgruppen bilden, so wirkt die Gesammtheit dieser internationalen Gesellschaftsverhältnisse den wesentlichen Inhalt des internationalen Rechtes aus. Die nationalen und einzelstaatlichen Gegenströmungen gegen die internationale Gesellschaft sind aber so stark, dass sie nur ein Nebeneinanderbestehen der Staaten, keine Organisation der Staatengemeinschaft hervorgerufen haben, von Gelegenheitsorganisationen und engeren Staatenverbindungen innerhalb der umfassenden Gemeinschaft abgesehen. Die Staatengemeinschaft ist daher rein anarchischer Natur, und das Völkerrecht, weil einer nicht organisirten und daher keine Herrschermacht besitzenden Autorität entspringend, kann füglich als ein anarchisches Recht bezeichnet werden, was zugleich seine Unvollkommenheiten und Mängel erklärt.“

${ }^{191}$ É dizer que servirão de marco à pesquisa tanto obras como KELSEN, Hans. Reine Rechtslehre - Einleitung in die rechtswissenschaftliche Problematik. Leipzig und Wien: Franz Deuticke, 1934, HART, H.L.A. The concept of law. Oxford: Clarendon Press, 1961 e JELLINEK, Georg. Das Recht des modernen Staates. Berlin: Verlag von O. Häring, 1900, como também WEBER, Max. Politik als Beruf. Stuttgart: Reclam, 2008, MONTESQUIEU, Charles de Secondat Baron de. De l'esprit des lois - Vol 1. Paris: Garnier-Flammarion, 1979, MONTESQUIEU, Charles de Secondat Baron de. De l'esprit des lois - Vol 2. Paris: GarnierFlammarion, 1979, LOCKE, John. Two treatises of government. London: Guernsey Press, 1986, ROUSSEAU, Jean-jacques. Du contrat social. Paris: Union Générale d'Éditions, 1973 e HOBBES, Thomas. Leviathan. Cambridge: hackett Publishing Company, 1994. 
morais poderia servir de caminho habilitado a evitar a adoção desse prisma em relação ao plano internacional $^{192}$.

A formulação tradicional da soberania pode ser, de fato, considerada uma ameaça à eficácia do direito das gentes, mas a teoria geral do estado, já em suas primeiras sistematizações vislumbrava a coordenação na esfera internacional como alternativa fundamental à subordinação característica das ordens particulares. Mais que isso, independentemente dos inconvenientes teóricos enfrentados pelo direito das gentes, seus preceitos normativos já eram admitidos como plenamente obrigatórios ${ }^{193}$.

Solução definitiva para a questão se encontraria na relativização da própria idéia de soberania. De fato, a percepção da vontade do estado como algo absoluto e ilimitável dificultaria o reconhecimento da ordem normativa internacional como jurídica, já que inviabiliza sua obrigatoriedade em abstrato. A vontade da comunidade internacional deve, para dar à normatização global contornos de direito, ser compreendida como superior à vontade de cada um de seus membros isoladamente. Sob a ótica atual da dinâmica do poder mundial, tampouco a vontade da comunidade internacional seria ilimitada e se pautaria necessariamente, por exemplo, nos valores fundamentais da humanidade - com toda a textura aberta que cabe a axiomas normativos ${ }^{194}$.

\footnotetext{
${ }^{192}$ LE FUR, Louis. La théorie du droit naturel depuis le XVIIe siècle et la doctrine moderne. In: Recueil des Cours. Academie de Droit International de la Haye, Volume 18, 1927-III, pp. 259-442. p. 418. "In verbis“: "C'est donc bien à tort qu'on a pu longtemps présenter la souveraineté de l'État, surtout considérée comme absolue, comme le fondement du droit international; elle ne peut pas plus être le fondement du droit international que la liberte de l'individu considérée comme inalienable et illimitée, ne peut étre le fondement du droit public interne; à elles seules, liberté individuelle et souveraineté nationale illimitées assureraient bien plutôt la destruction de tout le droit public, interne ou externe, par le ferment anarchique qu'elles représentent; pour être intégrées utilement dans l'organisation sociale, elles doivent être complétées toutes deux par la notion de droit, droit rationnel ou objectif à fondement moral, à base de justice et non plus de forcé, cette dernière ne constituant qu'un moyen de réalisation, d'ailleurs parfois nécessaire.“
}

193 JELLINEK, Georg. Das Recht des modernen Staates. Berlin: Verlag von O. Häring, 1900. p. 338. "In verbis": "Aber nicht nur die Grundlage, auch die Gesammtheit der aderen Merkmale des Rechtes sind beim Völkerrecht gegeben. Der wesentliche Unterschied des Völkerrechts von dem Staatsrechte liegt darin, dass in jenem keine Verhältnisse der Ueber und Unterordnung regulirt werden, es vielmehr ein Recht zwischen Koordinirten ist. Und zvar sind die das Völkerrecht setzenden Autoritäten, und zugleich die von ihm verpflichteten Subjekte die Staaten selbst. In deren gegenseitigen Beziehungen hat zuerst, wie auf anderen Rechtsgebieten, das historische Element des Rechtsbegriffes seine Wirkung geäussert. Das Faktum der Beobachtung von Regeln im internationalen Verkehr hat zu der Vorstellung ihrer rechtlich verpflichtenden Kraft geführt."

194 VERDROSS, Alfred. Le fondement du droit international. In: Recueil des Cours. Academie de Droit International de la Haye, Volume 16, 1927-I, pp. 247-323. pp. 311-319. "In verbis“: "Or, si le droit international dans le sens propre du mot a pour but d'obliger pour l'avenir les États coordonnés de la communauté internationale, on doit renoncer à l'existence du droit des gens ou au principe de la souveraineté absolue de l'État. Car ces deux notions sont entre elles inconciliables. La souveraineté absolue de l'État a donc pour conséquence logique, la négation du droit des gens. [...] Cependant, si la compétence des États est lunitée par le droit des gens, la compétence de la communauté internationale est juridi-quement illimitée; car la compétence de la compétence lui appartient. Pourtant, cette compétence n'est pas non plus une souvcraineté 
No que se refere aos conceitos de soberania interna e externa, a chave da confusão que se faz entre o exercício do poder pelo estado internamente com aquele que lhe corresponde no plano externo se deve, em grande medida, ao deslocamento da idéia de poder da perspectiva da qualidade do órgão que a exerce para aquela da atribuição da pessoa moral - do estado. Trasladou-se a investidura do exercício da soberania da pessoa - rei ou conjunto de indivíduos da sociedade - para o estado e essa perspectiva que serve muito bem à estruturação teórica do direito interno acaba sendo reproduzida internacionalmente e coloca o estado - com base em teorias mais tradicionais - equivocadamente em posição de monopolizador do exercício do poder, isto é, de ente excluído de qualquer posição de submissão a estruturas - de direito, por exemplo - cogentes sem seu prévio consentimento ${ }^{195}$.

A ordem internacional se vê confrontada na atualidade, ainda, com a decadência do conceito tradicional de soberania provocada por novos fenômenos eminentemente jurídicos, como, por exemplo, a formação de sistemas globais de direito sobre temas específicos. Também aspectos fáticos, como a relativização de fronteiras e a velocidade dos meios de comunicação, contribuem a esse novo panorama ${ }^{196}$.

absolue, si on entend par là un pouvoir arbitraire; car la communauté internationale elle-même est chargée d'une mission sociale. Ainsi la communauté internationale comme instance suprême dans la pyramide des autorités temporelles est, il est vrai, juridiquement illimitée, mais néanmoins soumise aux rêgles de l'humanité et de la justice."

${ }^{195}$ KELSEN, Hans. Les rapports de système entre le droit interne et le droit international public. In: Recueil des Cours. Academie de Droit International de la Haye, Volume 14, 1926-IV, pp. 227-331. pp. 254-255. "In verbis“: "Aux yeux des théoriciens modernes, la puissance étatique se caractéríserait par sa souveraineté. La souveraineté serait donc, non pas, comme on l'a longtemps enseigné, une qualité d'un organe de l'État, prince ou peuple, mais un attribut de l'État lui-même. Ils considêrent, a juste titre, cette doctrine comme un tres important progres. Si la puissance publique est souveraine, c'est qu'elle est la puissance suprême, celle à laquelle aucune autre n'est supérieure, et, — en tant qu'on interprête la puissance comme une « volonté,» — qui ne connait pas de volonté supérieure. Cet attribut qu'on lui reconnait montre précisément qu'il est impossible de voir en elle une qualité naturelle, une sorte de force physico-psychique. Car une semblable force, si elle était souveraine, ne serait pas moins qu'une «prima causa, » une cause premiêre, la force la plus puissante d'où découlerait tout phénomène, sans qu'elle eût elle-même de cause. Idée inconcevable La souveraineté de la puissance publique - ou plus exactement de l'État — ne se comprend donc que si on voit en celle-ci la validité d'un système de normes, de l'ordre étatique. Le qualificatif «souverain » exprime alore que l'État est l'ordre suprême, supérieur à tout autre, dont la validité ne se déduit d'aucune norme supérieure. Par lá même est tranchée la question de savoir si la souveraineté est un attribut de l'État ou du droit; si l'État est souverain en tant qu'ordre juridique, la souveraineté est un caractére de l'État parce qu'elle est un caractère du droit."

${ }^{196}$ BARROSO, Luís Roberto. Temas de direito constitucional - Tomo II. Rio: Renovar, 2003. p. 05. "In verbis": "A paisagem é complexa e fragmentada. No plano internacional, vive-se a decadência do conceito tradicional de soberania. As fronteiras rígidas cederam à formação de grandes blocos políticos e econômicos, à intensificação do movimento de pessoas e mercadorias e, mais recentemente, ao fetiche da circulação de capitais. A globalização, como conceito e como símbolo, é a manchete que anuncia a chegada do novo século. A desigualdade ofusca as conquistas da civilização e é potencializada por uma ordem mundial fundada no desequilíbrio das relações de poder político e econômico e no controle absoluto, pelos países ricos, dos órgãos multilaterais de finanças e comércio.” 
O aumento da importância de valores como a proteção do homem e do meio ambiente se refletem, ainda, no papel do estado no contexto global diminuindo sua relevância. Referido declínio de protagonismo amplia, por exemplo, as possibilidades de conflito entre o interesse da comunidade internacional e aquele da unidade estatal específica ${ }^{197}$.

Mas como explicar maior imposição de deveres aos estados em ambiente desfavorável ao direito internacional? Como entender a multiplicação de sistemas normativos especializados e sua relação entre si e com os estados? Por mais que parte importante da doutrina atual rejeite o uso do instrumental teórico interno da teoria do estado e do direito constitucional na descrição de fenômenos internacionais, exatamente no resgate dessas premissas poderia ser encontrada a chave da compreensão do direito internacional atual ${ }^{198}$.

No que se refere aos elementos, interessam à abordagem aqui proposta principalmente os conceitos de soberania interna e de povo, como sujeitos de direitos e deveres na ordem legal. Nesse sentido, a doutrina do poder seria aplicável ao estudo da relação entre as

${ }^{197}$ CASELLA, Paulo Borba. Evolução institucional do direito internacional: à luz do cinqüentenário do conceito de direito de Hart (1961). In: Revista Brasileira de Filosofia. Ano 60, Vol. 236, janeiro-junho, 2011. pp. 313329. pp. 322-323. "In verbis": "Existem evidências de comunidade internacional em sentido funcional. Estas podem ainda não abranger todos os campos do direito internacional, mas constituem o norte para assinalar o caminho, em campos como a proteção internacional dos direitos fundamentais, a proteção internacional do meio ambiente, $\mathrm{O}$ direito internacional do mar, com seu quadro normativo material e procedimental, inclusive com complexo e variado sistema de solução de controvérsias (tais como o Tribunal internacional para o direito do mar, ou TIDM e os demais meios acessórios a este, acoplados no elenco de mecanismos de solução de controvérsias, estipulados pela referida Convenção das Nações Unidas sobre o direito do mar, de 1982), bem como no desenvolvimento conceitual e institucional ocorrido em matéria de direito internacional penal. Todos estes são campos que não se podem conceber nem operar como simples transações bilaterais interestatais. Transcendem a dimensão de relação bilateral direta e se põem como expressões de sentido de comunidade internacional, e a esta, enquanto comunidade, se reconhecem direitos - tais como exprimem os conceitos de 'patrimônio comum da humanidade' e de 'interesse comum da humanidade'. São estes alguns dos campos do atual sistema institucional e normativo internacional que pressupõem interesse comum, e este serve de fundamento para o sistema. Não se compreendem tais campos do direito internacional pós-moderno sem a compreensão do interesse geral, mais amplo, tal como se formula em conceitos como o 'patrimônio comum da humanidade' ou 'interesse geral da humanidade' (cornmon concern of mankind). Estes pressupõem dimensão comum, mais ampla e menos sujeita s variações das políticas de estado e das flutuações decorrentes das oscilações das pesquisas de opinião e de intenção de voto nas jurisdições nacionais."

198 THIRLWAY, Hugh. Concepts, principles, rules and analogies: international and municipal legal reasoning. In: Recueil des Cours. Academie de Droit International de la Haye, tomo 294, 2002, pp. 265-405. pp. 299-300. "In verbis": "Furthermore, we must, as was observed earlier, be sure that in confronting national and international law we are comparing like with like. The question to be asked is this : is the structure and reasoning of international law sufficiently like that od 'law' as understood in the national sphere, to permit arguments by analogy? It is also from time to time necessary to repeat the refutatios of those who have questioned the existence of international law in the past, and to take account of more modern questionings of its existence and nature. [...] To seek to establish the existence of international law as law, necessarily implies a preconception os what law is; and to discuss the problem of private law analogies in international law similary implies the adoption of certain approach to international law." 
soberanias externas exercidas pelos estados no direito internacional e o conceito de povo como parâmetro de pesquisa dos sujeitos de direito que compõem a ordem internacional ${ }^{199}$.

Superar a soberania não significa necessariamente abandonar sua função para o direito das gentes, mas apenas relativizar, na verdade, sua concepção como dogma inabalável. Talvez ela seja, para o direito internacional, o maior resquício da concepção moderna de estado e do poder nele centralizado.

Nesse sentido, percebe-se que o desenvolvimento do direito das gentes implicou na paulatina limitação das características soberanas outrora consideradas absolutas e ilimitadas e, em todo esse contexto, tem-se no estudo da teoria geral do estado instrumental técnico fundamental a ser observado para que se possa compreender a ordem global da atualidade.

O abandono da teoria geral do estado pelos internacionalistas conforma equívoco imperdoável e injustificável. Em meio aos desafios que se apresentam atualmente à organização da ordem mundial, o resgate das estruturas de poder interno pode auxiliar o estabelecimento de parâmetros ao entendimento do direito das gentes. Nesse contexto, o estudo das características internas do conceito de soberania mostra-se não apenas necessário, mas também extremamente urgente.

\footnotetext{
${ }^{199}$ CASELLA, Paulo Borba. Conceito de sistema, contexto internacional e pós-modernidade. In: ADEODATO, João Maurício; BITTAR, Eduardo C. B. (Org.) - Filosofia e Teoria Geral do Direito: estudos em homenagem a Tércio Sampaio Ferraz Junior por seu septuagésimo aniversário. São Paulo: Quartier Latin, 2011. p. 1004. "In verbis": "A soberania, como expressão do poder, no campo do direito internacional, traz não a concentração, mas o fracionamento e o imperativo da convivência ordenada. Á, igualmente, se inscreve a necessidade de institucionalização, i.e., a criação de mecanismos e normas para a regulação da atuação dos estados, no plano externo, no sentido de direcionar o exercício do poder, segundo mecanismos institucionais que preservem, em considerável medida, as respectivas esferas de atuação (soberania, na sua face interna, ou domínio reservado do estado), como se dava no direito internacional de coexistência, e até mesmo de atuação conjunta, ou institucionalmente coordenada, como se dá no contexto do direito internacional de cooperação. De onde se pode pretender passar do antigo paradigma da não-intervenção para o de suposto dever de ingerência - que deve ser utilizado com não menos cuidado." Mais adiante, ibid. p. 1017. "In verbis": Para estabelecer o direito das gentes, aplicar-se-ão às relações entre as nações o mesmo que nas relações interpessoais. As nações devem ser consideradas, em suas relações recíprocas, como as pessoas livres, vivendo em estado de natureza. Daí resulta existir, para as nações, como para os indivíduos, uma lei natural, de onde derivam as mesmas obrigações e os mesmos direitos fundamentais. O sistema de direitos e obrigações constituirá o direito das gentes natural ou necessário."
} 


\section{A TEORIA GERAL DO ESTADO E O DIREITO INTERNACIONAL}

\subsection{Entre Compreender e Modular}

O passado está fora de moda. No direito, as teorias de validade, a doutrina hierárquica constitucionalista, o estudo do estado, tudo se encontra em desuso, remete ao atraso, ao equivocado e à desatualização. Os novos trabalhos apresentam perspectivas hermenêuticas valorativas, apontam à diminuição da importância do estado no direito internacional e propõem formulações sistêmicas alternativas e fragmentárias. Seria a atual conformação do direito, especialmente do direito das gentes, tão diversa das teorias tradicionais? Que fatores teriam determinado, então, essa guinada teórica?

Impossível se faz perceber hoje - ainda? - perfeita identidade entre as estruturas interna e internacional de direito muito além do fato de constituírem um conjunto de normas organizado para regulamentar relações sociais. Em muitos aspectos, portanto, seus mecanismos diferem como, por exemplo, no que se refere aos modelos de aplicação de sanções à violação de regras ${ }^{200}$ - tema considerado basilar, conforme salientado supra, por parte consistente da doutrina juspositivista moderna à própria caracterização de um sistema normativo como de direito ${ }^{201}$.

\footnotetext{
${ }^{200}$ KELSEN, Hans. Théorie du droit international public. In: Recueil des Cours. Academie de Droit International de la Haye, Volume 110, 1953-III, pp. 01-203. p. 182. "In verbis“: "“...] le droit international est un droit dans le même sens que le droit national, car il est un ordre coercitif, un ensemble de normes prévoyant des sanctions socialement organisées à titre de réaction contre des actes illicites. Toutefois le droit international est, à beaucoup d'égards, différent du droit national. Tandis que les sanctions principales du droit international sont les représailles et la guerre, celles du droit national sont les peines et l'exécution forcée. La distinction entre droit pénal et droit civil repose sur la différence entre la peine et l'exécution forcée. En revanche la différence entre les représailles et la guerre ne justifie pas une division du droit international en deux branches analogues au droit pénal et au droit civil, car le droit international n'a pas la structure dualiste du droit national, au moins en ce qui concerne la majeure partie de ses normes. Quoi qu'il en soit, la peine et l'exécution forcée ne sont pas complètement absentes en droit international. A titre exceptionnel on trouve des normes du droit international, général ou particulier, prévoyant des peines ou des mesures d'exécution forcée. L'opposition entre ces deux ordres juridiques, en ce qui concerne les sanctions qu'ils prévoient, est donc seulement relative.“
}

${ }^{201}$ KELSEN, Hans. Reine Rechtslehre - Einleitung in die rechtswissenschaftliche Problematik. Leipzig und Wien: Franz Deuticke, 1934. pp. 131-132. "In verbis“: "Und wenn dieser das behauptete Unrecht leugnet, fehlt es an einer objektiven Instanz, die den Streit in einem rechtlich geregelten Verfahren zu entscheiden hat. Und so ist es auch der in seinem Recht verletzte Staat selbst, der gegen den Rechtsverletzer mit dem vom allgemeinen Völkerrecht eingesetzten Zwangsakt, mit Repressalie oder Krieg, zu reagieren befugt ist. Es ist die Technik der Selbsthilfe, von der auch die Entwicklung der einzelstaatlichen Rechtsordnung ausgegangen ist." 
A analogia entre as estruturas de direito interno e aquelas do direito das gentes não constitui, entretanto, proposta inédita, mas parece ter se tornado verdadeiro tabu a partir de determinado momento na segunda metade do século $\mathrm{XX}^{202}$. Tornou-se, afirma-se, porque não é raro observar na doutrina mais tradicional, autores que claramente buscavam identificar em suas construções teóricas o estado, sujeito de direito internacional, com a pessoa, sujeito de direito na ordem jurídica interna ${ }^{203}$.

A teoria do estado pode auxiliar a compreensão da organização do poder na ordem internacional e esse conforma o núcleo do que se propõe no presente estudo. Mas "estado" constitui, ressalte-se, conceito artificial e teorizar acerca de suas estruturas de poder não comporta parâmetros definitivos, pré-estabelecidos ou imutáveis. Muitas vezes, essa característica de artificialidade se estende, na verdade, a outros institutos da teoria do estado concebidos freqüentemente como dados da natureza e isso deve ser levado em consideração em qualquer proposta de transposição teórica que se formule.

Nesse sentido e apenas a título de exemplo, "nação" conformaria um desses conceitos abstratos, é dizer, não naturais. Trata-se de construção histórico-social que não permite a enumeração de critérios objetivos fechados para sua identificação ${ }^{204}$. Não seriam simplesmente a língua comum ou a etnia os únicos elementos capazes de determinar o reconhecimento de uma nação. Conceitos como esses podem, de fato, auxiliar o surgimento de pertencimento, mas não constituem critério uniforme aplicável à sua identificação ${ }^{205}$. As

202 REUTER, Paul. Principes de droit international public. In: Recueil des Cours. Academie de Droit International de la Haye, Volume 103, 1961-II, pp. 425-656. p. 504. "In verbis“: "Il a dans les relations internationales des aspects analogues à ceux qu'il présente dans les systèmes nationaux ; mais la complexité de celles-ci mérite une attention particulière.“

${ }^{203}$ GIDEL, Gilbert. Droits et devoirs des nations: la théorie classique des droits fondamentaux des états. In: Recueil des Cours. Academie de Droit International de la Haye, Volume 10, 1925-V, pp. 537-597. p. 550. "In verbis“: "L'idée maitresse consista à assimiler les États à des individus, à reconnaitre à ces États un certain nombre de droits analogues à ceux que possèdent les personnes physiques. Le droit naturel et le droit romain furent à l'origine du nouveau système de droit interanational. L'influence sur le droit international des théories de l'état de nature a été capitale et est demeurée prépondérante. Nys a clairement montré la position du problème. «La juxtaposition d'États indépendants ouvre cette alternative qu'on peut les considérer comme n'étant soumis à aucune loi et qu'on peut aussi les envisager comme sujets du droit naturel. »"

204 JELLINEK, Georg. Das Recht des modernen Staates. Berlin: Verlag von O. Häring, 1900. p. 105. "In verbis": "Auszugehen bei dieser Untersuchung ist von der heute bereits als gesichert zu bezeichnenden Erkenntniss, dass Nationen nicht natürliche, sondern geschichtlich-sociale Bildungen sind. Das Wesen einer Nation festzustellen, gehört wie alles Fixieren von Erscheinungen, die in den ununterbrochenen Fluss des geschichtlichen Geschehens gestellt sind, zu den schwierigsten wissenschaftlichen Aufgaben. Es lässt sich nämlich kein feststehendes, für alle Nationen passendes Merkmal angeben. Nicht die natürliche Stammesgemeinschaft, da alle modernen Nationen aus verschiedenen, ethnologisch oft weit auseinanderliegenden Stämmen zusammengesetzt sind.”

205 JELLINEK, Georg. Das Recht des modernen Staates. Berlin: Verlag von O. Häring, 1900. p. 106. "In verbis": "Ist es demnach unmöglich, ein einziges sicheres, objektives Kriterium der Nation anzugeben, so kann 
mesmas considerações se fazem aplicáveis aos conteúdos de "povo" e, à luz do esmiuçado anteriormente, "soberania".

Crítica ao uso da estrutura interna de organização dos estados como parâmetro à compreensão do direito global pode se referir, ainda, ao fato de exemplos de normas com características de direito das gentes serem reconhecidos, por parte da doutrina, na mais remota convivência entre os seres humanos. A esse respeito, é de se perceber que a concepção atual de direito internacional se configurou a partir da modernidade e que sua compreensão se relaciona intimamente com a estrutura européia de estados ${ }^{206}$.

Sob tais parâmetros, posicionamentos internacionalistas que se afastam dos ensinamentos da teoria geral do estado relacionados à organização do poder pelo direito e, ao mesmo tempo, fazem referência à Paz da Westphalia - ou diretamente aos Tratados de Münster e Osnabrück - como verdadeiro marco fundacional da ordem internacional atual incorreriam em grave incoerência teórica. Referido evento histórico e os tratados relacionados tiveram, de fato, repercussão e conseqüências em todo continente europeu, mas pertencem, principalmente, à história do direito constitucional germânico, mais propriamente por haverem regulamentado a organização do poder nos antecedentes remotos da atual Alemanha $^{207}$.

ein solches auch nicht durch eine feststehende Kombination mehrerer Elemente gefunden werden. Daraus ergiebt sich, dass die Nation nichts Objektives im Sinne des äusserlich Existirenden ist. Sie gehört vielmehr zu der grossen Klasse socialer Erscheinungen, die mit äusseren Massstäben überhaupt nicht gemessen werden können."

${ }^{206}$ CLAPHAM, Andrew. Brierly's law of nations. Oxford: Oxford University Press, 2012. p. 01. "In verbis": "Ever since human beings began to organize their common life in political communities they have felt the need of some system of rules, however rudimentary, to regulate their intercommunity relations. Rules which may be described as rules of international law are to be found in the history of the ancient and medieval worlds. But as a definite branch of jurisprudence, the system now known as international law is relatively modern. It dates only from the sixteenth and seventeenth centuries. Its special character was determined by that of the modern European state system, which was itself shaped in the ferment of the Renaissance and the Reformation. Some understanding of the main features of this European state system is therefore necessary for an understanding of the nature of international law."

${ }^{207}$ BILFINGER, Carl. Les bases fondamentales de la communauté des états. In: Recueil des Cours. Academie de Droit International de la Haye, Volume 63, 1938-I, pp. 129-241. pp. 156-157. "In verbis": "Le Traité de Westphalie, généralement regardé comme la base juridique et positive de la première période du droit des gens moderne, était, en même temps qu'un traité de droit des gens, une loi fondamentale constitutionnelle de l'ancien Empire allemand. On a nettement distingué, il est vrai, les deux plans qui se croisaient et se combinaient, c'est-à-dire le droit des gens et le droit constitutionnel de l'Empire allemand. Mais pourtant, en qui concerne la catégorie «Etat», droit des gens et droit constitutionnel de l'Empire allemand ont été mêlés et confondus. Les «pays» (Länder) de l'Empire allemand furent finalement reconnus à l'encontre de la proposition française, non pas comme «souverains", mais seulement avec la superioritas territorii sous l'Empereur et l'Empire. Muis en même temps ces territoires se voyaient attribuer un droit limité de conclure des alliances, faculté qui, malgré certaines réserves en faveur de l'Empire, mit en jeu son unité.“ 
A assunção da inauguração do direito das gentes nesse momento histórico específico reflete forte concepção jurídica eurocêntrica, isto é, formulações teóricas desenvolvidas no continente europeu através dos tempos e restringe a perspectiva da ordem global à vontade de um grupo pontual de atores, os quais, não raramente, são considerados verdadeiros sócios fundadores do direito internacional ${ }^{208}$.

Existe, portanto, forte vinculação entre a compreensão atual do direito internacional e o estado, mormente sob a recorrente perspectiva doutrinária voluntarista da ordem internacional como um produto da vontade dos estados ${ }^{209}$. O distanciamento do direito das gentes das estruturas teóricas da teoria geral do estado - mormente no que diz respeito às formulações teóricas de poder - representaria, assim, dissociação da percepção atual da ordem internacional de suas matrizes estruturais.

Observa-se, contudo, que muito da conformação atual do direito das gentes não surgiu, de fato, diretamente da consolidação dos estados nacionais, mas da doutrina que se desenvolveu a partir desses novos paradigmas da ordem internacional. Desenvolveu-se e evoluiu, por exemplo, da perspectiva da guerra e da soberania absoluta dos países predominante outrora às preocupações com a paz e o bem-estar global. Panorama evolutivo que se reflete claramente na forma como a ordem jurídica global hoje se organiza ${ }^{210}$.

\footnotetext{
${ }^{208}$ FENWICK, Charles G.. The progress of international law during the past forty years. In: Recueil des Cours. Academie de Droit International de la Haye, Volume 79, 1951-II, pp. 01-71. pp. 19-20. "In verbis“: "If we take the year 1648, the date of the Peace of Westphalia, as starting point we find the international community consisting of a small group of European states which might for convenience be designated as the "Charter Members" of the international community. They had already a highly developed international law consisting of traditions handed down from Ancient Greece and Rome, supplemented by principles of Christian morality formulated by the doctors of the Church and by the canon lawyers. How elaborate these legal traditions and Christian principles were can be seen by the most cursory examination of the great treatise by the Dutch jurist, Hugo de Groot, better known as Grotius, who has been properly called 'The Father of International Law'.'
}

${ }^{209}$ WEIL, Prosper. Le droit international en quête de son identité: cours général de droit international public. In: Recueil des Cours. Academie de Droit International de la Haye, Volume 237, 1992-VI, pp. 09-370. p. 44. "In verbis": "Le droit international, dit-on, est un outil dont les Etats se servent bien plus qu'ils ne le servent. Les citations célèbres se pressent à l'esprit : «Les Etats ne sont tenus au respect des traités qu'aussi longtemps qu'ils y ont intérêt » (Hegel) ; «Le droit international existe pour les Etats, et non les Etats pour le droit international » (Jellinek); «Les traités internationaux sont comme les roses et les jeunes filles : ils durent ce qu'ils durent » (de Gaulle).“

${ }^{210}$ TRUYOL Y SERRA, Antonio. Théorie du droit international public : cours général. In: Recueil des Cours. Academie de Droit International de la Haye, Volume 173, 1981-IV, pp. 09-443. p. 360. "In verbis": "L'idée de l'organisation internationale s'est exprimée essentiellement dans la série de projets de "paix perpétuelle », relatifs soit à l'Europe soit au monde, qui se succèdent depuis l'origine même du système d'Etats européen à côté des manuels et des traités de droit des gens ou droit international, et dont les auteurs, à la différence des auteurs de ces derniers, proviennent pour la plupart, jusqu'à la seconde moitié du XIXe siècle (où apparaîtront les juristes), de la philosophie et de la politique (aussi bien pratique que théorique) ; des polygraphes figurent également parmi eux. L'intérêt de cette littérature est évident. Nous n'en faisons pas état ici dans un souci d'érudition, qui serait déplacé, mais parce que les projets qui s'y trouvent sont un apport doctrinal, à la fois historique et actuel, de premier ordre à l'idée de l'organisation internationale.“ 
O uso do direito interno como parâmetro ao direito das gentes pela doutrina jurídica antes de o constitucionalismo perder espaço na racionalização da ordem internacional no fim da segunda metade do século XX - apresentava propostas bastante contundentes que chegavam a submeter a validade do direito interno à conformidade com as normas internacionalmente estabelecidas ${ }^{211}$.

As organizações surgidas no pós-guerra na Europa, por exemplo, inspiraram reacenderam, na verdade - ideais federalistas na doutrina, a qual passou a imaginar ainda com mais freqüência um estado continental como modelo que garantiria a paz duradoura ${ }^{212}$. Doutrinadores, em claro esforço nesse sentido, buscavam extrair do tratado constitutivo da Comunidade Econômica Européia - CEE - objetivos federalistas de longo prazo $^{213}$.

Os defensores do argumento federal para o direito internacional - a posição certamente mais extrema no uso das estruturas internas dos estados como modelo ao sistema global - chegaram a sustentar, quando os grandes conflitos ainda eram recentes e as perspectivas eram nada animadoras na guerra fria, que um estado mundial seria a única opção hábil a evitar o colapso da humanidade ${ }^{214}$.

${ }^{211}$ SCELLE, Georges. Théorie et pratique de la fonction exécutive en droit international. In: Recueil des Cours. Academie de Droit International de la Haye, Volume 55, 1936-I, pp. 87-202. p. 98. "In verbis“: "Il se peut que la norme étatique subsiste concurremment avec la norme interétatique, mais alors les deux normes auront même contenu ; l'une des deux, la norme interne, devenue superfétatoire, sera absorbée par la norme internationale, tant que l'ordre de rapports intersociaux dont il s'agit sera réglé par la norme internationale. Au brocard allemand « Bundesrecht bricht Landesrecht » il y a lieu d'ajouter «Völkerrecht bricht Bundesrecht », pour des raisons identiques.“

212 TEITGEN, Pierre-Henri. La décision dans la Communauté économique européenne. In: Recueil des Cours. Academie de Droit International de la Haye, Volume 134, 1971-III, pp. 589-689. p. 595. "In verbis": "Les tenants de la conception «fédéraliste» (le récent ouvrage du professeur Hallstein, L'Europe inachevée, pourrait être considéré comme une sorte de manifeste de cette tendance) font tout d'abord état d'une constatation. Il est incontestable, disent-ils, que les six Etats qui ont successivement fondé les trois Communautés européennes, maintenant en voie de fusion, ne se sont pas simplement proposé d'en faire le cadre d'une coopération économique interétatique. Ils ont affirmé qu'elles devaient promouvoir l'intégration progressive de leurs marchés nationaux et de leurs économies dans un système economique commun, en vue qui plus est - de préparer leur intégration dans un système politique commun. La déclaration de Robert Schuman en date du 9 mai 1950 lançait et précisait l'idée : la Communauté européenne du charbon et de l'acier dont elle proposait l'institution devait constituer «les premières assises concrètes d'une fëdération européenne »."

213 TEITGEN, Pierre-Henri. La décision dans la Communauté économique européenne. In: Recueil des Cours. Academie de Droit International de la Haye, Volume 134, 1971-III, pp. 589-689. p. 600. "In verbis“": “C'est au vu de toutes ces données que les protagonistes d'une conception fédéraliste de la Communauté économique européenne concluent à l'exactitude de la représentation qu'ils s'en font : à tout le moins elle serait une institution fédérale en devenir et c'est dès lors dans le sens du fédéralisme potentiel qui l'anime qu'il faudrait interpréter sa charte constitutive."

${ }^{214}$ DE VISSCHER, Paul. Cours général de droit international public. In: Recueil des Cours. Academie de Droit International de la Haye, Volume 136, 1972-II, pp. 01-202. pp. 17-18. "In verbis“: "Cette hypothèse est celle d'une communauté d'Etats distincts, dotés de la souveraineté interne, placés dans une situation de coexistence ou de juxtaposition et dont la collaboration, parce qu'elle est essentiellement volontaire, est rarement à la 
Mais que isso, a ordem internacional chegou a ser concebida entre as duas grandes guerras como uma confederação, a qual evoluiria naturalmente a um estado global. Nesse contexto, o federalismo estatal constituiria uma espécie organizativa de poder consolidada e o direito das gentes seu contraponto transitório que teria na Sociedade das Nações - a antecessora da Organização das Nações Unidas - seu lugar de natural consolidação ${ }^{215}$.

A análise da Liga das Nações sob parâmetros confederativos da teoria geral do estado, aplicados como moduladores e não apenas como instrumental cognitivo, percebiam na falta de disposições em tratado acerca do regime político ou da forma de governo adotadas pelos membros da organização fragilidade estrutural que dificultaria a finalidade agregadora que se reconhecia. Preocupações do tipo parecem ter sido superadas nos atuais modelos regionais e multilaterais de aproximação não apenas pelo não reconhecimento da formação de um estado como finalidade basilar, mas também pelo especial valor dado pelos sistemas internacionais, de forma muitas vezes assentada no texto de tratados, à democracia ${ }^{216}$.

mesure de leur solidarité objective. Si telle est l'hypothèse à laquelle se rapporte le droit international, il est clair que l'on ne contribue guère au progrès d'un tel droit en lançant l'anathème contre la souveraineté ou contre le principe de l'égalité des Etats. On peut certes estimer que seule une technique juridique impliquant la concentration du pouvoir au niveau d'un Etat mondial permettrait à l'humanité de relever les défis auxquels elle se doit de faire face. En d'autres mots, on peut penser que le droit proprement international a épuisé ses dernières virtualités et que, si l'on n'y substitue pas à bref délai un droit public de type fédéral, l'humanité est vouée à sa perte.“

${ }^{215}$ SCELLE, Georges. Théorie et pratique de la fonction exécutive en droit international. In: Recueil des Cours. Academie de Droit International de la Haye, Volume 55, 1936-I, pp. 87-202. pp. 98-101. "In verbis“: "Les ordres juridiques internationaux se superposent d'ailleurs les uns aux autres, de la même façon qu'aux ordres nationaux les fédératifs. Du point de vue de la technique, il n'y a aucune distinction à faire entre le fédéralisme juridique et la construction juridique internationale. Tout le monde convient qu'entre la confédération d'Etats et l'Etat fédéral, il n'y a dans les faits que des différences d'organisatios et de répartition des compétences entre gouvernants fédéraux et gouvernants étatiques. L'Etat fédéral est un type achevé, la Confédération d'Etats un type de transition. Mais, pratiquement, la différence est importante entre le fédéralisme institutionel et le fédéralisme purement normatif, superposition des ordres juridiques. Du point de vue normatif, le phénomène est le même, mais si dans l'ordre juridique supérieur la hiérarchie des compétences gouvernementales ne s'établit pas parallèlement à la hiérarchie des normes, la supériorité des normes interétatiques sur les nonnes étatiques se trouve singulièrement compromise dans sa réalisation. Le véritable fédéralisme, celui que l'on est habitué à considérer comme tel, est le fédéralisme institutionel, dans lequel les autorités gouvernementales superétatiquies s'instituent progressivement au-dessus des autorités gouvernementales étatiques et qui aboutit à une répartition des compétences entre les deux personnels gouvernementaux. [...] La société internationale actuelle, qui connaît déjà de multiples expériences fédéralistes, dont plusieurs s'enlisent déjà dans l'unitarisme étatique, a fait avec la Société des Nations un effort généralisé de fédéralisme constructif.“

${ }^{216}$ SCHEUNER, Ulrich. L'influence du droit interne sur la formation du droit international. In: Recueil des Cours. Academie de Droit International de la Haye, Volume 68, 1939-II, pp. 95-206. p. 197. "In verbis“: "Dans le cas où plusieurs Etats se réunissent en association, union ou fédération internationale, les stipulations internationales sur les formes politiques intérieures ont un caractère légitime, pour ne pas dire raisonnable. On sait que la Constitution d'un Etat fédéral, celle des Etats-Unis comme celle de la Suisse, ou du Reich allemand de 1870 et de 1919, contiennent des dispositions qui prévoient une homogénéité constitutionnelle, soit monarchique, soit républicaine. De même, une conviction politique commune est, dans les alliances politiques, un élément efficace de solidité durable, sans être pour cela indispensable. La Société des Nations a renoncé à de telles dispositions ; il est évident que le manque de convictions communes a été une de ses faiblesses principales." 
Logo após a segunda guerra mundial, com a criação da Organização das Nações Unidas, já se pode perceber a diminuição da tendência ao uso das instituições dos estados como parâmetro hábil a orientar o estudo de seus órgãos pela doutrina. Deixou-se, de forma bastante nítida, a busca da identificação dos exercentes das atribuições conferidas às estruturas investidos das funções decorrentes do poder do estado na estrutura burocrática multilateral e abandonam-se termos como "executivo"e "deliberativo"217.

$\mathrm{Na}$ formulação de paralelos entre o direito interno e o internacional, várias estruturas não seriam, de fato, reproduzíveis. A possibilidade de os estados fazerem reservas à sua submissão às normas produzidas, por exemplo, mostra-se impossível localmente quando comparada à relação entre os indivíduos e a ordem normativa estatal ${ }^{218}$. Observa-se, nesse sentido, que na estrutura clássica do direito das gentes, que persiste em grande medida na atualidade, os estados podem condicionar a formação da vontade comum. Além disso, o poder global não se sobrepõe aos entes dotados de poder concretivo da mesma forma que o poder estatal o faz em relação aos indivíduos internamente ${ }^{219}$.

${ }^{217}$ KAECKENBEECK, Georges. La Charte de San-Francisco dans ses rapports avec le droit international. In: Recueil des Cours. Academie de Droit International de la Haye, Volume 70, 1947-I, pp. 109-330. p. 127. "In verbis": "Il y a des analogies très superficielles avec les organes d'un Etat, qu'on avait déjà relevées du temps de la Société des Nations. On a souvent parlé de l'analogie entre l'Assemblée et des Etats généraux ou un Parlement, entre le Conseil et le Pouvoir exécutif, entre le Secrétariat général et l'Administration. Si cela peut aider à une toute première et grossière différenciation de ces organes, soit. Mais ces analogies proviennent ou bien d'une vue extrêmement superficielle ou bien d'une téméraire anticipation sur les faits. Ce n'est pas à des analogies de ce genre ni à des comparaisons avec le droit public d'Etats déterminés que je vous convierai. Les organes des Nations Unies, nous les examinerons tels qu'ils sont prévus, tels qu'its sont créés. Nous les envisagerons comme des Organes sui generis, dont l'observation nous fera surprendre les qualités ou les défauts, les capacités ou les incapacités. Nous les examinerons dans leur formation et, autant que possible, dans leur action, mois toujours évidemment en nous rendant compte des limitations que non seulement le temps rnais notre sujet nous imposent, puisque ce dernier n'est pas la Charte tout court, mais la Charte dans ses rapports avec le droit international.“

${ }^{218}$ DAUDET, Yves. Actualités de la codification du droit international. In: Recueil des Cours. Academie de Droit International de la Haye, Volume 303, 2003, pp. 09-118. p. 36. "In verbis“: "Bien évidemment, les caractéristiques principales de la codification en droit interne ne sont qu'en partie transposables à l'ordre international. Moins en raison des motifs ou des finalités de la codification, qui sont assez largement comparables (clarifier le droit, stabiliser les situations juridiques, mettre à l'abri de l'aléa), que de ses effets nécessairement différents compte tenu de la spécificité de la structure de l'ordre juridique international. Ainsi qu'il sera développé plus loin, la norme internationale codifiée peut s'inscrire dans des textes de différentes natures. Leur effet est obligatoire si la codification est conventionnelle, seulement recommandatoire si elle consiste en une simple résolution ou une oeuvre de restatement. Dans tous les cas, la portée de la codification est réduite, soit — la remarque est évidente — par l'absence d'obligation s'il s'agit d'un texte à portée recommandatoire, soit par le caractère limité de l'obligation s'il s'agit d'une convention de codification qui, en principe, comme toute autre convention, ne doit produire d'effet qu'entre les Etats qui l'ont ratifiée. Ce qui pose l'épineuse question de l'admissibilité des réserves.“

${ }^{219}$ MENEZES, Wagner. Tribunais internacionais: jurisdição e competência. São Paulo: Saraiva, 2013. p. 57. "In verbis": "Aqui reside o problema fundamental e epicentro do debate sobre a existência de um sistema jurisdicional internacional, pois o Direito Internacional, ficou relegado e condicionado à manifestação de poder estatal e determinado pela vontade dos Estados sem a idéia da supremacia de uma ordem jurídico- 
Noutro sentido, percebe-se que a analogia entre o papel dos indivíduos internamente e dos estados no plano internacional assemelharia os conflitos surgidos entre os atores internacionais àqueles que se estabelecem entre seres humanos ${ }^{220}$. A esse respeito, a soberania cumpriria, ainda, importante papel na formulação teórica do direito das gentes e mesmo a teoria do estado, por mais auto-referenciada que possa parecer, reconheceu já em suas primeiras sistematizações teóricas a relação interestatal - ou seja, a soberania alheia - como importante limitador jurídico à atuação externa de um país ${ }^{221}$.

Não são, contudo, apenas os institutos da teoria geral do estado que podem ser transplantados ao direito internacional para promover sua melhor compreensão. Muitos institutos de direito privado servem de base a conceitos de direito internacional. Dentre os exemplos disponíveis se encontram as servidões internacionais e a própria noção de culpa quando da análise de lesões ao direito das gentes ${ }^{222}$.

Interessante se faz perceber que quando os estados constituíam os únicos sujeitos de direito das gentes reconhecidos e exclusivamente suas vontades criavam o sistema, a

normativa superior como se fosse desprendido e alienado da sociedade interestatal que se amoldava, da vida dos homens e dos diferentes povos."

${ }^{220}$ MONTESQUIEU, Charles de Secondat Baron de. De l'esprit des lois - Vol 1. Paris: Garnier-Flammarion, 1979. p. 127. "In verbis“": "Sitôt que les hommes sont en societé, ils perdent le sentiment de leur faiblesse; l'égalité qui était entre eux cesse, et l'état de guerre commence. Chaque societé particulère vient à sentir sa force; ce qui produit un état de guerre de nation à nation. Les particuliers, dans chaque société, commencent à sentir leur force; ils cherchent à tourner en leur faveur les principaux avantages de cette société; ce qui fait entre eux um état de guerre. Ces deux sortes d'états de guerre font établir les lois parmi les hommes. Considérés comme habitants d'une si grande planète, qu'il est nécessaire qu'il y ait différents peuples, ils ont des lois Dans le rapport que ces peuples ont entre eux; et c'est le DROIT DES GENS. Considérés comme vivants dans une société qui doit être maintenue, ils ont des lois dans le rapport qu'ont deux qui gouvernent avec deux qui sont gouvernés; et c'est le DROIT POLITIQUE. Ils en ont encore dans le rapport que tous les citroyens ont entre eux; et c'est le DROIT CIVIL.“"

${ }^{221}$ JELLINEK, Georg. Das Recht des modernen Staates. Berlin: Verlag von O. Häring, 1900. p. 108. "In verbis": "Weltausstellungen und internationale Kongesse aller Art sind die sichtbaren, jährlich wiederkehrenden Folgen des internationalen Gesellschaftslebens. Aber auch die souveränen Staaten als Mitglieder der Völkerrechtsgemeinschaft bilden die nicht organisirte oder doch nur in Gelegenheitsorganisationen sich äussernde Staatengesellsehaft, innerhalb welcher die politischen Interessen wechselnde, oft einander entgegengesetzte Gruppen bilden die in ihren gegenseitigen Beziehungen den Typus der den Staaten eingeordneten Gesellschaftsgruppen wiederholen. Eine dankenswerte Aufgabe wäre es, den besonderen Einfluss zu bestimmen, den die internationalen Gesellschaftsverhältnisse auf die einzelstaatliche Rechtsordnung ausüben. Der ganze Verfassungsbau der modernen Staaten ist durch sie mitbedingt.”

${ }^{222}$ LIMBURG, J.. L'autorité de chose jugée des décisions des juridictions internationales. In: Recueil des Cours. Academie de Droit International de la Haye, Volume 30, 1929-V, pp. 519-618. p. 525. "In verbis“": "Cela provient-il du fait qu'on a l'habitude d'appliquer les notions du droit interne - et particuliérement celles du droit privé - au droit intemational ? Ou du fait qu'on attribue en droit international la même valeur aux effets de la chose jugée qu'il en est en droit interne ? A vrai dire il me semble que les deux motifs entrent en ligne de compte. D'abord il est incontestable que dans le droit international on fait usage des régles du droit privé. On applique les notions telles que celle de «faute » (culpa) à ses divers degrés, on parle même de « servitudes » de droit public sans qu'une régle expresse de doit international ait confirmé cet usage. " 
definição do direito internacional dependia necessariamente de seus sujeitos criadores ${ }^{223}$. Dizia-se que o direito internacional consubstanciava o conjunto de normas criadas por seus membros para regulamentar sua relação ${ }^{224}$. Hoje, qualquer definição do direito comum deve trazer não apenas novos sujeitos reconhecidos como também direitos e valores cogentes, vinculantes e independentes de vontade dos agentes envolvidos com o poder concretivo.

Aos estados e ao seu protagonismo de outrora na ordem internacional como legisladores, juízes, executores e atores devem ser atribuídas as grandes responsabilidades relacionadas às dúvidas que havia quanto à condição de direito do direito das gentes ${ }^{225}$. A falta de centralização do poder na esfera internacional reservava à figura estatal e à sua característica soberana todas as atribuições vinculadas ao seu exercício da força e tal contexto outorgava à ordem global condição assemelhada àquela das comunidades humanas anteriores ao surgimento da própria idéia de ente moral que se conhece na atualidade ${ }^{226}$.

223 SPIROPOULOS, J.. L'individu et le droit international. In: Recueil des Cours. Academie de Droit International de la Haye, Volume 30, 1929-V, pp. 191-270. p. 222. "In verbis": "Partons maintenant d'une des nombreuses définitions possibles du droit des gens et acceptions par exemple de dire que le droit des gens est «l'ensemble des normes renfermant les droits et obligations des États dans leurs rapports entre eux. » Complétons cette défiition par celle du sujet du droit des gens à laquelle nous sommes arrivés plus haut et aux termes de laquelle les États sont les seules sujets du droit international public.“

224 SPIROPOULOS, J.. L'individu et le droit international. In: Recueil des Cours. Academie de Droit International de la Haye, Volume 30, 1929-V, pp. 191-270. p. 219. "In verbis“: "Avec une telle définition du sujet du droit des gens, les sujets de ce droit sont naturellement partie intégrante de la définition du droit des gens lui-même qui repose en effet sur eux. La définition du droit des gens est donc par conséquent ici fonction de la détermination des sujets du droit des gens. Par exemple dans la définition nominale : « Le droit des gens est constitué par les règles établissant des droits et des obligations pour les États entre eux « il n'y a, par défmition, que les États pour ètre sujets de droit des gens, et ceci parce que nous avons obtenu notre concept «droit des gens » à partir des États a priori qualifiés de sujets du droit international. Mais il est évident que ce concept du «sujet de droit des gens » est aussi arbitraire que le concept du « droit des gens » lui-même, l'un et l'autre n'ayant pas une origine empirique, mais étant déterminés a priori.“

${ }^{225}$ HENKIN, Louis. International law and the behavior of nations. In: Recueil des Cours. Academie de Droit International de la Haye, Volume 114, 1965-I, pp. 167-281. p. 171. "In verbis“: "Law has suffered many definitions and all of them proclaim the law's many lives. International law, on the other hand, has not been unduly troubled in definition, but it must still constantly defend its existence. Even friends whisper that there is no international law, or - like adults exposing Santa Claus to those who have outgrown him - there really is no international law. The judgment is not significantly more encouraging when we are told that there is no longer any international law or that there is as yet no international law. The student of international law is long inured to these accusations. He is not concerned with Austinian definitions that deny the title of law to any but commands of a sovereign, enforceable and enforced as such. He sees as regrettable, not fatal, that there is no final arbiter, and no effective system of adjudication. That 'sovereign' states are, in largest part, the actors, the judges, the executives, the legislators of international society gives to the law of that society a character significantly different from that of municipal law; this special character does not preclude, or vitiate, or render insignificant, the legal quality of international law."

${ }^{226}$ KELSEN, Hans. Reine Rechtslehre - Einleitung in die rechtswissenschaftliche Problematik. Leipzig und Wien: Franz Deuticke, 1934. p. 119. "In verbis": "Solange es aber der staatlichen Rechtsordnung noch keine höhere gibt, ist der Staat selbst die höchste, die souveräne Rechtsordnung oder Rechtsgemeinschaft. Das bedeutet insbesondere, daß der territoriale wie der materiale Geltungsbereich dieser Rechtsordnung zwar begrenzt sind, indem die staatliche Zwangsordnung ihre Geltung tatsächlich auf einen bestimmten Raum und auf bestimmte Gegenstände Selbst beschränkt, daß sie - zumindest materiell - nicht überall zu gelten 
Posturas em defesa do reconhecimento da condição de direito ao direito internacional chegavam claramente a admitir, sob tais parâmetros, a busca da reprodução no plano externo dos institutos e estruturas por meio dos quais as normatizações se organizavam internamente $^{227}$. Tais concepções teóricas não podem ser, contudo, transportadas à esfera internacional sem que se considerem suas especificidades que a distanciam do modelo de organização de poder local.

Interessante a ambigüidade dos extremos da aplicação referida, já que, se por um lado, as teorias que buscam explicar o estado se apresentam como proposta à justificação teórica do poder no direito das gentes, muito do reducionismo que vislumbra sua estrutura normativa como primitiva pode constituir resultado de transposições teóricas equivocadas ${ }^{228}$.

Ainda que doutrinadores defendam elementos de constitucionalidade em tratadosmarco de organizações internacionais - mormente multilaterais e mais especificamente das Nações Unidas na atualidade, cumpre ressaltar que a Corte Internacional de Justiça - e sua antecessora, a Permanente - em várias oportunidades implicitamente negaram tal percepção submetendo normas internacionais sempre ao direito das gentes ${ }^{229}$. Seria essa negação tácita

beansprucht und daß sie nicht alle menschlichen Beziehungen erfaßt; aber daß sie die durch keine höhere Rechtsordnung beschränkte Fähigkeit hat, ihre Geltung in territorialer wie materialer Hinsicht auszudehnen. Man pflegt dies als Kompetenzhoheit zu bezeichnen. Sobald sich aber über den einzelstaatlichen Rechtsordnungen die Völkerrechtsordnung erhebt, kann der Staat nicht mehr als souveräne, sondern nur als relativ höchste, als nur unter dem Völkerrecht stehende, als völkerrechtsunmittelbare Rechtsordnung begriffen werden. Seine nähere Bestimmung kann erst nach Darstellung seines Verhältnisses zur Völkerrechtsordnung gegeben werden. Die durch diese konstituierte überstaatliche Gemeinschaft kann so wie die vorstaatliche Rechtsgemeinschaft mangels hinreichender Zentralisation nicht als Staat angesprochen werden.“

${ }^{227}$ KELSEN, Hans. Théorie du droit international public. In: Recueil des Cours. Academie de Droit International de la Haye, Volume 110, 1953-III, pp. 01-203. p. 28. "In verbis": "La question de savoir si le droit international est un droit au sens que nous venons d'indiquer revient à celle de savoir si les phénomènes auxquels on donne communément le nom de droit international peuvent être décrits par des règles de droit semblables à celles qui servent à décrire un droit national.“

${ }^{228}$ CASELLA, Paulo Borba. Evolução institucional do direito internacional: à luz do cinqüentenário do conceito de direito de Hart (1961). In: Revista Brasileira de Filosofia. Ano 60, Vol. 236, janeiro-junho, 2011. pp. 313329. p. 316. "In verbis": "Volta Hart à velha argumentação quanto a ser o direito internacional um 'sistema primitivo'. O que ao mesmo tempo é verdadeiro, ao menos em certa extensão, até o presente, mas não deixa de causar distorção, como critério de análise, por ser reducionista a dado que reflete antes o perfazimento do percurso, do que o conteúdo e a natureza intrínsecos deste. Ou seja, a jurisdição internacional se constrói dentro e segundo os parâmetros do sistema institucional e normativo internacional. A transposição de conceitos e modelos dos direitos internos não pode ser feita sem considerar as especificidades do meio ao qual se destine."

229 LAUTERPACHT, E.. The development of the law of international organization by the decisions of international tribunals. In: Recueil des Cours. Academie de Droit International de la Haye, Volume 152, 1976IV, pp. 377-478. pp. 414-415. "In verbis“: "The Permanent Court and the International Court (either of which we may for convenience call 'the Court') have between them been called upon a score of times to interpret international constitutional instruments. Yet it is a feature of the relevant judgments and opinions, at least so far as the majority judgments of the Court itself are concerned, that they contain no express reference to the 'constitutional' character of the instruments to which they relate. Nor do they ever expressly suggest that 
suficiente para excluir do direito internacional os parâmetros da teoria do estado como meramente informadores?

Não se defende aqui o uso das teorias de distribuição de poder no plano interno dos estados como modelo para o direito das gentes e tampouco a reprodução absoluta de suas estruturas e instituições. Entende-se, contudo, que toda a produção teórica - das últimas várias centenas de anos principalmente - relacionada ao tema não pode ser ignorada e deve servir de exemplo e inspiração para a organização da ordem internacional.

O estudo do estado se dá na prática por meio da análise política. A abordagem política da compreensão da estrutura organizativa estatal se traduz na perspectiva teleológica, isto é, das finalidades da institucionalidade desenvolvida. Ao mesmo tempo - e por outro lado - a política leva o investigador à observação crítica da organização da sociedade na forma de um país $^{230}$.

A utilização de conceitos da teoria do estado no direito internacional pode servir, ainda, à melhor justificação de sua autonomia em relação à política. A compreensão da soberania interna a partir de sua legitimação pelo exercício volitivo popular e de seu papel na formação da vontade dos estados - como entes exercentes da função concretiva interna e externamente - separaria definitivamente a política - como expressão da vontade - do direito como produto dessa vontade expressada ${ }^{231}$.

special rules distinguishable from those normally applied to the interpretation of treaties are applicable to them. Indeed, the International Court has on occasion virtually said the contrary. For example, in the Advisory Opinion on Certain Expenses of the United Nations the Court said: 'On the previous occasions when the Court has had to interpret the Charter of the United Nations, it has followed the principles and rules applicable in general to the interpretation of treaties, since it has recognized that the Charter is a multilateral treaty, albeit a treaty having certain special characteristics.' "

${ }^{230}$ JELLINEK, Georg. Das Recht des modernen Staates. Berlin: Verlag von O. Häring, 1900. p. 12. "In verbis": "Die angewandte oder praktische Staatswissenschaft ist die Politik, d. h. die Lehre von der Erreichung bestimmter staatlicher Zwecke und daher die Betrachtung staatlicher Erscheinungen unter bestimmten teleologischen Gesichtspunkten, die zugleich den kritischen Maasstab für die Beurteilung der staatlichen Zustände und Verhältnisse liefern."

${ }^{231}$ GIRAUD, Emile. Le droit international public et la politique. In: Recueil des Cours. Academie de Droit International de la Haye, Volume 110, 1963-III, pp. 419-809. pp. 431-432. "In verbis“: "Si la politique est la source du droit, à la fois du droit interne que est l'expression de la volonté du pouvoir politique de l'Etat et du droit international qui est l'expression de la volonté des Etats, c'est-à-dire de leurs gouvernements, il reste que le droit, une fois qu'il a été créé ne se confond pas avec la politique. La créature a une vie distincte de celle de son créateur. Certes le droit conserve une certaine dépendance vis-à-vis de la politique qui, comme nous avons essayé plus haut de le montrer, influe sur l'application du droit, mais cette circonstance ne supprime pas l'autonomie du droit. Il faut relever que la séparation du droit et de la politique, une fois que le droit a été créé, est beaucoup plus marquée sur le plan interne que sur le plan international.“ 
A rejeição da teoria do estado em seu conjunto como instrumental hábil a explicar fenômenos organizacionais do direito internacional não deve, portanto, prosperar ${ }^{232}$. Estudiosos não podem se esquecer que tal teoria se dedica à compreensão de estruturas de direito - personificadas - que descrevem e organizam juridicamente fenômenos políticos ${ }^{233}$. As estruturas da teoria do estado devem servir, assim, de inspiração e à compreensão do direito internacional, mas seus modelos não precisam ser, ressalta-se, obrigatoriamente reproduzidos na esfera mundial ${ }^{234}$.

A teoria geral do estado deixou, em síntese, paulatinamente ao longo do século XX de ser aplicada ao direito das gentes. Percebe-se, nesse sentido, que talvez tenha havido na doutrina certa confusão entre a percepção do ente moral como barreira à consolidação das instituições de direito internacional e a teorização de poder disponibilizada pelo desenvolvimento da teoria geral do estado ao longo dos séculos.

Não existe, de fato, identidade entre as estruturas internas de poder e o direito internacional. A analogia estrutural - que não é inédita, mas que se propõe aqui sob a perspectiva do resgate - pode servir muito bem à melhor compreensão e ao aperfeiçoamento da ordem global.

Impossível se faz identificar na ordem internacional atual, apesar do entusiasmo pontual da doutrina com a Sociedade das Nações e com a Organização das Nações Unidas, processos claros de formação de uma confederação ou uma de uma federação global. Não há,

\footnotetext{
${ }^{232}$ FISCHER-LESCANO, Andréas; TEUBNER, Gunther. Regime-Kollisionen. Frankfurt am Main: Suhrkamp Verlag, 2006. p. 10. "In verbis": "Als Ursachen werden sieben Problembereiche identifiziert: Mangel zentralisierte Organe, Spezialisierung, Unterschiede in den Normstrukturen, Parallelregulierungen, konkurrierende Regulierungen, Ausweitung des Völkerrechts, unterschiedliche Regimes sekundärer Normen. Juristen sehen damit nur rechtsinterne Fragmentierungsphänomene und deren rechtsinterne Ursachen. Entsprechend streben sie dann auch rechtsinterne Lösungen des Problems an: die Etablierung von Gerichtshierarchien und einer Stufenordnung von Rechtsnormen auf der Weltebene, die das Ideal nationalstaatlicher Rechtshierarchien zwar nicht erreichen, aber sich ihm zumindest annähern.“

${ }^{233}$ DALLARI, Dalmo de Abreu. Elementos de teoria geral do estado. São Paulo: Saraiva, 2011. pp. 16-17. "In verbis": "[...] para a formação do jurista contemporâneo o estudo da Teoria Geral do Estado é indispensável. O Estado é universalmente reconhecido como pessoa jurídica, que expressa sua vontade através de determinadas pessoas ou determinados órgãos. Nesse dado é que se apoiam todas as teorias que sustentam a limitação jurídica do poder do Estado, bem como o reconhecimento do Estado como sujeito de direitos e de obrigações jurídicas. O poder do Estado é, portanto, poder jurídico, sem perder seu caráter político.“

${ }^{234}$ WRIGHT, Quincy. The strengthening of international law. In: Recueil des Cours. Academie de Droit International de la Haye, Volume 98, 1959-III, pp. 01-295. p. 226. "In verbis": "It is not suggested that adjudication could settle these disputes at the present time, though it might have made contributions toward such a settlement at earlier stages, but it is clear that the absence of an authoritative and acceptable method for settling international disputes, when force is ruled out and agreement fails, militates seriously against a world rule of law."
} 
definitivamente, um "estado mundial" ou algo assemelhado, mas isso não significaria entender que a teoria geral do estado não teria nada a ensinar ao direito das gentes.

Não se trata da promoção do uso das teorias de poder aplicadas ao estado como parâmetro de modulação do direito das gentes, mas de apresentá-las como instrumental de auxílio à sua compreensão. A teoria geral do estado tem muito a contribuir ao direito internacional e, no panorama atual de desafios que se apresentam à organização do poder global, urgente se faz a definitiva superação das resistências de internacionalistas ao seu estudo e aplicação.

\subsection{Poder, Teoria Geral do Estado e Direito Internacional}

Ainda que determinadas regras de direito internacional em vigor hoje tenham sua origem na antiguidade, a conformação atual desse direito remonta à formação dos entes morais modernos na Europa ocidental e à estruturação do poder que desse momento histórico resultou ${ }^{235}$.

A análise do poder não apenas contribui à percepção estrutural de uma ordem normativa como, na verdade, mostra-se essencial à sua fundamentação como jurídica ${ }^{236}$. Nesse sentido, observa-se que no contexto estatal interno o poder se organiza de forma claramente centralizada e tal característica se faz perceptível na produção normativa, na execução dos anseios sociais concretizados em regras e na extração da normatividade em caso de dúvida. Assim, o poder soberano, considerado indivisível na conformação do estado,

\footnotetext{
235 BISHOP, W.W.. General course of public international law. In: Recueil des Cours. Academie de Droit International de la Haye, Volume 115, 1965-II, pp. 147-470. p. 153. "In verbis“": "Specific international rules and institutions somewhat resembling those of the present world-wide international legal system may be found in ancient China and India, in classical Greece and the Mediterranean of over two thousand years ago, and throughout much of the history of Europe since Roman times, as well as in other parts of the world. But our present system may fairly be said to have developed in the fifteenth, sixteenth and seventeenth centuries as a law governing the relations between European nations. The development in Europe of the modem type of sovereign state, with its great concentration of political power and its monopoly of the use of force within its borders, set the stage."

${ }^{236}$ SLAUGHTER, Anne-Marie. International law and international relations. In: Recueil des Cours. Academie de Droit International de la Haye, Volume 285, 2000, pp. 09-249. p. 190, "in verbis": "First, international lawyers can profit from an analysis of power. Second legalized rules and institutions operate differently from nonlegalized rules and institutions. Third, soft law is as important as hard law in global governance but plays a different role. Fourth, régime design matters. Fifth, domestic politics are as important for international lawyers as international politics.“
} 
expressa-se localmente, portanto, por meio de órgãos específicos investidos das funções legislativa, executiva e judiciária, respectivamente.

As funções clássicas de exercício de poder podem ser reconhecidas também na ordem internacional, mas não necessariamente seu exercício em separado. Utilizando-se a institucionalidade estatal como parâmetro ao direito das gentes, observa-se que, muitas vezes, um mesmo órgão de uma organização internacional concentra atribuições típicas de mais de uma função de poder e que, em outros momentos, essas funções nem chegam a ser trasladadas da vontade direta dos estados às estruturas sobreestatais ${ }^{237}$.

A teoria do estado concebe o direito - ao lado da tradição e do carisma - como uma das formas de legitimação do poder ${ }^{238}$. Em breve resgate das discussões relacionadas à relação entre o direito e a política, realçada se mostra a vinculação de ambos os conceitos à idéia de poder. Assim, enquanto o direito estruturaria sua legitimação, a política sua organização, por exemplo, na elaboração das leis e no exercício das relações exteriores do estado $^{239}$.

A compreensão de uma estrutura de poder se relaciona, sob a perspectiva positivista do direito, com a validade das normas por ela emanadas. No caso específico dos estados, seus elementos estabelecem nada mais que os espectros de validade territorial e subjetivo -

\footnotetext{
${ }^{237}$ Sobre a "separação de poderes" no direito internacional, GUGGENHEIM, Paul. Les principes de droit international public. In: Recueil des Cours. Academie de Droit International de la Haye, Volume 80, 1952-I, pp. 01-189. p. 151. "In verbis": "Ce serait cependant une erreur de croire qu'en droit international la fonction judiciaire et la fonction administrative soient nettement séparées l'une de l'autre. Comme nous venons le démontrer, l'organe administratif peut être investi de la fonction judiciaire, sans d'ailleurs avoir la qualité inhrérent du juge, c'est-à-dire son indépendance de toutes instructions. La diférence entre la fonction judiciaire et la fonction législative est en effet essentiellement relative.“
}

238 WEBER, Max. Politik als Beruf. Stuttgart: Reclam, 2008. p. 08. "In verbis“: "Es gibt der inneren Rechtfertigungen, also: der Legitimitätsgründe einer Herrschaft - um mit ihnen zu beginnen - im Prinzip drei. Einmal die Autorität des >>ewig Gestrigen<<: der durch unvordenkliche Geltung und gewohnheitsmäßige Einstellung auf ihre Innehaltung geheiligten Sitte: $>>$ traditionale $<<$ Herrschaft, wie sie der Patriarch und der Patrimonialfürst alten Schlages übten. Dann: die Autorität der außeralltäglichen persönlichen Gnadengabe (Charisma), die ganz persönliche Hingabe und das persönliche Vertrauen zu Offenbarungen, Heldentum oder anderen Führereigenschaften eines Einzelnen: $>>$ charismatische $<<$ Herrschaft, wie sie der Prophet oder - auf dem Gebiet des Politischen - der gekorene Kriegsfürst oder der plebiszitäre Herrscher, der große Demagoge und politische Parteiführer ausüben. Endlich: Herrschaft kraft $>>$ Legalität $<<$, kraft des Glaubens an die Geltung legaler Satzung und der durch rational geschaffene Regeln begründeten sachlichen $>>$ Kompetenz $<<$, also: der Einstellung auf Gehorsam in der Erfüllung satzungsmäßiger Pflichten: eine Herrschaft, wie sie der moderne $>>$ Staatsdiener $<<$ und alle jene Träger von Macht ausüben, die ihm in dieser Hinsicht ähneln."

${ }^{239}$ LOCKE, John. Two treatises of government. London: Guernsey Press, 1986. p. 118. "In verbis“": "Political power, then, I take to be a right of making laws, with penalties of death, and consequently all less penalties for the regulating and preserving of property, and of employing the force of the community in the execution of such laws, and in the defence of the commonwealth from foreign injury, and all this only for the public good." 
território e povo - e, no caso do conceito de soberania, a justificativa da validade normativa propriamente $\operatorname{dita}^{240}$.

O deslocamento da idéia de poder de um órgão específico do estado - do monarca, por exemplo - para o estado como pessoa jurídica pode ser considerado um dos componentes do incremento do sentimento nacional observado no século XIX, o qual teve papel fundamental na fragmentação do sistema global promovida pelas ordens locais nacionais e por suas pretensões de exclusividade ${ }^{241}$.

Mais além do conceito e dos elementos do estado, o ponto central dessa teoria se encontra no estudo dos fundamentos e das formas de exercício do poder em determinada sociedade $^{242}$. A investigação do poder interno do estado poderia, assim, servir de parâmetro

\footnotetext{
${ }^{240}$ KELSEN, Hans. Reine Rechtslehre - Einleitung in die rechtswissenschaftliche Problematik. Leipzig und Wien: Franz Deuticke, 1934. p. 124. "In verbis" : "Die Erkenntnis, daß der Staat eine Rechtsordnung ist, findet ihre Bestätigung auch darin, daß sich die Probleme, die herkömmlicherweise unter dem Gesichtspunkt einer allgemeinen Staatslehre dargestellt werden, als rechtstheoretische Probleme, als Probleme der Geltung und Erzeugung der Rechtsordnung erweisen. Was man die <<Elemente〉> des Staates nennt: die Staatsgewalt, das Staatsgebiet und das Staatsvolk, sind nichts anderes als diese Geltung der staatlichen Ordnung an sich sowie der räumliche und personale Geltungsbereich dieser Ordnung."
}

${ }^{241}$ CLAPHAM, Andrew. Brierly's law of nations. Oxford: Oxford University Press, 2012. p. 14. "In verbis": "Still another modern development of the theory of sovereignty has been to give up the attempt to locate absolute power in any specific person or body within the state, and to ascribe it co the state itself, regarded as a juristic person. Here, again, we can see how changes in the doctrine of sovereignty reflect changes in political facts, for the sovereignty of the scare gave expression in theory to the growing strength and exclusiveness of the sentiment of nationality during the nineteenth century. By so doing, it raised a formidable difficulty for international law."

${ }^{242}$ BOBBIO, Norberto. Estado, governo, sociedade; por uma teoria geral da política. Rio : Paz e Terra, 1987. p. 82. "In verbis“: "Do ponto de vista dos vários critérios que foram adotados para distinguir as várias formas de poder, a definição do poder político como o poder que está em condições de recorrer em última instância à força (e está em condições de fazê-lo porque dela detém o monopólio) é uma definição que se refere ao meio de que se serve o detentor do poder para obter os efeitos desejados. O critério do meio é o mais comumente usado inclusive porque permite uma tipologia ao memso tempo simples e iluminadora: a tipologia assim chamada dos três poderes - econômico, ideológico e político, ou seja, da riqueza, do saber e da força. O poder econômico é aquele que se vale da posse de certos bens, necessários ou percebidos como tais, numa situação de escassez, para induzir os que não os possuem a adotar uma certa conduta, consistente principalmente na execução de um trabalho útil. Na posse dos meios de produção reside uma enorme fonte de poder por parte daqueles que os possuem contra os que não os possuem, exatamente no sentido específico da capacidade de determinar o comportamento alheio. Em qualquer sociedade onde existem proprietários e não proprietários, o poder do proprietário deriva da possibilidade que a disposição exclusiva de um bem lhe dá de obter o que o não proprietário (ou proprietário apenas de sua força-trabalho) trabalhe para ele e nas condições por ele estabelecidas. O poder ideológico é aquele que se vale da posse de certas formas de saber, doutrinas, conhecimentos, às vezes apenas de informações, ou de códigos de conduta, para exercer uma influência sobre o comportamento alheio e induzir os membros do grupo a realizar ou não realizar uma ação. Deste tipo de condicionamento deriva a importância social daqueles que sabem, sejam eles os sacerdotes nas sociedades tradicionais, ou os literatos, os cientistas, os técnicos, os assim chamados "intelectuais", nas sociedades secularizadas, porque através dos conhecimentos por eles difundidos ou dos valores por eles afirmados e inculcados realiza-se o processo de socialização do qual todo o grupo social necessita para poder estar junto. $\mathrm{O}$ que têm em comum essas três formas de poder é que elas contribuem conjuntamente para instituir e para manter sociedades de desiguais divididas em fortes e fracos com base no poder político, em ricos e pobres com base no poder econômico, em sábios e ignorantes com base no poder ideológico.“ 
aplicável à sociedade internacional ao menos como ponto de partida investigativo. Centenas de anos de estudo do poder devem, de alguma maneira, ser úteis ao direito internacional ${ }^{243}$.

O estudo do poder não é, na verdade, apenas útil, mas também necessário na compreensão do direito internacional. Também no estudo das relações internacionais a relação entre poder e direito apresenta importante papel tanto quando considerado o direito uma variável independente da política quanto sob a ótica de sua estrita dependência ${ }^{244}$.

A teoria geral do estado - mais que tratar de estado - trata, portanto, de poder. Seus institutos consolidam a teorização jurídico-política de sua organização, distribuição e exercício no plano interno.

Seu estudo não apenas contribui ao direito como se mostra essencial ao seu desenvolvimento e compreensão. Sua unidade, divisão de funções, legitimação e formas de exercício em uma ordem estatal não servem de parâmetro reproduzível na ordem global, mas podem dar indicações para que se compreenda melhor a dinâmica internacional e como essa deve evoluir em benefício do direito.

${ }^{243}$ CASELLA, Paulo Borba. Conceito de sistema, contexto internacional e pós-modernidade. In: ADEODATO, João Maurício; BITTAR, Eduardo C. B. (Org.) - Filosofia e Teoria Geral do Direito: estudos em homenagem a Tércio Sampaio Ferraz Junior por seu septuagésimo aniversário. São Paulo: Quartier Latin, 2011. p. 1002. "In verbis": "O direito tem difícil relação com o poder: nem pode estranhá-lo, e pretender manter-se distante deste, sob pena de deixar de ser direito, nem pode se confundir com este, e igualmente deixar de ser direito."

244 SLAUGHTER, Anne-Marie. International law and international relations. In: Recueil des Cours. Academie de Droit International de la Haye, Volume 285, 2000, pp. 09-249. p. 199, “in verbis“: “International lawyers can profit from an analysis of power. Perhaps unsurprisingly, lest the global order crowd get too carried away, the Realists have raised their heads again to remind the legal and policy-making community of the critical role of power in determining international outcomes. This time, however, with a twist. Whereas the traditional Realist-Legalist debate has been conducted in terms of whether law could play any autonomous role in shaping international outcomes, this round focuses more on the role of power in shaping law. In other words, even if Realists remain uninterested in law as an independent variable, a number are suddenly interested in law as a dependent variable - perhaps from the recognition that for whatever reasons, the prevailing great powers at this historical moment are keen to use legal rules and institutions to advance their interests and institutionalize their power." 


\section{DIREITO INTERNACIONAL, POLÍTICA, TEORIA GERAL DO ESTADO E PODER}

\subsection{Concreção, Normatividade e Direito Internacional}

A centralização do poder e a regulamentação de suas formas de exercício pelo direito conformam as principais características que diferenciam os estados dos outros atores da ordem internacional $^{245}$. A relação entre direito e poder reflete-se e pode ser analisada, portanto, na relação existente entre direito e estado, ou seja, no estudo dos limites estabelecidos pelas normas jurídicas ao exercício do poder internamente ${ }^{246}$.

Nas associações humanas, o sujeito deve ser individualmente observado, quanto à sua atuação e em relação aos outros particulares, como parte do soberano - do poder constituído e, em relação ao próprio soberano, como integrante do estado - do corpo social institucionalizado. No segundo caso, há que se perceber a diferença entre se obrigar consigo mesmo e com uma coletividade, a qual o sujeito integra ${ }^{247}$.

Ainda que a origem do termo "soberano" - como referência de poder - remonte às relações desenvolvidas durante a idade média, seu conteúdo convive com a humanidade já há

\footnotetext{
${ }^{245}$ GUGGENHEIM, Paul. Les principes de droit international public. In: Recueil des Cours. Academie de Droit International de la Haye, Volume 80, 1952-I, pp. 01-189. p. 83. "In verbis“: "La différence specifique qui existe entre l'Etat et tout autre ordre juridique réside à notre avis en premier lieu dans le degré élevé de centralisation qui caractérise l'ordre juridique étatique. Contrairement à la communauté du droit international coutumier, par exemple, l'ordre étatique est un ensemble de normes créées par des organes centraux et exécutées par des organes administratifs déterminant leur application.“

${ }^{246}$ BOBBIO, Norberto. Estado, governo, sociedade; por uma teoria geral da política. Rio: Paz e Terra, 1987. pp. 93-94. "In verbis“: "Ao lado do problema do fundamento do poder, a doutrina clássica do Estado sempre se ocupou também do problema dos limites do poder, problema que geralmente é apresentado como problema das relações entre direito e poder (ou direito e Estado).“

247 ROUSSEAU, Jean-jacques. Du contrat social. Paris: Union Générale d'Éditions, 1973. pp. 74-75. "In verbis": "On voit, par cette formule, que l'acte d'association renferme un engagement réciproque du public avec les particuliers, et que chaque individu, contractant pour ainsi dire avec lui-même, se trouve engage sous un double rapport: savoir, comme member du souverain envers les particuliers, et comme member de l'État envers le souverain. Mais on ne peut appliquer ici la maxime du droit civil, que nul n'est tenu aux engagements pris avec lui meme; car il y a bien de la différence entre s'obliger envers soi ou envers un tout don't on fait partie."
} 
bastante tempo, desde as primeiras formas de organização social que surgiram em comunidades de indivíduos ${ }^{248}$.

A idéia de poder pressupõe uma relação interpessoal - que pode ser entre pessoas físicas ou jurídicas e de direito público ou privado. Apesar de não se confundir com força, o poder repousa sobre a força, já que se funda na relação de superioridade de uma das partes envolvidas no contexto social específico ${ }^{249}$.

Poder, em sentido social amplo, significaria a capacidade de agir, de atuar concretivamente na sociedade impondo comportamentos a outros indivíduos ${ }^{250}$. Esse se diferenciaria do poder sobre coisas, o qual pode servir, contudo, de instrumento ao exercício do poder social. No caso de um estado, esse ente moral, dotado de personalidade, expressa vontade por meio do governo sobrepondo-se às pessoas e condicionando sua atuação em sociedade.

Para teóricos clássicos, como Locke, e contemporâneos, como Rawls, a compreensão do poder político exigiria prévia elaboração de situação imaginária anterior ideal, na qual os atores envolvidos na relação identificada como de poder se encontrariam em absoluta

\footnotetext{
${ }^{248}$ KLEFFENS, Eelco Nicolaas van. Sovereignty in international law : five lectures. In: Recueil des Cours. Academie de Droit International de la Haye, Volume 82, 1953-I, pp. 01-131. p. 11. "In verbis“. "The word "sovereign" for the highest, the supreme power in a given legal order may have been a product of the feudal age, but the notion it represents had forced itself upon the human mind ever since men began to establish independent political groups, and that goes back to the dawn of time."
}

${ }^{249}$ FLEINER-GERSTER, Thomas. Teoria geral do estado. São Paulo: Martins Fontes, 2006. p. 246. "In verbis": "O poder pressupõe sempre uma relação entre duas ou mais pessoas. Ele repousa sobre a força e a superioridade de uma parte e, simultaneamente, sobre a - relativa - dependência e fraqueza da outra."

${ }^{250}$ BOBBIO, Norberto; MATTEUCCI, Nicola; PASQUINO, Gianfranco. Dicionário de política - Vol. 1. Brasília: Editora Universidade de Brasília, 2010. pp. 933-934. "In verbis": "Em seu significado mais geral, a palavra Poder designa a capacidade ou a possibilidade de agir, de produzir efeitos. Tanto pode ser referida a indivíduos e a grupos humanos como a objetos ou a fenômenos naturais (como na expressão Poder calorífico, Poder de absorção). Se o entendermos em sentido especificamente social, ou seja, na sua relação com a vida do homem em sociedade, o Poder torna-se mais preciso, e seu espaço conceptual pode ir desde a capacidade geral de agir, até à capacidade do homem em determinar o comportamento do homem: Poder do homem sobre o homem. O homem é não só o sujeito mas também o objeto do Poder social. É Poder social a capacidade que um pai tem para dar ordens a seus filhos ou a capacidade de um Governo de dar ordens aos cidadãos. Por outro lado, não é Poder social a capacidade de controle que o homem tem sobre a natureza nem a utilização que faz dos recursos naturais. Naturalmente existem relações significativas entre o Poder sobre o homem e o Poder sobre a natureza ou sobre as coisas inanimadas. Muitas vezes, o primeiro é condição do segundo e vice-versa. Vamos dar um exemplo: uma determinada empresa extrai petróleo de um pedaço do solo terrestre porque tem o Poder de impedir que outros se apropriem ou usem aquele mesmo solo. Da mesma forma, um Governo pode obter concessões de outro Governo, porque tem em seu Poder certos recursos materiais que se tomam instrumentos de pressão econômica ou militar. Todavia, em linha de princípio, o Poder sobre o homem é sempre distinto do Poder sobre as coisas. E este último é relevante no estudo do Poder social, na medida em que pode se converter num recurso para exercer o Poder sobre o homem." 
igualdade $^{251}$. A "law of the nature", por um lado, instrumentaliza a fundamentação de direitos individuais como a vida, a saúde, a liberdade e a propriedade, os quais claramente servem de baliza ao conceito de poder ${ }^{252}$. Já a "original position" se apresentaria como sustentáculo à teorização da justiça e, apenas a partir da perspectiva dela, far-se-ia aplicável às relações de poder.

Conforme mencionado, a idéia de estado se confunde com a de uma comunidade jurídica e traduz-se em regulamentação de exercício do poder. Esse poder se manifesta, em regra e portanto, na forma de direito. Internamente, de certo, como direito escrito - codificado ou assentado em jurisprudência, mas mesmo no plano estatal o costume, é dizer, a regra não escrita, exerceria papel importante não apenas na produção normativa, mas também no próprio reconhecimento do estado como personificação do poder político ${ }^{253}$.

No contexto internacional ocorreria, em tese, o mesmo, mas a linha divisória entre o que se leva a termo em tratados e o costume se faz ainda mais tênue e, até mesmo, incerta. Subsiste na ordem global a exigência da regulamentação do poder, mas os sujeitos envolvidos nesse processo - os estados - demoraram a perceber que mesmo sendo possível estabelecer

\footnotetext{
${ }^{251}$ LOCKE, John. Two treatises of government. London: Guernsey Press, 1986. pp. 118-119. "In verbis“: "To understand political power aright, and derive it from its original, we must consider what estate all men are naturally in, and that is, a state of perfect freedom to order their actions, and dispose of their possessions and persons as they think fit, within the bounds of the law of Nature, without asking leave or depending upon the will of any other man. A state also of equality, wherein all the power and jurisdiction is reciprocal, no one having more than another, there being nothing more evident than that creatures of the same species and rank, promiscuously born to all the same advantages of Nature, and the use of the same faculties, should also be equal one amongst another, without subordination or subjection, unless the lord and master of them all should, by any manifest declaration of his will, set one above another, and confer on him, by an evident and clear appointment, an undoubted right to dominion and sovereignty." Rawls, em sua retórica contratualista baseada no conceito de posição original, defende a liberdade e a igualdade - subdividida nos princípios da eficiência e da diferença - como fundamentos procedimentais de seu conceito de justiça, senão vejamos: RAWLS, John. A theory of justice. Cambridge: Harvard University Press, 1971. p. 302. "in verbis": "First Principle - Each person is to have an equal right to the most extensive total system of equal basic liberties compatible with a similar system of liberty for all. Second Principle - Social and economic inequalities are to be arranged so that they are both: (a) to the greatest benefit of the least advantaged, consistent with the just savings principle, and (b) attached to offices and positions open to all under conditions of fair equality of opportunity."
}

${ }^{252}$ LOCKE, John. Two treatises of government. London: Guernsey Press, 1986. p. 119. "In verbis“": "The state of Nature has a law of Nature to govern it, which obliges every one, and reason, which is that law, teaches all mankind who will but consult it, that being all equal and independent, no one ought to harm another in his life, health, liberty or possessions; [...]"

${ }^{253}$ KRABBE, H.. L'idée moderne de l'état. In: Recueil des Cours. Academie de Droit International de la Haye, Volume 13, 1926-III, pp. 509-583. p. 575. "In verbis“: "L'État est donc une conmunauté juridique. Quant au caractère de l'État, caractère ancien, mais qu'on invoque toujours de nouveau : la puissance, et quant á sa déftnition comme manifestation de puissance, nous pouvons continuer les admettre, à cette condition pourtant que l'on reconnaisse que cette puissance se révèle dans le droit et qu'elle ne peut valablement s'exercer qu'en émettant une norme juridique. Mais, en méme temps, il ne faut pas perdre de vue cette idée que c'est la production du droit, soit au moyen de législation, soit à l'aide du droit non écrit, qui est le trait essentiel de l'État." 
paralelos entre o local e o global, o poder disputado pelos indivíduos e monopolizado pelo estado não se identificaria com aquele que é disputado pelos sujeitos de direito internacional e que não se faria possível exercer o mesmo monopólio internacionalmente. Nem mesmo de forma compartilhada.

Ao mesmo tempo em que na esfera sobre-estatal situações de igualdade - ao menos formal - encontrem-se verificáveis na relação entre os atores e permitam, em viés zetético, a identificação de parâmetros da "law of the nature", a aceitação da hipótese do monopólio do poder no estado e seu exercício com base em conceito absoluto de soberania externa conformaria situação análoga à erradicação do monopólio estatal da força no plano interno, ou seja, à institucionalização da barbárie.

Referida concepção se mostra inadmissível por subverter a própria lógica atual do direito. O direito das gentes clássico lançou mão de conceitos como o de soberania e buscou construir uma teoria normativa que harmonizasse essa perspectiva interna de monopólio de poder como em uma comunidade de sujeitos morais iguais. Transportada às relações internacionais, tem-se concepção assemelhada às teorias realistas das relações internacionais, as quais tendem a perceber os estados como bolas de bilhar.

O equívoco conceitual realista - que repercute no direito internacional clássico ou tem nele sua inspiração - não estaria na transposição das estruturas internas do estado à ordem internacional, mas na reprodução da concepção de monopólio do poder pelo estado nas relações internacionais. $\mathrm{O}$ estado monopoliza o poder internamente quando indivíduos são sujeitos de direito. No plano internacional, o poder seria compartilhado e conceitos como o de soberania não devem ser confundidos com o de exclusividade de exercício.

Soberania se refere ao poder supremo sobre uma organização política, mais propriamente sobre o estado. Seu conceito propõe a racionalização jurídica do poder, é dizer, a transformação de uma força fática em direito ${ }^{254}$. A extração do exercício pleno do poder pelo estado do contexto internacional permite que se admita a existência de limitações aderidas ou cogentes pelo mero costume - à atuação desses sujeitos na ordem global.

\footnotetext{
254 BOBBIO, Norberto; MATTEUCCI, Nicola; PASQUINO, Gianfranco. Dicionário de política - Vol. 1. Brasília: Editora Universidade de Brasília, 2010. p. 1179. "In verbis": "Em sentido lato, o conceito políticojurídico de Soberania indica o poder de mando de última instância, numa sociedade política e, conseqüentemente, a diferença entre esta e as demais associações humanas em cuja organização não se encontra este poder supremo, exclusivo e não derivado. Este conceito esta, pois, intimamente ligado ao de poder político : de fato, a Soberania pretende ser a racionalização jurídica do poder, no sentido da transformação da força em poder legítimo, do poder de fato em poder de direito. Obviamente, são diferentes as formas de caracterização da Soberania, de acordo com as diferentes formas de organização do poder que ocorreram na história humana: em todas elas é possível sempre identificar uma autoridade suprema, mesmo que, na prática, esta autoridade se explicite ou venha a ser exercida de modos bastante diferentes.”
} 
Tem-se, aqui, a chave definitiva para a consolidação da idéia - deveras abstrata muitas vezes - de direito como contraponto à política no plano internacional. Mais que isso, o estágio atual - e vivenciado pelo direito das gentes nos últimos 200 anos - reproduz, em grande medida, os conflitos sociais internos que estiveram presentes historicamente na conformação originária do poder nas ordens constitucionais internas dos estados ${ }^{255}$.

A ordem internacional se desenvolve de forma autônoma em relação aos estados, mas política é atividade exercida eminentemente por esses sujeitos de direito das gentes e é ela que forma a base concretiva da ordem jurídica global $^{256}$. Para que se compreenda essa construção teórica, fundamental surge a idéia de nação, de pertencimento a determinado grupo de indivíduos que freqüentemente se confunde com a noção de povo, um dos elementos caracterizadores de um estado.

Tal configuração encontrou tanto no absolutismo quanto nos movimentos democráticos do século XIX importante espaço para florescer. Claro se faz que, a partir do século XIX, o contexto político interno dos estados - que de forma geral reforçou os sentimentos nacionais - repercutiu e pautou essa nova estruturação do direito internacional tão marcadamente moderna ${ }^{257}$.

\footnotetext{
${ }^{255}$ KRABBE, H.. L'idée moderne de l'état. In: Recueil des Cours. Academie de Droit International de la Haye, Volume 13, 1926-III, pp. 509-583. p. 581. "In verbis": "Celle-ci, toutefois, ne pourra exister que le jour où une mesure juridique indépendante des différents États pourra être employée dans la formation du droit. Et, ce sera le cas, lorsque la conscience juridique mondiale sera organisée, comme cela s'est produit maintenant dans les États civilisés; alors, l'idée moderne de l'État aura été réalisée pour la grande communauté humaine, dans le monde civilisé tout entier. Mais, il faudra probablement, comme transition, qu'il y ait d'abord un état de choses semblable à celui qui s'établit au début de l'histoire moderne, où, au-dessus de l'émiettement des communautés juridiques, et au-dessus d'une juridiction irréguliére, une autorité arbitraire sut pénétrer le peuple tout entier de l'idée de pouvoir, après quoi, à l'aide des instruments de puissance dépendant d'elle seule, il fut possible et, pour la communauté internationale, il peut également être possible, d'implanter cette idée de la puissance morale, impersonnelle du droit.“
}

${ }^{256}$ SCHEUNER, Ulrich. L'influence du droit interne sur la formation du droit international. In: Recueil des Cours. Academie de Droit International de la Haye, Volume 68, 1939-II, pp. 95-206. p. 183. "In verbis“": "Il est évident que l'ordre international se développe d'après ses propres lois. C'est la vie politique des Etats qui forme la base réelle de la communauté internationale. Toujours le droit des gens sera en étroite relation avec la situation réelle dans laquelle le système des Etats se trouve.“

${ }^{257}$ SCHEUNER, Ulrich. L'influence du droit interne sur la formation du droit international. In: Recueil des Cours. Academie de Droit International de la Haye, Volume 68, 1939-II, pp. 95-206. pp. 194-195. "In verbis“: "Mais les principes politiques internes exercent une profonde influence sur l'activité extérieure des Etats. Certains principes qui naissent dans un Etat se développent trop tard en idées universelles. Ainsi, il n'existe aucun doute que la monarchie absolue, de même que les tendances démocratiques du xix'e siècle, ont profondément influé sur le droit international. D'une importance capitale a surtout été le principe des nationalités pour l'histoire du xix'e siècle et des temps présents. L'idée nationale s'est développée d'abord dans la politique intérieure des Etats, plus tard elle a joué un rôle décisif dans la politique européenne. Déjà avant la Révolution française, la pensée nationale avait pris naissance. C'est la Révolution de 1789 qui lui a donné son vrai épanouissement. Ce développement s'est accru pendant la première moitié du xix'e siècle, en étroite liaison avec les tendances démocratiques à l'intérieur des Etats. Ce n'est pourtant qu'an moment où l'idée 
O estado, como sujeito do direito das gentes, tem papel garantidor de sua validade como verdadeiro agente da sociedade humana presente em seu território, em relação a qual lhe cabe o dever de proteger ${ }^{258}$. Sujeitos estatais de direito não constituem, contudo, requisito para que se reconheça uma comunidade internacional regulamentada e organizada em grupos e subgrupos $^{259}$.

O estado pode ser concebido como conjunto das vontades individuais dos sujeitos que compõem seu povo, mas essa vontade comunitária não se identifica com aquela de cada pessoa em particular. Desse raciocínio se extrai a possibilidade de o ente moral agir contrariamente às pessoas a ele submetidas e, de forma cada vez mais freqüente na atualidade, de ser responsabilizado por esses atos não apenas no plano interno, mas também no internacional $^{260}$.

Muitas vezes, autores não faziam mera analogia entre o indivíduo e os estados, como sujeito de direito artificialmente personificado, mas observavam no soberano - quando confundido o conjunto povo, território e governo com a propriedade do monarca, mormente a pessoa que atuaria internacionalmente como indivíduo ${ }^{261}$.

nationale a proclamé le droilt des peuples à disposer d'eux-mêmes qu'elle est entrée dans la vie intrernationale."

${ }^{258}$ MOREAU-REIBEL, Jean. Le droit de société interhumaine et le 'jus gentium' : essai sur les origines et le développement des notions jusqu'à Grotius. In: Recueil des Cours. Academie de Droit International de la Haye, Volume 77, 1950-II, pp. 481-597. p. 574. "In verbis“": "L'Etat donne vigueur et validité au droit de nature et devient un organe de droit des gens; il est agent de la société humaine qu'il doit garantir sur son propre territoire.“

${ }^{259}$ MOREAU-REIBEL, Jean. Le droit de société interhumaine et le 'jus gentium' : essai sur les origines et le développement des notions jusqu'à Grotius. In: Recueil des Cours. Academie de Droit International de la Haye, Volume 77, 1950-II, pp. 481-597. p. 589. "In verbis": "La détermination de la communauté internationale, à la fois sous-jacente et enveloppante, est la réglementation ou normalisation de ces rapports, en fonction de l'existence de multiples groupes et sous-groupes, comme aussi bien de sujets individuels de droit, sans que la notion de souveraineté, de l'Etat apparisse nécessaire.“

${ }^{260}$ GUGGENHEIM, Paul. Les principes de droit international public. In: Recueil des Cours. Academie de Droit International de la Haye, Volume 80, 1952-I, pp. 01-189. p. 82. "In verbis“: "La population de l'Etat représente un ensemble d'attitudes humaines d'une variété infinie et on ne peut donc pas concevoir l'Etat comme une volonté générale surindividuetlle, indépendante des individus indirectement autorisés ou obligés. L'Etat agit pour un ensemble de individus qui lui sont attribués. A leur tour, les violations de droit commises par les individus peuvent, dans certaines circonstances, engager la responsabilité de l'Etat et l'exposer, c'est-àdire exposer l'ensemble des individus qui lui sont rattachés aux sanctions prévues par le droit international. Pour faire valoir ses droits et appliquer les sanctions qu'une violation du droit l'autorise à prendre, l'Etat se sert d'organes qu'il désigne lui-même et dont les actes sont imputés à la communauté juridique d'individus dont l'ordre juridique étatique est l'expression. Le problème de l'imputation à une ordre juridique de l'attitude $d$ 'un ensemble d'individus se pose donc exactement de la même manière que pour les personnes morales dans le cadre du droit interne."

${ }^{261}$ GIDEL, Gilbert. Droits et devoirs des nations : la théorie classique des droits fondamentaux des états. In: Recueil des Cours. Academie de Droit International de la Haye, Volume 10, 1925-V, pp. 537-597. p. 554. "In verbis": "D'autres causes poussent encore à assimiler les États aux individus et à admettre que la loi naturelle, 
Apesar de se verificarem exemplos anteriores, a tendência à centralização do poder na ordem política internacional começou a se desenvolver com maior freqüência na segunda metade do século XX, quando do surgimento das organizações internacionais - e de seu reconhecimento como sujeitos de direitos e deveres do sistema geral - e de sistemas sobreestatais de solução de controvérsias, os quais - mesmo não dotados de atribuições que lhes permitam a execução de suas decisões - caminham à centralização da extração da normatividade das regras disponíveis internacionalmente ${ }^{262}$.

Política e direito em alguns momentos não apenas interagem, mas também se confundem. O momento de concreção dos anseios sociais em normas é estritamente político e, assim, a formação do direito seria política ${ }^{263}$. Uma vez estabelecido, o direito se descola por um momento da política e passa a demandar estrita normatividade, isto é, a extração da vontade nele cristalizada ${ }^{264}$. Quando o caso concreto não encontra solução normativa adequada, surge novamente a política na concreção da vontade não mais exercida pelo legislador em função típica, mas pelo aplicador do direito atipicamente.

Política e direito seriam, portanto, interdependentes e reciprocamente indutivos. A observação política do direito demanda atuação legislativa constante para alterá-lo e adaptá-lo

qui régit les rapports des individus, régit aussi les rapports des États. Dans le type de constitution politique qui domine alors, la puissance publique est une véritable propriété du prince, maitre absolu de ses sujets et de son territoire : l'État est patrimonial; il se confond dans les relations internationales avec la personne du souverain. La pratique présente donc des relations entre États qui paraissent n'étre que des relations entre individus: il semble naturel de soumettre ces relations aux mémes règles que celles qui s'appliquent aux individus."

${ }^{262}$ KELSEN, Hans. Théorie du droit international public. In: Recueil des Cours. Academie de Droit International de la Haye, Volume 110, 1953-III, pp. 01-203. pp. 183-184. "In verbis“: "La différence la plus importante entre ces deux ordres juridiques réside dans le fait que le droit international est relativement décentralis, tandis que le droit national est relativement centralisé. Cela apparaît dans les méthodes de création et d'application des normes de ces deux droits. La coutume et les traités, qui sont les principales sources ou méthodes de création du droit international, sont des méthodes décentralisées, tandis que la législation, principale source du droit national, est une méthode centralisée de créer le droit. Le droit national confere à des tribunaux la compétence d'appliquer les normes juridiques et à des organes spéciaux le pouvoir exclusif de faire usage de la force en exécutant des sanctions. En droit international général au contraire il n'y a pas d'organes spéciaux pour 1'application du droit et notamment pas d'organes centraux pour l'exécution des sanctions. Ces fonctions sont taissées aux Etats en leur qualité de sujets du droit international, mais en droit international particulier Ia création et l'application des normes juridiques peuvent être centralisées et elles le sont effectivement dans bien des cas. On constate en outre une tendance à une centralisation progressive par l'établissement d'organes internationaux et notamment de tribunaux internationaux."

263 Trata-se de pescpectiva eminentemente positivista, reconhece-se. Esclarece-se, nesse sentido, que esta permeará todo o trabalho.

264 BARROSO, Luís Roberto. Temas de direito constitucional. Rio: Renovar, 2001. p. 610. "In verbis": "Consoante se desenvolveu no tópico procedente, a definição, a cada tempo, de quais são os valores a serem protegidos e os fins a serem buscados não é uma questão jurídica, mas sim política. Todavia, consumada a decisão pelo órgão próprio, ela se exterioriza, se formaliza pela via do Direito, que irá então conformar a realidade social. Por esse mecanismo, o poder transforma-se de político em jurídico.“ 
às novas realidades. Da mesma forma, o direito estabelece limites à atuação política e auxilia sua projeção do futuro almejado pela coletividade ${ }^{265}$.

A forte relação existente entre a política e o direito possui características orgânicas observáveis, conforme apontado, tanto no momento de criação das normas quanto durante sua aplicação. Nessa seara, surgem percepções de superioridade da política em relação ao direito e dúvidas quanto à legitimidade do exercício político na gênese do direito internacional ${ }^{266}$.

No contexto jurídico atual, ao lado da regulamentação estrita encontram-se os valores da sociedade como parâmetros axiomáticos cogentes. Nesse sentido, enquanto regras descreveriam condutas precisas, princípios se apresentariam como valores ou finalidades. Princípios possuem conteúdo valorativo e expressam comandos políticos ${ }^{267}$.

A centralidade dos direitos humanos na ordem legal interna - direitos fundamentais afastou o direito da normatividade e o aproximou da política, da concretude. Os princípios, com seu conteúdo aberto e seu poder de sobreposição às regras, incrementam a discricionariedade do aplicador do direito que não precisa mais buscar a concretude

\footnotetext{
${ }^{265}$ JELLINEK, Georg. Das Recht des modernen Staates. Berlin: Verlag von O. Häring, 1900. p. 17. "In verbis": "So hält denn der stete Hinblick auf die Realität des politischen Lebens die staatsrechtliche Theorie von Abirrungen frei. Andererseits erzeugt politische Erkenntniss fortwährend die Forderung nach neuem Recht. Solche Forderung setzt aber gründliche Kenntniss des herrschenden Rechtes voraus. Daher hat die Staatsrechtslehre grosse Bedeutung für die Politik, die ihre Aufgaben ohne jene nicht erfüllen kann. Eine Kritik der gegebenen Institute des öftentlichen Rechtes ist eine politische Aufgabe, welche die Staatsrechtslehre, sowohl die allgemeine und specielle als die des Einzelrechtes, zu erfüllen hat. Die Rechtswissenschaft würde den edleren Teil ihres Berufes gänzlich aufgeben, wenn sie nur nach rückwärts gewendet wäre und nicht auch nach vorwärts den Mächten der Zukunft den Weg zu bahnen mithülfe.”
}

${ }^{266}$ GIRAUD, Emile. Le droit international public et la politique. In: Recueil des Cours. Academie de Droit International de la Haye, Volume 110, 1963-III, pp. 419-809. pp. 427-428. "In verbis“: "Les liens qui unissent le droit et la politique sont des liens organiques. Ils se manifestent lors de la création du droit et pendant son application. [...] Le lien originel qui unit le droit à la politique, c'est le lien qui unit la créature à son créateur, à celui qui l'a engendré. Le droit est fils de la politique. Cette parenté est évidente, mais les choses les plus simples sont souvent celles qu'on perd de vue ou qu'on néglige. Qui fait la loi, qui, dans les Etats modernes est la source principale du droit ? C'est un Parlement, un dictateur, c'est-à-dire le pouvoir politique. Les lois les plus plus importantes apparaissent à notre époque comme le résultat d'une revendication politique. On réclame l'établissement du suffrage universel, la scolarité obligatoire pour les enfants, des retraites pour les vieux travailleurs. Le jour où la revendication politique abouti, elle a donné naissance à un un nouveau régime de droit. N'est-ce pas là la preuve de la dépendance du driot par rapport à la politique et la supériorité de la politique sur le droit?“”

${ }^{267}$ BARROSO, Luís Roberto. Temas de direito constitucional - Tomo III. Rio: Renovar, 2005. p. 17. "In verbis": "Quanto ao conteúdo, destacam-se os princípios como normas que identificam valores a serem preservados ou fins a serem alcançados. Trazem em si, normalmente, um conteúdo axiológico ou uma decisão política. Isonomia, moralidade, eficiência são valores. Justiça social, desenvolvimento nacional, redução das desigualdades regionais são fins públicos. Já as regras limitam-se a traçar uma conduta. A questão relativa valores ou a fins públicos não vem explicitada na norma porque já foi decidida pelo legislador, e não transferida ao intérprete. Daí ser possível afirmar-se que regras são descritivas de conduta, ao passo que princípios são valorativos ou finalísticos." 
legislativa - ser normativo - mas apenas o núcleo do bem jurídico que se pretendia originariamente proteger.

A objetividade normativa - moderna, positivista e genuinamente apartada da política não seria verificada hoje na prática exatamente por desatender, sob o prisma legislativo, o pressuposto liberal da concretude, segundo o qual o direito deveria se basear em algo palpável, como um comportamento social, para que subjetivismos políticos e constrangimentos ilegais pudessem ser evitados.

A normatividade conformaria, assim, a concretude legislativa enquanto a concretude propriamente dita se referiria ao aplicador do direito. Ambos os fenômenos possuiriam, contudo, caráter legislativo. A normatividade seria a concretude da vontade do legislador, que criou a lei, e a concretude seria a concreção da vontade do aplicador do direito, quando em seu ato hermenêutico reduziria a vontade legislativa original a um núcleo estéril, descontextualizado e acabaria, por meio de uma nova contextualização, legislando ao aplicar a regra, mas não mais seu ditame e sim seu conteúdo.

A concretude consubstanciaria, em síntese, a transformação da vontade social em comando jurídico. Uma vez estabelecida a normatividade, caberia ao aplicador do direito extrair seu conteúdo. A extração da normatividade constituiria, dessa forma, a atividade jurisdicional típica. Ocorre que, mesmo sem poder exercer normatividade - já que estaria, em tese, adstrito à extração da normatividade - o poder judiciário tem com cada vez mais freqüência exercido a função política da concreção.

A política exerce importante papel não apenas na criação do direito, mas domina hoje sobremaneira também sua aplicação. A forma como determinada norma criada por um processo político legislativo é interpretada depende fundamentalmente do resultado dos embates entre as forças políticas que possuem a atribuição hermenêutica. Essa formula vale tanto para o direito interno quanto para o direito internacional ${ }^{268}$.

\footnotetext{
268 GIRAUD, Emile. Le droit international public et la politique. In: Recueil des Cours. Academie de Droit International de la Haye, Volume 110, 1963-III, pp. 419-809. pp. 428-429. "In verbis“": "Si l'on considère, non plus la création du droit, mais l'application du droit qui a été formulé dans des textes, on constate que cette évolution esto dominée par le jeu des forces politiques. Ce phénomène est particulièrement frappant pour les constitutions aussi bien nationales qu'internationales. Quand un pays se donne une constitution ou quand une conférence diplomatique crée une institution internationale, on ne peut jamais prédire ce qu'il sortira de la constitution qui vient d'être adoptée. Analyser le texte d'une telle constitution en tenant compte des intentions de ses autreurs est un exercice scolaire classique et facile, mais d'un intérêt limité. C'est la pratique, c'est-àdire les forces politiques en jeu, qui donne la vie à la constitution et donne à un régime constitutionnel sa physionomir. Il en est ainsi même si la constitution n'est pas violée ou interprétée incorrectement, une telle irrégularité étant du reste assez fréquente, mais sans qu'elle se produise, il pourra être fait un large usage de cartaines facultés que donne la constitution, tandis que d'autres resteront inemployées.“
} 
Em situação ideal, contudo, o direito interno, uma vez criado, adquiriria plena autonomia da política. Essa autonomia nunca foi admitida plenamente ao direito internacional e se mostra cada vez mais rarefeita no direito estatal local ${ }^{269}$. Ainda que esses fenômenos sejam recorrentemente observados como exemplos da judicialização da política, mais precisa seria a admissão da politização do direito.

Na visão do direito, prevalece na teoria a busca da fixação do justo na consideração da atitude do indivíduo em relação ao ordenamento instituído pelo estado. Uma conduta justa ou injusta, isto é, jurídica ou antijurídica, poderia ser aferida, sob tal perspectiva, a partir do confronto de seu conteúdo com a lei posta. Logicamente, faz-se referência, no exemplo apontado, as regras que regem comportamentos sociais - excluídas, portanto, as de organização do estado ou que estabelecem apenas atribuições na vida das pessoas.

Decorre, de todo esse panorama, que a igualdade jurídica seria garantida pela manutenção do mesmo conteúdo e do mesmo procedimento normativo - inclusive na hipótese de substituição das pessoas que a ela se submetessem enquanto se mantinham as mesmas circunstâncias. Sendo a lei geral, abstrata e impessoal, bastariam o fato e a subsunção à norma para que o direito incidisse sobre todos os indivíduos igualmente.

Toda a construção lógica apontada se vê questionada internamente pelo apontado exercício concretivo atípico pelo poder judiciário. Mas qual seria a proposta para o direito internacional? Haveria uma proposta para o direito internacional? Seria possível a aplicação da transformação dos parâmetros rígidos à concreção e à extração de normatividade em contexto que ainda não os havia incorporado definitivamente?

Concretude e extração de normatividade conformariam, assim, variáveis essenciais às garantias de previsibilidade, segurança jurídica e coercibilidade inerentes à idéia sistêmica do direito que, de forma concentrada e unitarista, promoveriam sua independência da discricionariedade característica da política. A unidade do direito internacional poderia ser atualmente desarticulada, portanto, exatamente a partir da análise da dinâmica dos dois pressupostos positivistas descritos ${ }^{270}$. Dessa forma, apesar de ser absolutamente possível de

\footnotetext{
${ }^{269}$ GIRAUD, Emile. Le droit international public et la politique. In: Recueil des Cours. Academie de Droit International de la Haye, Volume 110, 1963-III, pp. 419-809. p. 437. "In verbis": "Sur la base de ces constatations, on est fondé à dire que le droit interne, après qu'il a été créé, est pleinement autonome par rapport à la politique; au contraire, l'autonomie du droit international, par rapport à la politique, est très restreinte.“

${ }^{270}$ KOSKENNIEMI, Martti. From apology to utopia: the structure of international legal argument. Nova Iorque: Cambridge University Press, 2005. p. 17. "In verbis": "To show that international law exists, with some degree of reality, the modern lawyer needs to show that the law is simultaneously normative and concrete - that it binds a State regardless of that State behaviour, will or interest but that its content can nevertheless be verified by reference to actual State behaviour, will or interest."
} 
forma analógica a identificação da concretude na aproximação da normativa posta às práticas estatais, tais práticas tenderiam hoje ao afastamento da normatividade e ao risco de aproximação da política.

De outro lado, no plano hermenêutico, outro pressuposto positivista não verificável de forma empírica na aplicação do direito internacional seria a extração da normatividade, ou seja, a necessidade de aplicação do direito de forma independente de preferências políticas dos agentes envolvidos. Caso a normatividade fosse plenamente vislumbrável na sistemática do direito internacional, a norma se aplicaria, assim, independentemente da vontade dos sujeitos a ela submetidos e essa vinculação cogente não se verifica de maneira plena, todavia no plano jurídico internacional ${ }^{271}$.

O poder judiciário interno exerce função legislativa atípica e concretiza direitos em caso de lacunas e obscuridades normativas. Dúvidas quanto essa atribuição excepcional já não mais subsistem. No direito das gentes atual, a concreção exercida por sistemas de solução de controvérsias ainda conforma novidade. O uso das concepções de distribuição do poder desenvolvidas pela doutrina da teoria do estado na ordem internacional poderia servir, a esse respeito, para demonstrar a urgência da ampla admissão do exercício concretivo por tribunais internacionais $^{272}$.

Já se afirmou por diversas vezes nesse trabalho que o estudo do direito exige e até mesmo pressupõe a compreensão do poder e das dinâmicas de seu exercício. A própria interação entre direito e política pode ser resumida, por exemplo, como uma relação de poder. Nesse contexto, a política constituiria, na verdade, a forma como o poder seria exercido inclusive quando da formação do direito - e o direito, por outro lado, estabeleceria os parâmetros que regulamentam a atividade política.

\footnotetext{
${ }^{271}$ KOSKENNIEMI, Martti. From apology to utopia: the structure of international legal argument. Nova Iorque: Cambridge University Press, 2005. p. 17. "In verbis": "A law which would lack distance from State behaviour, will or interest would amount to a non-normative apology, a mere sociological description. A law which would base itself on principles which are unrelated to State behaviour, will or interest would seem utopian, incapable of demonstrating its own content in a reliable way."

${ }^{272}$ GIRAUD, Emile. Le droit international public et la politique. In: Recueil des Cours. Academie de Droit International de la Haye, Volume 110, 1963-III, pp. 419-809. p. 426. "In verbis“: "Mais on sait, et cela est très important, que les tribunaux qui ont la mission d'appliquer la loi doivent l'interpréter quand elle est obscure, ambigué ou incomplète ; Ainsi l'interprétation jurisprudentielle est une source de droit aceessoire mais néanmoins importante. Les tribunaux apparaissent un peu comme des émules du pouvoir politique opérant sur un plan inférieur à celui du législateur. Cette fonction créatrice âu droit par le juge, qui a été voulue par le législateur, ne fait pas de difficulté à l'intérieur de l'Etat. Elle en fait, au contraire dans l'ordre international et elle constitue aujourd'hui un des principaux obstacles au développement de la juridiction internationale, comlne nous le verrons plus loin."
} 
Em síntese e em termos estritos e ideais, a formação do direito pela política se daria na forma de concreção, ou seja, da conversão da decisão em norma. Uma vez estabelecida a regra, sua aplicação se reduziria, assim, à mera extração da normatividade nela contida.

Percebe-se, na atualidade, que esse verdadeiro cânon teórico foi abalado pelo exercício cada vez mais freqüente da função concretiva por órgãos investidos de atribuições de mera extração de normatividade. No plano interno, a referida alteração de padrões apresenta hoje grandes desafios às estruturas clássicas de organização de poder.

No plano internacional, diversamente do que ocorre internamente, o exercício, por exemplo, de concreção por órgãos investidos de atribuições de extração de normatividade poderia representar forma interessante de desenvolvimento do direito das gentes. Qualquer tipo de evolução nesse sentido exigiria, contudo, prévio aperfeiçoamento da organização do poder na ordem global e daí a utilidade do instrumental teórico da teoria geral do estado.

\subsection{As Funções do Estado e o Direito Internacional}

$\mathrm{Na}$ esfera interna de um estado, a soberania pode ser descrita como o poder exercido por determinados órgãos que possuem prerrogativas relacionadas à direção, ao controle e à substituição de atividades humanas pelo exercício de certas funções - administrativa, legislativa e jurisdicional ${ }^{273}$. No estudo do poder do estado, pode-se identificar - e diferenciar, na verdade - ao menos duas perspectivas de abordagem: uma, relacionada à concentração do poder no estado e, outra, à separação de suas funções ${ }^{274}$.

\footnotetext{
${ }^{273}$ ROUSSEAU, Charles. L'indépendance de l'Etat dans l'ordre international. In: Recueil des Cours. Academie de Droit International de la Haye, Volume 73, 1948-II, pp. 167-253. p. 181. "In verbis": "Dans tout Etat il existe un pouvoir qui, détenu par certains organes, a pour objet de gouverner la nation en remplissant certaines attributions (direction, contrôle, assistance ou substitution à l'égard des activités humaines) et en exerçant certaines fonctions (fonctions administrative, législative, juridictionnelle), grêce à certaines prérogatives (privilège de l'action préalable, monopole de la contrainte matérielle, etc.). C'est ce pouvoir politique que l'on qualifie fréquemment de puissance publique et que pendant longtemps on a désigné en France du terme de « souveraineté ».“

${ }^{274}$ BOBBIO, Norberto. Estado, governo, sociedade; por uma teoria geral da política. Rio : Paz e Terra, 1987. pp. 99-100. "In verbis“: "Uma ulterior fase do processo de limitação jurídica do poder político é a que se afirma na teoria e na prática da separação dos poderes. Enquanto a disputa entre estamentos e príncipe diz respeito ao processo de centralização do poder do qual nasceram os grandes Estados territoriais modernos, a disputa sobre a divisibilidade ou indivisibilidade do poder diz respeito ao processo paralelo de concentração das típicas funções que são de competência de quem detém o supremo poder em um determinado território, o poder de fazer as leis, de fazê-las cumpridas e de julgar, com base nelas, o que é justo e o que é injusto. Embora os dois processos corram paralelamente, são mantidos bem diferenciados pois o primeiro tem a sua plena realização na divisão do poder legislativo entre rei e parlamento, como ocorre antes de todos os demais na história
} 
No que se refere à sua concentração, o conceito - por muito tempo observado como absoluto - contextualizou-se com a história desdobrando-se, de um lado, na expressão da vontade do povo que compõe o estado e, de outro, na concentração do uso da força - e, portanto, do exercício do poder - no ente estatal com exclusividade ${ }^{275}$. Tudo isso, gize-se, regulamentado em detalhes, ao menos em tese, pelo direito.

O modelo de estado constitucional organizado com base na separação de funções referida amplamente de forma anacrônica como "separação de poderes" - surgiu a partir das revoluções americana e francesa entre a segunda metade do século XVIII e o início do século $\mathrm{XIX}^{276}$. Trata-se de solução doutrinária engenhosa incorporada às estruturas de estado que previne a concentração do poder em um único setor da autoridade pública ${ }^{277}$.

O reconhecimento de três funções típicas como expressões do poder - a legislativa, a executiva e a judiciária - acabou se consolidando, ainda que formas alternativas de organização do poder subsistam na atualidade. A experiência histórica pode sugerir, na verdade, que tais alternativas possuiriam caráter efêmero e que não prosperariam exatamente por não atender às necessidades de organização do poder nos estados ${ }^{278}$.

constitucional inglesa, e o segundo desemboca na separação e na recíproca independência dos três poderes legislativo, executivo, judiciário -, que tem sua plena afirmação na constituição escrita dos Estados Unidos da América."

${ }^{275}$ SPERDUTI, Giuseppe. Le principe de souveraineté et le problème des rapports entre le droit international et le droit interne. In: Recueil des Cours. Academie de Droit International de la Haye, Volume 153, 1976-V, pp. 319-411. p. 378. "In verbis“: "En résumé, les développements de la vie moderne amènent à remplacer l'ancienne notion de souveraineté en tant que potestas legibus soluta par une distinction à faire dans l'emploi de ce terme. II faut, en effet, distinguer entre souveraineté originaire en tant que summa in populo auctoritas et souveraineté ressortissant à l'Etat en tant que superior a populo potestas.“

276 BONAVIDES, Paulo. Teoria geral do estado. São Paulo: Malheiros Editores, 2012. p. 43. "In verbis": "Assim se qualifica por Estado constitucional da separação de Poderes aquele que surgiu imediatamente após as duas grandes revoluções da segunda metade do século XVIII: a Revolução da Independência Americana e a Revolução Francesa.”

277 BONAVIDES, Paulo. Teoria geral do estado. São Paulo: Malheiros Editores, 2012. p. 44. "In verbis": "O princípio da separação de Poderes traçava, por indução, raias ao arbítrio do governante, em ordem a prevenir a concentração de poderes num só ramo da autoridade pública."

${ }^{278}$ JELLINEK, Georg. Das Recht des modernen Staates. Berlin: Verlag von O. Häring, 1900. p. 544. "In verbis": "Wer die Darstellungen der Theorien von den staatlichen Tätigkeiten überblickt, der gewinnt leicht die Meinung, dass abstrakte Untersuchung des Staates zu der richtigen Erkenntniss geführt habe. Schliesslich seien durch fortschreitende Einsicht die wesentlichen staatlichen Funktionen festgestellt worden. Die Literaturgesehichte des Staatsrechts weist eine verwirrende Fülle von Einteilungsversuchen auf. Von bleibender Bedeutung ist aber hauptsächlich nur jener geworden, der Gesetzgebung, Vollziehung (Regierung, Verwaltung) und Rechtsprechung als Hauptrichtungen der Staatsgewalt scheidet, bei aller Verschiedenheit der Auffassungen über Wesen und Art des Zusammenhanges dieser Funktionen in der neuren Literatur. Die anderen, ephemeren Einteilungen scheinen demnach durch fortschreitende Einsicht in das wahre Wesen des Staates, welche der allein zutreffenden Ansicht den Sieg verschaffte, beseitigt worden zu sein.” 
Exemplo atual de variação da divisão de funções do poder estatal pode ser encontrado na constituição venezuelana, a qual prevê cinco ao fazer referência às três tradicionais e também aos "poderes" popular e eleitoral. Observa-se, contudo, que, em qualquer organização política, a independência recíproca entre os órgãos investidos de atribuições relacionadas ao poder constituiria a mais marcante das características ${ }^{279}$.

Os inconvenientes da concentração de atribuições legislativas e executivas em um único ente - e as arbitrariedades que da adoção desse modelo decorreriam - são apontados como exemplo paradigmático da impossibilidade apontada ${ }^{280}$. Nas teorias liberais, a separação de funções do estado exerce - ao lado da representatividade - papel de instrumento limitador das arbitrariedades dos exercentes da função concretiva, é dizer, da atribuição legislativa $^{281}$.

O modelo de funções não constitui, entretanto, a única forma que se apresenta à organização de um estado. A institucionalidade estatal pode se fundar tanto na separação de funções de seu poder, quanto nos direitos fundamentais ou na participação democrática dos

${ }^{279}$ DALLARI JÚNIOR, Hélcio de Abreu. Teoria geral do estado contemporâneo. São Paulo: Rideel, 2008. p. 53. "In verbis": "Excepcionalmente, fugindo da constante preocupação de manter em todo o livro uma abordagem do Estado em abstrato, parece interessante ilustrar a liberdade do povo no estabelecimento dos Poderes do Estado trazendo um caso concreto. Seja citado apenas - sem qualquer observação mais detalhada, uma vez que estaríamos nos desviando demais do tema - o caso da Constituição da Venezuela, que constituiu cinco Poderes do Estado: Poder Legislativo, Poder Executivo, Poder. Judicial, Poder Eleitoral e Poder Cidadão. Retomando a visão do Estado em abstrato, vale a pena verificarmos brevemente o padrão mais comum de três Poderes constituídos - Legislativo, Executivo e judiciário. Na concepção geral, cada um deles deve gozar de independência em relação aos demais, todavia sendo preservada a harmonia de funcionamento conjunto, pois todos igualmente compõem a estrutura elementar de atuação do Estado.”

${ }^{280}$ LOCKE, John. Two treatises of government. London: Guernsey Press, 1986. p. 190. "In verbis“": "The legislative power is that which has a right to direct how the force of the commonwealth shall be employed for preserving the community and the members of it. Because those laws which are constantly to be executed, and whose force is always to continue, may be made in a little time, therefore there is no need that the legislative should be always in being, not having always business to do. And because it may be too great temptation to human frailty, apt to grasp at power, for the same persons who have the power of making laws to have also in their hands the power to execute them, whereby they may exempt themselves from obedience to the laws they make, and suit the law both in its making and execution, to their own private advantage, and thereby come to have a distinct interest from the rest of the community, contrary to the end of the society and government. Therefore in well-ordered commonwealths, where the good of the whole is so considered as it ought, the legislative power is put into the hands of drivers persons who, duly assembled, have by themselves, or jointly with others, a power to make laws, which when they have done, being separated again, they are themselves subject to the laws they have made; which is a new and near tie upon them to take care that they make them for the public good."

${ }^{281}$ BOBBIO, Norberto. O positivismo jurídico: lições de filosofia do direito. São Paulo: Ícone, 1995. p. 39. "In verbis": "Para impedir as arbitrariedades do legislador, O pensamento liberal investigou alguns expedientes constitucionais, dos quais os principais são dois: a) a separação dos poderes, pela qual o poder legislativo não é atribuído ao "príncipe" (isto é, ao poder executivo), mas a um colegiado que age junto a ele, com a conseqüência de que o governo fica subordinado à lei ; b) a representatividade, pela qual o poder legislativo não é mais expressão de uma restrita oligarquia, mas da nação inteira, mediante a técnica da representação política: sendo assim o poder exercido por todo o povo (ainda que não seja diretamente, mas através de seus representantes), é provável que seja também exercitado não arbitrariamente, mas para o bem do próprio povo." 
indivíduos $^{282}$. Esses três modelos não conformariam, entretanto, estruturas excludentes. Eles, na verdade, interagem e se complementam.

A separação das funções do estado serve de orientação à análise das sucessivas etapas de criação de uma ordem jurídica determinada ${ }^{283}$. Quando aplicada à estrutura interna de um estado, bastante claras se mostram as etapas de investidura da atribuição produtiva da norma, sua posterior aplicação e o controle - ressalvados, logicamente, os exercícios atípicos de função. Não se trata de poderes distintos ou de funções que expressam facetas de um poder, mas da organização de uma lógica jurídica que sistematiza as múltiplas etapas da formação da regulamentação por meio do direito ${ }^{284}$.

A substituição do jusnaturalismo pelo constitucionalismo na concepção do estado que monopoliza a força e distribui o poder entre órgãos que exercem funções determinadas e

${ }^{282}$ BONAVIDES, Paulo. Teoria geral do estado. São Paulo: Malheiros Editores, 2012. p. 43. "In verbis": "De sua inauguração até os tempos correntes, o Estado constitucional ostenta três distintas modalidades essenciais, de que a seguir nos ocuparemos. A primeira é o Estado constitucional da separação de Poderes (Estado Liberal), a segunda, O Estado constitucional dos direitos fundamentais (Estado Social), a terceira, O Estado constitucional da Democracia participativa (Estado Democrático-Participativo). Não há propriamente ruptura no tempo tocante ao teor dessas três formas imperantes de organização estatal, senão metamorfose, que é aperfeiçoamento e enriquecimento e acréscimo, ilustrados pela expansão crescente dos direitos fundamentais bem como pela criação de novos direitos."

${ }^{283}$ KELSEN, Hans. Les rapports de système entre le droit interne et le droit international public. In: Recueil des Cours. Academie de Droit International de la Haye, Volume 14, 1926-IV, pp. 227-331. pp. 247-248. "In verbis“: "Par « éléments » de l'État : puissance publique, territoire de l'État, nation, il faut simplement entendre la validité de l'ordre étatique en soi, et sa validité dans l'espace et quant aux personnes. La question de la nature des formations jundiques que donne une organisation territoriale de l'État est un cas particulier du problème gèneral du domaine de validité territoriale de l'ordre ètatique: on se trouve en présence des problèmes de la centralisation et de la décentralisation, point de vue duquel on peut envisager la décentralisation administrative, les circonscriptions décentralísées, les provinces, les fractions d'État, etc. et aussi, en particulier, toutes les unions d'États. - La théorie des trois pouvoirs ou fonctíions de l'État a pour objet les étapes successives de la création de l'ordre juridique. — Les organes de l'État ne peuvent étre conçus que comme des facteurs de la création du droit. Et les formes politiques ne sont que les différentes méthodes de création de l'ordre juridique que l'on qualifie métaphoriquement de « volonté de l'État. »““

${ }^{284}$ KELSEN, Hans. Les rapports de système entre le droit interne et le droit international public. In: Recueil des Cours. Academie de Droit International de la Haye, Volume 14, 1926-IV, pp. 227-331. p. 257. "In verbis“: "Cette ascension qui, de l'acte juridique individuel, conduit à la norme fondamentale, principe de l'unité de l'État et de tous les actes étatiques, permet seule de comprendre la véritable structure de l'ordre étatique, ou de ce qu'on appelle encore la puissance publique. Car cet étagement, cette hiérarchie des normes étatiques, la théorie traditionelle cherche — tèrs inexactement — à l'expliquer par une soi-disant division, un démembrement de la puissance étatique une en trois pouvoirs : le législatif, l'exécutif et le judiciaire. Ces trois pouvoirs corrcspondraient aux trois fonctions fondamentales de l'État : législation, juridiction et administration. En réalité, toute fonction de l'État étant une fonction juridique, toute théorie qui s'y rapporte doit envisager le fonctionnement du droit, son automatisme propre, autrement dit le droit au point de vue dynamique. Les fonctions de l'État sont donc des fonctions de création du droit, et l'ensemble en constitue le procès aux múltiples étapes de la réglementation juridique.“ 
controle mútuo constitui leitura continental francesa das instituições estabelecidas pelo modelo de estado inglês ${ }^{285}$.

$\mathrm{Na}$ esfera internacional, o processo legislativo apresenta uma série de desafios e incongruências e a forma tradicional de formação do direito por meio de tratados ainda predomina na atualidade ${ }^{286}$. Tratados celebrados entre estados, especificamente, seguem constituindo a principal fonte de direito vinculante.

Mais que isso, a organização do poder não se dá de forma tão simples internacionalmente. O modelo clássico, vigente sem grande flexibilidade dos tempos mais remotos até bem pouco tempo, apresenta o poder de maneira totalmente descentralizada na ordem global. Percebe-se não apenas descentralização na produção normativa, mas também na aplicação dos mandamentos produzidos e no controle necessário, todas funções exercidas de maneira dispersa - direta ou indiretamente - pelos sujeitos de direito internacional, mormente pelos estados no exercício de sua soberania externa.

Em síntese, o direito internacional não difere dos outros sistemas jurídicos. Ele apenas tem que se adaptar às peculiaridades da ordem internacional marcada por essa descentralização ${ }^{287}$. A aplicação das teorias constitucionalistas ao direito das gentes, por exemplo, levou a doutrina em algum momento a admitir a existência de uma ordem normativa internacional descolada daquela dos estados particulares que a integram. Mesmo tal

${ }^{285}$ JELLINEK, Georg. Das Recht des modernen Staates. Berlin: Verlag von O. Häring, 1900. p. 55. "In verbis": "Nach dem Falle der Vorherrschaft der naturrechtlichen Schule erlebt das in eine ausgesprochene politische Tendenz auslaufende allgemeine Staatsrecht eine Nachblüte in dem allgemeinen konstitutionellen Staatsrecht. Montesquieu hatte in seinem berühmten „,esprit des lois” ein diesseitiges politisches Ideal in dem Staate gefunden, dessen Zweck die politische Freiheit seiner Bürguer ist und datmit England als das konstitutionelle Musterbild hingestellt. Die englischen Institutionen in der Form, wie sie in Frankreich verstanden und nachgeahmt werden, geben Anlass zu einer Lehre von dem konstitutionellen Musterstaate [...]"

286 EAGLETON, Clyde. International organization and the law of responsibility. In: Recueil des Cours. Academie de Droit International de la Haye, Volume 76, 1950-I, pp. 319-425. p. 328. "In verbis": "While one may regret that the community of nations does not have better legislative procedures than it has - here, doubtless, is the weakest part of the developing system of international law and order - it is nevertheless true that the only way in which new legal obligations can be quickly established is through treaties. In what other way, then, could an entity - even a recognized state - acquire new rights and duties under international law except through a treaty? The treaty is the legally binding instrument through which members of the community confer upon an entity rights and duties which they will respect as legal."

${ }^{287}$ CARRILLO-SALCEDO, Juan-Antonio. Droit international et souveraineté des états : cours général de droit international public. In: Recueil des Cours. Academie de Droit International de la Haye, Volume 257, 1996, pp. 35-221. p. 47. "In verbis“: "Le droit international n'est pas différent des autres ordres juridiques. Simplement, il est marqué par les traits particuliers de la société qu'il a à régir : la société internationale. En effet, les conséquences de la structure décentralisée de cette dernière apparaissent clairement dans les traits qui caractérisent l'élaboration du droit et sa mise en oeuvre dans la société internationale." 
construção lógica não conseguiu libertar, contudo, a normatização internacional da necessidade de serem reconhecidas como tal direta ou indiretamente pelos estados ${ }^{288}$.

Costumava-se adjetivar tratados como constitucionais quanto estes não apresentavam conflito com o direito constitucional interno dos estados que dele eram parte. Mais recentemente - e em linha com o que nesse estudo se propõe, os tratados que criam instituições que refletem em estruturas internacionais comuns aspectos da distribuição do poder em funções no plano interno das ordens jurídicas costumam ser referidos como "constitucionais",289.

A aplicação da divisão do poder proposta pelas teorias de Montesquieu ao direito internacional não apenas não foi prevista pelo autor, como também foi por ele aparentemente rejeitada. Não é possível encontrar no Espírito das Leis expressa referência à sua incompatibilidade, mas Montesquieu percebe que a relação entre os príncipes era distinta daquela que existiria entre os indivíduos no plano interno de um estado. Isso porque a relação entre estados não se daria, para o autor, com base no direito ${ }^{290}$.

A normativa internacional apresenta, de fato, uma série de dificuldades em sua equiparação com o direito interno. Adotada a perspectiva positivista, percebe-se que ela se

\footnotetext{
${ }^{288}$ SALVIOLI, Gabariele. La règle de droit international. In: Recueil des Cours. Academie de Droit International de la Haye, Volume 73, 1948-II, pp. 369-405. p. 374. "In verbis": "A une époque plus proche de nous, et de manière plus exacte au point de vue technique, on a dit : «Les règles internationales sont les règles que la constitution internationale qualifie comme telles", autrement dit, elles sont les règles que groupe la constitution internationale. Mais, étant donné que, de l'avis de ces auteurs, la constitution internationale se rapporte directement ou indirectement aux Etats, c'est revenir encore de façon déguisée à la thèse précédente, selon laquelle les règles internationales sont les règles ainsi qualifiées par les Etats directement ou indirectement ; conception toujours infuencée par la présupposition que tout droit dérive de l'Etat.“
}

${ }^{289}$ OLIVER, Covey T.. Historical development of international law : contemporary problems of treaty law. In: Recueil des Cours. Academie de Droit International de la Haye, Volume 88, 1955-II, pp. 417-508. p. 485. "In verbis": "The term 'constitutional' treaty could refer merely to an international agreement which viewed from the standpoint of internal law does not conflict with a national constitution. The term, however, has come to be used in an entirely different and most significant manner. It is used here to denominate those international arrangements whereby new power structures are created consensually by national states, to which power structures some attributes of sovereignty or of government are granted.“

${ }^{290}$ MONTESQUIEU, Charles de Secondat Baron de. De l'esprit des lois - Vol 2. Paris: Garnier-Flammarion, 1979. p. 198. "In verbis“: "La liberté consiste, principalement, à ne pouvoir être forcé à faire une chose que la loi n'ordonne pas et on n'est dans cet état, que parce qu'on est gouverné par des lois civiles : nous sommes donc libres, parce que nous vivons sous des lois civiles. Il suit de là que les princes, qui ne vivent point entre eux sous des lois civiles, ne sont point libres ils sont gouvemés par la force ; ils peuvent continuellement forcer ou être forcés. De là il suit que les traités qu'ils ont faits par force sont aussi obligatoires que ceux qu'ils auraient faits de bon gré. Quand nous qui vivons sous des lois civiles, sommes contraints à faire quelque contrat que la loi n'exige pas, nous pouvons, à la faveur de la loi, revenir contre la violence : mais un prince, qui est toujours dans cet Etat dans lequel il force ou il est forcé, ne peut pas se plaindre d'un traité qu'on lui a fait faire par violence. C'est comme s'il se plaignait de son état naturel : c'est comme s'il voulait être prince à l'égard des autres princes, et que les autres princes fussent citoyens à son égard, c'est-à-dire, choquer la nature des choses." 
constitui a partir da vontade dos sujeitos de direito internacional - mormente estados. Por outro lado, não se identifica no direito das gentes uma norma fundamental com facilidade e inexiste, em perspectiva global, tanto a separação de poderes, quanto qualquer forma institucionalizada desses "poderes". Subsistem, entretanto, entre o direito internacional e o direito interno afinidades conceituais, principalmente entre aquele - ainda que não dotado de uma constituição - e as teorias constitucionais nacionais ${ }^{291}$.

Mesmo assim, a divisão de funções do estado constitui exemplo conceitual extremamente útil à compreensão da conformação jurídica da política internacional ${ }^{292}$. Nesse sentido, no estudo da função legislativa, pode-se identificar historicamente protagonismo dos estados, mas - por outro lado e também - a recente diversificação de sujeitos envolvidos em processos legítimos de produção normativa ${ }^{293}$.

${ }^{291}$ ROSENNE, Shabtai. The perplexities of modern international law: general course on public international law. In: Recueil des Cours. Academie de Droit International de la Haye, Volume 291, 2001, pp. 09-471. p. 38. "In verbis": "The name usually given to the law that the States create in this way is positive international law. That law has no superior sovereign power, and it is difficult if not impossible to put one's finger on its "basic norm". It has no formalized legislature, no clearly delineated separation of executive, legislative and judicial powers, no regular and hierarchical court system (more in Chapter III), no easy mechanism for correcting or adjusting possibly undesirable consequences of a major judicial decision, no clear system of precedents and no clear distinction between political and judicial precedents, no centralization - in fact none of the attributes and trappings usually associated with law within a State. On the other hand, it does have some intellectual and conceptual affinities with public law in general and with constitutional law in particular (despite the absence of any international constitution), particularly to the extent that constitutional law crises can often only be resolved by the interaction of internal political processes and not by the judiciary.“

${ }^{292}$ Na concepção de MONTESQUIEU, Charles de Secondat Baron de. De l'esprit des lois - Vol 1. Paris: Garnier-Flammarion, 1979. pp. 294-295. "In verbis“: "Il n’y a point encore de liberté, si la puissance de juger n'est pas séparée de la puissance législative et de l'exécutrice. Si elle était jointe à la puissance legislative, le pouvoir sur la vie et la liberté des citroyens serait arbitraire; car le juge serait législateur. Si elle était jointe à la puissance exécutrice, le juge pourrait avoir la force d'un oppresseur. Tout serait perdu, si le même homme, ou le même corps des principaux, ou des nobles, ou du peuple, exerçaient ces trois pouvoirs: celui de faire des lois, celui d'exécuteur les résolutions publiques, et celui de juger les crimes ou les différends dês particuliers." e também nos comentários de DALLARI, Dalmo de Abreu. Elementos de teoria geral do estado. São Paulo: Saraiva, 2011. pp. 214-215. "In verbis“: "Embora seja clássica a expressão separação de poderes, que alguns autores desvirtuaram para divisão de poderes, é ponto pacífico que o poder do Estado é uno e indivisível. É normal e necessário que haja muitos órgãos exercendo o poder soberando do Estado, mas a unidade do poder não se quebra por tal circunstância. Outro aspecto importante a considerar é que existe uma relação muito estreita entre as idéias de poder e de função do Estado, havendo mesmo quem sustente que é totalmente inadequado falar-se numa separação de poderes, quando o que existe de fato é apenas uma distribuição de funções."

${ }^{293}$ ROSENNE, Shabtai. The perplexities of modern international law: general course on public international law. In: Recueil des Cours. Academie de Droit International de la Haye, Volume 291, 2001, pp. 09-471. p. 38. "In verbis": "The expression law of co-ordination means that its own actors have created and apply it between themselves, and are responsible for enforcing it. These actors remain, as before, the independent sovereign States (acting directly or indirectly through intergovernmental organizations for their common purposes). International intergovernmental organizations, as distinct from the States composing them, are not actors in that sense. They do not as such create general international law. The same can be said of individual human beings as such."“ 
No decorrer do século XIX, com a transformação do conceito de soberania da pessoalidade à objetividade, seu caráter absoluto e indivisível foi relativizado por formas de organização do poder, por exemplo, em federações e confederações. Sob a perspectiva interna, a divisão das funções do estado exaure seu caráter supostamente indivisível, e, externamente, a exigida atuação de forma coordenada a outras soberanias, liquida seu caráter absoluto.

Tratados que trasladam a estruturas supranacionais atribuições muito próprias do poder soberano dos estados que dele fazem parte e criam estruturas que de alguma maneira possuem relação hierárquica com os exercentes internos das funções estatais - tal como observado hoje na União Européia - apresentam dilemas típicos da formação de federações e diferem bastante do conteúdo inicialmente conferido aos chamados "tratados constitucionais" 294 .

As associações internacionais, personificadas em organizações, podem ser consideradas verdadeiro embrião de um governo global, de um direito constitucional global $^{295}$. Essas instituições cumprem internacionalmente as funções que os órgãos internos cumprem em um estado, é dizer, podem ser identificadas nas estruturas associativas de direito das gentes o cumprimento de funções legislativa, executiva e judiciária ${ }^{296}$.

Assim, possível se faz perceber que, na estrutura atual da Organização das Nações Unidas, o Conselho de Segurança exerce funções eminentemente executivas, que a

\footnotetext{
${ }^{294}$ OLIVER, Covey T.. Historical development of international law : contemporary problems of treaty law. In: Recueil des Cours. Academie de Droit International de la Haye, Volume 88, 1955-II, pp. 417-508. p. 485. "In verbis": "Theoretically, however, where there are detailed and formal arrangements for the delegation of sovereignty to a new supra-national entity by international agreements, the problem of the 'constitutional treaty' would merge into that of the new constitution of the supra-national organization. The constitutional problems of such new organizations would thus be somewhat more comparable to those of growing federations of states than to those of 'constitutional treaties'. Whether in practice such arrangements differ substantially from constitutional treaties, however, is at this stage doubtful."
}

${ }^{295}$ CLAPHAM, Andrew. Brierly’s law of nations. Oxford: Oxford University Press, 2012. p. 102. "In verbis": "This development began about the middle of the nineteenth century, and it has led to the development of institutions which, while they cannot yet be regarded as giving a 'constitution' to the international society, may not unfairly be described as a beginning of its constitutional law. These institutions operate by organizing cooperation between national governments and not by superseding or dictating to them, and they are, therefore, probably not so much the beginnings of an international government : though the term is often convenient, as a substitute for one.“

${ }^{296}$ CLAPHAM, Andrew. Brierly’s law of nations. Oxford: Oxford University Press, 2012. p. 103. "In verbis": "Institutions perform for international law the functions which governmental institutions perform for national law, that is to say, the legislative, administrative, executive, and judicial functions." 
Assembléia Geral constitui órgão de - limitadas, admite-se - atribuições legislativas e que a Corte Internacional de Justiça como embrião de um órgão judiciário mundial ${ }^{297}$.

Quanto ao exercício jurisdicional, na ausência de atuação legislativa concreta por órgão que cumpre essa função de forma concentrada e sistemática na ordem mundial, estruturas jurisdicionais poderiam, assim, vir a exercer essa faceta de poder de forma atípica, tal qual observado internamente em um estado. Uma vez mais, a separação de funções e sua interação já tão estudada pela teoria geral do estado poderia muito bem auxiliar à racionalização dos desafios que hoje se apresentam à ordem mundial.

Assim sendo, no contexto interno, a doutrina divide o estudo do poder sob o prisma das funções exercidas e - de forma sistemática - a teoria geral do estado historicamente o faz por meio de uma repartição em três: a função executiva, a legislativa e a judiciária. Cumpre ressaltar, novamente sob tal aspecto, que a freqüência do uso da expressão "separação de poderes" não chancela - em razão da percepção una que cabe ao conceito de poder - sua propriedade.

No plano internacional, por outro lado, não se faz possível reproduzir o modelo de separação de funções aplicado aos estados. Isso se dá em razão da falta de centralização do poder, mas nada impede que os paradigmas internos sirvam à compreensão e ao desenvolvimento da institucionalidade da ordem do direito das gentes.

\footnotetext{
${ }^{297}$ DUPUY, Pierre-Marie. L'unité de l'ordre juridique international : cours général de droit international public. In: Recueil des Cours. Academie de Droit International de la Haye, Volume 297, 2002, pp. 09-489. p. 231. "In verbis": "Dans la perspective que l'on a appelée plus haut « macroconstitutionnelle », qui envisage la Charte non plus seulement comme la constitution des Nations Unies mais comme celle de l'ordre juridique de la communauté internationale, la question, déjà pertinemment examinée par plusieurs auteurs, parait devoir se condenser dans une interrogation de caractère autant politique que juridique : celle de savoir si deux des organes principaux de l'Organisation, à savoir le Conseil de sécurité et l'Assemblée générale, peuvent être considérés comme, pour l'un, l'exécutif sinon le gouvernement de la communauté internationale, pour l'autre, son parlement. A cette double interrogation, on en a parfois rajouté une troisième, plus délibérément juridique : celle de savoir si la Cour internationale de Justice doit être considérée comme une sorte de Cour suprême de l'ordre juridique international, question que l'on examinera toutefois plus loin dans ce cours. Sans encore s'engager dans la discussion approfondie de telles propositions, on constatera immédiatement l'extrême relativité des réponses que l'on peut apporter aux problèmes qu'elles posent. Du fait de la nature essentiellement conventionnelle de la Charte, la question de l'autorité relative des dispositions par lesquelles elle constitue ces organes et leur attribue des compétences saute aux yeux.“
} 


\subsection{A Organização do Poder Global e os Sujeitos de Direito Internacional}

A dicotomia entre sujeito e objeto de direito internacional é negada por parte da doutrina internacionalista principalmente quando do estudo do indivíduo como ator na ordem jurídica internacional ${ }^{298}$. Ocorre que a sistematização lógica da organização da ordem mundial exige que se individualizem os entes dotados de atribuições concretivas no espaço global, diferenciando-os daqueles que tão somente se submetem à normativa comum, e esses são geralmente - com as ressalvas feitas anteriormente - referidos como "sujeitos" do direito das gentes.

Outra questão lógica específica relacionada à organização do poder na ordem internacional e às categorias de sujeitos de direitos e deveres que dela participam que deve ser compreendida e superada também de plano refere-se à importância da figura estatal nesse contexto. O fim da atuação dos entes soberanos de forma exclusiva na ordem mundial não exclui o reconhecimento de estados independentes como premissa à própria existência do direito internacional ${ }^{299}$. Não se trata, gize-se, de um sobredimencionamento da importância da figura do estado e tampouco do reconhecimento de algum papel destacado que lhe caiba no sistema jurídico global. Trata-se de um mero pressuposto lógico.

Assim sendo, percebe-se que o direito internacional - entre as "nações" - busca regulamentar a titularidade e o exercício do poder na esfera global. Ainda que os indivíduos hoje cada vez mais encontrem espaço para seu reconhecimento como sujeito de direitos também nesse plano, a forma como o poder se estruturou entre os seres humanos exigiu - em razão, por exemplo, de limitações tecnológicas e das distâncias - evolução organizacional local aperfeiçoada nos últimos 400 anos na figura dos estados.

\footnotetext{
${ }^{298}$ MERON, Theodor. International law in the age of human rights: general course on public international law. In: Recueil des Cours. Academie de Droit International de la Haye, Volume 301, 2003, pp. 09-489. p. 328, "in verbis": "The dichotomy between "subject" and "object" of international law has been altogether rejected by some commentators. Rosalyn Higgins rightly complains that this dichotomy has "constrained" the terms of individuals' participation in international Law"

${ }^{299}$ DJUVARA, Mircea. Le fondement de l'ordre juridique positif en droit international. In: Recueil des Cours. Academie de Droit International de la Haye, Volume 64, 1938-II, pp. 479-625. p. 486. "In verbis": "Le terme « international » s'applique ici aux relations sociales qui s'établissent non à l'intérieur d'un Etat, mais dans le milieu social qui résulte du fait de l'existence de plusieurs Etats. Une règle de droit est donc internationale quand elle régit cette vie sociale internationale. L'existence d'une diversité d'Etats dans le monde, considrés comme des groupes humains organisés ayant l'autorité de décider de leurs propres intérêts, est un fait incontestable. Sans des Etats ainsi conçus, le droit international n'existerait pas.“
} 
O direito das gentes serve, portanto e em síntese apertada, para organizar a convivência entre os sujeitos de direito internacional e esses são, ainda hoje predominantemente, os países. Sob esse aspecto, é de se observar que conceitos como o de soberania e território cumprem papel fundamental à compreensão da dinâmica dessas relações de poder. A soberania estruturaria juridicamente, assim, a força no estado enquanto o território delimitaria seu espaço de atuação ${ }^{300}$.

Especificamente quanto ao poder em abstrato, marco fundamental da conformação atual da ordem jurídica global se deu quando da transferência de seu conceito temporal da igreja aos entes morais. $\mathrm{O}$ fenômeno indicado pode ser posicionado entre as principais causas do fim da percepção unitarista do direito das gentes vigente durante toda a era medieval.

Para que se entenda melhor o papel dos estados no contex to descrito, parte da doutrina estabelece o período final da idade média como marco inaugural do que se reconhece hoje por direito internacional. Resulta que, na verdade, é de se entender haver ocorrido nesse período mera alteração estrutural e não sua gênese. A unidade - que poderia dar lugar à percepção do indivíduo como sujeito do direito das gentes - deu lugar à compartimentação, à percepção de uma comunidade de entes independentes entre $\mathrm{si}^{301}$.

A referida forma de organização do poder local se fundou no monopólio do uso da força pelo governo - elemento que compõe o conceito de estado - e essa característica se refletiu externamente, isto é, em sua atuação exterior, mais especificamente em sua relação com outras expressões organizadas de $\operatorname{poder}^{302}$. A idéia de soberania como poder

\footnotetext{
${ }^{300}$ CASELLA, Paulo Borba. Direito internacional dos espaços. São Paulo: Atlas, 2009. pp. 03-04. "In verbis": "O espaço, simultaneamente, se torna mais fluido, mais permeável, mas este, dada a superlotação do mundo, se estreita e se restringe. E a convivência se toma imperatividade. Aqui se estuda direito internacional e se trata de princípios, normas e procedimentos, para ordenar a convivência internacional. Não somente o uso da força e a imposição unilateral da vontade do mais forte podem ser as chaves, para explicar a gênese e o funcionamento do sistema institucional e normativo internacional. A força, depois de elevar-se ao paroxismo, dá lugar à construção de quadro normativo, sob pena de tornar impossível qualquer convivência. A base territorial é dado indispensável para a delimitação espacial das respectivas esferas de competência e de atuação dos estados. Isto se denomina soberania. De cada um dos estados, bem como nos parâmetros para a interação entre estes. O sistema institucional e normativo internacional, paradoxalmente, se constrói a partir da delimitação da base territorial de cada estado, e da soberania de cada um destes. Como de outras categorias. E assim aí também se constroem os espaços insuscetíveis de apropriação pelos estados - os espaços comuns, ou espaços internacionalmente estipulados."
}

${ }^{301}$ SCHEUNER, Ulrich. L'influence du droit interne sur la formation du droit international. In: Recueil des Cours. Academie de Droit International de la Haye, Volume 68, 1939-II, pp. 95-206. p. 189. "In verbis“: "Ainsi le chemin du développement du droit des gens a conduit de l'unité européenne du Moyen Age à la communauté d'Etats indépendants qui ne sont unis que par leurs intérêts et par le lien du droit international. Longtemps, la science et la pratique reconnaissaient encore un droit naturel superétatique qui obligeait en même temps souverains et sujets et qui réglait la conduite des Etats entre eux.“

302 WEBER, Max. Politik als Beruf. Stuttgart: Reclam, 2008. pp. 06-07. “In verbis“": "Wenn nur soziale Gebilde beständen, denen die Gewaltsamkeit als Mittel unbekannt ware, dann würde der Begriff $>>$ Staat $<<$ 
concentrado, absoluto e ilimitado teve seu auge justamente no período em que o direito das gentes perdeu seus contornos de unidade, na verdade, contribuindo para tal conformação localizada.

Contemporaneamente, a relevância da figura do estado se vê realmente diminuída e assentado está que esses não são os únicos sujeitos de direito internacional. De uma forma ou de outra, contudo, e considerada sua atuação fundamental na ordem global, ao direito internacional caberia a fixação das características determinantes ao reconhecimento de uma agrupação humana como estado ${ }^{303}$.

Nesse sentido, sedimentada se encontra atualmente a regra que estabelece o reconhecimento por pares como premissa fundamental à atribuição da condição estatal a ente atuante na esfera global. Requisitos objetivos - os chamados elementos do estado - são amplamente aceitos como pressupostos, mas sua identificação não bastaria ao reconhecimento e necessário se faria, portanto, que, além disso, os outros sujeitos de direito internacional reconhecidos o identificassem como tal ${ }^{304}$.

De volta à questão do poder, ainda que os estados conformem os principais atores da ordem internacional, a soberania de cada um deles não pode ser concebida hoje como ilimitada sob pena de colocar em risco a própria integridade do direito internacional. A busca do equilíbrio entre os interesses dos sujeitos soberanos e aqueles dos mesmos em conjunto na ordem global constituiria, assim, a principal tarefa do direito das gentes na atualidade ${ }^{305}$.

fortgefallen sein, dann ware eingetreten, was man in diesem besonderen Sinne des Wortes als $>>$ Anarchie $<<$ bezeichnen würde. Gewaltsamkeit ist natürlich nicht etwa das normale oder einzige Mittel des Staates: - davon ist keine Rede -, wohl aber: das ihm spezifische. Gerade heute ist die Beziehung des Staates zur Gewaltsamkeit besonders intim. In der Vergangenheit haben die verschiedensten Verbände - von der Sippe angefangen - physische Gewaltsamkeit als ganz normales Mittel gekannt. Heute dagegen warden wir sagen müssen: Staat ist diejenige menschliche Gemeinschaft, welche innerhalb eines bestimmten Gebietes - dies: das >>Gebiet<<, gehört zum Merkmal - das Monopol legitimer physischer Gewaltsamkeit für sich (mit Erfolg) beanschprucht. Denn das der Gegenwart Spezifische ist: dass man allen anderen Verbänden oder Einzelpersonen das Recht zur physischen Gewaltsamkeitnur so weit zuschreibt, als der Staat sie von ihrer Seite zulässt: es gilt als alleinige Quelle des $>>$ Rechts $<<$ auf Gewaltsamkeit."

${ }^{303}$ KELSEN, Hans. Théorie générale du droit international public : problèmes choisis. In: Recueil des Cours. Academie de Droit International de la Haye, Volume 42, 1932-IV, pp. 117-351. p. 264. "In verbis": "[...] si les Etats sont sujets de droit international, le droit international doit bien déterminer lui-même quand on est en présence d'un Etat au sens du droit des gens.“

${ }^{304}$ KELSEN, Hans. Théorie générale du droit international public : problèmes choisis. In: Recueil des Cours. Academie de Droit International de la Haye, Volume 42, 1932-IV, pp. 117-351. p. 271. "In verbis“: "De la théorie du caractère constitutif de la reconnaissance, constitutive pour l'existence juridique de l'Etat, pour sa personnalité juridique, de cette théorie il résulterait qu'un Etat n'a d'existence juridique que vis-à-vis de ceux qui l'ont reconnu. On ne pourrait alors concevoir une existence juridique pure et simple, c'est-à-dire l'existence en un sens objectif des Etats.“

${ }^{305}$ KLEFFENS, Eelco Nicolaas van. Sovereignty in international law : five lectures. In: Recueil des Cours. Academie de Droit International de la Haye, Volume 82, 1953-I, pp. 01-131. p. 106. "In verbis“: "In any case, 
A concentração dos estudos internacionalistas na figura do estado como sujeito - por muito tempo exclusivo - não significa necessariamente, nesse sentido, que esses seriam os atores naturais per se na ordem mundial. Toda a construção teórica relacionada à subjetividade e à personalidade jurídica possui características extremamente abstratas e consubstanciam produto de uma evolução que, em algum momento, estabeleceu como paradigma que o cumprimento de determinados requisitos estabeleceriam um "tipo ideal" de pessoa moral: o estado moderno ${ }^{306}$.

O paralelo lógico entre o local e o geral - vislumbrado pela doutrina clássica da teoria do estado $^{307}$ - mostra-se atualmente bastante possível. No contexto interno, a força soberana, como conjunto de indivíduos, organiza-se de maneira claramente muito maior que aquela de cada sujeito individualmente ${ }^{308}$. Já internacionalmente, essa máxima poderia ser reproduzida na observação dos estados como atores individuais do cenário e das organizações internacionais como seu conjunto.

the human race can only prosper and progress if a wise balance is struck between the needs of the individual sovereign states and of the international community, and it seems to me to be the task of international law to ascertain and indicate that balance."

${ }^{306}$ ABI-SAAB, Georges. Cours général de droit international public. In: Recueil des Cours. Academie de Droit International de la Haye, Volume 207, 1987-VII, pp. 09-463. p. 80. "In verbis“": "En ce qui concerne les autres «acteurs » éventuels sur la scène internationale, la théorie des «sujets» de droit international n'a longtemps fait que refléter la position privilégiée et dominante de l'Etat, en le consacrant comme sujet principal et presque unique de ce droit, du moins comme «type idéal» (dans le sens weberien du terme) du sujet. De sorte que les quelques autres entités dont elle prend acte ne sont que des «dérivés» ou des «copies imparfaites» de ce modèle, qui sont reconnues comme sujets - partiels ou temporaires dans la plupart des cas - par assimilation à l'Etat. Ces sujets «imparfaits» sont soit un héritage du passé, tels le pape (jusqu'à ce qu'il ait retrouvé un Etat avec le Traité du Latran au XXe siècle) ou l'ordre de Malte (pour un certain temps), soit des étapes intermédiaires ou inférieures sur la courbe de l'évolution vers le «type idéal» de l'Etat indépendant, tels les protectorats ou les territoires sous mandat ou tutelle. Le statut juridique de ces entités, «ajusté» en fonction du degré de leur déviation par rapport au «type idéal», est établi par la reconnaissance générale des Etats portant sur ces catégories comme telles et cristallisée en règles de droit international général.“

${ }^{307}$ MONTESQUIEU, Charles de Secondat Baron de. De l'esprit des lois - Vol 1. Paris: Garnier-Flammarion, 1979. p. 273. "In verbis“: "La force offensive est réglée par le droit des gens, qui est la loi politique des nations considerées dans le rapport qu'elles on tunes avec les autres. [...] La vie des Etats est comme celle des homes. Ceux-ci ont droit de tuer, dans le cas de la defense naturelle; ceux-lá ont droit de faire la guerre pour leur proper conservation."

${ }^{308}$ ROUSSEAU, Jean-jacques. Du contrat social. Paris: Union Générale d'Éditions, 1973. p. 79. "In verbis": "Chaque membre de la communauté se donne à elle au moment qu'elle se forme, tel qu'il se trouve actuellement, lui et toutes ses forces, dont les biens qu'il possède font partie. Ce n'est pas que, par cet acte, la possession change de nature en changeant de mains, et devienne propriété dans celles du souverain; mais comme les forces de la cité sont incomparablement plus grandes que celles d'un particulier, la possession publique est aussi, dans le fait, plus forte et plus irrévocable, sans être plus légitime, au moins pour les étrangers: car l'État, à l'égard de ces membres, est maître de tous leurs biens par le contrat social, qui, dans l'État, sert de base à tous les droits, mais il n'est, à l'égard des autres puissances, que par le droit de premier occupant, qu'il tient des particuliers." 
Ainda que constituam entidades eminentemente abstratas, entes morais reconhecem e submetem-se a princípios que podem ser considerados fundamentais ao seu direito e inerentes ao sistema político por eles criado e que os rege interna e internacionalmente ${ }^{309}$. Nesse panorama, o aperfeiçoamento do direito internacional se faz bastante visível na multiplicação das classes, tipos e formas das normas produzidas. Princípios se consolidaram como jus cogens, sistemas passaram a exigir a compatibilidade de esquemas específicos e regras são hoje produzidas sem a participação direta de estados ${ }^{310}$. Não apenas a função legislativa se desenvolveu na forma e no conteúdo. Também a judiciária passou pelo mesmo processo e contribuiu à mencionada evolução ${ }^{311}$.

Conforme ressaltado, o conceito de sujeito de direito acaba sendo amplamente utilizado pelo direito das gentes por pura necessidade, isto é, para que possam ser reconhecidos os titulares das funções de poder na ordem global ${ }^{312}$. Nesse sentido, exigências históricas - relacionadas às estruturas comuns surgidas - distanciaram o direito internacional do dogma que - tendo no fim século XIX seu auge - reconhecia apenas a um deles a condição

${ }^{309}$ HENKIN, Louis. International law : politics, values and functions : general course on public international law. In: Recueil des Cours. Academie de Droit International de la Haye, Volume 216, 1989-IV, pp. 09-416. p. 24. "In verbis": "In sum, international law - inter-State law - is the law of the international political system of States interacting, having relations. By definition, inter-national law is law between nations, between States. And, by hypothesis, law is made and lives by and in the international political system, and is subject to its political 'laws'. The political system of States is governed by several fundamental principles. Some are axiomatic, implied in the character of a system composed of States as its basic units. Some may not be inherent but have achieved fundamental character."

${ }^{310}$ THIERRY, Hubert. L'évolution du droit international : cours général de droit international public. In: Recueil des Cours. Academie de Droit International de la Haye, Volume 222, 1990-III, pp. 09-186. p. 24. "In verbis": "Las techniques normatives ont été transformés par la diversification des modes de formation du droit, l'évolution du processus coutumier, la part des dispositions conventionnelles et des résolutions des organes internationaux dans cette formation, tandis que des catégories nouvelles de normes ont trouve place dans le droit international : celle du jus cogens et, d'un autre côté, celle de la soft law. La codification du droit intemational, qui a pris son essor sous l'empire de la Charte des Nations Unies, confére a certaines parties de ce droit une plus grande cohésion et une plus grande précision.“

311 THIERRY, Hubert. L'évolution du droit international : cours général de droit international public. In: Recueil des Cours. Academie de Droit International de la Haye, Volume 222, 1990-III, pp. 09-186. p. 24. "In verbis“: "Linstitution de la justice internationale a eté une étape capitale dans l'histoire du droit international et l'acclimatation progressive du règlement judiciaire dans les relations entre Etats est un aspect essentiel du développement des techniques de règlement des différends internationaux. Enfin les techniques qui ont pour objet dassurer lapplication du droit ont été, au cours des récentes années, multipliées, qu'il sagisse, dans des domaines différents, des opérations de maintien de la paix, de la vérification de lexécution de certains traités, des enquêtes, des procédures par lesquelles des organes indépendants sont appelés à se prononcer à la demande d'Etats ou de particuliers sur des violations alléguées des droits de l'homme."

312 QUADRI, R.. Cours général de droit international public. In: Recueil des Cours. Academie de Droit International de la Haye, Volume 113, 1964-III, pp. 237-483. p. 375. "In verbis“": "C'est la science du droit international et seulement elle qui pour des raisons systématiques manifestes a besoin d'utiliser l'idée abstraite de sujet de droit. Et celle idée doit être tirée de l'ordre juridique international dans son ensamble, de sa structure et de son esprit, s'agissant de mettre en relief au point de vue général de cet ordre.“ 
de sujeito de direito ${ }^{313}$. Atualmente, portanto, não apenas estados possuem personalidade internacional. Associações de entes soberanos, em suas diversas formas, podem ter personalidade internacional conferida por seus membros ${ }^{314}$.

A apontada evolução passou pelo reconhecimento da personalidade jurídica da Igreja Católica e pela conferência de capacidade subjetiva distinta daquela das partes a estruturas internacionais conformadas por estados ${ }^{315}$. As organizações internacionais, reconhecidas como sujeitos de direito das gentes, representam, dessa forma, o fim do monopólio subjetivo na ordem internacional e cada vez mais ganham espaço, atuam de forma concretiva, participam da solução de litígios e contribuem à institucionalização da comunidade internacional $^{316}$.

Em perspectiva doutrinária, de uma geração à outra de internacionalistas - separados pela segunda guerra mundial - observou-se contundente alteração de perspectiva com relação aos sujeitos de direito internacional. Do protagonismo estatal quase absoluto, passou-se à admissão de novas estruturas como atores do sistema e as organizações internacionais se

313 QUADRI, R.. Cours général de droit international public. In: Recueil des Cours. Academie de Droit International de la Haye, Volume 113, 1964-III, pp. 237-483. p. 383. "In verbis“: "En matière de sujet du droit international, les idées de la doctrine ont beaucoup changé ces derniers temps. A l'époque positiviste, et surtout à partir des dernières décades du XIXe siècle, on pouvait considérer presque comme un dogme que les seules personnes de droit international étaient les Etats.“

${ }^{314}$ PILOTTI, Massimo. Les unions d'états. In: Recueil des Cours. Academie de Droit International de la Haye, Volume 24, 1928-IV, pp. 441-546. pp. 480-481. "In verbis“: "Jusqu' à présent, toutefois, nous avons toujours parlé d'États membres de la communauté du droit des gens, en ayant en vue le fait normal que les membres sont surtout des États. Or, il nous faut en ce moment observer que, si l'on adopte le principe que la personnalité de droit intemational peut appartenir à des institutions autres que les États proprement dits, ríen ne s'oppose à reconnaître une personnalité à des associations d'États; mais, que, d'un autre côté, même si l'on s'en tient à la théorie que seuls les États ont la personnalité internationale, il ne s'ensuit pas nécesairement que les associations ne puissent pas acquérir cette personnalité.“

315 QUADRI, R.. Cours général de droit international public. In: Recueil des Cours. Academie de Droit International de la Haye, Volume 113, 1964-III, pp. 237-483. p. 384. "In verbis“: "La théorie des sujets du droit international subit des changements importants lorsqu'on commença à parler d'une personnalité internationale de l'Eglise catholique et plus encore lorsque certaines unions internationales furent considérées comme douées d'une capacité juridique internationale autonome."

${ }^{316}$ TRINDADE, Antônio Augusto Cançado. International law for humankind : towards a new jus gentium (I): general course on public international law. In: Recueil des Cours. Academie de Droit International de la Haye, Volume 316, 2005, pp. 09-439. p. 221. "In verbis“: "International organizations, of the most distinct kinds and characteristics, have effectively modified the structure of International Law: they have put an end to the former State monopoly of international legal personality and of privileges and immunities, have expanded treatymaking power, have altered the rules of their own composition, have come to participate in international judicial proceedings, and have considerably widened the means of international co-operation and regional and subregional integration. This phenomenon, which was already noticeable in the sixties and seventies, became more and more conspicuous, and can nowadays be adequately appreciated, in historical perspective, in the ambit of the Law of International Organizations“" 
consolidaram como tais definitivamente ${ }^{317}$. Ressalte-se, contudo, a esse respeito, que a Sociedade das Nações já era em seu momento amplamente reconhecida como sujeito de direito internacional ${ }^{318}$.

$\mathrm{O}$ aparte que se faz em relação à Sociedade das Nações deve ser, na verdade, ampliado, em razão de não se poder considerar a não exclusividade dos estados como atores plenos na esfera internacional novidade absoluta. Não se trata de construção teórica recente e já no fim do século XIX a atuação das organizações internacionais na esfera jurídica mundial era reconhecida ${ }^{319}$.

Quanto ao posicionamento temporal, o arrefecimento do poder soberano dos estados reposicionou a relevância das associações internacionais nos últimos cem anos e as consolidou como fenômeno bastante característico do século XX. O século passado pode ser, de fato, reconhecido pela história do direito das gentes como a era das associações internacionais, mas as primeiras experiências rudimentares do tipo remontam, contudo e conforme mencionado, aos cem anos imediatamente anteriores ${ }^{320}$.

${ }^{317}$ JENKS, C.Wilfred. Co-ordination : a new problem of international organization : a preliminary survey of the law and practice of inter-organizational relationships. In: Recueil des Cours. Academie de Droit International de la Haye, Volume 77, 1950-II, pp. 151-303. p. 157. "In verbis“: "The subjects of the rights and duties arising from the law of nations, wrote Oppenheim a generation ago, <<are states solely and exclusively >>. Although this was a controversial statement even when it was written: no one would then have questioned that international law was concerned primarily with States and other territorial units and their mutual relations, and even those who most stoutly contended that individuals had a recognized status in international law would have admitted that international law was concerned with them primarily as affected by the relations between states. A generation later, States and other territorial units are no longer the only constituent elements of international society. While they remain, and are likely to continue to remain, the basis of the existing international order, and constitute the membership of all the various public international organizations (including those which, like the International Labor Organization, the Bank of International Settlements and the Council of Europe, include non-governmental elements in the membership of certain of their organs), the States Members of the international community have now formed so many types of international organizations that the mutual relations of such organizations have become a significant part of the subject-matter of international law."

318 SIOTTO PINTOR, Manfredi. Les sujets du droit international autres que les états. In: Recueil des Cours. Academie de Droit International de la Haye, Volume 41, 1932-III, pp. 245-361. p. 303. "In verbis": "En conclusion, rien ne saurait, être mieux démontré que le caractère de sujet du droit international de la Société des Nations. Elle est une véritable association organique d'Etats, possédant une individualité propre et des droits propres."

319 DUPUY, René Jean. Le droit des relations entre les organisations internationales. In: Recueil des Cours. Academie de Droit International de la Haye, Volume 100, 1960-II, pp. 457-589. p. 461, “in verbis“: "Le Droit international, jusqu'à une date récente, était presque exclusivement un droit interétatique. Certes, il y avait, en dehors Etats, certains sujets du droit des Gens, comme notamment les Églises, mais leur nombre restraint ne permettait de leur reconneître qu'une portée réduite. Il ne s'agissait que d'exceptions au principe du monopole par l'Etat de la qualité de sujet du droit international. L'avènement à la fin du XIXème siècle, et encore après la première guerre mondiale, des organizations internationales, ne semblait pas devoir affecter profondément cette structure de la société internationale."

${ }^{320}$ CAFLISCH, Lucius. Cent ans de règlement pacifique des différends interétatiques. In: Recueil des Cours. Academie de Droit International de la Haye, Volume 288, 2001, pp. 245-467. p. 442. "In verbis“: "Le XXe 
Aspecto de extrema importância à compreensão da organização do poder internacional diz respeito à inexistência de hierarquia entre organizações internacionais. Mais que isso, impossível se faz estabelecer, na verdade, qualquer tipo de ordem de importância entre esses sujeitos de direito internacional. O maior ou menor número de membros dessas iniciativas ou suas finalidades, por exemplo, não serviriam de parâmetros para balizar classificações quanto à prevalência de uma em relação à outra ${ }^{321}$.

Especificamente quanto às organizações não governamentais, essas não se encontrariam regidas pelo direito público interno dos estados e menos ainda pelo direito internacional público. Tratam-se de associações de caráter civil registradas e regulamentadas como sujeitos de direito privado no país de sua sede e, eventualmente, também naqueles em

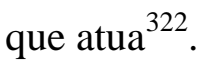

siècle pourrait entrer dans l'histoire du droit des gens comme ayant notamment été celui des organisations intergouvernementales. L'existence de ces entités, affectées soit au maintien de la paix et de la sécurité, soit à la coopération interétatique sur le plan universel, régional ou sous-régional, a indéniablement réduit la décentralisation de l'ordre international, signalée au chapitre I du présent cours 488 , dans les domaines législatif et administratif/exécutif. Elle a aussi provoqué, dès l'apparition de la Société des Nations, une certaine institutionnalisation des mécanismes de RPD." VELASCO, Manuel Diez de. Instituciones de derecho internacional público - Tomo II. Madrid: Editorial Tecnos, 1977. p. 32. "In verbis": "Pese a que las grandes Organizaciones internacionales son posteriores a 1945, daríamos una visión incompleta si no examináramos, aunque sea brevemente. su evolución en el orden del tiempo. Los primeros embriones de Organizaciones internacionales con carácter de permanencia se remontan a los inicios del siglo xix, siendo el primer ejemplo la creación de la Comisión Central del Rhin, creada en 1815 y que continúa en funcionamiento, a la que siguió en 1865 la Comisión para la Navegación del Danubio. No obstante fue la creación de las llamadas Uniones Administrativas - Organizaciones de carácter técnico - las que por su estructura administrativa y carácter de permanencia representan el antecedente más sobresaliente. De entre ellas debemos resaltar la Unión Telegráfica Internacional, creada en 1865, y la Unión Postal Universal, nacida en 1878, hoy transformadas en Organismos especializados de las N.U. La gestión de estas incipientes Organizaciones se confía a las Conferencias periódicas de representantes de los Estados miembros y a las Oficinas, que garantizan la permanencia del funcionamiento administrativo, pero que distan de las prerrogativas y amplitud de funciones de los actuales Secretariados."

${ }^{321}$ MARYAN GREEN, N.A. International law: law of peace. London: Macdonald and Evans, 1982. p. 45. "In verbis": "International organisations differ considerably both in size and in importance. The largest and most important, of course, the United Nations. A table could be drawn up of the size of all international organisations measured by reference to state membership, but there is no necessary correlation between size and importance. In any case, the importance of an international organisation is difficult to assess. The aims and purposes of international organisations, and therefore their activities, are equally various; indeed to such a point that it is probable that the only thing they have in common (besides their common origin in treaties) is their legal status. The same remark, however, might be made about corporations under national law."

${ }^{322}$ ACCIOLY, Hildebrando; NASCIMENTO E SILVA, G.E. do; CASELLA, Paulo Borba. Manual de direito internacional público. São Paulo: Saraiva, 2011. pp. 485-486. "In verbis": "As organizações não governamentais (ONGs), diversamente das organizações internacionais, estas criadas mediante tratado celebrado entre estados, ou - como se pode conceber -igualmente, entre estados e outras organizações internacionais, caracterizam-se por não serem compostas por estados nem regidas em sua constituição pelo direito internacional, mas normalmente o serão pelo direito interno do país, ou países, em que está constituída, registrada e tenha a sua sede legal." 
No início da década de cinqüenta, tanto estados quanto doutrina enfrentavam nítidas dificuldades para lidar com o novo parâmetro representado não apenas pela admissão de novos sujeitos na ordem internacional, mas pelo ritmo avassalador de criação dos mesmos e pelos conflitos gerados, principalmente, por sua atuação no plano estatal interno ${ }^{323}$. De igual maneira, multiplicaram-se as questões de compatibilização de estruturas associativas entre si.

Observa-se, no entanto, que ainda que as preocupações com a compatibilidade entre os arranjos regionais e multilaterais possa parecer algo recente - normalmente datado pela doutrina no período posterior à segunda guerra mundial, a relação entre esses acordos e o direito internacional geral já chamava a atenção de autores no início do século XX como exemplo de descentralização política na ordem internacional, é dizer, sob a perspectiva da organização e da distribuição do poder pelo direito das gentes ${ }^{324}$.

As organizações internacionais, como conceito, não ameaçam a construção doutrinária do direito internacional - ainda em vigor - baseada na soberania estatal ${ }^{325}$. Isso porque a

\footnotetext{
${ }^{323}$ JENKS, C.Wilfred. Co-ordination : a new problem of international organization : a preliminary survey of the law and practice of inter-organizational relationships. In: Recueil des Cours. Academie de Droit International de la Haye, Volume 77, 1950-II, pp. 151-303. pp. 159-160. "In verbis": "A large proportion of these organizations have been created during the last five years and a large proportion of the remainder have been reorganized during the same period. The intrinsic difficulty of the problem has therefore been accentuated by the sudden manner in which it has become acute at the time when most of the organizations concerned have themselves still been in a preliminary organizational phase and governments have been confronted, in the midst of all the other preoccupations arising out of the war and the cold war, with the problems involved in providing for effective national participation in international organizations on an entirely new scale. All of these bodies, with the exception of the subsidiary organs of the United Nations, derive their authority directly from their Member Governments and are directly responsible to their Member Governments for the discharge of the responsibilities to them."
}

${ }^{324}$ DE ORÚE Y ARREGUI, José Ramon. Le régionalisme dans l'organisation internationale. In: Recueil des Cours. Academie de Droit International de la Haye, Volume 53, 1935-III, pp. 01-95. p. 75. "In verbis“: "Le régionalisme international, étant considéré comme type véritable de la décentralisation politique, il nous faut, puisque nous nous préoccupons de ses répercussions sur l'organisation interétatique actuelle, nous arrèter à cette question préable : convient-il de continuer à faire fi de la tendance nouvelle, ou au contraire, avec prévoyance, d'essayer de la réglementer, en la contenaint autant que possible à l'intérieur de la Société des Nations ? Car, «de deux choses l'une, ou la Société ignorera les ententes régionales, et alors elle risque de les voir se former et évoluer dans un sens contraire à sa politique ou se dresser les unes contre les autres, ou elle les connaîtra et les encouragera, elle les surveillera et maintiendra le contact entre les Etats Membres en rétablissant leur collaboration toutes les fois qu'un intérêt général sera en jeu.“

${ }^{325}$ PASTOR RIDRUEJO, José Antonio. Le droit international à la veille du vingt et unième siècle : normes, faits et valeurs : cours général de droit international public. In: Recueil des Cours. Academie de Droit International de la Haye, Volume 274, 1998, pp. 09-308. pp. 194-195. "In verbis“: "Il faut ajouter que, malgré l'importance extraordinaire de ces répercussions, la présence des organisations internationales dans le système international n'a pas impliqué une modification essentielle de sa structure ni, par conséquent, un changement radical de la nature de base du droit international. Fondé celui-ci depuis son apparition au XVIe siècle sur la pierre angulaire des Etats souverains, la notion de souveraineté est toujours, comme nous l'avons déjà fait remarquer (supra, 9.1), une notion clé dans cet ordre juridique. Les Etats sont encore les protagonistes les plus actifs des relations internationales, ainsi que les sujets par excellence du droit international. Cet ordre juridique ne peut être compris qu'en prenant comme point de départ l'idée de la souveraineté étatique. Les organisations internationales sont justement créées par les Etats dans l'exercice de leurs facultés souveraines." 
formação de arranjo do tipo exige, em regra, prévia expressão da vontade de estados diretamente ou, indiretamente, por meio daquela de outro ente internacional - conformado por entidades soberanas - dotado de personalidade jurídica.

A importância das organizações internacionais à evolução do direito das gentes não se reduz a terem atingido o reconhecimento como sujeitos de direito ou à conformação da ordem global como uma trama sistêmica na atualidade. Tais estruturas inauguraram uma nova institucionalidade no direito internacional e contribuíram ao aperfeiçoamento de seu sistema legal.

Diretamente quanto à institucionalidade, percebe-se, por exemplo, na consolidação de sistemas institucionalizados de solução de controvérsias elemento fundamental à formação da vontade comum, da vontade que pode ser expressada pela personalidade jurídica de uma organização atuando de maneira concretiva na ordem internacional.

De se salientar quanto à vontade, além de serem constituídas por tratado, de possuírem como membros mormente estados e de terem personalidade jurídica, importante característica das organizações internacionais tem lugar na autonomia que possuem em relação aos seus membros $^{326}$.

Ainda que existam hoje outros sujeitos de direito internacional que não os estados, esses conservam grande parte do poder decisório na ordem global. Pode-se vislumbrar - antes mais, mas hoje ainda - uma verdadeira aristocracia internacional desses sujeitos, a qual seria responsável pela organização política e jurídica do planeta. Observa-se, entretanto, que a participação da sociedade civil, mais propriamente dos indivíduos, nesse contexto, mostra-se tendência atual que - conjuntamente com a atuação das organizações internacionais - torna o poder estatal cada vez mais rarefeito ${ }^{327}$.

\footnotetext{
${ }^{326}$ CAHIER, Philippe. Changements et continuité du droit international : cours général de droit international public. In: Recueil des Cours. Academie de Droit International de la Haye, Volume 195, 1985-VI, pp. 09-374. pp. 131-132. "In verbis": "Dans le cadre des travaux de la Commission sur le droit des traits, Fitzmaurice avait proposé une défmition de l'organisation internationale. Celle-ci « désigne une association d'Etats constituée par traité, dotée d'une constitution et d'organes communs et possédant une personnalité juridique distincte de celle des Etats membres ». Elle ne fut pas insérée dans la Convention de Vienne, mais les caractéristiques indiquées peuvent etre retenues : 1) les organisations intemationales sont créées par un traité, 2) elles sont constituées d'Etats, 3) elles sont distinctes de leurs membres, 4) elles jouissent de la personnalité juridique internationale.“

${ }^{327}$ TRUYOL Y SERRA, Antonio. Genèse et structure de la société internationale. In: Recueil des Cours. Academie de Droit International de la Haye, Volume 96, 1959-I, pp. 553-642. p. 42. "In verbis“: "Etant donné que les Etats ont acquis le monopole (qu'ils conservent en fait) de la contrainte inconditionnée, ce qui leur a assuré une place privilégiée dans la vie internationate, on a parlé (Schwarzenberger) de la société internationale comme d'une aristocratie internationale des Etats souverains. De cette aristocratie se sont détachées à leur tour les graindes puissances, dont l'action dirigeante peut être comparée, avec l'auteur cité, à une oligarchie internationale. A partir de ce point de vue, on peut considérer comme l'élément démocratique de la société internationale les forces et groupes non étatiques, susceptibles de prendre une part plus ou moins large à la gestion des affaires internationales indépendamment des Etats. Il y a d'ores et déjà des germes d'une
} 
No caso específico das organizações internacionais, o poder do estado se faz presente tanto na criação quanto no direcionamento do direito criado. Nesse sentido, os entes soberanos produzem e são, ao mesmo tempo, destinatários da ordem normativa produzida internamente pela organização internacional ${ }^{328}$. O desenvolvimento tecnológico e a facilitação dos meios de transporte e comunicação trasladou a interdependência da vontade à necessidade na atualidade ${ }^{329}$.

Especificamente no que diz respeito ao poder na esfera global e ao seu exercício quando observada sua relação com as estruturas estatais, verifica-se que as organizações internacionais tendem a concentrar a anuência das soberanias externas na função executiva dos entes envolvidos, afastando-a dos procedimentos legislativos - fundamentais nos regimes democráticos. Essa concentração volitiva no representante executivo já era verificada nas primeiras experiências cooperativas surgidas logo do término da segunda guerra mundial ${ }^{330}$.

Os representantes que compõem uma organização internacional, via de regra os exercentes da função executiva do poder interno, expressam a vontade do país, ao qual

telle intervention dans le rôle plus actif reconnu à l'individu et à certaines associations non gouvernementales par le droit international actuel.“

${ }^{328}$ VIRALLY, Michel. Panorama du droit international contemporain : cours général de droit international public. In: Recueil des Cours. Academie de Droit International de la Haye, Volume 183, 1983-V, pp. 09-382. p. 260. "In verbis": "Les Etats sont également les destinataires du droit interne de l'organisation (et soumis à ce droit), mais seulement de façon très spécifique : soit en qualité de membres d'un organe intergouvernemental (ce sont alors, concrètement, leurs représentants qui doivent s'y soumettre), soit dans leur statut de membres de l'organisation (décisions relatives à la suspension de leurs droits ou à leur exclusion), soit dans leurs obligations statutaires (décisions en matière de contributions). Comme dans tout ordre juridique, des différends peuvent se produire à l'occasion de son fonctionnement. L'objet de contestation le plus fréquent ici est celui de la régularité juridique des décisions prises par les organes : soit leur «constitutionnalité » (c'est-à-dire leur conformité avec l'acte constitutif), soit leur légalité (c'est-à-dire leur conformité avec les règles de forme et de fond dont l'organisation s'est dotée elle-même).“

${ }^{329}$ FLEINER-GERSTER, Thomas. Teoria geral do estado. São Paulo: Martins Fontes, 2006. p. 51. "In verbis": "Esses tipos de desenvolvimentos impressionantes não deixam incólumes o Estado e a sua organização. Não sabemos ainda, no entanto, como e em que direção o Estado evoluirá. Uma coisa porém é certa: da mesma forma que, em épocas precedentes, a autonomia da família alargada retrocedeu em razão da divisão crescente do trabalho e da interdependência das famílias, pode-se constatar atualmente o desaparecimento da autonomia do Estado em favor de poderes internacionais. O fato de que um golpe de Estado em um país produtor de petróleo pode paralisar a economia de muitos países industrializados evidencia esta interdependência internacional. Além disso, o abastecimento de matérias-primas, os problemas do meio ambiente, em especial a proteção dos oceanos e mares ou a proteção de outras águas internacionais, mas também a proteção da camada de ozônio e a proteção contra as modificações climáticas pelo hidrocarboneto, obrigam necessariamente os Estados à cooperação no plano internacional."

${ }^{330}$ ROBERTSON, Arthur Henry. Legal problems of European integration. In: Recueil des Cours. Academie de Droit International de la Haye, Volume 91, 1957-I, pp. 105-211. p. 204. "In verbis“: "The extensive creation of international organizations made parliamentary control over international affairs even more tenuous. There grew up many organs each of which had something of the character of an international executive, but they were responsible only to the national executives and not to the national parliaments or to any form of international legislature. In other words, they escaped from the ordinary process of democratic control." 
pertencem. A chave do desenvolvimento desses arranjos comuns como sujeitos de direito das gentes hábeis a atuar na ordem global em determinadas circunstâncias em pé de igualdade com os estados está no aperfeiçoamento da vontade comum, é dizer, da vontade do ente internacional $^{331}$.

$\mathrm{Na}$ esfera interna das associações, por outro lado, observa-se que a desvinculação da nacionalidade dos indivíduos que exercem atribuições de poder da vontade comum que expressam ou ajudam a conformar cumpre importante papel no reconhecimento da autonomia volitiva que aqui se refere ${ }^{332}$.

O reconhecimento da pessoa como ator na ordem internacional não constitui tampouco novidade doutrinária. Além dos estados e das organizações internacionais, autores já vislumbravam no início do século XX a possibilidade de se reconhecer o indivíduo como sujeito de direitos e deveres no contexto jurídico internacional ${ }^{333}$.

${ }^{331}$ CONFORTI, Benedetto. Cours général de droit international public. In: Recueil des Cours. Academie de Droit International de la Haye, Volume 212, 1988-V, pp. 09-210. pp. 120-121. "In verbis“: "La plupart des organes internationaux, er parmi ceux-ci les plus importants, sont formés d'Etats. Cela veut dire que les personnes qui composent l'organe représentent leur propre Etat, en manifestent la volonté, sont tenues d'en suivre les instructions, D'habitude elles représentent le pouvoir exécutif, duquel elles manifestent la volonté et suivent les instructions, étant donné que, à l'intérieur de chaque Etat, la conduite des affaires étrangères est normalement confiée au pouvoir exécutif. L'organe composé d'Etats reflète la conception classique du droit international, comme droit «exteme» par rapport à la communauté étatique, comme droit «pour diplomates». C'est le moins adapté pour faire progresser le phénomène de l'organisation, pour détacher celui-ci du particularisme étatique, pour en faire un phénomne au service d'intérêts communs aux peuples composant les différentes communautés étatiques au lieu des gouvernements.“

${ }^{332}$ CONFORTI, Benedetto. Cours général de droit international public. In: Recueil des Cours. Academie de Droit International de la Haye, Volume 212, 1988-V, pp. 09-210. p. 121. "In verbis“: "Une alternative à l'organe composé d'Etats est constituée par l'organe composé d'individus: la personne ou les personnes qui forment l'organe exercent leurs fonctions à titre purement individuel, sans manifester la volonté d'aucun Etat et sans recevoir, ou mieux, avec l'obligation de ne recevoir d'instructions d'aucun gouvemement. Il est évident que l'organe ainsi formé jouit par définition d'indépendance par rapport aux pays membres de l'organisation à laquelle il appartient, et il devrait agir exclusivement dans l'intérêt de cette dernière. Des organes composés d'individus existent dans toutes les organisations, mais ils remplissent exclusivement des fonctions exécutives (le Secrétaire général des Nations Unies, les secrétaires ou les directeurs généraux existant dans toute institution spécialisée des Nations Unies, etc.) ou juridictionnelles (la Cour internationale de Justice, la Cour des Communautés européennes, etc.). Il existe un seul cas d'organe composé d'individus qui n'exerce pas de fonctions exécutives ou juridictionnelles mais qui a de larges pouvoirs normatifs et qui est même l'organe principal au sein de son organisation : C'est la Commission des Communautés européennes, lorsqu'elle agit en tant qu'organe de la Communauté européenne du charbon et de l'acier, en exerçant les pouvoirs déjà exercés par la Haute Autorité de la CECA.“

${ }^{333}$ SIOTTO PINTOR, Manfredi. Les sujets du droit international autres que les états. In: Recueil des Cours. Academie de Droit International de la Haye, Volume 41, 1932-III, pp. 245-361. p. 292. "In verbis“: "Il me semble toutefois qu'on peut utilement suivre, tout en renonçaut, à la claissification, un certain ordre, en passant successivement des entités plus complexes aux plus simples. De ce point de vue, je crois pouvoir fixer la succession suivante : a) la communauté internationale ; b) la Société des Nations ; C) les Unions organiques d'Etats ; d) 1'Empire britannique et les entités qui le composent ; e) l'Eglise catholique ; f) les insurgés reconnus comme belligérants et les Gouvernements de fait ; g) les tribus sauvages et les groupements nationaux ( y compris les populations sous mandat) ; h) les organisations internationales ; i) les individus." 
Assim sendo e em síntese, observa-se que, ao lado dos entes soberanos, três figuras surgiram, consolidaram-se ou passaram a ser consideradas como atores na ordem internacional nos últimos cem anos: as organizações internacionais de direito público, as estruturas organizativas não governamentais e os indivíduos ${ }^{334}$.

Costuma-se afirmar - sem muito discutir - que apenas estados e organizações internacionais constituiriam entes atualmente aceitos na ordem internacional como sujeitos. Noutros momentos, admite-se aventar a hipótese de se reconhecer capacidade internacional também aos indivíduos. Das dúvidas conceituais que se apresentam a esse respeito, extrai-se a impossibilidade de se estabelecer uma classificação definitiva ou fixa ${ }^{335}$.

Nesse sentido, não raramente estruturas que não cumprem, por exemplo, os requisitos para o reconhecimento como estado - não possuindo território, povo e/ou governo - ou como organização internacional - personalidade e sistema de solução de litígios hábil à manutenção da coerência - atuam internacionalmente com capacidade concretiva. Exemplos claros seriam a admissão de uniões aduaneiras como membros da Organização Mundial do Comércio ou as relações diplomáticas estabelecidas com grupos rebeldes em contexto de guerra civil.

Ainda no que se refere aos seres humanos, os primeiros movimentos doutrinários que posicionavam o indivíduo no direito das gentes negavam - de forma ainda não superada atualmente - sua condição de sujeito, mas lhe reconheciam direitos na esfera global. Direitos, gize-se, mormente exigíveis de outros sujeitos de direito internacional e relacionados à

\footnotetext{
${ }^{334}$ CAFLISCH, Lucius. Cent ans de règlement pacifique des différends interétatiques. In: Recueil des Cours. Academie de Droit International de la Haye, Volume 288, 2001, pp. 245-467. pp. 449-450. "In verbis": "Le siècle qui vient de se terminer a vu l'apparition de trois catégories de nouveaux acteurs sur la scène internationale : les organisations intergouvernementales modernes, en particulier celles favorisant l'intégration économique et politique régionale ou sous-régionale; les individus; et les organisations non gouvernementales (ONG). Pour ce qui est des organisations intergouvernementales, elles ne sont pas intégrées dans le système de la CIJ, si ce n'est par le biais de la procédure consultative, celle-ci pouvant du reste aboutir à des arrêts contraignants en vertu de dispositions conventionnelles. Nombreux sont, cependant, les instruments récents en matière de RPD qui incluent ces entités, en particulier les organisations supranationales comme l'Union européenne, dans la liste de leurs « clients »; on citera, à titre d'exemple, l'article 7 de l'annexe IX à la Convention de 1982 sur le droit de la mer. “”
}

335 BARILE, Giuseppe. La structure de l'ordre juridique international : règles générales et règles conventionnelles. In: Recueil des Cours. Academie de Droit International de la Haye, Volume 161, 1978-III, pp. 09-126. p. 32. "In verbis": "C'est ainsi que certaines fois le droit international tient compte, à cet effet, d'une manière prépondérante de l'élément « organisation », par rapport à la population d'un territoire déterminé (c'est te cas, par exemple, des mouvements de libération nationale qui conservent leur identité quand ils s'emparent d'une façon stable du gouvernement d'un Etat). D'autres fois, par contre, la population et le territoire servent à affirmer d'eux-mêmes l'identité étatique, quels que soient les changements révolutionnaires intervenus dans la structure gouvernementale. Nous pouvons donc déduire de ces exemples que le droit international, lorsqu'il définit une entité déterminée, prend en considération divers éléments (gouvernement, population, territoire) en combinaisons différentes, guidé spécialement par l'exigence de préserver de la manière la plus ample possible l'identité internationale du sujet en question.“ 
proteção das pessoas ${ }^{336}$. Nesse sentido, fatores históricos e normativas produzidas na ordem global após a segunda guerra mundial, tais como o julgamento de Nürnberg, a Declaração Universal dos Direito Humanos e a Convenção do Genocídio - coincidem como marcos importantes no reconhecimento - ainda em processo - do ser humano como sujeito de direito internacional $^{337}$.

Seres humanos não possuem, portanto, capacidade internacional concretiva, isto é, não formulam normas de direito internacional, mas sempre sofreram impacto direto da normatividade que se extrai, por exemplo, de tratados de direito internacional privado ${ }^{338}$. Mais que isso, em análise mais profunda é de se perceber que os estados, ainda que dotados de capacidade concretiva não são, em regra, os destinatários das mesmas e que o ser humano constitui o verdadeiro objeto da normatividade que se extrai da ordem internacional ${ }^{339}$.

Além disso, mesmo que não possam ser considerados plenamente sujeitos de direito internacional, cada vez mais os particulares têm seu acesso aos sistemas jurisdicionais internacionais ampliado - em regra, contudo, ainda de forma subsidiária ${ }^{340}$.

\footnotetext{
${ }^{336}$ FITZMAURICE, Gerald. The general principles of international law considered from the standpoint of the rule of law. In: Recueil des Cours. Academie de Droit International de la Haye, Volume 92, 1957-II, pp. 01227. p. 11. "In verbis": "According to a more traditional view, the individual is, at the most, only indirectly the subject of international rights and duties, and he comes into international law largely because the latter confers certain rights, and imposes certain duties and responsibilities on States, in respect of the individual. In the result, he may find himself the beneficiary of certain advantages, and the subject of certain liabilities, but it goes no further than that."
}

${ }^{337}$ MCDOUGAL, Myres S.. International law, power, and policy: a contemporary conception. In: Recueil des Cours. Academie de Droit International de la Haye, Volume 82, 1953-I, pp. 133-259. p. 237. "In verbis“" "With respect to the impacts of international governmental organizations upon the individual human being, we may note the Universal Declaration of Human Rights, the Genocide Convention, the Nuremberg Verdict, and the increasing access being offered and proposed for individuals to the arenas of international organizations."

338 SPIROPOULOS, J.. L'individu et le droit international. In: Recueil des Cours. Academie de Droit International de la Haye, Volume 30, 1929-V, pp. 191-270. p. 204. "In verbis“": "Ces normes internationales lato sensu constituent de l'avis du savant viennois un droit administratif international, un droit pénal international et un droit privé international élaborés par les organes d'union internationale avec effet vis-à-vis des individus. [...] En principe les índividus ne sont pas des sujets de droit international stricto sensu; ils ne le sont qu'exceptionnellement. Par contre les índividus sont en principe sujets du droit international lato sensu. "

339 SPIROPOULOS, J.. L'individu et le droit international. In: Recueil des Cours. Academie de Droit International de la Haye, Volume 30, 1929-V, pp. 191-270. p. 209. "In verbis“: "Celles-ci, malgré leurs divergences sur certains points, s'accordent à reconnaître en principe aux États la qualité de personnes de droit international. Celle-là, par contre, ne voit que dans les seuls individus des sujets du droit des gens. Ainsi que nous le verrons plus tard, elle aboutit à ce résultat en faisant abstraction du concept «État» et en ne cherchant comme «destinataire » de la norme internationale que l'étre vivant, seul capable en effet de déférer aux prescriptions et prohibitions d'une règle de droit à savoir : l'homme.“

340 PODESTÁ COSTA, L.A. Derecho internacional público - tomo I. Buenos Aires, Tipográfica Editora Argentina, 1955. p. 61. "In verbis": "En conclusión, la persona privada no es en la actualidad sujeto del derecho internacional, pero es objeto de creciente interés internacional con el propósito de asegurar sus derechos por todos los medios legales, empleando la vía interna hasta agotarla y eventualmente recurriendo en subsidio a la vía internacional." 
Assim sendo, estados - por excelência, organizações internacionais - definitivamente e indivíduos - progressivamente - conformam as três espécies de sujeitos de direito internacional admitidas pela doutrina. O último desses três grupos, além de não ser reconhecido amplamente, está inserido naquilo que se poderia chamar de sociedade civil internacional, composta por organizações não governamentais, sociedades transnacionais e outros grupos associativos de caráter não estatal ${ }^{341}$.

Em síntese conclusiva, observa-se que a descentralização do poder na ordem internacional conforma sua maior característica. Além de, por um lado, não se poder reproduzir a estrita separação de funções que se percebe no direito interno, impossível se faz estabelecer com extrema precisão quem são os atores da ordem internacional. É de se perceber, nesse sentido, que nem mesmo a caracterização desses agentes como "sujeitos", em clara analogia com os indivíduos no direito interno, mostra-se possível.

Estados são os tradicionais e ainda mais importantes entes da esfera internacional. Seu papel na ordem global segue na atualidade fundamental e de importância central na produção e na aplicação do direito das gentes.

A evolução do direito internacional promoveu, ainda, o reconhecimento de outros atores como exercentes de poder. As organizações internacionais, por exemplo, já se encontram atualmente consolidadas como tal e os indivíduos conquistam paulatinamente espaço de atuação. No que se refere aos seres humanos, impossível se faz, contudo, percebêlos como dotados de poder concretivo.

Além de estados e organizações internacionais, organizações não governamentais, uniões aduaneiras e outras estruturas e grupos de indivíduos também atuam de forma limitada na ordem geral, ainda que não seja possível reconhecer aos mesmos tampouco plenas atribuições de exercício de funções de poder.

\footnotetext{
${ }^{341}$ ACCIOLY, Hildebrando; NASCIMENTO E SILVA, G.E. do; CASELLA, Paulo Borba. Manual de direito internacional público. São Paulo: Saraiva, 2011. p.249. "In verbis": "No direito internacional clássico, o sujeito por excelência do direito internacional, embora não mais se possa sustentar ser o único, era o estado, tal como se definia a partir de seu ordenamento interno. São também sujeitos de direito internacional as organizações internacionais enquanto associações de estados, ao lado do reconhecimento progressivo da condição internacional do ser humano. Participam das relações internacionais e atuam no contexto internacional, além dos estados e das organizações intergovernamentais, também as organizações não governamentais, as sociedades transnacionais, os rebeldes, os beligerantes, os povos, os movimentos de liberação nacional e mesmo os seres humanos, estejam de um modo ou de outro organizados, como expressão do que se vem chamar de sociedade civil internacional."
} 


\subsection{Direito e Função Jurisdicional}

A reprodução no direito internacional do sistema interno da formação das regras de direito, as quais se construiriam a partir da vontade soberana - hoje nos países democráticos entendida como expressão da vontade da maioria do conjunto da população - transfere ao ente moral a condição particular e o acordo com seus pares se consolida como verdadeira expressão de sua própria vontade ${ }^{342}$.

A existência de lacunas sempre representou desafio aos sistemas de direito. No plano local, consolidou-se na doutrina e na prática dos tribunais o mandamento que insta o magistrado a completar eventuais omissões legislativas, isto é, a ultrapassar os limites da extração da normatividade e exercer a concretude no caso concreto. Internacionalmente, contudo, rege ainda a possibilidade de os responsáveis pela resolução de litígios negarem a apresentação de solução por não ter havido expressão de vontade soberana - direta ou indireta - que a orientasse ${ }^{343}$.

O fator político e o uso estratégico de uma controvérsia constitui, ainda, outro desafio para os sistemas jurisdicionais internacionais, os quais, em regra, tendem a não marcar posição quando fatores alheios ao direito construído permeiam o diferendo ${ }^{344}$.

\footnotetext{
342 VERDROSS, Alfred. Le fondement du droit international. In: Recueil des Cours. Academie de Droit International de la Haye, Volume 16, 1927-I, pp. 247-323. pp. 275-276. "In verbis“: "Le droit de paix, dit-il, est donc basé sur une volonté collective des États. Cette théorie a été reprise à la fin du siècle dernier, notamment par le renommé professeur allemand Triepel. Il partage avec Hegel et Spinoza le point de départ philosophique : la volonté comme base du droit. «Une règle de droit — écrit Triepel — est le contenu d'une volonté supérieure aux volontés individuelles.... La formation de la règle juridique est aussi une déclaration de volonté, déclaration d'après laquelle quelque chose doit devenir un droit.... Dans le droit interne, la source de droit est en premier lieu la volonté de l'État lui-même. De même dans la sphêre des relations entre États, la source de droit ne peut être qu'une volonté émanant d'États. Mais il est évident que cette volonté, qui doit être obligatoire pour une pluralité d'États, ne peut pas apparteniràun seul État.... Mais si la volonté d'aucun État particulier ne peut créer un droit international on ne peut s'imaginer qu'une seule chose : c'est qu'une volonté commune, née de l'union de ces volontés particulières, se trouve capable de remplir cette tâche.... Nous regardons comme le moyen de constituer une telle unité de volonté la « Vereinbarung, » terme dont on se sert dans la doctrine allemande pour désigner les véri-tables unions de volontés et les distinguer de contrats qui sont des accords de plusieurs personnes pour des déclarations de volontés d'un contenu opposé."
}

${ }^{343}$ VISSCHER, Charles de. Cours général de principes de droit international public. In: Recueil des Cours. Academie de Droit International de la Haye, Volume 86, 1954-II, pp. 445-556. p. 524. "In verbis": "Sans doute se trouve-t-il des théoriciens qui, au nom de la doctrine dite de la "plénitude du droit », persistent à dire que, même dans ce cas, il existe toujours une solution judiciaire, tout système de droit étant nécessairement complet, exclusif de toute lacune. Raisonner ainsi, c'est le plus souvent se payer de mots et se mettre un bandeau sur les yeux. Il est assurément toujours possible au juge de rejeter une demande qui, même justifiée par les intérêts les plus pressants, est sans fondement suffisant au regard du droit international positif."

${ }^{344}$ VISSCHER, Charles de. Cours général de principes de droit international public. In: Recueil des Cours. Academie de Droit International de la Haye, Volume 86, 1954-II, pp. 445-556. p. 532. "In verbis“: "Un autre facteur contribue à raréfier aujound'hui le recours à la juridiction internationale. Il procède d'ailleurs du même 
O direito sempre enfrentou - nas construções positivistas modernas - questões relacionadas à moral sob a perspectiva da contradição. Com o passar dos anos, o exercício político concretivo dos sistemas jurisdicionais viu-se viabilizado pelo desenvolvimento de teorias morais fundadas na proteção do ser humano. O reconhecimento de um princípio como cogente pode muito bem refletir escolha política justificada por argumentos principiológicos e, portanto, pretensamente jurídicos.

No plano interno, percebe-se cada vez mais que as cortes constitucionais assumem características políticas e trabalham sobre parâmetros de concretude para estabelecer premissas normativas, no caso brasileiro, muitas vezes vinculantes para os tribunais inferiores. O reconhecimento do papel da moral no direito, muitas vezes, serviria apenas para escamotear escolhas políticas e a novidade que se faz necessária se refere à assunção do caráter concretivo dos sistemas jurisdicionais, ou seja, o fim da hipocrisia teórica valorativa.

Em grande engano incorreriam, desse modo, aqueles que reconhecem nos princípios absoluta normatividade. Trata-se de linha de pensamento a ser combatida ou, ao menos, questionada pelos juristas. $O$ tratamento da hermenêutica promovida por cortes constitucionais como reveladora e não como construtora de direito imagina a interpretação constitucional como exercício de exegese doutrinária e não como escolha política. Aplicam-se padrões normativos quase jusnaturalistas e aduz-se existir, no momento da escolha política, uma única resposta correta, como se uma única verdade estivesse disponível ${ }^{345}$.

Esse resgate de um direito natural nada mais conforma que possibilidade de transferência da decisão política do constituinte para a sentença. Em termos claros, não haveria muito que se falar em técnica, em princípios quase jusnaturalistas ou em revelação de direito, mas tão simplesmente de escolhas políticas baseadas em argumentação lógica e hierarquia decisória.

Nesse contexto, a judicialização consubstanciaria a transferência da decisão política para o judiciário revestida de revelação do direito. No direito constitucional, as cláusulas pétreas implícitas apresentam-se como exemplos da última ratio dessa vitória da política

état d'esprit que le précédent: c'est l'exploitation politique de certains difterends devant les Nations Unies. Certains recours au Conseil de Sécurité ont moins pour objet d'y obtenir le règlement pacifique d'un différend que de produire un effet de propagande. Dans un tel climat le rôle de la justice internationale reste forcément limité.“

345 Tal concepção é bastante marcante na obre de DWORKIN, Ronald. Taking rights seriously. Cambridge: Harvard University Press, 1977. pp. 279-290. É de se salientar, entretanto, que segundo suas idéias a única resposta correta deve ser concebida no caso concreto, ou seja, considerando-se as especificidades temporais e espaciais, nas quais a lide se insere. A única resposta correta não existiria, assim, de forma abstrata e préconcebida, mas apenas quando devidamente contextualizada. 
sobre as teorias de poder que reconhecem a estrita separação de suas funções como necessária ao correto funcionamento da ordem social.

O discurso jurídico passou, de forma bastante clara, a fundamentar a decisão política típica exercida pelos órgãos dotados de função concretiva apenas atípica na lógica da melhor revelação do direito, afastando-se, portanto, da estruturação democrática da decisão por maioria. A aventada anacronia estrutural se dá, muitas vezes, de forma quase metajurídica, isto é, por meio do uso de discursos abertos como o dos direitos fundamentais, ou seja, pelo idioma dos direitos humanos.

Padrões legais claros, que estabeleçam parâmetros de segurança e previsibilidade, não podem, contudo, ser abandonados pelo direito nesse contexto de exercício concretivo atípico por órgãos extratores de normatividade. $\mathrm{Na}$ esfera internacional, inclusive, a adoção do legalismo como política de estado de vinculação de seus pares ao acordo preestabelecido não dependeria, por exemplo, do tamanho dos países ou de sua condição econômica ou social, mas das questões em jogo nas relações internacionais no momento em que estes se engajam em parcerias ou mecanismos de cooperação ${ }^{346}$.

A validade desses acordos pouco flexíveis poderia se apresentar como desafio, mas tal questão encontra, contudo, soluções doutrinárias milenares. Os romanos, por exemplo, fundamentavam na antiguidade o reconhecimento de tratados em seu direito interno em uma espécie de dualismo. Cada ordem jurídica buscava o fundamento de validade do acordo estabelecido externamente nas normas internas e, assim, garantia-se o cumprimento de acordos sem que um centro de poder - cidade, reino etc. - se submetesse a outro ${ }^{347}$. Trata-se de forma bastante simples de solução de problemas de validade de normas internacionais.

\footnotetext{
346 SLAUGHTER, Anne-Marie. International law and international relations. In: Recueil des Cours. Academie de Droit International de la Haye, Volume 285, 2000, pp. 09-249. p. 207, “in verbis“: "Smaller European States, for instance, 'are strong proponents of legalization, not only because they wish to constrain the behaviour of their more powerful neighbors, but also because they possess legal resources out of proportion to their other capabilities'. Similarly, Asian Governments have resisted legalization with APEC largely due to the "imbalance of legal resources available to the United States within such a régime"
}

347 VERDROSS, Alfred. Le fondement du droit international. In: Recueil des Cours. Academie de Droit International de la Haye, Volume 16, 1927-I, pp. 247-323. pp. 262-263. "In verbis“: "Comme nous l'avons vu au chapître précédent, la question du fondement du droit international public est essentiellement un problème de la science du droit international moderne. Pourtant, sous un certain point, ce problème était déjá connu dans l'antiquité qui se trouvait aussi devant le problème de la validité, de la forc obligatoire des traités internationaux. La jurisprudence romaine résolut cette question de la manière suivante : un acte juridique conclu entre la Cité et un autre État était consideré comme un « nudum pactum,» c'est-à-dire que l'exécution dépendait de la bonne volonté de Rome. Mais tout engagement international devenait irrévocable, s'il était « sacro sanctum, 》 sanctionné par un serment des Parties contractantes. Par ce serment, chaque État se soumettait à la punition de ses Dieux pour le cas de la rupture du pacte en question. Cette sanction, appelée « execratio » qui devint un élément caractéristique des traités internationaux, se composait de deux actes parallèles; chaqué État s'engageait envers ses propres Dieux à observer rigoureusement les stipulations conclues avec l'autre État1. Le 
A consolidação dos judiciários nacionais se deu de forma lenta, com auxílio da extensa produção normativa - ao menos no civil law - e a partir de um aprendizado constante cristalizado em jurisprudência. $\mathrm{O}$ direito internacional ainda se encontra no início desse processo, mas bastante possível se faz imaginar a reprodução do modelo reconhecido e vinculante local à ordem internacional ${ }^{348}$. Dúvida maior restaria à arquitetura desse sistema, ou seja, na questão de se ele reproduzirá algum dia a estrutura hierárquica interna que garante a inexistência de antinomias ou se seguirá o caminho da distribuição de competência temática entre órgãos jurisdicionais internacionais.

Quanto à previsibilidade na estrutura jurisdicional, assentado se encontra nos dias atuais a submissão dos sujeitos de direito internacional a determinado sistema de solução de controvérsias, ao qual se tenha previamente vinculado, mas por muito tempo sustentou-se que tal anuência genérica anterior exigira confirmação quando do surgimento do litígio ${ }^{349}$. Em se tratando de execução, tem-se atualmente postura dos internacionalistas mais rígida relacionada à obrigatoriedade de uma sentença ou laudo internacional, mas seu cumprimento ainda se encontra, em regra, exclusivamente no espectro do exercício do poder estatal.

A solução pacífica de controvérsias, hoje uma obrigação estabelecida na carta das Nações Unidas, é reconhecida como um dos mais antigos dogmas do direito das gentes ${ }^{350}$.

traité n'était donc pas fondé sur une base commune, il découlait au contraire de deux sources tout à fait différentes. C'est dans ce procédé de l'esprit romain, qui affirme le talent juridique de ce grand peuple, qu'on peut trouver l'origine encore si mal connue de la fameuse doctrine de l'autolimitatíon des États.“

${ }^{348}$ VISSCHER, Charles de. Cours général de principes de droit international public. In: Recueil des Cours. Academie de Droit International de la Haye, Volume 86, 1954-II, pp. 445-556. pp. 542-543. "In verbis“: "La contribution de la jurisprudence internationale à la formation d'un corps de droit homogène et plus ou moins complet est une tâche aux objectifs encore lointains. Dans des conditions à tous égards plus favorables, il a fallu de longues années aux tribunaux internes pour édifier, en face d'un droit écrit et des systématisations de la doctrine, ce droit jurisprudentiel qui a tant contribué à enrichir et à vivifier les conceptions juridiques. Sans doute en faudra-t-il bien davantage à la Cour internationale de Justice avant que se construise, sur la base de décisions beaucoup plus nombreuses, un corps de jurisprudence couvrant l'ensemble des rapports entre Etats. Une cour dont la juridiction reste subordonnée à l'accord des parties et qui, sous tant de rapports, se heurte aux résistances politiques de la souveraineté, ne peut que s'acheminer lentement dans la voie que lui ont ouverte les rédacteurs de son Statut.“

349 BERLIA, Georges. Jurisprudence des tribunaux internationaux en ce qui concerne leur compétence. In: Recueil des Cours. Academie de Droit International de la Haye, Volume 88, 1955-II, pp. 105-157. p. 113. "In verbis": "Si, à un moment donné, l'Etat se trouve lié par des engagements inbernationaux antérieurs qui lui font une obligation d'aller devant le juge et si cette hypothèse est définie dans la littérature du droit international comme étant celle de l'arbitrage obligatoire, il n'en reste pas moins que l'Etat était juridiquement libre de ne pas accepter ces engagements qui devaient ultérieurement le lier."

${ }^{350}$ TUNKIN, Grigory. Politics, law and force in the interstate system. In: Recueil des Cours. Academie de Droit International de la Haye, Volume 219, 1989-VII, pp. 227-395. p. 378. "In verbis": "The international mechanisms for settling international disputes. They are one of the oldest institutions of international law. Contemporary international law provides for many such mechanisms, and obligates States to use only them. The principle of the peaceful settlement of disputes is one of the fundamental principles of contemporary international law and is applicable to all disputes. There are many international mechanisms for the settling of 
Nesse sentido, entre as atribuições de garantir a segurança jurídica, isto é, a previsibilidade, de promover a estabilidade do sistema e assegurar o cumprimento das normas de direito, o compromisso com a previsibilidade sobressai como parte do núcleo da função jurisdicional exercida por um tribunal ou corte $\operatorname{arbitral}^{351}$.

A jurisdição trabalha com conceitos sistêmicos importantes como o de coerência e o de completude. A coerência exigiria do ordenamento harmonia entre suas normas, isto é, ausência de antinomias e a completude, por sua vez, a constante eliminação de lacunas por meio da produção normativa ou da interpretação do direito ${ }^{352}$. Um sistema de direito exigiria, sob a perspectiva positivista, estruturação hierárquica que pudesse, ao menos, garantir sua coerência. Esse conforma aspecto cada vez mais apontado pela doutrina como necessário ao direito internacional e fundamental ao seu melhor desenvolvimento ${ }^{353}$.

international disputes. Article 33 of the United Nations Charter enumerates the following: negotiation, enquiry, mediation, conciliation, arbitration, judicial settlement, resort to regional agencies or arrangements, or other peaceful means chosen by the parties. One should add the growing role of international organizations, especially of the United Nations, in the settling of international disputes, especially when a dispute becomes a hot spot."

${ }^{351}$ ABI-SAAB, Georges. Cours général de droit international public. In: Recueil des Cours. Academie de Droit International de la Haye, Volume 207, 1987-VII, pp. 09-463. p. 214. "In verbis“: "L'existence des règles une fois établie, c'est leur mise en oevre qui concrétise leur emprise sur la réalité sociale, en fournissant le relai entre leurs propositions normatives générales el les situations particulières, ou en d'autres termes en les traduisant dans les faits, administrant ainsi la preuve ultime de leur effectivité. Car les règles de droit ne sont pas là pour être contemplées en tant que postulats abstraits. Mais pour être intégrées dans le comportement des sujets de droit. La mise en oeuvre des règles implique deux catégories de processus ou d'opérations juridiques. La première consiste il spécifier et à fixer la teneur de la règle et les conséquences juridiques qui en découlent par rapport à une situation donnée de manière définitive, pour les besoins de la sécurité juridique. La seconde vise à assurer le respect de cette solution, quitte à faire appel en dernier lieu à d'éventuelles sanctions pour garantir l'effectivité du système ainsi que sa stabilité : ce qui nous ramène à nouveau à la sécurité juridique. Cette dernière catégorie de processus ou d'opérations relève davantage de la troisième fonction du système juridique, la fonction exécutive. Elle se rapporte moins à la norme en tant que telle, à son contenu et à ses applications spécifiques, qu'à l'autorité et à la force légale qui s'attachent à ces applications, et que nous examinerons dans le chapitre suivant. C'est la première catégorie qui constitue la fonction juridictionnelle à proprement parler.“

${ }^{352}$ BOBBIO, Norberto. O positivismo jurídico: lições de filosofia do direito. São Paulo: Ícone, 1995. p. 203. "In verbis": "Concluindo: a incoerência do sistema é a situação em que "há" uma norma e "há" uma outra norma incompatível com a primeira; a incompletude é a situação em que não há "nem" uma norma, "nem" uma outra norma incompatível com esta. Na incoerência há uma norma a mais (há ... há) ; na incompletude há uma norma de menos (nem ... nem). [...] O principio, sustentado pelo positivismo jurídico, da coerência do ordenamento jurídico, consiste em negar que nele possa haver antinomias, isto é, normas incompatíveis entre si. Tal principio é garantido por uma norma, implícita em todo ordenamento, segundo a qual duas normas incompatíveis (ou antinômicas) não podem ser ambas válidas, mas somente uma delas pode (mas não necessariamente deve) fazer parte do referido ordenamento; ou, dito de outra forma, a compatibilidade de uma norma com seu ordenamento (isto é, com todas as outras normas) é condição necessária para a sua validade."

${ }^{353}$ CHARNEY, Jonathan I.. Is international law threatened by multiple international tribunals? In: Recueil des Cours. Academie de Droit International de la Haye, Volume 271, 1998, pp. 101-382. p. 134. "In verbis“": "In many respects, a single international adjudicatory body, such as the ICJ or a hierarchical system with the ICJ at its apex, would be highly desirable. Clearly, the multiplicity of independent forums increases the likelihood that those forums will find and apply international law differently. Decisions reaching different conclusions on 
Também a unidade constitui característica importante desenvolvida tanto pelas teorias jusnaturaliastas quanto juspositivistas - ainda que sob perspectivas distintas. A primeira se estabeleceria, assim, sob parâmetros materiais enquanto a segunda sob critérios formais, é dizer, de formação das regras jurídicas ${ }^{354}$.

Entre a unidade, a coerência e a completude - ou completitude, a última consubstanciaria premissa mais latente na idéia de ordenamento jurídico ${ }^{355}$. Uma ordem legal - sistêmica, distinta das normas singulares que a constituem - possuiria - ou almejaria, portanto, essas três características centrais ${ }^{356}$.

Ainda que de conformação arbitral ou de estrutura $a d$ hoc, tribunais internacionais não diferem dos nacionais no que se refere à observação da jurisprudência posta na tomada de decisões ${ }^{357}$. Tal assertiva serve às composições provisórias - e aos órgãos provisórios - e

the same international law subject by a variety of tribunals may undermine the appearance, if not the fact, of a unitary international legal system. These variations may be so great that they could damage the coherence of that system itself."

${ }^{354}$ BOBBIO, Norberto. O positivismo jurídico: lições de filosofia do direito. São Paulo: Ícone, 1995. p. 199. "In verbis": "A primeira característica do ordenamento jurídico é, pois, a unidade. Poder-se-ia objetar que esta não é uma concepção exclusiva do positivismo jurídico, visto que mesmo os jusnaturalistas pensam no direito como um sistema unitário de normas; e se poderia acrescentar que o impulso para a realização da unidade do direito mediante a codificação nasce de uma concepção jusnaturalista (ver as palavras de Cambacérès relatadas no § 18). Tudo isto é exato, mas não contraria a nossa afirmação segundo a qual a teoria do ordenamento jurídico é própria do juspositivismo. Há, realmente, modos e modos de conceber a unidade do direito, e o modo no qual a entende o jusnaturalismo é profundamente diferente daquele no qual a entende o juspositivismo: para o primeiro, se trata de uma unidade substancial ou material, relativa ao conteúdo das normas; para o segundo, trata-se de uma unidade formal, relativa ao modo pelo qual as normas são postas."

${ }^{355}$ BOBBIO, Norberto. O positivismo jurídico: lições de filosofia do direito. São Paulo: Ícone, 1995. p. 207. "In verbis": "Das três características nas quais se baseia a teoria do ordenamento jurídico, a da completitude é a mais importante, visto que é a mais típica e representa o ponto central, o coração do coração (se é lícita uma tal expressão) do positivismo jurídico. A característica da completitude é estreitamente ligada ao principio da certeza do direito, que é a ideologia fundamental deste movimento jurídico.”

${ }^{356}$ BOBBIO, Norberto. O positivismo jurídico: lições de filosofia do direito. São Paulo: Ícone, 1995. p. 198. "In verbis": "A teoria do ordenamento jurídico se baseia em três caracteres fundamentais a ela atribuídos: a unidade, a coerência, a completitude; são estas três características que fazem com que o direito no seu conjunto seja um ordenamento e, portanto, uma entidade nova, distinta das normas singulares que o constituem."

${ }^{357}$ FRANÇOIS, J.P.A.. La Cour permanente d'arbitrage son origine, sa jurisprudence, son avenir. In: Recueil des Cours. Academie de Droit International de la Haye, Volume 87, 1955-I, pp. 457-553. p. 474. "In verbis“: "Il y a encore d'autres points sur lesquels une comparaison enule les deux Cours tourne à l'avantage de la Cour de Justice : la plus grande autorité des décisions vis-à-vis des Etats tiers, et la creation d'une jurisprudence constante. Il est évident que la composition toujours différente des tribunaux arbitraux n'est pas favorable à la formation d'une jurisprudence stable. Toutefois il ne faut pas exagérer cet inconvénient. Il est bien sûr qu'un tribunal arbitral, constitué sous les auspices de la Convention de la Haye, tiendra compte, dans une très large mesure, de toute décision, rendue antérieurement par la Cour d'Arbitrage, même si cette décision a été rendue par d'autres membres. La continuité dans la jurisprudence d'un tribunal fixe et permanent ne dépend pas non plus du seul fait que les juges, qui l'ont rendue, sont les mêmes. Souvent il y a des changements dans la composition de la Cour dans une période assez brève. Aussi, à cet égard il s'agit plutôt d'une divergence dans les nuances que d'une distinction de fond." 
trona-se bastante previsível nas instituições de caráter permanente. Trata-se hoje, na verdade, de discussão já superada e substituída pela influência recíproca dos tribunais internacionais.

A existência de normas exige, seguindo o mesmo esquema teórico, a institucionalização de modelos garantidores de sua correta e coerente aplicação. Os sistemas de solução de controvérsias instituídos internacionalmente surgiriam, assim, como expressões incipientes da função judiciária apresentada pela teoria do estado. A maturidade legal e institucional do exercício dessas duas funções constituiria, em afirmação, contudo, pendente de confirmação científica, condição ao desenvolvimento dos sistemas legais internacionais ${ }^{358}$.

Lançando-se mão expressamente das teorias que buscam explicar a organização do poder no estado, os tribunais internacionais não devem, de fato, possuir funções executiva e legislativa como típicas, mas devem conservar para si a mais importante expressão do poder: a guarda da coerência do sistema jurídico ${ }^{359}$. A ausência de um órgão dotado de atribuições judiciárias constitui característica típica de estruturas rudimentares de organização social ${ }^{360}$. Hoje, contudo, tal característica não pode ser reconhecida no direito das gentes.

$\mathrm{Na}$ esfera jurídica, a separação de funções do poder não pode ser encarada de forma estrita. No plano interno, a concreção - exercida de forma típica pelos investidos da atribuição legislativa - passou a ser praticada também pelo judiciário dos países. Nesse contexto, a

${ }^{358}$ CASELLA, Paulo Borba. Conceito de sistema, contexto internacional e pós-modernidade. In: ADEODATO, João Maurício; BITTAR, Eduardo C. B. (Org.) - Filosofia e Teoria Geral do Direito: estudos em homenagem a Tércio Sampaio Ferraz Junior por seu septuagésimo aniversário. São Paulo: Quartier Latin, 2011. p. 1005. "In verbis": "A institucionalização da justiça e equidade no direito internacional, no contexto pós-moderno, permanece, simultaneamente, necessidade e desafio, para o futuro e sobrevivência da humanidade. O enfoque pós-moderno no direito internacional tenderá a se colocar no sentido de formular mais amplo campo de hipóteses de incidência, no tocante à formação e à regulação do direito internacional, da ação e influência estatal, como das modalidades para o exercício e ocorrência desta."

359 ROUSSEAU, Jean-jacques. Du contrat social. Paris: Union Générale d'Éditions, 1973. pp. 199-200. "In verbis": "Le tribunat n'est point une partie constitutive de la cité, et ne doit avoir ancune portion de la puissance législative ni de l'exécutive: mais c'est en cela même que la sienne est plus grande: car, ne pouvant rien faire, il peut tout empêcher. Il est plus sacré et plus révéré, comme défenseur des lois, que le prince qui les exécute, et que le souverain qui les donne."

${ }^{360}$ LOCKE, John. Two treatises of government. London: Guernsey Press, 1986. p. 160. "In verbis“": "Wherever, therefore, any number of men so unite into one society as to quit every one his executive power of the law of the Nature, and to resign it to the public, there and there only is a political or civil society. And this is done wherever any number of men, in the state of Nature, enter into society to make one people one body politic under one supreme government: or else when any one joins himself to, and incorporates with any government already made. For hereby he authorizes the society, or which is all one, the legislative thereof, to make laws for him as the public good of the society shall require, to the execution whereof his own assistance (as to his own decress) is due. And this puts men out of a state of Nature into that of a commonwealth, by setting up a judge on earth with authority to determine all the controversies and redress the injures that may happen to any member of the commonwealth, which judge is the legislative or magistrates appointed by it. And wherever there are any number of men, however associated, that have no such decisive power to appeal to, there they are still in the state of Nature." 
política, antes escamoteada nas decisões judiciais, passou a ser concretizada abertamente por órgãos que deveriam se restringir à letra do direito e, portanto, apenas à extração da normatividade.

No direito internacional, os sistemas de solução de controvérsias se multiplicaram e se consolidaram ao longo do século XX como garantidores da coerência, da segurança e da previsibilidade da ordem normativa geral, mas não existe, ressalte-se, um poder judiciário global e tampouco exercício concretivo pleno como verificado hoje internamente. Trata-se de peculiaridade com a qual o direito das gentes deve conviver, mas essa ausência de centralização não impede absolutamente o uso das estruturas da teoria geral do estado para auxiliar a compreensão do direito internacional. 


\section{ORGANIZAÇÕES INTERNACIONAIS E TRATADOS ASSOCIATIVOS: PERSONALIDADE JURÍDICA E SOLUÇÃO DE CONTROVÉRSIAS}

\subsection{Personalidade, Capacidade e Organizações Internacionais}

Uma das propostas ao reconhecimento de entes como sujeitos de direito internacional se funda, primeiro, na existência de entidade que possa ser caracterizada juridicamente como sujeito e, segundo, que essa não conforme mero objeto do direito das gentes ${ }^{361}$. Tal conceito se enquadra na percepção recorrente da personalidade como requisito essencial à atuação concretiva de estados e de organizações internacionais por meio do exercício da capacidade de expressar vontade.

A noção de personalidade jurídica não se confunde, contudo, com os direitos e obrigações das pessoas reais. Trata-se de um pressuposto das partes de situações jurídicas subjetivas $^{362}$. Estados, organizações internacionais e tratados associativos possuem, portanto, personalidade jurídica sem necessariamente dispor de capacidade ampla e global como aquela reconhecida, em regra, às pessoas reais.

A ordem internacional permite freqüentemente, inclusive, a atuação de atores não dotados nem mesmo de personificação. Exemplos reconhecidos pela doutrina seriam, nesse sentido, os insurgentes e os beligerantes ${ }^{363}$.

\footnotetext{
${ }^{361}$ BEREZOWSKI, Cezary. Les sujets non souverains du droit international. In: Recueil des Cours. Academie de Droit International de la Haye, Volume 65, 1938-III, pp. 10-11. p. 05. "In verbis": "Le premier élément, l'élément de la nature du droit, est d`ordre essentiel, car il ne saurait y avoir de sujets du droit international en dehors de l'existence de cette catégorie du droit. Le deuxième élément, opposant le sujet à l’objet du droit, est de nature additionnelle, car il ne décide de la subjectivité qu'en présence du premier élément. En se basant sur les deux éléments sus-mentionnés, on peut qualifier de sujets du droit international tous ceux dont les relations sont réglées par le droit international et qui, en même temps, ne sont pas des objets de ce droit.“
}

362 QUADRI, R.. Cours général de droit international public. In: Recueil des Cours. Academie de Droit International de la Haye, Volume 113, 1964-III, pp. 237-483. pp. 374-375. "In verbis“": "A notre avis il faut tout d'abord écarter l'idée que la personalité juridique coincide avec la situation juridique de la personne réelle, c'est-à-dire avec l'ensamble de ses droits et de ses obligations. La personnalité juridique indique une situation «de fait», elle indique les caractères que la personne réele doit présenter pour que les règles d'un ordre juridique donné puissent lui faire une situation juridique subjective. La personnalité juridique en tant que situation de fait (Tatbestand) est donc seulement «présupposée » par les situations juridiques subjectives; elle n'est que l'ensamble des conditions subjectives générales permanentes qui doivent subsister, à côté des autres conditions subjectives et objectives dont la présence est exigée par les différentes règles de conduite, afin qu'une personne réelle puisse acquérir des droits ou assumer des obligations.“

${ }^{363}$ MARYAN GREEN, N.A. International law: law of peace. London: Macdonald and Evans, 1982. pp. 67-69, cita como exemplos os insurgentes, os beligerantes, a Santa Sé e os protetorados. 
A existência de formações não reconhecidas como sujeitos atuando na ordem internacional - tais como hoje, por exemplo também, os grupos terroristas transnacionais denuncia muito claramente a artificialidade do conceito de pessoa moral. De certo, a atribuição de personalidade muitas vezes decorre de situações de fato, caso daquela decorrente do reconhecimento de um estado, mas, em regra, constitui ficção que serve à instrumentalização de práticas do direito ${ }^{364}$.

A questão constitui, portanto, tema dos mais sensíveis do direito das gentes. O debate em torno de seu conteúdo, requisitos e limites mostra-se, em regra, determinante ao reconhecimento de sujeitos de direito internacional e à fixação de suas capacidades, direitos e deveres $^{365}$.

Impossível se faz, contudo, estabelecer um conteúdo único e uniforme para a "personalidade jurídica internacional". Formalmente, esse conceito se funda na capacidade de atuação no plano global, mas os limites dessa atribuição variam, por exemplo e no que se refere às organizações internacionais especificamente, ao texto dos tratados que a estabelecem $^{366}$.

A questão apresenta contornos, entretanto, ainda mais complexos quando analisadas, por exemplo, as relações entre estados e pessoas jurídicas de direito privado e, principalmente em período mais recente, entre estados e indivíduos - mormente em questões relativas à

364 ROLIN, Henri. Les principes de droit international public. In: Recueil des Cours. Academie de Droit International de la Haye, Volume 77, 1950-II, pp. 305-479. pp. 322-323. "In verbis“: "Rappelons à cet égard la distinction classique de Haurou, qui voit dans la personnalité morale des corps constitués une institution sociale et morale, tandis que la personnalité juridique n'est qu'une institution juridique, conception de juriste, parfois pure fiction, parfois, comme dans le cas de l'Etat, s'appuyant sur le fait social, c'est-à-dire sur l'existence d'une personnalité morale.“

${ }^{365}$ FELDMANN, David. International personality. In: Recueil des Cours. Academie de Droit International de la Haye, Volume 191, 1985-II, pp. 343-414. p. 406. "In verbis“: "International personality continues to be one of the most actual problems of international legal science. It is penetrated by new trends corresponding to the process of the progressive development of international law. Though many aspects of international personality seem to be of a purely theoretical character, as a matter of fact they have a practical importance. It refers especially to the question of the types of international persons, rights and duties of States, recognition and others."

366 LAUTERPACHT, E.. The development of the law of international organization by the decisions of international tribunals. In: Recueil des Cours. Academie de Droit International de la Haye, Volume 152, 1976IV, pp. 377-478. p. 403. "In verbis“: "Therefore, when we speak of 'personality' in the context of international law we must be speaking of something to which, in theory, international law gives some identifiable content. In fact, there is no definition of personality in international law which is sufficiently comprehensive to apply in some constructive or realistic way to all the different types of entity which operate in the international field. If in the nineteenth century it was possible to say that only States were persons in international law (and even in the nineteenth century this was debatable), it is certainly not possible to make the same assertion in a period when both individuals and a diverse range of international organizations are accorded a wide variety of rights and duties under international law." 
proteção dos direitos humanos ${ }^{367}$. Arbitragens internacionais realizadas entre empresas e estados e as demandas de indivíduos contra estados denotam a emergência da reclassificação dos sujeitos de direito internacional.

Nesse sentido e quanto às associações internacionais de direito público, não se pode confundir, gize-se, a personalidade jurídica conferida pelo direito interno de um estado à estrutura burocrática relacionada a tratado para o exercício de capacidade jurídica localmente com aquela estabelecida para a atuação internacional mais ampla ${ }^{368}$.

O reconhecimento de sujeitos outros que os estados no plano internacional e a atribuição de personificação a organizações políticas de formato distinto sofreu resistência não apenas dos atores clássicos do direito das gentes, mas também da própria doutrina internacionalista ${ }^{369}$.

Até a segunda grande guerra, forte resistência havia ao reconhecimento de personalidade moral a outros entes que não os estados no cenário jurídico mundial. A multiplicação de estruturas organizativas descoladas dos entes estatais e sua

367 EAGLETON, Clyde. International organization and the law of responsibility. In: Recueil des Cours. Academie de Droit International de la Haye, Volume 76, 1950-I, pp. 319-425. p. 324-325. "In verbis“: "In the useful listing by Stuyt of international arbitrations, I found that agreements to arbitrate (compromis d'arbitrage) had been made between Bamangwato and Bakwena, neither of which appear to be regarded as states; between Egypt and the Suez Canal Co., or between Germany and the Trustee for the German Industrial Debentures, or between the Union of Socialist Soviet Republics and the Lena Gold fields Co. Are such entities to be regarded as subjects of international law, capable of making treaties and of engaging in the legal solution of their disputes? More recently, it was asserted in the Indonesian affair that the Renville agreement between the sovereign state of The Netherlands and the insurgent Indonesian group gave to the latter an international legal personality, thereby taking the matter out from Article 2, paragraph 7 of the Charter and allowing the Security Council to take it under jurisdiction. [...] If, as many writers maintain, individuals are subjects of international law, or if corporations or tribes can be parties in international arbitrations, or if the United Nations is now to be regarded as a person of international law, they must all have rights and duties; and as to these rights and duties disputes would arise requiring legal adjustment"

${ }^{368}$ PILOTTI, Massimo. Les unions d'états. In: Recueil des Cours. Academie de Droit International de la Haye, Volume 24, 1928-IV, pp. 441-546. p. 465. "In verbis": "L'Union administrative se réalise toujours au moyen de la création d'organes communs, appelés commissions, bureaux, offices, instituts, constitués par un seul des États associés au nom de tous les autres, ou constitués par tous les États associés ensemble. II se peut que ces organes acquèirent une personnalité juridique de droit interne dans l' État où ils ont leur siège, personnalité qui leur doit être reconnue également dans les autres États associés, au cas où elle aurait été prévue dans le traite d'union. On a même parlé, à certains points de vue, d'une personnalité juridique de droit international â propos de quelques organes qui ont reçu le pouvoir d'édicter des regles de droit et qui peuvent entretenir des rapports juridiques directs avec les États associés ou les États tiers. On a, dans cet ordre d'idées, émis l'opinión que la Commission européenne du Danube et la Commission internationale du Danube, réorganisées par la convention du 23 juillet 1921, ont une personnalité de droit international.“

${ }^{369}$ SIOTTO PINTOR, Manfredi. Les sujets du droit international autres que les états. In: Recueil des Cours. Academie de Droit International de la Haye, Volume 41, 1932-III, pp. 245-361. p. 289. "In verbis": "L'hypothèse qu'une communauté humaine quelconque soit abandonnée ù l'arbitraire effréné et brutal des Etats existants, si on ne l'empresse pas de lui attribuer la personnalité internationale, est purement académique dans la phase actuelle de la civilisation. Tout aussi académique est d'autre part l'hypothèse qu'une organisation politique stable, indépendante et effectivement responsable de ses actes, existe quelque part et que tous les anciens Etats se refusent arbitrairement à la reconnaître.“ 
institucionalização cada vez maior inviabilizaram percepção outra que não a da personificação moral das organizações internacionais ${ }^{370}$.

A condição de pessoa, antes restrita aos estados, tem nas estruturas assemelhadas a estados exemplo nítido dos primeiros reconhecimentos não restritos aos entes dotados dos elementos que caracterizam as estruturas estatais. Logo, como parte desse mesmo processo, reconheceu-se, nos locais de desempenho de atividades, a condição de sujeito das estruturas burocráticas das organizações de estados para, tacitamente, em um segundo momento e, expressamente, mais tarde, que se reconhecesse a personalidade jurídica internacional das organizações internacionais $^{371}$.

Se, por um lado, pode-se atribuir condição ficcional à capacidade de agir das organizações internacionais derivada da conferência desse status abstrato por tratado, o reconhecimento de um estado como pessoa jurídica de direito público capaz de expressar vontade concretiva internacionalmente tampouco deveria ser caracterizado como inerente. Em ambos os casos, a atribuição de personalidade e os limites de sua atuação se estabelecem pelo direito positivo, isto é, por tratado ou, por exemplo, pelas constituições ${ }^{372}$.

\footnotetext{
${ }^{370}$ DUPUY, René Jean. Le droit des relations entre les organisations internationales. In: Recueil des Cours. Academie de Droit International de la Haye, Volume 100, 1960-II, pp. 457-589. p. 461. "In verbis": "Cela tenait, d'une part, à des considérations quantitatives, ces organisations encore peu nombreuses, ne pesant qu'assez légèrement dans les rapports internationaux, en raison de leurs faibles compétences et, d'autre part, à des considérations qualitatives résultant de la prédisposition de la doctrine et des Gouvernants à ne voir dans les organisations internationales qu'un simple cadre à des activités interétatiques et à leur refuser la qualité de sujet de Droit des Gens. C'est ainsi que la Société des Nations elle-même, ne s'est pas vu accorder une personnalité juridique comparable à celle reconnue aux Etats. Une analyse aussi sommaire n'est plus possible aujourd'hui. Depuis la seconde guerre mondiale les organisations internationales, gouvernementales et nongouvernamentaless, dépassent le millier.“
}

371 PODESTÁ COSTA, L.A. Derecho internacional público - tomo I. Buenos Aires, Tipográfica Editora Argentina, 1955. pp. 57-58. "In verbis": "Por acuerdo expreso entre los Estados, se ha admitido en los últimos tiempos como personas del derecho internacional a ciertos componentes de algunos Estados: desde 1919 a los 'dominios' británicos, al entrar a formar parte de la Sociedad de las Naciones como miembros originarios; y desde 1945 a dos Estados integrantes de la Unión Soviética - Rusia Blanca y Ucrania - al ser admitidos por la Carta de San Francisco como miembros originarios de la Organización de las Naciones Unidas. También por voluntad de los Estados, manifestada en forma expresa o tácita, se ha reconocido relativa personalidad jurídica internacional a entidades colectivas que, aun cuando no son Estados, han sido erigidas por ellos: la Sociedad de las Naciones, la Organización Internacional del Trabajo y la Corte Permanente de Justicia Internacional, creadas en 1919-20, y la Organización de las Naciones Unidas así como la Corte Internacional de Justicia, que reemplazaron a aquéllas en 1945. Antes habíase reconocido personalidad relativa a las oficinas internacionales que sirven de Órgano permanente a las 'uniones públicas internacionales'; a determinadas comisiones internacionales de carácter administrativo, como la del Danubio; y, en ciertos casos de luchas civiles, a la 'comunidad beligerante'. Todas las referidas entidades son sujetos del derecho internacional, pero su personalidad jurídica es relativa en doble sentido, pues existe solamente con relación a los Estados que participan en ellas y está limitada a los fines de su creación."

${ }^{372}$ WOLFF, Karl. Les principes généraux du droit applicables dans les rapports internationaux. In: Recueil des Cours. Academie de Droit International de la Haye, Volume 36, 1931-II, pp. 479-553. p. 501. "In verbis": "L'attribution de la qualité d'être juridique dépend du droit positif. L'être juridique peut être en droit des gens le souverain ou l'Etat comme tel. C'est donc au contraire une fiction que d'attribuer la capacité d'agir à une notion 
Refuta-se, dessa maneira, tanto a hipótese de se considerarem as organizações internacionais como conjunto das vontades de seus membros - o que poderia, em última ratio, outorgar-lhes personalidade sem vontade expressa dos estados - quanto a percepção da soberania dos estados como mero produto da soma das vontades dos indivíduos a ele submetidos. No caso das organizações internacionais, impossível se faria, assim, o reconhecimento implícito e, em relação aos estados, desconsiderar-se-ia, por exemplo, que a democracia reflete desejo da maioria e que uma autocracia nem isso necessariamente.

Noutra perspectiva, é de se observar que a atribuição de personalidade internacional a ente distinto dos estados conformaria apenas aparentemente processo distinto daquele por meio do qual passam os estados. Nas organizações internacionais, por exemplo, ela seria, sob o modelo teórico indicado, conferida pelos estados por expressa manifestação de vontade por tratado enquanto a personificação dos entes estatais se daria pela manifestação - explícita ou tácita - do reconhecimento pelos atores da ordem mundial. Ambos os processos passam, portanto, necessariamente pelo elemento volitivo dos atores já dotados de capacidade concretiva internacional $^{373}$.

A condição subjetiva constitui hoje de forma sedimentada na doutrina requisito para o reconhecimento do status de sujeito a entes que atuam na ordem internacional, mas, uma vez ultrapassada essa premissa de existência, necessário se faz observar os limites da capacidade desses atores para, por exemplo, exercer concreção ou garantir a normatividade no espaço global $^{374}$. A personalidade traz consigo, em regra, a capacidade de agir, mas nem todo ente

alors que ce qui est compris sous cette notion est, en vérité, incapable d'agir. La théorie qui envisage le territoire comme élément nécessaire de l'Etat ne peut donc pas considérer la capacité juridique d'agir de l'Etat même comme capacité réelle. Ce n'est qu'une fiction. Il en est de même dans la plupart des cas pour ce qui est de la capacité juridique d'agir d'un Etat nomade parce que là aussi c'est le souverain ou ses organes qui agissent, et non pas tous les gouvernés ensemble avec le souverain.“

${ }^{373}$ PILOTTI, Massimo. Les unions d'états. In: Recueil des Cours. Academie de Droit International de la Haye, Volume 24, 1928-IV, pp. 441-546. p. 479. "In verbis“": “Or, puisque les règles de droit international ne dérivent que d'accords conclus entre les membres de la commnnauté, accords dont la forcé obligatoíre n'est pas établie par un acte de volonté d'une autorité supérieure aux contractants, la qualité de sujets, en d'autres termes la personnalité juridique des membres, commence à se manifester au moment où ils se lient explicitement par des accords, ou se comportent en fait comme s'ils étaient liés par des accords tacites. Dans le cas d'admission d'un nouveau membre dans la communauté internationale, il y a en général un premier accord entre ce membre et les autres, constitué par les actes de reconnaissance. Si ces actes sont conclus en des termes formels, aucun doute sur l'existence de la nouvelle personne ne peut substituer.“

${ }^{374}$ MARYAN GREEN, N.A. International law: law of peace. London: Macdonald and Evans, 1982. p. 49. "In verbis": "The extent of the Legal personality of an international organisation: legal capacity. Although each international organisation has a legal personality in international law to enable it to act in the performance of its functions, one may not invert that relation and assume that the mere possession of legal personality empowers the organisation to act by reference to that legal system. For as shown above the legal capacity of an international organisation depends upon powers, and the powers of an organisation are set out in or may be implied from its constituent instrument." 
personalizado pode exercer a concreção plenamente e atuar, portanto, como fonte produtora de direito das gentes.

O reconhecimento como pessoa - física ou moral - seria, para alguns doutrinadores, apenas em parte artificial. No caso dos seres humanos, consubstanciaria algo inerente. No que se refere, entretanto, a sujeitos de direito das gentes como os estados e organizações internacionais, o reconhecimento de personificação inata seria menos usual e de qualquer maneira, artificial seriam os limites de suas capacidades. Para cada organização, por exemplo, a expressão da vontade pode ter seus limites alterados e restringidos em contexto que não se diferencia muito, contudo, do que ocorre com os indivíduos ${ }^{375}$.

As primeiras experiências aproximativas que formaram tratados associativos nos primórdios da atual constelação de sujeitos de direito internacional podem ser reconhecidas nas comissões fluviais européias e na união telegráfica internacional no século $\mathrm{XIX}^{376}$. As “conferências diplomáticas" podem ser também consideradas uma forma primitiva de organização internacional, mas sua estrutura - ou quase absoluta falta de estrutura - as

375 REUTER, Paul. Principes de droit international public. In: Recueil des Cours. Academie de Droit International de la Haye, Volume 103, 1961-II, pp. 425-656. p. 499. "In verbis“: "Poser une norme juridique c'est poser en même temps et du seul fait de cette norme des sujets de droits, titulaires des droits et des obligations découlant de la norme. Tout sujet de droit ainsi défini exerce aussi à des degrés variables, mais jamais nuls, une fonction de création juridique dans la mesure où toute norme engendre nécessairement, pour la ralisation des droits et des obligations, des actes juridiques posés par le sujet. Il résulte de là que toute personnalité juridique est pour une part, mais pour une part seulement, artificielle. Quant une personne humaine a atteint l'âge de raison, quand une collectivité s'organise de manière que certains hommes puissent traiter en son nom des intérêts communs, l'artifice est réduit, surtout dans le premier cas ; mais il subsiste toujours jusqu'à un certain point. Un système juridique peut instituer des sujets de droit abstraitement équivalents en instituant une catégorie juridique dans laquelle chaque spécimen a une personnalité identique à celle des autres ; il peut aussi instituer des personnalités singulières, chaque personnalité ayant des droits et des obligations différents."

${ }^{376}$ BISHOP, W.W.. General course of public international law. In: Recueil des Cours. Academie de Droit International de la Haye, Volume 115, 1965-II, pp. 147-470. pp. 157-158. "In verbis“": "[...] I would point to the tremendous growth of international organizations of all types, commencing with the nineteenth century European river commissions and the International Telegraph Union of 100 years ago. These bring problems of multilateral negotiations and of parliamentary diplomacy, and of concern for the 'constitutional law' and the 'administrative law' of each organization; they play an ever-increasing part in the establishment of order and control in many types of activities which cross national boundaries: they often result in international agreements formalized in treaties, or left in the more doubtful status of resolutions." Ibid, p. 261. "In verbis“: "For at least the last several decades we see international organizations functioning on the international scene in a way which makes it clear that they have at least a limited degree of international personality, separate and distinct from that of their member states. It is hard to give a precise date when this phenomenon first appeared and the international personality of international organizations became recognized. One might suggest the European Commission of the Danube (created in 1856), or the Rhine Commissions of 1868, the International Commission for the Cape Spartel Lighthouse in Morocco, or the Universal Postal Union (1874) as among the earliest international organizations to possess clear international personality, even to a very limited degree. Other international organizations dealing with specialized problems preceded the League of Nations, but there appears to have been rather little discussion of how far such entities had 'personality' under international law." 
aproximariam mais do modelo de tratados associativos que daquele das organizações internacionais propriamente ditas 377 .

O pronunciamento da Corte Internacional de Justiça de 1949, apontado como verdadeiro leading case do reconhecimento do descolamento das organizações internacionais de seus membros, trouxe diferenciação extremamente útil à organização do direito das gentes e fundamental para o estudo que aqui se propõe $\mathrm{e}^{378}$. A referida decisão diferencia "personalidade" de "poder" e deixa claro que a atuação internacional de um ente dotado de personalidade dependeria do poder que lhe é atribuído pelo direito internacional ${ }^{379}$.

No caso concreto, ao reconhecer capacidade jurídica internacional das Nações Unidas, além de esclarecer que esse reconhecimento se fazia à raiz não apenas da titularidade de direitos, mas da possibilidade de fazê-los prevalecer, a Corte Internacional de Justiça, mesmo indiretamente, vinculou a personificação à possibilidade de se provocar algum tipo de expressão da função judiciária no plano internacional ${ }^{380}$. Ou seja, ao reconhecer a

\footnotetext{
${ }^{377}$ FAWCETT, J.E.S.. General course on public international law. In: Recueil des Cours. Academie de Droit International de la Haye, Volume 132, 1971-I, pp. 363-558. p. 542. "In verbis": "An early form of international organization was the diplomatic conference. The authority of the representatives at such conferences was at one time considerable, since they might have full powers to negotiate and conclude an agreement. More rapid communications tended perhaps to reduce the need for full powers and to substitute the method of reference back of draft agreements to governments for ratification. But modem means of communication, almost instantaneous, make it possible for governments to be in effect physically present at diplomatic conferences; and as we have seen earlier their work can have considerable effect and influence. Nevertheless, the conference process of consultation, and negotiation and construction of common policy will become institutionalized only where there is some organic need for a permanent structure."
}

${ }^{378}$ MERON, Theodor. International law in the age of human rights: general course on public international law. In: Recueil des Cours. Academie de Droit International de la Haye, Volume 301, 2003, pp. 09-489. p. 325, "in verbis": "The international legal personality of international organizations, first recognized in the Advisory Opinion of the ICJ on Reparation for Injuries Suffered in the Service of the United Nations 1093 is now universally accepted.“

379 LAUTERPACHT, E.. The development of the law of international organization by the decisions of international tribunals. In: Recueil des Cours. Academie de Droit International de la Haye, Volume 152, 1976IV, pp. 377-478. p. 407. "In verbis“: “The distinction thus drawn by the Court between 'personality' and 'powers' is one of major importance. The making of this distinction acknowledges that the mere possession of personality does not dispense with the need to determine whether in the particular case the person possesses the appropriate power. And so it may be asked, if it is in any event necessary to determine the scope of powers, what function is performed by the concept of personality ? With this point, it must be acknowledged, the Court does not grapple. It says, in a sense in anticipation of the conclusion it reaches by subsequent examination of powers, that personality means that the Organization is a subject of international law, is capable of possessing international rights and duties and has the capacity to maintain its rights by bringing international claims. At the same time, the Court is entirely unequivocal about its acknowledgment of the personality of the United Nations."

${ }^{380}$ GUGGENHEIM, Paul. Les principes de droit international public. In: Recueil des Cours. Academie de Droit International de la Haye, Volume 80, 1952-I, pp. 01-189. p. 80. "In verbis“: "Un des problèmes des plus controverses dans la doctrine du droit des gens est la définition du dornaine de validité personnel du droit international, c'est-à-dire la réponse à la question de savoir à quelles entités et à quels individus il confere la qualité de sujets de droit et de devoirs. Contrairement à une opinion répandue, mais qui a perdu beaucoup d'adhérents depuis que la Cour internationale de Justice dans son avis consultatif concernant la responsabilité 
personalidade jurídica da organização, o órgão jurisdicional não a equiparou aos estados ou a percebeu como um superestado, mas expressamente vinculou esse reconhecimento à capacidade de ser parte em demandas internacionais ${ }^{381}$.

Da dotação de personalidade jurídica às estruturas organizativas internacionais decorrem não apenas direitos, mas também deveres em relação à comunidade internacional ${ }^{382}$. Ultrapassada tal premissa, importa perceber, por exemplo, a obrigação e as responsabilidades por eventuais danos decorrentes de sua atividade ${ }^{383}$. Indo mais além, a sentença deixa consignada a impossibilidade de se adotar um padrão uniforme aplicável aos limites da condição subjetiva desses entes de direito internacional e fixa como critério dessa atribuição as necessidades da comunidade internacional ${ }^{384}$.

internationale pour les dommages causés aux fonctionnaires internationaux, a admis la capacité juridique des organisations internationales, la qualité de sujet de droits n'est pas conferée aux seuls Etats.“

381 EAGLETON, Clyde. International organization and the law of responsibility. In: Recueil des Cours. Academie de Droit International de la Haye, Volume 76, 1950-I, pp. 319-425. p. 340. "In verbis“: "To say that the United Nations is an international person, said the Court, does not moan that it has the same rights and duties as a State; nor that it is a $<<$ super-State, whatever that expression may mean. >> Its rights and duties $<<$ depend upon its purposes and functions as specified or implied in its constituent documents and developed in practice. $>>$ This is sufficient, in the judgment of the Court, to establish the capacity of the Organization $<<$ to bring an international claim against, one of its Members which has caused injury to it by a breach of its international obligations towards it $>>$."

382 EAGLETON, Clyde. International organization and the law of responsibility. In: Recueil des Cours. Academie de Droit International de la Haye, Volume 76, 1950-I, pp. 319-425. p. 323. "In verbis": "In the quarter of a century since that time, there has been much growth of law and literature in this field, and also much growth in the community of nations. An important part of that growth has been the development of international organizations, established by treaty, and legally authorized by the states which created them to perform certain functions on behalf of the community of nations. When the International Court of Justice, in the case of Reparation for Injuries Suffered in the Service of the United Nations, spoke of the rights of the United Nations, I thought also of the <<responsibility>> of the United Nations, and of other such international bodies, for rights and duties are usually correlative.“"

383 EAGLETON, Clyde. International organization and the law of responsibility. In: Recueil des Cours. Academie de Droit International de la Haye, Volume 76, 1950-I, pp. 319-425. p. 324. "In verbis": "Responsibility, then, $<<$ is simply the principle which establishes an obligation to make good any violation of international law producing injury committed by the respondent state >. [...] Though it has been stated only in terms of states, this law is properly applicable to all international legal persons. It was quite natural that earlier discussion should be in terms of states, for it was not until the present century that serious consideration was given to the possibility that entities other than states could be considered as subjects of international law."

${ }^{384}$ ACCIOLY, Hildebrando; NASCIMENTO E SILVA, G.E. do; CASELLA, Paulo Borba. Manual de direito internacional público. São Paulo: Saraiva, 2011. p. 251. "In verbis": "A noção da capacidade efetiva de exercício de direitos e obrigações como atributiva de personalidade internacional foi definida com clareza pela CIJ em 1949, ao declarar que era sujeito do direito internacional a organização que 'tem capacidade de ser titular de direitos e deveres internacionais e que esta tem a capacidade de fazer prevalecer os seus direitos através de reclamação internacional'. Nesse parecer de 1949 foi relevante a distinção feita pela Corte Internacional de Justiça no sentido de que 'os sujeitos de direito, em determinado sistema jurídico não são necessariamente idênticos, quanto à sua natureza ou à extensão de seus direitos: sua natureza depende das necessidades da comunidade'". 
Interessante se faz perceber, finalmente, que a personalidade jurídica internacional da Organização das Nações Unidas, conforme mencionado, decorreu de atuação concretiva de órgão investido inicialmente de atribuições de extração de normatividade. Para esclarecer qualquer dúvida que reste, cumpre ressaltar que o artigo 104 da carta constitutiva se refere exclusivamente à sua personificação interna nos estados, nos quais possua sede, escritórios ou representações ${ }^{385}$.

A corte consignou, ainda, que um estado não membro das Nações Unidas - como era o caso de Israel à época - estaria obrigado a reconhecer a organização como pessoa. A corte não explicou, contudo, se tal entendimento caberia apenas em relação às Nações Unidas ou de que forma se estenderia e seria aplicável a outras organizações internacionais ${ }^{386}$.

De maneira geral, nesse sentido, o reconhecimento tácito de personalidade às organizações internacionais constitui tema controvertido expressamente negado por parte da doutrina. Para grande parcela dos autores, apenas o acordo expresso dos membros poderia criar capacidade internacional. A prática tem, contudo e conforme verificado acima, permitido em alguns casos o reconhecimento implícito da condição de pessoa a esses sistemas ${ }^{387}$.

385 Mencionando as Nações Unidas, EAGLETON, Clyde. International organization and the law of responsibility. In: Recueil des Cours. Academie de Droit International de la Haye, Volume 76, 1950-I, pp. 319-425. p. 335. "In verbis": "With so much development toward legal personality for international organizations behind it, it would have been surprising if such personality had been denied to the United Nations. Article 104 deals with the question directly but inadequately: <<The Organization shall enjoy in the territory of each of its Members such legal capacity as may be necessary for the exercise of its functions and the fulfillment of its purposes. $>>$."

${ }^{386}$ MARYAN GREEN, N.A. International law: law of peace. London: Macdonald and Evans, 1982. p. 49. "In verbis": "Subjective or objective personality. It is one thing for a group of states, by treaty, to create an international organisation, endowed with separate legal personality: it is quite another for other states to be obliged to recognise it. In the case of the Reparations for Injures suffered in the Service of the United Nations (I. C. J., 1949) the court was asked to give an Advisory Opinion on the question whether Israel, at that time not a member of the United Nations, was required to recognise the legal personality of the United Nations for the purposes of a claim to reparation made by the United Nations against Israel and arising out of the killing of Count Bernadotte and other persons while on special United Nations duty in Palestine. The court answered this question in the affirmative. While this decision may be supported in the special case of the United Nations in view of the central place assigned to that organisation by the international community, it would be unwise for any other international organisation to work on the basis that it too had objective personality, in view of the rule regarding the effect of treaties on third parties. The United Nations must be considered in this, as in other important respects, as an organisation sui generis."

${ }^{387}$ SEYERSTED, Finn. Applicable law in relations between intergovernmental organizations and private parties. In: Recueil des Cours. Academie de Droit International de la Haye, Volume 122, 1967-III, pp. 427-616. pp. 437-438. "In verbis": "It is true that legal writers are uncertain as to the extent to which IGOs are subjects of international law, or 'international persons'. The general view is that only some organizations are international persons and only in certain respects, and that it can be deduced from the provisions of the constitution of each organization whether or not it is an international person and in what respects. However no writer has been able on this basis to indicate what organizations lack what capacities, without contradicting practice. Practice, on the other hand, is clear and consistent. All IGOs, large and small, political and technical, important and unimportant, powerful and powerless, in fact perform all those international acts which they are in a practical 
O evento jurisdicional anteriormente apontado provocou, ainda, o desenvolvimento de duas doutrinas - opostas - entre os internacionalistas. De um lado, reuniram-se aqueles que restringiam a capacidade da organização às atribuições contidas no tratado constitutivo e, de outro, aqueles que defendiam sua equiparação aos estados ${ }^{388}$. A doutrina parece ter chegado, hoje, a um meio-termo entre ambas as posturas referidas.

De uma forma ou de outra, resta assentado que o reconhecimento das organizações internacionais como sujeitos de direito internacional não implica sua equiparação aos estados. Apenas admite-se sistematicamente que tais estruturas possuiriam direitos e deveres na ordem jurídica global. A decisão da Corte Internacional de Justiça não significou, gize-se - e tampouco significa atualmente - tratar-se de um estado global ou de algo semelhante ${ }^{389}$.

Extrai-se de todo esse debate, em definitivo, que a capacidade de atuar internacionalmente como sujeito e de expressar, portanto, vontade influenciando politicamente a formação do direito das gentes não se restringe hoje aos estados. Ainda que superadas determinadas dúvidas, questões a esse respeito são bastante atuais e envolvem, por exemplo, a condição dos indivíduos como sujeitos de direitos e deveres no plano internacional. $\mathrm{O}$ caráter incipiente e imaturo dos referidos questionamentos se assemelha na

position to perform, irrespective of whether the acts have been specified, or can be inferred from, any provision of their constitution."

${ }^{388}$ TRINDADE, Antônio Augusto Cançado. International law for humankind : towards a new jus gentium (I): general course on public international law. In: Recueil des Cours. Academie de Droit International de la Haye, Volume 316, 2005, pp. 09-439. pp. 224-225. "In verbis“: "The international legal personality of the United Nations - and, a fortiori, of other international organizations — was soon to obtain judicial recognition. Once the International Court of Justice (ICJ) acknowledged in its landmark Advisory Opinion of 1949 on Reparations for Injuries Suffered in the Service of the United Nations that the United Nations was endowed with an objective international legal personality, it could no longer be denied that the United Nations, and a fortiori other international organizations, could act as distinct entities in the exercise of their respective functions, irrespective of the "will" of individual member States. Soon distinct doctrinal trends developed as to the extent of the powers conferred upon them : to the strict approach that the United Nations could only do what was expressly provided in its Charter, the opposite view was advanced that the United Nations had wide "inherent powers" which placed it in the same legal position than States"

${ }^{389}$ KUNZ, Josef L.. La crise et les transformations du droit des gens. In: Recueil des Cours. Academie de Droit International de la Haye, Volume 88, 1955-II, pp. 01-104. p. 57. "In verbis": "Si une organisation internationale est un sujet du droit des gens et, dans l'affirmatif, quels sont ses droits et devoirs internationaux, doit être toujours constaté par l'analyse du droit international positif. Car, comme la Cour internationale de Justice l'a remarqué dans son avis consultatif de 1949, les sujets de droit dass un ordre juridique quelconque ne sont pas nécessairement identiques en ce qui concerne leur nature et l'extension de leurs droits et devoirs. Dire que les Nations Unies sont sujet du droit des gens ne revient pas à dire qu'elles sont un Etat ou un « superEtat ». Cela veut dire seulement que, comme sujet du droit des gens, elles sont capables d'avoir des droits et devoirs internationaux. Pour savoir quels sont ces droits et devoirs il faut considérer les normes de la Charte à la lumière des principes du droit international.“ 
atualidade em grande medida àquele que era travado logo do fim da primeira guerra mundial em relação à personalidade internacional da Igreja Católica e da Sociedade das Nações ${ }^{390}$.

Em regra e de maneira mais segura e previsível, a capacidade jurídica de uma organização internacional é determinada internacionalmente pelo mesmo critério utilizado no direito interno para as pessoas morais. As atribuições estabelecidas no ato constitutivo constituiriam, assim, os limites da expressão da vontade dos sujeitos de direito internacional $^{391}$.

Em perspectiva comparativa, no que se refere aos estados, do reconhecimento decorreria a personalidade e os limites de sua capacidade se confundiriam com os limites vigentes na comunidade internacional à atuação soberana. No caso das organizações internacionais, contudo, não se subentenderiam competências de atuação e essas decorreriam, ao menos em princípio, diretamente da vontade expressa pelos sujeitos que as compõem e se encontrariam, em regra, fixadas em tratado ${ }^{392}$.

${ }^{390}$ LE FUR, Louis. La théorie du droit naturel depuis le XVIIe siècle et la doctrine moderne. In: Recueil des Cours. Academie de Droit International de la Haye, Volume 18, 1927-III, pp. 259-442. p. 408. "In verbis": "Les mêmes règles sont applicables aux collectivités internationales autres que l'État. II en est ainsi par exemple de l'Église catholique représentée par le Saint-Siège. Groupe-t-elle des intérêts distincts et possède-t-elle une volonté capable de les représenter? Cela n'est pas douteux; elle a doné par lá même la personnalité juridique. Et comme il n'est pas plus douteux qu'elle déborde les frontières d'un État donné, puisqu'elle s'étend sur tous, elle a la personnalité intemationale. J'en dirais autant bien entendu de toute autre Église qui remplirait ces mêmes conditions, mais l'Église catholique est la seule jusqu'ici qui se trouve dans ce cas et réalise á son profit à la ibis l'universalité et l'indépendance à l'égard du pouvoir temporel. Qu'en est-il, à ce point de vue de la personnalité juridique, de la Société des Nations? On la lui a parfois contestée, parce qu'elle serait un simple mandataire des États. Cette thèse est aujourd'hui de moins en moins soutenue, et, en effet, elle est contraire à une réalité certaine. Nous en voyons une preuve bien claire dans le cas o ùles décisions de ses organes, Assemblée ou Conseil, peuvent étre prises á la majorité. II est évident qu'en ce casia decisión du groupe est distincte de la volonté des membres opposants. Or, il y a plusieurs cas où la decisión peut être prise en dehors de l'unanimité qui constituait auparavant la règle du droit international publie : lors de l'introduction de nouveaux membres, par exemple, ou pour les questions de procédure et de revisión du Pacte.“

${ }^{391}$ DUPUY, René Jean. Le droit des relations entre les organisations internationales. In: Recueil des Cours. Academie de Droit International de la Haye, Volume 100, 1960-II, pp. 457-589. p. 533. "In verbis“: "C'est ce que l'on appelle la règle de la spécialité, norme qui commande la capacité juridique des personnes morales en droit interne et international. Elle a pour conséquence l'impossibilité juridique pour les organes d'agir dans des buts autres que ceux qui lui ont été assignés. Cependant, la limitation de pouvoir qui en resulte est en pratique corrigée dans une certaine mesure par la nécessité de ne pas freiner, par une interprétation trop littérale des textes de base, l'exercice de ses fonctions par l'organisation, Il faut qu'en dépit de la spécialité posée dans ses statuts, elle puisse fonctionner utilement. Ainsi la règle dc la spécialité se trouve-t-elle conjuguée avec celle de l'effet utile pour conferer aux institutions intemationales, une compétence fonctionnelle."

392 MARYAN GREEN, N.A. International law: law of peace. London: Macdonald and Evans, 1982. p. 24. "In verbis": "The personality of a subject of international law is the measure of its capacity to act. Some subjects have, like individuals in national law, the full measure of legal personality. These are the fully sovereign and independent states. Others, like companies in national law, have only such personality as has been specially accorded to them. The legal personality of international organisations is of this sort. The two following questions should therefore be carefully distinguished: does an entity have international legal personality; and if so, what is the extent of this personality If the answer to the first question is no, then it is not a subject of international law. If the answer is yes, the second question must be asked: 'how much' legal personality, or as it is more commonly put, what is the extent of its capacity." 
Nesse sentido, ainda que seja possível admitir o reconhecimento tácito, um instrumento que estabeleça suas capacidades - em regra, o ato constitutivo - mostra-se fundamental à atribuição do caráter de sujeito de direito às organizações internacionais. Além disso, os limites instituídos por tratado variam conforme a vontade expressada por seus constituintes $^{393}$. Tais limites delineiam os contornos de seus direitos e podem estabelecer fronteiras à suas responsabilidades também ${ }^{394}$.

Não apenas a questão da personalidade das associações internacionais de estados se encontra atualmente superada, também a capacidade para celebrar tratados é hoje plenamente admitida. Resta observar se todo tipo de associação internacional, dotada de personalidade, possuiria tal atribuição internacional ${ }^{395}$.

Ainda que subsistam dúvidas quanto ao uso indiscriminado dos termos "capacidade", "subjetividade" e personalidade", nesse estudo esses devem ser entendidos muitas vezes como

${ }^{393}$ ZEMANEK, Karl. The legal foundations of the international system : general course on public international law. In: Recueil des Cours. Academie de Droit International de la Haye, Volume 266, 1997, pp. 09-335. pp. 88-91. "In verbis": "According to the most widely held view the source of personality is the constituent instrument of the respective organization. The legal personality of an intergovernmental organization is thus an ad hoc creation by the founding States. The constituent instrument establishes not only the personality but determines also, by conferring certain functions and powers on the organization, the limits of its capacity to act under international law. The Advisory Opinion of the ICJ on Reparation for Injuries Suffered in the Service of the United Nations 248 is generally cited as authority for that doctrine. [...] For those who consider the powers of an international organization as delegated by their member States, such powers derive explicitly or implicitly from the constituent treaty which is the instrument of delegation. Differences of opinion exist, though, on how the implicitly delegated powers should be determined, especially on what level such determination should take place. While the earlier Advisory Opinion of the ICJ on Reparation for Injuries had recourse to "implied powers", a doctrine familiar in United States constitutional law, the later Advisory Opinion on Certain Expenses of the United Nations chose the more abstract level of functions for reference to justify its doctrine of "functional necessity"، "

394 EAGLETON, Clyde. International organization and the law of responsibility. In: Recueil des Cours. Academie de Droit International de la Haye, Volume 76, 1950-I, pp. 319-425. p. 327. "In verbis“: "A legal person, I think, is an entity having rights and duties under a system of law, which rights and, duties are conferred upon it by that law. It is a personality separate from and independent of those persons who created it or are part of it. The extent of these rights and duties may vary with each entity, and the procedure by which they are claimed or enforced may likewise vary in each situation. The application of the international law of responsibility would therefore be different for each such entity."

${ }^{395}$ LISSITZYN, Oliver J.. Territorial entities other than independent states in the law of treaties. In: Recueil des Cours. Academie de Droit International de la Haye, Volume 125, 1968-III, pp. 01-92. p. 87. "In verbis": "In general, we must conclude that there is no norm of international law that limits the class of territorial entities with treaty-making capacity to independent States, or indeed to 'States' however defined. There is no objective standard of treaty-making capacity. Whether or not a particular entity has such capacity ultimately depends on the policies of the dominant State and of other States that may or may not be interested in establishing separate treaty relations with it. Independent States, of course, remain the most important actors on the international arena for fairly evident reasons. The extent to which dependent entities appear as distinct partners in treaty relations will probably continue to fluctuate in the future as it has in the past, although the present over-all trend seems to be in the direction of diminishing it. But the growing complexity of transnational relations and concerns may yet reverse this trend." 
sinônimos por pura questão de estilo, já que não se pretende aprofundar mais em sua diferenciação ${ }^{396}$.

Uma das classificações possíveis às estruturas internacionais reconhecidas como atores na esfera global as divide em dois grupos: o das organizações interestatais e aquele das "não governamentais". Na proposta que se apresenta adiante neste trabalho, essa classificação faria pouco sentido, já que apenas as primeiras poderiam ser consideradas sujeitos de direito das gentes e, mesmo nesse primeiro grupo, distintas conformações de extrema importância não restariam nítidas ${ }^{397}$.

Os sujeitos de direito internacional que não possuem base territorial como os estados exigem, a partir de toda a construção teórica apontada, um ato constitutivo expresso que reconheça sua condição de pessoa. Em conclusão lógica, poder-se-ia afirmar, assim, que o território constituiria o mais importante elemento do reconhecimento da condição de sujeito de direito das gentes a um estado e, portanto, de sua personalidade jurídica internacional ${ }^{398}$.

No caso das organizações, conforme apontado, a oponibilidade da personificação não decorre de um elemento inerente, mas de uma expressão volitiva. Dessa forma, se, por um lado, exige-se um tratado, isto é, um ato internacional que cumpra certos requisitos de forma para que se reconheça a personalidade jurídica de uma organização internacional, contrariamente poder-se-ia afirmar que, uma vez cumpridos os requisitos exigidos pelo direito

\footnotetext{
${ }^{396}$ QUADRI, R.. Cours général de droit international public. In: Recueil des Cours. Academie de Droit International de la Haye, Volume 113, 1964-III, pp. 237-483. p. 373. "In verbis“: "Il est à peu près admis que la notion de «capacité juridique» coincide avec celle de «subjectivité juridique » ou de "personalité juridique », mais on n'est nullement d'accord sur le contenu et sur la nature de cette notion. Parfois, on a égard à la titularité «effective » des droits et des obligations, parfois, au contraire, à un simple «aptitude », à une simple «possibilité ». D'autre part cette aptitude ou possibilité, d'après certaines auteurs, donnerait lieu à une «qualification » normative de la personne réelle, qualification présupposée par les règles matérielles ; tandis que d'après d'autres il ne s'agirait que d'une pure notion scientifique ou dogmatique indiquant d'une manière syntthétique et abstraite un élément commun aux différents règles matérielles.".

397 TUNKIN, Grigory. International law in the international system. In: Recueil des Cours. Academie de Droit International de la Haye, Volume 147, 1975-IV, pp. 01-218. p. 153. "In verbis": "There are two categories of international organizations: intergovernmental (or more precisely interstate) international organizations and non-governmental international organizations. The latter category greatly outnumbers the former. The difference between these categories of international organizations is essential. Intergovernmental international organizations only constitute part of the international system as defined earlier. Non-governmental international organizations are outside this system. Intergovernmental international organizations only can be subjects of international law, take part in its development and functioning. Non-governmental international organizations do influence the development and functioning of international law, and this influence is important, but it is not direct. It is exercised through States or intergovernmental international organizations."

${ }^{398}$ SØRENSEN, Max. Principes de droit international public : cours général. In: Recueil des Cours. Academie de Droit International de la Haye, Volume 101, 1960-III, pp. 01-254. p. 136. "In verbis“: "Les sujets de droit international qui n'ont pas, comme les Etats ou parties constitutives d'Etats, une base territoriale, doivent tous leur personnalité juridique internationale à un acte quelconque de droit international. C'est le cas, en premier lieu, des organirations internationales."
} 
das gentes a um tratado, a condição de pessoa moral internacional do ente criado seria oponível a todos sujeitos de direito internacional ${ }^{399}$.

Se a idéia de soberania se confunde com o direito de comandar, isto é, de determinar condutas e de estabelecer normas, complicado se faz identificar internacionalmente um órgão investido dessas características. Por essa razão, costuma-se lançar mão do conceito de soberania interna dos estados - sob o prisma da independência - para explicar a dinâmica do poder na ordem internacional, mas tal conceito não pode ser tomado por absoluto, sob pena de negação da própria existência do direito internacional ${ }^{400}$.

$\mathrm{Na}$ verdade, a máxima descrita não se aplica apenas ao direito das gentes. Internamente também a soberania ilimitada inviabilizaria a existência do direito como algo coerente, sistêmico, estável e obrigatório. De qualquer maneira, as limitações - ou não - à soberania constituem questão de direito interno e não se aplicariam às organizações internacionais e aos seus sistemas de direito. O conceito de soberania não cabe às organizações internacionais ${ }^{401}$.

Parte da doutrina resistia e defendia que apenas os estados possuíam as características que tornavam possível a personificação. Muitos não percebiam utilidade em tal reconhecimento às associações internacionais ${ }^{402}$. Na prática, a personalidade jurídica das

\footnotetext{
${ }^{399}$ SØRENSEN, Max. Principes de droit international public : cours général. In: Recueil des Cours. Academie de Droit International de la Haye, Volume 101, 1960-III, pp. 01-254. p. 139. "In verbis“: "Ceci semble indiquer qu'on a accepté la personnalité objective des organisations internationales de caractère non-universel. Sans doute y a-t-il une coutume internationale en voie de formation, d'après laquelle nul Etat tiers ne peut contester la personnalité internationale d'une organisation internationale établie conformément aux principes du droit international dans un but légitime.“
}

${ }^{400}$ LE FUR, Louis. La théorie du droit naturel depuis le XVIIe siècle et la doctrine moderne. In: Recueil des Cours. Academie de Droit International de la Haye, Volume 18, 1927-III, pp. 259-442. p. 412. "In verbis": "Tel est l'état de la question en droit interne. Qu'en est-il en droit international? La souveraineté, nous l'avons vu, c'est le droit de commander. Existe-t-il en matière internationale un organe investi de ce droit? Évidemment non. Donc, la prétendue souveraineté internationale des États n'existe pas. Tout au plus peut-on parler de leur indépendance, simple reflet de leur souveraineté interne, comme l'a dit très justement Jellinek. Même ainsi comprise, cette souveraineté ne saurait être absolue, sans quoi ce serait la négation du droit, et spécialement du droit international. Tel a été longtemps le cas, et il en est resulté une période d'anarchie qui s'est prolongée pendant des siècles et où la communauté internationale se trouvait dans un état pré-juridique.“

${ }^{401}$ LE FUR, Louis. La théorie du droit naturel depuis le XVIIe siècle et la doctrine moderne. In: Recueil des Cours. Academie de Droit International de la Haye, Volume 18, 1927-III, pp. 259-442. p. 415. "In verbis": "L'existence d'une souveraineté prétendue illimitée, c'est donc tout au plus une question de droit positif interne, et il ne saurait être question d'une règle positive de ce genre pour la Société des Nations."

402 REUTER, Paul. Principes de droit international public. In: Recueil des Cours. Academie de Droit International de la Haye, Volume 103, 1961-II, pp. 425-656. p. 502. "In verbis“: "Alors que les Etats, par la généralité et l'importance de leurs pouvoirs, par la constance des éléments physiques qui déterminent leur assiette (territoire et population) se présentent tous suivant un schéma identique, les organisations ne se définissent que par leurs fonctions, qui varient beaucoup ; elles soulèvent même des doutes fondamentaux en ce qui concerne leur qualité de personnes juridiques ; peut-on déceler parmi elles une ou au moins quelques catégories générales, ou bien constituent-elles chacune un cas paniculier? On a même pu - au moins dans 
organizações internacionais distingue o conjunto - mormente de estados - tanto de suas vontades individuais quanto da soma das mesmas. Esses sujeitos de direito internacional associativos devem ser reconhecidos como possuidores de vontade própria, caracterizada e exercida nos limites estabelecidos em seu marco legal ${ }^{403}$.

O reconhecimento como ator não equipara esse ente necessariamente aos estados quanto à possibilidade de atuar concretivamente na ordem internacional criando normas de direito das gentes. Apenas se investe o ente da aptidão de possuir direitos e obrigações na esfera mundial $^{404}$. Uma coisa seria, portanto, possuir direitos e obrigações e, outra, algum tipo de expressão de poder equiparável ao poder soberano dos estados para produzir regras jurídicas.

A transferência de parcela de poder estatal a uma organização internacional relacionada, por exemplo, à possibilidade desta celebrar tratados - constitui expressão clara da autonomia decorrente do reconhecimento da personalidade. Ocorre que, muitas vezes, a vontade soberana dos estados resiste no interior das organizações, as quais, muitas vezes, adotam o critério da unanimidade em seus colegiados ${ }^{405}$.

certanes cas ou dans certaines doctrines - soutenir que le recours au mécanisme de la personnalité juridique était en ce qui les concernait parfaitement inutile."

${ }^{403}$ FITZMAURICE, Gerald. The general principles of international law considered from the standpoint of the rule of law. In: Recueil des Cours. Academie de Droit International de la Haye, Volume 92, 1957-II, pp. 01227. pp. 10-11. "In verbis“: "Then there is the case of certain kinds of international Organizations composed of States, such as the United Nations, the Specialized Agencies, and others, of which it can be said, since the decision of the International Court of Justice in the case of Injuries to United Nations Servants, that they do or may possess an international personality distinct from that of their component member-States, or even of the aggregate of these. These Organizations are not just assemblages of individual States, but distinct entities, possessing a corporate international personality of their own. But again, this personality is a limited one, conditioned by the character and purposes of the Organization."

${ }^{404}$ PESCATORE, Pierre. Les relations extérieures des communautés européennes : contribution à la doctrine de la personnalité des organisations internationales. In: Recueil des Cours. Academie de Droit International de la Haye, Volume 103, 1961-II, pp. 01-244. p. 30. "In verbis“: "Dire qu'une entité - que ce soit un Etat ou une organisation - est investie de la personnalité internationale signifie donc que cette entité est apte à être sujet de droits, de fonctions et, corrélativement, d'obligations de caractère international, qu'elle est, en d'autres termes, apte à agir juridiquement dans les relations internationales. Voilà donc en quoi consiste le phénomène de la personnification : c'est la constitution d'une structure d'organisation suffisamment distincte pour former une individualité propre par rapport aux Etats qui l'ont constituée et suffisamment cohérente pour être, en ellemême, le «centre d'imputation » de relations juridiques internationales qui lui sont particulières."

405 DUPUY, René Jean. Le droit des relations entre les organisations internationales. In: Recueil des Cours. Academie de Droit International de la Haye, Volume 100, 1960-II, pp. 457-589. p. 544. "In verbis": "Le transfert du pouvoir de conclure des traités dans certains domaines témoigne de l'autonomie de l'organisation vis-à-vis des Etats membres. Il lui permet en effet, d'exercer des compétences extérieures propres. On pourrait s'y tromper en remarquant que la conclusion des accords impose souvent leur approbation, soit par une assemblée plénière, soit même par un organe se prononçant à l'unanimité, ce qui traduirait l'action déterminante des Etats.“ 
As explicações quanto à origem da atribuição de capacidades a uma organização opõem, de um lado, os voluntaristas, que entendem não possuir um ente moral personalidade inata e que a instituição da mesma por tratado consubstanciaria exigência insuperável, e, contrariamente, os que sustentam o reconhecimento tácito da condição subjetiva uma vez criada a associação ${ }^{406}$.

Observa-se, apenas introdutoriamente, nesse sentido, que o reconhecimento dessa característica como elemento fundamental exclusivo para a caracterização de uma estrutura internacional poderia igualar de maneira bastante incoerente qualquer tratado que estabelecesse personalidade a uma estrutura burocrática dele decorrente a organizações internacionais hábeis a expressar vontade internacionalmente e a atuar em determinados contextos em pé de igualdade com estados.

Nesse ponto, é de se perceber uma vez mais a relação entre política e direito no interior de um ente associativo. Assim, ainda que, juridicamente, a expressão da vontade possa vir a ser considerada da organização, a formação dessa vontade se daria politicamente no órgão responsável pela concertação das vontades dos membros que a compõem ${ }^{407}$.

Importante se faz ressaltar, ainda, que organizações internacionais não se estabelecem como tais necessariamente em seus primeiros atos constitutivos. Tratados associativos, que guardam pleno poder aos estados podem evoluir paulatinamente para formar ente comum complexo, o qual pode, inclusive, adotar mecanismos de supranacionalidade. A história do

\footnotetext{
${ }^{406}$ PESCATORE, Pierre. Les relations extérieures des communautés européennes : contribution à la doctrine de la personnalité des organisations internationales. In: Recueil des Cours. Academie de Droit International de la Haye, Volume 103, 1961-II, pp. 01-244. pp. 36-37. "In verbis": "Théorie de l'attribution « ipso iure ». Selon une formule du professeur Reuter, qui a fait école, les organisations internationales ont une compétence naturelle pour participer à la vie internationale. Selon cette opinion, la capacité d'agir dans les relations extérieures est inhérente, sauf stipulation contraire expresse, à l'existence même d'une institution internationale, à condition que celle-ci ait reçu un minimum d'autonomie et une vocation assez stable et assez large pour prétendre à une action propre. [...] Théorie de l'attribution votontaire de la personnalité. Selon notre opinion, la subjectivité internationale ne doit pas être reconnue à une entité pour la simple raison que celle-ci existe et fait sentir son action dans le domaine international. La personnalité d'une organisation internationale dans les relations extérieures ne peut exister qu'en vertu d'un acte de volonté, dans la constitution même de l'organisation, destiné à conférer à celle-ci des tâches concrètes et une capacité juridique dans les relations extérieures.“
}

${ }^{407}$ DUPUY, René Jean. Le droit des relations entre les organisations internationales. In: Recueil des Cours. Academie de Droit International de la Haye, Volume 100, 1960-II, pp. 457-589. p. 545. "In verbis“: "Aussi faut-il distinguer avec soin les plans politiques et juridiques. Des considérations politiques pourront conduire à adopter certaines procédures, ou à reconnaitre, dans la conclusion des accords, un rôle déterminant à l'organe exprimant une force politique donnée, il n'empêche que juridiquement, l'engagement sera celui de l'organisation.“ 
direito das gentes fornece vários exemplos nesse sentido, tal como, por exemplo, o ocorrido na evolução da União Européia ${ }^{408}$.

A dúvida que existia quanto à personalidade jurídica internacional das confederações se referia, por outro lado, mormente à presença ou não de estruturas burocráticas comuns. Tal preocupação pode servir para demonstrar que a personificação decorre muito mais de uma necessidade que de uma intenção das partes de um tratado, as quais poderiam conferir personalidade sem vontade de criar ente a elas equiparável no que se refere a capacidade internacional de expressar vontade política concretiva ${ }^{409}$. A chave do descolamento das confederações de seus estados confederados e de seu reconhecimento como sujeito estaria na existência de órgãos autônomos, isto é, distintos - mesmo que análogos - daqueles dos seus membros ${ }^{410}$.

Ressalte-se, neste momento, que muitos estados que existem na atualidade foram formados por associações de sujeitos de direito internacional. Reconhece-se, portanto, que a convivência de personalidades jurídicas com uma personificação comum - como hoje se

408 REUTER, Paul. Principes de droit international public. In: Recueil des Cours. Academie de Droit International de la Haye, Volume 103, 1961-II, pp. 425-656. pp. 516-517. "In verbis“": “Comme on l'a déjà indiqué les organisations internationales apparaissent historiquement comme un prolongement du phénomène étatique. Les Etats tiennent des conférences internationales ; celles-ci d'abord occasionnelles, deviennent priodiques, puis elles se dotent de secrétariats permanents, leurs attributions vont en croissant et par des atténuations, puis par des dérogations à la règle de l'unanimité, s'affirme une volonté propre de l'organisation. [...] On ne saurait donc être surpris que la notion de volonté propre, indissociable de celle de personnalité juridique ne se soit développée que petit à petit, et qu'elle ne se présente encore aujourd'hui que d'une manière souvent très limitée ou imparfaite.“

${ }^{409}$ PILOTTI, Massimo. Les unions d'états. In: Recueil des Cours. Academie de Droit International de la Haye, Volume 24, 1928-IV, pp. 441-546. p. 475. "In verbis“: "II a été longuement discuté entre les auteurs, du point de savoir si la forme d'union d'États qui a reçu le nom de Confédération est, ou non, une personne juridique du droit international. La question sera examinée plus loin; cequ'il importe d'observer pour l'instant est qu'il peut sans doute exister des systèmes d'association, parfois dépourvus de toute organisation, parfois possédant des organes communs, mais sans que le système dans son ensemble en acquière la personnalité. II est préférable de réserver le nom de confédérations à des formes d'association plus évoluées et plus complexes : on doit toutefois reconnaître qu'une confédération peut surgir du développement d'un système plus simple, tel qu'une alliance qui serait devenue permanente."

${ }^{410}$ PILOTTI, Massimo. Les unions d'états. In: Recueil des Cours. Academie de Droit International de la Haye, Volume 24, 1928-IV, pp. 441-546. pp. 489-490. "In verbis“": "On a parfois soutenu que la Confédération n'est qu'un simple vinculum juris entre États, une raison collective de droit international, un simple o «rapport» de droit sans personnalíté juridique: elle ne posséderait pas de droits propres et n'agirait en réalité qu'au nom et par délégation des États confédérés. [...] Mais si ces organes agissent au nom de la Confédération, et non des États confédérés, et si les États tiers entrent en rapport avec eux en les considérant comme des organes de la Confédération prise dans son ensemble, et non comme des organes reunís des divers États memores ou comme des organes communs à tous ees États, cela veut diré que l'union est devenue une collectivité personnifiée.“ 
percebe em organizações internacionais de integração - pode constituir mero estágio tendente à formação de estados ${ }^{411}$.

As organizações internacionais conformam, por um lado, resultado da maior interação entre os estados e, por outro, ferramenta à maior institucionalização da ordem global e esses arranjos comuns acabam, portanto, preenchendo lacunas inerentes à estrutura da comunidade internacional $^{412}$.

A personalidade jurídica não seria, contudo, inerente a qualquer tipo de associação internacional $^{413}$. Nem todo tratado com estrutura burocrática exigiria, assim, personalidade jurídica internacional, ainda que - ao menos em regra - necessitasse de sua atribuição na ordem interna do estado de sua sede ou do lugar onde se encontram seus órgãos ${ }^{414}$. Esse

411 REUTER, Paul. Principes de droit international public. In: Recueil des Cours. Academie de Droit International de la Haye, Volume 103, 1961-II, pp. 425-656. p. 501. "In verbis“: "Les organisations intergouvemementales sont, comme sujets de droit, intimement lies à l'évolution de l'Etat lui-même. En effet la société internationale connaissait depuis longtemps des exemples d'unions d'Etats évoluant progressivement du type confédéral au type fédéral et présentant des stades d'évolution dont le premier (l'existence de plusieurs Etats) et le dernier (la subsistance d'une seul l'Etat fédéral) étaient indiscutables, mais dont les stades intermédiaires étaient plus complexes ; ils se caractérisaient nécessairement par la coexiatence d'une personnalité internationale des entités composantes avec la personnalité internationale de l'Union.“

412 VELASCO, Manuel Diez de. Instituciones de derecho internacional público - Tomo II. Madrid: Editorial Tecnos, 1977. p. 31. "In verbis": "La vida internacional contemporánea presenta como una de sus características más sobresalientes la proliferación y el perfeccionamiento de las Organizaciones internacionales. Una serie de razones explican el fenómeno reseñado. En primer término, el aumento de la vida de interrelación entre los Estados, el convencimiento de la imposibilidad de vivir aislados y la necesidad, como corolario de lo anterior, de gestionar en común una serie de intereses que aparecen con toda evidencia como colectivos. No es, pues, extraño que los Estados tiendan a institucionalizar de forma permanente sus relaciones y la gestión de sus intereses comunes a través de las Organizaciones internacionales. Una influencia notable y profunda en el fenómeno descrito la encontramos en las imperfecciones de la Comunidad internacional general, ya examinada, y muy especialmente en la inexistencia en la misma de órganos permanentes y de un poder legislativo unificado. No es aventurado, pues, decir que las Organizaciones internacionales, especialmente aquellas de fines generales como las Naciones Unidas, contribuyen a suplir las deficiencias de la Comunidad internacional general principalmente en sus aspectos legislativo y organizativo."

413 EAGLETON, Clyde. International organization and the law of responsibility. In: Recueil des Cours. Academie de Droit International de la Haye, Volume 76, 1950-I, pp. 319-425. pp. 329-330. "In verbis": "I do not think the conclusion can be reached that all the organizations designated as International Public Unions are endowed with legal personality, if for no other reason than because they are of so many different kinds that they cannot be put together as a type. [...] Each of them is based upon a treaty, but the agreement does not always make clear whether or how much, international legal personality the signatories intended to confer upon the institution created. It is not an essential part of the definition of an international legal person that it should be able to give orders to or to conduct legal relationships with sovereign states; international institutions deal with entities not hitherto regarded as subjects of international law (individuals, corporations), and for the most part under municipal law (e. g., contracts) rather than under international law."

414 EAGLETON, Clyde. International organization and the law of responsibility. In: Recueil des Cours. Academie de Droit International de la Haye, Volume 76, 1950-I, pp. 319-425. p. 333. "In verbis“: "The few examples we have taken reveal the uncertainty and lack of clear provision as to the legal status of the Unions; but it seems clear enough that many of them were given some legal status, either by a treaty, or by declaration, or incorporation, or by other act, by the government near which it is located. At the least, they were able to make contracts and to take other legal actions under the law of the state in which they function." 
constitui o critério hoje amplamente adotado à caracterização de uma organização internacional. Organizações internacionais podem ser, assim, conceituadas em sentido amplo como associações - mormente de estados, mas também de outras organizações - dotadas de personalidade jurídica, com órgãos permanentes e orientadas por um tratado constitutivo ${ }^{415}$.

De todo o exposto, a personalidade jurídica consubstancia característica essencial para a atuação de um ente no ambiente internacional. O caráter absoluto dessa premissa subsiste ainda que se reconheçam estruturas não dotadas da característica que de alguma forma atuam no contexto global. Isso se deve, em grande medida, ao fato de o não reconhecimento como pessoa jurídica internacional dificultar a ampla atuação desses entes, por exemplo, na produção do direito das gentes.

Estados foram durante muito tempo reconhecidos como únicas estruturas internacionais dotadas de personalidade. No decorrer do século $\mathrm{XX}$, a personificação das organizações internacionais se consolidou e conforma hoje questão sedimentada pela doutrina e pela jurisprudência. A atribuição de personalidade, contudo, não basta à atuação na ordem global. Seu exercício depende dos limites estabelecidos à capacidade do agente, a qual nos estados se confunde com os limites da soberania e nas organizações internacionais, em regra, se encontra estabelecida pela vontade expressa nos tratados.

\subsection{A Ordem Internacional, Solução de Controvérsias e Organizações Internacionais}

Estados tradicionalmente, mas atualmente também as organizações internacionais possuem atribuição criativa de normas no direito internacional ${ }^{416}$. No momento em que sujeitos de direito internacional criam uma ordem legal específica celebrando um tratado que

\footnotetext{
415 TUNKIN, Grigory. International law in the international system. In: Recueil des Cours. Academie de Droit International de la Haye, Volume 147, 1975-IV, pp. 01-218. pp. 157-168. "In verbis“: "An international organization is generally defined as an association of States based on an international treaty and having permanent organs. Each international organization is a system within the framework of an international system. Components of such a system are States members, organs of an organization, comprising representatives of member States and a secretariat. The basic components are evidently States. The system of an international organization includes also specific elements. Namely interactions between the components, norms of international law and some other norms of the international juridical system."

${ }^{416}$ GIRAUD, Emile. Le droit international public et la politique. In: Recueil des Cours. Academie de Droit International de la Haye, Volume 110, 1963-III, pp. 419-809. p. 428. "In verbis": "Qui crée le droit international ? Ce sont les gouvernements qui concluent des conventions et décident d'y devenir partie ou qui par leur pratique ou par des manifestations collectives de volonté (résolutions votées par des assembles internationales) créent la coutume dans sa forme traditionnelle ou dans ses formes nouvelles.“
} 
constitui um sistema associativo, passam a se submeter não apenas ao direito internacional geral, mas também ao direito criado naquela esfera jurídica específica ${ }^{417}$.

Ultrapassadas essas premissas, cumpre perceber que os sistemas de governança específicos amoldam-se pelo direito e evoluem podendo partir de formações rudimentares e chegar à institucionalização de sistemas de solução de controvérsias ${ }^{418}$.

Estruturas normativas mais elaboradas podem, nesse sentido, criar tribunais permanentes para o julgamento de contendas. Uma das características que poderia ser apontada como marcante em uma ordem jurídica internacional seria, assim, a possibilidade de se solucionarem de maneira institucionalizada as dúvidas surgidas em seu marco legal ${ }^{419}$.

\begin{abstract}
${ }^{417}$ MONACO, Riccardo. Cours général de droit international public. In: Recueil des Cours. Academie de Droit International de la Haye, Volume 125, 1968-III, pp. 93-336. pp. 285-286. "In verbis": "Nous avons déjà remarqué que c'est surtout en fonction des normes du droit international particulier que de nouveaux sujets, et spécialement des individus, ont acquis des capacités juridiques internationales, Il faut tout d'abord mettre en évidence que les ordres juridiques dans lesquels ce phénomène se réalise sont ceux appartenant à des organisations internationales. L'ordre juridique d'une organisation internationale déterminée n'est pas semblable à celui des autres organisations, ce qui peut avoir des conséquences également à l'égard de la qualité et du nombre des sujets. En principe, seulement les Etats membres sont sujets de l'ordre juridique particulier créé par l'acte institutif de l'organisation : cela signifie que ces Etats sont en même temps sujets du droit international et du droit de l'organisation. Ce dernier règle aussi les rapports internes de l'organisation, et il se peut, par conséquent, que les personnes qui ont des rapports avec les activités de l'organisation deviennent titulaires de droits et d'obligations dans l'ordre interne de l'organisation même. C'est le cas des fonctionnaires et agents de l'organisation, des représentants des Etats membres et d'Etats tiers auprès de l'organisation lorsqu'ils sont considérés non pas comme des organes de l'Etat auquel ils appartiement, mais comme des individus qui sont destinataires, à titre individuel, de certaines normes émises par l'organisation.“
\end{abstract}

${ }^{418}$ SLAUGHTER, Anne-Marie. International law and international relations. In: Recueil des Cours. Academie de Droit International de la Haye, Volume 285, 2000, pp. 09-249. p. 178, "in verbis": "Stone Sweet offers a general theory of the emergence and evolution of systems of governance. 'The theory holds that we can move, by virtue of a self-sustaining process from a single dispute about the terms of a dyadic contract to an elaborate governmental system.' The process divides into four discrete stages. It begins with a rudimentary normative structure, including at least the norm of reciprocity and probably also some established patterns of doing business. The existence of this structure makes it possible for two individuals to enter a simple contract, or a "dyad", both by helping prevent disputes and helping resolve them once they arise. Step two is to delegate the task of dispute resolution to a third party, moving from "dyad" to "triad". This step is logical as long as the two parties have a greater interest in resolving the dispute than maintaining their conflict; if so, "the move to triadic governance is a means of overcoming low levels of trust and weak behavioural norms'. Assuming the inevitability of disputes arising from contracts and the inability of the two parties to a contract to resolve their disputes on their own or to impose solutions on each other, the likelihood of delegation to a third party in many cases is high. Dyad is thus likely to lead to triad. Step three of the model involves a shift in the adjudicator's function from simple dispute resolution to norm generation, or from triad to 'triadic rulemaking"”.

${ }^{419}$ ACCIOLY, Hildebrando; NASCIMENTO E SILVA, G.E. do; CASELLA, Paulo Borba. Manual de direito internacional público. São Paulo: Saraiva, 2011. p. 821. "In verbis": "A institucionalização dos mecanismos de solução de controvérsias entre estados é canal e caminho para a redução dos efeitos disruptores sobre o sistema, decorrentes das tensões e da permanência de controvérsias não ou mal resolvidas, entre sujeitos de direito internacional (esperando que o contexto pós-moderno abra caminho para exercício do direito de ação pelo ser humano e outros agentes, enquanto expressões da sociedade civil internacional, ao lado dos estados e das organizações internacionais). A existência do mecanismo institucionalmente estipulado é canal e caminho para que as controvérsias entre estados possam ser resolvidas de modo pacífico, mediante mecanismos judiciais e arbitrais.“ 
Cumpre ressaltar, que uma ordem intergovernamental não precisa adotar necessariamente mecanismos políticos de resolução de controvérsias. Em outras palavras, não apenas arranjos supranacionais podem adotar soluções institucionais de litígios como regra.

Tribunais funcionam como mecanismos de proteção da normatividade e constituem naturalmente o ponto central de uma estrutura legal. No caso específico do direito internacional, sistemas de solução de controvérsias podem servir para garantir a preservação de marcos acordados em tratado e seu desenvolvimento surgiria, assim, como condição fundamental à prevalência do jurídico na esfera internacional da atualidade.

A estabilidade de um ordenamento jurídico residiria, portanto, no exercício do poder pelos sujeitos regularmente investidos de competência para tanto ${ }^{420}$. A preservação do sistema exige, contudo, estrutura garantidora de sua coerência e isso se daria por meio dos sistemas de solução de controvérsias entre os sujeitos que compõem e se submetem ao ordenamento.

Importante se faz ressaltar que entre os aspectos significativos de uma organização internacional estão suas regras de funcionamento interno e, dentre essas, destaca-se sua normativa para dirimir $\operatorname{conflitos}^{421}$. A busca por órgãos responsáveis pela solução de controvérsias no sistema interno de uma organização, inclusive para sua caracterização como tal, não deve ser ofuscada pela identificação de estruturas administrativas, é dizer, por um secretariado, pela burocracia internacional ${ }^{422}$.

No que diz respeito à autonomia dos tribunais internacionais, essa não se refere apenas à relação desses órgãos com os estados e os mesmos, ainda que componham o sistema de solução de litígios de uma organização internacional, devem ser considerados independentes dela $^{423}$.

\footnotetext{
${ }^{420}$ SCELLE, Georges. Théorie et pratique de la fonction exécutive en droit international. In: Recueil des Cours. Academie de Droit International de la Haye, Volume 55, 1936-I, pp. 87-202. p. 107. "In verbis“": "La première manifestation de l'activité exécutive consiste dans le contrôle, et ce contrôle s'exerce tout d'abord sur l'investiture des compétences. Il importe en effet à la stabilité de l'ordonnancement juridique que les actes juridiques ne soient faits que par des agents ou sujets de droit régulièrement investis de leurs compétences.“
}

${ }^{421}$ LACHS, Manfred. The development and general trends of international law in our time. In: Recueil des Cours. Academie de Droit International de la Haye, Volume 169, 1980-IV, pp. 09-377. p. 138. "In verbis“" "Another significant aspect of the life of an international organization is what I would call its internal law regulations: provisions concerning the whole of its structure. This constitutes in large international organizations a whole system of rules - rules of procedure for its Organs, financial and staff regulations, provisions for the settlement of disputes, etc."

${ }^{422}$ Em TRUYOL Y SERRA, Antonio. Théorie du droit international public : cours général. In: Recueil des Cours. Academie de Droit International de la Haye, Volume 173, 1981-IV, pp. 09-443. p. 377-380, o autor identifica três tipos de órgãos nas orgaizações internacionais: deliberativos, executivos e administrativos.

${ }^{423}$ MENEZES, Wagner. Tribunais internacionais: jurisdição e competência. São Paulo: Saraiva, 2013. p. 151. "In verbis": "Os Tribunais ou Cortes Internacionais são órgãos autônomos, dotados de poder jurisdicional conferido pelos Estados, com competência para dirimir sob a égide do Direito Internacional questões ligadas à 
Os sistemas de solução de controvérsias institucionalizados estabelecidos pelos tratados que conformam a base jurídica de um arranjo internacional específico constituem instrumentos fundamentais à preservação da coerência dessas ordens normativas que se descolam do direito das gentes geral ${ }^{424}$.

A solução de litígios não constitui fenômeno novo, mas o controle do cumprimento das normas internacionais, por outro lado, surgiu apenas quando da constituição de entes que atuam no plano interestatal de maneira autônoma: as organizações internacionais ${ }^{425}$. Tratamse de duas funções distintas, a jurisdicional, exercida pelos sistemas internacionais de resolução de diferendos, e a executivo/administrativa, exercida por estruturas burocráticas das associações internacionais.

Nesse sentido, percebe-se que, na evolução da institucionalidade da organização política européia, a função julgadora desempenhou papel determinante. A semente judiciária exercida pelo tribunal comunitário e pelos tribunais de cada um dos estados membros não

\begin{abstract}
sua aplicação, por meio de um rito processual e procedimental judiciário que tem seu fim em uma sentença que deve ser obrigatoriamente cumprida pelas partes. Assim, na raiz do conceito de Tribunais Internacionais está o poder decisório conferido a eles para dizer o direito, a sua jurisdição e esse poder/dever é determinante para que se possa entender um determinado órgão ou entidade como um tribunal ou corte, pois é de onde emana a sua autoridade e força jurídico-normativa no sistema internacional. A autonomia é também elemento fundamental à medida que ela vai garantir a impessoalidade nas decisões, a não ingerência na atuação e nas decisões do Tribunal. A Corte pode até ser criada no quadro de uma organização internacional, mas tem que guardar em relação a ela certa margem de liberdade, visto que a autoridade da decisão reside na liberdade de conhecer o direito, sem limitações, ingerências ou tutelas de entidades ou Estados. Ademais, esse poder de decidir deve vir acompanhado da autoridade decisória de gerar um ilícito, caso a decisão não seja cumprida pela parte julgada culpada."
\end{abstract}

${ }^{424}$ SOHN, Louis B.. Settlement of disputes relating to the interpretation and application of treaties. In: Recueil des Cours. Academie de Droit International de la Haye, Volume 150, 1976-II, pp. 195-294. p. 205. "In verbis": "Frequently, the parties to a treaty anticipate the possibility of future disputes and provide expressly in the treaty itself for a method of settlement. In some cases provisions for a dispute settlement procedure are a necessary ingredient of the treaty, without which it may not be possible to reach a compromise on some crucial treaty clauses. Otherwise the result of complex negotiations can be easily destroyed by unilateral interpretations and bitter conflicts may replace the euphoria created by the successful conclusion of the negotiating process. Effective legal procedures for dispute settlement are especially important for small countries and for economically weak States. While the larger and more powerful countries can apply extralegal, political and economic pressures, it is safer for smaller and weaker ones to have the dispute directed into legal channels where the principle of equality before the law prevails. As far as multipartite treaties are concerned, there is the added need for achieving uniformity of their application through some centralization of the interpretative function. In recent codification conferences held under the auspices of the United Nations questions have arisen several times with respect to the most appropriate institution and procedure for settling disputes relating to the interpretation and application of codificatory treaties."

${ }^{425}$ TUNKIN, Grigory. Politics, law and force in the interstate system. In: Recueil des Cours. Academie de Droit International de la Haye, Volume 219, 1989-VII, pp. 227-395. p. 382. "In verbis“: "The mechanisms of international control over the fulfillment by States of their international obligations is a comparatively recent phenomenon. The legal basis of this mechanism is the international treaties or decisions of international organizations. As it exists now it is applied only to international treaties and, in some cases, to resolutions of international organizations. In most cases the control is exercised by international organizations and international organs." 
apenas extraiu normatividade do sistema regional, mas também concretizou a vontade comum ampliando a forma e a estrutura da organização internacional ${ }^{426}$.

Não raramente surgem comparações entre o modelo da União Européia - reconhecido como uma das estruturas de organizações internacionais que mais evoluíram - e um estado federal $^{427}$. Percepções do tipo costumam sustentar argumentos daqueles internacionalistas que entendem as organizações como uma etapa do processo de centralização do poder político mundial.

Noutro aspecto importante, a ressaltada institucionalização não conforma característica apenas de sistemas normativos que envolvem numero reduzido de estados como os fenômenos regionais. Exemplos multilaterais surgem tanto na sistemática da Organização Mundial do Comércio quanto naquela criada com base na Convenção do Mar, as quais possuem mecanismos institucionalizados de solução de controvérsias ${ }^{428}$.

Em perspectiva mais estrita, o acesso aos sistemas de solução de controvérsias internacionais pelas organizações internacionais pode fornecer importantes elementos para a classificação de sujeitos internacionais proposta nesse estudo. A mera personalidade jurídica

${ }^{426}$ CAPOTORTI, Francesco. Cours général de droit international public. In: Recueil des Cours. Academie de Droit International de la Haye, Volume 248, 1994-IV, pp. 09-343. p. 340. "In verbis“: "La procédure du renvoi préjudiciel a beaucoup de mérites. Elle a permis à la Cour d'intervenir sur des questions qui probablement ne lui auraient jamais été soumises à l'initiative d'une institution ou d'un Etat membre. Il suffit de penser à l'élaboration des notions d'efficacité directe et de primauté. Le développement du droit communautaire et son renforcement doivent donc beaucoup à l'article 177 et à la jurisprudence que la Cour a promulguée en application de cette norme. En outre, à travers les réponses données par la Cour à propos de l'interprétation de normes communautaires, il a été permis aux juges nationaux de vérifier la conformité à ces normes du droit interne. On a établi, ainsi, un système de contrôle communautaire «capillaire» des comportements des Etats membres."

${ }^{427}$ CAPOTORTI, Francesco. Cours général de droit international public. In: Recueil des Cours. Academie de Droit International de la Haye, Volume 248, 1994-IV, pp. 09-343. p. 322. "In verbis“: "Plus en particulier, il faut se demander si les Communautés européennes et l'Union européenne nouveau-née sont susceptibles d'être ramenées au modèle classique des organisations internationales, dont elles seraient l'exemple le plus évolué (et pour la même raison te plus intéressant). ou si, au contraire, ce phénomène a assumé une dimension étatique et, plus précisément, serait devenu un Etat de type fédéral ou au moins préfédéral. En choisissant cette deuxième approche, les traités au travers desquels on a établi les Communautés et ensuite l'Union européenne, même en se présentant comme des traités internationaux normaux conclus par des Etats souverains, auraient, par rapport aux Communautés et à l'Union, la même fonction que celle qui revient à une constitution par rapport à un Etat.“

${ }^{428}$ CHARNEY, Jonathan I.. Is international law threatened by multiple international tribunals? In: Recueil des Cours. Academie de Droit International de la Haye, Volume 271, 1998, pp. 101-382. p. 121. "In verbis“: “[...] the field has become more crowded in the period subsequent to World War II. In this period, the international community witnessed the establishment of several standing courts and other dispute settlement bodies formed to resolve disputes in specialized areas of international law. These include, the Court of Justice of the European Community, the European Court of Human Rights, the Inter-American Court of Human Rights, the General Agreement on Tariffs and Trade (GATT)/World Trade Organization (WTO) dispute settlement system and the similar systems of the North American Free Trade Agreement (NAFTA) and the Free Trade Agreement (FTA), as well as the recently established Tribunal on the Law of the Sea." 
internacional não garante acesso a qualquer entidade reconhecida como organização internacional nos dias atuais à Corte Internacional de Justiça, por exemplo.

A esse respeito, percebe-se que o artigo 34 de seu estatuto se refere expressamente a organizações internacionais de direito público, não como partes de demandas, mas como terceiros afetados ou que podem ser convocados à prestação de informações ${ }^{429}$. Mas a que organizações internacionais se refere o estatuto? Indiscriminadamente a toda e qualquer associação de estados - dotada ou não de personalidade jurídica internacional - ou àquelas reconhecidamente equiparáveis aos estados na concreção do direito internacional?

A importância do reconhecimento das organizações como "pessoas" é seguramente basilar, mas seria a personalidade, de fato, a única característica que se apresenta como requisito ao reconhecimento de uma associação de estados como uma organização internacional?

${ }^{429}$ Comentando o artigo 34 do estatuto da Corte, HAMBRO, Edvard. The jurisdiction of the International Court of justice. In: Recueil des Cours. Academie de Droit International de la Haye, Volume 76, 1950-I, pp. 121215. p. 162. "In verbis": "It should be noted that the organizations referred to in this article of the Statute are pubic international organizations. According to ordinary accepted usage, this must mean organizations where States or governments are members. “ 


\section{ORGANIZAÇÕES INTERNACIONAIS, PERSONALIDADE JURÍDICA E SOLUÇÃO DE CONTROVÉRSIAS: UMA PROPOSTA DE CLASSIFICAÇÃO}

O termo organização internacional - de direito público - é utilizado, em regra, de forma abrangente pela doutrina, a qual costuma referir-se como tal aleatoriamente a qualquer tipo de aglomeração institucionalizada de representantes de sujeitos de direito internacional ${ }^{430}$.

Teorias mais tradicionais identificam ao menos três características comuns às organizações internacionais: serem constituídas por estados por meio de tratados, consubstanciarem meios de cooperação voluntária e possuírem caráter permanente ${ }^{431}$. Ao menos no que se refere à primeira das características apontadas, tal concepção clássica não mais se sustenta e organizações - e outras formas de estruturas internacionais - podem ser partes de acordos constitutivos de organizações internacionais.

No que se refere aos tipos de arranjos, várias são as classificações propostas pelos internacionalistas e essas estruturas podem ser divididas, por exemplo, entre esquemas de cooperação e de integração ou entre iniciativas regionais e globais ${ }^{432}$. Além da finalidade, a

\footnotetext{
${ }^{430}$ MCDOUGAL, Myres S.. International law, power, and policy: a contemporary conception. In: Recueil des Cours. Academie de Droit International de la Haye, Volume 82, 1953-I, pp. 133-259. p. 143. "In verbis": "By international governmental organization we refer to such organizations as nation-states establish by agreement among themselves for the promotion of common purposes. Sometimes these organizations are general-purpose and are granted a competence, as in the League of Nations and the United Nations, which may in measure affect all values. More commonly, of course, the organization is created for certain very specialized purposes with respect to certain specific values and its competence is strictly limited to its purposes. Well-known examples of such specialized and limited organizations are the International Labor Organization, The Food and Agriculture Organization,. The International Bank for Reconstruction and Development, The International Monetary Fund, The World Heath Organization, U. N. E. S. C. O., The Universal Postal Union, and The International Telecommunications."

${ }^{431}$ LACHS, Manfred. The development and general trends of international law in our time. In: Recueil des Cours. Academie de Droit International de la Haye, Volume 169, 1980-IV, pp. 09-377. p. 132. "In verbis“": "There have been many attempts to define international organizations. May I confine myself to indicating three features of such bodies: they are established by agreements between States; they are intended as instruments of voluntary co-operation; they are typically a permanent character, but it is not excluded that an international organization may be set up to last only for a given period or until a given purpose is achieved."

${ }^{432}$ Sobre os tipos de organizações internacionais, dividindo-as em de cooperação e integração; mundiais e parciais; políticas e setoriais; e consultativas e normativas, VIRALLY, Michel. Panorama du droit international contemporain : cours général de droit international public. In: Recueil des Cours. Academie de Droit International de la Haye, Volume 183, 1983-V, pp. 09-382. pp. 254-255.
} 
amplitude territorial e a abrangência constituem, portanto, fatores importantes à análise desses esquemas $^{433}$.

Também a diferenciação cronológica adotada pela doutrina entre as organizações internacionais "estandatizantes", isto é, criadas para o estabelecimento de padrões internacionais em setores específicos e cuja normativa poderia ser aplicada pelos estados individualmente, e as organizações "institucionais", como as Nações Unidas e a Organização Mundial do Comércio, serve atualmente de maneira bastante aceitável como parâmetro atemporal de classificação desses arranjos do direito das gentes dotados de personalidade jurídica $^{434}$.

Não se pode negar a importância da personificação para o reconhecimento de estruturas associativas capazes de atuar internacionalmente, mas ela encontra dificuldades para se sustentar como critério exclusivo para tanto. Nesse sentido, a delegação de poder às estruturas formadas pelos sujeitos de direito internacional, mormente estados, pode, em

${ }^{433}$ VELASCO, Manuel Diez de. Instituciones de derecho internacional público - Tomo II. Madrid: Editorial Tecnos, 1977. p. 34. "In verbis": "Los criterios clasificativos pueden ser varios. Desde un punto de vista sociológico podríamos distinguir entre Organizaciones que persiguen preferentemente la simple cooperación entre los miembros, y que son las más numerosas, y aquellas que pretenden la integración, entendiendo por tal un medio específico de cooperación caracterizado por el hecho de que los miembros que componen la Organización <<deciden en todo o en parte someterse a una autoridad exterior〉> [...] Dicha autoridad, debemos precisar, está fuera de los Estados que la componen, pero se concreta generalmente en uno o varios órganos de la propia Organización. Prácticamente desde un punto de vista equivalente se ha distinguido entre Organizaciones intergubernamentales y supranacionales, conceptos en los que profundizaremos al estudiar la naturaleza jurídica de las distintas 0.I. y en especial las Comunidades Europeas en el Capítulo LIV. Dada 1a sistemática del presente Manual expondremos con mayor detenimiento los dos criterios clasificativos siguientes: A) Atendiendo a los fines principales que las Organizaciones persiguen, y, B) Teniendo en cuenta la amplitud territorial, y prestando atención al regionalismo internacional.”

${ }^{434}$ ABI-SAAB, Georges. Cours général de droit international public. In: Recueil des Cours. Academie de Droit International de la Haye, Volume 207, 1987-VII, pp. 09-463. pp. 446-447. "In verbis“: "Le premier but de ces traités était souvent la «standardisation», par l'unification des critères et des réglementations internes d'une même activité. Une réglementation internationale qui, bien qu'elle impose une obligation de «faire», pouvait être gérée directement par les Etats individuellement. [...] Il s'agit d'une deuxième génération d'organisations internationales, et notamment d'une organisation internationale générale porteuse de l'approche du droit international de coopération au centre des préoccupations du droit et des relations internationales, la problématique de la guerre et de la paix ; avec des résultats médiocres il est vrai, comme nous avons eu l'occasion de le voir. Cette tendance s'accentue et s'affirme davantage après la seconde guerre mondiale avec l'organisation des Nations Unies au centre d'une constellation d'autres organisations à vocation universelle. Pour cette deuxime génération et notamment pour l'organisation internationale générale, c'est le traité qui est au service de l'organisation. Il lui sert d'instrument d'habilitation (enabling instrument), définissant, en tant que cadre constitutionnel, le champ d'activité et les pouvoirs de l'organisation dans l'accomplissement de fonctions et la poursuite de buts très étendus. Ceux-ci, dans le cas des Nations Unies, embrassent tout le champ des relations internationales, c'està-dire également du droit international, l'envisageant ainsi comme champ de coopération, autrement dit sous l'angle du droit de coopération.“ 
alguma medida, constituir elemento alternativo que se apresentaria como ponto de partida teórico à classificação mais apropriada desses sujeitos de direito das gentes ${ }^{435}$.

Assim sendo, as categorizações atualmente disponíveis não se mostram, sob a perspectiva deste estudo, eficientes como padrão explicativo aplicável à racionalização da organização do poder global. Sem critérios baseados nos limites da atuação concretiva dessas conformações, em uma mesma espécie de associação acabam sendo alocadas estruturas meramente burocráticas e organizações capazes de atuar em pé de igualdade com estados na ordem global.

Possível se faz propor, assim, a categorização das estruturas associativas internacionais em três grupos distintos. O primeiro seria conformado pelos acordos que normatizam setores específicos da sociedade - como o serviço postal, telefônico e o bancário. Nesse primeiro agrupamento, estariam inseridas, por exemplo, as experiências reconhecidas no século XIX como precursoras das complexas iniciativas associativas atuais.

Em um segundo grupo, poderiam ser reunidos os tratados que criam estruturas burocráticas internacionais, de caráter meramente registral e no terceiro grupo, finalmente e apenas nele, as organizações internacionais, sujeitos de direito internacional com atribuições concretivas em determinadas situações equiparáveis aos estados ${ }^{436}$.

\footnotetext{
${ }^{435}$ MCDOUGAL, Myres S.. International law, power, and policy: a contemporary conception. In: Recueil des Cours. Academie de Droit International de la Haye, Volume 82, 1953-I, pp. 133-259. pp. 230-231. "In verbis": "For most international governmental organizations the most important base of power is obviously formal power itself, the competence in terms of formal authority granted by the member nation-states to the organization. The formal authority so granted varies greatly of course from organization to organizations in terms of the range of values that may be affected by decisions of the organization, of the degree of authority that may be exercised in making decision, and of the domain of people who may be affected by decision. With the broad competence granted to the United Nations which may be exercised to affect all values, which embraces a very high degree of authority in meeting threats to the peace, breaches of the peace and acts of aggression, and which is authorized to extend even to non-member nation-states, may be contrasted the lesser competences granted to such organizations as the International Monetary Fund and other specialized agencies. Whatever the measure and degree of competence granted by member nation-states to any particular organization, however, that measure and degree, with attendant sanctions, become a part of the expectations of all participants in the world power process and such expectations may be invoked by the organizations so established as a base of power."
}

${ }^{436}$ ROSENNE, Shabtai. The perplexities of modern international law: general course on public international law. In: Recueil des Cours. Academie de Droit International de la Haye, Volume 291, 2001, pp. 09-471. pp. 36-37. "In verbis": "The period also saw the beginnings of what are today called international intergovernmental organizations. These were not international organizations as we now know them, with wide international responsibilities, broad membership, and a largely common structure with recognized personality under international law and frequently in internal law also. They were rather administrative clearing houses as international intercommunication, both of States and of individuals, intensified. Telegraphic unions between neighbouring European and later American States started coming into existence in the middle of the century, leading to today's International Telecommunication Union 28. The Treaty of 3 May 1875 established the General Postal Union, a precursor of the Universal Postal Union. International regulation of public health matters, now concentrated in the World Health Organization, began with the International Sanitary Convention of 30 January 1892 which was of particular concern to navigation through the Suez Canal. The two Peace Conferences were forerunners of the League of Nations in providing deliberative organs for a wide range of 
Nas duas primeiras categorias, ainda que os entes sejam dotados de personalidade, sua capacidade de atuação na ordem internacional seria limitada. No que se refere ao terceiro grupo, contrariamente, as estruturas que cumprem seus requisitos não teriam, observa-se, capacidade internacional absolutamente análoga a dos estados, mas em determinadas circunstâncias e contextos exerceriam vontade concretiva plena.

Em uma tentativa de se sistematizar uma gradação de capacidades na lógica proposta, apenas estados teriam capacidade internacional plena. Autuando por vezes com capacidade concretiva plena, mas nunca absolutamente equiparáveis aos entes estatais se encontrariam as organizações internacionais e, de forma bastante reduzida e limitada, finalmente os dois últimos grupos de experiências associativas.

A aplicação da teorização proposta gera, de certo, dúvidas e questiona dogmas doutrinários já amplamente consolidados. No caso da Organização Internacional do Trabalho - OIT, por exemplo, seu pioneirismo é apontado no reconhecimento de seu status como primeiro foro produtor de regras jurídicas genuinamente internacionais, ainda que sobre tema específico e alcance limitado e condicionadas à expressão de vontade pelos estados ${ }^{437}$. Seria, contudo e à luz do que se propõe, a OIT uma organização internacional classificável no mesmo patamar dos estados ou um mero sistema de tratados dotado de estrutura burocrática permanente? Qual seria, então, o fator determinante ao reconhecimento de uma organização internacional?

Conforme mencionado, a doutrina majoritária reconhece como requisito fundamental do status de organização a um sistema internacional de direito a dotação de personalidade jurídica ao mesmo pelos estados que aderem ao seu tratado ${ }^{438}$. Bastaria, então, que um tratado

issues of concern to the international community, with each State having one vote. That was a major departure from the earlier practice (remaining today under different names) of having these matters formally decided on the basis of the mutual accommodation of a few Great Powers. Those Conferences also saw the beginnings of non-governmental concern with the progress of the Conferences, and of controlled publicity about the progress of their work."

437 LIANG, Yuen-Li. Le développement et la codification du droit international. In: Recueil des Cours. Academie de Droit International de la Haye, Volume 73, 1948-II, pp. 422-423. p. 427. "In verbis“": "Il ne faut pas oublier, d'autre part, que l'Organisation Internationale du Travail a été créée en même temps que la Société des Nations et a fonctionné à son côté comme une véritable législature internationale, bien qu'avec une compétence relativement limitée, pendant tout le cours de son existence. L'Organisation Intrernationale du Travail est un corps dont la constitution et les fonctions correspondent plus qu'aucun autre à celles d'une législature proprement dite. Une de ses principales fonctions, comme on le sait, a été de provoquer, soit par la méthode de l'adoption de projets de conventions, soit en faisant des recommandations, des améliorations des conditions du travail. En ce qui concerne les projets de conventions, leur adoption impose aux Etats Membres de l'Organisation une obligation de les proposer, au moins à leurs législatures respectives, en vue de leur mise en vigueur."

${ }^{438}$ SHAW, Malcolm N. International law. Cambridge: Cambridge University Press, 2003. p. 1188-1189. referese à Organização das Nações Unidas, mas descreve os efeitos da dotação de uma organização internacional de 
estabelecesse em seu texto a existência de personalidade jurídica para que a estrutura fosse considerada uma organização internacional?

Tal entendimento não deve prosperar. As organizações internacionais para serem reconhecidas como tal - e para que lhes sejam exigidas obrigações muitas vezes equiparadas a dos estados - devem possuir uma estrutura institucional mínima que preserve, ao menos, seu sistema de direito. Para que seja reconhecida como tal faz-se necessário, portanto, que sua estrutura preveja meio institucionalizado para a solução de litígios em seu marco.

Excluídos os tratados normatizantes, a observação das estruturas dos arranjos internacionais reconhecidos atualmente como organizações internacionais torna possível a identificação de experiências associativas de duas espécies: os tratados dotados de estrutura burocrática permanente e as organizações internacionais propriamente ditas.

As características que se podem apontar ao reconhecimento de uma organização internacional seriam, por exemplo, seu caráter interestatal, órgãos permanentes e vontade autônoma $^{439}$. Mas como garantir sua integridade sem que um sistema institucionalizado de solução de controvérsias seja reconhecido como requisito? Por isso, ao lado da personalidade jurídica que lhe possibilita o exercício de capacidades, um sistema de solução de controvérsias constitui elemento fundamental do reconhecimento de uma organização capaz de expressar vontade e de construir direito internacional, muitas vezes, acima dos ou em pé de igualdade com estados soberanos.

Uma estrutura internacional, dotada de personalidade jurídica por tratado, mas desprovida de sistema institucionalizado de solução de controvérsias constituiria, nesse sentido, mero tratado que dispõe de estrutura burocrática. Não uma organização.

personalidade jurídica, "in verbis": "The possession of international personality meant that the organisation was a subject of international law and capable of having international rights and duties and enforcing them by bringing international claims [...] The attribution of international legal personality to an international organization is therefore important in establishing that organization as an entity operating directly upon the international stage rather than obliging the organization to function internationally through its member states, who may number in the tens or dozens or more"

${ }^{439}$ PASTOR RIDRUEJO, José Antonio. Le droit international à la veille du vingt et unième siècle : normes, faits et valeurs : cours général de droit international public. In: Recueil des Cours. Academie de Droit International de la Haye, Volume 274, 1998, pp. 09-308. pp. 195-197. "In verbis“: "Six éléments ou signes distinctifs entrent à notre avis dans la définition d'organisation internationale, à savoir : caractère interétatique, base volontaire, organes permanents, volonté autonome, compétence propre et, finalement, coopération entre les Etats membres pour la satisfaction de leurs intérêts communs. Si une entité agissant sur le plan international en tant qu'instrument de la coopération interétatique réunit tous ces éléments, elle est incontestablement une organisation internationale.[...] Le troisième signe distinctif des organisations internationales est celui de la possession d'un système permanent d'organes assurant la continuité de leur action. Voilà un élément qui permet de distinguer nettement une organisation internationale d'une conférence diplomatique. Dans celle-ci, en effet, les organes sont éphémères par nature." 
A maioria das associações internacionais de estados não possui órgãos jurisdicionais para a solução de litígios e essas não poderiam ser consideradas, a partir do que se propõe, organizações internacionais ${ }^{440}$. Apesar de possuírem, em alguns casos, estrutura burocrática dotada de personalidade jurídica, referidas estruturas conformariam tratados associativos e não organizações internacionais genuínas.

Cumpre ressaltar que os tribunais autônomos constituídos para solucionar controvérsias entre as associações internacionais e seus funcionários, ainda que independentes e, muitas vezes, de caráter jurisdicional, não se enquadram no exercício de função de poder que se busca reconhecer para fins de garantia de coerência sistêmica ampla.

As organizações internacionais conformariam associações institucionalizadas, enquanto os tratados associativos configurariam associações simples, cujas estruturas burocráticas não guardariam funções derivadas do poder dos estados que dele fazem parte ${ }^{441}$. Apenas as organizações internacionais possuem capacidade de expressar a vontade concretiva do conjunto de estados que representa com sua personalidade jurídica no plano internacional. Tratados associativos, ainda que dotados de personalidade jurídica estabelecida por norma, não possuiriam, assim, atribuição representativa concretiva ${ }^{442}$.

\footnotetext{
${ }^{440}$ PASTOR RIDRUEJO, José Antonio. Le droit international à la veille du vingt et unième siècle : normes, faits et valeurs : cours général de droit international public. In: Recueil des Cours. Academie de Droit International de la Haye, Volume 274, 1998, pp. 09-308. p. 205. "In verbis": "Les organes judiciaires sont logiquement composés par des personnes indépendantes. L'article 2 du Statut de la Cour internationale de Justice dit justement à ce propos que « la Cour est un corps de magistrats indépendants, élus sans égard à leur nationalité ». Il faut signaler que la plupart des organisations internationales ne possèdent pas d'organe judiciaire, et que quelques-unes (Organisation des Nations Unies, Organisation internationale du Travail) ont un tribunal administratif pour régler les différends surgis entre l'organisation concernée et ses fonctionnaires. Ces derniers tribunaux sont aussi des institutions indépendantes.“
}

${ }^{441}$ MORELLI, Gaetano. Cours général de droit international public. In: Recueil des Cours. Academie de Droit International de la Haye, Volume 89, 1956-I, pp. 437-604. p. 558. "In verbis“: "Les unions internationales se distinguent en deux catgories, eu égard aux moyens qu'elles emploient pour atteindre les buts communs. L'une des deux catégories embrasse les unions que l'on appelle simples, c'est-à-dire les unions qui se bornent à coordonner les activités de leurs membres, activités qui sont exercées au moyen d'organes appartenant à chaque Etat membre. Un exemple de ce type d'union est donné par les alliances. C'est au même type qu'appartiennent les unions qui prévoient, comme moyen pour atteindre les buts communs, une activité unitaire : une activité toutefois exercée par l'un des Etats membres seulement, moyennant ses organes ordinaires, et produisant ses effets, outre pour cet Etat, pour les autres Etats membres en vertu d'un rapport de représentation. Tel est le cas des unions douanières entre la Belgique et le Luxembourg (convention de Bruxelles du 25 juillet 1921) et entre la Suisse et le Liechtenstein (traité de Berne du 29 mars 1923). Aux unions simples s'opposent les unions organisées ou institutionnelles. Celles-ci prévoient une activité unitaire à exercer, non pas par l'un des Etats membres, comme dans l'hypothèse que l'on vient d'indiquer, mais par des organes expressément créés ou bien directement par le pacte d'union ou bien sur la base de celui-ci. C'est à cette catégorie qu'appartiennent les unions relies, les confédérations, l'Organisation des Nations Unies, etc.“

${ }^{442}$ MORELLI, Gaetano. Cours général de droit international public. In: Recueil des Cours. Academie de Droit International de la Haye, Volume 89, 1956-I, pp. 437-604. p. 563. "In verbis“: “Comme on l'a dit, dans les unions organisées ou institutionnelles le moyen visant à réaliser l'intérêt commun consiste dans une activité unitaire confiée à des organes expressément crées par le pacte d'union. Une telle activité est imputée par le 
A identificação de expressões do poder estatal nas estruturas de uma organização internacional como forma de diferenciar as mesmas dos meros acordos associativos repercute nos limites da atuação desses sujeitos de direito internacional. Diferentemente do que ocorre nos acordos meramente associativos, as organizações internacionais expressariam vontade concretiva na ordem internacional pela celebração de tratados que produzem direito das gentes e isso se instrumentalizaria na percepção de que atrás da vontade comum expressada se encontraria a vontade de cada um de seus membros nos termos do tratado que criou a estrutura comum ${ }^{443}$.

A condição de sujeito de direito internacional poderia ter, portanto, a personalidade jurídica como requisito, mas não como o único requisito para que se aperfeiçoe. Pode-se, por exemplo, dividir as pessoas de direito internacional entre aquelas capazes de - conjuntamente com os estados - produzir normas jurídicas e aquelas incapazes de fazê-lo e também entre os meramente submetidos ao direito internacional - como os indivíduos - e aquelas que se submetem e atuam de fato internacionalmente. No caso dos que apenas se submetem ao corpo normativo, sua capacidade de atuação internacional depende, em regra, de contexto específico e do reconhecimento da mesma ao menos limitadamente ${ }^{444}$.

A todos os entes dotados de personalidade jurídica internacional se apresenta o direito internacional geral e o direito interno dos estados. As organizações internacionais, por sua

droit international simultanément aux diftérents Etats membres de l'union. L'individu ou l'ensemble des individus qui exercent cette activité est l'organe par lequel deux ou plusieurs Etats agissent d'une façon simultanée et identique ; c'est un organe commun à ces Etats. Les organes de ce type peuveint etre dénommés organes collectifs, parce qu'ils constituent le moyen par lequel il peut y avoir une volonté et une activité d'une collectivité d'Etats.“"

${ }^{443}$ MORELLI, Gaetano. Cours général de droit international public. In: Recueil des Cours. Academie de Droit International de la Haye, Volume 89, 1956-I, pp. 437-604. p. 565. "In verbis“: "L'activité exercée par l'organe d'une union, en tant qu'organe collectif, est une activité que le droit international impute simultanément aux Etats membres de l'union. C'est justement une activité unitaire à imputer simultanément aux différents Etats membres que l'accord d'union considère comme le moyen pour atteindre ses buts.“

${ }^{444}$ KOROWICZ, Marek Stanislaw. Some present aspects of sovereignty in international law. In: Recueil des Cours. Academie de Droit International de la Haye, Volume 102, 1961-I, pp. 01-120. p. 102. "In verbis": "The study of legal personality in present-day international law leads to a division of the subjects of that law into two main categories, namely those of sovereign and of non-sovereign subjects. We can define subjects of international law as legal (juristic) or physical persons upon whom international law directly imposes duties and confers rights. Sovereign subjects of international law are sovereign States. [...] Non-sovereign subjects may be further divided into two categories: (a) those which, although created by and dependent on the will of the sovereign (original) subjects, may, like the latter, create international law, like other subjects of that law ; (b) mere recipients of rights and duties under international law whose international personality, in its scope and duration, depends on the will of sovereign subjects or of non-sovereign law-creating subjects." 
vez, convivem ainda com e produzem seu próprio direito sistêmico, algo que os tratados associativos não fazem, em razão de se submeterem exclusivamente às duas esferas gerais ${ }^{445}$.

Fundamental para a diferenciação das organizações internacionais dos tratados associativos que possuem estrutura burocrática se mostra também a natureza jurídica de seus acordos constitutivos. Enquanto as organizações internacionais seriam estabelecidas por meio de tratados constitucionais, que estabelecem estruturas institucionais dotadas de funções assemelhadas à dinâmica do poder interno de um estado, tratados associativos apenas criariam regulamentações internacionais que prevêem estruturas burocráticas de apoio às suas finalidades ${ }^{446}$.

As relações entre estados no interior das organizações internacionais possuem, em razão da própria institucionalidade do arranjo sistêmico, contornos distintos daquelas relações travadas na esfera do direito das gentes geral $^{447}$. Exatamente quanto a essa característica emerge a importância basilar dos sistemas internos de solução de controvérsias.

Assim sendo, percebe-se que, em regra, as organizações tendem a ser criadas com foco, alternativamente, nas funções legislativas ou executivas. As de caráter executivo coordenariam, assim, a relação entre os sujeitos de direito internacional, enquanto as legislativas produziriam normas para regulamentar determinada esfera do direito das gentes. Qualquer das duas funções típicas exigem o desenvolvimento de sistemas de controle, os

\footnotetext{
${ }^{445}$ PESCATORE, Pierre. Les relations extérieures des communautés européennes : contribution à la doctrine de la personnalité des organisations internationales. In: Recueil des Cours. Academie de Droit International de la Haye, Volume 103, 1961-II, pp. 01-244. pp. 32-33. "In verbis": "Ceci nous amène donc à discerner non pas deux, mais en réalité trois sphères juridiques distinctes dans lesquelles, suivant les circonstances, les Communautés (comme toute autre organisation internationale) peuvent être dans le cas d'agir, à savoir : la sphère de l'ordre juridique interne des Etats membres, ou sphère de la personnalité civile ; la sphère de l'ordre juridique immanent à l'organisation, c. à. d., dans le cas des Communautés, la sphère de l'ordre intracommunautaire, ou fédéral ; la sphère de l'ordre juridique international général, ou sphère des relations extérieures.“
}

${ }^{446}$ OLIVER, Covey T.. Historical development of international law : contemporary problems of treaty law. In: Recueil des Cours. Academie de Droit International de la Haye, Volume 88, 1955-II, pp. 417-508. p. 486. "In verbis": "We must not confuse "constitutional' treaties with 'law-making' treaties. The law-making treaty is that treaty which in its specific provisions establishes a precise basis for the governing of conduct in a normative fashion. The law-making treaty is usually thought of as an instrument of a legislative character; it is like a statute, or, if properly organized, a code. The 'constitutional treaty', on the other hand, creates a new power-structure and it is skeletal and general in its provisions."

${ }^{447}$ TUNKIN, Grigory. International law in the international system. In: Recueil des Cours. Academie de Droit International de la Haye, Volume 147, 1975-IV, pp. 01-218. pp. 158-159. "In verbis“: "Interaction between States within the framework of a system of international organization has a decisive influence on the functioning of an international organization. Specific features of this interaction in comparison to those outside the international organization are of primary interest. [...] Interactions between States inside international organizations are more complex than their interactions outside international organizations. In an international organization these interactions are effected through a more or less sophisticated mechanism of this organization with other elements of the system, such as organs and a secretariat, which are always involved." 
quais podem ser muito bem exercidos por um sistema de solução de litígios, ou seja, pelo órgão que exerce funções judiciárias na - ou em relação à - organização ${ }^{448}$.

Em arranjos intergovernamentais, as restrições à estrutura comum que reservam aos estados o exercício de funções soberanas típicas - legislativa, executiva e judiciária constituem limitações funcionais, mas tal característica não lhes retiraria, uma vez identificadas a personalidade jurídica e a institucionalização da solução de litígios, o caráter de organização internacional ${ }^{449}$.

Nesse sentido, enquanto nas organizações internacionais se verificariam formas primitivas típicas das funções do poder estatal, nos acordos associativos suas estruturas seriam absolutamente desprovidas de tais funções e dependeriam completamente da atuação volitiva das partes que os compõem para que qualquer forma de poder possa ser expressada.

O caráter multilateral dos tratados mostra-se comum, observa-se, a todas as estruturas associativas apontadas. Assim sendo, tanto os tratados associativos quanto as organizações internacionais seriam instituídos por meio de instrumentos multilaterais, os quais - no caso das organizações - funcionam como verdadeiras constituições ou estatutos ${ }^{450}$. Ainda a esse respeito, observa-se que os acordos cooperativos seriam, sob a perspectiva classificativa teleológica, os que melhor traduziriam o ideal do multilateralismo ${ }^{451}$.

\footnotetext{
${ }^{448}$ BINDSCHEDLER, D.. Le règlement des différends relatifs au statut d'un organisme international. In: Recueil des Cours. Academie de Droit International de la Haye, Volume 124, 1968-II, pp. 453-548. p. 512. "In verbis": "Un des aspects importants sera le caractère des fonctions principales confiées à l'organisme fonctions législatives ou fonctions administratives. On peut distinguer deux types foadamcntaux: ou bien l'orgarnisme est de type législatif, c'est-à-dire qu'il a pour but de réglementer les activités des Etats membres éventuellement des particuliers - dans certains domaines, ou bien il se voit attribuer un domaine d'activité propre dans un intérêt commun. La première formule pose essentiellement le problème du contrôle de l'application par les Etats - ou par les particuliers -, la seconde le problème du contrôle de l'activité et de l'organisation et de ses organes."
}

${ }^{449}$ HAHN, Hugo J.. Constitutional limitations in the law of the European organisations. In: Recueil des Cours. Academie de Droit International de la Haye, Volume 108, 1963-I, pp. 189-306. p. 209. "In verbis": "Inasmuch as these limitations on the legislative, executive and judicial activities of the European organization safeguard the reserved domain of the Member States and their organs vis-à-vis the intergovernmental bodies corporate, they restrict the exercise by the latter of functions of sovereignty. It seems therefore appropriate to call these restraints 'functional limitations.' "“

${ }^{450}$ LACHS, Manfred. Le développement et les fonctions des traités multilatéraux. In: Recueil des Cours. Academie de Droit International de la Haye, Volume 92, 1957-II, pp. 229-341. p. 235. "In verbis“: "Le traité multilatéral constitue donc aujourd'hui un chapitre important dans un volume qui comprend ce qu'on pourrait appeler le droit des traités. Le processus de la formation de toutes sortes d'organisations internationales est étroitement lié à ces traités car les conventions multilatérales sont génératrices de ces organisations en donnant la forme juridique à leurs constitutions ou statuts.“

${ }^{451}$ LACHS, Manfred. Le développement et les fonctions des traités multilatéraux. In: Recueil des Cours. Academie de Droit International de la Haye, Volume 92, 1957-II, pp. 229-341. p. 240-241. "In verbis“: "Voilà la base sur laquelle se formait et se développait un nouveau type de traité, le traité multilatéral au sens propre du mot. Ce traité n'oppose pas un ou plusieurs signataires à d'autres mais lie tous les signataires par un réseau des droits et obligations réciproques. C'est ainsi que naissaient les traités instituant des organisations 
As organizações internacionais propriamente ditas devem ser investidas, assim, de funções de poder que não apenas permitam atuação para cumprir seus objetivos fundamentais, mas também disponibilizem meios de garantir o cumprimento de seu direito. Arranjo internacional que apresente debilidade ou pendência em uma dessas duas atribuições não poderia ser considerado uma organização hábil a atuar em conjunto com os estados, mas mero tratado associativo dotado, no máximo, de estrutura burocrática permanente ${ }^{452}$.

As primeiras observações doutrinárias feitas acerca do reconhecimento de personalidade jurídica aos agrupamentos internacionais de estados - aqui divididos entre organizações e tratados associativos - não mostravam preocupação com as consequiências dessa tendência para a evolução do direito das gentes. Restringia-se, na verdade, a utilidade da referida personificação freqüentemente às relações que se estabeleciam entre esses entes e os estados, nos quais possuíam sede ou escritório ${ }^{453}$. Não se imaginava claramente a complexidade do direito internacional atual e o papel desses sujeitos em sua evolução.

Diferenciação proposta pela doutrina - que se identifica em grande medida com a proposta deste estudo, mas não usa o mesmo critério diferenciador e pode acabar levando a resultado diverso - reparte as organizações internacionais entre políticas e técnicas. Nas políticas seriam identificadas funções análogas àquelas típicas do poder estatal, é dizer,

internationales. Au moment de sa naissance le traité multilatéral a été certainement une oeuvre du progrès. II traduisait le rapprochement croissant entre Etats et nations et reflétait le caractère même de ce rapprochement. Ces normes devaient déterminer, dans le champ de leur application, les étapes suivantes de l'évolution de ce rapprochement.“

${ }^{452}$ TUNKIN, Grigory. International law in the international system. In: Recueil des Cours. Academie de Droit International de la Haye, Volume 147, 1975-IV, pp. 01-218. pp. 181-182. "In verbis“: "It is of considerable importance to distinguish between the foundation of the legal powers of States in international relations and those of international organizations. It is also of importance to comprehend that the powers of an international organization comprise two indivisible arts: powers relating to the purposes of the organization, including the sphere of its activities and its aims, and powers relating to the means for attaining these aims (jurisdictional powers). These two parts of the powers are inseparable as each action of an international organization relates to a certain sphere of interstate relations, is intended to achieve a certain aim and is exercised with certain means."

${ }^{453}$ PESCATORE, Pierre. Les relations extérieures des communautés européennes : contribution à la doctrine de la personnalité des organisations internationales. In: Recueil des Cours. Academie de Droit International de la Haye, Volume 103, 1961-II, pp. 01-244. p. 34. "In verbis“: "Quant à la personnalité Juridique des organisations internationales dans tes relations avec leurs propres Etats membres, celle-ci pose un problème théorique. Comment une organisation peut-elle être personnifiée, c'est-à-dire recevoir une existence juridique distincte, en face des Etats mêmes qui en font partie ? En effet, l'organisation n'est autre chose que la collectivité des Etats qui la composent et qui participent, en tant que membres, à sa vie juridique intérieure, à ce reseau de droits et d'obligations découlant de leur qualité de membres. Mais en dehors de ces relations découlant de la qualité de membre, il est possible pour un Etat membre individuel de constituer des liens juridiques particuliers avec l'organisation, p. ex. du fait que son territoire est choisi pour l'établissement du siège, du fait que l'organisation lui apporte dcs prestations particulières d'aide financière ou d'assistance technique, ou encore du fait qu'un Etat membre encourt, à la suite d'un acte illicite, une responsabilité particulière à l'égard de l'organisation.“ 
executiva, legislativa e judiciária. Já nas de caráter técnico seriam identificadas características meramente regulamentadoras de setores específicos, ou seja, teriam caráter meramente normativo ${ }^{454}$.

Ainda que em conformação distinta da interna do estado, observa-se na estrutura das Nações Unidas um aprimoramento institucional relevante quando contrastada com a Liga das Nações. Entre seus órgãos - com funções e responsabilidades detalhadamente inseridas no tratado constitutivo - encontam-se embriões de uma racionalização do poder comparável à separação de funções adotada - em regra - internamente pelos estados ${ }^{455}$.

Uma organização internacional não nasce com sua estrutura definitiva. Os sujeitos de direito que dela fazem parte concedem à instituição atribuições típicas de seu poder interno e podem limitar, assim, sua soberania. Essa delegação inicial costuma ser bastante restrita e isso pode provocar - como já provocou em diversos casos - movimentos evolutivos na estrutura comum que tendem a reproduzir externamente a dinâmica de poder interna de cada membro em particular.

Lançando-se mão das Nações Unidas mais uma vez como parâmetro, percebe-se que o fenômeno descrito pode ser observado na ampliação das funções da Assembléia Geral em prol da manutenção da paz. Enquanto o Conselho de Segurança possuía tal característica desde o princípio instituída pelo tratado constitutivo, a Assembléia Geral a conquistou por meio de um amadurecimento institucional $^{456}$.

\footnotetext{
${ }^{454}$ DUPUY, René Jean. Le droit des relations entre les organisations internationales. In: Recueil des Cours. Academie de Droit International de la Haye, Volume 100, 1960-II, pp. 457-589. p. 463. "In verbis": "On posera alors une distinction fondamentale entre les organisations politiques et les organisations techniques. Les premières comprennent elles-mêmes, soit des organisations à buts politiques multiples, comme l' O.N.U. ou l'Organisation des Etats américains, s'efforçant d'exercer des fonctions de législation, de juridiction, d'exécution, soit des organisations moins ambitieuses et bornant leur rôle politique au dégagement d'une certaine opinion internationale, c'est le cas du Conseil de l'Europe, soit enfin des organisations à but essentiellement militaire, comme l' O.T.A.N. que l'on serait tenté, si l'on oubliait l'importance politique des problèmes de sécurité, de ranger parmi les organisations techniques. Celles-ci répondent à un besoin de spécialisation qui s'exprime dans les domaines les plus divers : communications, culture, santé, finances, économie.“
}

455 Sugerindo a "separação de poderes", JENKS, C.Wilfred. Co-ordination : a new problem of international organization : a preliminary survey of the law and practice of inter-organizational relationships. In: Recueil des Cours. Academie de Droit International de la Haye, Volume 77, 1950-II, pp. 151-303. p. 160. "In verbis“" "The constitutional arrangements of be United Nations, in contrast to those of the League, are based on a definite principle of decentralized authority. The Charter establishes six principal organs of the United Nations, the General Assembly, the Security Council, the Economic and Social Council, the Trusteeship Council, the International Court of Justice and the Secretariat, and assigns functions and responsibilities to each of these organs in considerable detail."

${ }^{456}$ OLIVER, Covey T.. Historical development of international law: contemporary problems of treaty law. In: Recueil des Cours. Academie de Droit International de la Haye, Volume 88, 1955-II, pp. 417-508. pp. 494495. "In verbis": "The Security Council and the General Assembly, as is well known, have been the principal instrumentalities for dealing with aggression since World War II, the former under formal Charter 
Mas cumpririam as Nações Unidas o segundo requisito proposto à caracterização de uma organização como sujeito de direito internacional equiparável aos estados, é dizer, haveria em sua estrutura um sistema institucionalizado disponível à solução de eventuais controvérsias entre seus membros? Serviria a Corte Internacional de Justiça para cumprir esse papel? Ainda que a corte não seja reconhecida como órgão dotado de características de preservação da coerência sistêmica do sistema multilateral da Carta de São Francisco, não raramente a doutrina identifica em outras estruturas, como na do Conselho de Segurança, exercício de função garantidora de coerência, segurança e previsibilidade e disponíveis se encontram, portanto, elementos ao enquadramento do arranjo geral como tal ${ }^{457}$.

Ainda que a classificação de arranjos de direito internacional dotados de personalidade jurídica que não constituam estados possa aparentemente não possuir grande utilidade, essa se mostra fundamental para a proposta de diferenciação que aqui se sustenta entre os tratados associativos e as organizações internacionais propriamente ditas, as quais - tal qual um estado - possuiriam atribuições concretivas na ordem jurídica global ${ }^{458}$.

Assim sendo, observa-se que as organizações internacionais cumprem atualmente, junto aos estados, importante papel na ordem internacional. Essas estruturas produzem normas, aplicam o direito e se responsabilizam - de maneira ainda imperfeita, mas cada vez mais - pelo efetivo cumprimento de seu conjunto normativo. São entes hoje responsáveis em grande medida pela organização da convivência no ambiente global.

authorization, the latter as a matter of constitutional evolution in the face of Security Council ineffectiveness in a pressing situation. [...] In a broad and undifferentiated way, then, since norm-making and norm-applying are certainly 'legal action', bodies thought of as political are seen to be taking legal action with respect to community control of aggression under a 'constitutional treaty'."

${ }^{457}$ Sobre o conselho de segurança como meio de solução de controvérsias, GUGGENHEIM, Paul. Les principes de droit international public. In: Recueil des Cours. Academie de Droit International de la Haye, Volume 80, 1952-I, pp. 01-189. p. 116. "In verbis“: "Mais une fois crée, l'organe arbitral ou judiciaire est un organe indépendant. Ce qui distingue en effet un tribunal arbitral ou judiciaire, tel que la Cour intenationale de Justice, du Conseil de Sécurié ou de tout autre organe administratif de la vie internationale qui est aussi en mesure de trancher un différend, c'est que les juges d'un tribunal arbitral ou d'une cour de justice ne sont liés à aucune instruction, qu'ils sont en mesure d'individualiser les normes générales indépendamment de tout autre organe."

458 REUTER, Paul. Principes de droit international public. In: Recueil des Cours. Academie de Droit International de la Haye, Volume 103, 1961-II, pp. 425-656. pp. 524-525. "In verbis“": "La nécessité, sur un plan descriptif, de classer les organisations n'en apparaît que plus nécessaire. L'on pourra donc se placer successivement à tous les points de vue imaginables et distinguer ainsi au point de vue extension les organisations universelles et les régionales. Au point de vue accès celles qui sont ouvertes te celles qui sont pius ou moins fermées, au point de vue de leur objet celles qui sont générales et celles qui sont spécialisées dans des domaines plus ou moins définis, au point de vue de leur structure celles qui admettent des organes particuliers (secrétariat indépendant, Cour de justice, représentations extra-gouvernementales), au point de vue de leurs pouvoirs celles qui n'ont que des fonctions de contrôle, celles qui exercent une administration directe, celles qui ont reçu des délégations de souveraineté, etc, etc.“ 
A doutrina majoritária identifica com freqüência a personalidade jurídica como elemento hábil a, sozinho, caracterizar uma organização internacional. Nesse sentido, sujeitos de direito internacional, mormente estados, decidiram criar uma organização simplesmente atribuindo personalidade jurídica a um tratado associativo.

Não seria, contudo, razoável entender que todo tratado dotado de personalidade deve ser considerado investido de atribuições para atuar na ordem internacional de maneira concretiva - e muitas vezes no mesmo patamar dos estados - simplesmente por ter personalidade reconhecida.

Organizações internacionais estabelecem sistemas normativos próprios e esses sistemas devem possuir, além de capacidade de atuação, também formas “judiciárias" para garantir sua coerência e estabilidade. Nesse panorama, a personalidade jurídica internacional pode, por exemplo e com base na teorização estatal do poder, se identificar com a função executiva e a produção de normas nos termos estabelecidos em tratado, por outro lado, com o exercício da função legislativa.

O poder, contudo e a partir das construções teóricas desenvolvidas pela teoria geral do estado ao longo dos últimos séculos, expressa-se também por meio do exercício da função judiciária e dessa analogia aqui proposta decorreria, portanto, a exigência de que, nas estruturas das organizações internacionais, também a função judiciária fosse encarada como requisito de seu reconhecimento como tal.

Assim sendo, apenas quando identificável na estrutura associativa um sistema institucionalizado para a solução de controvérsias eventualmente surgidas entre seus membros haveria uma organização internacional capaz de, nos limites das capacidades que lhe são atribuídas, atuar internacionalmente em patamares equiparáveis aos estados.

Não se trata, gize-se, de igualar organizações a estados, mas de reconhecer que, em determinadas circunstâncias, esses entes atuam na ordem internacional em pé de igualdade e que nem todas as associações internacionais possuem tais predicados.

Uma estrutura comum, mesmo dotada de personalidade, encontra-se confrontada com importantes barreiras para garantir sua estabilidade sistêmica e, conseqüentemente, severas limitações existem à sua atuação internacional como um corpo uno e consolidado caso não disponha de um sistema de solução de controvérsias hábil a estabilizar seu direito. Ordens jurídicas desse tipo não constituiriam, assim, organizações, mas meros tratados associativos dotados de personalidade.

$\mathrm{O}$ estabelecimento de critérios que diferenciem de maneira clara as organizações internacionais dos tratados associativos impõe-se com urgência em contexto de franca 
proliferação de estruturas internacionais. A partir da classificação que se propõe, mais facilmente se poderiam reconhecer e diferenciar os entes que interagem com os estados daqueles sistemas que servem apenas de instrumento de interação entre soberanias. 


\section{SEGUNDA PARTE}

\section{A FRAGMENTAÇÃO DO DIREITO INTERNACIONAL E A POLÍTICA}

A sistematização teórica do direito, especificamente do direito internacional, tem enfrentado atualmente grandes desafios. Parte considerável da doutrina sustenta que os esquemas unitaristas tradicionais - baseados no papel do estado como ator exclusivo na normatização internacional - não serviriam para explicar a multiplicação de organizações internacionais com capacidade legiferante e a complexa trama normativa que se forma a partir da sobreposição dessas competências ${ }^{459}$.

O direito das gentes passou por grandes transformações a partir da segunda grande guerra. Tais transformações possuem caráter tanto horizontal, por exemplo no surgimento e na consolidação da existência de novos atores na ordem global, quanto vertical, no avanço da normatização comum sobre áreas da vida antes não tratadas fora da esfera dos estados ${ }^{460}$.

Em meio a tais fenômenos, os referenciais unitaristas do direito deram lugar, aos poucos, a teorias que sustentam sua fragmentação ${ }^{461}$. Cada vez mais se estuda a ordem

\footnotetext{
${ }^{459}$ FISCHER-LESCANO, Andréas; TEUBNER, Gunther. Regime-Kollisionen. Frankfurt am Main: Suhrkamp Verlag, 2006. p. 10. "In verbis“: "Allerdings ist hier ein eigentümlicher juridischer Reduktionismus zu beobachten, der das Verständnis der Normenkonflikte verflacht und deren Lösungsperspektiven beschränkt. Juristen registrieren im Prinzip nur die verwirrende Vielfalt von autonomen, politisch gesetzten Bereichsrechten, »self-contained regimes« und hochspezialisierten Tribunalen. Sie sehen die Einheit des internationalen Rechts deshalb gefährdet, weil im Weltrecht eine begrifflich-dogmatische Konsistenz, eine klare Normenhierarchie und eine durchsetzungskräftige Gerischtshierarchie, wie sie die Nationalstaaten herausgebildet haben, fehlten“. Também KOSKENNIEMI, Martti. Global legal pluralism: multiple regimes and multiple modes of thought. Harvard, 05 de março de 2005 - Palestra.. p. 05. No original: "Unity is a hegemonic project. It seeks the predominance of my perspective, my institution. Against this, we are accustomed to depicting the world - or some aspect of it - as oppressively homogenous, ruled by a totalizing logic of power, globalization, empire. Plurality as a counter-hegemonic strategy. Multiplicity of laws and regimes - and sovereignties, why not? - as a receipt for freedom, innovation, novelty."
}

${ }^{460}$ CARREAU, Dominique. Droit international. Paris: Pedone, 1986. p. 24. "In verbis“: "Depuis la fin de la seconde guerre mondiale, la société internationale a connu des bouleversements considérables. Ces transformations profondes sont de deux types, horizontal et vertical. Sur le plan horizontal, de nouveaux et nombreux acteurs de la société internationale sont apparus de sorte que cette dernière a perdu son homogénéité initiale pour se caractériser maintenattt par son «hétérogénéité ». Sur le plan vertical, de nouveaux et nombreux domaines sont apparus et ont ainsi élargi la sphère d'influence du droit international. Le jeu combiné de ces deux phénomènes a incontestablement rendu plus complexe la compréhension du droit international et de son rôle - sans parler de sa définition.“

${ }^{461}$ KOSKENNIEMI, Martti. Global governance and public international Law. In: Kritische Justitz, 37, 2004. p. 243. "In verbis": "The second threat to the traditional image arises from what international lawyers call 
internacional a partir de suas parcelas sem enfoque no todo ${ }^{462}$. Algumas correntes teóricas mais radicais chegam a assumir a diversidade sistêmica como geradora de estruturas jurídicas autônomas e incomunicáveis ${ }^{463}$.

Pode-se sustentar, por outro lado e entretanto, que apenas a maneira como esses fenômenos se apresentariam seria, de fato, plural e que não seria possível, ao menos por enquanto, estabelecer uma concepção teórica definitivamente fragmentada para o direito global $^{464}$. Nesse sentido, o sistema unitarista que tinha o estado nacional no centro da produção legislativa internacional, de certo, não se sustenta nessa nova realidade, mas ainda resta saber, contudo, se a fragmentação conformaria questão jurídica consolidada ou mera situação fática compatível com alguma teoria unitarista, ainda que diversa daquelas do positivismo tradicional.

Em meio ao referido contexto plural é de se verificar que a fragmentação que se observa não se resume apenas à atividade legiferante repartida entre diversas ordens legais temáticas, mas também se refere à pluralidade de fontes existente em cada uma dessas

>>fragmentation<<, the division of international regulation into specialized branches, deferring to special interests and managed by technical experts.".

462 O problema da coordenação das parcelas da ordem jurídica internacional já era apontado em 1950 por JENKS, C.Wilfred. Co-ordination: a new problem of international organization: a preliminary survey of the law and practice of inter-organizational relationships. In: Recueil des Cours. Academie de Droit International de la Haye, Volume 77, 1950-II, pp. 151-303. pp. 159-160. "In verbis": "The mere enumeration of these organizations, which is by no means complete, is in itself an indication of the scale and complexity of the problems involved in establishing orderly relationships between them. A large proportion of these organizations have been created during the last five years and a large proportion of the remainder have been reorganized during the same period. The intrinsic difficulty of the problem has therefore been accentuated by the sudden manner in which it has become acute at a time when most of the organizations concerned have themselves still been in a preliminary organizational phase and governments have been confronted, in the midst of all the other preoccupations arising out of the war and the cold war, with the problems involved in providing for effective national participation in international organizations on an entirely new scale.“

${ }^{463}$ BOBBIO, Norberto. Teoria do ordenamento jurídico. Brasília: Editora Universidade de Brasília, 1999. p. 71. "In verbis": "Entendemos por 'sistema' uma totalidade ordenada, um conjunto de entes entre os quais existe uma certa ordem. Para que se possa falar em uma ordem, é necessário que os entes que a constituem não estejam somente em relacionamento com o todo, mas também num relacionamento de coerência entre si. Quando nos perguntamos se um ordenamento jurídico constitui um sistema, nos perguntamos se as normas que o compõem estão num relacionamento de coerência entre si, e em que condiçõe é possível essa relação.“.

${ }^{464}$ INTERNATIONAL LAW COMMISSION. Report of the Study Group of the International Law Comission. UN Doc A/CN.4/L.682. 2006. p. 12. "In verbis": "While the reality and importance of fragmentation, both in its legislative and institutional form, cannot be doubted, international lawyers have been divided in their assessment of the phenomenon. Some commentators have been highly critical of what they have seen as the erosion of general international law, emergence of conflicting jurisprudence, forum-shopping and loss of legal security. Others have seen here a merely technical problem that has emerged naturally with the increase of international legal activity may be controlled by the use of technical streamlining and coordination." 
esferas $^{465}$. O maior exemplo dessa vertente ainda mais complexa da fragmentação do direito internacional tem lugar no regionalismo e no multilateralismo como fenômenos sistêmicos que se estruturam de forma independente.

Percebe-se internacionalmente, ainda, que as alterações conceituais mais significativas se relacionam com a unidade do direito. De fato, uma das principais características da teoria positivista tem a ver com a perspectiva sistêmica do conjunto de normas jurídicas e, conseqüentemente, com seu caráter unitário fundado em preceitos de hierarquia e validade. A pluralidade de fontes, órgãos legiferantes, jurisdições e, fundamentalmente, o surgimento de novos sujeitos de direitos e deveres internacionais, os quais atuam de forma paralela, independente e que, em alguns casos, chegam a se sobrepor aos estados, consubstanciam as situações fáticas que funcionam como matrizes do pluralismo que relativiza as teorias tradicionais $^{466}$.

Especificamente na relação entre o regional e o multilateral, haveria importante exemplo de repartição da atividade normativa entre organismos locais e globais, ou seja, entre o específico e o geral. Na verdade, quando organizações internacionais multilaterais convivem com organizações regionais de competência legislativa na mesma vertente jurídica, ocorre a divisão dessas competências entre normas abrangentes e específicas, sendo aquelas contidas na seara global e essas na local. Exemplo dessa conformação seria o sistema econômicocomercial estruturado no multilateralismo da Organização Mundial do Comércio - OMC - e no regionalismo do North American Free Trade Agreement - NAFTA ou do Mercado Comum do Sul - MERCOSUL.

\footnotetext{
${ }^{465}$ INTERNATIONAL LAW COMMISSION. Report of the Study Group of the International Law Comission. UN Doc A/CN.4/L.682. 2006. pp. 30-31. "In verbis": "One of the most well-known techniques of analysis of normative conflicts focuses on the generality vs. the particularity of the conflicting norms. In this regard, it is possible to distinguish between three types of conflict, namely: (a) Conflicts between general law and a particular, unorthodox interpretation of general law; (b) Conflicts between general law and a particular rule that claims to exist as an exception to it; and (c) Conflicts between two types of special law."

466 INTERNATIONAL LAW COMMISSION. Report of the Study Group of the International Law Comission. UN Doc A/CN.4/L.682. 2006. p. 11. "In verbis": "The fragmentation of the international social world has attained legal significance especially as it has been accompanied by the emergence of specialized and (relatively) autonomous rules or rule-complexes, legal institutions and spheres of legal practice. What once appeared to be governed by "general international law" has become the field of operation for such specialist systems as 'trade law', 'human rights law', 'environmental law', 'law of the sea', 'European law' and even such exotic and highly specialized knowledges as "investment law" or "international refugee law" etc. - each possessing their own principles and institutions. The problem, as lawyers have seen it, is that such specialized law-making and institution-building tends to take place with relative ignorance of legislative and institutional activities in the adjoining fields and of the general principles and practices of international law. The result is conflicts between rules or rule-systems, deviating institutional practices and, possibly, the loss of an overall perspective on the law."
} 
A primeira guerra mundial pode ser considerada um marco histórico que separa o direito internacional clássico do contemporâneo, a descentralização completa das primeiras iniciativas de centralização, a soberania externa clássica de sua relativização, mas a evolução de um sistema de direito não pode ser reduzida a um momento da história ${ }^{467}$. Direito é um processo.

Antes do surgimento do modelo de estado moderno, dotado de ordem normativa local específica, a ordem internacional era dotada de certa universalidade, ainda que não se pudessem identificar claramente os contornos do que hoje se reconhece como direito das gentes. Em um segundo momento, então, a soberania dos estados firmou-se como fonte produtora primaz da ordem global. Em processo de constante aperfeiçoamento, exatamente em razão da observação da evolução como um processo, o direito internacional pauta-se hoje ainda como universal, mas ganhou, conforme aqui se salienta, aparência fragmentada ${ }^{468}$.

O equilíbrio entre a independência dos estados - soberania externa - e a primazia do direito internacional apresenta-se há bastante tempo, conforme indicado, como desafio doutrinário. Nesse sentido, possível se faz verificar a sanção positivista, por exemplo, nos mecanismos de retaliação permitidos em sistemas específicos como o da Organização Mundial do Comércio. A institucionalidade internacional seria, dessa forma, necessária em razão do perigo e da demasiada inconsistência de se reservar ao judiciário interno dos estados a possibilidade de punir o poder local por violação externamente identificada e declarada ${ }^{469}$.

\footnotetext{
${ }^{467}$ KUNZ, Josef L.. La crise et les transformations du droit des gens. In: Recueil des Cours. Academie de Droit International de la Haye, Volume 88, 1955-II, pp. 01-104. p. 99. "In verbis“: "L'année 1914 est la ligne de séparation entre ce qu'on appelée le droit des gens classique et le droit des gens nouveau. C'est la période de transition entre un droit des gens comptètement décentralisé et un droit des gens plus centralisé et organisé, entre la réduction de la souveraineté classique et un droit plus supra-qu'inter-national. Des institutions nouvelles telles que la Société des Nations, les mandats, la protection des minorités ont disparu.“
}

${ }^{468}$ ACCIOLY, Hildebrando; NASCIMENTO E SILVA, G.E. do; CASELLA, Paulo Borba. Manual de direito internacional público. São Paulo: Saraiva, 2011. p. 121. "In verbis“ : "Entre universalidade e fragmentação, inscreve-se a perspectiva do direito internacional para o século XXI : o anseio pauta-se pela primeira; a realidade impõe seu peso, em relação à segunda. Mas as mutações sempre ocorreram e estão em curso na história: para tanto é preciso adotar a perspectiva da pós-modernidade, para a compreensão do mundo e neste, também, do direito internacional. A lição de Hugo GRÓCIO, a quem se atribui a paternidade do direito internacional, é clara: o sistema institucional e normativo internacional é falho e limitado, mas é passível de aperfeiçoamento. A constatação das limitações não deve levar ao desânimo, mas, antes, fazer atentar para a necessidade de aperfeiçoamento dos mecanismos institucionais e regulatórios internacionais. Entre o idealismo de KANT e o realismo de HOBBES, o que poderia ser chamado de pragmatismo responsável de GRÓCIO melhor responde ao quadro do mundo atual: pode ser aperfeiçoado.“

469 VISSCHER, Paul De. Les tendances internationales des constitutions modernes. In: Recueil des Cours. Academie de Droit International de la Haye, Volume 80, 1952-I, pp. 511-578. pp. 532-533. "In verbis": "Dans l'état actuel des choses, la proclamation de la supériorité du droit international généralement reconnu, assortie d'un contrôle juridictionnel, constitue le degré d'internationalisme le plus avancé qui se puisse concevoir. Un tel système s'analyse dans l'adoption globale du droit international commun combinée avec un mécanisme interne de sanctions fourni par le droit international lui-même et consistant dans la mise en jeu de la 
No que se refere à estrutura institucional do direito internacional, dois aspectos devem ser atualmente ressaltados como exemplos marcantes de sua aparência fragmentada. Por um lado, a divisão da atividade legislativa global em competências temáticas estabeleceu grandes entraves à visão unitarista tradicional. O processo de institucionalização, surgido para consolidar e em decorrência de tais construções legislativas, acabou por distanciar a normatização da figura do estado e criou verdadeiras ordens jurídicas gerais sobre matérias específicas.

A produção legislativa internacional não é mais, portanto, monopólio dos estados, os quais aderem freqüentemente a organizações internacionais que, com maior ou menor autonomia, passaram a produzir direito. A ordem mundial, antes sistematizada principalmente de forma una - ainda que existissem teorias dualistas - com enfoque na relação existente entre a ordem interna dos estados e a internacional, passou a ser observada pelo prisma da interação entre as diferentes temáticas organizadas sob lógicas específicas e contidas nas diversas organizações internacionais que surgiram principalmente após a segunda guerra mundial.

Exatamente da forma como as organizações internacionais se estruturaram extraem-se os exemplos da conformação aparentemente fragmentada do direito internacional. Acordos inter-estatais estabelecem, por um lado, ordens jurídicas multilaterais, as quais abarcam um número indefinido de estados e adquirem características conseqüentemente globais, enquanto, de outro lado, os mesmos sujeitos de direito internacional tendem a se organizar regionalmente e procuram se afirmar no contexto global por meio desses sistemas jurídicos locais.

O direito internacional, como todos os sistemas jurídicos, está em construção. Suas instituições e estruturas não são definitivas. Eventual receio de fragmentação ou de qualquer risco à sua coerência deve ser relevado, inclusive, por não ser a primeira vez na história que a ordem internacional se vê confrontada com a proliferação de órgãos em sua estrutura ${ }^{470}$.

responsabilité internationale, s'ajoute très heureusement un mécanisme de sanctions internes dont la mise en oeuvre préventive limitera considérablement le déclenchement de la sanction internationale. Il serait dangereux de pousser plus loin les exigences logiques de l'internationalisme. Spécialement, confier au juge interne le pouvoir d'imposer à son Etat le respect de règles internationales qu'il a traditionnelement répudiées : reviendrait à consacrer une solution utopique et dangereuse qui ne se concilie ni avec le caractère imprécis du droit international commun ni avec le caractère représentatif que revêt nécessairement le pouvoir politique dans l'ordre interne.“

${ }^{470}$ CASELLA, Paulo Borba. Evolução institucional do direito internacional: à luz do cinqüentenário do conceito de direito de Hart (1961). In: Revista Brasileira de Filosofia. Ano 60, Vol. 236, janeiro-junho, 2011. pp. 313329. p. 321. "In verbis": "A construção de sistema institucional e normativo internacional está em curso. Se, de um lado, a proliferação de tribunais é percebida como risco para a unidade do sistema internacional, é evidente que não há razões de ordem técnico jurídica, para tal interpretação. O fenômeno se produzira anteriormente com a multiplicação das instâncias arbitrais, sem causar danos ao sistema jurídico globalmente considerado." 
Nesse sentido, a questão das rivalidades entre estados - claramente disputas de caráter político e, portanto, que se referem diretamente ao poder - era tratada, por exemplo, por essa doutrina menos recente que já analisava e considerava o pertencimento de um estado a mais de um sistema regional de direito sem necessariamente se referir às organizações internacionais como conceito ${ }^{471}$.

A questão do interno com o internacional, fundada no paradigma do estado-nação, acabou sucumbindo ao reconhecimento de novos atores como sujeitos de direitos e deveres na esfera do direito das gentes e o debate passou a se concentrar na possibilidade de se estabelecerem regras gerais aos múltiplos sistemas jurídicos especializados que surgiram e nas dificuldades em se aplicarem as teorias positivistas fundadas em critérios hierárquicos de validade a esse novo contexto global $^{472}$.

Mais que isso, a discussão em voga nessa época acerca da sustentação da unicidade do direito internacional na relação entre as ordens internas e a ordem internacional não se refletia necessariamente no estudo do regionalismo incipiente, o qual chegava a ser admitido pela doutrina sem ameaçar o sistema geral e a ser projetado como repartição interna da organização da Sociedade das Nações, por exemplo ${ }^{473}$.

Cumpre salientar que não bastaria o elemento volitivo dos sujeitos de direito internacional para que um agrupamento de estados fosse formado com finalidade cooperativa. Exigível se faz, complementariamente, que a iniciativa cumpra os desígnios estabelecidos pelas regras aceitas de direito das gentes ${ }^{474}$. Sob tal prisma encontra-se a necessidade, por

${ }^{471}$ DE ORÚE Y ARREGUI, José Ramon. Le régionalisme dans l'organisation internationale. In: Recueil des Cours. Academie de Droit International de la Haye, Volume 53, 1935-III, pp. 01-95. p. 80. “In verbis“: "L'un des plus grands dangers de l'idée régionaliste, c'est la possibilité d'Etats ayant des intérêts différents, et qui, par leurs antagonismes avec un autre groupement que celui dont ils font partie, ferait de ce dernier une véritable pépinière de rivalités. Pour ce motif, on doit reconnaître la faculté pour chaque Etat d'appartenir simultanément à différents groupements régionaux."

472 KOSKENNIEMI, Martti. The fate of public international law: constitutional utopia or fragmentation? Chorley Lecture: London School of Economics, 2006. "In verbis": "The force of the fragmentation debate has obscured the degree to which it captures a classical international law problem. 'How is law between sovereign States possible?' is not too different from the question 'how is law between multiple regimes possible?"

${ }^{473}$ DE ORÚE Y ARREGUI, José Ramon. Le régionalisme dans l'organisation internationale. In: Recueil des Cours. Academie de Droit International de la Haye, Volume 53, 1935-III, pp. 01-95. p. 88. “In verbis“: “[...] même en reconnaissant la viabilité du régionalisme international, nous nous déclarerons partisans décidés de l'unitarisme dans l'organisation entre Etats, mais en admettant la validité de divisions régionales soigneusement étudiées dans le sein de la Société des Nations.“

${ }^{474}$ MORELLI, Gaetano. Cours général de droit international public. In: Recueil des Cours. Academie de Droit International de la Haye, Volume 89, 1956-I, pp. 437-604. p. 557. "In verbis“: "Si l'on emploie le terme d'union internationale d'Etats dans un sens très large, on pourrait dire que tout accord international crée une union internationale d'Etats. On indiquerait, par ce terme, un groupe d'Etats qui sont destinataires d'un certain 
exemplo, de que acordos regionais sejam compatíveis com outras estruturas sistêmicas existentes na ordem global.

Nesse sentido, o regionalismo - cooperativista ou integracionista fortalecido nos últimos sessenta anos - surge como exemplo dessa dinâmica que, paralelamente ao paradigma do estado moderno, em algum momento dos séculos XIX e XX passou a desafiar - ainda que apenas aparentemente - o sentido de unidade do direito internacional arrefecido fortemente a partir do fim da idade média ${ }^{475}$.

No contexto temporal indicado, consolidou-se a supranacionalidade como fenômeno paradigmático para a organização do poder mundial hábil a relativizar o conceito tradicional de soberania externa e a questionar o papel da vontade dos estados na produção de normas de direito das gentes. Observa-se, a esse respeito, que uma organização internacional supranacional tem como característica determinante a adoção do critério da maioria na tomada de decisões e que, nos exemplos hoje disponíveis, essa instrumentalização da vontade conjunta pode conviver muito bem com a soberania - suavizada - dos estados que são partes do sistema jurídico.

Tal percepção decorre necessariamente da lógica de que os órgãos da organização não seriam necessariamente supranacionais, mas, sim, seu direito. A supranacionalidade se expressaria politicamente na ordem internacional, portanto, primeiro pelo direito e apenas em momento posterior por meio dos órgãos comuns ${ }^{476}$. O grande paradigma desse panorama seria

nombre de règles de droit international particulier : précisément des règles posées par l'accord. Mais, en général, on ne parle d'union que lorsque les normes de l'accord visent à satisfaire un intérêt commun aux différents Etats entre lesquels l'accord est passé et qu'elles prédisposent, dans ce but, une coopération entre les mêmes Etats ; ce qui revient à dire qu'elles règlent les conflits d'intérêts ayant trait à la coopération qu'il faut prêter pour que l'intérêt commun soit satisfait. Il faut préciser que, pour qu'il y ait une union inlemalionale d'Etats, il ne suffit pas qu'un accord international ait été conclu et qu'un tel accord prévoie une coopération entre les Etats en tant que moyen pour la satisfaction de l'intérêt commun ; il est aussi nécessaire que cette coopération soit réglée par des normes internationales.“

${ }^{475}$ YEPES, J.M.. Les accords régionaux et le droit international. In: Recueil des Cours. Academie de Droit International de la Haye, Volume 71, 1947-II, pp. 227-344. p. 242. "In verbis“: "Il est évident qu'il existe, en droit international, des problèmes spécifiquement américains, européens, asiatiques ou africains qui ne se présentent pas ailleurs et qui exigent une solution en accord avec la constitution spéciale du milieu politique et géographique où ils se sont posés. L'ensemble des institutions, des doctrines, des conventions et des coutumes existant dans chaque continent pour les rapports internationaux, forme ce qu'on peut appeler le droit international particulier à ce continent.“

476 TEITGEN, Pierre-Henri. La décision dans la Communauté économique européenne. In: Recueil des Cours. Academie de Droit International de la Haye, Volume 134, 1971-III, pp. 589-689. p. 688. "In verbis“: "Envisagées dans leur établissement les décisions communautaires - abstraction faite de celles qui relèvent des pouvoirs propres de la Commission - résultent dans l'état présent des choses d'un systme de coopération interétatique. Envisagées une fois établies dans leur portée et leur sanction, elles bénéficient en principe dans l'ordre internes des Etats membres d'une immédiateté et d'une primauté qui permettraient de dire «Droit communautaire passe droit national » comme on dit «Droit fédéral passe droit de pays ». Dès lors, dans la 
na atualidade a União Européia. Assim sendo, de se ressaltar de início seria que a referida experiência integracionista não pode ser reduzida a seu conteúdo econômico. Trata-se de fenômeno de características políticas, de um projeto muito maior que teve na paz sua forma motriz e ponto de partida histórico ${ }^{477}$.

As técnicas modernas de organização do poder não devem ser, portanto e conforme o que aqui se propõe, abandonadas quando da análise do direito internacional. $\mathrm{O}$ aperfeiçoamento das iniciativas de aproximação, por exemplo, conduz suas estruturas inevitavelmente à adoção de modelos assemelhados à institucionalidade interna de um estado $^{478}$.

O sistema legal de uma organização internacional possui autonomia tanto em relação ao direito local de membros quanto ao direito internacional geral ${ }^{479}$. Autonomia não significa,

Communauté économique européenne, ce n'est pas l'Autorité communautaire qui peut être actuellement qualifiée de «supranationale » mais la règle communautaire.“

477 SEBESTA, Lorenza. Del balance de poder a la integración europea: una reflexión histórica. In: NEGRO, Sandra C. (Coord.). Lecturas sobre integración regional y comercio internacional. Buenos Aires: La Ley, 2012. pp. 587-609. p. 608. "In verbis": “Quien desconoce el sentido del punto de inflexión que representó la integración europea en este sentido, reduciéndola a una mera operación de conveniencia económica, no sólo traiciona el pensamiento de muchos entre los quienes pensaron y crearon Europa, sino, sobre todo, impide una comprensión del fenómeno como etapa del desarrollo del sistema mundial hacia formas más civilizadas de relaciones internacionales y, entonces, frena la posibilidad de sacarle consecuencias políticas contundentes a su propia historia. El continente que encarnó la política de poder y pagó tan duramente las consecuencias de sus fallas, tiene ahora no sólo la responsabilidad ética, sino el conocimiento histórico y la posibilidad material de adelantar un poco este paso necesario de civilización."

${ }^{478}$ GANSHOF VAN DER MEERSCH, Walter. L'ordre juridique des communautés européennes et le droit international. In: Recueil des Cours. Academie de Droit International de la Haye, Volume 148, 1975-V, pp. 01-433. pp. 91-92. "In verbis“: "Sans doute, peut et doit-on espérer, l'intégration progressive produisant son effet sur le plan institutionnel, que les procédures de revision conduiront les Etats membres dans les voies de l'Etat fédéral. Mais ce serait à la fois forcer la réalité institutionnelle dans l'analyse des relations entre les Communautés et les Etats et introduire dans les concepts juridiques une approximation difficilement acceptable, que de ranger les structures existantes des Communautés sous une qualification qui, malgré la souplesse d'adaptation des formules fédératives, répond en droit public à des données essentielles, insuffisamment reflétées dans les Communautés.“

${ }^{479}$ MORELLI, Gaetano. Cours général de droit international public. In: Recueil des Cours. Academie de Droit International de la Haye, Volume 89, 1956-I, pp. 437-604. p. 575. "In verbis“: "L'union, une fois constituée, peut avoir un ordre juridique interne qui lui est propre et qui est distinct en même temps de l'ordre international ainsi que des différents ordres juridiques des Etats membres. Cet ordre interne de l'union, de même que les ordres étatiques, vise à régler des rapports intéressant des individus, tels que, notamment, le rapport d'emploi des fonctionnaires de l'union. Or il se peut que l'ordre interne de l'union confère la personnalité juridique, outre à des individus, à l'union elle-même et, s'il y a lieu, à d'autres entités. Cela ne peut arriver que lorsque l'union est pourvue d'organes par lesquels elle agit justement en tant que sujet de droit dans son propre ordre interne, exerçant des activités à évaluer sur la base du même ordre. Un exemple d'organe d'une union internationale considérée en tant que sujet de son propre ordre interne est donné par le Tribunal administratif institué par l'Organisation des Nations Unies en vue de la décision des différends entre l'Organisation ellemême et ses fonctionnaires. Les organes de ce type se distinguent des organes des unions dont nous avons déjà parlé, parce que l'ordre juridique qui les institue et les règle, qui en évalue l'activité et qui impute la même activité à l'union, est un ordre juridique autre que l'ordre juridique international.“ 
contudo, descontinuidade teórica ou rígida separação. A divisão do direito entre interno, internacional, regional ou de uma organização internacional deve ser compreendida como forma de racionalização do sistema, que é uno e indivisível. Direito é direito e simplesmente direito.

A compartimentação sistêmica se faz para melhor sistematização e desenvolvimento, mas todos esses sistemas autônomos estão comprometidos com a compatibilidade mútua. Esse é o pensamento unitário que se mostra exigível dos juristas na atualidade. Qualquer assunção de autonomia sistêmica que leve a antinomias ou incongruências decorre de análises da ordem internacional mais próximas do espectro político. Nada mais.

De certo, se comparada a percepção da Sociedade das Nações como catalisador dos regionalismos com a atual perspectiva de compatibilidade interssistêmica sem critérios hierárquicos, restaria denotada maior aproximação da teoria do direito das gentes do passado com a estruturação estabelecida internamente pela distribuição do poder pelo direito dos estados. A hierarquização dos sistemas internacionais de direito nunca constituiu consenso e em algum momento do século XX deixou de ser considerada e proposta pelos internacionalistas $^{480}$.

Não se defende aqui, gize-se, a adoção de critérios de validade que estabeleçam distintos níveis verticais de valor aos sistemas de direito internacional. Apenas sugere-se que o abandono de tais propostas pela doutrina constitui claro sintoma do distanciamento do pensamento internacionalista da teoria do estado e do constitucionalismo.

A assunção da impossibilidade - ao menos até a atualidade - de se estabelecerem amplamente regras internacionais hábeis a orientar a conduta dos sujeitos de direito internacional não exclui a possibilidade de se reconhecer um núcleo de universalidade no direito das gentes. Tal discussão, muito contemporânea ao estudo dos direitos humanos, não é recente e, para os universalistas, pode denunciar preocupação ao menos com a transição entre pluralismo - de estados e de percepções de direitos - e a uniformização do direito que poderia, inclusive, culminar projetivamente com uma organização política global supraestatal $^{481}$.

\footnotetext{
${ }^{480}$ Exemplo de negação da hierarquização já na primeira metade do século XX em SCELLE, Georges. Théorie et pratique de la fonction exécutive en droit international. In: Recueil des Cours. Academie de Droit International de la Haye, Volume 55, 1936-I, pp. 87-202. p. 96. "In verbis“: "Cela tient à ce que les sociétés internationales, et la plus grande de toutes, la Société oecuménique du droit des gens, est une société complexe dans laquelle la superposition des ordres juridiques n'est pas hiérarchisée.“

${ }^{481}$ YEPES, J.M.. Les accords régionaux et le droit international. In: Recueil des Cours. Academie de Droit International de la Haye, Volume 71, 1947-II, pp. 227-344. p. 236. "In verbis“" "Affirmer l'existence d'un droit international particulier n'est nullement méconnaître l'existence d'un droit universel, ou commun, dont les
} 
A partir de toda a construção teórica apresentada, admitir pluralidade sistêmica na ordem internacional não significaria pressupor a separação total entre cada um dos conjuntos normativos $^{482}$. Absolutamente possível se faz considerar, assim, a existência de elementos comuns - em sua origem, fundamento de validade ou princípios - hábeis a sustentar a coerência normativa de todo o conjunto ${ }^{483}$.

O uso do sistema jurisdicional interno unificado dos estados como modelo para o direito internacional pode indicar que o ideal seria um sistema unificado, hierárquico, mas nem mesmo os estados, em regra e por um lado, possuem um único sistema - vide a possibilidade de arbitragem - e o direito como um todo não pode ignorar os meios - regulares ou alternativos - que se apresentem à solução de controvérsias ${ }^{484}$.

A análise da estrutura da Organização das Nações Unidas pode levar à conclusão de que ao Conselho de Segurança restou consignado quase exclusivamente apenas o exercício do poder político relacionado à manutenção da paz e que todas as outras atribuições da

principes fondamentaux sont valables dans leur essence pour tous les Etats, mais seulement accepter que l'application de la règle de droit varie selon les régions pour tenir compte des éléments qui leur sont particuliers. Le droit ne remplirait pas sa fonction d'ensemble de règles normatives de la conduite humaine, s'il ne pouvait s'adapter aux conditions particulières de chaque groupe humain. Et cela est plus vrai encore du droit international, discipline juridique encore en formation et dont l'évolution ultime n'est guère prévisible.“

${ }^{482}$ ZICCARDI, Piero. Les caractères de l'ordre juridique international. In: Recueil des Cours. Academie de Droit International de la Haye, Volume 95, 1958-III, pp. 263-407. p. 331. "In verbis“: "Une conception pluraliste présuppose, en effet, une séparation totale entre les milieux qui donneraient lieu à autant de systèmes juridiques différents et sans aucune coordination entre eux. Il faut par contre toujours rechercher une explication unitaire par rapport à toute pluralité de systèmes juridiques quand ces systèmes ont pour référence la même base humaine, ce qui oblige à étudier comment ont pu se produire la différenciation et l'harmonisation des systèmes juridiques. Il s'agit alors d'une enquête portant sur le milieu humain où ces systèmes ont puisé leur origine et où ils vivent réellement.“

${ }^{483}$ ZICCARDI, Piero. Les caractères de l'ordre juridique international. In: Recueil des Cours. Academie de Droit International de la Haye, Volume 95, 1958-III, pp. 263-407. p. 337. "Il est également vrai que dans la formation de ces communautés interviennent des liens plus ou moins étroits, des affinités diverses en mesure et en intensité, de sorte qu'elles semblent entrer en jeu dans des sphères distinctes, caractérisées par la plus ou moins grande intensité du degré de civilisation commune. Cela est vrai aussi par rapport à la communauté internationale d'aujourd'hui, d'étendue universelle, mais à la fois multiple et unitaire, dans les difrerentes sphères d'association plus ou moins intense, et de civilisation commune, qui coexistent dans son unité actuelle.“

${ }^{484}$ SEFERIADES, Stelio. Le problème de l'accès des particuliers à des juridictions internationales. In: Recueil des Cours. Academie de Droit International de la Haye, Volume 51, 1935-I, pp. 01-120. p. 115. "In verbis“: "Toutefois, malgré ces observations et ma préférence en faveur du système de la justice unique, il me faut convenir qu'aucune raison juridique ne saurait empêcher l'existence simultanée de Tribunaux internationaux institués par des actes bilatéraux. Ce serait une situation analogue à celle de 1'existence de commissions de conciliation et d'arbitrage à côté des organismes de la Société dee Nations, commissions dont le rôle conciliateur n'a jamais été considéré comme inutile. Les efforts pacifistes doivent être acceptés, d'où qu'ils viennent, et nul ne peut prétrendre les monopoliser. " 
organização caberiam à Assembléia Geral e ao secretariado. Mas não se deve ignorar que a manutenção da paz constitui a finalidade motriz desse sujeito comum de direito das gentes ${ }^{485}$.

Muitos autores observam entre as Nações Unidas e a Liga das Nações uma relação de sucessão de atribuições cujo maior ou menor sucesso teria dependido quase exclusivamente do contexto histórico de cada uma delas. A acepção histórica apontada não deve se restringir, contudo, à evolução das duas institucionalidades. Os próprios acordos fundacionais já denotam de maneira bem explícita o objetivo dos estados que os firmavam.

No pacto da Liga das Nações, a maior parte de seus dispositivos tratavam de obrigações e da atuação dos estados. Já na carta, a formação de uma organização internacional e o estabelecimento de obrigações coletivas numa perspectiva cooperativa estavam claros desde o princípio ${ }^{486}$.

O sistema multilateral da Organização das Nações Unidas não apenas prevê a existência de acordos regionais com atribuições semelhantes às de sua carta no que se refere principalmente à manutenção da paz, como também regulamenta a interação entre o local e o geral $^{487}$.

${ }^{485}$ WALDOCK, Humphrey. General course on public international law. In: Recueil des Cours. Academie de Droit International de la Haye, Volume 106, 1962-II, pp. 01-251. p. 22. "In verbis": "The Charter, however virtually confines the Security Council's functions to the conciliation of disputes and to the maintenance of peace; and it places au the rest of the United Nations functions, other than the administration of international justice, under the General Assembly. Furthermore, the frustration of the Council owing to the differences between the Permanent Members has had the effect of transferring the political initiative in large measure from the Council to the Assembly even in the conciliation of disputes and the maintenance of peace. States have more and more taken advantage of their right under Article 35 to bring a dispute or situation before the Assembly rather than the Council;"

${ }^{486}$ WALDOCK, Humphrey. General course on public international law. In: Recueil des Cours. Academie de Droit International de la Haye, Volume 106, 1962-II, pp. 01-251. p. 20. "In verbis“: "The Charter, like the Covenant, is technically a multilateral treaty between States. But the Charter proclaims itself, more openly than the Covenant, to be the constitution of an Organization and not merely a treaty. The preamble ends with the words 'Our respective Governments... have agreed to the present Charter and do hereby establish an international organization to be known as the United Nations'. Moreover, whereas the Covenant almost always spoke of the purposes or actions of members of the League, the Charter begins in Article I with a statement of the purposes of the 'United Nations', and constantly refers to the purposes, principles and actions either of the 'United Nations' or of 'the Organization'. In short, the whole atmosphere of the Charter is that of the constitution of an organized society rather than of a simple treaty to co-operate."

${ }^{487}$ VILLANI, Ugo. Les rapports entre l'ONU et les organisations régionales dans le domaine du maintien de la paix. In: Recueil des Cours. Academie de Droit International de la Haye, Volume 290, 2001, pp. 225-436. p. 259. "In verbis": "Comme nous l'avons déjà dit, la Charte des Nations Unies consacre spécifiquement le chapitre VIII aux organisations régionales (ainsi qu'aux accords régionaux). Dans ce chapitre est affirmée avant tout la compatibilité avec la Charte des organisations régionales et des accords régionaux destinés à régler les affaires qui, touchant au maintien de la paix et de la sécurité internationales, se prêtent à une action de caractère régional, à condition qu'ils soient conformes aux buts et aux principes des Nations Unies (art. 52, par. 1). En second lieu, l'article 52 (par. 2 et 3) affirme l'obligation, pour les parties à un différend d'ordre local, de tenter de le régler au moyen d'organisations (ou d'accords) régionaux, avant de le soumettre au Conseil de sécurité, et déclare que ce dernier encourage de telles solutions (sauf, toutefois, les articles 34 et 35 de la Charte). En vertu de l'article 53, qui concerne, plus particulièrement, le maintien de la paix, le Conseil de 
Quando observada a relação existente entre a Organização do Tratado do Atlântico Norte - OTAN - e a Organização das Nações Unidas, pode surgir questionamento relacionado à utilidade - a menos para o direito - da primeira se a segunda já exigiria de seus membros a paz como objetivo motriz e a atuação em consonância com o determinado pelo Conselho de Segurança. Não existe contradição, contudo. O tratado da OTAN busca conceder proteção imediata a seus membros em caso de ataque e não se encontra em conflito com o princípio geral da carta global ${ }^{488}$.

As garantias de coerência fornecidas pelos arcabouços teóricos não conseguem, contudo, eliminar as dúvidas que surgem nos contextos de produção e de cumprimento do direito das gentes. A centralidade da soberania estatal, da qual decorre a autoridade jurisdicional absoluta do estado em seu território, e a horizontalidade da relação entre esses núcleos de poder na ordem internacional estabeleceram um descompasso entre a produção de normas e sua efetivação na esfera global ${ }^{489}$.

Os desafios indicados serviram de base às teorias que afirmam ter havido substituição do universalismo pelo pluralismo no direito internacional. Esclarece-se, entretanto e como já sugerido anteriormente, que o termo pluralismo, como antítese do universalismo, pode se referir tanto à substituição das concepções jusnaturalistas do direito das gentes mais remoto pelo reconhecimento da vontade estatal como fonte exclusiva de direito quanto, mais

sécurité peut utiliser les organisations ou les accords régionaux pour des mesures coercitives sous sa direction ou autoriser ces mesures. Enfin, selon l'article 54, le Conseil de sécurité doit, en tout temps, être tenu pleinement au courant de toute action entreprise ou envisagée, en vertu d'accords régionaux ou par des organisations régionales, pour le maintien de la paix et de la sécurité internationales."

488 GOODHART, A.L.. The North Atlantic treaty of 1949. In: Recueil des Cours. Academie de Droit International de la Haye, Volume 79, 1951-II, pp. 183-236. p. 235. "In verbis": "In conclusion it may be asked what is the purpose of the Treaty if the signatories are already bound by the Charter to assist the United Nations Organization in the maintenance of peace? The answer is that the Members of the United Nations are not bound to act until the Security Council has called on them to act, and that that call may either be delayed or may never come owing to the exercise of the veto. The Treaty therefore gives to its signatories immediate protection against a sudden attack which might otherwise threaten to overwhelm them. It is therefore not in conflict with but in furtherance of the basic purposes of the Charter of the United Nations."

${ }^{489}$ MENEZES, Wagner. Tribunais internacionais: jurisdição e competência. São Paulo: Saraiva, 2013. p. 55. “In verbis": "Em razão da sistematização do direito com base na soberania estatal e como expressão jurisdicional desta, o Direito Internacional é concebido como um sistema jurídico, assentado na soberania externa, absoluta e indivisível dos Estados, que se consubstancia na sua vontade de contrair ou não, livremente, obrigações no plano internacional, não reconhecendo nenhuma autoridade superior à sua, imprimindo, em razão disso, uma relação de coordenação horizontal com outras soberanias. O Estado é concebido como a autoridade jurisdicional central, em que somente ele poderia resolver definitivamente os conflitos ocorridos em seu território e no plano externo/internacional restou um hiato entre os pressupostos teóricos de sistematização do direito e seus mecanismos jurídicos, ou judiciais, de efetivação." 
recentemente, à multiplicação de normatizações temáticas específicas na esfera global freqüentemente revestidas da institucionalidade de uma organização internacional ${ }^{490}$.

Nesse contexto recente, a normativa internacional passou a ser construída com vocabulários específicos, técnicos, cujas interpretações tornaram-se essencialmente dependentes de especialistas para o preenchimento, por exemplo, de lacunas jurídicas. A aplicação do direito parece cada vez mais não se pautar estritamente no comprometimento com a equidade e a justiça, mas no pragmatismo técnico, muitas vezes, de características claramente tendenciosas ${ }^{491}$.

${ }^{490}$ BOBBIO, Norberto. Teoria do ordenamento jurídico. Brasília: Editora Universidade de Brasília, 1999. pp. 162-163. "In verbis": "Os processos através dos quais a ideologia universalista do Direito decaiu são dois, principalemente, e sucederam-se no tempo : Se chamamos de 'monismo jurídico' a idéia universalista, com base na qual existe só um ordenamento jurídico universal, e de 'pluralismo jurídico' a idéia oposta, podemos dizer que o pluralismo jurídico percorreu duas fases. A primeira fase é a que corresponde ao nascimento e ao desenvolvimento do historicismo jurídico, que, sobretudo através da escola histórica do Direito, afirma a nacionalidade dos direitos que emanam direta ou indiretamente da consciência popular. Dessa forma, ao direito natural único, comum a todos os povos, se contrapõem tantos direitos quantos são os povos ou as nações. Do assim chamado gênio das nações, que constituirá um dos motivos recorrentes das doutrinas nacionais do século passado, é produto típico também o direito. Essa primeira forma de pluralismo tem caráter estatalista. Há não apenas um, mas muitos ordenamentos jurídicos, porque há muitas nações, que tendem a exprimir cada uma em um ordenamento unitário (o ordenamento estatal) a sua personalidade, ou se quisermos, o seu gênio jurídico. Essa fragmentação do Direito universal em tantos Direitos particulares, interdependentes entre si, é confirmada e teorizada pela corrente jurídica que acabou por prevalecer na segunda metade do século passado : falo do positivismo jurídico, isto é, da corrente segundo a qual não existe outro Direito além do Direito positivo, e a característica do Direito positivo é ser criado por uma vontade soberana (o positivismo jurídico identifica-se com a corrente voluntarista do Direito). Onde existe um poder soberano existe um direito e, todo poder soberano sendo por definição independente de qualquer outro poder soberano, cada Direito constitui ordenamento autônomo. Há tantos direitos diferentes entre si quantos são os poderes soberanos. Que os poderes soberanos sejam muitos e independentes é um fato. Partindo do dogma voluntarista do Direito, um direito universal não pode ser concebido senão pela hipótese de um único poder soberano universal ; essa hipótese dera origem à idéia de que o Direito emanasse de uma única vontade soberana, a vontade de Deus, e os singulares poderes soberanos históricos fossem emanações diretas ou indiretas da vontade de Deus. Porém, a idéia foi abandonada ao surgir o pensamento político moderno, no qual a idéia universalista do Direito reapareceu sob a forma do Direito natural, cujo órgão criativo não era mais a vontade, mas a razão. Mas, reconhecendo-se novamente como fonte do Direito não a razão, mas a vontade, e tendo caído a concepção teológica do universo na filosofia e nas ciências modernas, derivará, como consequência inevitável, o pluralismo jurídico. A segunda fase do pluralismo jurídico é aquela que podemos chamar de institucional (para distingui-la da primeira, que podemos chamar de estatal ou nacional). Aqui 'pluralismo' tem um significado mais pleno (tanto que, se se fala de 'pluralismo' sem maiores especificações, nos referimos a esta corrente e não à precedente) : significa não somente que há muitos ordenamentos jurídicos (mas todos do mesmo tipo), em contraposição ao Direito universal único, mas que há ordenamentos jurídicos de muitos e variados tipos. Chamamo-lo de 'institucional' porque a sua tese principal é a que existe existe um ordenamento jurídico onde existe uma instituição, ou seja, um grupo social organizado. As correntes de pensamento que lhe deram origem são as mesmas correntes sociológicas, antiestatais, que vimos na origem da escola do livre Direito [...]“.

${ }^{491}$ INTERNATIONAL LAW COMMISSION. Report of the Study Group of the International Law Comission. UN Doc A/CN.4/L.682. 2006. p. 14. "In verbis": "Each rule-complex or 'regime' comes with its own principles, its own form of expertise and its own 'ethos', not necessarily identical to the ethos of neighbouring specialization. 'Trade law' and 'environmental law', for example, have highly specific objectives and rely on principles that may often point in different directions. In order for the new law to be efficient, it often includes new types of treaty clauses or practices that may not be compatible with old general law or the law of some other specialized branch. Very often new rules or regimes develop precisely in order to deviate from what was earlier provided by the general law. When such deviations or become general and frequent, the unity of the law suffers." 
Soma-se aos fenômenos descritos a questão da governança. Sob o paradigma da governança, os interesses políticos acabaram se sobrepondo a qualquer sistematização do direito e a discussão unitarista perdeu em grande medida sentido e espaço não apenas para o pluralismo fragmentado em diversos discursos sistêmicos, mas, principalmente, para a captura da produção legislativa internacional por grupos com interesses específicos.

Torna-se possível observar, assim, nessa conformação política cada vez mais influenciada pelo paradigma da governança, instrumentalizado, por exemplo, no fenômeno da fragmentação, que as diversas esferas jurídicas tenderiam a atuar hoje de forma autônoma, obedecendo a lógicas e estruturas jurídicas próprias, as quais não respeitariam os referidos pressupostos positivistas da concretude e da normatividade.

Dentre os fatores que impediriam a viabilidade dos parâmetros sistêmicos clássicos estaria, mais uma vez e fundamentalmente, a impossibilidade de se sustentar o tradicional protagonismo dos estados na estrutura do direito internacional. Caso não se admitisse a referida alteração de perspectiva, complicado se tornaria justificar, por exemplo, o surgimento e desenvolvimento de mecanismos independentes e órgãos específicos para assegurar a eficácia das regras produzidas e a estabilidade das relações estabelecidas atualmente na comunidade internacional ${ }^{492}$.

Importante ressaltar o conteúdo e os limites dessa comunidade que se vê submetida, já que se trata de um termo que se refere não a uma coletividade humana, mas mormente a uma congregação de entes políticos não-físicos, agentes do direito internacional e freqüentemente - mas não necessariamente - dotados de soberania ${ }^{493}$.

A diminuição da importância dos estados como atores do direito internacional observado o papel das organizações internacionais e da admissão cada vez maior do ser humano como sujeito de direito internacional - fez com que ao lado das teorias fragmentárias

\footnotetext{
${ }^{492}$ KOSKENNIEMI, Martti. Global governance and public international Law. In: Kritische Justitz, 37, 2004. p. 248. Koskenniemi ressalta que a ONU tem vivenciado tais dificuldades ao depender, por não possuir suas próprias forças armadas, da concessão de soldados por seus membros. Marcante é, nesse exemplo, o império descrito por Koskenniemi tendo em vista o fato de apenas aqueles Estados que já possuem supremacia política internacional têm um contingente militar apropriado para possibilitar essas concessões. Tal estruturação torna, portanto, impossível a aplicação de intervenções militares nesses "Estados-império" e retira da ONU a possibilidade de utilização de mecanismos de coerção contra eles.

493 AGO, Roberto. Communauté internationale et organisation internationale. In: DUPUY, René-Jean. Manuel sur les organisations internationales. Dordrecht: Martinus Nijhoff Publishers, 1998. p. 3. "In verbis": "Le terme <<communauté internacionale>> désigne en général une collectivité humaine qui se distingue avant tout par le fait d'avoir pour membres primaires des entités non pas physiques, mais politiques et souveraines“.
} 
- ou de maneira mesclada a elas - estudiosos do direito começassem a negar os modelos da teoria geral do estado e o constitucionalismo como teorias aplicáveis ao direito internacional.

Nesse panorama e ironicamente, o embate entre o global uniformizante e o local fragmentado torna cada vez mais relevante o estudo dos modelos positivistas clássicos e da estrutura interna de poder dos estados como alternativa louvável de racionalização nos dilemas que se apresentam hoje ao contexto jurídico internacional.

Especificamente quanto à questão da governança, percebe-se que na multiplicidade de estruturas legais que se formam de maneira aparentemente autônoma no direito internacional, a fragmentação propriamente não configuraria um desafio estrutural formal tão sério e inconciliável com as teorias unitaristas como aquele representado pelo modelo da governança, o qual nessa estrutura repartida acaba se incorporando aos procedimentos normativos e, desafiando a unidade, capturando suas perspectivas fragmentadas.

Os parâmetros de governança, isto é, de interesses específicos, os quais orientam grande parte da produção normativa internacional atual, constituem fenômenos claramente políticos. Direito e política não podem ser, no entanto, separados ${ }^{494}$. Muitas abordagens da ordem internacional revestidas de argumentos jurídicos podem se embasar, na verdade e no direito das gentes muitas vezes com bastante franqueza, em premissas políticas ${ }^{495}$.

O direito internacional conviveu com importantes reflexões teóricas durante o período imediatamente posterior à segunda grande guerra ${ }^{496}$. Vários de seus paradigmas foram questionados, rompidos e reformulados. A lógica da unidade positivista foi sendo aos poucos desafiada por teorias fragmentárias, as quais se baseiam na estruturação do direito das gentes em uma série de esferas de normatização específicas que, principalmente no contexto das organizações internacionais, regulamentam a ordem mundial em uma série de sistemas independentes.

${ }^{494}$ ROUSSEAU, Charles. Principes de droit international public. In: Recueil des Cours. Academie de Droit International de la Haye, Volume 93, 1958-I, pp. 369-550. p. 381. "In verbis“: "Reste le facteur politique. Le droit des gens a été longtemps et est encore largement contrarié dans son développement par la combinaison du point de vue politique et du point de vue juridique : le résultat previsible en est la trop fréquente altération des princips du droit par des considérations d'intéret et d'opportunité"

${ }^{495}$ ROUSSEAU, Charles. Principes de droit international public. In: Recueil des Cours. Academie de Droit International de la Haye, Volume 93, 1958-I, pp. 369-550. pp. 382-383. "In verbis“: "La difficulté consiste à établir une ligne de partage entre l'étude des relations internationales et celle du droit international. Peut-être l'un des critères que l'on pourrait proposer résidet-il dans le caractère nécessairement utilitaire de la première et dans l'esprit de recherche désintéressée qui doit caractériser l'étude du droit des gens.“

${ }^{496}$ KUNZ, Josef L. La crise et les transformations du droit des gens. In: Recueil des Cours. Academie de Droit International de la Haye, Volume 88, 1955-II, pp. 01-104. p. 09. "In verbis“: "Superficiellement, cette crise mondiale, dont la crise du droit des gens forme une partie intégrante, est le résultar des deux guerres mondiales, et surtout de la deuxième.“ 
Quando no direito internacional uma justificativa jurídica não se apresenta, costuma-se usar abertamente a política e assumir tratar-se de questão política e, portanto, não de direito. Assumindo os limites de sua disciplina, os internacionalistas mostram-se, assim, mais francos e transformam o direito das gentes no ramo mais honesto do direito: aquele que não nega exercício de concreção atípica ou imprevista pelo sistema.

Diferentemente do direito interno, o direito das gentes sempre admitiu a política em sua sistemática. A observação do direito internacional por meio do uso do direito interno como parâmetro constitui, na verdade, a chave da compreensão da lógica das teorias fragmentárias do direito internacional. Doutrinadores buscam com bastante entusiasmo e freqüência negar a aplicação das técnicas jurídicas de organização do poder interno ao direito internacional e, por não conseguirem, aduzem não reconhecerem unidade na ordem normativa global e que o direito internacional seria, portanto, fragmentado.

Nesse ponto, pode-se vislumbrar relevante risco surgido a partir da pretensão de fragmentação do direito das gentes. De fato, percebidas as normas internacionais de maneira unitarista e uniforme, os costumes e tradições nela inseridos tenderiam a traduzir uma perspectiva globalmente compartilhada, ainda que inexistam, certamente, garantias de que projetos políticos hegemônicos particulares não capturariam a estrutura global predominante. De qualquer maneira, a assunção de uma correlação lógico-normativa entre as estruturas aparentemente autônomas poderia, sim e entretanto, dificultar tal usurpação.

O direito internacional traz a decisão política para sua normatividade e, exatamente por tal característica, por muito tempo não foi amplamente reconhecido como um ordenamento jurídico. As doutrinas que negam - mormente negavam - a condição de direito ao direito das gentes estabelecem separações muito estritas entre o jurídico e o político e, por questões de coerência, deveriam fazê-lo também em relação ao direito interno. Trata-se de perspectiva distorcida, muito em voga na primeira metade do século $\mathrm{XX}$, de um pretenso direito científico, mecânico, moderno. Uma teoria do direito incapaz de reconhecer o papel da política na extração de normatividade dos preceitos de textura aberta, isto é, da concreção que se faz possível no momento da aplicação dos princípios.

Em síntese sobre as considerações feitas, percebe-se que a política se encontra presente - hoje mais que nunca - tanto na formação quanto na aplicação do direito. O direito internacional parece aceitar tal realidade com mais facilidade que o direito interno e a 
assunção de tal característica como fato torna o direito das gentes talvez o mais sincero ramo do direito ${ }^{497}$.

De volta à coerência sistêmica do direito das gentes, tampouco o combate às teorias fragmentárias por meio do discurso universalista dos direitos humanos, com viés jusnaturalista, cumpre sua função integrativa de forma eficiente. A tentativa de dar caráter normativo universal e cogente aos direitos humanos consubstancia dado teórico eminentemente ocidental sempre confrontado com os questionamentos acerca da existência de um núcleo duro de preceitos de proteção dos indivíduos universalmente compartilhado.

Em argumentação absolutamente diversa, a unidade poderia ser, ainda, encarada e criticada como enfoque ultrapassado fundado em perspectivas relacionadas a projetos políticos hegemônicos ${ }^{498}$, aos quais a fragmentação se apresentaria não como um risco sistêmico, mas como válida alternativa ${ }^{499}$. Essa resposta fragmentária à unidade positivista moderna apresentar-se-ia, assim, atualmente, ao menos, em três vertentes principais.

A primeira dessas vertentes se referiria às novas interpretações do direito surgidas no contexto de instituições internacionais especializadas, as quais seriam, elas próprias, quando reconhecidas como regimes autônomos e excepcionais às normas do direito internacional geral, a segunda dessas modalidades. Já a terceira forma de exteriorização da fragmentação se

\footnotetext{
${ }^{497}$ SLAUGHTER, Anne-Marie. International law and international relations. In: Recueil des Cours. Academie de Droit International de la Haye, Volume 285, 2000, pp. 09-249. p. 21, "in verbis“" "Politics permeates law, even as law justifiably and necessarily holds itself apart. And in international law, perhaps even more than domestic law, the political, economic, and even cultural and social relations among States define what must be regulated and what can be regulated.“
}

${ }^{498}$ SANTOS, Boaventura de Souza. Uma concepção multicultural de direitos humanos. In: Lua Nova: Revista de Cultura e Política 39, 1997, pp. 105-124. pp 110 - 111. Constrói sua proposta de hermenêutica diatópica a partir das críticas ao universalismo dos direitos humanos como uma concepção hegemônica, de dominação. "In verbis": "A complexidade dos direitos humanos reside em que eles podem ser concebidos, quer como forma de localismo globalizado, quer como forma de cosmopolitismo ou, por outras palavras, quer como globalização hegemônica, quer como globalização contra-hegemónica. Proponho-me de seguida identificas as condições culturais através das quais os direitos podem ser concebidos como cosmopolitismo ou globalização contra-hegemónica. A minha tese é que, enquanto forem concebidos como direitos humanos universais, os direitos humanos tenderão a operar como localismo globalizado - uma forma de globalização de-cima-parabaixo. [...] A sua abrangência global será obtida à custa de sua legitimidade local. Para poderem operar como forma de cosmopolitismo, como globalização de-baixo-para-cima ou contra-hegemónica, os direitos humanos têm de ser reconceptualizados como multiculturais. O multiculturalismo, tal como eu o entendo, é précondição de uma relação equilibrada e mutuamente potenciadora entre e competência global e a legitimidade local, que constituem os dois atributos de uma política contra-hegemónica de direitos humanos no nosso tempo."

${ }^{499}$ KOSKENNIEMI, Martti. Global legal pluralism: multiple regimes and multiple modes of thought. Harvard, 05 de março de 2005 - Palestra.. p. 05. No original: "Unity is a hegemonic project. It seeks the predominance of my perspective, my institution. Against this, we are accustomed to depicting the world - or some aspect of it - as oppressively homogenous, ruled by a totalizing logic of power, globalization, empire. Plurality as a counter-hegemonic strategy. Multiplicity of laws and regimes - and sovereignties, why not? - as a receipt for freedom, innovation, novelty." 
verificaria na idéia da contraposição, do choque, entre as diversas lógicas jurídicas autônomas que se estruturam nas múltiplas esferas atuais do direito internacional.

De uma forma ou de outra, o pluralismo decorrente, principalmente, da maior institucionalização do direito internacional consubstancia hoje fato e qualquer perspectiva que se adote em sua abordagem deve levar em consideração as alterações ocorridas na organização do espaço global como, por exemplo, o reconhecimento da existência de novos sujeitos de direitos e de obrigações. Nesse sentido, os projetos políticos com pretensões gerais na estruturação fragmentada do direito das gentes não conformariam exclusivamente questões de estado, submetendo-se à atualmente necessária distinção observável entre os paradigmas do governo e da governança ${ }^{500}$.

Assim, enquanto a idéia de governo se relacionaria à tradicional concepção política organizacional voltada ao benefício comum, no conceito de governança se encontrariam contidos os interesses individuais que, por diversos fatores, se infiltrariam no sistema político internacional em um jogo de influências que tenderia a favorecer os anseios dos mais fortes $^{501}$. A distinção teórica proposta pela doutrina busca sustentação, principalmente, na superação do estudo do direito internacional com base nas premissas eminentemente européias modeladas para os governos dos estados-nacionais, os quais exigem a estruturação de uma ordem legal baseada em um direito forte, centralizado, com regras claras e hierarquicamente organizadas, ou seja, claramente positivistas e modernas ${ }^{502}$.

Sob tal análise - do paradigma da governança - os interesses políticos acabariam se sobrepondo a qualquer sistematização do direito e a discussão unitarista em grande medida perderia sentido. A coerência abriria espaço não apenas para o pluralismo fragmentado em

${ }^{500}$ KOSKENNIEMI, Martti. Global governance and public international Law. In: Kritische Justitz, 37, 2004. pp. $241-254$.

${ }^{501}$ KOSKENNIEMI, Martti. Global governance and public international Law. In: Kritische Justitz, 37, 2004. p. 243. "In verbis": “[...] globalization invokes not government, but governance, a spontaneous process, pushed by private interests and actors in a thoroughly pragmatic process, accountable to no functional equivalent of a public realm but to an amorphous aggregate of stakeholders." A governança, como um processo pragmático de organização de poderes poderia ser facilmente observado, por exemplo, nos encontros econômicos e políticos, nos quais corporações transnacionais, governos, e instituições financeiras interagem em busca do alcance de objetivos comuns.

${ }^{502}$ KOSKENNIEMI, Martti. Global governance and public international Law. In: Kritische Justitz, 37, 2004. p. 241. O autor aponta para três teorias européias que seguem este pensamento. Immanuel Kant desenvolveu a idéia de uma federação cosmopolita, onde os estados independentes estariam regidos por uma única lei, que basear-se-ia nos direitos humanos como princípios comuns de uma única ordem global. Já Auguste Comte e Durkheim propuseram um sistema de soberanias dentro de uma sociedade global una, na qual a racionalidade universal governaria controlada por especialistas técnicos. E finalmente, como uma releitura das teorias anteriormente mencionadas, o "quintessentially", no qual poder-se-ia enxergar a Carta da ONU como uma constituição da humanidade, e não como mero ato de coordenação diplomática. 
diversos discursos sistêmicos, mas, principalmente, para a captura da produção legislativa internacional por grupos com interesses específicos. O embate entre o global uniformizante e o local fragmentado se tornaria, nessa linha, cada vez mais relevante a partir do momento em que o modelo de governança se impusesse. Nesse momento, a proposta teórica positivista do protagonista estatal, ironicamente, poderia surgir como alternativa louvável no contexto jurídico internacional $^{503}$.

Também a interdisciplinaridade entre direito e relações internacionais pode contribuir muito à evolução de ambas as perspectivas da ordem internacional e auxiliar o debate entre a fragmentação e a unidade do sistema jurídico das gentes ${ }^{504}$. Várias são as formas por meio das quais se busca diferenciar o direito das relações internacionais estabelecendo-se, de um lado, a normatividade e, de outro, a institucionalidade envolvida com o exercício da decisão política $^{505}$.

Sob o prisma da relação entre direito e política e observando-se as relações internacionais como sub-disciplina da ciência política, sua abordagem da ordem mundial pode ser estruturada de maneira concertada com as três principais teorias da ciência política: o realismo, o institucionalismo e o liberalismo ${ }^{506}$.

\footnotetext{
${ }^{503}$ KOSKENNIEMI, Martti. Global governance and public international Law. In: Kritische Justitz, 37, 2004. p. 243. "In verbis": "[...] globalization invokes not government, but governance, a spontaneous process, pushed by private interests and actors in a thoroughly pragmatic process, accountable to no functional equivalent of a public realm but to an amorphous aggregate of stakeholders." A governança, como um processo pragmático de organização de poderes poderia ser facilmente observado, por exemplo, nos encontros econômicos e políticos, nos quais corporações transnacionais, governos, e instituições financeiras interagem em busca do alcance de objetivos comuns.
}

${ }^{504}$ SLAUGHTER, Anne-Marie. International law and international relations. In: Recueil des Cours. Academie de Droit International de la Haye, Volume 285, 2000, pp. 09-249. p. 233, "in verbis": "The next step is for international lawyers and political scientists to work together on specific issues, as some are already doing. For international lawyers, such collaboration is important to avoid the danger of engaging in 'potted political science', just as historians often accuse lawyers of using "potted history" to advance a particular position. The essence of inter-disciplinary work is to understand the other discipline from the inside, particularly the constraints on its analysis resulting from efforts to enhance the rigor and coherence of disciplinary methodologies. Just as lawyers grow irritated at claims by non-lawyers that 'it is possible to argue anything', without regard to the years of training that help lawyers distinguish good arguments from bad, political scientists can often accuse lawyers of ignoring the internal standards they use to assess the quality of their own work."

505 SLAUGHTER, Anne-Marie. International law and international relations. In: Recueil des Cours. Academie de Droit International de la Haye, Volume 285, 2000, pp. 09-249. p. 25, "in verbis": "Normative versus instrumental, normative versus empirical, idealist versus realist - these are just some of the ways that scholars have tried to define and distinguish IL and IR.“

506 SLAUGHTER, Anne-Marie. International law and international relations. In: Recueil des Cours. Academie de Droit International de la Haye, Volume 285, 2000, pp. 09-249. p. 26, "in verbis“: "Scholars of international relations, a sub-discipline of political science, generate a wide range of theories to solve the problems and puzzles of State behaviour. Each theory offers a causal account of a particular outcome or pattern of behaviour in inter-State relations in a form that isolates independent and dependent variables precisely enough to 
Ainda que a dicotomia entre realismo e idealismo possa ser criticada, observam-se concepções distintas entre os adeptos de ambas correntes teóricas. Nesse sentido, enquanto os realistas ocupam-se principalmente da dinâmica de poder entre os sujeitos da ordem global, os idealistas buscariam explicá-la por meio de construções teóricas organizativas ${ }^{507}$.

Institucionalistas tendem a apresentar explicação da ordem mundial que atende mais às perspectivas de normatividade jurídica que o realismo puro porque analisam o contexto mundial a partir das instituições e não apenas com base nos estados e em seu exercício de poder concretivo ${ }^{508}$. Na medida em que o institucionalismo reflete a concepção de que o direito pode mitigar os efeitos da anarquia entre os estados e permitir sua cooperação, todos os juristas, em sua busca pela normatividade, poderiam ser considerados institucionalistas ${ }^{509}$.

No que se refere à perspectiva liberal, essa busca claramente legitimar as decisões de determinada sociedade na representatividade da declaração de vontade apresentada ${ }^{510}$. Sob tal

generate hypotheses (predictions) that can be empirically tested. At a higher level of generality, these theories can be grouped into different families or approaches on the basis of their underlying analytical assumptions about the nature of States and the relative explanatory power of broad classes of causal factors, such as the distribution of power in the international system, international institutions, national ideology and domestic political structure. This lecture will summarize the three main theoretical approaches used in contemporary American political science : Realism, Institutionalism and Liberalism.“

507 SLAUGHTER, Anne-Marie. International law and international relations. In: Recueil des Cours. Academie de Droit International de la Haye, Volume 285, 2000, pp. 09-249. pp. 23-24, "in verbis“: "Realism versus idealism? This dichotomy is silly but peculiarly persistent. Morgenthau, Kennan and others charged international lawyers with privileging ideals of world order over the realities of power politics. "Realists" have been caricaturing "liberals", and particularly "liberal lawyers", under this label ever since 8. But assuming that the dichotomy actually captures a distinction worth dwelling on, whether between optimists and pessimists, observers and dreamers, students of human nature and devotees of the divine, it is a dichotomy that recurs as frequently within disciplines as across them. Martti Koskenniemi assures us that the oscillation from "apology to utopia" has characterized all of international law 9. And John Mearsheimer, a leading political scientist, does not hesitate to laugh at liberal opponents as hopeless romantics 10 . In both cases, it is unclear that the supposed divide between Realists and Idealists serves anything other than polemical purposes. But in any event, it maps very poorly onto IR/IL.“

508 SLAUGHTER, Anne-Marie. International law and international relations. In: Recueil des Cours. Academie de Droit International de la Haye, Volume 285, 2000, pp. 09-249. p. 37, "in verbis": "Here, then, is the divergence from Realism. Whereas Institutionalists would agree that States are the primary actors in the international system and that, absent institutions, States are engaged in the pursuit of power, they would contend that the presence of institutions modifies the organizing principle of anarchy. The uncertainty and ever-present possibility of conflict that lead States in a Realist world to expect and prepare for the worst is diffused by the information provided by and through institutions."

509 SLAUGHTER, Anne-Marie. International law and international relations. In: Recueil des Cours. Academie de Droit International de la Haye, Volume 285, 2000, pp. 09-249. p. 35, "in verbis“: "To the extent that Institutionalism reflects the belief that 'rules, norms, principles and decision-making procedures' can mitigate the effects of anarchy and allow States to co-operate in the pursuit of common ends, all international lawyers are Institutionalists. 'Rules, norms, principles and decision-making procedures" is the definition of an international "régime', the much studied phenomenon that reintroduced international law to political scientists in the $1980 \mathrm{~s}$ "

${ }^{510}$ SLAUGHTER, Anne-Marie. International law and international relations. In: Recueil des Cours. Academie de Droit International de la Haye, Volume 285, 2000, pp. 09-249. p. 42, "in verbis“: "In the military context, 
prisma, os estados funcionariam como objetos de seus agentes, verdadeiros soberanos, mas isso não lhes retiraria a condição de sujeitos de direito internacional ${ }^{511}$.

De todo o apontado, é de se observar que as relações internacionais não podem ser compreendidas de maneira uniforme. Dependendo do instrumental teórico adotado, os resultados verificados nos movimentos políticos internacionais serão distintos. A perspectiva realista tende, por exemplo, a fortalecer a soberania estatal enquanto doutrinas liberais podem justificar iniciativas de intervenção humanitária. A adoção de uma ou de outra pelo direito internacional pode influenciar diretamente sua hermenêutica e pautar sua construção ${ }^{512}$.

A diferença principal entre o direito e as relações internacionais se encontraria, assim, na ótica pela qual cada uma de suas propostas teóricas percebe a ordem internacional: o normativismo de uma e o instrumentalismo da outra ${ }^{513}$. Exemplo do instrumentalismo se encontra, por exemplo, na equiparação feita pela doutrina das relações internacionais incorporada por alguns estudiosos do direito - entre obrigações legais internacionais e

prescriptive Liberal international relations theories thus seek to ensure that all sectors of a given society who are likely to be directly affected by a war are represented in the decision to go to war. In the economic context, Liberal international relations theorists seek to avoid trade wars by ensuring that special interest groups with trading interests that are not representative of the population as a whole do not capture the decision-making process."

511 SLAUGHTER, Anne-Marie. International law and international relations. In: Recueil des Cours. Academie de Droit International de la Haye, Volume 285, 2000, pp. 09-249. pp. 42-43, "in verbis“: "A Liberal conception of international law focuses on States as the agents of individual and group interests. This means that the law designed to achieve specific international outcomes does not have States as its objects, but rather the individuals and groups that States are assumed to represent 63. It does not mean, however, that international legal rules and institutions would no longer have States as subjects. Traditional international law, after all, imposes a duty of domestic implementation, requiring States to make whatever domestic legal changes are necessary to conform to their international obligations. The decision whether to achieve a particular policy solution by laws binding on States alone or by laws and institutions aimed directly at individuals and groups would depend on an empirical determination as to which strategy would be most effective in altering either the behaviour of individual and groups as represented by States, or the mode and scope of State representation."

512 SLAUGHTER, Anne-Marie. International law and international relations. In: Recueil des Cours. Academie de Droit International de la Haye, Volume 285, 2000, pp. 09-249. p. 196, “in verbis“: "In some situations, however, the diplomatic or national policymaking process will generate decision nodes in which different paradigms point to very different policy positions. A Realist view of the world, for instance, argues that the best guarantee of international peace and security is preserving State sovereignty, leading to support for a strong norm of non-intervention. A Liberal view, on the other hand, argues that the sources of insecurity are domestic, and that humanitarian catastrophe is a kind of early warning for a region if not for the world. Humanitarian intervention can thus be justified on security grounds."

513 SLAUGHTER, Anne-Marie. International law and international relations. In: Recueil des Cours. Academie de Droit International de la Haye, Volume 285, 2000, pp. 09-249. p. 24, "in verbis“: "The principal difference between international lawyers and international relations scholars is that they use different 'optics' on the world: an 'instrumentalist' versus a 'normative' optic 11. The instrumentalist optic sees the world in terms of the clash and complementarity of interests, whereas the normative optic prefers obligation - the force not of what States want but of what they think they should or must do according to the "rules of the game"." 
acordos informais. Tal perspectiva tende, contudo, na atualidade a ser abandonada, inclusive, pela ciência política ${ }^{514}$.

As teorias internacionalistas que buscam adotar concepções absolutamente instrumentais tendem a desconsiderar a relação entre estados tomando por base o conflito de poderes em favor da investigação dos interesses estatais envolvidos. Para tanto, os estados surgem como representantes dos interesses de coletividades, exprimindo sua vontade como única $^{515}$.

Direito e relações internacionais não estão, no entanto, sempre em desacordo e podem obter consenso mesmo em posições aparentemente antagônicas ainda que o próprio desenho das instituições que fazem parte da estrutura do direito internacional possa variar de acordo com a perspectiva política - de relações internacionais - adotada ${ }^{516}$. A política está, tal qual no direito interno, claramente presente na formação do direito das gentes e as teorias das

\footnotetext{
${ }^{514}$ SLAUGHTER, Anne-Marie. International law and international relations. In: Recueil des Cours. Academie de Droit International de la Haye, Volume 285, 2000, pp. 09-249. pp. 204-205, "in verbis": "As political scientists discovered and embraced régime theory in the 1980s and 1990s, many international lawyers questioned the value of lumping "rules, norms, principles and decision-making procedures" together, thereby denying any difference between a legal obligation and an informal agreement. Michael Byers, for instance, insists that "international relations scholars need to be told that international law is different from the other factors they study". A growing number of political scientists now accept this proposition (in addition to the many, particularly outside the United States, who never doubted it !). Translated into American political science jargon, the question then becomes how "legalized" régimes differ from "non-legalized régimes" in both their origins and impact on State behaviour.“
}

${ }^{515}$ SLAUGHTER, Anne-Marie. International law and international relations. In: Recueil des Cours. Academie de Droit International de la Haye, Volume 285, 2000, pp. 09-249. p. 42, "in verbis": "An international legal system seeking to accomplish instrumental goals such as the reduction of conflict and the increase of cooperation through laws grounded on Liberal assumptions looks very different from traditional international law 62. To begin with, it assumes that the primary source of conflict among States is not a clash or imbalance of power, but a conflict of State interests. Further, it assumes that these interests vary from State to State as a function of the individual preferences of individuals and groups operating in society; of the distribution of different preferences within a particular society; and of the degree to which a particular Government is representative of individuals and groups in its own society and in transnational society. Based on these assumptions, the best way to resolve conflict and to promote co-operation in the service of common ends is to find ways to align these underlying State interests, either by changing individual and group preferences or by ensuring that they are accurately represented.“

${ }^{516}$ SLAUGHTER, Anne-Marie. International law and international relations. In: Recueil des Cours. Academie de Droit International de la Haye, Volume 285, 2000, pp. 09-249. p. 189, "in verbis“: "Mapping this debate through an IR/IL lens not only clarified a complicated web of arguments, but also revealed a much greater degree of consensus among apparently competing positions than is generally apparent. Realists, Institutionalists and Liberals, albeit for different reasons, all support at most a sharply limited and carefully constrained doctrine of humanitarian intervention. For the lawyers whose task it is to flesh out the precise nature of those limits and constraints, each of these different strands of theory offers a different set of priorities and justifications." 
relações internacionais devem ser levadas em consideração quando da análise, em perspectiva positivista, da gênese da normativa comum global $^{517}$.

As concepções políticas - realistas ou idealistas - da ordem internacional não explicam, entretanto e segundo o que se defende neste estudo, de forma eficiente a institucionalidade do direito internacional ${ }^{518}$. Uma abordagem verdadeiramente internacionalista das estruturas que se apresentam ao observador e o uso das estruturas internas dos estados como modelo inspirador constituiria, portanto, o cerne da alternativa que se propõe.

Mas qual seria a finalidade da dicotomia entre direito e relações internacionais ${ }^{519}$ ? Disputas internacionais não podem ser classificadas como políticas ou jurídicas. Essa diferenciação conformaria questão meramente de abordagem ${ }^{520}$. Muitos sistemas de solução de controvérsias internacionais, inclusive, prevêem fases políticas e jurisdicionais e uma

517 SLAUGHTER, Anne-Marie. International law and international relations. In: Recueil des Cours. Academie de Droit International de la Haye, Volume 285, 2000, pp. 09-249. pp. 196-197, "in verbis“: "Assume that a lawyer has made a policy determination that the WTO is a desirable institution and should be strengthened and made as effective as possible. If, as a Realist would predict, power differentials among States dictate outcomes, then the WTO must develop longterm institutional mechanisms to accommodate, at least within limits, the preferences of the most powerful States. If, on the other hand, State interests are subject to change or modification through constructivist practices of normative obligation and persuasion, then the WTO should foster gradual and sustained processes of multilateral engagement on key issues. Given a hypothetical pair of lawyers, both may share a commitment to free trade and both may favour advancing trade liberalization through the WTO, yet if each were committed to a different IR paradigm or variant of a paradigm, each would design a different WTO.“

518 WRIGHT, Quincy. The strengthening of international law. In: Recueil des Cours. Academie de Droit International de la Haye, Volume 98, 1959-III, pp. 01-295. p. 30. "In verbis“: "In this stage of history, I think both realism and idealism demand wider comprehension of, and deeper sentimental attachment to, internationalism, as distinct from imperialism, nationalism or cosmopolitanism. The development of that comprehension and sentiment among the peoples and governments of the world is in my opinion the first condition for strengthening international law."

${ }^{519}$ SLAUGHTER, Anne-Marie. International law and international relations. In: Recueil des Cours. Academie de Droit International de la Haye, Volume 285, 2000, pp. 09-249. p. 22, "in verbis“: "So why the dichotomy between international law (IL) and international relations (IR)? Why distinguish them only to reintegrate them? One answer is that the dichotomy reflects how far the academy has moved from the world it purports to study. One thing on which the various narratives of the evolution of international law and international relations as academic disciplines agree is the emergence of a great schism between them after the World War II. The self-styled 'Realists' in political science challenged the international lawyers to prove their relevance to actual State behaviour."

${ }^{520}$ FRIEDMANN, W.. General course in public international law. In: Recueil des Cours. Academie de Droit International de la Haye, Volume 127, 1969-II, pp. 39-246. p. 158. "In verbis“: "Whether a dispute between States is considered as 'legal' or 'political' is a matter not of objective distinction but of approach. The status of a divided Berlin, the right of Israel to use the Suez Canal, or the borders between Israel and its various Arab neighbors, the introduction of apartheid by South Africa into her former South West African mandated territory, these and many other highly sensitive and explosive political disputes are also legal disputes. If they are not treated as such, it is because the parties to the dispute choose not to do so for political reasons. The parties may prefer to settle such matters by direct political negotiations or, indeed, to leave them in abeyance as has so often been the case in the postwar period, e. g., the status of Berlin or the partition of Germany." 
concepção jurídica da ordem internacional não pode desconsiderar completamente as teorizações propostas pela ciência política às estruturas de poder.

Nesse sentido, mesmo mediante a comprovação empírica da existência de indícios de aparente fragmentação, a estrutura atual do direito não representaria, quando de uma análise mais profunda, a negação do modelo de poder interno dos estados como parâmetro à compreensão da ordem internacional. De certo, questionáveis restariam, entretanto, as vantagens da adoção desse modelo para o plano do direito das gentes.

Há que se marcar, nesse momento, o fato de que o direito internacional não teria se estagnado ou retrocedido nesses anos de aparente prevalência da política e de extensa teorização fragmentária do exercício do poder global. Apenas sua evolução teria se tornado mais lenta e os entraves se apresentariam maiores. Vários seriam os exemplos disponíveis nesse sentido.

Há mais de dez anos se arrasta a Rodada Doha na Organização Mundial do Comércio OMC, mas economias importantes como a República Popular da China e a Federação Russa ingressaram na organização ${ }^{521}$. Os estados partes do Mercado Comum do Sul - MERCOSUL - não avançam nas negociações para a reforma do sistema de solução de controvérsias regional, mas fortaleceram os esforços de integração com a criação de um Fundo para a Convergência Estrutural - FOCEM - e de instituições como o Instituto Social do MERCOSUL - ISM ${ }^{522}$.

Além disso, diversas são as atuais propostas de reformas normativas em organizações internacionais como o Fundo Monetário Internacional - FMI - e a Organização das Nações Unidas - ONU ${ }^{523}$. Também a crise econômica européia pode indicar, observados os últimos

521 Informações extraídas do sítio eletrônico da Organização Mundial do Comércio - www.wto.org - em 12.01.2014.

522 Cumpre ressaltar que os Estados partes do MERCOSUL firmaram em 2007 o Protocolo Modificativo do Protocolo de Olivos para a Solução de Controvérsias no MERCOSUL, mas este não apresenta grandes alterações estruturais no sistema atualmente existente. Mencionado protocolo teve seus procedimentos de internalização cumpridos apenas em parte dos Estados (Dado de 10.05.2012). O FOCEM foi criado pela MERCOSUL/CMC/DEC. $\mathrm{N}^{\circ}$ 45/04 e o Instituto Social do MERCOSUL pela MERCOSUL/CMC/DEC. $\mathrm{N}^{\circ}$ 03/07. As três normativas encontram-se disponíveis em http://www.mercosur.int .

${ }^{523}$ Ao explicar a posição brasileira em relação à reforma do Conselho de Segurança da Organização das Nações Unidas, o Ministério das Relações Exteriores afirma, "in verbis": "Um Conselho de Segurança mais representativo contribuirá de forma mais eficaz para uma ordem mundial mais justa e segura. Ao incluir novos atores, seu processo decisório será mais legítimo e poderá contribuir com mais vigor para a resolução dos conflitos e das crises que afligem o mundo" (Disponível em: http://www.itamaraty.gov.br/temas/temasmultilaterais/governanca-global/reforma-da-onu - Acesso em 10.05.2012). No que se refere ao FMI, BATISTA JÚNIOR, Paulo Nogueira . Crise no FMI. O Globo, 09.04.2010, afirma "in verbis": "Aumentaram as chances de que a reforma do Fundo possa acontecer. Vai ser uma guerra de nervos. Os europeus vão continuar lutando milímetro por milímetro. Mas o resultado mais provável desses embates deve ser certa 
acordos firmados, momento transitório que anteciparia o aperfeiçoamento da regulamentação jurídica da relação entre os membros da União ${ }^{524}$.

Em síntese, até a primeira metade do século $\mathrm{XX}$, a preocupação com a unidade do direito internacional se referia basicamente à relação entre as várias ordens estatais autônomas e a ordem jurídica global comum. Com o passar dos anos, superou-se a maior parte das questões teóricas relacionadas à relação entre o local estatal e o internacional geral e, conseqüentemente, as dúvidas do caráter de direito do direito das gentes que por muito tempo afligiram os juristas.

Com o fim da segunda guerra mundial, esquemas internacionais associativos se consolidaram e multiplicaram. Organizações internacionais multilaterais e regionais foram sendo criadas e estabeleceram sistemas normativos internacionais autônomos por diversas razões temáticas, geográficas e até mesmo teleológicas. Essas ordens jurídicas que surgiram foram aos poucos se sobrepondo e criaram uma complexa trama sistêmica desafiadora da coerência e da estabilidade exigidas pelo direito.

O chamado pluralismo fez com que a doutrina apontasse dúvidas quanto à unidade do direito das gentes. Nesse processo, cada vez mais os paradigmas das relações internacionais passaram a ser adotados como parâmetros à compreensão da ordem internacional e dessa dinâmica resultaram as percepções fragmentárias do direito das gentes.

A perspectiva política não é, contudo, contrária ao direito internacional. Estruturas e conceitos desenvolvidos pela teoria das relações internacionais não são incompatíveis com o direito. A escolha política se encontra na formação e na aplicação do direito e integra, portanto, os sistemas interno e internacional, os quais - conforme aventado anteriormente conformam um ordenamento único.

A concepção dos planos local e global como um bloco normativo coeso não impede, entretanto, que se percebam idiossincrasias que caracterizam as duas esferas. Nesse sentido, cumpre perceber que, no que se refere à relação entre política e direito, o ramo internacional aceita com maior facilidade a expressão política do poder. Enquanto, de um lado, juristas internamente buscam neutralizar as escolhas políticas e demonstram dificuldade de aceitar a concreção feita pelos exercentes de funções judiciárias, internacionalistas reconhecem, por

recomposição da Diretoria, com alguma perda de cadeiras européias, e uma transferência de poder de voto para países emergentes e em desenvolvimento."

524 É de se salientar, contudo, que o pacto de controle fiscal e orçamentário surge como iniciativa intergovernamental, não inserida na ordem normativa supranacional da União Européia. 
exemplo, em órgãos investidos de funções legislativo-executivas a legitimidade da extração de normatividade.

Direito internacional é política. Direito é política. E nesse aspecto específico, o direito internacional seria apenas mais honesto. Talvez o mais honesto dos ramos do direito. Nesse contexto, enquanto o direito interno parece buscar atualmente conviver melhor com suas atribuições relacionadas às escolhas políticas, o direito internacional deve, com urgência, resgatar os conceitos jurídicos que garantam sua compreensão sistêmica. 


\section{ORGANIZAÇÕES INTERNACIONAIS, O BRASIL E O MERCOSUL}

O estado pode servir como modelo organizativo, mas a comunidade internacional não se organizou - ainda? - em arranjo assemelhado à estrutura estatal. Independentemente da forma como se institucionaliza a ordem internacional, contudo, as premissas estabelecidas pela teoria do estado podem auxiliar a compreensão da organização do poder no contexto global e, nesse sentido, a separação de funções se faz aplicável à dinâmica entre poder e direito na esfera mundial.

Iniciativas regionais - de caráter econômico, militar ou qualquer outro - que surgiam logo da criação das Nações Unidas eram analisadas pela doutrina com desconfiança e ceticismo. O regionalismo era considerado por alguns autores um verdadeiro retrocesso à conquista representada pela Carta de São Francisco, é dizer, uma ameaça à integridade do sistema internacional de direito que se consolidava ${ }^{525}$. Já naquela época, tornava-se possível

525 JENKS, C.Wilfred. Co-ordination: a new problem of international organization: a preliminary survey of the law and practice of inter-organizational relationships. In: Recueil des Cours. Academie de Droit International de la Haye, Volume 77, 1950-II, pp. 151-303. pp. 170-172, "in verbis": "The first major reason for the complexity of the existing structure is that this structure is the outcome of the rapid succession, in a period of less than fifty years, of six distinct historical phases in the development of international organization which have been dominated by widely varying political forces [...] The first phase, that preceding the First World War, was marked by the Hague Conferences and the development of the public international unions, a mumber of which still survive. The second phase was that of the establishment of the League of Nations and the International Labour Organization. While the League phase will probable be regarded in the future as the decisive phase in the history of international organization, since the League was the forerunner of the United Nations, it has left virtually no heritage of organizational complications. The Permanent Court of International Justice has been reorganized as, or in the view of some replaced by, the International Court of Justice ; the International Labour Organization has entered into relationship with the United Nations as the senior specialized agency; and the continuing functions of the League have been assumed by various United Nations organs under arrangements approved by the General Assembly. The third phase was that following the decision of the United states not to become a Member of the League of Nations when it became clear that the League of Nations would not become a universal organization and a tendency developed to create new machinery outside the framework of the League. As the inter-war period ran its course the tendency to create new organizations outside the League framework became more pronounced, partly because of the desire to facilitate United States membership of such organizations and sometiimes because of a desire to restrict membership of such organizations to states directly concerned in the matters at issue. The fourth phase, which lasted from the final decline of the League to the signature of the Charter of the United Nations was a period of vigorous experiment in the creation of new internationsl organizations on a functional basis. It was during this period that U.N.R.R.A., F.A.O., I.C.A.O., the International Monetary Fund and the International Bank for Reconstruction and Development were all created. The fifth phase was that of the establishment of the United Nations, including the network of regional and functional commissions of the Economic and Social Council and the group of specialized agencies specifically designed to be brought into relationship with the United Nations as established by the Charter. The sixth phase is one of disillusionment with the immediate prospects of the United Nations. It has been characterised by a renewed tendency to pursue international action outside the United Nations in the hope of securing concrete results more readily by action limited to restricted groups of like-minded states. During this phase A.E.E.C., the Council of Europe and the North Atlantic Treaty Organization have all been created. This phase must be asumed to be followed by a regression and it is imperative that it should be followed by a renewed effort to re-establish the position and influence of the United Nations, but the impact of this regression on the general structure of international organization may be long-lived or even permanent. Such a description by phases of the organizational history of the last fifty years 
perceber uma evolução - lenta, mas constante - na consolidação das organizações como sujeitos de direito internacional.

O termo "regional" não apresenta conteúdo meramente geográfico e serve para apontar também outras formas de identificação entre sujeitos, tais como pelas afinidades culturais, econômicas ou até mesmo pelo mero interesse estratégico e militar ${ }^{526}$. Sua definição possui, em regra, forte ligação com a noção de solidariedade e se aplica, por exemplo, às estruturas de cooperação e de integração que se multiplicam na ordem mundial contemporânea $^{527}$.

Grande parte das iniciativas aproximativas regionais surgidas nas últimas décadas possuem caráter econômico. A partir do modelo proposto neste estudo, várias delas assumiram ao longo do tempo contornos de organização internacional e, nessas estruturas jurídicas mais complexas, os sistemas de solução de controvérsias cumprem função fundamental na preservação da coerência do direito.

No que se refere aos tratados associativos, trata-se de regionalismo que possui autonomia mais limitada que a das organizações internacionais e que segue, em regra, o padrão estabelecido nos primórdios dessas associações. Esses acordos tendem a conformar, na verdade, secretarias meramente registrais e de suporte, as quais em nenhum momento

cleary does not tell the whole story and ignores innumerable cross-currents and eddies, but it does throw into sharp relief the manner in which the ebb and flow of changing political forces has exercised a determining influence on the complexity of the present structure."

${ }^{526}$ SABA, Hanna. Les accords régionaux dans la Charte de l'O.N.U. In: Recueil des Cours. Academie de Droit International de la Haye, Volume 80, 1952-I, pp. 635-720. pp. 639-640. "In verbis“: "Le mot régional a eu à l'origine une portée purement géographique. Une région se définit comme un ensemble de territoires qui, en raison de leur formation géologique, de leurs ressources, des facilités de communications naturelles ou des voies tracées par l'homme, et de leurs populations, présentent un caractère d'unité. Mais cette unité ne peut s'apprécier et se mesurer que par rapport aux autres parties de l'Univers et en fonction de leurs caractéristiques. Une région, aussi vaste soit-elle, ne constitue, en effet, qu'une partie de la Terre, et le terme régional implique dans ces conditionis le concept d'une fraction par rapport à un tout. Cependant, la portée de l'épithète régional a été étendue de manière à dépasser son contenu proprement géographique, voire même à l'en abstraire dans une certaine mesure. Le terrne régional a été, en effet, souvent utiliisé pour se référer à certains liens de similarité ou de solidarité qui unissent des groupements humains et les distinguent des populations du reste de l'Univers.“"

${ }^{527}$ SABA, Hanna. Les accords régionaux dans la Charte de l'O.N.U. In: Recueil des Cours. Academie de Droit International de la Haye, Volume 80, 1952-I, pp. 635-720. p. 675. "In verbis“: "La définition la plus complète et aussi la plus connue est celle présentée par la délégation égyptienne. Elle consistait à ajouter au $§ 1$ de la Section C les termes suivants : «Seront considérées comme ententes régionales, les organisations permanentes, groupant dans une région géographique déterminée, plusieus pays qui, en raison de leur voisinage, de leur communauté d'inérets ou leur affinités linguistiques, historiques ou spirituelles, se sotidarisent pour le règlement pacifique de tout différend pouvant souvenir entre eux pour le meintien de la paix et de la sécurité dans leur région comme pour la sauvaguarde de leurs intérets et le développement de leurs relations économiques et culturelles ».“ 
expressam de fato a vontade conjunta de seus membros ${ }^{528}$. Exemplo claro de tratado associativo do qual o Brasil faz parte, à luz dos requisitos aqui propostos, seria a Associação Latino-americana de Integração, a ALADI.

Já o Mercado Comum do Sul - MERCOSUL, ainda que intergovernamental, possui, além de um sistema de solução de controvérsias hábil a garantir sua coerência sistêmica, estrutura clara de expressão conjunta de vontade no Grupo Mercado Comum - GMC - e no Conselho Mercado Comum - CMC.

Em uma organização de cunho integracionista conformada por estados pode-se perceber, ainda, aproximação estrutural com formas federativas de institucionalização, mas esses arranjos, gize-se, devem ser observados como um processo e não como um cenário consolidado e a distribuição do poder nesses casos não pode ser considerada, portanto, completamente aperfeiçoada ${ }^{529}$.

No contexto europeu, a doutrina já reconhecia no Plano Marshall compatibilidade entre a aspiração aproximativa européia e a Carta das Nações Unidas e chegava a fazer uso em razão de obviedade terminológica seguramente, mas de maneira interessante - do termo "união européia" para referir-se, esperançosamente, à forma como se pretendia estruturar paz duradoura naquele momento ${ }^{530}$.

\footnotetext{
${ }^{528}$ ZEMANEK, Karl. The legal foundations of the international system: general course on public international law. In: Recueil des Cours. Academie de Droit International de la Haye, Volume 266, 1997, pp. 09-335. p. 109. "In verbis": "Secretariats of traditional international organizations are primarily administrative institutions with supportive functions for representative organs. They further carry out mandates which are given them by representative organs which retain supervision. Very often these mandates are strict and do not leave much room for Secretariat initiatives. Subsequent decisions of representative organs can only be influenced through the manner in which requested reports are formulated. Although the possible influence on the choice of options is not negligible it should, rather, be called persuasion than influence."
}

${ }^{529}$ ZOLLER, Elisabeth. Aspects internationaux du droit constitutionnel: contribution à la théorie de la fédération d'Etats. In: Recueil des Cours. Academie de Droit International de la Haye, Volume 294, 2002, pp. 39-166. pp. 71-72. "In verbis": "Une fédération d'Etats est moins une structure qu'un processus. Forme de gouvernement qui se recompose et se redéfinit sans cesse, elle est un navire qui cherche le chenal entre deux écueils, la consolidation et le démembrement. C'est pourquoi elle ne se prête pas facilement à un effort de théorisation. Forme évolutive de gouvernement, elle doit toujours réinventer l'organisation et la gestion de la souveraineté partagée. C'est en ce sens qu'une fédération d'Etats est une; structure composée d'Etats qui se situe entre le droit constitutionnel et le droit international. Rien n'est rigide dans cette forme de gouvernement sauf sa base juridique, la constitution. Aussi bien le droit constitutionnel d'une fédération d'Etats définit-il un ordre constitutionnel, donc en principe un droit d'ordre interne, mais qui, quoique canstitutionnel, ne s'interdit pas d'emprunter à l'ordre international les éléments dont il a besoin pour garantir sa longévité de gouvernement national incomplet.“

530 YEPES, J.M.. Les accords régionaux et le droit international. In: Recueil des Cours. Academie de Droit International de la Haye, Volume 71, 1947-II, pp. 227-344. p. 337. "In verbis“: "Espérons que l'accord régional européen, nécessaire pour l'application du plan Marshall, accord qui serait parfaitement compatible avec la Charte des Nations Unies et qui est destiné réaliser un jour l'idéal de l'Union européenne, pourra être bientôt conclu entre tous les membres de la famille européenne des nations, ou tout au moins entre les pays de I'Europe occidentale. C'est sur cette note d'optimisme et d'espoir que nous voulons clore ces leçons.“ 
O modelo europeu constitui hoje inspiração e exemplo de evolução para os sistemas regionais de integração, mas a Europa não foi a grande precursora das tentativas aproximativas regionais ${ }^{531}$. Ainda que o processo siga atualmente com entraves e evolua de maneira relativamente lenta, na América Latina o ideal solidário regional contava com iniciativas concretas já no século XIX.

Percebe-se que no continente americano a interdependência entre os estados mostra-se reconhecida pelos que integram o conceito de povo de cada um deles já há muito tempo e que as iniciativas nesse sentido foram instrumentalizadas com maior vigor nos últimos anos. $\mathrm{O}$ reconhecimento de interesses comuns fez do continente americano uma das regiões mais estáveis do planeta e mais exitosas na manutenção da paz com base na solidariedade continental como princípio ${ }^{532}$.

No que se refere às experiências aproximativas de caráter econômico, especificamente, pode-se exercitar fácil digressão histórica até o século XIX e aos ideais integrativos de Simon Bolívar $^{533}$. Durante o século XX, as iniciativas mais relevantes entre os estados foram a experiência frustrada da Associação Latino-Americana de Livre Comércio de 1960 - ALALC

531 CASSESE, A.. Modern constitutions and international law. In: Recueil des Cours. Academie de Droit International de la Haye, Volume 192, 1985-III, pp. 331-476. p. 418. "In verbis": "Western European integration, as it has developed among the European Economic Community countries on the one side and the Nordic countries on the other side, is quite unique. It accounts for the striking progress achieved in many fields, including the area of national compliance with international or supranational standards (despite all the loopholes and deficiencies to which I have tried to draw attention). It is a truism that such legal advances can only be attained against a background of economic, political and cultural integration. Since, at present, there is no area where such marked integration is taking place, it would be illusory to expect other States to follow the example of those Western European countries by granting priority over national law to international primary and secondary legislation. The Western European situation can, however, serve as a useful model and a powerful source of inspiration for any other State which may decide to follow the path of regional integration."

${ }^{532}$ FENWICK, Charles G.. The progress of international law during the past forty years. In: Recueil des Cours. Academie de Droit International de la Haye, Volume 79, 1951-II, pp. 01-71. p. 42. "In verbis“: "More and more the American States have come to realize their interdependence, not only in law but in economic and social matters, and this recognition of their interdependence has greatly strengthened the sense of unity among them. 'Continental solidarity', a phrase so often used in the past, has now taken on a new meaning; and there is every reason to believe that the public opinion of the American States has now developed to such a degree that no one of their number would consider seriously resorting to force against a neighboring state. This development of the common interest of the American Republics in their collective security has thus made it far easier to bring their other conflicting interests under the control of law."

${ }^{533}$ ETCHEVERRY, Raul Aníbal. MERCOSUR negocios y empresas. Buenos Aires: Ciudad Argentina, 2001. p. 43. "In verbis": "Los primeros intentos de crear algún tipo de entidad supranacional en América latina se remontan a los años de la independencia. Entre 1826 y 1865 se celebraron cuatro conferencias internacionales en busca de una suerte de federación o alianza, fundamentalmente para hacer frente a las amenazas extranjeras (España y la Santa Alianza, el expansionismo norteamericano, Inglaterra, Francia, etc.). No obstante, por entonces el nacionalismo de los distintos Estados hacía imposible que los acuerdos logrados (de mutua defensa, defensa del principio de no intervención, etc.) sobrevivieran a la desaparición de los peligros externos citados." 
- e sua sucessora, Associação Latino-Americana de Integração - ALADI, criada em 1980 pela assinatura do Tratado de Montevidéu ${ }^{534}$.

Em contexto local geograficamente ainda mais restrito, encontram-se hoje em pleno funcionamento nas Amércias as experiências do Mercado Comum do SUL -MERCOSUL, da Comunidade Andina - CAN, do Sistema de Integração Centro Americano - SICA, da Comunidade do Caribe - CARICOM e do North American Free Trade Agreement - NAFTA.

As dificuldades apresentadas pela soberania estatal à criação de sistemas supranacionais podem se refletir nos meios institucionais adotados para dirimir conflitos. Estruturas administrativas tendem a ser preferidas pelos estados e isso implica, por exemplo, na adoção de meios mais políticos que jurisdicionais por organizações internacionais intergovernamentais. Mesmo arranjos que possuem sistemas institucionalizados para a solução de controvérsias podem dotar também órgãos de natureza executiva dessa função. Esse seria o caso da competência para solução de controvérsias outorgada por tratado à Secretaria Geral da Comunidade Andina e ao Grupo Mercado Comum, no sistema de Olivos do MERCOSUL ${ }^{535}$.

No MERCOSUL - regionalismo do qual o Brasil faz parte - a solução de litígios esteve prevista desde o texto Tratado de Assunção. Não havia, contudo, no referido marco legal de 1991, sistema institucionalizado de solução de controvérsias e os meios para dirimir conflitos eram, nesse momento, meramente diplomáticos ${ }^{536}$. Com a entrada em vigor do Protocolo de Brasília, ao final do mesmo ano, estabeleceu-se meio jurisdicional para a solução de conflitos entre os estados partes do acordo inicial ${ }^{537}$. Havia, naquele contexto, uma fase política de negociações e a possibilidade de instituição de tribunais arbitrais ad-hoc para a solução de eventuais lides.

Gize-se, neste momento, que a personalidade jurídica do MERCOSUL apenas foi estabelecida por tratado em 1994, quando da assinatura do Protocolo de Ouro Preto, o qual

\footnotetext{
${ }^{534}$ O Tratado de Montevidéu, que criou a Associação Latino-Americana de Integração - ALADI, foi firmado em 12/08/80, decreto legislativo $n^{\circ} .66$ de 16/11/81, decreto executivo $n^{\circ} .87 .054$, de 23/03/82.

535 NEGRO, Sandra. Derecho de la integración. Buenos Aires: BDEF, 2013. p. 171. "In verbis": "Las controversias en el marco de la Comunidad Andina de Naciones se pueden resolver a través de dos órganos, uno de carácter ejecutivo y el otro jurisdiccional los cuales son, respectivamente, la Secretaría General y el Tribunal de Justicia."

${ }^{536}$ Firmado em 26/03/91, decreto legislativo $n^{\text {o }} .197$ de 25/09/91, decreto executivo $n^{\circ}$. 350 de 21/11/91 e internacionalmente em vigor em 29/11/91.

${ }^{537}$ Firmado em 17/12/91, decreto legislativo $\mathrm{n}^{\circ} .88$ de 01/12/92, decreto executivo $\mathrm{n}^{\mathrm{o}}$. 922 de 10/09/93 e internacionalmente em vigor em 24/04/93.
} 
costuma ser amplamente reconhecido pela doutrina como marco da elevação da experiência regional da condição de sistema de direito à de organização internacional ${ }^{538}$.

Sob os parâmetros aqui propostos, contudo, os estados partes do Tratado de Assunção se tornaram membros de uma organização internacional quando do reconhecimento da personalidade jurídica do MERCOSUL em razão da entrada em vigor do Protocolo de Ouro Preto, mas não apenas dele. O status de sujeito de direito internacional dependeu, também, da plena vigência do Protocolo de Brasília, tratado que disciplinava naquele momento o sistema de solução de controvérsias regional.

Os procedimentos políticos e diplomáticos iniciais foram se aperfeiçoando na medida em que a organização regional se institucionalizava ${ }^{539}$. No ano de 2002 , o sistema jurisdicional de solução de controvérsias do MERCOSUL passou por uma grande reforma e conta hoje com três fases regulamentadas, principalmente, no Protocolo de Olivos e em seu Regulamento $^{540}$.

O referido protocolo manteve a fases estabelecidas no Protocolo de Brasília acrescentando uma segunda instância na fase jurisdicional do sistema. Pelo procedimento

\footnotetext{
${ }^{538}$ Firmado em 17/12/94, decreto legislativo $\mathrm{n}^{\circ} .188$ de 15/12/95, decreto executivo $\mathrm{n}^{\circ} .1901$ de 09/05/96 e em vigor para o Brasil em 16/02/96, data do depósito da carta de ratificação correspondente. "In verbis": "Artigo 34 O MERCOSUL terá personalidade jurídica de Direito Internacional.”

539 VASCONCELOS, Raphael Carvalho. O sistema de solução de controvérsias do MERCOSUL. Ética e Filosofia Política, v. jur., p. 01-30, 2009. p. 27. "In verbis": "A importância de se instituir um sistema de solução de controvérsias como forma de se consolidar a integração regional foi reconhecida pelos Estadosmembros na gênese do MERCOSUL por meio da adoção do anexo III do Tratado de Assunção, que instituiu o primeiro sistema de solução de controvérsias da organização. A precariedade do mecanismo original, o qual nunca foi utilizado, foi logo substituída pelas regras do Protocolo de Brasília que, baseado na arbitragem ad hoc, cumpriu de forma exemplar sua função no contexto regional. Os procedimentos adotados em Brasília foram mantidos inclusive após a entrada em vigor do Protocolo de Ouro Preto, o qual estabeleceu a configuração institucional definitiva do MERCOSUL. O Protocolo de Brasília foi revogado pela entrada em vigor do Protocolo de Olivos em 2002, regulamentado pela decisão 37/03 do Conselho do Mercado Comum. Dentre as inovações trazidas por Olivos, destacam-se a possibilidade de eleição de foro e a criação do Tribunal Permanente de Revisão.”
}

540 Além do Protocolo de Olivos - firmado em 18/02/02, decreto legislativo n ${ }^{\circ}$. 712 de 14/10/03, decreto executivo $\mathrm{n}^{\circ} .4982$ de 09/02/04 e internacionalmente em vigor em 01/01/04 - destacam-se, no atual sistema de solução de controvérsias do MERCOSUL, as seguintes normas: CMC/DEC N³7/03 - Regulamento do Protocolo de Olivos, a CMC/DEC N²3/04 - Procedimento para atender casos excepcionais de urgência, a CMC/DEC N²6/05 - Controvérsias originadas nos acordos de Reuniões de Ministros, a CMC/DEC N³0/05 - Regras de Procedimento do Tribunal Permanente de Revisão, a CMC/DEC N49/10 - Proposta para os Acordos com os Estados Associados, a CMC/DEC No37/03 - Regulamento do Protocolo de Olivos, a CMC/DEC Nº2/07 - Regulamento para solicitar opiniões consultivas por os TSJ, a CMC/DEC N²15/10: Prazos para emissão de opiniões consultivas e a CMC/DEC №31/11 - Código de Conduta para os árbitros, especialistas e funcionários, todas disponíveis em www.tprmercosur.org. Ressalta-se, ainda, a expectativa em torno da internalização pelos estados e conseqüente entrada em vigor do chamado Protocolo Modificatório do Protocolo de Olivos, firmado no Rio de Janeiro em 19 de janeiro de 2007. Referido protocolo se faz imprescindível para adaptar o sistema de solução de controvérsias do MERCOSUL à adesão da República Bolivariana da Venezuela à organização regional. 
atual, as demandas devem, portanto, cumprir as negociações diretas entre os estados para, facultativamente, poderem ser elevadas ao Grupo Mercado Comum - GMC - ou diretamente apresentadas aos órgãos jurisdicionais, compostos pelos tribunais ad hoc e pelo Tribunal Permanente de Revisão - TPR.

A fase diplomática inicial é marcada, em regra, pelas negociações diretas entre as chamadas "coordenações nacionais", isto é, entre os diplomatas indicados por seus países como coordenadores do GMC. O texto do protocolo não impede, entretanto, que as partes estabeleçam negociações por outros meios ou representantes ${ }^{541}$.

Cumprida essa fase, os estados podem - mas não são obrigados - seguir debatendo o litígio no órgão político da estrutura institucional do MERCOSUL, o $\mathrm{GMC}^{542}$. Os referidos coordenadores nacionais que compõem o órgão levariam o debate às reuniões e o tema poderia ser discutido entre todos os membros da organização regional e não necessariamente apenas pelos envolvidos. A vantagem das negociações no GMC estaria na institucionalização dos debates, já que as reuniões são estruturadas de maneira a propiciar análises conjuntas mais profundas dos temas sensíveis da organização e constituem o núcleo central do desenvolvimento normativo do processo de integração do MERCOSUL.

Ultrapassada a primeira etapa obrigatoriamente e, facultativamente, a segunda, as partes interessadas podem aceder finalmente à fase jurisdicional ${ }^{543}$. A grande novidade de Olivos se deu na criação do TPR, o qual funciona como órgão revisor da instância arbitral $a d$ hoc. Um laudo emitido pelos tribunais constituídos para solucionar um caso concreto pode ser, assim, revisto pela instância arbitral definitiva - guardiã última do direito regional.

Assim sendo, as partes devem, em regra, recorrer aos tribunais ad hoc e - apenas após a emissão de um laudo - ao TPR. Observa-se, nesse sentido, que o tribunal possui em seu próprio nome o termo "revisão", o qual serve para demarcar de maneira bastante clara a vontade dos estados quando de sua criação, isto é, seu funcionamento típico como instância revisora $^{544}$. Subsiste, contudo, forma de acesso direto ao TPR.

Estabeleceram-se em 2002 os fundamentos para a criação de um sistema arbitral permanente, mas a estrutura provisória segue, mais de dez anos depois, competente para a

\footnotetext{
${ }^{541}$ Art. 4 do Protocolo de Olivos.

${ }^{542}$ Art. 6 do Protocolo de Olivos.

${ }^{543}$ Art. 9 do Protocolo de Olivos.

${ }^{544}$ Art. 17 do Protocolo de Olivos.
} 
solução de litígios quanto à aplicação e à interpretação das normas regionais ${ }^{545}$. Ainda que o sistema regional do MERCOSUL conte com fase jurisdicional dotada, inclusive, de estrutura arbitral permanente, seus membros têm optado sistematicamente pelo uso de soluções político-administrativas para a solução de seus diferendos ${ }^{546}$.

Em linhas gerais, percebe-se que o MERCOSUL, como organização internacional, possui hoje características intergovernamentais bastante nítidas, mas é dotado de um sistema de solução de controvérsias institucionalizado que conta com um tribunal perene, ainda que, contudo, arbitral ${ }^{547}$.

Em contexto mais geral, ainda que a manutenção da paz constitua estímulo aproximativo importante, as preferências recíprocas estabelecidas entre estados na terceira década do século XX são comumente apontadas como antecedentes daquilo que se conhece hoje por regionalismo econômico ${ }^{548}$. Esses arranjos regionais se institucionalizaram ao longo

\footnotetext{
${ }^{545}$ Firmado na Argentina em 18 de fevereiro de 2002, aprovado pelo congresso nacional brasileiro por meio do decreto legislativo $n^{\circ} .712$ de 14 de outubro de 2003, texto publicado anexo ao decreto executivo $n^{\circ} .4982$ de 09 de fevereiro de 2004 e internacionalmente em vigor em 01 de janeiro de 2004.
}

${ }^{546}$ CHARPENTIER, Jean. Le contrôle par les organisations internationales de l'exécution des obligations des états. In: Recueil des Cours. Academie de Droit International de la Haye, Volume 182, 1983-IV, pp. 143-245. p. 154. "In verbis": "Mais plus importante est la distinction entre le contrôle juridictionnel et le contrôle administratif. Sa portée est, à vrai dire, moins claire qu'il n'y paraît. S'agit-il de distinguer, selon un critère organique, le contrôle exercé par un tribunal et celui exercé par un organe administratif ? On peut certes retrouver dans la vie internationale la première catégorie, mais les autres formes de contrôle se regroupent difficilement sous un vocable - celui de contrôle administratif - qui, évoquant la mise en oeuvre d'une politique gouvernementale, ne saurait être, au mieux, qu'une image de l'activité des organisations internationales. Si on analyse, en revanche, la distinction entre le contrôle juridictionnel et le contrôle administratif selon un critère fonctionnel, on entend alors par le premier terme les techniques de contrôle susceptibles de régler un différend en statuant sur la violation alléguée d'une obligation et par le second les techniques de contrôle susceptibles de prévenir les infractions par des vérifications systématiques. On débouche alors sur la distinction, essentielle pour le contrôle international, entre le contrôle contentieux et le contrôle systématique. C'est le second qui constitue l'instrument privilégié des organisations internationales, facilement accepté par les Etats membres dans le respect de leur égalité, en vue de renforcer l'application des normes qu'elles édictent ; mais elles peuvent aussi, à l'instar des tribunaux et des arbitres internationaux, exercer un contrôle contentieux declenché par voie de plainte et qui, par sa valeur dissuasive, se conjugue à l'action du contrôle systématique.“

${ }^{547}$ MENEZES, Wagner. Tribunais internacionais: jurisdição e competência. São Paulo: Saraiva, 2013. p. 179. "In verbis": "De forma simplificada e geral, pode-se concluir, em relação aos aspectos jurídicos do MERCOSUL, que o direito existente em seu âmbito e que se esboça é o Direito da Integração, intergovernamental, com instrumentos de aplicação do Direito Internacional Clássico, onde o mecanismo jurídico de solução de controvérsias é o Tribunal Arbitral ad hoc com um sistema permanente de revisão. Esse busca subsídios para suas decisões e orientações nas fontes jurídicas do MERCOSUL, assim compreendidas: no Tratado de Assunção e em seus protocolos adicionais, nos acordos celebrados no âmbito do Tratado de Assunção e seus protocolos, nas decisões dos órgãos diretivos como o Conselho do Mercado Comum, nas resoluções do Grupo Mercado Comum e nas diretrizes da Comissão de Comércio do MERCOSUL.”

548 JACKSON, John Howard. Sovereignty, the WTO, and changing fundamentals of international law. New York: Cambridge University Press, 2006. pp. 85-86. "In verbis": "Although not explicitly highlighted in these trade texts [GATT 1948 e 1994], another underlying goal was extremely instrumental in expressions of policy by free world political leaders during World War II and after. This was the goal to 'keep the peace' and avoid another world war. So it is reasonable to believe that the principal original goals for GATT were broadly 
do tempo e formaram organizações internacionais, cujo exemplo atual mais contundente seria, conforme apontado anteriormente, a União Européia ${ }^{549}$. A iniciativa aproximativa européia pode - por seu grau de consolidação - servir atualmente de modelo a outros sistemas regionais de direito, mas determinadas idiossincrasias não podem ser ignoradas e nem tudo pode ser sempre importado e aplicado diretamente ${ }^{550}$.

No que se refere às dúvidas quanto à unidade do direito das gentes, a relação entre o local e o geral mostra-se bastante útil ao debate. Assim, quando, por exemplo, o MERCOSUL observa as normas multilaterais da Organização Mundial do Comércio, ocorre a conformação da pluralidade de sistemas contidos na esfera jurídica local com o sistema jurídico econômicocomercial da organização global. A compatibilidade do regional com o multilateral acabaria em um contexto de integração, dessa forma, podendo servir para harmonizar um a um todos os sistemas fragmentados construídos autonomamente ao redor das diversas lógicas jurídicas existentes.

O regionalismo econômico não é mais tendência no direito internacional. Trata-se de fenômeno consolidado e centenas são os acordos desse tipo vigentes hoje ao redor do

twofold: keeping the peace, and expanding world economic development and world welfare, and that these two were not unrelated to each other." VASCONCELOS, Raphael Carvalho. Regionalismo: Premissas à Compreensão de um Fenômeno Jurídico. In: Wagner Menezes. (Org.). Direito Internacional em Expansão. 1ed.Belo Horizonte: Arraes, 2012, v. 2, p. 477-489.

${ }^{549}$ SOARES, Mário Lúcio Quintão. MERCOSUL - Direitos humanos, globalização e soberania. Belo Horizonte: Del Rey, 1999. p. 29. "In verbis": "A diluição do conceito de soberania ocorre a partir do Plano Schuman, inspirado em Jean Monnet, quando seis Estados europeus gradativamente se incorporaram a entidades supranacionais, vinculando-se entre si com laços jurídicos, econômicos e políticos mais acentuados do que os derivados dos tratados internacionais clássicos. Essa integração desenvolveu-se durante a década de 50 com a criação da Comunidade Européia do Carvão e do Aço - CECA (Tratado de Paris - 18/abr./1951) na Europa Ocidental, através dos Estados-partes da França, Alemanha Federal, Itália, Bélgica, Holanda e Luxemburgo, objetivando manter mercado comum para o carvão, minério de ferro e aço, com harmonização de preços e transporte dos referidos produtos."

${ }^{550}$ GOMES, Eduardo Biacchi. A supranacionalidade e os blocos econômicos. Revista do Direito Constitucional e Internacional. São Paulo, n. 53, pp. 310-335, out./dez. 2005. p. 323. "In verbis”: “Distinta é a natureza jurídica do Direito Comunitário e do Direito Internacional Público. Carmen Lúcia Antunes Rocha explica a diferença entre Direito Comunitário e Direito da Integração. 'Aquele [o Direito Comunitário] tem natureza, fonte, objeto e características diversas do Direito Internacional. Entende-se que , não obstante as características serem diversas por se tratar de um ordenamento jurídico próprio, o Direito Comunitário tem sua origem no Direito Internacional Público, porque próprio de uma Comunidade de Estados que afirmam o elo formador de uma composição política supra-estatal porém não estranha ao Estado. Já o denominado direito da integração é, reafirme-se, um conjunto das normas de Direito Internacional formuladas e aplicáveis no processo de integração dos Estados conformadores de uma pessoa jurídica de Direito Internacional derivada da integração das partes e que são recepcionadas no ordenamento interno'." Sobre as fases de integração, CASELLA, Paulo Borba. MERCOSUL: exigências e perspectivas - Integração e consolidação de espaço econômico (1995-20012006). São Paulo: Ltr, 2006. pp. 33-34. "In verbis": "Dentre as modalidades possíveis de integração contamse, como tipos principais, a zona de livre comércio, a união aduaneira e o mercado comum, com a possibilidade de evolução subseqüente rumo a mercado interno ou mercado único, podendo alcançar os patamares de união econômica e monetária, ou mesmo de grau maior ou menos de união política." 
mundo $^{551}$. Tais iniciativas regionais convivem e, muitas vezes, chegam a se sobrepor. A relação entre elas e a compatibilidade de cada uma em particular com a ordem multilateral da Organização Mundial do Comércio constitui importante desafio, mas pode indicar caminho seguro à preservação da unidade do direito das gentes ${ }^{552}$.

Especificamente no contexto das organizações de integração pode-se vislumbrar mais facilmente, em meio à aparente fragmentação, algum tipo de unidade sistêmica estável no direito das gentes. Isso se deve, principalmente, ao fato de nesse tipo de organização local várias lógicas jurídicas estarem contidas e coexistirem regras das mais diversas esferas do direito, necessariamente, de forma harmônica. Em contrapartida e simultaneamente, no multilateralismo estruturam-se, via de regra de forma independente e estabelecem normas gerais para cada uma das esferas que são localmente observadas de forma conjunta. Tudo isso, ressalte-se novamente, sem que exista nenhum tipo de hierarquia entre os sistemas normativos.

O traslado de estruturas internas, típicas do constitucionalismo e da teoria geral do estado, ao direito internacional passou a ser mal vista pelos estudiosos do direito nos últimos trinta anos. As críticas mais recorrentes se referiam às incompatibilidades estruturais denunciadas pela transposição irrestrita de conceitos internos à estrutura da ordem internacional. Equívoco recorrente, nesse sentido, corresponderia, por exemplo, à busca inútil de uma relação hierárquica fixa entre sistemas internacionais de direito. Não existe - ao menos por enquanto - hierarquia entre os sistemas internacionais, mas essa falta de organização hierárquica não significa, entretanto, inexistência de unicidade no direito internacional.

A solução para evitar tais problemas não se deu, conforme ressaltado, na eliminação de antinomias, mas na busca pela compatibilidade. O MERCOSUL - reconhecido pela

\footnotetext{
${ }^{551}$ MATSUSHITA, Mitsuo; SHOENBAUM, Thomas; MAVROIDIS, Petros. The World Trade Organization. Law, Practice and Policy. New York: Oxford, 2003. p. 342. "In verbis": "When the WTO was established, all but three of its original 120 Members were parties to at least one of the 62 regional trade agreements then in force (the three exceptions being japan, Korea and Hong Kong)."

${ }^{552}$ BALDWIN, Robert E. Adapting the GATT to a more regionalized world: a political economy perspective. In: ANDRESON, Kym; BLACKHURST, Richard. Regional integration and the global trading system. Nova York: Harvester Wheatscheaf, 1994. p. 399. "In verbis": "The draft arrangements embodying the results of the Uruguay Round negotiations definitely represent an improvement over the Tokyo Round codes. For example, they cover important new areas such as textiles and clothing, agriculture, safeguards, trade in services, and trade-related intellectual property issues. The new articles are also more precise and internally consistent. However, while the tentative Uruguay Round agreement represents an important step in the right direction, in my view it will not be sufficient to prevent the continued erosion of the multilateral approach to trade policy and to restore the GATT to its earlier, more effective role in promoting the multilateral liberalization of world trade."
} 
ALADI como Acordo de Cooperação Econômica 18 - deve respeitar a normativa regional mais ampla para que seus membros não incorram em descumprimento de normas da Associação ${ }^{553}$. Em síntese, tem-se que o MERCOSUL se compatibiliza com a ALADI e ambos buscam a compatibilidade com a OMC sem que exista hierarquia normativa entre qualquer dos sistemas. Cada um deles cuida tão simplesmente do cumprimento ou não de suas próprias regras jurídicas internacionais ${ }^{554}$. A OMC não constitui, assim, ordem legal hierarquicamente superior ao MERCOSUL e apenas exige da organização regional compatibilidade para que os membros do acordo menor possam seguir participando também da organização multilateral.

A unidade do direito internacional se constrói, portanto, por meio da exigência de compatibilidade entre sistemas. Cada sistema específico tem competência para garantir a coerência entre as normas internamente produzidas e para verificar o descumprimento das mesmas por seus membros. Algumas vezes, os participantes de iniciativas internacionais são partes em mais de um acordo regional ou multilateral e ao cumprir determinada norma estabelecida em um sistema, podem descumprir regra de outro ${ }^{555}$.

As estruturas constitucionalistas internas não servem, de fato, como modelo absoluto ao direito internacional. Seus conceitos e institutos desenvolvidos durante séculos pela doutrina jurídica não devem ser, entretanto, completamente ignorados e podem servir à teorização e à compreensão das peculiaridades do direito internacional.

\footnotetext{
553 Quanto à vigência das regras da ALADI após a assinatura do Tratado de Assunção e a criação do MERCOSUL, BAPTISTA, Luiz Olavo. O Brasil e suas várias encruzilhadas. In: Panorama da conjuntura internacional. São Paulo, v. 3, n. 9/10, p. 8-9, jul./ago. 2001.

${ }^{554}$ PUPO, Rodrigo Luís. Regionalismo e multilateralismo. In: CASELLA, Paulo Borba. (Coord.). Direito de integração. São Paulo: Quartier Latin, 2006. p. 167-168. "In verbis": "Com relação ao exame feito nos casos de Acordos Regionais notificados com base na Cláusula de Habilitação ou Artigo V do GATS, os procedimentos são mais simples. No primeiro caso, a notificação é encaminhada ao Comitê sobre Comércio e Desenvolvimento e acompanha uma breve descrição do Acordo Regional, e os membros devem informar as mudanças em relatórios periódicos mais simples que os envolvidos na análise com base no Artigo XXIV do GATT 1994."
}

555 THORSTENSEN, Vera. Os acordos regionais e as regras da OMC. In: AMARAL JÚNIOR, Alberto do. OMC e o comércio internacional. São Paulo: Aduaneiras, 2002. p. 161. "In verbis": "A questão da multiplicação dos acordos regionais de comércio no mundo atual vem despertando crescente interesse. A discussão se centra no entendimento, de um lado, de que os acordos regionais, por liberalizarem o comércio entre as partes e incluírem temas ainda não negociados no âmbito da OMC, estariam fortalecendo o sistema multilateral de comércio. De outro lado, o argumento é de que os acordos regionais estariam criando suas próprias regras e essas estariam minando o sistema multilateral. Diante desse conflito, o papel a ser desempenhado pela OMC torna-se ainda mais relevante, não só para o estabelecimento de regras sobre a compatibilidade dos acordos regionais com as regras sobre a compatibilidade doa acordos regionais com as regras multilaterais, como também para a supervisão da aplicação de tais regras na formação e na evolução desses acordos." 
A contraposição entre intergovernabilidade, que exige a unanimidade dos sujeitos envolvidos, e supranacionalidade, que adota o princípio da maioria conforma uma das grandes questões atuais do direito das gentes. A ordem internacional reproduziria, nesse sentido, as ordens internas democráticas estabelecendo a necessidade da unanimidade para tornar uma normativa obrigatória. Hoje, apenas estruturas regionais como a União Européia já ultrapassaram o mecanismo clássico e adotam o princípio da maioria. Daí a possibilidade de destacar o direito comunitário - europeu, por exemplo, do direito internacional geral.

Consoante a proposta que se defende neste estudo, uma organização internacional propriamente dita, isto é, uma associação internacional capaz de atuar na esfera global em determinados contextos de forma análoga aos estados, não sustentaria sua condição apenas na personificação jurídica, mas necessariamente deveria possuir sistema institucionalizado de solução de controvérsias hábil a garantir a coerência e a estabilidade de seu sistema de direito. Entes dotados de personalidade internacional, mas incapazes de garantir sua ordem normativa - ainda que possuam estruturas burocráticas estabelecidas - conformariam, sob tais premissas, meros tratados associativos.

Reconhecidas a personalidade e a capacidade de garantir sua estabilidade jurídica, o MERCOSUL cumpriria os requisitos propostos e possuiria os predicados para ser reconhecido como uma organização internacional habilitada a atuar internacionalmente de maneira concretiva expressando a vontade comum de seus membros.

No que se refere à ALADI, por outro lado, a análise de sua estrutura institucional leva a conclusão diversa. Ainda que possua personalidade e estrutura burocrática, a iniciativa continental de integração não conta com meio institucionalizado de solução de controvérsias. Eventuais desacordos entre os membros que a compõem devem ser resolvidos exclusivamente por meios políticos e inexiste, portanto, forma de se garantir a estabilidade do sistema. Sem garantia de coerência jurídica, não haveria na ALADI forma de se reconhecer capacidade de atuação concretiva na ordem internacional e esta se resumiria, então, a um tratado associativo dotado de estrutura burocrática.

Ao garantir a coerência do sistema mundial, os sistemas de solução de controvérsias institucionalizados estabilizam a vontade dos membros de uma organização e permitem que a expressão da vontade comum seja exercida de maneira concretiva pela personalidade jurídica estabelecida em tratado.

Importante se faz ressaltar, finalmente, que não se está sugerindo que a vontade conjunta deva ser necessariamente reconhecida como distinta e independente daquela de seus membros - como em ordens internacionais que adotam processo decisório supranacional. A 
intergovernabilidade não impede, portanto, que um sistema específico seja reconhecido como uma organização internacional. 


\section{A TEORIA GERAL DO ESTADO E A COMPREENSÃO DA ORDEM GLOBAL}

A paz e sua busca constante pela humanidade pode ser considerada uma das finalidades maiores do direito internacional. Mas como conceituar paz? Como reconhecer seus contornos e estabelecer suas bases? O direito internacional por muito tempo teve na guerra um de seus principais parâmetros, mas a agressão, como ação, aperfeiçoa uma vontade, a qual pode constituir uma violação do direito reconhecido ${ }^{556}$.

Soma-se ao contexto apontado a conformação atual do direito das gentes, a qual foi marcada de maneira determinante pelos eventos históricos ocorridos no século XX. As próprias organizações internacionais - tanto no que se refere ao seu reconhecimento como sujeitos de direito quanto à sua multiplicação e incremento em complexidade - podem ser reconhecidas como fenômeno essencialmente desse conturbado e beligerante período da historia $^{557}$.

O estudo da organização do poder na ordem internacional, o qual pode ser auxiliado pela experiência interna dos estados, concentra-se, contudo, em momento prévio ao da guerra, isto é, anterior ao do exercício da vontade de agredir pelos sujeitos de direito internacional. Nesse ponto poderia ser identificada mais uma vantagem do uso auxiliar da teoria geral do

\footnotetext{
${ }^{556}$ WALSH, Edmund A.. Les principes fondamentaux de la vie internationale. In: Recueil des Cours. Academie de Droit International de la Haye, Volume 53, 1935-III, pp. 97-175. p. 135. "In verbis“": "Donc, la paix, comme tous les autres problèmes pratiques ou spéculatifs, doit d'abord recevoir une définition positive. Ignoti nulla cupido, dit le sage proverbe latin. Nul n'éprouve le désir pour ce qu'il ne connaît pas. Par conséquent la paix commence dans l'intellect, et non pas d'abord dans la volonté, qui est la source de l'opération extérieure, de la violation, non de la compréhension. La meilleure définition de la paix que je connaisse est Tranquillitas ordinis..., de saint Augustin. "La paix consiste dans la tranquillité de l'ordre établi. » Car là où le désordre existe, que ce soit dans le processus mental ou dans la vie morale des individus et des collectivités, il n'est point de tranquillité d'esprit. Inversement, là où 1'ordre régit l'intellect et la volonté, la satisfaction (un autre mot pour tranquillité) en résulte. La paix internationale résultera donc d'un ordre établi satisfaisant pour les droits, les devoirs et la conduite réciproques.“
}

${ }^{557}$ ROBERTSON, Arthur Henry. Legal problems of European integration. In: Recueil des Cours. Academie de Droit International de la Haye, Volume 91, 1957-I, pp. 105-211. p. 112. "In verbis“: "In the twentieth century the number of problems requiring international discussion and action has intensified the need for international organizations to deal with them. The League of Nations and the International Labour Organization were born immediately after the first World War, the United Nations and its whole family of Specialized Agencies after the second. Concurrently with this development, the last ten years have seen the growth of a large number of regional organizations in different parts of the world, but more particularly in Europe. The result is that a great deal of the world's international business is now carried on in international organizations of one sort or another and this change necessarily finds a reflection in the science of international law. Since the relations between states have partly changed in character, the body of rules binding on states in the conduct of these relations must reflect that change. International law must examine the character of the organizations created for the conduct of relations, ascertain their juridical character, consider how their creation affects the international obligations of the participating states and study their functioning and activities, which will themselves, with the passage of time, produce new changes in international relationships." 
estado para a compreensão da ordem jurídica das gentes. A regulamentação do poder interno pelo direito constitui estágio que ultrapassa a situação primitiva das relações entre os indivíduos, submetidas à vontade individual e aos conflitos dela decorrentes.

Observa-se, noutro sentido, que a concepção clássica do direito internacional tem sua origem estreitamente vinculada ao surgimento do estado moderno. Percebe-se, assim, que mesmo que muitas das estruturas teóricas relacionadas a esse período da história ainda sirvam à compreensão da ordem internacional, o direito das gentes tradicional não poderia ser como um todo aplicado ao panorama global contemporâneo ${ }^{558}$.

A referida perspectiva tradicional se fundou, em grande medida, na observação da estrutura organizacional que hoje identificamos por "estado" como uma comunidade ideal. Prisma que marcou a perspectiva aristotélica vigente no período medieval e repercutiu, por exemplo, nos escritos internacionalistas modernos que chegavam a usar tais parâmetros como argumentos de autoridade sem justificativa racional. Apenas mais tarde surgiu a percepção da importância do papel do poder autárquico na estrutura do estado e a apontada idealização inicial foi finalmente abandonada ${ }^{559}$.

Contemporaneamente, em meio às dúvidas apresentadas pela pluralidade sistêmica à concepção unitarista do direito das gentes, percebe-se que enquanto cientistas políticos trabalham freqüentemente com modelos, parece existir certa resistência de juristas à elaboração e adoção de esquemas teóricos como parâmetro de racionalização ${ }^{560}$. Que seriam esses modelos e como poderiam os mesmos auxiliar a compreensão do direito ${ }^{561}$ ?

\footnotetext{
${ }^{558}$ CARREAU, Dominique. Droit international. Paris: Pedone, 1986. p 15. "In verbis“": "Il existe des liens étroits entre la naissance de l'Etat moderne et le développement du droit international « classique », c'est-à-dire du droit international conçu comme l'ensemble des règles présidant aux relations inter-étatiques. Si une telle conception a bien rendu compte de la société internationale telle qu'elle a existé - surtout au xixe siècle -, elle ne saurait être pleinement acceptée de nos jours bien qu'elle explique encore bon nombre de solutions traditionnelles toujours présentes dans le droit international contemporain.“

559 JELLINEK, Georg. Das Recht des modernen Staates. Berlin: Verlag von O. Häring, 1900. p. 397. "In verbis": "Dass das Mittelalter unter dem Einflusse der ungeheuren Autorität des Aristoteles die Lehre vom Staate als der perfecta communitas unbesehen aufnahm, ist in dem ganzen wissenschaftlichen Geist dieser Epoche begründet. Der Zauber antiker Begriffsbestimmungen beherrschte aber auch moderne Geister häufig selbst da, wo sie schöpferisch vorgingen. Das zeigt sich auch bei Hugo Grotius, bei dem ja der Hinweis auf ein klassisches Citat nicht selten die Stelle eines Beweises vertritt. In seiner Definition des Staates tritt ein halbes Jahrhundert nach Bodin die Autarkie von neuem als wesentliches Merkmal auf.“
}

${ }^{560}$ SLAUGHTER, Anne-Marie. International law and international relations. In: Recueil des Cours. Academie de Droit International de la Haye, Volume 285, 2000, pp. 09-249. p. 191, “in verbis“: "International lawyers, and lawyers generally, often accuse political scientists with being in love with models. Perhaps rightly — as eminent a political scientist as Robert Keohane has warned his colleagues of the dangers of "model mania". Political scientists must measure their models against careful and extensive empirical work. Absent such empirical support, lawyers often mistrust the abstract certainty that models appear to afford. The parsimony characteristic of the most powerful models contrasts sharply with the mass of complex doctrinal and institutional detail that lawyers must master. Nevertheless, models serve important functions for lawyers and 
Ainda que seja possível fazer ressalvas, o reconhecimento dos arranjos coletivos internacionais - organizações internacionais e tratados associativos - como sujeitos de direito capazes de agir na ordem global por meio de sua personalidade jurídica representou desarticulação de premissa que orientou o direito das gentes por séculos: a de que apenas estados seriam atores na interação humana extraestatal ${ }^{562}$.

Assim como um indivíduo apenas pode ser compreendido plenamente quando contextualizado em sociedade, o estado exige também a análise de seus aspectos exógenos. $\mathrm{O}$ estudo da estrutura estatal concentrado em seu interior decorrente da perspectiva isolada ofuscada por concepções equivocadas da soberania - mostra-se extremamente incompleto. Muitas vezes, na verdade, o estado acaba sendo percebido como duas coisas distintas, interna e externamente, como se sua expressão externa constituísse algo totalmente diferente e independente de seu funcionamento e estruturas interiores. A aproximação da teoria do estado ao direito internacional pode ser o caminho para evitar esse tipo de intercorrência teórica ${ }^{563}$.

political scientists alike. How lawyers use them, however, depends ultimately on their underlying conception of what a model is - their mental model of models."

${ }^{561}$ SLAUGHTER, Anne-Marie. International law and international relations. In: Recueil des Cours. Academie de Droit International de la Haye, Volume 285, 2000, pp. 09-249. pp. 191-192, “in verbis“: "In one conception, models are like lenses. They are the prisms, conscious or unconscious, through which all individuals see and interpret the world. Change the lenses, and we change both what we see and how we see what we saw before. The advantage of developing different models is that it fosters the crystallization of different perspectives and permits analysts to shift between them quickly and systematically in examining any particular problem. A second conception of models sees them as causal constructs, analogous to physical structures in which pressing a button or pulling a lever in one part of the model dictates a series of consequences in other parts. This is a more Newtonian image, older but not outdated. Causal constructs are inevitably imperfect approximations of physical or social reality, but they remain the foundation of much of our knowledge. If lawyers are to accord the social sciences any value at all, they must be prepared to accept or at least evaluate the merits of causal models based on theoretical propositions and backed by empirical testing of various kinds. They can then use these models not only to diagnose policy problems but also to generate a range of legal solutions."

${ }^{562}$ WEIL, Prosper. Le droit international en quete de son identité : cours général de droit international public. In: Recueil des Cours. Academie de Droit International de la Haye, Volume 237, 1992-VI, pp. 09-370. p. 103. "In verbis“": "Malgré les précautions prises, l'innovation juridique était fondamentale : les Etats ne sont plus seuls à posséder la personnalité internationale. Les organisations internationales sont, elles aussi, des sujets du droit intemational : elles concluent des traités, bénéficient d'immunités diplomatiques, peuvent encourir une responsabilité internationale : elles ont des organes propres, un personnel propre qui relève d'un droit interne incorporé au droit intemational, des tribunaux propres qui ont la qualité de tribunaux internationaux, etc."

563 BRIERLY, J.-L.. Le fondement du caractère obligatoire du droit international. In: Recueil des Cours. Academie de Droit International de la Haye, Volume 23, 1928-III, pp. 463-552. p. 503. "In verbis“: "C'est seulement dans la période contemporaine que ceux qui ont étudié l'État semblent avoir commencé à reconnaître que nous vivons dans un monde de pluralité d'États, ou du moins qu'ils ont commencé à considérer ce fait évident comme un facteur important de la compréhension exacte de la nature d'un État en tant que tel. L'éthique n'étudie pas les problèmes de la conduite de l'individu sans considérer le fait que cet índividu a un voisin, mais la théorie politique a généralement traite l'État comme s'il existait dans le vide; et les conclusions auxquelles on aboutit à partir de telles suppositions sont probablement aussi trompeuses que les conclusions des astronomes avant les découvertes de Copernic. Non seulement elles ne peuvent que partiellement exprimer la vérité en ce qui concerne l'État, mais encoré elles courent le risque de déformer même cette vérité partielle, 
Nesse ponto, possível se faz questionar se o uso do estado como parâmetro e base para a compreensão do direito internacional não incluiria suas estruturas internas e fundamentações teóricas de direito correspondentes. De qualquer maneira, verifica-se que a comparação da posição dos indivíduos na esfera local dos estados e dos membros das organizações com o sistema de direito da associação mostra-se, na verdade, inevitável ${ }^{564}$. O paralelismo referido permite, em última ratio, que se reconheça, no pacto social dos indivíduos que compõem o estado a mesma obrigatoriedade normativa que se extrai da pacta sunt servanda dos sujeitos que se associam internacionalmente ${ }^{565}$.

Cumpre ressaltar que os sujeitos de direito das gentes, ao celebrarem um tratado, também atuariam, nesse contexto, de forma que pode ser considerada análoga aos atores que produzem normas internamente em um estado. Em ambiente democrático local, por exemplo, as leis são instituídas pelos representantes da vontade soberana dos indivíduos que compõem aquela sociedade determinada. Na esfera global, os acordos são celebrados pelos representantes dos sujeitos de direito reconhecidos - estados e organizações internacionais, os quais representam o conjunto das vontades de cada um deles individualmente que, no caso específico dos estados, corresponderia à soberania externa cristalizada em sua independência em relação aos demais sujeitos ${ }^{566}$.

car un État ne peut être compris convenablement s'il n'est vu dans son ensemble. II ne constitue pas deux entités, que l'on puisse séparer selon qu'elles fonctionnent intérieurement et extérieurement, mais une seule entité considérée sous deux aspects différents, national et international.“

${ }^{564}$ SEYERSTED, Finn. Applicable law in relations between intergovernmental organizations and private parties. In: Recueil des Cours. Academie de Droit International de la Haye, Volume 122, 1967-III, pp. 427-616. p. 450. "In verbis": "IGOs are not communities of individuals, but communities of States (federal States are both). The natural parallel to the jurisdiction of States over their nationals is therefore the jurisdiction of IGOs over States. Indeed, some organizations have the power to enact regulations and/or make administrative or judicial decisions binding upon their member States. But in most cases these bind directly only the States as such, not persons under their jurisdiction (their nationals and inhabitants). The States remain the only authorities empowered to exercise territorial jurisdiction over persons and things in their territory and personal jurisdiction over their nationals."

565 KELSEN, Hans. Théorie générale du droit international public : problèmes choisis. In: Recueil des Cours. Academie de Droit International de la Haye, Volume 42, 1932-IV, pp. 117-351. p. 262. "In verbis“: "L'Etat est sujet de droit par rapport au droit international au même sens que des personnes juridiques, comme les associations le sont par rapport au droit interne. Et si l'on fait abstraction du droit international, la naissance et la fin des Etats sont des phénomènes «sociaux », tout de même que la formation ou la dissolution des associations si l'on fait abstraction du droit interne. Mais les faits de l'une ou de l'autre catégorie n'ont de caractère juridique que dans la mesure où un ordre juridique y attache des conséquences de droit : l'association, la conséquence que les statuts de l'association : au fait, dit fondation de élaborés par les fondateurs a un caractère juridique et obligatoire ; au fait de la fondation de l'Etat, la conséquence que l'ordre établi par la puissance étatique nouvelle aura ce même caractère, c'est-à-dire le caractère d'un ordre jtuidique et obligatoire."

${ }^{566}$ KELSEN, Hans. Théorie du droit international public. In: Recueil des Cours. Academie de Droit International de la Haye, Volume 110, 1953-III, pp. 01-203. pp. 198-199. "In verbis“": "On ne peut comprendre la formation des normes juridiques internationales qu'en se plaçant au point de vue du droit international général. C'est lui 
No plano mundial hoje - a partir da alteração da concepção da soberania da perspectiva pessoal para a territorial - não há que se falar de expressão individual de vontade pelo representante do sujeito de direitos reconhecido. Assim sendo, a celebração de um tratado pelo exercente da função executiva de um estado não deve ser entendida como expressão de sua vontade, senão da vontade do conjunto de indivíduos que ele representa cristalizada e identificada com aquela do estado ${ }^{567}$.

Também a igualdade entre os estados na esfera internacional cumpre importante papel na compreensão atual do direito das gentes e esta pode ser compreendida como igualdade material, igualdade jurídica absoluta ou funcional - tal qual observado em alguns modelos regionais como, por exemplo, no MERCOSUL - ou como igualdade perante as regras de direito internacional. Essa última perspectiva seria a adotada pela Organização das Nações Unidas $^{568}$.

Não se propõe neste trabalho a harmonização do direito das gentes com o direito constitucional dos estados ou a regulamentação de um pelo outro. Mesmo porque não haveria novidade em proposta do tipo já que existem campos, como o da regulamentação e garantia à

en effet qui détermine comment ces normes se forment, en qualifiant notamment le traité d'acte créateur de droit et en obligeant les Etats à respecter les traités qu'ils ont conclus. Les représentants de deux Etats qui participent à la conclusion d'un trait constituent un organe composé, mais unique, de la communauté d'Etats formée par le droit international général et non un organe commun aux deux Etats. Le pouvoir de désigner la personne charge d'exprimer au nom de I'Etat sa volonté de conclure un traité est délégué par le droit international au droit national. Les représentants des Etats contractants qui, par leur réunion, constituent l'organe créateur de la norme conventionnelle sont donc en premier lieu des organes du droit international et en second lieu seulement des organes de l'Etat qu'ils reprsentent. Sous l'influence du dogme de la souveraineté on dit souvent que le droit internatronal conventionnel est créé par les Etats. En fait il l'est par la communauté internationale de même que c'est l'Etat qui par ses organes crée le droit national.“

${ }^{567}$ MORELLI, Gaetano. Cours général de droit international public. In: Recueil des Cours. Academie de Droit International de la Haye, Volume 89, 1956-I, pp. 437-604. p. 510. "In verbis“": "Enfin on ne peut parler non plus de pouvoirs juridiques internationaux de l'individu. Sans doute le droit international prend-il en considération des manifestations de volonté pour y rattacher des efiets juridiques donnés. Il S'agit nécessairement de manifestations de volonté produites, au point de vue psychologique, par des individus humains. Mais ces manifestations de volonté sont, le plus souvent, imputées par le droit international à une entité abstraite, qui est la personnification d'un groupe social (notamment d'un Etat). Dans ces cas (par exemple, dans le cas de la ratification d'un traité accomplie par le chef d'un Etat) la manifestation de volonté est, au point de vue juridique, la manifestation de volonté d'une entité abstraite. C'est à cette entité qu'est conféré le pouvoir juridiquee correspondant."

${ }^{568}$ BOUTROS-GHALI, Boutros. Le principe d'égalité des états et les organisations internationales. In: Recueil des Cours. Academie de Droit International de la Haye, Volume 100, 1960-II, pp. 01-73. pp. 14-15. "In verbis": "Dans le cadre du droit des organisations internationales, le principe d'égalité des Etats se présente de trois manières différentes : 1) Egalité matérielle des Etats membres de l'organisation internationale (c'est le projet de Sully) ; 2) Egalité juridique absolue ou fonctionnelle des Etats mernbres de l'organisation internationale (c'est le principe adopté encore par certaines Ententes régionales, comme l'Union panaméricaine) ; 3) Egalité juridique ne signifiant ni égalité matérielle, ni égalité de participation aux fonctions internationales, mais égalité devant la loi internationale (C'est la formule adoptée par la S. D. N., l' O. N. U. et les différentes institutions spécialisées). 
paz, que se encontram amplamente delineados nas ordens jurídicas locais ${ }^{569}$. O que se sustenta seria tão somente a aplicação de parâmetros adotados pela teoria do estado à ordem internacional como forma de facilitar sua compreensão e promover seu desenvolvimento fundado em premissas jurídico-políticas.

Nesse sentido, em abordagem eminentemente contratualista e centrada na figura dos estados e na idéia de soberania externa, o princípio da pacta sunt servanda poderia ser considerado a regra fundamental do direito internacional. Base normativa de validade comparável, inclusive, com as constituições nas ordens jurídicas internas ${ }^{570}$. Não raramente, autores chegaram - em razão do paralelo apontado - não apenas a comparar a estrutura da Organização das Nações Unidas à de um estado, mas também seu tratado constitutivo com as constituições nacionais ${ }^{571}$.

O caráter "constitucional" dos tratados que criam organizações internacionais reside, principalmente, nas regras que regulamentam o funcionamento das instituições criadas. Tais regras diferem claramente dos dispositivos meramente convencionais que criam direitos e obrigações recíprocas para as partes do acordo e estabelecem parâmetros à organização do poder no plano mundial ${ }^{572}$.

\footnotetext{
${ }^{569}$ MIRKINE-GUETZEVITCH, Boris. Le droit constitutionnel et l'organisation de la paix (droit constitutionnel de la paix). In: Recueil des Cours. Academie de Droit International de la Haye, Volume 45, 1933-III, pp. 667773. p. 772. "In verbis": "La conscience juridique des peuples est suffisamment éclairée pour reconnaître que l'organisation internationale de la paix nécessite des règles constitutionnelles, que la mise en harmonie du droit constitutionnel avec les règles internationales de la paix n'est pas seulement un problètme d'école, mais un besoin pratique de la consolidation de la paix. Bien mieux, le droit constitutionnel de la paix est déjà un droit positif : nous avons étudié à lelur place des règles constitutionnelles de la paix que certains Etats ont introduites dans leurs chartes fondamentales ; ce ne sont donc plus seulement, de toute évidence, les théoriciens mais aussi les praticiens qui ont compris la valeur, l'opportunité, la nécessité d'un droit constitutionnel de la paix. La consolidation de la paix par le droit constitutionnel est une tendance manifeste du droit public moderne.“
}

${ }^{570}$ CASTBERG, Frede. International law in our time. In: Recueil des Cours. Academie de Droit International de la Haye, Volume 138, 1973-I, pp. 01-26. p. 5. "In verbis": "The difference between public international law and internal law is clear in principle: public international law is the legal order created in the common life of States and legally binding for them. Its most important basis is the great principle 'Pacta sunt servanda'. It is this fundamental principle of public international law which corresponds to the written or unwritten constitutions forming the basis for legislation within States. Therefore, in principle, the difference between public international law and internal law is clear."

${ }^{571}$ WALDOCK, Humphrey. General course on public international law. In: Recueil des Cours. Academie de Droit International de la Haye, Volume 106, 1962-II, pp. 01-251. p. 36. "In verbis“: "The United Nations has come more and more to wear the look of a true political organization of the world and the Charter that of a world constitution."

${ }^{572}$ HAHN, Hugo J.. Constitutional limitations in the law of the European organisations. In: Recueil des Cours. Academie de Droit International de la Haye, Volume 108, 1963-I, pp. 189-306. p. 197. "In verbis“: "To begin with, a multilateral treaty which at the same time is the constituent act of an international organization is initially an agreement between sovereign States, like many others. Some of its clauses retain their contractual, conventional character throughout the life of the undertaking. To this group belong, in particular, provisions 
Em redução simplista, constituição se refere a um conjunto de normas que possuem prevalência em relação às outras do ordenamento e conteúdo organizativo do poder político $^{573}$. Tais características podem muito bem ser aplicadas a um tratado e algumas organizações internacionais já possuem atualmente marcos legais que podem ser, a partir da identificação das características descritas, reconhecidos como constituições ${ }^{574}$.

O paralelo do direito internacional geral com o constitucionalismo na esfera local se relaciona diretamente com a questão da validade da normativa extraestatal constituindo argumento que adere muito bem aos anseios internacionalistas pelo reconhecimento definitivo da obrigatoriedade do direito das gentes ${ }^{575}$.

Em análise estrita, percebe-se que, de fato, o tratado constitutivo de uma organização internacional, ao estabelecer suas finalidades, sua estrutura e os meios a serem empregados

\footnotetext{
which restate canons of general international law prevailing traditionally among sovereign nations as such, e. g. amendment procedures which call for ratification by all Member States. Other parts of the same instrument, however, transcend the domain ordinarily dealt with under the law of treaties as they specify the functions, the structure and the basic procedures of a multinational institution. These rules, once implemented by the Member States of the new entity through the setting up of the international bodies by the intermediary of which the Organization may begin to act, and, thereafter, by the proper action of these organs, provide the entity with the essentials of its internal order and govern its relations to Member as well as non-Member States and other subjects of international law. The distinction between the conventional and non-conventional parts of an organizational compact, however, only paves the way towards a substantive definition of the term 'constitucion'."
}

573 SIMMA, Bruno. From bilateralism to community interest in international law. In: Recueil des Cours. Academie de Droit International de la Haye, Volume 250, 1994-VI, pp. 217-384. p. 260. "In verbis": "Today, the great majority of writers see the specific meaning of the concept of a 'constitution' in the combination of two elements. On the formal side, a constitution enjoys priority over 'ordinary' rules: with regard to substance, it lays down the basic rules governing the life of a community."

${ }^{574}$ O modelo europeu constitui exemplo menos sujeito a críticas, mas autores observam tais características também na carta d ONU, SIMMA, Bruno. From bilateralism to community interest in international law. In: Recueil des Cours. Academie de Droit International de la Haye, Volume 250, 1994-VI, pp. 217-384. p. 262. "In verbis": "Returning to the constitutional paradigm, let us now see what parallels exist between the different branches of State authority, that is powers, and their separation in domestic constitutions vis-à-vis the structure of the organization of the United Nations. First, let us have a look at the General Assembly and ask in what sense it can be called a world parliament. In this regard, some of the necessary elements seem to be in place. Thus, the General Assembly represents the entire United Nations membership and functions in accordance with the principle of 'one State, one vote'. Article 10 confers on it the general competence to make recommendations on all questions within the scope of the United Nations Charter, except, however, on the prerogatives of the Security Council. Even more importantly, the General Assembly exercises a certain degree of control over the other organs through the consideration of their annual and special reports submitted in accordance with Article 15, and, particularly, by the 'power of the purse' enshrined in Article 17."

${ }^{575}$ DUPUY, Pierre-Marie. L'unité de l'ordre juridique international : cours général de droit international public. In: Recueil des Cours. Academie de Droit International de la Haye, Volume 297, 2002, pp. 09-489. p. 216. "In verbis": "Pourtant, si jamais la thèse constitutionnaliste, dans l'une ou l'autre de ses traductions, comportait une part de vrai, elle présenterait un intérêt déterminant pour l'appréciation de l'unité matérielle de l'ordre juridique international. D'un point de vue normatif, c'est toute une conception, théorique et pratique, de la validité des normes juridiques internationales qui se trouve ici en jeu ; cela, avant même que l'on n'évoque la question de l'existence d'un droit impératif international, question qui nous occupera plus loin.“ 
por seus órgãos para que seu objetivo seja atingido, pode ser considerado uma verdadeira lei fundamental, ou seja, o direito básico da estrutura associativa que se busca institucionalizar ${ }^{576}$. A Carta das Nações Unidas, contudo e por exemplo, não pode ser identificada de forma absoluta com o modelo teórico aplicado às cartas dos estados. $\mathrm{O}$ documento deve ser interpretado como um tratado híbrido apesar de, por um lado, estabelecer as bases constitutivas da organização, cria, por outro, direitos e obrigações para suas partes - como um contrato entre estados.

No que se refere à primeira característica apontada do acordo, importante se faz observar que seus termos são dotados da flexibilidade necessária à evolução institucional da organização e atendem, portanto, à percepção da institucionalização jurídica do poder como um processo ${ }^{577}$. A doutrina chega a comparar, nesse sentido, a possibilidade de mutabilidade na interpretação dos termos do tratado constitutivo referido com as constituições de países, as quais se encontrariam sempre em evolução e apenas concluiriam as bases da institucionalização dos estados na prática, isto é, em sua exegese e aplicação ${ }^{578}$.

Em análise específica, verifica-se que a Carta de São Francisco possui, conforme sugerido, características inegavelmente típicas da organização interna de um estado inserida em textos constitucionais. A mais clara delas diz respeito ao fato de o monopólio das decisões sobre o uso da força no contexto internacional se encontrar regulamentada em sua normativa e instrumentalizada em seus órgãos ${ }^{579}$. As comparações do documento com constituições eram

\footnotetext{
${ }^{576}$ HAHN, Hugo J.. Constitutional limitations in the law of the European organisations. In: Recueil des Cours. Academie de Droit International de la Haye, Volume 108, 1963-I, pp. 189-306. p. 195. "In verbis“" "Like any other body politic, an international public organization is governed by a set of rules providing for its establishment, defining its purposes and determining its structure, as well as the means which its organs may employ in order to achieve these purposes. That body of fundamental norms is die basic law of the origination, its constitution."
}

577 VALLAT, Francis Aimé. The competence of the United Nations General Assembly. In: Recueil des Cours. Academie de Droit International de la Haye, Volume 97, 1959-II9I, pp. 203-292. p. 249. "In verbis": "Although the Charter is a treaty and has effect as such in international law, creating rights and obligations between the Members of the United Nations, it also provides the constitution of the Organization. In relation to the organs of the United Nations it should be interpreted not literally or rigidly as a contract or a statute might be in municipal law, but with flexibility so that the organization may develop and be effective to fulfill its basic purposes."

${ }^{578}$ VALLAT, Francis Aimé. The competence of the United Nations General Assembly. In: Recueil des Cours. Academie de Droit International de la Haye, Volume 97, 1959-II9I, pp. 203-292. p. 250. "In verbis": "Documents such as the Constitution of the United States and Magna Charta have been given meaning and life by practice and interpretation. By comparison, the Charter of the United Nations is a young document, but already its literal meaning has undergone change and development. We can no longer look to the text atone to ascertain the truth. We have to look also at the constitution in operation. We shall now turn, therefore, to the story of the Organization as the keeper of the peace."

579 SIMMA, Bruno. From bilateralism to community interest in international law. In: Recueil des Cours. Academie de Droit International de la Haye, Volume 250, 1994-VI, pp. 217-384. pp. 258-259. "In verbis": 
mais freqüentes na fase inicial da organização, é dizer, no período imediatamente posterior à guerra. O próprio presidente americano, Harry Truman, comparou o documento com um texto constitucional em seu discurso em São Francisco em $1945^{580}$.

A imperfeição da transposição teórica de um contexto ao outro mostra-se hoje, no entanto e com base - ou apesar - de todos os fatores apontados, bastante nítida. Duas características podem ser ressaltadas na estrutura de poder interna de um estado: a centralização coercitiva e o sacrifício de interesses pessoais em prol da coletividade. Nenhuma dessas características são reconhecíveis na conformação atual da ordem internacional.

A própria Organização das Nações Unidas não conseguiu desenvolver nenhumas desses dois predicados e, mesmo que se - em certa medida - eles sejam identificáveis na atual estrutura da União Européia, aproximam o acordo regional dos processos de formação de estados como o italiano, alemão ou dos Estados Unidos. Adere-se, portanto, à estrutura estatal e não aos parâmetros adotados pelo direito das gentes ${ }^{581}$.

\footnotetext{
"With regard to the institutional structure of the United Nations, it reminds us of domestic constitutions in several respects: thus, Article 2 codifies not only the ground rules for the activities of the organization, but also the principles which are to govern the overall political system, that is, sovereign equality, the prohibition of the threat or use of force, good faith and the principle of the intangibility of the 'domaine réserve'. As to the internal structure of the United Nations, it reminds of the traditional separation of the executive, legislative anti judicial powers in ways on which I will elaborate a little latter. Chapters VIII and IX of the Charter aim at the integration of all other international organizations into the overarching system of the United Nations. According to Article 103, the Charter claims priority over all other international legal obligations of its Member States. Further, as was just mentioned, Article 2, paragraph 6, even deals with non-members. And to repeat once more the most fundamental point: the organization claims a monopoly with regard to the legitimate use of force, with the sole exception of the right of (individual or collective) self-defence."
}

${ }^{580}$ DUPUY, Pierre-Marie. L'unité de l'ordre juridique international : cours général de droit international public. In: Recueil des Cours. Academie de Droit International de la Haye, Volume 297, 2002, pp. 09-489. pp. $217-$ 218. "In verbis“: "De là à ce qu'on voie dans ce phénomène une prémisse de constitution universelle, il n'y a qu'un pas, qu'on ne peut cependant franchir sans d'importantes précautions. Il faut d'ailleurs préciser une chose. La Charte ne peut être considérée, dès les origines, indépendamment de la « Real Politik » des grandes puissances : l'acte constitutif de l'Organisation des Nations Unies entre en effet en vigueur consécutivement à la nouvelle partition du monde entre deux blocs rivaux et Yalta prime à bien des égards San Francisco. Pourtant, l'un ne se place pas sur le même plan que l'autre. Sous le bénéfice d'un tel rappel, il faut, quoi qu'il en soit, cerner l'ampleur de la novation de principe apportée par la Charte (section I). Après quoi, on pourra examiner selon quelles perspectives pourrait être lue la constitution selon la Charte (section II). Après tout, n'est-ce pas Harry Truman lui-même, dans son discours du 26 juin 1945 clôturant les travaux de la Conférence de San Francisco, qui, le premier, compara la Charte à une constitution, appelée à croître et à se développer au fil du temps?“

${ }^{581}$ GOLDSMITH, Jack; POSNER, Eric. The limits of international law. New York: Oxford University Press, 2005. p. 224. "In verbis": "Successful governance in the domestic realm works differently from this purely instrumental conception of international governance. There are two distinguishing factors in the domestic realm: genuine communal sacrifices (whereby some members sacrifice interests for others) and centralized coercion (compare Carr 1946). Neither of these factors can work on a global scale. The standard proposal for international coercion is to strengthen the United Nations (for example, I. Young 2000). But the United Nations failed in its original ambition of having a freestanding police force, and it has failed to transcend the problem of enforcement ever since. Like all collective security schemes, the United Nations depends wholly 
A comparação das organizações internacionais com os estados permite, na verdade, que se reconheçam aspectos típicos do conceito de soberania em suas estruturas. Exemplo disso seria o fato de, exceto nos casos estabelecidos pelos tratados constitutivos, esse sujeitos não se submeterem ao poder de nenhum outro que lhe seja equiparável - tal qual ocorre, em regra, com os estados ${ }^{582}$.

Mais que isso, a própria independência - soberana - dos estados na esfera global permite claro paralelo com a autonomia dos indivíduos no plano interno. Trata-se do reconhecimento de pessoalidade nos atributos que lhe são conferidos e, conseqüentemente, de personalidade jurídica capaz de expressar vontade criadora de normas ${ }^{583}$.

Não se trata de aplicação direta, mas de suporte teórico à compreensão da dinâmica mundial de poder. A teoria do estado, ao apresentar soluções já experimentadas internamente pode servir de artifício teórico preventivo, hábil a inspirar formas jurídicas de distribuição e organização do poder na ordem internacional que poderiam evitar conflitos entre os sujeitos de direito internacional. Exemplo prático da formulação proposta se daria no uso da teoria da separação das funções do estado na institucionalização dos sistemas internacionais de solução

\footnotetext{
on member states' self-interested (and thus uneven) acts for coercion. It is hard to see how or why militarily powerful states would ever agree to any other scheme. As for community, there are natural limitations on the size of democratic government. The larger and more ambitious the government becomes, the more varied the governed population becomes (in endowment, culture, language, preferences, and the like) and the more difficult it becomes to maintain social harmony (Walzer 2000). The EU is often invoked as a counterexample, but the EU is more like the United States in the eighteenth century and Italy and Germany in the nineteenth: it reflects state building by smaller units with a common heritage and common interests. The EU example shows the difficulties that inhere in such a process even among subunit states that in many respects share a common culture and that have been unified in various ways over two millennia (for example, the Roman Empire, the Catholic Church, the Holy Roman Empire, and the Concert of Europe). It does not provide a map for global government of peoples of radically different cultures, histories, and endowments.'
}

${ }^{582}$ SEYERSTED, Finn. Applicable law in relations between intergovernmental organizations and private parties. In: Recueil des Cours. Academie de Droit International de la Haye, Volume 122, 1967-III, pp. 427-616. p. 437. "In verbis": "As has been more fully explained elsewhere, the external relations of an IGO with States or other IGOs (or other types of subjects of international law), acting as such, are governed by public international law. Indeed, international law is traditionally the law governing relations between sovereign communities as such, and such relations cannot be governed by any other law. And all intergovernmental organizations are sovereign, in the sense that they are not subject to the jurisdiction of any other organized community."

${ }^{583}$ HENKIN, Louis. International law : politics, values and functions : general course on public international law. In: Recueil des Cours. Academie de Droit International de la Haye, Volume 216, 1989-IV, pp. 09-416. p. 28. "In verbis": "Autonomy implies 'personhood', State autonomy in a State system implies personhood for systemic purposes. Under the older law of nations, the prince had attributes of legal personality akin to those that human beings enjoyed under natural law and under Roman law. In the modem international system, a State is a person with attributes of 'personhood' like those of human persons in domestic legal systems - status in the system, rights and obligations before the law, power to acquire and own property, to make contracts, to assert legal claims, to pursue legal remedies." 
de controvérsias e, no caso particular das organizações internacionais, no aperfeiçoamento de suas estruturas jurídicas.

O uso e a regulamentação do uso da força conformam o cerne da política internacional e do direito das gentes ${ }^{584}$. Em meio às dificuldades que se apresentam, a institucionalização e a teoria geral do estado poderiam se apresentar como corpo teórico hábil a orientar a neutralização do uso da força como parâmetro ao poder nas relações entre os atores da ordem internacional.

Na realidade, a proposta apresentada não constitui novidade. Nesse sentido, observa-se que, diferentemente das reservas da doutrina atual, quando da formação das iniciativas associativas que culminaram na atual União Européia, autores internacionalistas identificavam claramente tendência federalista e analisavam, portanto, aspectos do direito das gentes a partir da perspectiva da teoria geral do estado ${ }^{585}$.

$\mathrm{O}$ embate entre a supranacionalidade e a intergovernabilidade ou entre o federalismo e a cooperação esteve presente nas negociações dos tratados regionais europeus posteriores à segunda grande guerra ${ }^{586}$. Naquele momento, nenhuma das duas posições prevaleceu e

${ }^{584}$ GIRAUD, Emile. Le droit international public et la politique. In: Recueil des Cours. Academie de Droit International de la Haye, Volume 110, 1963-III, pp. 419-809. p. 801. "In verbis": "[...] la politique et le droit international sont dominés par la force, mais que derrière ces formes matérielles on trouvait des forces psychologiques et morales. Formulons l'espoir, bien que ce soit là une question philosophique et morale, que ces forces psychologiques et morales seront orientées vers l'organisation internationale, la justice et la paix.“

585 Analisando as iniciativas regionais européias sob a perspectiva da teoria geral do estado, ROBERTSON, Arthur Henry. Legal problems of European integration. In: Recueil des Cours. Academie de Droit International de la Haye, Volume 91, 1957-I, pp. 105-211. p. 124. "In verbis": "The autumn of 1954 then produced a resurgence of the idea of intergovernmental cooperation in Europe. The federalist idea having failed by a narrow majority - for five of the six countries had ratified the E. D. C. [European Defence Community] treaty - an alternative solution was sought for the problem of organizing European defense on lines that were more conservative and therefore more acceptable for the United Kingdom. [...] The federalist idea, however, was not dead. Having suffered a setback in 1954 on the military and political fronts, its resurgence began in 1955 in the economic field. The six foreign ministers met in June of that year at Messina and set up an Intergovernmental Conference at Brussels under the chairmanship of M. Paul-Henri Spaak to study the creation of a customs union between the six countries and a joint organization for the development and utilization of atomic energy. In May 1956 at Venice they approved the recommendations of the Brussels Conference and work then began on drafting the two treaties for the Common Market and Euratom, which were finally signed in Rome on 25 March 1957. Provided they are duly ratified, they will also set up European institutions of great importance, rather on the lines of the institutions of the Coal and Steel Community. The federalist tendency in Europe is therefore not dead and may soon be once more in the ascendant."

586 NEGRO, Sandra. Derecho de la integración. Buenos Aires: BDEF, 2013. pp. 261-262. "In verbis": "'Federalismo y cooperación intergubernamental, supranacionalidad y cooperación. Entre las distintas naciones: dos conceptos distintos de Europa definidos con diversos nombres han rivalizado desde los primeros días de la Comunidad, los padres fundadores no habían permitido que ninguno prevaleciera en e1 Tratado de Roma, que representa un delicado equilibrio entre los dos'. Cabe destacar que sólo en 1947, después de la Segunda Guerra Mundial y con la formación de numerosas organizaciones europeístas, logró constituirse un Comité de Coordinación de los Movimientos para la Unidad Europea integrado por el Movimiento Europa Unida (de Churchill), la Unión Europea de Demócratas Cristianos y el Movimiento Federalista Europeo. Este Comité convocó en La Haya al Consejo de Europa, del 7 al 10 de mayo de 1948, y allí se enfrentaron tres 
predominou no texto do Tratado de Roma. A suranacionalidade não se deu de plano. Foi construída, portanto.

Em contexto espacial mais abrangente e temporal anterior, ainda que a criação da Liga das Nações tenha inspirado na doutrina a projeção da criação de um superestado - algo como uma organização política global institucionalizada, a supranacionalidade baseada na conformação interna do poder apresentava-se muito mais como uma tendência que como um objetivo dos sujeitos de direito internacional em sua atuação ${ }^{587}$. Nenhuma alteração consistente a esse respeito percebe-se nas concepções aproximativas da atualidade.

A percepção do direito das gentes como uma ordem primitiva, adotada pela doutrina positivista, racionaliza a ordem internacional a partir das estruturas internas dos estados no que se refere à centralização do poder político. Trata-se de perspectiva de evolução, a qual não exige da parte do internacionalista postura de conflito em relação ao poder dos estados, mas tão somente a preocupação com a institucionalização das estruturas internacionais para sua consolidação e maturidade ${ }^{588}$.

\footnotetext{
tendencias que luego adquirirían una importancia significativa en el proceso de integración europea: 1) Los unionistas o partidarios de la Confederación, que se orientaban hacia una Unión Europea basada en mecanismos de cooperación intergubernamental pero sin menoscabo de la soberanía nacional absoluta. 2) El federalismo, que se apoyaba en el Movimiento Federalista Europeo (MFE) fundado y conducido por Altiero Spinelli, que sostenía que sólo una Federación de Estados era capaz de garantizar una unificación duradera de Europa Occidental. El desarrollo económico y democrático y la posibilidad de contribuir eficazmente a las soluciones de los problemas mundiales debían partir, según la posición federalista, de una efectiva limitación de las soberanías nacionales a favor de la conformación de instituciones federales europeas. Para ello era necesario convocar a una Asamblea Constituyente Europea, de manera de involucrar en forma directa a la opinión pública en la construcción europea. La doctrina del federalismo internacional fue desarrollada, desde el punto de vista teórico, especialmente por la ciencia política."
}

587 ROLIN, Henri. Les principes de droit international public. In: Recueil des Cours. Academie de Droit International de la Haye, Volume 77, 1950-II, pp. 305-479. p. 463. "In verbis“: "Le terme super-Etat a été en effet, imaginé, si nos souvenirs sont exacts, dans les premiers temps de la Société des Nations pour désigner l'excès d'internationalisme vers lequel s'acheminait l'institution de Genève suivant ses détracteurs, et que les partisans de Genève se déclaraient d'accord pour répudier « la Société des Nations n'est pas et ne peut pas devenir un super-Etat ». Le super-Etat que condamalait aussi M. Hymans, le premier président de l'Assemblée, c'était l'organisation universelle à compétence illimitée absorbant tous les Etats Membres ou les réduisant au degré très relatif d'autonomie dont jouissent les Etats fédérés dans les fédérations du type américain ou suisse. Le degré de centralisation qu'impliquerait la fédération mondiale se heirterait sand doute aujourd'hui encore, dans la plupart des pays, à une vive résistance, et je ne pense pas qu'il soit dans les voeux de M. Chaumont ou de son maître M. Scelle. Ce dernier parle volontiers sans doute «d'ordre juridique oecuménique » et corrélativement de «l'institutionalisme superétatique» que cet ordre juridique postule, mais il qualifie également de superétatiques les fédérations à compétence très spécialisée, en sorte que l'on peut considérer que l'idéal de superétatisme proposé marque plutôt une tendance qu'un objectif défini, cette tendance étant la formation présumée indispensable d'une ou plusieurs sutorités supérieures aux Etats.“

${ }^{588}$ KUNZ, Josef L.. La crise et les transformations du droit des gens. In: Recueil des Cours. Academie de Droit International de la Haye, Volume 88, 1955-II, pp. 01-104. p. 46. "In verbis“: "Que le droit des gens classique soit un droit primitif, cela est généralement admis. Ceux qui, comme le professeur Kelsen, argumentent que ce caractère primitif est l'unique différence entre le droit des gens général et les droits nationaux avancés, voient une analogie historique entre le développement du droit des gens et des droits nationaux dans la voie de la centralisation. L'exemple des droits nationaux montre que cette idée de centralisation mène à un type d'ordre 
Não existe atualmente na esfera mundial um órgão administrativo centralizado - que exerça funções executivas. Os governos perceberam ao menos desde o século XIX, contudo, que a regulação conjunta de determinados setores da atividade social não apenas facilitaria os esforços individuais, mas constituía, na verdade, uma necessidade da comunidade internacional. Dessa percepção surgiram iniciativas que resultaram, por exemplo, na União Postal Universal e na União telegráfica Internacional ${ }^{589}$.

A descentralização do poder e a ausência de soberania na ordem internacional não significam absoluta anarquia. A regulamentação das relações entre os sujeitos de direito das gentes existe e se encontra em pleno processo de consolidação, mas ainda não pode ter sua maturidade e eficácia comparada àquela desenvolvida pela teoria geral do estado nos últimos séculos ${ }^{590}$.

Assim sendo, a principal diferença reconhecida entre o sistema internacional de poder e o interno de um estado diria respeito à centralização. Não haveria - ainda? - nada no plano global que pudesse ser comparado ao monopólio da força exercido pelo governo em um país ${ }^{591}$.

Autores que concebiam na primeira metade do século XX a possibilidade de construção de um estado global o faziam, em regra, imaginando a estrutura política européia ocidental como modelo. A concepção de uma comunidade humana verdadeiramente mundial

juridique que nous appelons a Etat souverainn. La logique inévitable de ce développement est aujourd'hui le grand argument dca adhérents de l'Etat mondial. Mais la majorité des internationalistes veulent seulement développer le droit des gens, et non pas le remplacer par l'ordre juridique national d'un Etat mondial.“

${ }^{589}$ CLAPHAM, Andrew. Brierly’s law of nations. Oxford: Oxford University Press, 2012. p. 111. "In verbis": "The administrative function, like the executive, is not provided in the international system with any centralized organ. But in the latter half of the nineteenth century a number of separate institutions with specialized administrative functions were created. They arose not from any idealistic theory of international relations, but from the compelling force of circumstances. In one national administrative department after another, experience showed that government could not be even reasonably efficient if it continued to be organized on a purely national basis. These institutions were known as public international unions: The first such union was the International Telegraphic Union formed in 1865; others are the Universal Postal Union of 1874, the International Institute of Agriculture of 1905, and the Radiotelegraphic Union of 1906."

${ }^{590}$ TUNKIN, Grigory. Politics, law and force in the interstate system. In: Recueil des Cours. Academie de Droit International de la Haye, Volume 219, 1989-VII, pp. 227-395. p. 372. "In verbis": "The absence of sovereignty in the interstate system does not mean an absence of order. In this system, as in any system, there are elements of anarchy and elements of order, but the degree of anarchy and the degree of order in the interstate system is different from those in the State systems. The degree of anarchy in the interstate system is higher than in State systems."

${ }^{591}$ TUNKIN, Grigory. Politics, law and force in the interstate system. In: Recueil des Cours. Academie de Droit International de la Haye, Volume 219, 1989-VII, pp. 227-395. p. 371. "In verbis“": "The interstate system is a social system, different from State systems. There is no such central and powerful authority that exists in every organized contemporary State system." 
exigiria que todos os indivíduos da comunidade global fossem definitivamente incluídos na sociedade internacional ${ }^{592}$.

Impossível se faz desvincular os escritos de um doutrinador do tempo histórico, no qual ele se inseria. Tal percepção pode servir muito bem para auxiliar a aplicação de teorias tradicionais a estruturas institucionais atuais e o uso da teoria geral do estado na compreensão do direito das gentes não pode ignorar essa premissa ${ }^{593}$. Em outras palavras, a falta de menção expressa ao direito internacional em determinada teoria clássica de organização do poder não impede absolutamente seu aproveitamento na tentativa de se compreender a ordem mundial.

Ressalva caberia, por exemplo, ao uso do termo "soberania" em referência ao poder das organizações internacionais. Uma organização internacional que atinja o grau de centralização de poder e institucionalidade que permita o reconhecimento de características soberanas claramente deixaria de ser uma associação e se converteria em um estado. Organizações internacionais possuem na limitação de atribuição e de poder pela soberania dos entes que a as compõem - estados - um de seus elementos mais marcantes ${ }^{594}$.

\footnotetext{
592 WRIGHT, Quincy. The strengthening of international law. In: Recueil des Cours. Academie de Droit International de la Haye, Volume 98, 1959-III, pp. 01-295. p. 28. "In verbis“: "A considerable movement has, it is true, developed for World Government, but the most popular advocates of this movement would confine it to the democracies springing from European civilization, thus accepting the thesis which limits democracy to people of a similar culture. They conceive of a North Atlantic Community as a lager Nationality, differing from Latin America, the Far East, South Asia, Southeast Asia, the Middle East, the communist world, and perhaps other regions which manifest such similarities as to be potentially capable of effective Union. Only a minority contemplate World Government in a literal sense, basing themselves on a cosmopolitan sentiment such as that held by some savants in the age of enlightenment and by the Stoics in antiquity. They identified homo potilicus with homo sapiens and assumed that Man as a rational animal could order his entire species politically when instruments of communication had become sufficient to maintain contacts of all with all. Perhaps eventually all human beings will feel themselves world citizens, members of the human community, but before they do I think they will feel themselves members of the international society."
}

${ }^{593}$ CLAPHAM, Andrew. Brierly's law of nations. Oxford: Oxford University Press, 2012. p. 07. "In verbis": "Like all works of political theory, even when they profess to be merely objective, Bodin's Republic was deeply influenced by the circumstances of its time, and by its author's sentiments towards them; indeed one of Bodin's merits is that he drew his conclusions from observation of political facts, and not, as writers both before and since have too often done, from supposedly eternal principles concerning the nature of states as such. France in Bodin's time had been rent by faction and civil war. Bodin was convinced that the cause of France's miseries was the lack of a government strong enough to curb the subversive influences of feudal rivalries and religious intolerance, and that the best way to combat these evils was to strengthen the French monarchy."

594 REUTER, Paul. Principes de droit international public. In: Recueil des Cours. Academie de Droit International de la Haye, Volume 103, 1961-II, pp. 425-656. p. 519. "In verbis“: "En dépit des formules employées dans certains débats politiques, soit aux Nations Unies soit dans d'autres organisations, les organisations internationales n'ont pas de «souveraineté » dans le sens où ce terme est employé pour les Etats. En effet la souveraineté ne vaut qu'en termes de juxtaposition, d'exclusivité territoriale, or les organisations se trouvent dans une situation toute différente. A la difrerence des Etats elles ne portent pas la responsabilité finale du destin d'une communauté humaine ; elles n'ont ni population, ni territoire ; elles n'ont, par rapport aux Etats, que des attributions limitées et des pouvoirs restreints.“" 
Nesse sentido, infere-se que o poder exercido pelas experiências associativas, em percepção clássica, por meio das atribuições relacionadas à sua personalidade conferidas por tratado não se identificaria com aquele que corresponde aos estados ${ }^{595}$. A evolução de iniciativas como a da atual União Européia subverteram a lógica desse entendimento ao menos em relação às normas jurídicas e cada vez mais o direito europeu comum se identifica com o do estado particular.

Outro paralelo possível a ser feito entre as organizações internacionais e os estados teria lugar na perspectiva de duração indeterminada aplicável a ambas as estruturas associativas humanas. No caso das organizações, suas finalidades tendem a ser genéricas e se relacionam com objetivos sociais, econômicos ou à manutenção da paz ${ }^{596}$. Não há como se fixar a conclusão de objetivos contínuos.

A predominância da soberania como verdadeira teoria que orienta a participação dos estados na ordem internacional e as dificuldades de se conceber a relação entre os sujeitos de direito das gentes como cooperativa e possivelmente democrática conduz à percepção

\footnotetext{
${ }^{595}$ GANSHOF VAN DER MEERSCH, Walter. L'ordre juridique des communautés européennes et le droit international. In: Recueil des Cours. Academie de Droit International de la Haye, Volume 148, 1975-V, pp. 01-433. pp. 24-25. "In verbis": "Les éléments d'un droit constitutionnel international s'affirment de manière précise et systématique lorsque la communauté internationele, ayant atteint dans les relations entre les sujets de droit qui la composent une solidarité suffisante, constitue en vue d'un but à réaliser en commun une organisation internationale et que les règles de finalité de cette organisation déterminées dans le traité constitutif sont encadrées par des dispositions qui régissent le fonctionnement de ses organes. La doctrine largement dominante admet et la pratique reconnaîte que «dans l'exercice de leur souveraineté et pour la satisfaction de leurs intérêts communs deux ou plusieurs Etats peuvent conférer des capacités juridiques et donc une certaine qualité de sujet de droit inernational à une organisation internationale, instituée par un traité ». L'organisation est régie par un corps de règles particulières au sein du droit international. Son existence, en tant que personne internationale, est à la mesure des finalités nées des volontés souveraines convergentes des Etats. Par définition l'objet et les compétences de l'organisation n'atteignent jamais la totale compétence étatique.“
}

596 MONACO, Riccardo. Les principes régissant la structure et le fonctionnement des organisations internationales In: Recueil des Cours. Academie de Droit International de la Haye, Volume 156, 1977-III, pp. 79-226. p. 105. "In verbis": "Dans les accords instituant des organisations internationales, les objectifs poursuivis non seulement ont un caractère de continuité, mais ne peuvent souvent être atteints qu'au moyen d'une action commune exercée pour un temps indéfini. Il en est ainsi pour les organisations ayant des finalités sociales ou économiques générales, de même que pour celles poursuivant des finalités permanentes dans la domaine de la technique et de la recherche scientifique. Par exemple on pourrait mal imaginer que la Constitution de l'Unesco ait une durée limitée dans le temps, du moment que l'éducation, la science et la culture sont des exigences fondamentales de la société contemporaine qui no peuvent être promues et sauvegardées que par des activités so prolongeant indéfiniment. Naturellement les modalités selon lesquelles ces finalités peuvent être poursuivies peuvent varier avec le temps, ce qui explique que l'on doive parfois procéder à des adaptations de ces actes constitutifs par la procédure de la révision. La durée de ces actes nous amène tout naturellement à établir un parallélisme entre la constitution d'une organisation internationale et celle de l'Etat. Les constitutions nationates sont conçues dans une perspective de permanence et ne se posent aucune limite de durée. Les motifs en sont tellement évidents qu'il est inutile de les exposer.“ 
autoritária e hierárquica do direito internacional ${ }^{597}$. Historicamente, essa tem prevalecido e prosperado.

Contudo, a relativização do conceito clássico de soberania externa - com a transposição da atribuição de exercício de determinadas funções derivadas do poder estatal a associações internacionais de estados - tem em alterações constitucionais ocorridas em países europeus nítido exemplo dessa nova dinâmica observada, mormente, após a segunda grande guerra $^{598}$.

Antes mesmo, algumas constituições modernas já buscavam regulamentar a relação de poder e sua distribuição entre o estado e a ordem internacional de maneira, inclusive, extremada submetendo o poder local expressamente às normas de direito das gentes ${ }^{599}$. Os dispositivos internos que podem ser reconhecidos como de relativização da soberania externa enfrentam críticas relacionadas a sua inutilidade decorrente da desnecessidade de se estabelecer regra interna fundamentada na ordem legal externa e ao perigo de surgirem dúvidas quanto à sua exigibilidade - dentro e fora do estado ${ }^{600}$.

\footnotetext{
${ }^{597}$ WRIGHT, Quincy. The strengthening of international law. In: Recueil des Cours. Academie de Droit International de la Haye, Volume 98, 1959-III, pp. 01-295. pp. 27-28. "In verbis“: "The theory of sovereignty as commonly interpreted, together with the practical difficulty of applying democracy to govern peoples of varied culture and ideology, induces most people and governments, when they think of controls which can be effective at tine supra-national level, to think either of empire, a rule of force from the top down, or of a balance of power among States most of which are autocratically organized. The concept of authority has prevailed over that of consent in the average man's thoughts about law and government."
}

598 VISSCHER, Paul De. Les tendances internationales des constitutions modernes. In: Recueil des Cours. Academie de Droit International de la Haye, Volume 80, 1952-I, pp. 511-578. pp. 515-516. "In verbis": "Les profonds bouleversements constitutionnels que la plupart des Etats d'Europe ont connus au cours de ces dernières années, ainsi que la multiplication des instruments internationaux impliquant limitation ou délégation de souveraineté, pouvaient justifier à eux-seuls une nouvelle étude de ce sujet à la fois sous l'angle théorique et sous l'angle pratique.“

${ }^{599}$ VISSCHER, Paul De. Les tendances internationales des constitutions modernes. In: Recueil des Cours. Academie de Droit International de la Haye, Volume 80, 1952-I, pp. 511-578. p. 518. "In verbis": "Il est surprenant de constater que certaines constitutions modernes aient jugé nécessaire de proclamer le principe fondamental de la soumission de I'État au droit internationaux dans ses rapports internationaux. C'cst ainsi que la Constitution de I'Irlande du 1er juillet 1937 dispose en son article $29,3^{\circ}$ que «l'Irlande accepte les principes de droit international génralement reconnus comme règles de conduite dans ses rapports avec les autres Etats ». Le préambule de la Constitution française du 27 octobre de 1946 énonce de même que : «la République, fidèle à ses traditions, se conforme aux règles du droit public international ». La Constitution adoptée en 1947 par la Birmanie contient également un article 211 aux termes duquel : «L'Union de Birmanie... adopte les principes du droit international généralement reconnus comme règles de conduite dans ses relations avec les autres Etats ».“

${ }^{600}$ VISSCHER, Paul De. Les tendances internationales des constitutions modernes. In: Recueil des Cours. Academie de Droit International de la Haye, Volume 80, 1952-I, pp. 511-578. p. 520. "In verbis“: "En réalité, les textes constitutionnels qui proclament la soumission de l'Etat au droit international dans ses rapports interétatiques ne souffrent pas la critique juridique. Ils sont à la fois inutiles et dangereux. Inutiles, parcequ'ils énoncent une règle évidente qui trouve son fondement dans l'ordre juridique international. Dangereux, parce que leur inclusion dans la constitution interne est susceptible de créer le doute quant au fondement de cette règle et quant à l'étendue de l'obligation qu'elle implique.“" 
Ao mesmo tempo em que a soberania se vê hoje relativizada pela participação dos estados em organizações internacionais, não se pode afirmar que a ordem global tende atualmente à plena centralização do poder e à formação de um estado global. Afirmar que o estado enfrenta uma crise de identidade relacionada a sua posição no direito das gentes não significaria, assim, perda de espaço e de importância. Os estados seguem os principais atores da ordem internacional e passaram apenas a compartilhar esse espaço com outros agentes ${ }^{601}$.

Mesmo sem claramente defender a adoção da perspectiva interna de organização do poder como parâmetro à compreensão dos fenômenos internacionais, não raramente doutrinadores buscam reproduzir estruturas internas dos estados na ordem internacional aferindo identidade ${ }^{602}$.

Especificamente quanto à dinâmica do poder mundial, verifica-se que a noção de soberania exigiria nas relações entre estados necessariamente o conceito de igualdade. Sem igualdade entre esses sujeitos de direito internacional, não se poderia garantir a independência e não haveria, assim, soberania ${ }^{603}$. O caráter formal da referida igualdade não impede, entretanto, falta de isonomia na força e em seu uso.

As organizações internacionais, ao relativizarem o poder dos estados constituindo outro titular de atribuição concretiva na ordem jurídica global, regulamentaram em grande

${ }^{601}$ CAFLISCH, Lucius. Cent ans de règlement pacifique des différends interétatiques. In: Recueil des Cours. Academie de Droit International de la Haye, Volume 288, 2001, pp. 245-467. pp. 443-444. "In verbis": "La tendance à la centralisation ainsi esquissée est loin d'avoir produit un « super-Etat » sur le plan international, même là où le processus d'intégration est relativement avancé, comme c'est le cas des mécanismes de Luxembourg et de Strasbourg. La réticence des Etats à sacrifier leur « souveraineté », au sens politique de ce terme, reste vive ; on peut même estimer qu'avec le culte que lui vouent parfois des Etats nouvellement indépendants - pourquoi, en effet, abandonneraient-ils un bien si chèrement acquis ? —, cette souveraineté est, aujourd'hui, plus forte encore qu'hier. L'Etat souverain, dont on ne cesse de prédire la disparition, se porte bien, même s'il n'est plus, comme par le passé, l'unique acteur sur la scène internationale.”

${ }^{602}$ PESCATORE, Pierre. Les relations extérieures des communautés européennes : contribution à la doctrine de la personnalité des organisations internationales. In: Recueil des Cours. Academie de Droit International de la Haye, Volume 103, 1961-II, pp. 01-244. pp. 46-48. "In verbis“: "Nous venons de voir que les Communautés ont été investies d'une personnalité propre et de compétences effectives dans le domaine des relations extérieures. Ceci implique nécessairement l'existence d'organes investis du pouvoir d'exercer cette prérogative, sinon, l'attribution de ces capacités aurait peu de sens. Or, quels sont ces organes ? [...] Dans un Etat, les relations extérieures relèvent normalement de la branche exécutive ; ce serait donc à l'exécutif communautaire qu'il faudrait reconnaître le droit de représenter chacune des Communautés.“

${ }^{603}$ KOROWICZ, Marek Stanislaw. Some present aspects of sovereignty in international law. In: Recueil des Cours. Academie de Droit International de la Haye, Volume 102, 1961-I, pp. 01-120. p. 109. "In verbis": "The principle of sovereignty of States is inseparable from that of their equality. Sovereignty of a State implies its coordination with and not any subordination to other States; without coordination on the basis of equality there is subordination and, thus, no independence, i. e. no sovereignty, since independence is its integral, organic part." 
medida a relação entre os países e cada vez se mostram mais capazes de neutralizar excessos na atuação internacional dos clássicos sujeitos de direito das gentes ${ }^{604}$.

A possibilidade de exercício concretivo de direito por organizações internacionais representa, na verdade, enorme passo do direito das gentes para além da lógica da soberania estatal. A vontade comum vislumbrada como autônoma em relação a cada parte acaba gerando centralização de poder na ordem internacional e ameaça a lógica dispersiva que historicamente predominou ${ }^{605}$.

Em análise empírica do afirmado, ainda que a Assembléia Geral possa ser reconhecida como órgão mais representativo da ordem internacional, não possui poder concretivo e não constrói, portanto, direito em sentido estrito ${ }^{606}$. Mas o órgão recomenda, gera debate, produz e consolida princípios e premissas aplicáveis pelo direito internacional e possui, portanto, ao menos a semente de tal função de poder.

A secretaria geral, por outro lado, possui funções executivas - como a de execução do orçamento da organização - e a Corte Internacional de Justiça, judiciária. Na Organização das Nações Unidas, ainda que de forma absolutamente primitiva, possível se faz reconhecer o poder internacional e a semente da divisão de suas funções ${ }^{607}$.

${ }^{604}$ TRUYOL Y SERRA, Antonio. Genèse et structure de la société internationale. In: Recueil des Cours. Academie de Droit International de la Haye, Volume 96, 1959-I, pp. 553-642. p. 596. "In verbis“": "Le monde des Etats est donc un monde essentiellement mouvant. On y trouve des astres permanents à côté de météores plus ou moins durables. En un mot, le monde des Etats a été, et est encore soumis à un devenir que seul le cadre d'une organisation intematibnate efficiente pourra stabiliser."

${ }^{605}$ SØRENSEN, Max. Principes de droit international public : cours général. In: Recueil des Cours. Academie de Droit International de la Haye, Volume 101, 1960-III, pp. 01-254. p. 74. "In verbis“: "Les nouveaux modes d'élaboration de normes juridiques comportent un élément important de centralisation. La fonction créatrice est exercée par des organes internationaux qui, d'un point de vue juridique, dépassent la somme des entités constitutives, les représentants des Etats, et exercent des pouvoirs et compétences qui leur sont spécialement attribués. Il est vrai que l'ensemble des organisations internationales est loin de constituer une structure centralisée, et en est plutôt l'antinomie.“

${ }^{606}$ SØRENSEN, Max. Principes de droit international public : cours général. In: Recueil des Cours. Academie de Droit International de la Haye, Volume 101, 1960-III, pp. 01-254. p. 92. "In verbis“: "L'organe le plus représentatif dans la communauté internationale d'aujourd'hui est l'Assemblée générale des Nations Unies. Quelle est sa compétence en ce qui concerne la création de normes juridiques ? En réponse à cette question, une constatation négative s'impose en premier lieu. L'Assemblée générale n'est pas dotée de pouvoir législatif au sens propre de ce terme."

${ }^{607}$ SØRENSEN, Max. Principes de droit international public : cours général. In: Recueil des Cours. Academie de Droit International de la Haye, Volume 101, 1960-III, pp. 01-254. p. 95. "In verbis“: "Les organes exécutifs de l'organisation, tels que le Secrétaire général sont probablement tenus de donner la primauté à la norme interne, c'est-à-dire de respecter le budget. Les organes judiciaires, d'autre part, surtout la Cour internationale de Justice, sont certainement tenus d'accorder la primauté à la norme internationale proprement dite. En d'autre termes, l'Assemblée générale dans l'exercice de ses pouvoirs budgétaires ne peut pas établir des normes qui dérogent aux autres normes du droit international.“ 
Avançando-se um pouco mais na perspectiva analítica, o Conselho de Segurança observado como órgão que exerce poder no contexto global - tem sua legitimidade fulcrada no tratado constitutivo da organização, por meio do qual o conjunto de estados que compõem a iniciativa abriram mão de parcela de sua soberania claramente em favor de um grupo de estados que - de maneira permanente ou transitória e reconhecendo poder de veto ao primeiro grupo - representariam a vontade coletiva das nações.

Impossível se faz não reconhecer nessa estrutura e a partir do que se propõe nesse estudo não apenas um sistema de representatividade, fundado no direito reduzido voluntariamente a termo no tratado, mas também o exercício de funções executivas, legislativas e mesmo judiciárias pelo conselho em questão ${ }^{608}$.

Não se pode propor o uso da teoria geral do estado como uma alternativa teórica válida à compreensão da organização e da distribuição do poder na ordem internacional sem esclarecer que seus mais importantes elementos constituem resultado concretivo humano, isto é, instituições criadas pelos seres humanos para facilitar seu convívio em sociedade.

Nesse sentido, é de se perceber que entre estado, governo e território, apenas o último pode ser considerado concreto, ainda que seus limites constituam clara abstração ${ }^{609}$. No que se refere ao governo, é de se admitir que os exercentes do poder do estado, representantes da coletividade, são indivíduos, mas suas capacidades de expressar a vontade do todo são nitidamente abstratas.

\footnotetext{
${ }^{608}$ ACCIOLY, Hildebrando; NASCIMENTO E SILVA, G.E. do; CASELLA, Paulo Borba. Manual de direito internacional público. São Paulo: Saraiva, 2011. p. 440. "In verbis": "As decisões do Conselho são tomadas pelo voto afirmativo de nove dos seus membros, quando se trata de questões processuais, e pelo voto afirmativo de nove membros, com a inclusão, entre estes, de todos os membros permanentes em todos os outros assuntos. Essa exigência do voto afirmativo de todos os membros permanentes do Conselho é o reconhecimento do chamado 'direito de veto', de qualquer deles contra a maioria, ou até a unanimidade dos demais. O uso abusivo do direito de veto paralisou durante longos anos o Conselho e acabou por enfraquecê-lo com o conseqüente fortalecimento da Assembléia Geral, que passou a opinar naqueles assuntos em que o Conselho de Segurança não conseguia alcançar uma solução. Deve abster-se de votar o membro do Conselho que for parte numa controvérsia prevista no Capítulo VI da Carta das Nações Unidas ('controvérsia que possa vir a constituir uma ameaça à paz e à segurança internacionais') ou numa controvérsia de caráter local, a respeito da qual o Conselho deva tomar alguma resolução, nos termos da alínea $3^{\text {a }}$ do artigo 52 da dita Carta. Qualquer membro das Nações Unidas que não for membro do Conselho poderá tomar parte, sem direito de voto, na discussão de qualquer questão submetida ao Conselho, se este considerar que os interesses do referido membro se acham, especialmente, em jogo."
}

${ }^{609}$ HENKIN, Louis. International law : politics, values and functions : general course on public international law. In: Recueil des Cours. Academie de Droit International de la Haye, Volume 216, 1989-IV, pp. 09-416. p. 23. "In verbis": "The State is an abstraction, a conception. In relations with other States, a State is represented by a Government, also an abstraction, a conception. Governments are represented by human beings, who are not a conception, but as officials they act in a representative capacity, and representation is also an abstraction, a conception." 
Admitir essa característica dos institutos principais da teoria geral do estado não afeta a possibilidade de seu uso pelo direito internacional para suas instituições. Afinal, além do estado, organizações internacionais, soberania externa, nação e vários outros institutos de direito das gentes são notadamente abstratos.

Também a forma como ocorre a produção normativa do direito das gentes se difere bastante do contexto das ordens jurídicas internas. A falta de órgãos centralizados com atribuições concretivas promoveu, por exemplo, no início do século XX evolução da ordem extralocal muito mais em razão de decisões judiciais e arbitrais que da codificação propriamente $^{610}$. A concreção feita no momento da extração da normatividade não constitui, portanto, algo novo no direito internacional ${ }^{611}$. Logo na primeira década de sua criação, a então Corte Permanente de Justiça já era reconhecida como importante fonte criativa do direito das gentes ${ }^{612}$.

No que se refere à organização do poder, a idéia de aplicação da teoria da separação de funções da teoria do estado no direito internacional não se faz inédita. Internacionalistas já levantaram tal hipótese, mas estudos do tipo - que partem da centralidade do poder na esfera interna - sempre esbarram em sua dispersão no direito das gentes ${ }^{613}$.

${ }^{610}$ GARNER, James W.. Le développement et les tendances récentes du droit international. In: Recueil des Cours. Academie de Droit International de la Haye, Volume 35, 1931-I, pp. 605-720. p. 662. "In verbis“: "Il est généralement reconue que la jurisprudence des tribunaux judiciaires, et surtout celle des tribunaux internationeux, sont des sources importantes du droit international.“

${ }^{611}$ GARNER, James W.. Le développement et les tendances récentes du droit international. In: Recueil des Cours. Academie de Droit International de la Haye, Volume 35, 1931-I, pp. 605-720. p. 661. "In verbis": "Quelque les additions les plus notables au corps du droit international, surtout dans ces dernières années, aient été faites par le moyen de ce que j'ai dénommé la « législation internationale », l'importance de la contribution des tribunaux judiciaires et arbitraux n'en a pas moins été appréciable et progresse d'une façon continue. En fait, il ne manque pas de juristes éminents pour croire que le dévelopement du droit international devrait être confié pour la plus grande mesure aux tribunaux plutôt qu'à la méthode de codification, à peu près comme le droit, commun de l'Anglaterre et des Etats-Unis a été développé par leurs tribunaux nationaux“

612 GARNER, James W.. Le développement et les tendances récentes du droit international. In: Recueil des Cours. Academie de Droit International de la Haye, Volume 35, 1931-I, pp. 605-720. p. 671. "In verbis“: "Les juristes qui ont étudié la jurisprudence de la Cour permanente, sont unanimes à reconnaître que la Cour a déjà fourni une notable contribution au dévéloppement du droit international, soit par les arrêts qu'elle a rendus, soit par les avis consultatifs qu'elle a donnés depuis son inauguration en 1922.“

613 MONACO, Riccardo. Les principes régissant la structure et le fonctionnement des organisations internationales In: Recueil des Cours. Academie de Droit International de la Haye, Volume 156, 1977-III, pp. 79-226. pp. 110-111. "In verbis“": "Ce vide pourra être comblé lorsque s'affirmeront, par analogie avec le système juridique de l'Etat, également dans la sphère des organisations internationales les plus évoluées, des coutumes de caractère constitutionnel, ou, tout au moins, des règles sur la bonne conduite des organes, qui remplissent la même fonction que celle qu'ils ont dans l'ordre constitutionnel interne. On pourrait en outre se demander dans quelle mesure le principe de la division des pouvoirs serait ici utilisable. Il faut reconnaître que, en ce qui concerne les organisations internationales, la situation est autre que celle de l'ordre étatique. En effet, au sein des organisations internationales les attributions des organes constitutionnels ne sont presque jamais rigoureusement définies : ainsi l'organe parlementaire -1à où il existe - se borne à être un organe 
A identificação na estrutura de organizações internacionais do exercício de funções típicas do poder estudado pela teoria geral do estado enfrenta, contudo, forte resistência doutrinária. As negativas costumam sublinhar que esses arranjos não possuem soberania e que seu poder, portanto, se reduziria tão somente a uma extensão da soberania dos estados que deles são membros. Em organizações intergovernamentais, como o MERCOSUL, por exemplo, essa ausência de poder autônomo do sistema internacional apresenta-se de forma muito clara, mas em estruturas realmente supranacionais, como a da União Européia ${ }^{614}$, a vontade dos estados já se mostra bastante limitada pelo interesse comum e possível se faz reconhecer um poder internacional descolado das unidades soberanas ${ }^{615}$.

d'orientation politique générale et n'exerce pas sa fonction typique, qui est cette de créer des normes juridiques. De même, les organes qui se présentent comme exécutifs ou de gouvernement exercent souvent des fonctions de réglementation qui touchent parfois au domaine de ia production juridique et suppléent ainsi au manque d'organes juridictionnels proprement dits. C'est pourquoi, lorsque l'on doit examiner les problèmes de la coexistence et de la coordination des organes dans le cadre des organisations internationales, on ne peut pas procéder sur la base des grandes catégories qui sont liées au principe de la division des pouvoirs. Il est par contre plus aisé de tenir compte de la division des compétences car, dans la plupart des cas, les organes se caractérisent en fonction des attributions qui leur sont confiées."

${ }^{614}$ OREJA AGUIRRE, Marcelino. La révision institutionnelle de l'Union européenne. In: Recueil des Cours. Academie de Droit International de la Haye, Volume 267, 1997, pp. 345-386. p. 363. "In verbis“: "La Conférence a, certes, pu dégager des principes constitutionnels significatifs qui laissent entrevoir un haut degré d'unité politique, extrêmement plus important que celui qui existe actuellement. En revanche, elle n'a pas tiré les conséquences qui auraient permis de renforcer le caractère politique du système institutionnel de l'Union afin de la préparer à son élargissement. D'une certaine manière, les Etats semblent avoir compris que l'élargissement de l'Union et le développement de ses compétences exigent des règles constitutionnelles communes qui, nécessairement, conduisent à une limitation du poids individuel de chaque Etat dans le système institutionnel. Cependant, ils ont préfiguré un système de plus en plus complexe et, dans des domaines essentiels - tels que les mesures qui accompagnent la liberté de circulation, la lutte contre la discrimination ou la fiscalité et la sécurité sociale —, complètement bloqué par le vote à l'unanimité. Parfois, les domaines protégés semblent répondre plus à des pressions de lobbies qu'à des questions de souveraineté ou d'intérêts nationaux. Il nous faut examiner maintenant les principes qui ont été introduits dans le Traité et quelques problèmes relatifs à la confirmation du principe de la liberté de circulation."

${ }^{615}$ ZEMANEK, Karl. The legal foundations of the international system: general course on public international law. In: Recueil des Cours. Academie de Droit International de la Haye, Volume 266, 1997, pp. 09-335. pp. 97-98. "In verbis": "When one refers to the "powers" of international organizations one uses the word in a specific legal sense, not in the sense of its general use. International organizations do not have real power since they lack the resources which are the origin of power. Their "power" is (legal) authority and limited authority at that, as indicated by Article 2 (7) of the Charter which safeguards the domestic jurisdiction of member States. [...] As a general rule, international organizations may bind their members only in institutional and budgetary matters 284 . Authority to adopt decisions which the members of the organization are required to apply in relations among themselves or in their relations with nonmembers, like that of the Security Council when acting under Chapter VII of the Charter 285 or that of the Council of the EC pillar of the EU, is an exception. Usually, organizations address only recommendations to member States which the latter are free to follow, though such recommendations may have a strong pervasive or even legitimizing effect: system partners may be stopped to claim the illegality of the conduct of other system partners who implement a recommendation. This creates a delicate problem when the recommended conduct would violate international customary or treaty rights of other States, for instance through economic sanctions. This problem will be examined in the context of inter-source relations." 
A transposição de estruturas internas de estados às organizações internacionais repercute não apenas na identificação de órgãos dotados de atribuições legislativas, mas também na construção de estruturas de controle, por exemplo, jurisdicional. A institucionalização desses sujeitos de direito internacional tende claramente a assemelhar a distribuição de poder que se organiza internamente com o modelo adotado pelos estados, por exemplo, no que se refere à separação de suas funções ${ }^{616}$.

De uma forma ou de outra, o uso da teoria do estado para a compreensão do direito das gentes não exige que se reconheça, por exemplo, poder análogo ao dos estados na atuação das organizações internacionais. Trata-se de uma proposta para a compreensão do sistema e não para a reprodução de uma estrutura na outra.

Nessa comparação da dinâmica do poder interno dos estados com aquela da ordem internacional verifica-se, na verdade, que enquanto toda a estrutura estatal instrumentaliza sua concentração, no direito das gentes o poder tende a se organizar cooperativamente ${ }^{617}$. Tratamse de movimentos distintos aplicáveis à organização do poder e que inviabilizam perspectivas de identidade dos mesmos.

O quadro institucional de organizações internacionais - no conceito adotado neste estudo, muito claramente - permite que se identifiquem órgãos internos dotados de funções executiva, legislativa e judiciária ${ }^{618}$. Nada impede que o mesmo órgão, quando a estrutura

616 REUTER, Paul. Principes de droit international public. In: Recueil des Cours. Academie de Droit International de la Haye, Volume 103, 1961-II, pp. 425-656. p. 522. "In verbis“: "On devrait par exemple examiner si les notions communément admises pour les fonctions étatiquaes sont transposables aux organisations internationales et suffisent aux besoins de l'analyse juridique en ce qui les concerne. Ainsi divers droits nationaux ont une théorie de la fonction législative, parfois opposée à la fonction réglementaire ; dans quelle mesure peut-on élaborer sur la base des principes généraux du droit une théorie analogue en matiére d'organisations? Dans quelle mesure ne faut-il pas élaborer une notion de «contrôle» ou encore d' «administration indirecte» qui serait propre aux organisations internationales et qui définirait les relations assez particulières que celles-ci entretiennent avec les administrations nationales ? [...] D'une manière tout à fait générale et dans le prolongement de ce que l'on a dit plus haut concernant les compétences de l'Etat, toutes les compétences des organisations sont étroitement spécifiées par leur but, par le service à rendre. Ceci implique que lorsque leur exercice est soumis à contrôle juridictionnel, le respect du but soit un élément intégrant de leur validité.“

${ }^{617}$ VIRALLY, Michel. Panorama du droit international contemporain : cours général de droit international public. In: Recueil des Cours. Academie de Droit International de la Haye, Volume 183, 1983-V, pp. 09-382. p. 251. "In verbis": "Par la constitution d'organisations internationales, l'ordre juridique intemational démontre son aptitude (qui avait été mise en doute) à remplir la fonction d'organisation inhérente à tout ordre juridique, même si la façon dont il s'en acquitte est très différente de celle des ordres juridiques étatiques, en ce qu'elle est orientée précisément vers le développement de la coopération et non pas vers la concentration du pouvoir."

618 MONACO, Riccardo. Les principes régissant la structure et le fonctionnement des organisations internationales In: Recueil des Cours. Academie de Droit International de la Haye, Volume 156, 1977-III, pp. 79-226. p. 185. "In verbis“: "Bien que ces conceptions soient fondées sur des justifications théoriques différentes et bien que les formules qu'elles emploient semblent assez éloignées entre elles, il faut reconnaître qu'elles se rapprochent beaucoup quant au résultat. Par exemple, bien que le jeu des trois pouvoirs ou fonctions s'exerce dans l'ordre international d'une façon différente de celle propre au droit étatique, il est bien sûr que 
institucional da associação ainda se mostra rudimentar, assuma mais de uma função, mas a solução de controvérsias - isto é, a função judiciária - constituiria exigência do próprio reconhecimento da organização como sujeito de direito das gentes dotado de atribuições conferidas inicialmente apenas aos estados.

De certo, o estado de direito vem desde o século XVIII, ao lado dos princípios liberais do Iluminismo, sendo utilizado pelos juristas como paradigma conceitual aplicável à sociedade internacional, a qual tende a ser percebida de forma análoga ao domínio jurídico interno de um país. Essa analogia tende claramente à estruturação e à justificação do direito internacional como uma ordem jurídica una, dotada de objetividade não constatável nas idéias, preferências e visões políticas e que seria hábil a produzir, portanto, normas gerais, abstratas e pretensamente universais.

O abandono do plano teórico da teoria do estado e sua substituição por propostas que defendam a fragmentação e contradigam preceitos fundamentais da teoria do direito - como ordenação e unidade - representaria, assim, o abandono do próprio direito e a produção acadêmica resultante desse processo investigativo não seria, portanto, jurídica. Não se está afirmando aqui que esse constituiria único parâmetro doutrinário aplicável ao direito internacional, mas, no entanto, que o abandono da teoria do direito em decorrência de rejeição dos esquemas teóricos aplicados ao estado aproximaria os estudiosos da política e não serviria de alternativa ao direito.

Extremamente relevante se faz ressaltar, uma vez mais em razão da importância de tal observação, que o uso das teorias estatais de organização do poder para a compreensão do direito internacional não significaria necessariamente a reprodução de institutos e modelos internos no plano geral ${ }^{619}$. Não se trata de exigir do direito das gentes as estruturas internas de

dans toute organisation internationale complexe on retrouve des organes qui exercent la fonction normative, d'autres organes qui doivent établir quel est, dans le cas d'espèce, l'état du droit et enfin des organes auxquels est confiée la tâche de réaliser le droit par des moyens coercitifs. Cela dit, on pourrait même affirmer que les fonctions précitées tendent à organiser le système normatif qui réunit l'ensemble des normes internationales, en lui donnant un caractère stable et unitaire ainsi qu'une conformation organique. Mais tout cela serait acceptable si les fonctions qu'on vient de mentionner n'existaient pas dans la plupart des organisations internationales et si, par conséquent, il faudrait, dans chaque cas, faire appel aux fonctions propres à l'ordre international tout entier."

${ }^{619}$ WEIL, Prosper. Le droit international en quete de son identité : cours général de droit international public. In: Recueil des Cours. Academie de Droit International de la Haye, Volume 237, 1992-VI, pp. 09-370. p. 55. "In verbis": "Il n'est certes pas illégitime de se faire du développement d'un système juridique une représentation quasi organique qui, partant d'une racine un peu fruste, subirait une lente maturation le rendant de plus en plus complexe, élaboré et sophistiqué. Ce qui est critiquabte, c'est le postulat selon lequel le droit interne constituerait l'étalon de référence qui permetterait d'évaluer le niveau de développement atteint par le système international. Un système juridique, une institution, une règle donnée ne sont pas bons ou mauvais selon qu'ils s'approcheraient plus ou moins d'un modèle idéal, mais selon qu'ils remplissent plus ou moins efficacement les fonctions qui sont les leurs dans un environnement social donné. Le droit international est appelé à régir une 
um estado, mas da utilização das mesmas como instrumento que auxilie o amadurecimento da ordem internacional.

A comparação da distribuição do poder no plano interno de um estado com aquela da ordem internacional é não apenas possível, mas apropriada. Pode-se compreender melhor a organização da vida global quando se lança mão das teorias que explicam tal dinâmica em sociedade organizada específica ${ }^{620}$.

A sinergia entre a teoria geral do estado e o direito internacional não configura uma mera proposta. Trata-se de fato. Conforme salientado anteriormente, a aversão dos internacionalistas ao estado, mais propriamente às concepções extremadas de seu poder soberano, afastaram o direito das gentes dos conceitos fixados pela teoria geral do estado. Tudo isso, ressalte-se, sem que o estado tenha perdido seu caráter de sujeito internacional por excelência.

Defende-se aqui, por exemplo, que institutos da teoria geral do estado se fazem plenamente aplicáveis à compreensão das estruturas internas de poder das organizações internacionais. As teorias que buscam compreender a distribuição do poder no estado se aplicam, na verdade, plenamente ao entendimento da ordem global como um todo, ainda que nela o poder se encontre eminentemente descentralizado.

A teoria geral do estado não apenas explica a organização do poder pelo direito, mas também viabiliza o direito. Trazer a teoria geral do estado definitivamente de volta ao direito

société fondamentalement différente de la société étatique interne ; ses fonctions sont spécifiques aux besoins de cette société. Dès lors, l'écart aussi bien que le rapprochement du système international avec le modèle du droit interne sont dépourvus de pertinence.“

${ }^{620}$ DUPUY, Pierre-Marie. L'unité de l'ordre juridique international : cours général de droit international public. In: Recueil des Cours. Academie de Droit International de la Haye, Volume 297, 2002, pp. 09-489. p. 216. "In verbis": "Dans l'ordre interne, la constitution est une loi à portée générale, par définition applicable à tous, à l'intérieur de l'ordre juridique qu'elle organise. Or, quant à elle, la Charte des Nations Unies n'est jamais qu'un traité, obéissant au principe de l'autorité relative. Fûtce au titre de pure métaphore juridique, l'usage du terme de constitution n'est-il pas, dès lors, parfaitement inapproprié à la réalité persistante d'une décentralisation de pouvoirs placés par leur égale souveraineté dans la position d'éternels rivaux ? Enfin, que l'on se tourne vers l'histoire du « constitutionnalisme », à partir de l'exemple britannique, puis des façons bien différentes dont les révolutions américaine et française s'en sont inspirées, avant de servir elles-mêmes de références à tant d'institutions ultérieures à travers le monde, et l'on constatera que deux idées au moins se trouvent idéalement mêlées à l'idée de constitution : d'une part, celle de limitation imposée aux pouvoirs des détenteurs de la puissance publique (y compris le pouvoir législatif); d'autre part, et par voie de conséquences, celle de garanties minimales offertes aux gouvernés face aux gouvernants. On mesure ainsi la difficulté qu'il peut y avoir à adapter ces schémas à une société internationale caractérisée par la violence et l'insubordination du pouvoir, dans un monde en principe réduit, du moins dans la tradition positiviste classique, à la dimension interétatique. Accepter d'examiner la thèse constitutionnaliste, attachée à la Charte ou à l'ordre juridique international dans son ensemble, ne peut, dès lors, se faire qu'au prix d'une révision drastique des fondements classiques de cet ordre.“ 
internacional poderia significar, nesse contexto e na verdade, o resgate definitivo do próprio direito no direito internacional. 


\section{A FUNÇÃO JURISDICIONAL COMO FERRAMENTA DA UNIDADE DO DIREITO INTERNACIONAL}

Conflitos são inerentes à convivência humana. Essa máxima se aplica tanto entre os seres humanos quanto à relação entre estruturas de poder criadas para organizar a vida em sociedade - os estados. Conflitos não constituem, contudo, algo intrinsecamente ruim. Um litígio pode interferir em seu contexto fático e provocar mudanças importantes no status $q u o^{621}$.

Sob tais premissas, percebe-se que a multiplicação de sistemas internacionais de solução de controvérsias tem desencadeado relevantes processos que implicam mudanças de concepção do direito das gentes. Os limites da atuação jurisdicional estão sendo constantemente testados na atualidade e a abstração que durante anos era considerada um dado do direito internacional aproximou-se dos casos concretos. Por meio das controvérsias o sistema progride e se constrói ${ }^{622}$.

A adoção de meios jurisdicionais - mormente arbitrais - para a solução de diferendos internacionais não se circunscreve aos períodos moderno e contemporâneo. Antecedentes

\footnotetext{
${ }^{621}$ RIVAROLA PAOLI, Juan Bautista. Derecho internacional público. Asunción: Ediciones y Arte, 2013. p. 719. "In verbis": "El conflicto es necesario para el cambio, pues permite la adaptación a nuevas situaciones y da la capacidad de auto transformarse. En consecuencia, se debe tener presente que lo único permanente es el cambio. Lo que se necesita para que el conflicto dé su parte positiva sin que degenere en una confrontación abierta, es que se logre institucionalizarlo. Es se establezcan reglas claras del cómo se dirimen y se resuelven las controversias, expresa Maúrtua de Romaña. Es deber de todos los Estados-expresa Gamboa-, y en general de los sujetos del Derecho de Gentes, evitar que por controversia entre ellos pueda originarse una guerra. Todo el sistema mundial actual de la sociedad internacional persigue el mantenimiento de la paz y la seguridad internacional. Así se ha manifestado solemnemente en la Carta de las Naciones Unidas en San Francisco, California, en el año 1945. A través de la historia, los pueblos, han ideado diversos sistemas para evitar que una controversia entre ellos pueda originar un estallido bélico. Estos sistemas tienen diversos caracteres, según sea el modus operandi y según sea el origen de la controversia. Tendremos así medios de solución pacifica de las controversias de carácter diplomático-político según que el origen de ella sea netamente político o susceptible de solución por esta vía ; o jurídico, si la controversia emana de una interpretación de un texto (tratado, convención, estatuto, etc.) o es hecho por un Tribunal de Derecho (arbitral o Tribunal de Justicia) y, finalmente, de carácter coercitivo, pero que no implica una guerra propiamente tal, cuando se ejecutan determinados actos para obligar a un estado a cumplir con sus deberes internacionales."

${ }^{622}$ CLAPHAM, Andrew. Brierly's law of nations. Oxford: Oxford University Press, 2012. p. 65. "In verbis": "There was originally only a restricted scope for the operation of this tendency in international law, for the practical reason that since international adjudications were relatively few reports were not readily accessible. This is rapidly changing due to the proliferation of tribunals and ease of access to their rulings though the internet. Judicial decisions are raking their proper place in the system. The change is a wholly beneficial one; it is creating for international law a vast stock of detailed rules, testing abstract principles against their capacity to solve practical problems, and depriving international law of its rather academic character.“
} 
históricos importantes da solução pacífica de litígios podem ser identificados, por exemplo, na idade média e mesmo na antiguidade ${ }^{623}$.

Atualmente, a jurisdicionalização da sociedade internacional por meio da multiplicação de meios institucionalizados para a solução de controvérsias constitui fenômeno crescente e denuncia claramente o maior comprometimento dos estados com a paz promovida pelo direito ${ }^{624}$. Se, por um lado, no entanto, a função jurisdicional constitui a esfera internacional que mais se desenvolveu nas últimas décadas, quando, por outro lado, observase a evolução da ordem jurídica mundial como um todo, foi ela a que mais lentamente progrediu $^{625}$.

De se resgatar faz-se, nesse ponto, necessário o entendimento justificado em detalhes anteriormente de que "jurisdição" - ou "jurisdicionalidade" - se referiria à possibilidade de

${ }^{623}$ TAUBE, Michel de. Les origines de l'arbitrage international : antiquité et Moyen Age. In: Recueil des Cours. Academie de Droit International de la Haye, Volume 42, 1932-IV, pp. 01-115. p. 05. "In verbis“: "Parmi les «découvertes » scientifiques qu'un futur historien de la science du droit international aux xix et xx siècles pourra enregistrer dans ses écrits, on doit certainement compter la constatation, faite depuis quelques dizaines d'années par certains érudits, que la pratique de l'arbitrage international (dont ces deux derniers siècles pouvent être liers à juste titre) est loin d'être le résultat des progrès de la civilisation moderne. Bien au contraire, à force d'étudier dans ses détails l'histoire des relations internationales, on est arrivé la conviction que la pratique arbitraie dans ce domaine peut se glorifier de précédents aussi intéressants que nombreux, et cela non seulement dans ce qu'on appelle l'histoire nouvelle, mais encore à l'époque du Moyen Age et même dans l'Antiquité, - surtout dans l'Antiquité hellénique.“

${ }^{624}$ MENEZES, Wagner. Tribunais internacionais: jurisdição e competência. São Paulo: Saraiva, 2013. p. 142. "In verbis": "A jurisdição internacional dos Tribunais Internacionais é o poder a eles conferido pelos Estados para dirimir, à luz da justiça e dos ideais do direito, suas controvérsias decorrentes do sistema de princípios, regras e normas internacionais e a ser um instrumento para a pacificação entre estados e povos, a ser um instrumento para a paz mundial. Nesse contexto, a jurisdicionalização da sociedade internacional pode ser definida, então, como o crescente comprometimento da sociedade internacional com a adoção de mecanismos jurídicos para solucionar as controvérsias e com a produção de um conjunto de regras e para garantir a sua aplicação. Resulta daí a criação de Tribunais Internacionais para julgar essas matérias, consubstanciada no aparelhamento sistemático de esquemas de solução de controvérsias e regras preestabelecidas, tendo como objetivo principal o primado do direito para a manutenção da paz e da ordem internacionais. Esse fenômeno se corporifica na transferência de poder a Tribunais estabelecidos com base na vontade criadora dos Estados, pelo qual esses estipulam um conjunto de regras a serem observadas e se autossubmetem a um poder decisório de uma corte, baseado no direito e nos ritos judiciários, tendo como corolário fundamental a realização efetiva da justiça. Além disso, os Tribunais se organizam em termos de funcionamento a partir da assinatura de um estatuto que define seu regimento e a extensão das regras que compõem o exercício de sua jurisdição."

${ }^{625}$ BOBBIO, Norberto; MATTEUCCI, Nicola; PASQUINO, Gianfranco. Dicionário de política - Vol. 2. Brasília: Editora Universidade de Brasília, 2010. p. 861. "In verbis": "Uma função que teve um particular desenvolvimento nas mais recentes manifestações das organizações internacionais foi a jurisdicional. $\mathrm{O}$ surgimento desta função foi assaz lento, devido, entre outras razões, à resistência tradicionalmente oposta pelos Estados à instituição de órgãos judiciários com competência para julgar os seus atos, mesmo que apenas dentro de um contexto especifico. A atribuição de poderes judiciários é particularmente ampla e eficaz em algumas organizações internacionais, como, por exemplo, o Conselho da Europa, em cujo âmbito, conquanto restrito à Convenção Européia dos Direitos do Homem, foram instituídas uma Comissão e uma Corte, perante as quais se desenvolve um efetivo 'processo' que, passando pelas fases de instrução e decisão, termina com uma sentença obrigatória e vinculadora. Um exemplo ainda mais eficaz, embora até hoje único, é o que nos oferecem as comunidades européias cuja estrutura compreende a Corte de Justiça, criada como juiz permanente, com competência exclusiva no âmbito do ordenamento comunitário.” 
determinada questão ser apreciada em termos jurídicos por um sistema jurisdicional de solução de controvérsias e de que, portanto, não caberia fazer referência à jurisdição interna e internacional, mas, na verdade, a distintas competências ${ }^{626}$.

Nesse sentido, o direito brasileiro interno, por exemplo, sempre esteve comprometido com a solução pacífica de controvérsias na esfera internacional. Tal afirmação não encontra respaldo apenas no resultado histórico da solução majoritariamente pacífica de litígios de fronteira, mas também na alusão feita pelas constituições nacionais às formas não beligerantes de concórdia ${ }^{627}$. Se o direito local se habilita a regulamentar questões do poder internacional, o mesmo não se pode afirmar plenamente acerca do poder judiciário interno de um país. Com todas as limitações hoje observáveis, o exercício jurisdicional de questões de direito das gentes cabe, em regra e tipicamente, a sistemas de solução de controvérsia internacionais.

Os tribunais internacionais nunca estiveram, de fato, no centro da ordem jurídica internacional, protagonizada em regra pelos estados, mas tais cortes desempenham importante papel no desenvolvimento do direito e tal importância tende a aumentar à medida em que o sistema jurídico se institucionaliza e aperfeiçoa ${ }^{628}$.

\footnotetext{
${ }^{626}$ A doutrina não é uníssona nesse sentido e, muitas vezes, faz uso irrestrito desses termos sem estabelecer conteúdo preciso para diferenciação. Nesse sentido, PODESTÁ COSTA, L.A. Derecho internacional público tomo II. Buenos Aires, Tipográfica Editora Argentina, 1955. p. 30. "In verbis": "Para determinar la competencia parecería viable consignar en el tratado una enumeración taxativa de las cuestiones arbitrables; pero esta fórmula resulta insuficiente dada la imposibilidad de hacer una enumeración que sea a la vez clara y exhaustiva. Y, si hubiera de adoptarse el método de las exclusiones, preferible sería la fórmula que hemos llamado dinamarquesa - que no es sino una evolución de la fórmula argentina -, según la cual se excluyen del arbitraje institucional solamente 'las cuestiones que correspondan a la jurisdicción local de los tribunales judiciales o administrativos'. No difiere substancialmente de ésta, aunque expresada en otros términos, la fórmula introducida en los tratados más recientes, que consiste en someter al arbitraje 'todas las cuestiones con excepción de las que correspondan a la jurisdicción interna del Estado'; pero esta, fórmula tropieza con una dificultad, porque no se ha encontrado otro recurso, para precisar aquella jurisdicción, que limitarla a los casos en que ella sea 'exclusiva' o sea 'esencial', y la verdad es que el alcance de estas calificaciones resulta obscuro."
}

${ }^{627}$ TIBURCIO, Carmen; BARROSO, Luís Roberto. Direito constitucional internacional. Rio: Renovar, 2013. p. 32. "In verbis": "O compromisso do país com a paz é reiterado com a referência expressa ao princípio da solução pacífica dos conflitos em seguida ao que determina a defesa da paz. Os meios pacíficos de solução de controvérsias são as negociações diplomáticas; bons ofícios; investigação; conciliação; regime de consulta; solução judiciária e arbitragem e as decisões de organismos internacionais. Sugere a doutrina que a solução pacífica dos conflitos significa, para o Brasil, comprometimento "não só com as soluções não-violentas, mas, também, com as soluções que se eximam de qualquer traço de coação". Implícita ou expressamente, a solução pacífica dos conflitos sempre integrou o texto constitucional, como apontado. Ainda que nas Constituições de 1891 e 1934 não tenha havido expressa menção ao princípio, pode-se considerá-lo implícito nesses textos por força da previsão de recurso à arbitragem como passo anterior necessário à declaração de guerra. Atualmente, o princípio é trazido já no preâmbulo do texto constitucional e se desdobra em mandamento do artigo 21 , XXIII, a, também da constituição [...]"

${ }^{628}$ CHARNEY, Jonathan I.. Is international law threatened by multiple international tribunals? In: Recueil des Cours. Academie de Droit International de la Haye, Volume 271, 1998, pp. 101-382. p. 117. "In verbis": "Throughout the history of international law, courts and other tribunals have never been at the centre of the international legal system, nor have they played the most important role in forming and developing 
O reconhecimento de decisões de tribunais ou de estruturas arbitrais como fonte de direito internacional, além de se encontrar hoje disseminada de forma consolidada, já foi devidamente assentada em tratados internacionais como, por exemplo, no Estatuto da Corte Internacional de Justiça em seu artigo $38^{629}$. Dentre os serviços prestados, elenca-se a afirmação - tímida, mas recorrente - promovida por órgãos jurisdicionais internacionais tribunais ou cortes arbitrais - da prevalência do direito das gentes em relação ao direito interno dos estados ${ }^{630}$.

A formação de tribunais internacionais, principalmente ao longo do século XX, trouxe consigo a definitiva institucionalização do direito internacional. Trata-se, na verdade, de elemento do processo de reconhecimento do direito extraestatal como direito em razão de apenas poder ser reconhecida uma ordem normativa quando meios à solução de divergências entre aqueles que a ela se submetem se encontram disponíveis ${ }^{631}$.

A referida institucionalidade não significou consolidação ampla do acesso de indivíduos a esses meios jurisdicionais comuns. Apenas excepcionalmente, na verdade, pode o indivíduo reclamar a lesão de direitos por organização internacional de forma direta no direito das gentes. Essa atribuição ainda se restringe, mormente, aos estados em representação de seus nacionais ${ }^{632}$.

international law. The centre of gravity in international law is the State. Nevertheless, third party dispute settlement forums also play important roles."

${ }^{629}$ A doutrina resiste bastante à interpretação da jurisprudência definitivamente como fonte de direito internacional. Reconhecem-se, recorrentemente, aos precedentes a característica de "meio auxiliar para determinação de regras de direito", conforme estabelecido literalmente no referido tratado. Entende-se, neste trabalho e contudo, já haver sido superado o momento de que tal entendimento seja modificado.

${ }^{630}$ Citando, na prática arbitral, os casos "Alabama" - 1872, "Montijo“ - 1875 - e "Georges Pinson - 1928 - e, na prática judiciária, o caso da Corte Permanente de Justiça Internacional "Tratamento dos nacionais poloneses em Danzig“ e os casos do Tribunal de Justiça das Comunidades Européias "Costa c. Enel" - 1964 - e "Lynne Watson“ - 1976, CARREAU, Dominique. Droit international. Paris: Pedone, 1986. p. 42. "In verbis": "Ce principe de supériorité signifie que le droit international (c'est-à-dire tout le droit international positif et pas seulement les traités) l'emporte sur l'ensemble du droit interne, qu'il s'agisse des normes constitutionnelles, législatives, réglementaires ou des décisions judiciaires. Ce principe et sa portée ont été affirmés et précisés maintes fois par l'arbitre et le juge international.“

${ }^{631}$ MENEZES, Wagner. Tribunais internacionais: jurisdição e competência. São Paulo: Saraiva, 2013. p. 75. "In verbis": "De qualquer forma, a vigência da Corte tem seu mérito, pois a partir de sua existência e labor é que se consolida na sociedade internacional a idéia da atribuição a uma instituição de jurisdição para decidir litígios entre Estados sob o imperativo do Direito, voltado especificamente para sua consolidação, garantia e eficácia."

${ }^{632}$ SØRENSEN, Max. Principes de droit international public : cours général. In: Recueil des Cours. Academie de Droit International de la Haye, Volume 101, 1960-III, pp. 01-254. p. 143. "In verbis“: "Il est toujours exceptionnel, qu'un individu puisse saisir un organe international d'une plainte à l'occasion d'un acte contraire au droit international. Abstraction faite de ces exceptions le principe est toujours que c'est l'Etat qui doit prendre fait et cause pour ses ressortissants qui sont lésés par un acte contraire au droit international.“ 
Conforme mencionado, multiplicam-se atualmente os sistemas de solução de controvérsias na ordem internacional. Mais que uma conquista quantitativa, o grande número de meios jurisdicionais institucionalizados denota processo de paulatino aperfeiçoamento do direito das gentes nas esferas local e multilateral ${ }^{633}$.

A América Latina sempre foi pioneira no direito internacional. Esse pioneirismo se refletiu na adoção de meios pacíficos de solução de controvérsias para resolver diferendos entre os estados ${ }^{634}$. Já durante o Congresso do Panamá de 1826 a arbitragem surgiu como complemento indispensável à comunidade internacional ${ }^{635}$. Ainda no plano regional latinoamericano, o primeiro exemplo mundial de tribunal de justiça com jurisdição sobre estados

${ }^{633}$ JENNINGS, R.Y.. General course on principles of international law. In: Recueil des Cours. Academie de Droit International de la Haye, Volume 121, 1967-II, pp. 323-605. pp. 588-589. "In verbis“: "The procedures actually available for the pacific settlement of disputes are rich in their variety. Apart from the International Court of Justice, with its contentious and advisory jurisdiction, there are many other established tribunals for the adjudication or conciliation of particular classes of dispute. There are of course the organs of regional political organizations; the inter-American system; the African Connection of Mediation, Conciliation and Arbitration; the European Communities Court; the European Commission of Human Rights and the Court of Human Rights. There is also the Permanent Court of Arbitration with its settled procedure and standing secretariat; and the European Convention for the Settlement of International Disputes. There are also tribunals either standing or in some cases to be set up ad hoc attached to bilateral agreements for arbitration and conciliation. There are very many tribunals provided for in particular treaties. There are tribunals ad hoc, including Claims Tribunals which have been set up from time to time by governments for disposing of particular classes of case. There is the Convention of the International Bank of Reconstruction and Development for the Settlement of Investment Disputes, which at the time of writing has been signed by 52 States and ratified by 32 . There are the specialist tribunals of various kinds which form part of the specialized agencies of the United Nations or other international organizations dealing with particular topics: the Council of the International Civil Aviation Organization, or the machinery for dealing with disputes which forms part of the General Agreement on Tariffs and Trade and so on. The specialized agencies of the United Nations have of course themselves the power, as a result of authorization by the General Assembly, of asking the International Court of Justice for an advisory opinion on a matter which falls within the competence of the Organization. Institutional machinery for dealing with disputes in the large sense is also a characteristic of some regional economic organizations which are themselves legion: e.g., the Organization for Economic Cooperation and Development, the Communist Council for Mutual Economic Aid, the Caribbean Organization, the Colombo Plan, the European Free Trade Organization, the European Economic Community, to mention only a few."

${ }^{634}$ YEPES, J.-M.. La contribution de l'Amérique latine au développement du droit international public et privé. In: Recueil des Cours. Academie de Droit International de la Haye, Volume 32, 1930-II, pp. 691-799. p. 752. "In verbis": "Un des aspects les plus intéressants de la mentalité internationale de l'Amérique latine est la façon dont elle envisage la solution des conflits entre Etats. Nous avons déjà vu certaines conceptions latino-américaines tendant à l'abolition de la guerre par la négation des prétendus droits de la victoire et par l'interdiction d'agrandir le territoire national par la violence. S'il n'est pas possible d'éliminer complètemant la guerre dans les relations inernationales, étant donné l'évolution encore imparfaite du droit des gens, il est possible de la rendre de plus en plus rare grâce à des lois impératives qui lui enlèvent tous ses avantages et grâce aussi à l'emploi obligatoire des moyens pacifiques pour résoudre les différends internationaux. L'Amérique latine a donné des exemples très éloquents à ce double point de vue“

${ }^{635}$ YEPES, J.-M.. La contribution de l'Amérique latine au développement du droit international public et privé. In: Recueil des Cours. Academie de Droit International de la Haye, Volume 32, 1930-II, pp. 691-799. p. 756. "In verbis“: "Bolivar considérait l'adoption de l'arbitrage comme le complément indispensable de la société des nations qu'il s'efforçait d'organiser au Congrès de Panama de 1826. Ainsi pouvons-nous constater que dans le traité qui y fut signé, et dont nous avons longuement parlé déjà, l'idée centrale, après celle de la confédération, était celle de l'arbitrage entre les confédéres." 
soberanos teria sido a Corte Centro-americana de Justiça ${ }^{636}$. Sua estrutura possui caráter permanente e suas decisões vinculam estados e particulares que compõem o Sistema de Intergração Centro-americano ${ }^{637}$. A Corte foi, na verdade, o primeiro tribunal internacional, de fato, constituído ${ }^{638}$.

A inexistência de sistemas jurisdicionais de solução de litígios sujeitaria o direito internacional exclusivamente à política, isto é, unicamente à vontade dos sujeitos de direito que além de aplicar, também são responsáveis pelo exercício de criação da ordem jurídica comum transnacional ${ }^{639}$. A produção do direito primeiro deixou de ser exclusivamente do legislador e aos poucos se desloca cada vez mais para o aplicador do direito.

Instrumento do mencionado exercício concretivo por tribunal seriam as referências a julgamentos anteriores. Em um sistema jurisdicional internacional, a jurisprudência não se faz, em regra e entretanto, aplicável, mas cada vez mais esses tribunais têm buscado manter a coerência exigida de um sistema jurídico entre as suas decisões presentes e anteriores ${ }^{640}$.

\footnotetext{
${ }^{636}$ YEPES, J.-M.. La contribution de l'Amérique latine au développement du droit international public et privé. In: Recueil des Cours. Academie de Droit International de la Haye, Volume 32, 1930-II, pp. 691-799. p. 761. "In verbis“: "En ce qui concerne l'organisation de la justice internationale en Amérique latine, il y a lieu de mentionner ici un fait d'une extrême importance : la création de la Cour de Justice centro-américaine. C'est, dans l'histoire du monde, le premier exemple d'un tribunal de justice ayant droit de juridiction sur des Etats souverains."
}

${ }^{637}$ NEGRO, Sandra. Derecho de la integración. Buenos Aires: BDEF, 2013. p. 202. "In verbis": "La Corte Centroamericana de Justicia fue creada por el Protocolo de Tegucigalpa, y de acuerdo a sus disposiciones es la encargada do garantizar el respeto del derecho de la integración. En 1992 los Estados miembro aprobaron su Estatuto, instrumento mediante el cual se amplían sus facultades y competencias, y se la convierte en tribunal internacional y en tribunal de arbitraje. Su instalación se produjo en octubre de 1994. Guatemala ratificó el Estatuto en el año 2009 pero se encuentra pendiente la designación de los magistrados. Panamá y Costa Rica no se han incorporado hasta la actualidad. Es el órgano judicial principal y permanente de SICA, y su jurisdicción y competencia son de carácter obligatorio para los Estados parte. La Corte tiene potestad para juzgar a petición de parte y resolver con autoridad de cosa juzgada, y su doctrina tiene efectos vinculantes para todos los Estados miembro, los órganos e instituciones que forman parte de SICA y para sujetos de derecho privado."

${ }^{638}$ YEPES, J.-M.. La contribution de l'Amérique latine au développement du droit international public et privé. In: Recueil des Cours. Academie de Droit International de la Haye, Volume 32, 1930-II, pp. 691-799. p. 762. "In verbis": "Il est vrai que, dans la pratique, la Cour de Justice centro-américaine n'a pas donné tous les résultats qu'on en attendait, elle n'en constitue pas moins comme essai de justice internationale un fait historique dont il faut tenir compte : elle est, en effet, le premier tribunal vraiment international qui ait existé dans le monde, et elle est un des antécédents les plus intéressants de la Cour permanente de Justice internationale instituée à La Haye au cours de ces dernières années."

${ }^{639}$ GIRAUD, Emile. Le droit international public et la politique. In: Recueil des Cours. Academie de Droit International de la Haye, Volume 110, 1963-III, pp. 419-809. pp. 435. "In verbis“: "Sans l'intervention obligatoire d'un tribunal international, l'application du droit international reste sous l'influence de la politique, et cela d'autant plus que dans son état actuel le droit international est incertain, incomplet, assez souvent imprécis, parfois contesté et que par suite, il se prête à des interpretations diverses.“

${ }^{640}$ CHARNEY, Jonathan I.. Is international law threatened by multiple international tribunals? In: Recueil des Cours. Academie de Droit International de la Haye, Volume 271, 1998, pp. 101-382. p. 129. "In verbis": "This does not necessarily mean that each forum has its own international law jurisprudence. Since stare decisis generally is not applicable in international law, references to prior judgments or awards are limited. Although a strict common law doctrine of stare decisis is not used, the ICJ and other standing courts of international law increasingly rely on reasoning found in prior cases. Thus, there is precedent in international law. Even though this precedent is not of a binding character, it is highly persuasive." 
Essa perda de importância do legislador - ou de exclusividade concretiva - e a permissão para que o aplicador do direito produza a norma, ou seja, exerça a escolha política, abriu caminho para que no direito internacional os estados perdessem importância no processo de elaboração normativa e que até mesmo privados - bancos, instituições certificadoras etc. - passassem a poder também criar o direito. Nesse caminho entre o moderno e o pós-moderno, cabe a reflexão de que o jurídico ainda se mostra refém da razão, da argumentação que permita a escolha política na produção da norma pelo julgador, o qual se tornou em certa medida também legislador.

$\mathrm{Na}$ esfera internacional, qualquer tribunal, corte, comissão ou sistema é capaz de produzir o direito desde que consiga sua imposição ou a adesão da comunidade internacional. Nesse sentido, o papel concretivo da jurisprudência internacional ainda não pode ser comparado com aquele observado recorrentemente na ordem interna dos estados na atualidade.

Apesar dessas ressalvas, não se pode negar a importância das decisões prolatadas por órgãos jurisdicionais na formação e sedimentação do direito das gentes contemporâneo ${ }^{641}$. Exercício internacional bem menos simples que na esfera interna. Localmente, a separação de funções sofre mutações e o poder judiciário assume sem cerimônia as escolhas políticas "técnicas" - revestidas de princípios éticos e morais. O direito das gentes ainda se encontra no início desse processo.

No caso, por exemplo, do constitucionalismo aplicável ao direito internacional, a hierarquização das normas e dos órgãos jurisdicionais estaria, conforme explicitado anteriormente, no cerne da transposição da perspectiva local àquilo que seria o sistema

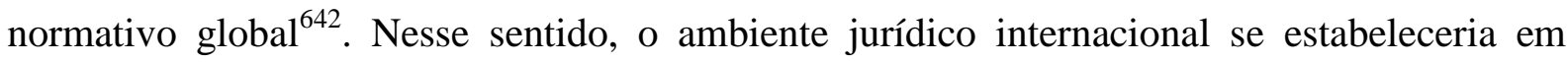
modelos de criação e consolidação de entes supraestatais e na uniformização jurisprudencial,

\footnotetext{
${ }^{641}$ VELASCO, Manuel Diez de. Instituciones de derecho internacional público - Tomo I. Madrid: Editorial Tecnos, 1978. p. 92. "In verbis": "Al modo como en el Derecho interno las decisiones judiciales tienen un valor extraordinario, dando lugar a la forma más notable de la interpretación del Derecho, nos encontramos hoy también en el Derecho Internacional, después del florecimiento en nuestro siglo de las jurisdicciones internacionales, en una situación que, salvadas las distancias de tiempo y de cantidad, pudiéramos decir que es similar. La Jurisprudencia internacional no podemos definirla como una fuente formal de nuestro Derecho en sentido estricto, pese a autorizadísimas opiniones en contrario. No obstante lo anterior, no podemos desconocer que en la práctica el valor del precedente jurisprudencial es tan grande después del florecimiento de los Tribunales internacionales [...]."

${ }^{642}$ FASSBENDER, Bardo. The meaning of international constitutional law. In: MacDonald/Johnston (Hrsg.). Towards World Constitutionalism. Amsterdam: R.St.J., 2005. p. 838. "In verbis": “[...] there is no compelling reason to reserve the term constitution for the supreme law of a (soverign) state but that, instead, the fundamental legal order of any autonomous community or body politic can be addressed as a constitution."
} 
ou seja, de forma a se aplicar a estrutura político-jurídica interna dos estados à esfera internacional

No positivismo/modernidade, a decisão política ficava nas mãos do legislador. Hoje cada vez mais o aplicador do direito toma a decisão política, o pós-positivismo, a partir da incerteza, parece conceder ao órgão decisório essa prerrogativa com maior facilidade.

O outro lado da moeda dessa dependência do direito internacional da política seria o incremento da discricionariedade dos membros de tribunais internacionais, é dizer, o poder criativo do juiz ao decidir quanto ao direito internacional é muito maior que aquele do direito interno. No direito internacional, o exercício jurisdicional também pode ser criador do direito $^{643}$.

Concepções unitaristas universais tendem a buscar no direito natural as justificativas teóricas que lhe sustentariam, mas também o positivismo jurídico pode ser utilizado como ferramenta da perspectiva universalista do direito ${ }^{644}$. Para tanto, bastaria que se considerasse o exercício dos distintos poderes envolvidos com a expressão da vontade concretiva.

O elemento estrangeiro em uma controvérsia não seria suficiente para caracterizá-la como exemplo de justiça internacional. Um litígio que envolva uma parte estrangeira mesmo sendo um estado - resolvido pelo judiciário interno de um estado não pode ser

\footnotetext{
${ }^{643}$ GIRAUD, Emile. Le droit international public et la politique. In: Recueil des Cours. Academie de Droit International de la Haye, Volume 110, 1963-III, pp. 419-809. pp. 460-461. "In verbis“: "Nous avons essayé de définir la situation du pouvoir judiciaire dans l'ordre interne, mais est elle la même dans l'ordre international? A la verité, elle apparaît sensiblement différente. Le droit international qui n'a pas été l'objet d'une codification générale présente beaucoup plus d'incertitudes et de lacunes que le droit national, cependant il est reconnu que le juge international pas plis que le juge national ne peut en principe se refuser à statuer en arguant des incertitudes ou des lacunes du droit. Mais par ailleurs, il n'y a pas au-dessus du juge international un pouvoir légistatif toujours disponible et souverain qui puisse à tout moment substituer son appréciation à celle juge en édictant pour l'avenir de nouvelles règles. Dans ces conditions le pouvoir créateur du juge international est susceptible d'être beaucoup plus grand que celui du juge national, étroitement limité par la loi. La situation présente une certaine analogie avec les sociétés primitives oú la législation proprement dite tient peu de place, mais où le pouvoir judiciaire joue un rôle primordial. Mais si dans ces sociétés primitives le juge est la source principale du droit, c'est parce que la souveraineté s'exprime par lui. Il n'en est évidemment pas de même dans la société internationale présente."
}

${ }^{644}$ BOBBIO, Norberto. Teoria do ordenamento jurídico. Brasília: Editora Universidade de Brasília, 1999. pp. 164-165. "In verbis“" : "[...] o universalismo como tendência nunca morreu, e nesses últimos anos, sobretudo depois da Segunda Guerra Mundial e da Organização das Nações Unidas, está mais vivo do que nunca. O universalismo jurídico ressurge hoje não mais como crença num eterno Direito natural, mas como vontade de constituir um Direito positivo único, que recolha em unidade todos os direitos positivos existentes, e que seja produto não da natureza, mas da história, e esteja não no início do desenvolvimento social e histórico (como o Direito natural e o estado da natureza), mas no fim. A idéia do Estado mundial único é a idéia-limite do universalismo jurídico contemporâneo ; é uma unidade procurada não contra o positivismo jurídico, com um retorno à idéia de um Direito natural revelado à razão, mas através do desenvolvimento, até o limite extremo, do positivismo jurídico, isto é, até a constituição de um Direito positivo universal.“ 
caracterizado como internacional. Verdadeiramente internacional seria, portanto, apenas as contendas submetidas a um sistema de solução de controvérsias internacional ${ }^{645}$.

Quando da criação da Sociedade das Nações, a alternativa arbitral para a solução de controvérsias entre os sujeitos de direito internacional foi recebida com bastante entusiasmo e esperança pela doutrina. Percebe-se que a solução pacífica constitui uma demanda histórica do direito internacional, o qual sempre foi tão marcado e pautado pela guerra. Em outra medida, cem anos se passaram e ainda não se fez possível estruturar um sistema global para a solução pacífica de controvérsias ${ }^{646}$.

Pode-se dizer que alguns doutrinadores do período entre as duas grandes guerras mundiais recebeu a criação da Corte Permanente de Justiça com certo entusiasmo projetivo, aduzindo, inclusive, a obrigatoriedade de jurisdição e a ampliação de suas competências ${ }^{647}$.

A consolidação de um sistema jurisdicional de controvérsias passa, contudo, por paciência, perseverança e principalmente por prudência ${ }^{648}$. Tudo isso porque um tribunal internacional não pode contar, em regra, com os meios coercitivos do poder judiciário interno

${ }^{645}$ CASTBERG, Frede. L'excès de pouvoir dans la justice internationale. In: Recueil des Cours. Academie de Droit International de la Haye, Volume 35, 1931-I, pp. 353-472. p. 358. "In verbis“: "Le terme « justice internationale » doit néanmoins être pris dans un sens assez large pour comprendre aussi certains cas où il s'agit d'un procès entre un particulier d'une part et un Etat de l'autre. Si un différend entre un Etat et un particuliler est soumis à la décision d'un tribunal international en vertu d'un traité, nous nous trouvons devant un cas de justice internationale. Un différend qui est jugé par les propres tribunaux d'un Etat, en vertu de dispositions de la législation interne, ne devient pas un différend international pour la seule raison qu'une des parties est un ressortissant d'un Etat étranger, ou même un Etat étranger. Le procès n'aura un caractère international que s'il est plaidé devant un tribunal dont le pouvoir se fonde sur le droit international““

${ }^{646}$ SCHINDLER, Diètrich. Les progrès de l'arbitrage obligatoire depuis la création de la Société des Nations. In: Recueil des Cours. Academie de Droit International de la Haye, Volume 25, 1928-V, pp. 233-364. p. 241. "In verbis": "Le but final de l'organisation de l'arbitrage doit être l'élaboraration d'un système d'instances qui, dans sa totalité, pourrait assurer le reglement pacifique de tous les différends. Ce système n'a pas encoré été elaboré. Mais on a des aujourd'hui construit des parties très importantes de l'édifice qui, espérons-le, sera achevé un jour."

${ }^{647}$ CALOYANNI, Mégalos A.. L'organisation de la Cour permanente de justice et son avenir. In: Recueil des Cours. Academie de Droit International de la Haye, Volume 38, 1931-IV, pp. 651-786. pp. 655-656. "In verbis": "Après que chaque compétence particulière a déjà été étudiée par divers organismes et par la Société des Nations elle-même, tout augure d'un commencement de progrès nouveaux concernant l'extension de sa compétence et correspondant un avenir tel que le fait présager l'acceptation progressive par les peuples de sa compétence obligatoire, qui s'étend de plus en plus tous les jours.“

648 CALOYANNI, Mégalos A.. L'organisation de la Cour permanente de justice et son avenir. In: Recueil des Cours. Academie de Droit International de la Haye, Volume 38, 1931-IV, pp. 651-786. p. 777. "In verbis“: "Pour ceux qui voient en la Cour permanente l'institution qui, par le droit, contribuera le plus puissamment à l'établissement de la Justice internationale, la prudence est toujours leur guide dans leurs efforts pour développer la compétence de la Cour; ils savent bien que des intérêts de tous genres, le plus souvent politiques, en tout cas des intérèts, entravent la marche du progrès; ceux-là mêmes, donc, non seulement pratiquent la prudence, mais savent aussi pratiquer la patience. Cependant l'oeuvre de la justice est si impérieusement réclamée qu'ils ae doivent persévérance.“ 
para fazer cumprir suas decisões. Não se aplicam a eles, assim, as diretivas positivistas da sanção de Kelsen.

Resta a esses sistemas o reconhecimento de sua legitimidade sem que haja, necessariamente, obrigatoriedade, a qual, algumas vezes, poderia se chocar com os lineamentos de soberania estatal. Um tribunal internacional depende atualmente ainda da vontade da parte condenada para que sua decisão tenha efeito e essa condição torna a prudência na tomada de decisões fundamental à preservação não apenas de sua competência, mas do próprio sistema internacional de direito.

Um órgão jurisdicional internacional tem em seu fundamento a confiança depositada pelos sujeitos de direito que a ele se submetem. A referida confiança não se apresenta como um dado, mas como uma construção e sua manutenção se faz fundamental para que as decisões emanadas no marco de um sistema de solução de controvérsias sejam cumpridas ${ }^{649}$. Essa dinâmica entre confiança e cumprimento de decisões constitui requisito essencial à própria existência de uma corte internacional. Sem o par, um sistema de solução de litígios raramente se sustenta. Outro entrave à consolidação dos tribunais internacionais estaria relacionado, ainda, aos custos de manutenção da estrutura burocrática jurisdicional. Os custos constituem, na verdade, importante limite à multiplicação dessas instâncias jurisdicionais ${ }^{650}$.

Em linhas gerais, percebe-se que a institucionalidade jurisdicional do direito internacional exige esforços na harmonização hermenêutica reconhecida pelos atores internacionais, no desenvolvimento da segurança comum e, portanto, do equilíbrio de poder entre os envolvidos, no desenvolvimento também dos métodos diplomáticos, de mediação e

${ }^{649}$ BERLIA, Georges. Jurisprudence des tribunaux internationaux en ce qui concerne leur compétence. In: Recueil des Cours. Academie de Droit International de la Haye, Volume 88, 1955-II, pp. 105-157. p. 109. "In verbis": "On reconnaît, en général, un tribunal international dans tout organe que la confiance des Etats investit de la mission de résoudre, par application du droit en vigueur, un différend ou un groupe de différends existant ou susceptibles de survenir entre eux. C'est là une simple constatation qui ne saurait être récusée dans son principe; aussi bien nous paraît-elle appeler seulement quelques brefs commentaires destinés à la nuancer."

${ }^{650}$ CHARNEY, Jonathan I.. Is international law threatened by multiple international tribunals? In: Recueil des Cours. Academie de Droit International de la Haye, Volume 271, 1998, pp. 101-382. p. 124. "In verbis“": "Even though the number of international tribunals has grown significantly in recent years, this does not mean that there are no limits to that growth. The financial implications of establishing and maintaining separate tribunals are not insignificant. This includes, for example, the cost of the facility to house the tribunal and its staff, the salaries and other benefits required for the members of the tribunal and the staff, library facilities, office equipment, travel and other communications expenses, as well as the publication and distribution of the various decisions of the tribunal.“ 
de jurisdições internacionais e, finalmente, na submissão definitiva dos sujeitos de direito internacional aos meios pacíficos de solução de controvérsias ${ }^{651}$.

Qual seriam os limites da atuação dos sistemas internacionais de solução de controvérsias? Como meios jurisdicionais hábeis a julgar questões de direito, existe forte tendência à exclusão de toda e qualquer questão política da jurisdição de um tribunal internacional. Por outro lado, os princípios gerais de equidade e justiça surgem como alternativas que poderiam servir muito bem à solução de controvérsias políticas que se apresentem na ordem global $^{652}$.

$\mathrm{Na}$ verdade, mostra-se cada vez mais complicado delimitar o campo normativo que se encontra na competência de um tribunal internacional. Ao sistema específico, do qual o órgão faz parte, podem vir a se somar também o direito interno dos estados membros e, sem dúvida, premissas fundamentais do direito internacional geral ${ }^{653}$.

Conforme ressaltado acima, o direito evolui também pela hermenêutica. A exegese do conteúdo da carta das Nações Unidas pela Assembléia Geral, por exemplo, tem papel importante nesse sentido. No plano interno de um estado, a interpretação construtiva de direito é feita pelo poder judiciário. Na esfera multilateral, não se pode reconhecer na Corte Internacional de Justiça o topo de um poder judiciário constituído, mas, sim, um embrião do

${ }^{651}$ WRIGHT, Quincy. The strengthening of international law. In: Recueil des Cours. Academie de Droit International de la Haye, Volume 98, 1959-III, pp. 01-295. pp. 226-227. "In verbis": "What are the conditions which must be realized before international adjudication can be relied upon to maintain the rule of law in the international community? These conditions undoubtedly include ; (1) the development of international law so that its application will generally conform to the intuitions and the conceptions of interest of all important nations ; (2) the development of collective security and stabilization of the balance of power so that the prospects of any State obtaining justice by forcible self-help is reduced to vanishing point ; (3) the development of the arts and facilities of diplomacy, mediation, conciliation and conference to maximize the prospects of agreement between the parties ; (4) the improvement of the agencies of arbitration and judicial settlement so that such an agency, commanding the confidence of both parties to any dispute will be easily available, and (5) the increase in the commitments of the States of the world to utilize such an agency when there are no longer prospects of reaching agreement by direct negotiation or any of the persuasive devices which may supplement it."

${ }^{652}$ FENWICK, Charles G.. The progress of international law during the past forty years. In: Recueil des Cours. Academie de Droit International de la Haye, Volume 79, 1951-II, pp. 01-71. p. 58. "In verbis": "Why should political disputes not be submitted to arbitration, or to the alternative procedure of judicial settlement by the International Court of Justice? Many jurists think that they should be so submitted, on the ground that where specific rules of law fail us there are the general principles of equity and justice to guide us."

${ }^{653}$ PANHUYS, H.F. van. Relations and interactions between international and national scenes of law. In: Recueil des Cours. Academie de Droit International de la Haye, Volume 112, 1964-II, pp. 01-89. p. 18. "In verbis“: "It is not always an easy matter to delimit the exact scope of a tribunal's mandate as regards the law to be applied by it. This is true, e. g., of the Court of Justice of the European Communities. Though this Court is generally held to be called upon to apply the 'law of the Communities', it is admitted at the same time, that general principles recognized in the municipal laws of the member States constitute one of the sources to which the Court may have resort. Nor is it denied that exceptionally general rules of international law may be applicable." 
mesmo ${ }^{654}$. Talvez o primeiro passo à construção hierárquica do sistema mundial de solução de controvérsias $^{655}$.

Admite-se, de uma forma geral, que um sistema jurisdicional internacional possa lançar mão dos princípios gerais do direito das gentes em caso de lacuna do sistema local. Em situação de divergência entre o corpo normativo local e o direito internacional geral, o sistema especial tende a prevalecer, mas a ordem específica pode prever expressamente sua submissão a regras de jus cogens internacional ${ }^{656}$.

Parte da doutrina jurídica internacionalista parece ter se convencido da ineficiência dos parâmetros de unidade baseados na normatividade jurídica. A aplicação das estruturas hierárquicas ou da divisão das funções do poder do estado ao direito internacional sofre resistência e a teoria geral do estado - e o constitucionalismo - passaram de modelo a estigma de ultrapassado, desatualizado e desinteressante.

\footnotetext{
${ }^{654}$ WALDOCK, Humphrey. General course on public international law. In: Recueil des Cours. Academie de Droit International de la Haye, Volume 106, 1962-II, pp. 01-251. pp. 34-35. "In verbis“": "Any interpretation of a constitution has a certain legislative effect, and no international lawyer would wish to deny to the United Nations, and more especially to the General Assembly, a measure of freedom in developing the 'law of the Charter' by interpretation. But there is a danger that bold interpretations imposed by a majority may place too heavy a strain on the political foundations of the Organization. The problem is thus to reconcile the need to allow some flexibility in the interpretation of the Charter with selfguarding individual States against having completely novel obligations imposed upon them merely as a result of being outvoted. In a Federal State this safeguard is normally found by providing for interpretations of the constitution to be subject to judicial scrutiny."
}

${ }^{655}$ WALDOCK, Humphrey. General course on public international law. In: Recueil des Cours. Academie de Droit International de la Haye, Volume 106, 1962-II, pp. 01-251. p. 35. "In verbis": "The Permanent Court was not an organ of the League. The Charter, on the other hand, made the Court one of the principal organs of the United Nations and its Statute an integral part of the Charter. Moreover, Article 96 of the Charter authorizes the General Assembly and the Security Council to request the Court to give an advisory opinion on any legal question; while other organs of the United Nations or a Specialized Agency may be authorized to do so by the General Assembly. The Court is thus not merely an international court of justice; it is the Supreme Court of the United Nations."

${ }^{656}$ PANHUYS, H.F. van. Relations and interactions between international and national scenes of law. In: Recueil des Cours. Academie de Droit International de la Haye, Volume 112, 1964-II, pp. 01-89. pp. 16-17. "In verbis": "As things are today, international tribunals generally derive their authority from the States which have called them into existence through their joint action. It is with these States that the members of the tribunal have entered into what has been described above as a mandate-relation. [...] Conceivably, international tribunals may also be set up by international organizations, such as is the case with the UN Administrative Tribunal, but this is rather an exceptional type. [...] As a general rule it may be said that for international tribunals, international law is the lex for. Yet other questions may arise, as for instance in cases where a tribunal is called upon to apply and interpret the provisions of a specific treaty. The view generally held is that in this event the mandate of the tribunal impliedly includes the duty to apply General rules of the law of nations. Difficulties may arise where there is a divergence between the treaty and those General rules. If nothing has been stipulated, the provisions of the treaty may be assumed to prevail. An exception must be made should the treaty contain provisions infringing general rules of international law of a peremptory character (jus cogens)." 
Não existe, de fato, na ordem atual do direito das gentes hierarquia entre sistemas de direito ou de tribunais ${ }^{657}$. A competência dos tribunais internacionais depende das partes que o instituíram e que a eles se submetem ${ }^{658}$. Mas nada, absolutamente nada impediria que estruturas da teoria geral do estado fossem utilizadas como parâmetros à compreensão de institutos, conceitos e elementos do direito internacional.

A falta de institucionalização da resolução de controvérsias internacionalmente em sistemas jurisdicionais submeteria o direito à política e traria dúvidas para os sujeitos que passam a evitar submeter suas questões aos tribunais que encontram dificuldades para se institucionalizar $^{659}$. Um verdadeiro ciclo vicioso estaria, portanto, criado.

No que se refere às espécies de formas pacíficas de solução de conflitos, verifica-se que a arbitragem constitui meio bastante popular no comércio internacional. Grande parcela desse êxito costuma ser imputada à neutralidade característica desse procedimento, principalmente no que se refere à relação entre os membros de um tribunal arbitral e seus estados de origem ${ }^{660}$.

${ }^{657}$ WALDOCK, Humphrey. General course on public international law. In: Recueil des Cours. Academie de Droit International de la Haye, Volume 106, 1962-II, pp. 01-251. p. 106. "In verbis“: "The International Court, although highest in importance among international tribunals, is strictly speaking not a superior court but only primus inter pares. For there is no hierarchy of tribunals in the international system, nor any general system of appeals from lesser tribunals to the Court."

${ }^{658}$ WALDOCK, Humphrey. General course on public international law. In: Recueil des Cours. Academie de Droit International de la Haye, Volume 106, 1962-II, pp. 01-251. p. 108. "In verbis": "[...] the jurisdiction of every international tribunal, large or small, legal or political, depends on the interested parties having consented to its exercise $[\ldots]^{“}$

${ }^{659}$ GIRAUD, Emile. Le droit international public et la politique. In: Recueil des Cours. Academie de Droit International de la Haye, Volume 110, 1963-III, pp. 419-809. p. 435. "In verbis": "Sans l'intervention obligatoire d'un tribunal international, l'application du droit international reste sous l'influence de la politique, et cela d'autant plus que dans son état actuet le droit international est incertain, incomplet, assez souvent imprécis, parfois contesté et que par suite, il se prete à des interprtations diverses. II se trouve que c'est justement cette insuffisance du droit international qui est une des raisons ponr lesquelles de nombreux Etats ne veulent pas que leurs différends soient soumis à un règlement judiciaire. Des gouvernements pensent que les jugements des tribunaux internationaux comportent de la part des juges une trop grand part d'appréciation personelle."

${ }^{660}$ MAYER, Pierre. L'autonomie de l'arbitre international dans l'appréciation de sa propre compétence. In: Recueil des Cours. Academie de Droit International de la Haye, Volume 217, 1989-V, pp. 319-454. p. 327. "In verbis": "L'arbitrage est le mode le plus fréquent de résolution des litiges du commerce international. La raison principale du succès qu'il remporte auprès des justiciables est sa neutralité, liée à son caractère privé : les arbitres ne statuant pas au nom d'un Etat, mais uniquement en leur nom propre, ne sont pas soupçonnés de partialité envers l'une ou l'autre partie. Mais cette indépendance des arbitres vis-à-vis des Etats particulièrement précieuse lorsque, comme c'est souvent le cas, l'une des parties est un Etat ou un organisme public - soulève la question de la source de leur compétence ou, selon l'expression retenue par le droit français, de leur pouvoir juridictionnel. Tandis que la source de la compétence des tribunaux qui composent un ordre juridictionnel est l'Etat, les arbitres tiennent leurs pouvoirs des parties : la justice arbitrale repose sur une convention d'arbitrage.“ 
A arbitragem não constitui, porém, modelo recente para a solução de litígios internacionais. Há pelo menos dois mil anos existem relatos de seu uso e no período mais pacífico do século XIX houve o auge de sua adoção pelos estados ${ }^{661}$. A própria Carta das Nações Unidas incluiu a arbitragem como meio ao qual se deve necessariamente lançar mão para evitar e solucionar conflitos internacionais ${ }^{662}$.

O progresso da arbitragem internacional como meio pacífico de solução de controvérsias entre estados se deve, em parte, aos tratados que a fixam como instrumento jurisdicional, mas não se pode desconsiderar sua aceitação cada vez maior por parte dos sujeitos de direito das gentes, os quais podem se submeter - e, de fato, o fazem - ainda que inexista prévio acordo nesse sentido ${ }^{663}$. $\mathrm{Na}$ arbitragem entre estados, de direito público eminentemente, a isenção do julgador representa condição ainda mais relevante em razão das limitações à imposição de decisões a entes dotados de soberania.

A doutrina tradicional reluta bastante para aceitar a aplicação da noção de jurisprudência à arbitragem. Essa resistência se deve, em grande medida, ao caráter efêmero tradicionalmente reconhecido aos tribunais arbitrais. De fato, a maioria avassaladora dos procedimentos do tipo foram - e ainda são - levados a cabo por tribunais ad hoc, isto é, constituídos exclusivamente para a solução de determinada questão concreta.

${ }^{661}$ SOHN, Louis B.. The function of international arbitration today. In: Recueil des Cours. Academie de Droit International de la Haye, Volume 108, 1963-I, pp. 01-113. p. 09. "In verbis“: "For more than 2000 years, the nations of the world have resorted to arbitration in order to settle important international disputes. There have been many periods, of course, during which arbitration had to recede into the background while power politics, war, or anarchy ruled the world. But in the relatively peaceful years of the nineteenth century more than 200 arbitrations were held, dealing with boundaries, claims, neutral rights and many other problems of international law."

${ }^{662}$ SOHN, Louis B.. The function of international arbitration today. In: Recueil des Cours. Academie de Droit International de la Haye, Volume 108, 1963-I, pp. 01-113. p. 11. "In verbis": "The Charter of the United Nations provides that prior to a consideration of a dispute by the Security Council (or the General Assembly) of the United Nations, the parties 'to any dispute, the continuance of which is likely to endanger the maintenance of international peace and security, shall, first of all, seek a solution by negotiation, enquiry, mediation, conciliation, arbitration, judicial settlement, resort to regional agencies or arrangements, or other peaceful means of their own choice.' (Article 33: paragraph 1). Thus arbitration is considered an intermediary step between conciliation and judicial settlement on the scale adopted by the framers of the Charter;"

663 PODESTÁ COSTA, L.A. Derecho internacional público - tomo II. Buenos Aires, Tipográfica Editora Argentina, 1955. p. 27. "In verbis": "Claro está que los progresos del arbitraje no residen solamente en la concertación de los tratados generales. El sometimiento de las cuestiones internacionales al procedimiento arbitral obedece a un estado de espíritu. Si éste se ha disipado, puede tornarse muy difícil llegar al arbitraje aunque esté en vigor un tratado general; porque, planteado un caso de aplicación posible, es indispensable - a menos que dicho tratado contenga una cláusula sobre el particular - convenir entre las partes un acuerdo formal con ese objeto, que es el 'compromiso arbitral'. Y cuando aquel estado de espíritu existe, puede llegarse al arbitraje aunque no medie tratado general anterior. Lo cierto es que el valor del arbitraje está demostrado por los hechos." 
Mesmo o chamado Tribunal Permanente de Arbitragem da Haia, um dos mais antigos meios institucionalizados de solução de controvérsias criados e ainda em funcionamento, não constitui órgão propriamente permanente. Sua secretaria, de certo, é permanente, mas sua composição não ${ }^{664}$.

Novidade, nesse sentido, trouxe ao direito das gentes o Protocolo de Olivos para a Solução de Controvérsias no MERCOSUL ao inserir em sua estrutura um órgão dotado de composição permanente investido da atribuição de interpretar em última instância o direito regional. Trata-se do Tribunal Permanente de Revisão - TPR, sediado na cidade de Assunção, no Paraguai.

No caso específico do TPR, seria possível imaginar que durante o mandato de seus árbitros - de dois anos, renováveis por dois períodos - os laudos produzidos possam fazer referência a laudos anteriores emitidos pelos mesmos membros do tribunal. O exemplo do TPR pode ser sustentado por puristas do direito das gentes, mas restringir o uso de precedentes de um mesma estrutura de solução de litígios à reprodução de sua composição se mostra atualmente totalmente descabido. $\mathrm{Na}$ verdade, a própria restrição ao uso de precedentes exclusivamente ao próprio sistema se faz hoje absolutamente despropositada.

A doutrina costumava apontar a efemeridade da composição dos tribunais arbitrais ao lado daquela relacionada às suas funções estabelecidas pelas partes - a maior diferença entre estes e as cortes internacionais, as quais possuem composição mais estável. O TPR subverte essa regra geral e demonstra claramente que nada que evolui pode ser concebido como definitivo ${ }^{665}$.

${ }^{664}$ PODESTÁ COSTA, L.A. Derecho internacional público - tomo II. Buenos Aires, Tipográfica Editora Argentina, 1955. p. 32. "In verbis": "La organización y el funcionamiento del llamado Tribunal Permanente de Arbitraje de La Haya están reglados por la convención para el arreglo pacifico de los conflictos internacionales elaborada en La Haya en 1899 y modificada en 1907; pero la primera subsiste entre los Estados que respectivamente la han ratificado sin haber hecho lo mismo con la segunda. Pueden utilizar los servicios de ese tribunal dichos Estados y también los no contratantes que lo acuerden entre si en un caso concreto; pero todos tienen libertad para acudir, si así lo convienen, a un tribunal ad hoc. A pesar de su nombre, el referido tribunal de La Haya no está constituido de modo permanente. Sólo se ha instituido un régimen que permite organizar un tribunal tan pronto como dos o más Estados convengan en recurrir a sus servicios. Ese régimen consiste en una secretaria permanente, establecida en La Haya, que conserva una lista de personalidades designadas a razón de cuatro por cada uno de los Estados ligados por las referidas convenciones de 1899 o 1907."

${ }^{665}$ SOHN, Louis B.. The function of international arbitration today. In: Recueil des Cours. Academie de Droit International de la Haye, Volume 108, 1963-I, pp. 01-113. p. 22. "In verbis": "“[...] it is generally agreed that there is at least one difference, formal or structural rather that substantive, between international arbitral tribunals and international courts. Traditionally, that difference lies not in their respective functions but in the method of selection of the arbitrators and judges. While the parties usually have free choice with respect to the membership of an arbitral tribunal, they have to accept a court as it is and can vary its membership to only a slight degree." 
A partir da premissa de que o estabelecimento de procedimentos de solução de litígios constitui pressuposto para a existência de grupo de normas organizadas internacionalmente como um sistema, necessário se faz investigar a forma que esses mecanismos podem ter. Estruturas mais simples, mormente adotadas em iniciativas aproximativas incipientes ou em ordens especializadas com objetivos limitados assumem, via de regra, contornos políticos, isto é, absolutamente dependentes da vontade dos sujeitos de direito que acordaram o conjunto normativo. Sistemas intergovernamentais podem estabelecer, assim e por exemplo, que litígios surgidos devem ser resolvidos por meios diplomáticos ${ }^{666}$.

As negociações diplomáticas são método clássico de solução de litígios internacionais, mas tendem a favorecer estados mais desenvolvidos e, portanto, melhor aparelhados politicamente. A constituição de tribunais verdadeiramente autônomos serve à institucionalização do direito das gentes e conforma meio eficiente à efetivação do princípio da igualdade, inerente ao sistema que tanto depende da idéia de soberania estatal ${ }^{667}$.

As soluções políticas seguem preferidas pelos sujeitos de direito internacional como método para a solução de controvérsias. Em muitos casos, constituem o único meio previsto em tratado para a solução de litígios entre suas partes ${ }^{668}$. Conforme o que se defende nesse

${ }^{666}$ BAPTISTA, Luiz Olavo. O MERCOSUL, suas instituições e ordenamento jurídico. São Paulo: Ltr, 1998. p. 147 ressalta, antes do Protocolo de Olivos, mas de forma ainda bastante atual, que, "in verbis", "em nenhum dos aspectos das instituições do MERCOSUL o caráter político e diplomático ficou tão evidente como no sistema de solução de disputas. Desde o Tratado de Assunção, passando pelo Protocolo de Brasília e até a implementação da fase definitiva pelo Protocolo de Ouro Preto, vemos o predomínio da atividade diplomática sobre qualquer outra."

${ }^{667}$ GROSS, Leo. The International Court of Justice and the United Nations. In: Recueil des Cours. Academie de Droit International de la Haye, Volume 120, 1967-I, pp. 313-440. pp. 435. "In verbis“: "If a controversy can be settled by diplomatic negotiations, of course, that procedure should be adopted. However, it should be borne in mind that that method offers special attraction to Great Powers. They have the power, the resources, the staff, the expertise, the time, which are necessary for successful negotiations. States which are not equally well endowed may find that they will come out at the short end of diplomatic negotiations unless they can take advantage of the antagonism between the Great Powers or some other contingency. But apart from special situations, it would seem that the judicial procedure has advantages which diplomatic negotiations do not offer. Adjudication is the only procedure in which the power of the litigants is minimized and legal considerations including principles of equity are maximized. The Court has also shown that it is aware of social and economic factors and that it wilt take them into consideration in appropriate situations. I am not arguing that recourse to the Court is always and invariably preferable to other alternatives. What I am suggesting is much more modest. I am suggesting that governments should consider recourse to judicial procedure, advisory or contentious, as one of the alternatives and that in making their choice they should take into account their tong range interest in promoting the development of a society in which law will increasingly come to controlling and civilizing the exercise of power. In this development the function of the Court is inevitable, both as an organ of the United Nations and an organ of international law."

${ }^{668}$ SOHN, Louis B.. The function of international arbitration today. In: Recueil des Cours. Academie de Droit International de la Haye, Volume 108, 1963-I, pp. 01-113. p. 12. "In verbis“": "That diplomatic negotiations still constitute the preferred method for settling disputes is made clear by innumerable provisions of international treaties for the pacific settlement of disputes which limit the sphere of applicability of these treaties to disputes 'which it has not been possible to settle by diplomacy.' Similar limitations are also included 
estudo, entretanto, uma associação internacional apenas poderia ser considerada organização internacional quando seu sistema de solução de controvérsias contasse com a institucionalidade de órgãos autônomos. Do contrário, o arranjo não passaria de um tratado associativo.

Também o uso limitado das competências consultivas dos tribunais internacionais pode ser considerado exemplo da histórica preferência dos estados pelas soluções políticas em detrimento dos sistemas jurisdicionais de solução de litígios ${ }^{669}$.

Concretamente, questões como a legitimidade de um tribunal internacional, sua competência para decidir e a obrigatoriedade de suas decisões não constituem premissas inerentes à ordem do direito das gentes. A inexistência de autoridade superior aos estados, capaz de submetê-los individualmente à vontade coletiva por meio da força, condiciona a eficácia de um sistema de solução de controvérsias à sua aceitação, é dizer, ao reconhecimento de sua legitimidade e autoridade ${ }^{670}$.

Em abstrato, contudo, a extensão da competência de um tribunal internacional é determinada pelas atribuições que lhe são conferidas por tratado e, nos casos de desenvolvimento normativo-concretivo, por sua jurisprudência. Esses espectros de atuação podem ser classificados como: em razão da matéria, da pessoa, do tempo ou do lugar ${ }^{671}$.

in many compromissory clauses conferring jurisdiction on an international tribunal to interpret the provisions of a particular treaty. Thus an obligation to resort to arbitration will ordinarily be limited by the requirement that the particular dispute must be one which it has not been possible to settle 'by diplomacy', 'by the normal methods of diplomacy', 'by direct negotiations through the, usual diplomatic channels' or simply 'by direct negotiations'."

${ }^{669}$ WALDOCK, Humphrey. General course on public international law. In: Recueil des Cours. Academie de Droit International de la Haye, Volume 106, 1962-II, pp. 01-251. p. 115. "In verbis": "The preference of States for political rather than judicial procedures manifests itself also in the limited use of the Court's advisory jurisdiction."

${ }^{670}$ ACCIOLY, Hildebrando; NASCIMENTO E SILVA, G.E. do; CASELLA, Paulo Borba. Manual de direito internacional público. São Paulo: Saraiva, 2011. p. 841. "In verbis": "No direito internacional a jurisdição tem de ser construída e a extensão da jurisdição de tribunal internacional, como da Corte Internacional de Justiça, dependerá da aceitação desta pelos estados."

${ }^{671}$ MENEZES, Wagner. Tribunais internacionais: jurisdição e competência. São Paulo: Saraiva, 2013. p. 332. "In verbis": "Está claro, efetivamente, que todo Tribunal Internacional possui jurisdição internacional, mas o que precisa objetivamente ficar claro é: quais os limites dessa jurisdição? Qual a extensão do poder conferido pelos Estados a um tribunal especializado para julgar cercas matérias? E, em caso de potencial conflito, como resolver isso a partir da delimitação da competência que aquele tribunal possui? Nesse sentido, a competência internacional está vinculada à idéia de atribuição de um poder agir em razão da matéria - rotione materiae. Como exemplo pode ser citado o Tribunal do Mar, especializado em solução de conflitos que envolvam a Convenção de Montego Bay em Direito do Mar; do tempo - ratione temporis, podendo ser citado o Tribunal Penal Internacional que prevê o julgamento de crimes cometidos contra a Humanidade depois de 2002; ou sujeitos específicos - ratione personae, como a União Européia, que tem jurisdição unicamente sobre Estados Comunitários; ou espaço geográfico - ratione loci, como a Corte Centro-americana que tem um âmbito de atuação regional como um poder agir, mas dentro de limites preestabelecidos, no caso do Direito Internacional, nos Tratados institutivos. Nada obsta, como está evidente, que um Tribunal concentre mais de um determinado 
A solução de litígios por tribunais internacionais viu-se por um longo tempo de forma quase absoluta condicionada à expressão da vontade do estado no momento de surgimento da controvérsia. O panorama atual apresenta clara evolução tendente à submissão obrigatória, mas ainda exige prévio consentimento, o qual é expressado, em regra, no momento em que o sujeito de direito internacional passa a integrar determinado sistema particular do direito das gentes $^{672}$.

Ainda que subsistam resistências doutrinárias à caracterização da obrigatoriedade ou facultatividade de determinado órgão jurisdicional internacional pelo costume, ou seja, sem que se fizesse necessária a vinculação por expressão da vontade, determinadas matérias como os direitos humanos com toda sua textura aberta e imprecisão de conteúdo - têm angariado adeptos de perspectiva cogente independente de adesão ${ }^{673}$. De qualquer maneira, na falta de execução coercitiva, um órgão jurisdicional internacional tem no reconhecimento de suas decisões como obrigatórias ponto fundamental à preservação de sua existência. Isso porque a competência para julgar determinada questão deixa de fazer sentido caso a decisão não seja cumprida.

O consentimento ainda é considerado, portanto, extremamente relevante à atribuição de competência a determinado meio internacional de solução de controvérsias. Essa condição tem admitido cada vez mais formas não expressas de manifestação de vontade. Exemplo dessa relativização seria a submissão automática a tribunais regionais de organizações que adotam o sistema de incorporação global - single undertaking - de seu sistema normativo por novos membros quando da adesão ${ }^{674}$.

tipo de competência, mas sempre levando em conta a vontade dos Estados no sentido de, no Tratado, especificar os limites de ação do Tribunal."

${ }^{672}$ GUGGENHEIM, Paul. Les principes de droit international public. In: Recueil des Cours. Academie de Droit International de la Haye, Volume 80, 1952-I, pp. 01-189. pp. 153-154. "In verbis“: "Les parties contractantes peuvent, dans chaque cas particulier, soumettre le conflit à l'arbitrage ou à la juridiction ; mais elles peuvent également se déclarer d'accord de leur déférer tous les différends juridiques, sans lirnitation aucune ou sous certaines réserves. On parle alors d'arbitrage ou de juridiction obligatoires. Cette méthode a trouvé sa consécration dans un grand nombre de traits bilatéraux et collectifs et surtout dans la clause facultative prévue par le statut de la Cour internationale de Justice.“

${ }^{673}$ RUNDSTEIN, Simon. La Cour permanente de justice internationale comme instance de recours. In: Recueil des Cours. Academie de Droit International de la Haye, Volume 43, 1933-I, pp. 01-113. p. 10. "In verbis“: "Qu'ils soient à compétence facultative ou à compétence obligatoire, les organismes arbitraux et judiciaires sont créés par des traités. Le droit coutumier ne peut, en aucune façon, réaliser proprio motu l'établissement spontané d'une institution, même si le sentiment de la nécessité faisait pression sur la volonté des Etats, et les amenait à se prononcer de leur plein gré en faveur de l'acceptation d'un compromis relatif aux possibilités de réexamen d'un différend déjà tranché.“

${ }^{674}$ BOWETT, Derek William. Contemporary developments in legal techniques in the settlement of disputes. In: Recueil des Cours. Academie de Droit International de la Haye, Volume 180, 1983-II, pp. 169-235. p. 179. "In 
Apesar de toda a evolução doutrinária, jurisprudencial e tratadista descrita, percebe-se que a regra estabelecida pela Corte Permanente de Justiça quando da apreciação da situação da Carélia Oriental em 1923 - que condiciona a submissão de um estado a um tribunal internacional ao seu expresso consentimento - não foi completamente superada até os dias atuais $^{675}$.

Noutro sentido, a harmonização dos acordos regionais com o sistema da carta das Nações Unidas - que prevê expressamente sua celebração ${ }^{676}$ - foi instrumentalizado na forma como as controvérsias entre os membros das organizações seriam solucionadas e na possibilidade de aplicação de sanções entre os mesmos. Observa-se, portanto, que na normatividade do tratado a solução de litígios constitui elemento essencial desse tipo de arranjo internacional ${ }^{677}$. No marco do referido documento, mencionada se encontra de forma clara, ressalta-se, apenas a possibilidade de criação de iniciativas destinadas à manutenção da paz, mas isso não significa, contudo, que o sistema geral não permita aproximações de caráter cultural, econômico ou social ${ }^{678}$.

verbis": "The jurisdiction of all these Courts and, in the very nature of the process, of arbitral tribunals depends on consent. The need for consent is axiomatic, for it is the consequence of the sovereignty of States. Yet, once given, the scope of the consent varies enormously. Once the treaties constituting the European Community are accepted, consent is given to the very wide jurisdiction of the Court of the Communities and, therefore, one is dealing with what appears. To be a 'compulsory' jurisdiction."

${ }^{675}$ GUGGENHEIM, Paul. Les principes de droit international public. In: Recueil des Cours. Academie de Droit International de la Haye, Volume 80, 1952-I, pp. 01-189. p. 116. "In verbis“": "Le droit international gnéral admet que l'acte illicite soit constaté par les parties en litige et que ses consequences aussi soient exécutées dans le cadre de leur appréciation unilaterale. Mais les parties peuvent conclure une convention en vue de soumettre le litige à un tribunal. Toutefois, la constitution d'un tribunal arbitral ou judiciaire a encore aujourd'hui un caractère facultatif. La Cour permanente de Justice internationale l'a dit très nettement dans l'affaire de la Carélie orientale (Série B, $\mathrm{n}^{\circ}$ 5, p. 27: «Il est bien établi en droit international qu'aucun Etat ne saurait être obligé de soumettre ses différends avec ls autres Etats, soit à la médiation, soit à l'arbitrage, soit enfin à n'importe quel procédé de solution pacifique sans son consentement.“

${ }^{676}$ SABA, Hanna. Les accords régionaux dans la Charte de l'O.N.U. In: Recueil des Cours. Academie de Droit International de la Haye, Volume 80, 1952-I, pp. 635-720. p. 684. "In verbis“: "Il n'en résulte pas néanmoins que la Charte ne contienne aucun critère permettant de déterminer ce que doit être un accord régional. Aux termes de l'article '52, $\S 1$, de la Charte, les accords régionaux sont des traités qui ont un caractére régional, que ces traités aient, comme le voulait la proposition égyptienne, établi des organes spéciaux, l'article 52 dit des organismes, pour procéder aux activités qu'ils prévoient, ou que pareils organismes n'aient pas été constitus, auquel cas ce sont les Etats parties à ces accords qui procèdent directement à ces activités.“

${ }^{677}$ SABA, Hanna. Les accords régionaux dans la Charte de l'O.N.U. In: Recueil des Cours. Academie de Droit International de la Haye, Volume 80, 1952-I, pp. 635-720. pp. 677-678. "In verbis“: "Les préoccupations des délégations visaient à cet gand deux domaines d'action déterminés : $1^{\circ}$ ) d'abord le règlement pacifique par l'organisation régionale de tout différend pouvant survenir entre ses membres, et $2^{\circ}$ ) l'action coercitive de l'organisation régionale en cas d'agression contre l'un de ses membres, et la conciliation du système de sécurité régionale avec selui de la sécurité collective. [...] Par contre, la question de l'autonomie des organismes régionaux en matière d'action coercitive fut infiniment plus dificille à résoudre."

${ }^{678}$ SABA, Hanna. Les accords régionaux dans la Charte de l'O.N.U. In: Recueil des Cours. Academie de Droit International de la Haye, Volume 80, 1952-I, pp. 635-720. p. 686. "In verbis“: "Les accords régionaux visés 
Mais complicada que a comparação das estruturas institucionais decisórias dos sistemas internacionais de solução de controvérsias com aquela observada internamente nos estados seria, entretanto, a identificação entre os instrumentos disponíveis em ambas as esferas para garantir o cumprimento das decisões proferidas.

Não existe um poder de coerção centralizado na esfera global e a execução de uma sentença ou laudo depende da vontade dos potenciais violadores do direito. Ocorre que, quando os potenciais descumpridores das regras são, ao mesmo tempo, os detentores do poder de coerção, impossível se faz a estruturação de um sistema coeso e confiável de aferição de legalidade capaz de garantir a coerência do sistema ${ }^{679}$.

No sistema multilateral principal, o Conselho de Segurança e a Assembléia Geral são reconhecidos como órgãos com atribuições para a solução de controvérsias entre os membros do acordo geral - considerando-se, nesse ponto, a facultatividade da jurisdição obrigatória da Corte. A investidura de ambos nesse poder ocorre mesmo quando as partes do litígio asseguram estar buscando uma solução consensuada. Tal questão já foi analisada pelo Comitê de Especialistas do Conselho e decorreria da responsabilidade geral de manutenção da paz estabelecida no artigo 24 da normativa constitutiva da organização ${ }^{680}$.

A atuação do Conselho de Segurança das Nações Unidas como órgão de solução de controvérsias do sistema internacional possui, portanto, na ameaça à paz seu limite reduzido a termo em tratado. Questões de menor importância que não apresentem riscos à integridade soberana dos estados não seriam, assim, suscetíveis de apreciação por esse órgão multilateral

par la Charte sont, par ailleurs, ceux qui se réferent aux questions relatives au maintien de la paix et de la sécurité. Ceci ne signifie pas du tout, comme nous le verrons, qu'un accord régional ne puisse pas comportés d'autres dispositions ni prévoir, par exemple, comme le voulaient certaines délégations, une coopération économique, sociale et culturelle entre ses membres."

${ }^{679}$ CLAPHAM, Andrew. Brierly's law of nations. Oxford: Oxford University Press, 2012. p. 119. "In verbis": "The difficulties of introducing any radical change into the presence means of enforcing international law are formidable. The problem has little analogy with that of the enforcement of law within the state, and the idea of an 'international police force' tends to make it appear much simpler than it really is. Police action suggests the bringing to bear of the overwhelming force of the community against a comparatively feeble individual lawbreaker, but such action is more problematic in the international sphere, where the potential law-breakers are states, and the preponderance of force may even be on the side of the law-breaking state."

${ }^{680}$ SABA, Hanna. Les accords régionaux dans la Charte de l'O.N.U. In: Recueil des Cours. Academie de Droit International de la Haye, Volume 80, 1952-I, pp. 635-720. p. 700. "In verbis“: "La compétence du Conseil de Sécurité et, sans doute, aussi celle de l'Assemblée générale, subsiste alors même que toutes les parties au différend indiqueraiment que celui-ci est en voie de solution, et demanderaient le désaisissement du Conseil. C'est rapport du Comité d'experts du Conseil de Sécurité, en date d'avril 1946, et relatif l'affaire d'Iran, indique que a grande majorité du Comité estimait que bien que l'Iran ait demandé le retrait de plainte et que l'U. R. S. $\mathrm{S}$ contre laquelle elle était dirigée, ait conclu au desaisissement du Conseil, ce dernier demeurait compétent pour en traiter en vertu de la responsabilité principale du maintien de la paix et de la sécurité internationale que lui confère l'article 24 de la Charte." 
específico $^{681}$. Desse modo, percebe-se que na estrutura institucional das Nações Unidas tanto o Conselho de Segurança quanto a Assembléia Geral possuem reconhecimento pela doutrina como órgãos políticos que cumprem funções de solução de controvérsias na esfera internacional $^{682}$.

As funções do Conselho de Segurança são, no entanto, muito mais amplas que as da Assembléia Geral. A vinculatividade das resoluções por ele prolatadas e sua atribuição específica de garantir a manutenção da paz lhe dão contornos mais claros que os da Assembléia como instância para a solução de controvérsias por ser dotado de capacidade de dar eficácia às suas decisões por meio do uso da força ${ }^{683}$. Esse constituiria, assim, o primeiro

${ }^{681}$ JIMENEZ DE ARECHAGA, Eduardo. Le traitement des différends internationaux par le Conseil de Sécurité. In: Recueil des Cours. Academie de Droit International de la Haye, Volume 85, 1954-I, pp. 01-105. p. 13. "In verbis“: "C'est là une conséquence du fait déjà signalé: la raison d'etre fondamentale, le but supréme de l'organisation est de maintenir la paix et la sécurité inernationales; le règlement pacifique des différends n'est qu'une fonction instrumentale, l'un des moyens dont disposent les Nations Unies pour atteindre ce but primordial. [...] Le Conseil sera, en principe, indifférent à l'égard du règlement des litiges, à moins que l'ordre public international soit susceptible d'être troublé. Ainsi qu'il a été dit dans le rapport du Comité respectif, à la Conference de San Francisco, «en princlpe, l'Organisation ne doit pas se charger de difrerends de minime importance qui ne mettent pas en danger la paix entre les parties ». Cette limite imposée aux fonctions du Conseil s'appuie aussi sur des considérations d'ordre pratique, comme par exemple, celle d'éviter que le Conseil puisse être accablé par tous les conflits, même les plus insignifiants, qui pourraient surgir entre les Etats.“

${ }^{682}$ BROWNLIE, Ian. Principles of public international law. Oxford: Oxford University Press, 2003. p. 671. "In verbis": "The settlement of disputes between states by judicial action is only one facet of the enormous problem of the maintenance of international peace and security. In the period of the United Nations Charter the use of force by individual states as a means of settling disputes is impermissible. Peaceful settlement is the only available means. However, there is no obligation in general international law to settle disputes, and procedures for settlement by formal and legal procedures rest on the consent of the parties. The context of judicial settlement in international relations is thus very different to that of the function of municipal courts, and this type of settlement is relatively exceptional in state relations.[...] The large field of settlement by political means, it must not be thought that there is a complete divorce between the two approaches to settlement. Political organs, like the General Assembly and Security Council of the United Nations, may and often do concern themselves with evidence and legal argument, although the basis for action remains primarily political. The General Assembly, in particular, has provided a useful forum for settling disputes although its work in this respect tends to be forgotten. So also governments conducting negotiations with a view to settling disputes commonly take legal advice, and confidential legal advice from specialist advisers to the executive maybe weighty and reasonably objective."

${ }^{683}$ PODESTÁ COSTA, L.A. Derecho internacional público - tomo II. Buenos Aires, Tipográfica Editora Argentina, 1955. p. 330. "In verbis": "Las atribuciones de la Asamblea General y del Consejo de Seguridad difieren considerablemente: el Consejo de Seguridad posee atribuciones exclusivas y amplísimas, según se vera más adelante, en lo que respecta a las controversias y conflictos internacionales, y las atribuciones de la Asamblea General son muy limitadas en ese campo. Debe observarse que, según lo expresa el articulo 24 de la Carta, 'a fin de asegurar acción rápida y eficaz por parte de las Naciones Unidas, sus miembros confieren al Consejo de Seguridad la responsabilidad primordial de mantener la paz y la seguridad internacionales, y reconocen que el Consejo de Seguridad actúa a nombre de ellos al desempeñar las funciones que le impone aquella responsabilidad'; y el artículo 25 agrega: 'Los miembros de las Naciones Unidas convienen en aceptar y cumplir las decisiones del Consejo de Seguridad de acuerdo con esta Carta'. La Asamblea General tiene solamente funciones de carácter deliberativo, de fiscalización y de administración. Sus deliberaciones, en lo relativo al mantenimiento de la paz y de la seguridad internacionales pueden traducirse en recomendaciones dirigidas a los otros órganos o a los miembros de la Organización de las Naciones Unidas, con respecto a los poderes y funciones de cualquiera de los Órganos creados por la Carta, como también en lo referente a los 
órgão internacional - não jurisdicional, gize-se - dotado de atribuições para dirimir conflitos que tem verdadeiramente meios de garantir a eficácia de suas decisões.

Assim sendo, a doutrina ao mesmo tempo em que reconhece no Conselho de Segurança características executivas, de "governo" das Nações Unidas, identifica seu atributo de emitir decisões de caráter obrigatório. Em sendo tais decisões em grande medida de conteúdo extrativo de normatividade - de interpretação da garantia à paz inscrita no tratado, possível se faz reconhecer também, portanto, características jurisdicionais ${ }^{684}$. A função executiva parece, na verdade, atípica.

Importante se faz ressaltar, neste momento, que o Conselho de Segurança não conseguiu cumprir o papel de garantidor da paz mundial que lhe foi atribuído na carta ${ }^{685}$ e que a Assembléia Geral acabou ampliando suas atribuições e ocupando o espaço vago que cabia ao órgão político máximo da organização ${ }^{686}$.

Dúvidas se apresentam, ainda, em relação à possibilidade de revisão jurisdicional das decisões do Conselho pela Corte Internacional de Justiça. A carta parece omissa nesse sentido e essa pode ser uma das evoluções possíveis vislumbráveis no desenvolvimento natural da

principios generales de la cooperación para asegurar la paz, el desarme y la regulación de los armamentos, etc.; pero no puede hacer recomendaciones al Consejo de Seguridad cuando éste, en un caso dado, se halla desempeñando las funciones que le asigna la Carta."

${ }^{684}$ SIMMA, Bruno. From bilateralism to community interest in international law. In: Recueil des Cours. Academie de Droit International de la Haye, Volume 250, 1994-VI, pp. 217-384. p. 264. "In verbis“: "Let us now turn to the security council and discuss whether, and in what regard, it could be called a world Government. Since the end of the Cold War the Security Council has undoubtedly established itself as the most dynamic element within the United Nations system. In the present context, my observations will be more or less confined to the most interesting (as well as most controversial) function of the Council, i.e. its capacity to adopt decisions which are legally binding on Member States. The constitutional starting point in this regard is Article 25, according to which 'the Members of the United Nations agree to accept and carry out the decisions of the Security Council in accordance with the present Charter'."

${ }^{685}$ VALLAT, Francis Aimé. The competence of the United Nations General Assembly. In: Recueil des Cours. Academie de Droit International de la Haye, Volume 97, 1959-II9I, pp. 203-292. p. 247. "In verbis": "These provisions of the Charter were based on two assumptions - (a) that the Security Council would exercise its function of keeping the peace and (b) that armed forces would be made available to it under arguments concluded in accordance with Article 43. The Charter made no express provision to meet the contingency, which has, of course, occurred, of complete failure to conclude any of these agreements. On the other hand, those who drafted the Charter were not blind to the possibility that the Security Council might not exercise its function to the satisfaction of all Members of the Organization."

${ }^{686}$ VALLAT, Francis Aimé. The competence of the United Nations General Assembly. In: Recueil des Cours. Academie de Droit International de la Haye, Volume 97, 1959-II9I, pp. 203-292. p. 246. "In verbis": "It is common knowledge that the Security Council has failed to meet its responsibility and that the role of guardian of the peace has passed to the General Assembly. For the purpose of considering how this has happened and under what authority, it is first necessary to recall the respective functions and powers of the Security Council and the General Assembly as they appear from the text of the Charter." 
organização $^{687}$. Sob tal aspecto, a função executiva poderia ser considerada típica e o órgão teria assumido a função jurisdicional atípica como principal em razão da inviabilidade de

transferi-la integralmente a um órgão jurisdicional verdadeiramente autônomo, não composto por membros da organização ${ }^{688}$.

De todo o retratado, restaria que a solução pacífica de controvérsias se encontra hoje consolidada como uma das premissas basilares da ordem internacional reiterada por diversas vezes por seus membros, por exemplo, no desenvolvimento histórico-normativo da Organização das Nações Unidas ${ }^{689}$.

Especificamente quanto à Corte Internacional de Justiça, trata-se de órgão jurisdicional que não possui hierarquia superior àqueles dos outros sistemas de solução de

${ }^{687}$ SIMMA, Bruno. From bilateralism to community interest in international law. In: Recueil des Cours. Academie de Droit International de la Haye, Volume 250, 1994-VI, pp. 217-384. pp. 279-280. "In verbis“: "This leads to the issue of the feasibility - or desirability - of judicial review of Council actions, corresponding to the model of domestic constitutional courts and certain international courts, such as the Court of Justice of the European Communities. The question, then, is whether the Hague Court, after all 'the principal judicial organ of the United Nations', may also function as a constitutional court. In this regard the law of the Charter is extremely hesitant. Nowhere does it provide for the possibility of general judicial review of Council or Assembly decisions. And, as the Court itself has remarked, United Nations organs can - at least prima facie themselves determine the scope of their respective competences."

688 SIMMA, Bruno. From bilateralism to community interest in international law. In: Recueil des Cours. Academie de Droit International de la Haye, Volume 250, 1994-VI, pp. 217-384. pp. 280-281. "In verbis": "Under existing Charter law, there are only two ways by which the International Court of Justice (ICJ) could review the legality of a Security Council decision. First, according to Article 96 of the Charter, the General Assembly or the Security Council may request the Court to give an advisory opinion 'on any legal question'. However, these opinions are neither legally binding per se nor always respected in practice, as the example of the Certain Expenses case has shown. Besides, it is hard to imagine a request by the General Assembly or the Council itself for the Court to review a Council decision. Thus, since judicial review would have to serve the purpose of protecting the right of individual States not to be subjected to illegal Security Council measures, the avenue of an advisory opinion could not provide sufficient protection. In theory, a second avenue leading to judicial review of Security Council resolutions would be open in the context of contentious proceedings initiated before the Court by two or more States, In these circumstances, the Court could be asked, incidenter, to judge the legality of a Security Council decision relevant to the inter-State proceedings before it."

${ }^{689}$ BOWETT, Derek William. Contemporary developments in legal techniques in the settlement of disputes. In: Recueil des Cours. Academie de Droit International de la Haye, Volume 180, 1983-II, pp. 169-235. p. 177. "In verbis": "The principle of settlement of disputes by peaceful means is, of course, one of the principles basic to the whole structure of international society. Its juxtaposition in Article 2 (3) of the United Nations Charter with Article 2 (4) is no accident of drafting: for it is the corollary of the prohibition of the use or threat of force as a means of resolving international disputes. This emerges clearly from the Manila declaration on the Peaceful Settlement of Disputes adopted by the General Assembly in 1982 at its thirty-seventh session: for there the constant reiteration of the obligation not to use force for the settlement of disputes emphasizes the fundamental link between these two Charter provisions. Yet settlement of disputes by peaceful means is not the same as settlement by legal means. Realistically, we have to accept that the vast majority of disputes will be settled by political rather than by legal means. Settlement is normally achieved by negotiation, with or without the assistance of some third party. The third party may be a State or an organ of some organization such as the Security Council, or the Council of Ministers of the Organization for African Unity, or the Council of the Arab League. And the third party involvement may be formalized good offices, or mediation, or conciliation; or it may be quite informal, and undertaken as a more Or less routine part of the functioning of the many international organizations, or even the diplomatic function." 
controvérsias no atual sistema global de direito das gentes, mas o diálogo - tímido e progressivo - entre essas estruturas pode permitir que se vislumbre em algum momento a adoção de critérios hierárquicos para evitar eventuais antinomias hermenêuticas ${ }^{690}$.

$\mathrm{O}$ acesso de organizações internacionais à Corte Internacional de Justiça como demandante já encontra hoje defensores na doutrina, os quais se sustentam, principalmente, no argumento de que os sujeitos que, em regra, compõem essas estruturas - estados possuem a referida atribuição e que isso, conseqüentemente, habilitaria tais associações como atuação do conjunto de cada um dos investidos da prerrogativa isoladamente ${ }^{691}$.

Em contexto local, não se pode deixar de mencionar o Tribunal de Justiça das Comunidades Européias e seu papel fundamental na relativização de soberanias e na afirmação da prevalência do direito regional. Esse constitui o mais emblemático exemplo do exercício da função judiciária na esfera internacional de forma promotora de seu amadurecimento sistêmico $^{692}$.

${ }^{690}$ CHARNEY, Jonathan I.. Is international law threatened by multiple international tribunals?. In: Recueil des Cours. Academie de Droit International de la Haye, Volume 271, 1998, pp. 101-382. p. 371. "In verbis": "If I am correct that a hierarchical judicial system will not be established, two factors will work to counter those centrifugal forces. First, as mentioned above, the ICJ must continue to maintain its intellectual leadership role in the field. If it does so, the other tribunals will be under pressure to abide by the ICJ's determinations regarding the rules of international law. Second, the other tribunals and the ICJ should be encouraged to increase the dialogue that already exists among them."

691 ARÉCHAGA, Eduardo Jiménez; ARBUET-VIGNALI, Heber; PUCEIRO ROPOLL; Roberto. Derecho internacional público - Tomo III. Montevideo: Fundación de Cultura Universitaria, 2012. p. 155. "In verbis": "En cambio, en el procedimiento consultivo las Organizaciones Internacionales, y no solo las públicas, sino también las privadas, como la Liga Internacional de Derechos del Hombre, por ejemplo, pueden hacer llegar a la Corte comunicaciones escritas e incluso son invitadas a hacerse oír en audiencia pública (art. 66, parágrafo $2^{\circ}$ del Estatuto). Existen hoy razones persuasivas para conceder acceso como partes ante la Corte a las Organizaciones Internacionales públicas o gubernamentales, esto es, compuestas por Estados. Si los Estados, actuando en su capacidad individual, son admitidos como partes ante la Corte, no hay motivo fundado para negarles esa facultad cuando actúen en forma conjunta. Son actualmente numerosos los tratados celebrados por organismos internacionales gubernamentales con los Estados y entre sí, En ellos no existe posibilidad de recurrir a la Corte, salvo que se utilice el expediente de acudir a su jurisdicción consultiva, dándole por anticipado carácter obligatorio.”

${ }^{692}$ SEBESTA, Lorenza. Del balance de poder a la integración europea: una reflexión histórica. In: NEGRO, Sandra C. (Coord.). Lecturas sobre integración regional y comercio internacional. Buenos Aires: La Ley, 2012. pp. 587-609. p. 588. "In verbis": "La característica más revolucionaria del proceso de integración europeo ha sido identificada por varios autores, especialmente en las fases iniciales de su desarrollo, bajo la fuerte impronta de las audaces sentencias del Tribunal de Justicia, en su capacidad para erosionar la soberanía de los estados miembros. Sucesivamente, esta interpretación dio espacio a una visión opuesta que hacía referencia a la "obstinación" de los mismos - de acuerdo con la célebre fórmula de Stanley Hoffmann, profundizada luego con ejemplos históricos por Alan Milward - y al uso sagaz que habían sabido hacer de la integración con el objeto de mejorar su inserción en la cambiante estructura económica y comercial internacional. Más recientemente, la atención de los estudiosos se ha orientado más bien hacia la novedosa naturaleza del sistema político que ha tomado forma en el curso de los últimos cincuenta años en Bruselas. Aun no existe acuerdo sobre ninguno de los tres temas, siendo todos ellos objeto de una exuberancia analítica realmente sorprendente." 
Direito e política são lados de uma mesma face. A política está na formação e na aplicação do direito e vice-versa. O que existe, na verdade, são espectros, nos quais se podem classificar, por exemplo, os litígios internacionais entre o direito e a política. Quando mais próximos da política que do direito, a doutrina que pode auxiliar melhor sua solução seria a da ciência política e das relações internacionais. $\mathrm{O}$ pensamento jurídico teria mais serventia quando o litígio tem como fonte a violação de uma norma internacional ${ }^{693}$. Nos dias atuais, contudo, impossível se faz vislumbrar um conflito jurídico que não possua elementos políticos e, na outra ponta, um conflito estritamente político, que não traz dúvidas quanto à violação ou não de uma regra do direito das gentes.

As características de autonomia, de institucionalidade permanente, de obrigatoriedade de decisões e do reconhecimento do direito internacional como fonte, todas atribuídas aos tribunais internacionais, aproximam o exercício da função judiciária na esfera extraestatal à organização interna do poder do estado. Vários são os exemplos de tribunais que apresentam tais contornos tipicamente atribuídos ao "poder" judiciário interno de um estado ${ }^{694}$.

Grande entrave se impõe, entretanto, no fato de o exercício jurisdicional não ter se desenvolvido de maneira uniforme e hierárquica no contexto mundial. Não existe, conforme reafirmado diversas vezes nesse estudo, uma corte suprema do mundo e cada sistema tende a estabelecer seu próprio esquema de solução de controvérsias que se ocupa apenas do direito

\footnotetext{
${ }^{693}$ VISSCHER, Charles de. Cours général de principes de droit international public. In: Recueil des Cours. Academie de Droit International de la Haye, Volume 86, 1954-II, pp. 445-556. p. 551. "In verbis": "Comme toutes les sciences politiques, la science des relations internationales se doit d'observer dans leur réalité totale tous les aspects des rapports internationaux. La mission du droit n'est pas la même : le droit est discipline normative. Or qui dit norme, dit précepte et jamais le précepte ne se confond avec le fait. Il y a, au départ même de toute élaboration du droit, un choix, une sélection des éléments sociaux. Ceux-là seuls sont retenus qui sont conçus comme répondant à certaines fins et qu'un ensemble de caractères spécifiques désigne comme juridiquement utilisables à la technique du droit.“
}

${ }^{694}$ ACCIOLY, Hildebrando; NASCIMENTO E SILVA, G.E. do; CASELLA, Paulo Borba. Manual de direito internacional público. São Paulo: Saraiva, 2011. p. 833. "In verbis”: “Os tribunais e as cortes internacionais são entidades judiciárias permanentes, compostas de juízes independentes, cuja função é o julgamento de conflitos internacionais tendo como base o direito internacional, de conformidade com um processo preestabelecido e cujas sentenças são obrigatórias para as partes. Em princípio, as questões são submetidas aos tribunais internacionais permanentes por estados, mas nada impede que uma ou ambas as partes sejam organizações internacionais. A possibilidade de ser criado um tribunal de caráter permanente foi suscitada por ocasião da Segunda Conferência da Paz de Haia; mas somente viria a ocorrer mais tarde. Na prática dos estados, na atuação das organizações internacionais, nas decisões e pareceres, emanados dos tribunais internacionais, com destaque inevitável para a Corte Internacional de Justiça, sua predecessora, a Corte Permanente de Justiça Internacional, ao lado destas, permanece a mais que centenária Corte Permanente de Arbitragem, somando-se-lhes outros tribunais internacionais, como o Tribunal Internacional do Mar, o Tribunal Penal Internacional, bem como os Tribunais penais internacionais ad hoc (desde Nuremberg e Tóquio, até Ruanda e ex-Iugoslávia), e os tribunais regionais, tais como as Cortes Européia e Interamericana de direitos humanos (e equivalentes de outras regiões).” 
criado e desenvolvido nos limites daquele tratado ou organização ${ }^{695}$. A possibilidade de um estado não ser compelido a cumprir o internacionalmente acordado ou reconhecido como vinculante a toda a comunidade internacional realmente ameaça a ordem internacional, mas a solução hierárquica como única alternativa que se apresentaria ao sistema não deve $\operatorname{prosperar}^{696}$.

Importante fator que denota, por outro lado, identidade entre os exercícios interno e externo da função judiciária tem lugar na possibilidade de um tribunal atuar, tal qual cada vez mais seus análogos estatais, de maneira concretiva, isto é, não apenas como extratores de normatividade, mas também como fontes de direito ${ }^{697}$. Não se podem negar as dificuldades de se garantir o cumprimento das regras internacionais e a execução das decisões de tribunais internacionais, mas vincular a eficácia do direito à eficácia dos meios coercitivos constitui reducionismo. $\mathrm{O}$ cumprimento seria a finalidade a ser buscada e a coerção apenas um dos meios para atingi-la ${ }^{698}$.

\footnotetext{
${ }^{695}$ ACCIOLY, Hildebrando; NASCIMENTO E SILVA, G.E. do; CASELLA, Paulo Borba. Manual de direito internacional público. São Paulo: Saraiva, 2011. p. 833. "In verbis": “Aos poucos, novos tribunais internacionais permanentes vão surgindo com o objetivo de adjudicar ampla gama de problemas, podendo-se mencionar os tribunais de caráter universal e os de natureza regional. Podem ter funções amplas, conforme ocorre com a CIJ, ou então ter um objetivo restrito, como ocorre com o Tribunal Internacional do Direito do Mar, criado pela Convenção sobre o Direito do Mar, com sede em Hamburgo."
}

${ }^{696}$ WRIGHT, Quincy. The strengthening of international law. In: Recueil des Cours. Academie de Droit International de la Haye, Volume 98, 1959-III, pp. 01-295. p. 44. "In verbis": "The absence of an ultimate jurisdiction able to settle all international disputes which have resisted other modes of settlement has often been considered the major weakness of international law. In so far as each State can be the ultimate judge in its own case, it has been said, there is no law, and war -the final court of princes-will eventually be resorted to. If some States are under obligations to submit to international jurisdiction and others are not, equal protection of law is denied, as it is if self-help is the only remedy, because it is no remedy for the weak. This argument assumes that the essence of law, as of peace, resides in the certainty of authoritative third party judgment, rather than in the clarity and comprehensiveness of the rules, principles and standards of conduct sanctioned by the legal community."

${ }^{697}$ ACCIOLY, Hildebrando; NASCIMENTO E SILVA, G.E. do; CASELLA, Paulo Borba. Manual de direito internacional público. São Paulo: Saraiva, 2011. p. 833. "In verbis": "A construção do direito internacional, no contexto pós-moderno, tem marcos intrinsecamente internacionais específicos, e estes constituem as ferramentas básicas de trabalho para os profissionais da área: ninguém pode estudar e pretender conhecer direito internacional sem manejar as bases da jurisprudência internacional (especialmente da Corte Internacional de Justiça, sua predccessora, a Corte Permanente de Justiça Internacional, e da Corte Permanente de Arbitragem)."

${ }^{698}$ DAMROSCH, Lori Fisler. Enforcing international law through non-forcible measures. In: Recueil des Cours. Academie de Droit International de la Haye, Volume 269, 1997, pp. 09-250. p. 23. "In verbis": "[...] I am convinced that the truly "misguided" attitude would be to conclude that enforcing international law is unnecessary or unrealistic. It may well be true that compliance is the ultimate goal and enforcement is merely a means to that end ; and if non-enforcement strategies are more effective than coercive ones in inducing certain kinds of compliance, then of course it would make sense to favour the policy most likely to yield the desired result. But this does not mean abandoning enforcement as one among various strategies for achieving compliance." 
A falta de uma estrutura hierárquica à jurisdição internacional torna, de fato, a uniformização das decisões impossível, mas a busca da coerência por parte das cortes internacionais parece nítida e não haveria que se falar em ameaça à unidade sistêmica pela multiplicação de tribunais ${ }^{699}$.

O abandono de soluções políticas para litígio em favor de sistemas jurisdicionais para dirimir controvérsias constitui um dos mais importantes passos para a institucionalização definitiva de uma organização internacional e, portanto, de sua equiparação aos estados na estruturação e no exercício de poder na esfera internacional ${ }^{700}$.

Tampouco a multiplicação dos tribunais internacionais no fim do século $\mathrm{XX}$ representaria ameaça à unidade do direito internacional. Suas bases principiológicas comuns tornam a autonomia entre eles meramente aparente e, além disso, são construídos paulatinamente meios diretos e indiretos de comunicação. A multiplicidade de sistemas jurisdicionais sobre a mesma matéria não significa necessariamente a fragmentação do direito internacional $^{701}$.

Essa apenas ocorreria caso os distintos tribunais não mantivessem coerência quanto seu entendimento do direito e não compartilhassem a mesma dialética jurídica. Observados os sistemas de solução de controvérsia que se sobrepõem atualmente, as duas premissas apontadas parecem ser respeitadas e contribuir à manutenção da unidade do direito

${ }^{699}$ CHARNEY, Jonathan I.. Is international law threatened by multiple international tribunals? In: Recueil des Cours. Academie de Droit International de la Haye, Volume 271, 1998, pp. 101-382. p. 347. "In verbis“: "The increasing number of international law tribunals without a fully effective hierarchical system makes complete uniformity of decisions impossible. On the other hand, it is clear that the continuing specialized international tribunals tend to follow the reasoning of their prior decisions. Furthermore, the views of the ICJ, when on point, are given considerable weight and those of other international tribunals often are considered. This is not unlike domestic legal systems. Thus, in my opinion, an increase in the number of international tribunals appears to pose no threat to the international legal system."

${ }^{700}$ WALDOCK, Humphrey. General course on public international law. In: Recueil des Cours. Academie de Droit International de la Haye, Volume 106, 1962-II, pp. 01-251. p. 119. "In verbis“: "The use of the Court to resolve the constitutional problem of the United Nations, of which it is the 'principal judicial organ' is, of course, entirely logical, as the Court itself has pointed out more than once. But the United Nations cannot yet be said to regard recourse to the judicial process as the normal means by which a legal constitutional question should be settled. When the competence of the General Assembly or Security Council to deal with a matter has been challenged by individual States, the body in question has almost consistently declined to give serious consideration to the constitutional issue and has simply asserted its competence. The reluctance of the political organs to obtain the Court's opinion as to their Own competence is to be regretted ; for the constitutional structure of the United Nations would in the long run be greatly strengthened by more recourse to the Court for resolving disputed questions."

701 INTERNATIONAL LAW COMMISSION. Report of the Study Group of the International Law Comission. UN Doc A/CN.4/L.682. 2006. p. 245. "In verbis": "This is the background to the concern about fragmentation of international law: the rise of specialized rules and rule-systems that have no clear relationship to each other. Answers to legal questions become dependent on whom you ask, what rule-system is your focus on." 
internacional $^{702}$. As propostas de reforma dos sistemas internacionais de solução de controvérsias podem ser formuladas tomando por base esquemas teóricos mais gerais e se afastar de perspectivas específicas ${ }^{703}$.

O atual processo de institucionalização da jurisdição internacional já apresenta características hábeis a refutar concepções fragmentárias da ordem internacional. Sua conformação sistêmica deve ser, ressalte-se, sustentada sobre duas perspectivas, uma operacional e outra conceitual. Operacionalmente, a possibilidade de antinomias e decisões conflitantes emanadas por distintos foros internacionais deve ser evitada, por exemplo, por uma maior comunicação entre os órgãos jurisdicionais. Conceitualmente, os sistemas devem, antes de analisar o interesse das partes envolvidas em um litígio, observar o interesse geral da comunidade internacional ${ }^{704}$.

O exercício da função jurisdicional se encontra em franco crescimento e consolidação na esfera internacional. Cortes judiciais e tribunais arbitrais têm se proliferado e, de acordo com o que se defende neste estudo, constituem, por exemplo e ao lado da personalidade jurídica, elemento caracterizador de organizações internacionais.

${ }^{702}$ CHARNEY, Jonathan I.. Is international law threatened by multiple international tribunals? In: Recueil des Cours. Academie de Droit International de la Haye, Volume 271, 1998, pp. 101-382. p. 347. "In verbis“: "[...] in several core areas of international law the different international tribunals of the late twentieth century do share a coherent understanding of that law. Although differences exist, these tribunals are clearly engaged in the same dialectic. The fundamentals of general international law remain the same regardless of which tribunal is deciding the issue. This conclusion is probably also applicable to other areas of international law and other tribunals that were not studied. One could predict that this past experience will continue into the future. Certainly, the situation is not perfect and improvements could be prescribed.“

703 SLAUGHTER, Anne-Marie. International law and international relations. In: Recueil des Cours. Academie de Droit International de la Haye, Volume 285, 2000, pp. 09-249. p. 190, “in verbis“. " “...] proposed reforms of the WTO dispute resolution process directly engage different conceptions of how States behave in the international system. Professor Richard Shell has drawn on both Institutionalism and Liberalism in formulating WTO legalism. These different models, in turn, give rise to different reform proposals and different prescriptions for how WTO panellists and members of the Appellate Body should approach their task of interpreting provisions of the WTO agreements. Moving beyond these models, it is possible to apply more general theories of supranational adjudication to assess the likely impact of a proposal to expand WTO standing to private parties, including not only commercial interests but also NGOs.“"

${ }^{704}$ CASELLA, Paulo Borba. Evolução institucional do direito internacional: à luz do cinqüentenário do conceito de direito de Hart (1961). In: Revista Brasileira de Filosofia. Ano 60, Vol. 236, janeiro-junho, 2011. pp. 313 329. pp. 328-329. "In verbis": "A institucionalização da idéia de jurisdição no plano internacional, no estado presente, dota o direito internacional pós-moderno de mecanismos adequados para responder à antiga critica que contra este se formulava, no sentido de contar com a dimensão de normas, mas carecer de procedimentos de implementação. Referida evolução institucional deve, contudo, considerar duas vertentes: uma operacional e outra conceitual: - operacionalmente, cumpre evitar que a anterior ausência suceda a ocorrência de fragmentação, como poderia resultar de decisões conflitantes, entre as diferentes instituições judiciais internacionais, antes mencionadas; e, também, - conceitualmente, devem as jurisdições internacionais atuar sempre no sentido de se manter o foco de toda a sua ação voltado para o perfazimento da dimensão do interesse comum, no direito internacional pós-moderno." 
Em perspectiva mais ampla, a inexistência de sistemas de solução de controvérsias institucionalizados deixaria a ordem internacional à mercê das escolhas políticas dos membros da comunidade global. Ainda que na atualidade não se possa reconhecer uma estrutura organizada de maneira hierárquica e coesa, os sistemas disponíveis buscam cumprir seu papel estabilizando e garantindo a coerência da ordem normativa do direito das gentes.

Assim como internamente, ainda que em freqüência e intensidade muito menor, os sistemas de solução de controvérsias internacionais teriam, inicialmente, funções exclusivamente de extração de normatividade. Com o passar dos anos, esses órgãos de função judiciária passaram a exercer também a concreção e a produzir direito. Tem-se como exemplo dessa nova realidade o reconhecimento paulatino da jurisprudência como fonte do direito das gentes.

Nesse sentido, a percepção da multiplicação dos sistemas de solução de controvérsias como fragmentação, é dizer, como ameaça à unidade do direito global, constituiria perspectiva rasa da realidade da ordem mundial. Teorias fragmentárias partem, portanto, de concepções políticas que, aplicadas ao direito, mostram-se imperfeitas e superficiais.

Sistemas jurisdicionais não exigem, nesse contexto, estruturas hierárquicas ou meios formais de comunicação para compatibilizar seu entendimento da ordem internacional. Mesmo quando não previsto em tratados, tribunais tendem a levar em consideração a competência de outras cortes para estabelecer os limites de suas próprias competências.

Os sistemas normativos internacionais e seus órgãos de solução de controvérsias, ainda que não se encontrem unificados, não se isolam. As cortes se observam por sobre os muros de seus próprios sistemas de direito e buscam, assim, garantir, ainda que assistematicamente, a coerência e a unidade do direito internacional. 


\section{A UNIDADE DO DIREITO INTERNACIONAL, A FOTO E O FILME}

A universalidade do direito internacional que prevaleceu durante toda a idade média teve por base eminentemente o direito romano, reinterpretado e adaptado a concepções jusnaturalistas $^{705}$. A unicidade apontada se viu, contudo, superada na modernidade por questões mormente estruturais decorrentes da multiplicação de ordens normativas estatais. No panorama atual, a relativização da importância da soberania estatal não deve provocar o abandono das técnicas modernas de organização no momento de análise do direito internacional e, nessa toada, não se faz possível negar a presença da política no direito internacional.

Assim, por exemplo, quando utilizado o plano interno dos estados como modelo, percebe-se que o soberano - real ou popular - estabelece as regras que regem determinada sociedade $^{706}$. A mencionada normatividade apenas se manteria estável e seria cumprida, entretanto, por meio da adesão ou pela força. Quando houvesse a adesão espontânea ao marco legal, floresceria o direito ${ }^{707}$. Quando a força prevalecesse, dominaria a política ${ }^{708}$. Urgente se

\footnotetext{
${ }^{705}$ CLAPHAM, Andrew. Brierly's law of nations. Oxford: Oxford University Press, 2012. p. 16. "In verbis": "In brief, the process of expansion and adaptation took the form of admitting, side by side with the jus civile, or original law peculiar to Rome, a more liberal and progressive element, the jus gentium, so called because it was believed or feigned to be of universal application: its principles being regarded as so simple and reasonable that they must be recognized everywhere and by everyone. This practical development was reinforced towards the end of the Republican era by the philosophical conception of a jus naturale which, as developed by the Stoics in Greece and borrowed from them by the Romans, meant, in effect, the sum of those principles which ought co control human conduct, because founded in the very nature of man as a rational and social being. In course of time jus gentium, the new progressive element which the practical genius of the Romans had imported into their actual law, and jus naturale rule, the ideal law conforming to reason, came to be regarded as generally synonymous. In effect, they were the same set of rules looked at from different points of view; for rules which were everywhere observed. i.e. jus gentium, must surely be rules which the rational nature of man prescribes to him, i.e. jus naturale, and vice versa. Medieval writers later developed this conception of a law of nature-sometimes elaborating it in ways which appear to the modern mind both fanciful and tedious; but so powerful was its influence that the Church accepted it into the doctrinal system. St Thomas Aquinas, for example, taught that the law of nature was that part of the law of God which was discoverable by human reason, in contrast with the part which is directly revealed. Such an identification of natural with divine law necessarily gave the former an authority superior to that of any merely positive law of human ordinance, and some writers even held that positive law which conflicted with natural law could not claim any binding force."
}

${ }^{706}$ ROUSSEAU, Jean-jacques. Du contrat social. Paris: Union Générale d’Éditions, 1973. pp. 162-163. “In verbis": "A l'instant que le peuple est légitimement assemblé en conps souverain, toute juridiction du gouvernement cesse, la puissance exécutive est suspendue, et la personne du dernier citoyen est aussi sacrée et inviolable que celle du premier magistrat, parce qu'où se trouve le représenté il n'y a plus de représentants."

707 A perspectiva interna do estado aplicável, por que não, também ao direito internacional como descrita por ROUSSEAU, Jean-jacques. Du contrat social. Paris: Union Générale d'Éditions, 1973. pp. 125-126. "In verbis": "Il y a cette différence essentielle entre ces deux corps, que l'État existe par lui-même, et que le gouvernement n'existe que par le souverain. Ainsi la volonté dominante du prince n'est ou ne doit être que la 
faz, nesse momento e por exemplo, questionar em que medida - e se - o direito internacional passou nas últimas décadas das flores à força ${ }^{709}$.

$\mathrm{O}$ direito das gentes centrado na figura do estado, mesmo relativizado, ainda predomina na atualidade. Interessante se faz perceber que o discurso soberano ainda constitui ferramenta de afirmação de novos atores na esfera internacional e que estados se vêem hoje constantemente ameaçados por movimentos locais que buscam autonomia e dar origem a novos sujeitos a partir das parcelas resultantes ${ }^{710}$.

A ordem internacional descolada da lógica da teoria do estado e, portanto, da divisão de funções descrita anteriormente, permite que se desestabilizem os fatores que conformam o poder e favorece o uso desmedido da força por sujeitos de direito internacional. Nesse

volonté générale ou la loi; sa force n'est que la force publique concentrée en lui: sitôt qu'il veut tirer de luimême quelque acte absolu en indépendant, la liaison du tout commence à se relâcher. S'il arrivoit enfin que le prince eût une volonté particulière plus active que celle du souverain, et qu'il usât, pour obéir à cette volonté particulière, de la force publique qui est dans ses mains, en sorte qu'on eût, pour ainsi dire, deux souverains, l'un de droit et l'autre de fait, à l'instant l'union sociale s'évanouiront, et le corps politique seroit dissous."

708 Política como dinâmica do poder de WEBER, Max. Politik als Beruf. Stuttgart: Reclam, 2008. p. 07. "In verbis": ">>Politik $<<$ würde für uns also heißen: Streben nach Machtanteil oder nach Beeinflussung der Machtverteilung, sei es zwischen Staaten, sei es innerhalb eines Staates zwischen den Menschengruppen, die er umschließt."

${ }^{709}$ CASELLA, Paulo Borba. Conceito de sistema, contexto internacional e pós-modernidade. In: ADEODATO, João Maurício; BITTAR, Eduardo C. B. (Org.) - Filosofia e Teoria Geral do Direito: estudos em homenagem a Tércio Sampaio Ferraz Junior por seu septuagésimo aniversário. São Paulo: Quartier Latin, 2011. pp. 1000 1001. "In verbis": "O direito, como regulador da vida em sociedade, serve para excluir ou, ao menos, para limitar o recurso unilateral à força, e ao que, em direito penal interno, se chamaria o exercício arbitrário das próprias razões. Mas esses poderes primitivos se fazem presentes e atuantes, nas ordens internas e, de modo recorrente, no contexto internacional. Para contrapor-se a tais anseios, se fixa o conceito de justiça, e se vão buscar critérios para a implementação deste. A escolha tem que ser feita de maneira clara, entre força e justiça. Quer nas ordens internas, como na internacional. Seja para enfatizar a confrontação, no que se convenciona denominar política de poder, seja para enfatizar a possibilidade - e a necessidade - de construção de operação de estruturas, válidas e eficazes, para a regulação do assim chamado sistema institucional e normativo internacional. A mudança de contexto não muda a natureza e nem a extensão da busca de tal equilíbrio. Somente acrescenta a esta busca mais algumas variáveis, como lhe acresce a percepção da complexidade e da fragilidade, características do nosso tempo."

${ }^{710}$ FRIEDMANN, W.. General course in public international law. In: Recueil des Cours. Academie de Droit International de la Haye, Volume 127, 1969-II, pp. 39-246. p. 233. "In verbis“: "The first model assumes that international society will continue to be built upon the 'sovereign equality' of States, essentially a continuation of the structure of international society, as it prevailed in the eighteenth and nineteenth centuries and as, in theory, it dominates to a large extent even the contemporary structure of international society. The United Nations Charter, the various resolutions on 'friendly relations among nations', the posture and language of the new States. The philosophy and rhetoric of statesmen of 'old' nations, all seem to be predicated upon a coincidence between emotional allegiance to the national State and the reality of political and legal national sovereignty. More than double the number of States claim the attributes of sovereignty as compared with 20 years ago. Certainly the emotions of nationalism have seldom been more evident. While the new States insist on their rights to economic, as well as political and legal sovereignty-largely in reaction to centuries of suppression and lack of independence from which they have emerged-older States, such as Belgium or Canada, are threatened with disruption by the translation of ethnic, cultural, linguistic, and, sometimes, religious differences into demands for separate statehood." 
sentido, o aperfeiçoamento institucional dos sistemas de solução de controvérsias pode conformar também instrumento fundamental de estabilização normativa e de manutenção da unidade jurídica global $^{711}$. Na relação entre o interno e o internacional, o direito internacional tem buscado cada vez mais e a cada dia mecanismos para se fazer cogente internamente e para lançar mão do judiciário local como garante do direito internacional ${ }^{712}$.

O panorama descrito incide sobre importantes matérias e contribui para que se coloquem em dúvida a coerência e a unidade da ordem internacional: dois fundamentos essenciais da teoria jurídica moderna. Diante disso, a doutrina do direito internacional ensaiou na última década certo distanciamento da teoria geral do estado, vertente jurídico-política do estudo do poder. Distanciamento que parece ter sido interpretado pelas abordagens estritamente políticas como afastamento da teoria do direito como um todo.

A observação do direito das gentes como um processo em construção e não como um sistema consolidado e estático pode muito bem servir para conduzir uma análise de suas estruturas com projeção temporal. Aplicadas as premissas da teoria geral do estado, as quais se relacionam fundamentalmente com a organização e a distribuição de forças em uma sociedade, ao direito das gentes, autores costumam depreciar a forma como o poder se organiza no plano global. De fato, a forma centralizada e as estruturas que servem para distribuir funções no plano interno dos estados não pode ser reconhecida no direito internacional. Tampouco governo ou "separação de poderes" se encontram nitidamente observáveis.

A reação mais freqüente é de desconfiança e de perspectiva de abandono dessas teorias pelos internacionalistas. A percepção do direito internacional como um processo, contudo, serve para demonstrar a extrema utilidade do estudo do poder na ordem geral sob a ótica internamente consolidada nos estados. Ainda que constitua um sistema passível de

\footnotetext{
${ }^{711}$ CASELLA, Paulo Borba. Conceito de sistema, contexto internacional e pós-modernidade. In: ADEODATO, João Maurício; BITTAR, Eduardo C. B. (Org.) - Filosofia e Teoria Geral do Direito: estudos em homenagem a Tércio Sampaio Ferraz Junior por seu septuagésimo aniversário. São Paulo: Quartier Latin, 2011. p. 1014. "In verbis": "Dada a natureza intrínseca do sistema internacional, onde as relações entre sujeitos de direito internacional se inscrevem entre iguais, ordenadas segundo a premissa de não haver jurisdição entre iguais par in parem non habet jurisdictio - daí se instaura a necessidade de terceiro, ao qual se atribua em geral a intermediação (seja mediação ou outro mecanismo pacífico de solução de controvérsias) ou submetendo a julgamento de terceiro (quer tribunal arbitral ou tribunal internacional permanente). A jurisdicionalização seria assim dado crucial para o desenvolvimento do direito internacional, enquanto sistema institucional e normativo."

${ }^{712}$ DUPUY, Pierre-Marie. Unité d’application du droit International à l'echelle globale et responsabilité des juges. European Journal of Legal Studies, December, 2007. p. 06. "In verbis": "L'expansion des droits de l'home a encore renforcé le phenomène. Les dizaines de conventions adoptees en ce domaine sont, certes, souvent dotes de mécanismes de suivi destinés à assurer le respect par les états des obligations souscrites."
} 
críticas, percebe-se, por exemplo, na Organização das Nações Unidas clara tentativa de centralização do poder mundial relacionado à paz. Mais especificamente na atuação de um de seus órgãos: o conselho de segurança ${ }^{713}$.

Também os limites entre as jurisdições nacionais e internacionais e o reconhecimento desses contornos de atribuições estaria no centro da vertente jurídica da unidade do direito internacional $^{714}$. As teorias fragmentárias do direito das gentes apresentariam, portanto, ainda que de forma implícita e por meio de abordagens contestadoras, constantes e recorrentes aspectos unitaristas e, apesar de partirem, em regra, de desafios dos modelos positivistas, ou seja, modernos, amparados na técnica e na estruturação sistêmica, não impedem que se encontrem argumentos universalistas hábeis a fortalecer e reafirmar o caráter uno do direito internacional.

A investigação da forma como as instituições cumprem suas funções no direito das gentes surge, nesse contexto, como possível ponto de partida teórico à compreensão do fenômeno descrito ${ }^{715}$. Impõe-se a história e o passado se revela essencial ao entendimento e ao planejamento do futuro ${ }^{716}$.

\footnotetext{
${ }^{713}$ KELSEN, Hans. Théorie du droit international public. In: Recueil des Cours. Academie de Droit International de la Haye, Volume 110, 1953-III, pp. 01-203. p. 51. "In verbis": "Dans le cadre de la Charte des Nations Unies le recours à la force, qui est en principe interdit dans les relations entre Etats pris isolément, est réservé à l'organisation elle-même. Dans l'histoire du droit international la Charte est la première convention tendant à l'universalité qui ait créé un monopole centralisé de la force au profit de la communauté des Etats. Les actions qui sont interdites aux Etats membres sont permises au Conseil de Sécurité.“
}

${ }^{714}$ DUPUY, Pierre-Marie. Unité d'application du droit International à lechelle globale et responsabilité des juges. European Journal of Legal Studies, December, 2007. p. 03. "In verbis": "Chacun voit immédiatement les obstacles qui entravent la pleine realization de cette coordination des orders juridiques passant par leur reconnaissance mutuelle et par l'acceptation effective et pas seulement déclarée, de la part de l'ordre juridique national, de la preeminence de lìnternational sur l'interne, allant ainsi dans le sens d’une integration au moins partielle du second dans le premier."

715 SLAUGHTER, Anne-Marie. International law and international relations. In: Recueil des Cours. Academie de Droit International de la Haye, Volume 285, 2000, pp. 09-249. p. 38, "in verbis": "How do institutions accomplish this function? In a wide variety of ways. In Keohane's account, they decrease the transaction costs of inter-State relations, increase information to reduce uncertainty, and facilitate communication. In addition, institutions can promote learning, create conditions for orderly negotiations, and facilitate linkages in complex negotiations. They can also legitimize or delegitimize different kinds of behaviour. Finally, they can enhance the value of a State's reputation for honouring commitments, facilitate monitoring of State behaviour, and make decentralized enforcement possible by creating conditions under which reciprocity can operate. Other theorists, explored in greater detail below, emphasize the ways in which institutions can create a particular normative environment that helps shape both State identity and interests."

${ }^{716}$ CASELLA, Paulo Borba. ABZ - ensaios didáticos. São Paulo: Imprensa Oficial do Estado, 2009. p. 115. "In verbis": "A sucessão de práticas do passado constituiria o legado do que opera nas referências presentes e deve orientar a formulação de condutas de ação futura. Assim podem ser destacados elementos: a tradição, as referências presentes e parâmetros para orientar a ação futura." 
A racionalização da ordem internacional a partir dos referenciais da teoria geral do estado e sob o prisma da relação entre direito e política decorre de necessidades lógicas e estruturais do sistema. O resgate dos referenciais clássicos pode ser apresentar, por exemplo, como alternativa à melhor coordenação entre os órgãos jurisdicionais ${ }^{717}$. Em certa medida, observa-se que a coordenação das competências entre essas estruturas decisórias passa de alguma forma pela harmonização das diversas ordens normativas internas com a esfera internacional geral ${ }^{718}$.

O direito internacional experimenta a centralização do poder nas organizações internacionais e sua descentralização na aplicação extrema do princípio da autodeterminação dos povos. Sua concentração definitiva em uma organização multilateral teria como premissas a participação de todos os estados do planeta, a atribuição de - e os instrumentos para garantir a paz, meios para combater as mazelas econômicas e sociais da humanidade e, principalmente - gize-se, um sistema de solução de controvérsias capaz de garantir a coerência do sistema internacional de direito ${ }^{719}$.

Em que pese a existência de iniciativas anteriores - como a da Liga das Nações, a doutrina chega a afirmar que um sistema interestatal com características realmente globais

${ }^{717}$ DUPUY, Pierre-Marie. Unité d'application du droit International à l'echelle globale et responsabilité des juges. European Journal of Legal Studies, December, 2007. p. 01. "In verbis": "Cette vision idéale se heurte dans la réalité à une série d’obstacles de natures diverses. Tous ne sont cependant pas dirimants et l’on doit observer tan tune evolution des rapports entre droit interne et droit international qu'au plan strictement international, entre jurisdictions concurrents, la recherché encore tâtonnante d'une meilleure coordination.”

${ }^{718}$ DUPUY, Pierre-Marie. Unité d’application du droit International à l'echelle globale et responsabilité des juges. European Journal of Legal Studies, December, 2007. p. 01. "In verbis": “A cette fin, ce système judiciaire global devrait d’abord s`appuyer sur une simplification harmonisée des rapports entre droits internes et droit international. Il organiserait ensuite, dans l'ordre international lui-même, la coordination des competences entre jurisdictions internationales".

${ }^{719}$ FRIEDMANN, W.. General course in public international law. In: Recueil des Cours. Academie de Droit International de la Haye, Volume 127, 1969-II, pp. 39-246. pp. 235-236. "In verbis": "At the other end of the spectrum, we can envisage a world Community equipped with legal authority and effective power to fulfill the essential needs of mankind in the realms of security and welfare. There have been many blueprints for a constitutional structure of such a world community, ranging from a fully-fledged world State or a world federation, to a vastly improved and more effective version of the United Nations. Whatever the constitutional form of such an organization, it is clear that it must have four requisites: First, it must be universal in scope and membership; an international authority that, like the United Nations at the present time, does not include mainland China and Germany, cannot attain the objective of worldwide security against aggression and want. Second, it must have the authority to preserve the peace of the world by controlling the use of force. And this means that it must have military forces at its disposal, subject to instant call and mobilization, to enforce its decisions. This indeed was clearly foreseen by the framers of the United Nations Charter. If the articles of the Charter concerning the armed forces to be made available to the Security Council had been implemented, this requisite of world order would have been largely fulfilled. Third, the world authority must be equipped with the organization and means to cope with the major social and economic needs of mankind, i. e., principally of the majority of the nations which are usually described as "less-developed". Fourth, it must have judicial or quasi. Judicial institutions which can not only insure that disputes are solved by legal means, but can implement peaceful change. This can be done by a variety of means." 
apenas teria surgido com a finalidade de se buscar e garantir a manutenção da paz na segunda metade do século XX com a Carta de São Francisco ${ }^{720}$.

A consolidação da paz por meio do desenvolvimento do direito internacional pode ser percebida, empiricamente, na criação de sistemas e órgãos especializados vinculados a organizações internacionais que buscam promover o desenvolvimento econômico e social na esfera planetária ${ }^{721}$. Trata-se de evolução em processo contínuo. Dessa evolução extrai-se, por exemplo, a constante perspectiva de afirmação da prevalência do direito internacional em relação ao interno e a cada vez mais freqüente institucionalização da ordem internacional de forma assemelhada à separação de funções observada localmente nos estados ${ }^{722}$.

A Organização das Nações Unidas atual, por exemplo, muito se diferencia em vários aspectos do modelo fixado em tratado por seus primeiros membros ${ }^{723}$. Países menos

\footnotetext{
${ }^{720}$ TUNKIN, Grigory. Politics, law and force in the interstate system. In: Recueil des Cours. Academie de Droit International de la Haye, Volume 219, 1989-VII, pp. 227-395. p. 371. "In verbis“: "The global interstate system is a comparatively new phenomenon. It actually appeared in the second half of the XXth century. Any integrated system has its regulatory capacity. An integrated system without regulation is impossible: it would be chaos and would disintegrate. There are different definitions of regulation as there are different definitions of any societal event."
}

${ }^{721}$ ABI-SAAB, Georges. Cours général de droit international public. In: Recueil des Cours. Academie de Droit International de la Haye, Volume 207, 1987-VII, pp. 09-463. p. 149. "In verbis“: "Le fait que la codification et le développement progressif du droit international soient associés dans cette disposition au développement de la coopération politique montre clairement que ia Charte considère qu'ils s'insèrent dans les efforts destinés à perfectionner le système politique international : tâche dont l'Assemblée générale s'est acquiuée en premier lieu par la création en 1947 d'un organe subsidiaire spécialisé, la Commission du droit international. Il s'agit d'un organe permanent composé d'experts «représentatifs», et maintes fois élargi (de quinze au début à trentequatre actuellement), qui oeuvre pour la préparation de projets d'articles sur des sujets ou des pans complets du droit international, destinés en général à revêtir la forme de conventions de codification qui seraient adoptées lors des conférences diplomatiques.“

${ }^{722}$ TRINDADE, Antônio Augusto Cançado. International law for humankind : towards a new jus gentium (I): general course on public international law. In: Recueil des Cours. Academie de Droit International de la Haye, Volume 316, 2005, pp. 09-439. p. 229. "In verbis“: "In their operation throughout the last six decades, international organizations have sought guidance from the relevant norms of their constitutive charters, affirming, as to matters which fall in the ambit of their respective competences, the primacy of the international legal order over the domestic legal order of the member States. International organizations (above all those of universal vocation, such as the United Nations) have come to apply general International Law, at the same time that they have, in turn, given rise to international legal norms. The internal structure itself of international organizations has evolved, as time has gone on, further generating the establishment of international contacts between the powers of the State other than the Executive."

723 ANAND, R.P.. Sovereign equality of States in international law. In: Recueil des Cours. Academie de Droit International de la Haye, Volume 197, 1986-II, pp. 09-228. p. 191. "In verbis“: "The only road to progress in our increasingly interdependent world society, therefore, lies in strengthening the United Nations. It is important to note that the world Organization is not the same as it was when established in 1945 though the purpose for which it was established, viz. to save the succeeding generations from the scourge of war --, has become even more urgent. For one thing, the United Nations has expanded from a small European or Western Organization, dominated by a few western powers, to become a world-wide Organization and a forum for the small, poor, underdeveloped and militarily inconsequential States who until yesterday had no power and no status and could not dare to speak or take a stand against the big powers." 
desenvolvidos cada vez mais encontram espaço para fazer ecoar suas posições, a Assembléia Geral assumiu atribuições que não lhe haviam sido outorgadas e suas agências se multiplicaram e aproximaram a estrutura burocrática internacional da sociedade.

Em todo o referido panorama, observa-se que direito e relações internacionais trabalham com perspectivas distintas, mas se aproximam por uma série de fatores. Juntas conformam prisma importante de observação do mundo e do direito ${ }^{724}$. A conjugação das doutrinas de direito e da ciência política pode auxiliar os referidos processos por apresentar distintas percepções de um mesmo fenômeno e por multiplicar, portanto, as explicações disponíveis aos paradigmas enfrentados. Direito e relações internacionais não se opõem, gizese, e podem, inclusive prestar auxílio mútuo na compreensão dos fenômenos da ordem internacional $^{725}$.

No que se refere à soberania, por exemplo, verifica-se nítida alteração conceitual sem nova estabilização de conteúdo - a visão eminentemente política parece tomar hoje espaços antes ocupados pelo direito na descrição dos fenômenos organizacionais humanos ${ }^{726}$. Daí o registro como resultado daquilo que poderia constituir apenas parte do processo: a fragmentação do direito internacional ${ }^{727}$.

\footnotetext{
${ }^{724}$ SLAUGHTER, Anne-Marie. International law and international relations. In: Recueil des Cours. Academie de Droit International de la Haye, Volume 285, 2000, pp. 09-249. p. 190, "in verbis“: "It is impossible to draw one moral from these varied accounts, just as it is impossible to reduce the myriad ways in which IR and IL can be knit together to a few simple propositions. Different students and scholars will determine for themselves what they find most useful. In the end, IR/IL is as much a mode of thinking as a body of knowledge, a way of looking at both the world and the law."
}

725 SLAUGHTER, Anne-Marie. International law and international relations. In: Recueil des Cours. Academie de Droit International de la Haye, Volume 285, 2000, pp. 09-249. p. 195, “in verbis“: "A particular causal conception of international politics allows an international lawyer to move from a legal problem to an underlying policy problem and to frame various possible solutions. Conversely, thinking about IL in IR terms strengthens a lawyer's ability to begin with a set of policy considerations and reason forward to a set of legal rules that will effectively implement them. Working with Shell's models of WTO legalism, for instance, highlighted the ways in which institutional structure could be designed to achieve very different policies and normative visions."

${ }^{726}$ KOSKENNIEMI, Martti. From apology to utopia: the structure of international legal argument. Nova Iorque: Cambridge University Press, 2005. p. 16. "In verbis": "International law is kept distinct from descriptions of the international political order by assuming that it tells people what to do and does not just describe what they have been doing. It is delimited against principles of international politics by assuming it to be less dependent on subjective beliefs about what the order among States should be like. These two delimitations establish what lawyers commonly assume to be the 'objectivity' of international law. Inasmuch as international law has an identity, it must differ from descriptive and normative politics in the two senses outlined."

${ }^{727}$ CASELLA, Paulo Borba. Conceito de sistema, contexto internacional e pós-modernidade. In: ADEODATO, João Maurício; BITTAR, Eduardo C. B. (Org.) - Filosofia e Teoria Geral do Direito: estudos em homenagem a Tércio Sampaio Ferraz Junior por seu septuagésimo aniversário. São Paulo: Quartier Latin, 2011. p. 1001. "In verbis": "Esse dado característico do tempo presente [existência de outros "agentes" no direito internacional além dos Estados e a indeterminação de suas funções] aumenta a percepção de fragmentação e aparente desconexão entre as partes desse sistema internacional." 
Pensamentos doutrinários e iniciativas políticas pontuais tendentes a sobrepor os interesses da humanidade ao interesse específico de um povo expressado por um estado não são recentes, mas, de fato, apenas se desenvolveram mais fortemente nos últimos cem anos ${ }^{728}$.

Nesse sentido, a assunção da existência de um grupo de princípios universalmente aplicáveis sofre resistência mesmo dentro das correntes de pensamento européias, as quais comumente não apenas admitem a existência de um grupo de valores superiores extraíveis de sua organização sócio-cultural, mas também tendem com freqüência a encará-los como genericamente aplicáveis a toda a humanidade ${ }^{729}$. Fator que poderia favorecer a concepção de um núcleo conceitual geral seria o papel desempenhado atualmente pela sociedade civil, a qual, em meio à aparente fragmentação do direito, muitas vezes exige o cumprimento dos acordos e a defesa de determinados valores gerais por seus governos ${ }^{730}$.

Há que se ressaltar, ainda, que o direito internacional tende a demonstrar que em momentos críticos determinados valores universais, os quais consubstanciariam princípios gerais de direito seriam reconhecidos e informariam as lógicas aparentemente autônomas de forma uniformizante. ${ }^{731}$

${ }^{728}$ DUPUY, René-Jean. La révolution française et le droit international actuel : conférence prononcée le 25 juillet 1989. In: Recueil des Cours. Academie de Droit International de la Haye, Volume 214, 1989-II, pp. 0929. p. 20. "In verbis": "A défaut d'une structure institutionnelle dont les circonstances no favorisaient pas la constitution, des principes que les Etats devraient appliquer pour faciliter le maintien de la paix juste ont été énoncés par la Révolution française. On doit faire une place particulire à la Déclaration du droit des gens que l'abbé Grégoire propose à la Convention, en 1793 et en 1795. Bien que celle-ci, engagée dans la guerre, ne l'ait pas votée, elle est considérée comme exprimant un état d'esprit très répandu chez les révolutionnaires. Ce texte (art. 5) affirme : «l'intérêt particulier d'un peuple est subordonn a l'intérêt général de la famille humaine.»"“

${ }^{729}$ SANTOS, Boaventura de Souza. Uma concepção multicultural de direitos humanos. In: Lua Nova: Revista de Cultura e Política 39, 1997, pp. 105-124. p. 111. "In verbis": "Todas as culturas tendem a considerar os seus valores máximos como os mais abrangentes, mas apenas a cultura ocidental tende a formulá-los como universais.".

730 DUPUY, Pierre-Marie. Some reflections on contemporary international law and the appeal to universal values : a response to Martti Koskenniemi. In: European Journal International Law 16, 2005. p. 137. o autor ataca de forma direta o pluralismo fragmentário radical de Koskenniemi, que parece desconsiderar o papel da sociedade civil por exemplo, "in verbis": Koskenniemi's reflections, while they enable him to ease his guilty conscience at having been born European, also fail to address another major phenomenon in the contemporary world: the mergence of an 'international civil society' (which if far from being merely European), which demands of states that they respect the obligations that they have accepted in terms of the promotion of the rights of humans, peoples or Nature. International law is today considered by many to be too important to be left in the hands of politicians and their diplomats."

731 Também as teorias do minimalismo e do maximalismo moral de Michel Walzer trabalham a idéia da existência de valores universalmente compartilhados que seriam claramente perceptíveis apenas nos momentos de exceção. WALZER, Michael. Thick and thin, moral argument at home and abroad. Notre Dame: undp, 1994. p. 39. "In verbis": "A minimalist view is a view from a distance or a view in a crisis, so that we can recognize injustice only in the large." 
Se, de um lado, podem ser reconhecidos esquemas procedimentais compartilhados universalmente pelo direito - interno, regional e internacional - a aplicação desses princípios depende do aplicador - do juiz - e daí surgiria seu papel fundamental na manutenção da unidade do direito, inclusive do direito internacional ${ }^{732}$. A unicidade reside na aplicação harmônica de suas normas e os julgadores estariam se convencendo disso - ou deveriam ser convencidos - antes de tudo ${ }^{733}$.

No processo de evolução do direito das gentes e de consagração de sua força cogente e do respeito de seu marco legal pelos estados destaca-se, ainda, a decisão da Corte Internacional de justiça de 1970 que reconheceu força obrigatória à Convenção de Viena sobre o direito dos tratados ${ }^{734}$. Independentemente de seu exercício concretivo, a Corte Internacional de Justiça pode ser concebida como um embrião de uma corte suprema do mundo $^{735}$. Mas ainda estaria muito longe de cumprir esse papel na ordem internacional ${ }^{736}$.

Parte da proposta de manutenção da unidade do direito internacional a partir de sua interação entre o direito interno e a ordem global está no aperfeiçoamento da relação entre as jurisdições especificas internas e as internacionais, isto é, no chamado princípio da

\footnotetext{
${ }^{732}$ DUPUY, Pierre-Marie. Unité d`application du droit International à 'echelle globale et responsabilité des juges. European Journal of Legal Studies, December, 2007. pp. 20-25. "In verbis": "Tous les principes procéduraux relatifs par exemple à la litispendence ou même à l'autorité de chose jugée (res iudicata) ont été forgés dans Le cadre de systèmes juridiques dejà integres, aussi bien organiquement que matériellement. [...] En l'absence de mécnismes et de príncipes procéduraux garantissant une coordination toujours efficace au fonctionnement des jurisdictions internationales, on constate qu'en definitive, l'integration du droit international sera ce que les juges sauront en fare.“
}

${ }^{733}$ DUPUY, Pierre-Marie. Unité d'application du droit International à l'echelle globale et responsabilité des juges. European Journal of Legal Studies, December, 2007. pp. 01-02. "In verbis": "Qu'ils [les juges] soient convaincus de la necessité d’application harmonisée des règles du droit International et l'unité de celui-ci sera assurée."

${ }^{734}$ DUPUY, Pierre-Marie. Unité d'application du droit International à lechelle globale et responsabilité des juges. European Journal of Legal Studies, December, 2007. pp. 06-07. "In verbis": "Dans le cadre d'evolution contemporaine du driot de la responsabilicé internationale des états, le phénomène le plus marquant, consagré par l'effort de codification don't il a fait l'objet, est à n'en pas douter a relever du coté des incidences de la multilateralisation des obligations internationales. L'affirmation des obligations erga omnes par la Cour internationale de justice en 1970, pratiquement correlative à celle du ius cogens dans la Convention de Vienne sur le droit des traits [...]".

${ }^{735}$ DUPUY, Pierre-Marie. Unité d`application du droit International à l'echelle globale et responsabilité des juges. European Journal of Legal Studies, December, 2007. p. 02. "In verbis": "Cet ensemble structure combinerait l'integration normative et la coordination organique. Il déboucherait aînsi logiquement sur un modèle moniste. La Cour internationale de justice, sorte de cour suprime universelle, y occuperait le sommet."

${ }^{736}$ DUPUY, Pierre-Marie. Unité d’application du droit International à l'echelle globale et responsabilité des juges. European Journal of Legal Studies, December, 2007. p. 13. "In verbis": “Quels que soient son prestige considerable et son autoricé morale, l'un et l'autre d’ailleurs soumis Dans une certaine mesure aux aléas de sa jurisprudence, la CIJ est assez loin d’être reconnue comme une cour suprême internationale.” 
complementaridade ${ }^{737}$. A harmonização do interno com o internacional e a unidade do direito internacional se dá não como um esquema utópico, mas decorre da institucionalização da ordem mundial e do aprofundamento da relação entre o global, o regional e o local ${ }^{738}$.

A multiplicação de ordens normativas e a falta de hierarquia ou organização sistêmica definida entre as mesmas e também entre os seus sistemas de solução de controvérsias acabam promovendo a percepção fragmentada da ordem jurídica internacional. Tal perspectiva ignora, contudo, o fato de que direito não constitui algo estático. Direito é, na verdade, um processo. Um processo em constante desenvolvimento e evolução. Especificamente no que se refere ao direito das gentes, esse processo deve ser percebido não apenas como de consolidação jurídica, mas de institucionalização - e, daí, seu caráter político tão latente.

Nesse contexto, a teorização jurídica perderia importante instrumental caso abandonasse os conceitos e institutos da teoria geral do estado para explicar e projetar a organização institucional da ordem normativa internacional. O estudo das formas de organização do poder estatal pode muito claramente, assim, apresentar soluções para a organização política do poder no direito das gentes.

O referido diagnóstico fragmentado corresponderia, portanto, à captura fotográfica de apenas um momento do processo evolutivo do direito internacional. Momento, no qual a transição entre o modelo de relação entre estados centrado no conceito clássico de soberania e as novas estruturas baseadas em seu arrefecimento e no traslado de competência a instâncias organizacionais comuns ainda exigiria tempo e esforços para sua consolidação.

O direito internacional não pode ser observado estaticamente como uma foto, mas de maneira dinâmica, ou seja, como um filme. Desse modo, enquanto os defensores da fragmentação perceberiam apenas o recorte histórico da organização da ordem mundial como

\footnotetext{
${ }^{737}$ DUPUY, Pierre-Marie. Unité d’application du droit International à l'echelle globale et responsabilité des juges. European Journal of Legal Studies, December, 2007. p. 08. "In verbis": "La nouveauté du principe de complémentarité vient du fait qu`intervennant dans un cadre statutaire, il organize larticulation entre la competence des jurisdictions internes et celle d’une jurisdiction international spéciale."

${ }^{738}$ DUPUY, Pierre-Marie. Unité d’application du droit International à l'echelle globale et responsabilité des juges. European Journal of Legal Studies, December, 2007. p. 09. "In verbis": "On voit ainsi que le schéma ideal d’intégration normative et organique décrit précédemment est loin d’être simplement un rêve utopique. Des institutions classiques comme la règle d’épuisement des voies de recours interne, mais, plus encore, des développements contemporaines, tous lies à l'institutionalization de la communauté internationale, tells le droit du maintien de la paix, la multilateralisation des obligations et leurs consequences sur le droit international general de la responsabilité ou des innovations plus récentes encore concernant le domaine spécial du droit international pénal ilustrent cette articulation des orders juridiques, interne et international. Elle va à l’encontre des tendances dualistes, par ailleurs persistantes.”
} 
fotógrafos, os unitaristas assistiriam ao processo como imagens em movimento, como expectadores de um filme. 


\section{TERCEIRA PARTE}

\section{CONCLUSÃO}

A multiplicação de sistemas normativos na ordem internacional apresenta grandes desafios e essa pluralidade sistêmica constitui premissa de qualquer estudo que se desenvolva atualmente acerca do direito das gentes.

Em nenhum momento pretendeu-se neste trabalho refutar a complexidade da organização do poder no contexto global atual e suas conseqüências para o direito. Seu objetivo central, de formulação de alternativas teóricas hábeis a resgatar perspectivas unitaristas, teve como ponto de partida a verificação da natureza dos conceitos utilizados pelas teorias fragmentárias do direito internacional que tendem a desestabilizar suas características jurídicas de coerência e unidade.

Política e direito conformam preceitos que não apenas interagem, mas muitas vezes se identificam. A política, como escolha social, está na criação e - hoje definitivamente - na aplicação do direito. Observa-se, na verdade, que - em regra - a política se referiria ao exercício do poder, enquanto o direito cuidaria de sua organização.

Buscou-se nesta pesquisa demonstrar que a fragmentação do direito das gentes não constituiria alternativa às teorias sistêmicas unitárias e representaria mero traslado equivocado de percepções estritamente políticas à esfera jurídica. Investigou-se, para tanto, em que medida o resgate de estruturas jurídico-políticas tradicionais - tais como os esquemas publicistas da teoria geral do estado - poderia contribuir à institucionalização do direito internacional.

A proposta estimou, ainda, as possibilidades apresentadas, por exemplo, pela utilização dos instrumentais teóricos tradicionais eminentemente jurídicos na compreensão do desenvolvimento dos sistemas jurisdicionais internacionais de solução de controvérsias. Especificamente, observou-se de que maneira a separação de funções do estado poderia servir de modelo aplicável às organizações internacionais.

Quanto ao debate fragmentário, questionou-se se a repartição sistêmica reconhecida por parte importante da doutrina atual representaria situação jurídica consolidada, a qual, portanto, exigiria verdadeiro abandono do paradigma unitarista moderno ou se 
consubstanciaria arranjo transitório compatível com algum tipo de construção una - ainda que diversa daquela concebida pelo positivismo tradicional.

No que se refere à relevância acadêmica, faz-se necessário, inicialmente, ressaltar que não se pretendeu em nenhum momento esgotar o tema, mas, na verdade, investigar como fundamentos teóricos da teoria geral do direito e, especificamente, da teoria geral do estado poderiam auxiliar a compreensão do direito das gentes na atualidade.

O estudo teve como objetivo, desse modo e em um primeiro momento, abordar os aspectos políticos da ordem global envolvidos na discussão entre unidade e fragmentação do direito internacional para diagnosticar até que ponto as teorias políticas fundamentariam posições nesse debate. A partir das conclusões parciais obtidas, verificou-se se existiriam elementos da teoria do direito hábeis a orientar a percepção da ordem jurídica mundial atual como um sistema normativo, no qual as características de ordenação e unidade estariam preservadas.

A relevância para a academia residiria no resgate dos instrumentais da teoria do estado e sua aplicação sistemática ao direito das gentes para demonstrar sua unidade. Buscou-se registrar, nesse sentido, que as teorias fragmentárias não seriam genuinamente jurídicas e serviriam exclusivamente a abordagens teóricas da organização do poder relacionadas, por exemplo, às relações internacionais.

$\mathrm{Na}$ aplicação de pontos específicos da teoria geral do estado ao direito internacional se encontraria o elemento inovador da pesquisa. Estruturas comumente úteis apenas à compreensão do direito interno dos estados foram transportadas ao estudo do direito internacional e à fundamentação de propostas à sua compreensão e evolução institucional. A novidade não estaria, assim, no tema abordado, já que a aplicação da teoria do estado ao direito global não constitui incomum doutrina. Inovador seria o resgate da sinergia entre as teorias do direito interno dos estados e as de direito internacional - análise que parece ter caído em desuso nas últimas décadas.

Para atingir os objetivos estabelecidos, o seguinte problema foi apresentado:

Seria possível afirmar, a partir do prisma da relação entre política e direito, que as teorias fragmentárias resultariam de premissas alheias ao direito, tais como aquelas adotadas pelas relações internacionais, e que o resgate da aplicação da teoria geral do estado ao direito internacional se apresentaria como alternativa viável à preservação de suas características sistêmicas de ordenação e unidade e, ainda, que o traslado da perspectiva da separação de 
funções do estado - separação de poderes - à institucionalização dos sistemas de solução de controvérsias internacionais poderia servir de instrumento promotor da referida unidade?

Ao problema teórico, a seguinte hipótese foi proposta:

Considerando a aplicação das premissas da teoria geral do estado ao direito internacional a partir do prisma da relação entre política e direito, afirma-se que a fragmentação resultaria de premissas alheias ao direito, tais como aquelas adotadas pelas relações internacionais, e que o resgate da aplicação da teoria geral do estado ao direito internacional se apresentaria como alternativa viável à preservação de suas características sistêmicas de ordenação e unidade e, ainda, que o traslado da perspectiva da separação de funções do estado - separação de poderes - à institucionalização dos sistemas de solução de controvérsias internacionais poderia servir de instrumento promotor da referida unidade.

Tomando por base o método dedutivo-indutivo de pesquisa, estabeleceram-se marcos particulares a partir das referências teóricas estabelecidas pela teoria geral do estado e de sua aplicação ao direito das gentes e às propostas doutrinárias fragmentárias, os quais foram analisados e debatidos na busca de constatações mais abrangentes e gerais quanto à relação existente entre política e direito.

Durante a elaboração do trabalho, foram observados elementos internos do direito público envolvido na compreensão do estado e a possibilidade desses serem derivados às relações interestatais, mormente no que se refere à institucionalização da ordem jurídica mundial. Tal proposta, compatível com o método jurídico-dogmático de pesquisa, teve como objetivo verificar como - e se - o direito internacional atual poderia ser harmonizado com as premissas de ordenação e unidade tradicionalmente identificáveis em conjuntos coerentes de normas.

Em termos estruturais, optou-se por uma divisão lógica do trabalho em três partes distintas, mas interdependentes. Na seção inicial, foram apresentados os elementos teóricos que embasam a pesquisa desenvolvida. Assim sendo, buscou-se fixar na primeira parte do capítulo inaugural a perspectiva do direito como um sistema, no qual o interno e o internacional conformariam partes de um todo. Em seguida, apresentaram-se as premissas iniciais da relação existente entre política e direito e, logo, procedeu-se à delimitação de conteúdos a conceitos fundamentais ao estudo. 
No capítulo segundo, concentraram-se os esforços no delineamento dos conceitos de estado e de soberania para sugerir, então, a importância dos mesmos para o direito das gentes. As conclusões iniciais foram aprofundadas no capítulo seguinte, quando se explicitou a aplicação das teorias estudadas à compreensão e, portanto, não necessariamente à formatação do direito internacional. No mesmo capítulo terceiro, iniciou-se a vinculação das teorias da organização do estado à idéia de poder.

A questão do poder pautou o capítulo seguinte do trabalho, que inicialmente desenvolveu o conceito à luz dos exercícios de concreção e de extração de normatividade para, logo, estabelecer paralelos com as funções exercidas pelo estado internamente. No mesmo capítulo, iniciou-se a aplicação dos mesmos conceitos à organização do poder no contexto internacional a partir da figura dos sujeitos dotados de capacidade para seu exercício. A função jurisdicional mereceu, finalmente, atenção especial na última parte do capítulo, na qual se buscou introduzir seu exercício na esfera global.

A pesquisa seguiu no capítulo quinto à análise das organizações internacionais a partir dos parâmetros previamente estabelecidos. Para tanto, a personalidade e a capacidade dos atores da ordem internacional, principalmente das organizações internacionais, foram analisadas e, em uma segunda parte, a importância dos sistemas de solução de controvérsias no exercício de poder por tais estruturas pautou a investigação.

Nesse sentido, uma nova classificação para as organizações internacionais foi apresentada no sexto capítulo estabelecendo como paradigma fundamental à sua caracterização a existência de sistema institucionalizado de solução de litígios entre seus membros.

Uma vez consolidadas as premissas teóricas mais importantes da pesquisa na primeira seção do trabalho, partiu-se para o desenvolvimento da proposta apresentada. Fixaram-se, assim, no capítulo sétimo do estudo as linhas gerais da relação existente entre as teorizações fragmentárias do direito das gentes e a política para que possível se fizesse investigar, no capítulo oitavo, a existência de elementos empíricos que comprovassem o que se defende em experiências regionais, das quais o Brasil faz parte.

A nona parte do trabalho buscou demonstrar como a teoria geral do estado se aplicaria à compreensão do direito das gentes de forma propositiva e, em seguida, como a função jurisdicional identificada na ordem mundial poderia servir à preservação da unidade do direito internacional. No décimo e último capítulo, foram consolidados argumentos já de caráter conclusivo que sustentam ser a percepção fragmentada do direito internacional mero retrato estático de um processo evolutivo. 
As conclusões parciais da pesquisa proposta neste trabalho, as quais - conforme mencionado - sustentam que as teorias que sistematizam a organização do poder interno em um estado podem servir de parâmetro e de orientação à evolução do direito das gentes, são consolidadas, finalmente, a seguir:

\subsection{A Teoria Geral do Estado como Ferramenta à Compreensão do Direito Internacional}

A existência do direito internacional conforma tema atualmente superado. Direito internacional é direito. Teorias que apresentavam dúvidas quanto às suas estruturas de validade de normas e concentravam-se no estudo da relação entre as várias ordens legais dos estados e o direito das gentes não se sustentam na atualidade.

Uma das responsáveis pela mencionada alteração de perspectiva foi a paulatina valorização do ser humano, a qual promoveu uma nova percepção do direito que, indiretamente, devolveu ao sistema jurídico internacional a pretensão de universalidade que lhe cabia em período anterior à formação dos estados modernos. O direito se fundamenta hoje não apenas nas regras de validade positivistas, mas também definitivamente em princípios e valores.

Nesse contexto, ainda que sejam reconhecidas ordens normativas locais autônomas, essas convivem como partes de um sistema global comum. Marcos legais estabelecidos por tratado e princípios reconhecidos como inerentes trabalham em conjunto promovendo a unicidade sistêmica do direito. Assim sendo, a dicotomia entre interno e internacional impõese atualmente aos juristas como algo ultrapassado. A observação do direito como um sistema sugere o abandono do estudo do local e do geral como estruturas dissociadas.

Política e direito são partes de uma mesma estrutura na organização da vida em sociedade. A política está na decisão tomada na formação do direito positivo e no reconhecimento de valores axiológicos, mas também quando da extração da normatividade exercida na interpretação das normas. A organização das relações sociais por toda essa dinâmica decorre diretamente da necessidade de se estabelecerem parâmetros de regulamentação e controle ao exercício do poder na convivência humana e, sob tais premissas, surge o estado como a mais bem-sucedida forma de organização social fundada em estruturas políticas e jurídicas. 
Nesse sentido, é de se perceber que a estabilidade social é garantida no plano interno dos países pelo controle do poder por meio do uso de instrumentos de política e de direito. $\mathrm{O}$ contexto internacional, por outro lado, possui complexidade maior. Nele, política e direito disputam espaço na regulação do poder e, nessa perspectiva, observa-se nos excessos da política a urgência da definitiva organização da ordem global pelo direito.

O estado conforma, em linha com o ressaltado, a forma paradigmática de organização do poder sob a qual os indivíduos esquematizam a vida comum estabelecendo limites ao uso da força. Percebe-se em sua institucionalidade a instrumentalização da paz social e não seria razoável conceber o abandono dessas teorizações pelo direito internacional. De certa maneira, tem-se que a observação da soberania do estado por internacionalistas como entrave à evolução do direito das gentes teria provocado aversão à teoria do estado como parâmetro à organização do poder hábil a auxiliar a compreensão e o desenvolvimento do direito das gentes.

Estado e teoria geral do estado constituem conceitos distintos. Nesse sentido, ainda que o ente possa ter sua importância reduzida ou relativizada, o mesmo não se aplicaria necessariamente às estruturas de poder teorizadas e esquematizadas pelo direito e pela política para seu funcionamento como estabilizador da vida em sociedade.

Sob a perspectiva estatal, a soberania se encontra diretamente vinculada ao poder. Seu conceito justifica internamente, na verdade, a própria existência de uma autoridade superior às pessoas na sociedade, responsável por organizar e coordenar a interação social. No plano internacional, por outro lado, a expressão externa do poder das coletividades determinadas se confunde com a idéia de independência e, além de se submeter historicamente à dinâmica natural da força na relação com as outras soberanias e, mais recentemente, a valores axiológicos assumidos como cogentes, mais que nunca se mostra relativizada pelos compromissos assumidos, ou seja, pelo princípio da pacta sunt servanda, um dos fundamentos elementares do direito.

Extremamente rarefeitos se fazem atualmente os resquícios do caráter ilimitado e absoluto da soberania estatal. O direito das gentes não apenas provoca, mas também exige essa relativização, a qual pode se dar de forma voluntária, como no caso da adesão a organizações internacionais supranacionais, ou, involuntariamente, como no reconhecimento de regras internacionais cogentes.

Tem-se que, em síntese, o desenvolvimento do direito das gentes implicou na paulatina limitação das características soberanas outrora consideradas absolutas e ilimitadas e, em todo esse contexto, verifica-se no estudo da teoria geral do estado, sem grandes entraves, 
instrumental técnico fundamental a ser observado para que se possa compreender a ordem global da atualidade. Nesse sentido, o resgate das estruturas de poder interno como parâmetro ao entendimento do direito das gentes não se mostra apenas necessário, mas também extremamente urgente.

Não existe, ressalte-se uma vez mais, identidade entre as estruturas internas de poder e o direito internacional. A analogia estrutural - que não é inédita, mas que se propõe aqui sob a perspectiva do resgate - serve, entretanto, muito bem à melhor compreensão e ao aperfeiçoamento da ordem global. A esse respeito, se, por um lado, impossível se faz identificar internacionalmente hoje processos claros de formação de uma confederação ou de uma federação global, isso não significaria entender que a teoria geral do estado não teria nada a ensinar ao direito das gentes.

Não se trata da promoção do uso das teorias de poder aplicadas ao estado como parâmetro à modulação do direito internacional, mas de apresentá-las como instrumental de auxílio à sua compreensão. A teoria geral do estado tem muito a contribuir ao direito internacional e, no panorama atual de desafios que se apresentam à organização do poder global, urgente se faz a definitiva superação das resistências de internacionalistas ao seu estudo e aplicação.

A teoria geral do estado, mais que tratar de estado, trata de poder. Seus institutos consolidam a teorização jurídica da organização, da distribuição e do exercício do poder no plano interno. $\mathrm{O}$ estudo do poder não apenas contribui ao direito como se mostra essencial ao seu desenvolvimento e compreensão. De todas as considerações feitas, é de se concluir que a unidade, a divisão de funções, a legitimação e as formas de exercício do poder em uma ordem estatal não servem de parâmetro reproduzível na ordem global, mas podem indicar caminhos à sua melhor formulação teórica.

Em perspectiva ideal, a formação do direito pela política se daria na forma de concreção, ou seja, por meio da conversão da decisão em norma. Uma vez estabelecida a regra, sua aplicação se reduziria à mera extração da normatividade nela contida. Percebe-se, na atualidade, claro abalado dessa construção teórica pelo exercício cada vez mais freqüente da função concretiva por órgãos investidos de atribuições de mera extração de normatividade. No plano interno, por exemplo, essa alteração de padrões apresenta hoje grandes desafios às estruturas clássicas de organização de poder.

$\mathrm{Na}$ esfera internacional, projetivamente, o exercício de concreção por órgãos investidos de atribuições de extração de normatividade poderia representar forma interessante de desenvolvimento do direito. Qualquer tipo de evolução nesse sentido exigiria, no entanto, 
prévio aperfeiçoamento da organização do poder na ordem global e daí a utilidade do instrumental teórico da teoria geral do estado.

No contexto estatal, a doutrina divide o estudo do poder sob o prisma das funções exercidas. De forma sistemática, a teoria geral do estado historicamente o faz por meio de uma repartição em três: a função executiva, a legislativa e a judiciária. Internacionalmente, por outro lado, não se faz possível reproduzir o modelo de separação de funções aplicado aos estados e isso se dá em razão da falta de centralização do poder. Nada impede, entretanto, que esses paradigmas internos sirvam ao entendimento e ao desenvolvimento da institucionalidade da ordem do direito das gentes.

A descentralização constitui a maior característica do poder na ordem mundial. Além de não se poder reproduzir a estrita separação de funções que se percebe no direito interno, impossível se faz estabelecer com extrema precisão quem seriam os seus atores. De certo, estados são os tradicionais e ainda mais importantes entes que atuam na esfera global, mas a evolução do direito internacional promoveu o reconhecimento de outras estruturas como exercentes de poder e as organizações internacionais, por exemplo, já se encontram consolidadas como tal.

No direito internacional, os sistemas de solução de controvérsias se multiplicaram e se consolidaram ao longo do século XX como garantidores da coerência, da segurança e da previsibilidade da ordem normativa geral, mas não existe, contudo, um poder judiciário global e tampouco exercício concretivo pleno como verificado internamente nos estados. Essa ausência de centralização não impediria absolutamente, entende-se e reafirma-se, o uso das estruturas da teoria geral do estado para auxiliar a compreensão do direito internacional.

A atuação de um ente no ambiente internacional depende da personalidade. O caráter absoluto dessa premissa subsiste ainda que se reconheçam estruturas não dotadas de personalidade que de alguma forma atuam no contexto global. A atribuição de personalidade, não basta, entretanto, ao exercício de poder na ordem global, o qual se encontraria condicionado aos limites estabelecidos à capacidade do agente. Nos estados, capacidade se confundiria com os contornos da soberania e nas organizações internacionais estaria, em regra, contida na vontade expressa nos tratados.

Dessa forma, a doutrina costuma identificar a personalidade jurídica como elemento hábil a caracterizar, sozinho, uma organização internacional. Exercentes de funções de poder na esfera internacional decidiram criar, portanto, uma organização simplesmente atribuindo personalidade jurídica a um tratado associativo. 
Não seria, entretanto, razoável entender que todo tratado dotado de personalidade deveria ser considerado investido de atribuições para atuar na ordem internacional de maneira concretiva - e muitas vezes no mesmo patamar dos estados - simplesmente por ter personalidade reconhecida. Assim, conformado o sistema de direito da associação, apenas quando identificável em sua estrutura um sistema institucionalizado para a solução de controvérsias eventualmente surgidas entre seus membros haveria uma organização internacional capaz de, nos limites das capacidades que lhe são atribuídas, atuar internacionalmente em patamares equiparáveis aos estados.

Uma estrutura comum, mesmo dotada de personalidade, encontra-se confrontada com importantes limitações para garantir sua estabilidade sistêmica e, conseqüentemente, severas limitações se apresentam à sua atuação internacional como um corpo uno e consolidado caso não disponha de um sistema de solução de controvérsias hábil a estabilizar seu direito. Ordens jurídicas desse tipo não constituiriam, assim, organizações, mas meros tratados associativos dotados de personalidade.

O estabelecimento de critérios que diferenciem de maneira clara as organizações internacionais dos tratados associativos impõe-se com urgência em contexto de franca proliferação de estruturas internacionais. A partir da classificação que se propõe, mais facilmente se poderiam reconhecer os entes que interagem com os estados e diferenciá-los daqueles sistemas que servem apenas de instrumento de interação entre os estados.

\subsection{A Teoria Geral do Estado e a Unidade Sistêmica do Direito Internacional}

As dúvidas quanto à unidade do direito internacional se referiam há cem anos basicamente à relação entre as várias ordens estatais e a ordem jurídica global. A maior parte das questões teóricas relacionadas à relação entre o local e o internacional geral encontram-se atualmente superadas e, assim, os grandes desafios que colocavam à prova o caráter de direito do direito das gentes acabaram dissipados.

Estruturas internacionais associativas se consolidaram e se multiplicaram na segunda metade do século XX. Organizações internacionais multilaterais e regionais foram sendo criadas e estabeleceram sistemas normativos autônomos. Essas ordens jurídicas que surgiram foram aos poucos se sobrepondo e criaram uma complexa trama sistêmica desafiadora da coerência e da estabilidade exigidas pelo direito. 
$\mathrm{O}$ referido pluralismo fez com que a doutrina passasse a questionar novamente a unidade do direito das gentes. Nesse processo, cada vez mais os paradigmas das relações internacionais passaram a ser adotados como parâmetros à compreensão da ordem global e, a partir deles, estabeleceram-se percepções fragmentárias do direito das gentes.

A abordagem política não se mostra, contudo, contrária ao direito internacional. Nesse sentido, estruturas e conceitos desenvolvidos pela teoria política não são, de todo, incompatíveis com o direito. A escolha política se encontra na formação e na aplicação do direito e integra, portanto, os sistemas jurídicos interno e internacional.

A concepção dos planos local e global como um bloco normativo coeso não impede, entretanto, que se percebam idiossincrasias que caracterizam as duas esferas. Nesse sentido, verifica-se que, no que se refere à relação entre política e direito, o ramo internacional aceita com maior facilidade a expressão política do poder e que juristas internamente buscam neutralizar as escolhas políticas e demonstram dificuldade de aceitar a concreção feita pelos exercentes de funções judiciárias.

Direito internacional é política. Direito é política. E nesse aspecto específico, o direito internacional seria apenas mais honesto. Talvez o mais honesto dos ramos do direito. Nesse contexto, enquanto o direito interno parece buscar atualmente conviver melhor com suas atribuições relacionadas às escolhas políticas, o direito internacional deve, com urgência, resgatar os conceitos jurídicos que garantam sua compreensão sistêmica.

Consoante a proposta que se defendeu neste estudo, uma organização internacional propriamente dita, isto é, uma associação internacional capaz de atuar na esfera global em determinados contextos de forma análoga aos estados, não sustentaria sua condição apenas na personificação jurídica, mas necessariamente deveria possuir estrutura institucionalizada de solução de controvérsias hábil a garantir a coerência e a estabilidade de seu sistema de direito. Entes dotados de personalidade internacional, mas incapazes de garantir sua ordem normativa - ainda que possuam estruturas burocráticas estabelecidas - conformariam, sob tais premissas, meros tratados associativos.

Ao garantir a coerência da ordem jurídica, os sistemas de solução de controvérsias institucionalizados estabilizam a vontade dos membros de uma organização e permitem que a expressão da vontade comum seja exercida de maneira concretiva pela personalidade jurídica estabelecida em tratado.

A sinergia entre a teoria geral do estado e o direito internacional não configura uma mera proposta. Trata-se de fato. A aversão dos internacionalistas ao estado, mais propriamente às concepções extremadas de seu poder soberano, parecem ter afastado o direito 
das gentes dos conceitos fixados pela teoria geral do estado. Tudo isso, ressalte-se, sem que o estado tenha perdido seu caráter de sujeito internacional por excelência.

Institutos da teoria geral do estado não se fazem, entretanto, plenamente aplicáveis apenas à compreensão das estruturas internas de poder das organizações internacionais. As teorias que buscam compreender a distribuição do poder no estado servem, na verdade, plenamente ao entendimento da ordem global como um todo, ainda que nela o poder se encontre eminentemente descentralizado.

A teoria geral do estado se propõe, na verdade, não apenas a explicar a organização do poder pelo direito, mas também viabilizam o direito. $\mathrm{O}$ resgate de sua aplicação plena ao direito das gentes não se mostra apenas útil: faz-se urgente e necessário. Trazer a teoria geral do estado definitivamente de volta ao direito internacional significaria, portanto, o próprio resgate do direito no direito internacional.

O exercício da função jurisdicional se encontra em franco crescimento e consolidação na esfera global. Ainda que na atualidade não se possa reconhecer uma estrutura organizada de maneira hierárquica e coesa, os esquemas disponíveis buscam cumprir seu papel estabilizando e garantindo a coerência da ordem normativa do direito das gentes.

Assim como internamente, ainda que em freqüência e intensidade muito menor, os sistemas de solução de controvérsias internacionais tinham, inicialmente, funções exclusivamente de extração de normatividade. Com o passar dos anos, esses órgãos de função judiciária passaram a exercer também a concreção e a produzir direito. Tem-se como exemplo dessa nova realidade o reconhecimento paulatino da jurisprudência como fonte do direito das gentes.

A percepção da multiplicação dos sistemas de solução de controvérsias como fragmentação, é dizer, como ameaça à unidade do direito global, constituiria, assim, perspectiva rasa da realidade da ordem mundial. Teorias fragmentárias partem de concepções exclusivamente políticas que, aplicadas ao direito, mostram-se imperfeitas e superficiais.

Sistemas jurisdicionais não exigiriam, em linha com o que se defende, estruturas hierárquicas ou meios formais de comunicação para compatibilizar seu entendimento da ordem internacional. Mesmo quando não previsto em tratados, tribunais tendem a levar em consideração a competência de outras cortes para estabelecer os limites de suas próprias competências. Da mesma forma, árbitros e juízes de um tribunal com bastante frequiência exercem função análoga em outro sistema de solução de controvérsias quando do término de seus mandatos no órgão anterior e cada vez mais a jurisprudência de um sistema específico tende a ser observada, considerada e até mesmo expressamente mencionada por outros. 
Os sistemas normativos internacionais e seus órgãos de solução de controvérsias, ainda que não se encontrem unificados, não se isolam. As cortes se observam por sobre os muros de seus próprios sistemas de direito e buscam, assim, garantir, ainda que assistematicamente, a coerência e a unidade do direito internacional.

A multiplicação de ordens normativas e a falta de hierarquia ou organização sistêmica definida entre as mesmas e também entre os seus sistemas de solução de controvérsias promovem, de fato, a percepção fragmentada da ordem jurídica internacional. Tais perspectivas ignoram, contudo, o fato de que direito não constitui algo estático. Direito seria, na verdade, um processo. Um processo em constante desenvolvimento e evolução que deve ser percebido não apenas como de consolidação jurídica, mas de institucionalização.

A teorização jurídica perderia, a partir de todo esse panorama, importante instrumental caso abandonasse os conceitos e institutos da teoria geral do estado para explicar e projetar a organização institucional da ordem normativa internacional. O estudo das formas de organização do poder estatal pode muito claramente apresentar soluções para a organização política do poder no direito das gentes.

O diagnóstico fragmentado da ordem global corresponderia à captura fotográfica de apenas um momento do processo evolutivo do direito internacional. Momento, no qual a transição entre o modelo de relação entre estados centrado no conceito clássico de soberania e as novas estruturas baseadas em seu arrefecimento e no traslado de competência a instâncias organizacionais comuns ainda exigiria tempo e esforços para sua consolidação.

\subsection{Considerações Finais}

A organização das relações humanas depende do estabelecimento de parâmetros de regulamentação e controle ao exercício do poder. Não existe, contudo, identidade entre as estruturas internas de poder e o direito internacional, mas as diferenças não implicam compreender que a teoria geral do estado não teria nada a ensinar ao direito das gentes.

Não se defendeu, neste estudo, a utilização das teorias de poder aplicadas ao estado como parâmetro de modulação do direito internacional, mas como instrumental teórico hábil a auxiliar sua compreensão e estruturação. A teoria geral do estado, mais que tratar de estado, consolida a teorização jurídica da organização, da distribuição e do exercício do poder no plano interno. 
A descentralização constitui a maior característica apontada ao poder na ordem mundial. Além de, por um lado, não se poder reproduzir a estrita separação de funções que se percebe no direito interno, impossível se faz estabelecer com extrema precisão quais seriam os atores que participam da concreção do direito das gentes.

A doutrina costuma identificar a personalidade jurídica como elemento hábil a caracterizar, sozinho, uma organização internacional, mas a partir da análise de suas estruturas internas à luz das teorias de poder, recomendável se faz também o uso da capacidade de garantir a coerência sistêmica do conjunto normativo como condição de sua institucionalidade.

Estruturas internacionais associativas se consolidaram e multiplicaram na segunda metade do século XX. Essas ordens jurídicas que surgiram foram aos poucos se sobrepondo e criaram uma complexa trama sistêmica desafiadora da coerência e da estabilidade exigidas pelo direito. Nesse processo, cada vez mais os paradigmas das relações internacionais passaram a ser adotados como parâmetros à compreensão da ordem global e, a partir deles, estabeleceram-se percepções fragmentárias do direito das gentes.

A sinergia entre a teoria geral do estado e o direito internacional não configura uma mera proposta. As teorias que buscam compreender a distribuição do poder no estado se aplicam plenamente ao entendimento da ordem global como um todo, ainda que nela o poder se encontre eminentemente descentralizado.

A teoria geral do estado se propõe não apenas a explicar a organização do poder pelo direito, mas, principalmente, a instrumentalizá-la. O exercício da função jurisdicional se encontra em franco crescimento e consolidação na esfera internacional. Ainda que na atualidade não se possa reconhecer uma estrutura organizada de maneira hierárquica e coesa, os esquemas disponíveis buscam cumprir seu papel estabilizando e garantindo a coerência da ordem normativa do direito das gentes.

A percepção da multiplicação dos sistemas de solução de controvérsias como fragmentação, é dizer, como ameaça à unidade do direito global, constitui perspectiva superficial da realidade da ordem mundial. Teorias fragmentárias partem de concepções políticas que, aplicadas ao direito, mostram-se imperfeitas e superficiais.

Sistemas jurisdicionais não exigem, nesse contexto, estruturas hierárquicas ou meios formais de comunicação para compatibilizar seu entendimento da ordem internacional. Os sistemas normativos internacionais e seus órgãos de solução de controvérsias, ainda que não se encontrem unificados, não se organizam em paralelo. As cortes se observam mutuamente e 
buscam, constantemente, garantir, ainda que assistematicamente, a coerência e a unidade do direito internacional.

A multiplicação de estruturas normativas e a falta de organização sistêmica definida entre as mesmas e entre os seus sistemas de solução de controvérsias promovem, de fato, a percepção fragmentada da ordem jurídica internacional. Tais perspectivas ignoram, contudo, que direito não constitui algo estático. $\mathrm{O}$ direito internacional não pode ser observado como uma foto. Direito é dinâmico: desenvolve-se como um filme.

Assim, doutrinadores que hoje defendem a fragmentação sustentariam suas críticas ao filme do direito das gentes na perspectiva exclusiva de seu cartaz de divulgação. Caso tenham dificuldade de encontrar recursos no direito internacional para o ingresso, que a teoria geral do estado possa lhes servir, então, de convite à sala de exibição. 


\section{BIBLIOGRAFIA}

ABI-SAAB, Georges. Cours général de droit international public. In: Recueil des Cours. Academie de Droit International de la Haye, Volume 207, 1987-VII, pp. 09-463.

ACCIOLY, Hildebrando; NASCIMENTO E SILVA, G.E. do; CASELLA, Paulo Borba. Manual de direito internacional público. São Paulo: Saraiva, 2011.

AGO, Roberto. Science juridique et droit international. In: Recueil des Cours. Academie de Droit International de la Haye, Volume 90, 1956-II, pp. 851-958.

AGO, Roberto. Communauté internationale et organisation internationale. In: DUPUY, RenéJean. Manuel sur les organisations internationales. Dordrecht: Martinus Nijhoff Publishers, 1998.

ANAND, R.P.. Sovereign equality of States in international law. In: Recueil des Cours. Academie de Droit International de la Haye, Volume 197, 1986-II, pp. 09-228.

ANDRASSY, Georges. La souveraineté et la Société des Nations. In: Recueil des Cours. Academie de Droit International de la Haye, Volume 61, 1937-III, pp. 637-762.

ARÉCHAGA, Eduardo Jiménez; ARBUET-VIGNALI, Heber; PUCEIRO ROPOLL; Roberto. Derecho internacional público - Tomo I. Montevideo: Fundación de Cultura Universitaria, 2005.

ARÉCHAGA, Eduardo Jiménez; ARBUET-VIGNALI, Heber; PUCEIRO ROPOLL; Roberto. Derecho internacional público - Tomo III. Montevideo: Fundación de Cultura Universitaria, 2012.

BAPTISTA, Luiz Olavo. O MERCOSUL, suas instituições e ordenamento jurídico. São Paulo: Ltr, 1998.

BARILE, Giuseppe. La structure de l'ordre juridique international : règles générales et règles conventionnelles. In: Recueil des Cours. Academie de Droit International de la Haye, Volume 161, 1978-III, pp. 09-126.

BARROSO, Luís Roberto. Temas de direito constitucional. Rio: Renovar, 2001.

BARROSO, Luís Roberto. Temas de direito constitucional - Tomo II. Rio: Renovar, 2003.

BARROSO, Luís Roberto. Temas de direito constitucional - Tomo III. Rio: Renovar, 2005.

BATISTA JÚNIOR, Paulo Nogueira . Crise no FMI. O Globo, 09.04.2010.

BENOIST, Charles. L'influence des idées de Machiavel. In: Recueil des Cours. Academie de Droit International de la Haye, Volume 9, 1925-IV, pp. 127-306.

BEREZOWSKI, Cezary. Les sujets non souverains du droit international. In: Recueil des Cours. Academie de Droit International de la Haye, Volume 65, 1938-III, pp. 01-85. 
BERLIA, Georges. Jurisprudence des tribunaux internationaux en ce qui concerne leur compétence. In: Recueil des Cours. Academie de Droit International de la Haye, Volume 88, 1955-II, pp. 105-157.

BILFINGER, Carl. Les bases fondamentales de la communauté des états. In: Recueil des Cours. Academie de Droit International de la Haye, Volume 63, 1938-I, pp. 129-241.

BINDSCHEDLER, D.. Le règlement des différends relatifs au statut d'un organisme international. In: Recueil des Cours. Academie de Droit International de la Haye, Volume 124, 1968-II, pp. 453-548.

BISHOP, W.W.. General course of public international law. In: Recueil des Cours. Academie de Droit International de la Haye, Volume 115, 1965-II, pp. 147-470.

BOBBIO, Norberto. Estado, governo, sociedade; por uma teoria geral da política. Rio: Paz e Terra, 1987.

BOBBIO, Norberto. O positivismo jurídico: lições de filosofia do direito. São Paulo: Ícone, 1995.

BOBBIO, Norberto. Teoria do ordenamento jurídico. Brasília: Editora Universidade de Brasília, 1999.

BOBBIO, Norberto; MATTEUCCI, Nicola; PASQUINO, Gianfranco. Dicionário de política - Vol. 1. Brasília: Editora Universidade de Brasília, 2010.

BONAVIDES, Paulo. Teoria geral do estado. São Paulo: Malheiros Editores, 2012.

BOUTROS-GHALI, Boutros. Le principe d'égalité des états et les organisations internationales. In: Recueil des Cours. Academie de Droit International de la Haye, Volume 100, 1960-II, pp. 01-73.

BOWETT, Derek William. Contemporary developments in legal techniques in the settlement of disputes. In: Recueil des Cours. Academie de Droit International de la Haye, Volume 180, 1983-II, pp. 169-235.

BRIERLY, J.-L.. Le fondement du caractère obligatoire du droit international. In: Recueil des Cours. Academie de Droit International de la Haye, Volume 23, 1928-III, pp. 463-552.

BROWNLIE, Ian. Principles of public international law. Oxford: Oxford University Press, 2003.

CAFLISCH, Lucius. Cent ans de règlement pacifique des différends interétatiques. In: Recueil des Cours. Academie de Droit International de la Haye, Volume 288, 2001, pp. 245467.

CAHIER, Philippe. Changements et continuité du droit international : cours général de droit international public. In: Recueil des Cours. Academie de Droit International de la Haye, Volume 195, 1985-VI, pp. 09-374. 
CALDERA, Rafael. The juridical basis of a new international order : conference held on 8 July 1986. In: Recueil des Cours. Academie de Droit International de la Haye, Volume 196, 1986-I, pp. 385-400.

CALOYANNI, Mégalos A.. L'organisation de la Cour permanente de justice et son avenir. In: Recueil des Cours. Academie de Droit International de la Haye, Volume 38, 1931-IV, pp. 651-786.

CANARIS, Claus-Wilhelm. Pensamento Sistemático e Conceito de Sistema na Ciência do Direito. Introdução e tradução de António Menezes Cordeiro. $3^{\mathrm{a}}$. ed. Lisboa: Fundação Calouste Gulbenkian, 2002.

CAPOTORTI, Francesco. Cours général de droit international public. In: Recueil des Cours. Academie de Droit International de la Haye, Volume 248, 1994-IV, pp. 09-343.

CARREAU, Dominique. Droit international. Paris: Pedone, 1986.

CARRILLO-SALCEDO, Juan-Antonio. Droit international et souveraineté des états : cours général de droit international public. In: Recueil des Cours. Academie de Droit International de la Haye, Volume 257, 1996, pp. 35-221.

CASELLA, Paulo Borba. ABZ - ensaios didáticos. São Paulo: Imprensa Oficial do Estado, 2009.

CASELLA, Paulo Borba. Direito internacional dos espaços. São Paulo: Atlas, 2009.

CASELLA, Paulo Borba. BRIC: Uma perspectiva de cooperação internacional. São Paulo: Atlas, 2011.

CASELLA, Paulo Borba. Conceito de sistema, contexto internacional e pós-modernidade. In: ADEODATO, João Maurício; BITTAR, Eduardo C. B. (Org.) - Filosofia e Teoria Geral do Direito: estudos em homenagem a Tércio Sampaio Ferraz Junior por seu septuagésimo aniversário. São Paulo: Quartier Latin, 2011.

CASELLA, Paulo Borba. Evolução institucional do direito internacional: à luz do cinqüentenário do conceito de direito de Hart (1961). In: Revista Brasileira de Filosofia. Ano 60, Vol. 236, janeiro-junho, 2011. pp. 313-329.

CASELLA, Paulo Borba. Direito internacional no tempo medieval e moderno até vitoria. São Paulo: Atlas, 2012.

CASSESE, A.. Modern constitutions and international law. In: Recueil des Cours. Academie de Droit International de la Haye, Volume 192, 1985-III, pp. 331-476.

CASTBERG, Frede. L'excès de pouvoir dans la justice internationale. In: Recueil des Cours. Academie de Droit International de la Haye, Volume 35, 1931-I, pp. 353-472.

CASTBERG, Frede. La méthodologie du droit international public. In: Recueil des Cours. Academie de Droit International de la Haye, Volume 43, 1933-I, pp. 309-383. 
CASTBERG, Frede. International law in our time. In: Recueil des Cours. Academie de Droit International de la Haye, Volume 138, 1973-I, pp. 01-26.

CHARNEY, Jonathan I.. Is international law threatened by multiple international tribunals? In: Recueil des Cours. Academie de Droit International de la Haye, Volume 271, 1998, pp. 101-382.

CHARPENTIER, Jean. Le contrôle par les organisations internationales de l'exécution des obligations des états. In: Recueil des Cours. Academie de Droit International de la Haye, Volume 182, 1983-IV, pp. 143-245.

CHAUMONT, Charles. Cours général de droit international public. In: Recueil des Cours. Academie de Droit International de la Haye, Volume 129, 1970-I, pp. 333-527.

CLAPHAM, Andrew. Brierly's law of nations. Oxford: Oxford University Press, 2012.

CONFORTI, Benedetto. Cours général de droit international public. In: Recueil des Cours. Academie de Droit International de la Haye, Volume 212, 1988-V, pp. 09-210.

DALLARI JÚNIOR, Hélcio de Abreu. Teoria geral do estado contemporâneo. São Paulo: Rideel, 2008.

DALLARI, Dalmo de Abreu. Elementos de teoria geral do estado. São Paulo: Saraiva, 2011.

DAMROSCH, Lori Fisler. Enforcing international law through non-forcible measures. In: Recueil des Cours. Academie de Droit International de la Haye, Volume 269, 1997, pp. 09250.

DAUDET, Yves. Actualités de la codification du droit international. In: Recueil des Cours. Academie de Droit International de la Haye, Volume 303, 2003, pp. 09-118.

DE ORÚE Y ARREGUI, José Ramon. Le régionalisme dans l'organisation internationale. In: Recueil des Cours. Academie de Droit International de la Haye, Volume 53, 1935-III, pp. 0195.

DE VISSCHER, Charles. La codification du droit international. In: Recueil des Cours. Academie de Droit International de la Haye, Volume 6, 1925-I, pp. 325-455.

DE VISSCHER, Paul. Cours général de droit international public. In: Recueil des Cours. Academie de Droit International de la Haye, Volume 136, 1972-II, pp. 01-202.

DJUVARA, Mircea. Le fondement de l'ordre juridique positif en droit international. In: Recueil des Cours. Academie de Droit International de la Haye, Volume 64, 1938-II, pp. 479625.

DUPUY, René Jean. Le droit des relations entre les organisations internationales. In: Recueil des Cours. Academie de Droit International de la Haye, Volume 100, 1960-II, pp. 457-589. 
DUPUY, René-Jean. La révolution française et le droit international actuel : conférence prononcée le 25 juillet 1989. In: Recueil des Cours. Academie de Droit International de la Haye, Volume 214, 1989-II, pp. 09-29.

DUPUY, Pierre-Marie. L'unité de l'ordre juridique international : cours général de droit international public. In: Recueil des Cours. Academie de Droit International de la Haye, Volume 297, 2002, pp. 09-489.

DUPUY, Pierre-Marie. Some reflections on contemporary international law and the appeal to universal values : a response to Martti Koskenniemi. In: European Journal International Law 16, 2005.

DUPUY, Pierre-Marie. Unité d’application du droit International à l'echelle globale et responsabilité des juges. European Journal of Legal Studies, December, 2007.

DWORKIN, Ronald. Taking rights seriously. Cambridge: Harvard University Press, 1977.

EAGLETON, Clyde. International organization and the law of responsibility. In: Recueil des Cours. Academie de Droit International de la Haye, Volume 76, 1950-I, pp. 319-425.

EHRLICH, Ludwik. The development of international law as a science. In: Recueil des Cours. Academie de Droit International de la Haye, Volume 105, 1962-I, pp. 173-265.

FASSBENDER, Bardo. The meaning of international constitutional law. In: MacDonald/Johnston (Hrsg.). Towards World Constitutionalism. Amsterdam: R.St.J., 2005.

FAWCETT, J.E.S.. General course on public international law. In: Recueil des Cours. Academie de Droit International de la Haye, Volume 132, 1971-I, pp. 363-558.

FELDMANN, David. International personality. In: Recueil des Cours. Academie de Droit International de la Haye, Volume 191, 1985-II, pp. 343-414.

FENWICK, Charles G.. The progress of international law during the past forty years. In: Recueil des Cours. Academie de Droit International de la Haye, Volume 79, 1951-II, pp. 0171.

FINCH, George A.. Les sources modernes du droit international. In: Recueil des Cours. Academie de Droit International de la Haye, Volume 53, 1935-III, pp. 531-629.

FISCHER-LESCANO, Andréas; TEUBNER, Gunther. Regime-Kollisionen. Frankfurt am Main: Suhrkamp Verlag, 2006.

FITZMAURICE, Gerald. The general principles of international law considered from the standpoint of the rule of law. In: Recueil des Cours. Academie de Droit International de la Haye, Volume 92, 1957-II, pp. 01-227.

FLEINER-GERSTER, Thomas. Teoria geral do estado. São Paulo: Martins Fontes, 2006. 
FRANÇOIS, J.P.A.. La Cour permanente d'arbitrage son origine, sa jurisprudence, son avenir. In: Recueil des Cours. Academie de Droit International de la Haye, Volume 87, 1955-I, pp. 457-553.

FRIEDMANN, W.. General course in public international law. In: Recueil des Cours. Academie de Droit International de la Haye, Volume 127, 1969-II, pp. 39-246.

GANSHOF VAN DER MEERSCH, Walter. L'ordre juridique des communautés européennes et le droit international. In: Recueil des Cours. Academie de Droit International de la Haye, Volume 148, 1975-V, pp. 01-433.

GARNER, James W.. Le développement et les tendances récentes du droit international. In: Recueil des Cours. Academie de Droit International de la Haye, Volume 35, 1931-I, pp. 605720.

GIDEL, Gilbert. Droits et devoirs des nations: la théorie classique des droits fondamentaux des états. In: Recueil des Cours. Academie de Droit International de la Haye, Volume 10, 1925-V, pp. 537-597.

GIRAUD, Emile. Le droit international public et la politique. In: Recueil des Cours. Academie de Droit International de la Haye, Volume 110, 1963-III, pp. 419-809.

GOLDSMITH, Jack; POSNER, Eric. The limits of international law. New York: Oxford University Press, 2005.

GOODHART, A.L.. The North Atlantic treaty of 1949. In: Recueil des Cours. Academie de Droit International de la Haye, Volume 79, 1951-II, pp. 183-236.

GROSS, Leo. The International Court of Justice and the United Nations. In: Recueil des Cours. Academie de Droit International de la Haye, Volume 120, 1967-I, pp. 313-440.

GUGGENHEIM, Paul. Les mesures conservatoires dans la procédure arbitrale et judiciaire. In: Recueil des Cours. Academie de Droit International de la Haye, Volume 40, 1932-II, pp. 645-764.

GUGGENHEIM, Paul. Les principes de droit international public. In: Recueil des Cours. Academie de Droit International de la Haye, Volume 80, 1952-I, pp. 01-189.

GUGGENHEIM, Paul. Contribution à l'histoire des sources du droit des gens. In: Recueil des Cours. Academie de Droit International de la Haye, Volume 94, 1958-II, pp. 01-84.

HAHN, Hugo J.. Constitutional limitations in the law of the European organisations. In: Recueil des Cours. Academie de Droit International de la Haye, Volume 108, 1963-I, pp. 189306.

HAMBRO, Edvard. The jurisdiction of the International Court of justice. In: Recueil des Cours. Academie de Droit International de la Haye, Volume 76, 1950-I, pp. 121-215.

HART, H.L.A. The concept of law. Oxford: Clarendon Press, 1961. 
HEILBORN, Paul. Les sources du droit international. In: Recueil des Cours. Academie de Droit International de la Haye, Volume 11, 1926-I, pp. 01-63.

HENKIN, Louis. International law and the behavior of nations. In: Recueil des Cours. Academie de Droit International de la Haye, Volume 114, 1965-I, pp. 167-281.

HENKIN, Louis. International law : politics, values and functions : general course on public international law. In: Recueil des Cours. Academie de Droit International de la Haye, Volume 216, 1989-IV, pp. 09-416.

HIGGINS, Rosalyn. Problems and process: international law and how we use it. Oxford: Clarendon Press, 1994.

HOBBES, Thomas. Leviathan. Cambridge: hackett Publishing Company, 1994.

INTERNATIONAL LAW COMMISSION. Report of the Study Group of the International Law Comission. UN Doc A/CN.4/L.682. 2006.

JELLINEK, Georg. Das Recht des modernen Staates. Berlin: Verlag von O. Häring, 1900.

JENKS, C.Wilfred. Co-ordination : a new problem of international organization : a preliminary survey of the law and practice of inter-organizational relationships. In: Recueil des Cours. Academie de Droit International de la Haye, Volume 77, 1950-II, pp. 151-303.

JENNINGS, R.Y.. General course on principles of international law. In: Recueil des Cours. Academie de Droit International de la Haye, Volume 121, 1967-II, pp. 323-605.

JIMENEZ DE ARECHAGA, Eduardo. Le traitement des différends internationaux par le Conseil de Sécurité. In: Recueil des Cours. Academie de Droit International de la Haye, Volume 85, 1954-I, pp. 01-105.

KAECKENBEECK, Georges. La Charte de San-Francisco dans ses rapports avec le droit international. In: Recueil des Cours. Academie de Droit International de la Haye, Volume 70, 1947-I, pp. 109-330.

KELSEN, Hans. Les rapports de système entre le droit interne et le droit international public. In: Recueil des Cours. Academie de Droit International de la Haye, Volume 14, 1926-IV, pp. 227-331.

KELSEN, Hans. Théorie générale du droit international public : problèmes choisis. In: Recueil des Cours. Academie de Droit International de la Haye, Volume 42, 1932-IV, pp. 117-351.

KELSEN, Hans. Reine Rechtslehre - Einleitung in die rechtswissenschaftliche Problematik. Leipzig und Wien: Franz Deuticke, 1934.

KELSEN, Hans. Théorie du droit international public. In: Recueil des Cours. Academie de Droit International de la Haye, Volume 110, 1953-III, pp. 01-203. 
KLEFFENS, Eelco Nicolaas van. Sovereignty in international law : five lectures. In: Recueil des Cours. Academie de Droit International de la Haye, Volume 82, 1953-I, pp. 01-131.

KOROWICZ, Marek Stanislaw. Some present aspects of sovereignty in international law. In: Recueil des Cours. Academie de Droit International de la Haye, Volume 102, 1961-I, pp. 01120.

KOSKENNIEMI, Martti. Global governance and public international Law. In: Kritische Justitz, 37, 2004.

KOSKENNIEMI, Martti. From apology to utopia: the structure of international legal argument. Nova Iorque: Cambridge University Press, 2005.

KOSKENNIEMI, Martti. Global legal pluralism: multiple regimes and multiple modes of thought. Harvard, 05 de março de 2005 - Palestra.

KOSKENNIEMI, Martti. The fate of public international law: constitutional utopia or fragmentation? Chorley Lecture: London School of Economics, 2006.

KRABBE, H.. L'idée moderne de l'état. In: Recueil des Cours. Academie de Droit International de la Haye, Volume 13, 1926-III, pp. 509-583.

KUNZ, Josef L.. La crise et les transformations du droit des gens. In: Recueil des Cours. Academie de Droit International de la Haye, Volume 88, 1955-II, pp. 01-104.

LACHS, Manfred. Le développement et les fonctions des traités multilatéraux. In: Recueil des Cours. Academie de Droit International de la Haye, Volume 92, 1957-II, pp. 229-341.

LACHS, Manfred. The development and general trends of international law in our time. In: Recueil des Cours. Academie de Droit International de la Haye, Volume 169, 1980-IV, pp. 09-377.

LAUTERPACHT, H. La théorie des différends non justiciables en droit international. In: Recueil des Cours. Academie de Droit International de la Haye, Volume 34, 1930-IV, pp. 493-654.

LAUTERPACHT, E.. The development of the law of international organization by the decisions of international tribunals. In: Recueil des Cours. Academie de Droit International de la Haye, Volume 152, 1976-IV, pp. 377-478.

LE FUR, Louis. La théorie du droit naturel depuis le XVIIe siècle et la doctrine moderne. In: Recueil des Cours. Academie de Droit International de la Haye, Volume 18, 1927-III, pp. 259-442.

LIANG, Yuen-Li. Le développement et la codification du droit international. In: Recueil des Cours. Academie de Droit International de la Haye, Volume 73, 1948-II, pp. 407-532.

LIMBURG, J.. L'autorité de chose jugée des décisions des juridictions internationales. In: Recueil des Cours. Academie de Droit International de la Haye, Volume 30, 1929-V, pp. 519618. 
LISSITZYN, Oliver J.. Territorial entities other than independent states in the law of treaties. In: Recueil des Cours. Academie de Droit International de la Haye, Volume 125, 1968-III, pp. 01-92.

LOCKE, John. Two treatises of government. London: Guernsey Press, 1986.

MANN, F.A.P.. The doctrine of jurisdiction in international law. In: Recueil des Cours. Academie de Droit International de la Haye, Volume 111, 1964, pp. 01-162.

MAQUIAVEL, Nicolau. O príncipe. Rio: Paz e Terra, 1996.

MARYAN GREEN, N.A. International law: law of peace. London: Macdonald and Evans, 1982.

MAYER, Pierre. L'autonomie de l'arbitre international dans l'appréciation de sa propre compétence. In: Recueil des Cours. Academie de Droit International de la Haye, Volume 217, 1989-V, pp. 319-454.

MCDOUGAL, Myres S.. International law, power, and policy: a contemporary conception. In: Recueil des Cours. Academie de Droit International de la Haye, Volume 82, 1953-I, pp. 133-259.

MELLO, Celso Duvivier de Albuquerque. Curso de direito internacional público - v 1. Rio: Renovar, 1994.

MENEZES, Wagner. Direito internacional: legislação \& textos básicos. Curitiba: Juruá, 2003

MENEZES, Wagner. Tribunais internacionais: jurisdição e competência. São Paulo: Saraiva, 2013.

MERON, Theodor. International law in the age of human rights: general course on public international law. In: Recueil des Cours. Academie de Droit International de la Haye, Volume 301, 2003, pp. 09-489.

MIRKINE-GUETZEVITCH, B.. Droit international et droit constitutionnel. In: Recueil des Cours. Academie de Droit International de la Haye, Volume 38, 1931-IV, pp. 307-465.

MIRKINE-GUETZEVITCH, Boris. Le droit constitutionnel et l'organisation de la paix (droit constitutionnel de la paix). In: Recueil des Cours. Academie de Droit International de la Haye, Volume 45, 1933-III, pp. 667-773.

MONACO, Riccardo. Cours général de droit international public. In: Recueil des Cours. Academie de Droit International de la Haye, Volume 125, 1968-III, pp. 93-336.

MONACO, Riccardo. Les principes régissant la structure et le fonctionnement des organisations internationales In: Recueil des Cours. Academie de Droit International de la Haye, Volume 156, 1977-III, pp. 79-226.

MONTESQUIEU, Charles de Secondat Baron de. De l'esprit des lois - Vol 1. Paris: GarnierFlammarion, 1979. 
MONTESQUIEU, Charles de Secondat Baron de. De l'esprit des lois - Vol 2. Paris: GarnierFlammarion, 1979.

MOREAU-REIBEL, Jean. Le droit de société interhumaine et le 'jus gentium' : essai sur les origines et le développement des notions jusqu'à Grotius. In: Recueil des Cours. Academie de Droit International de la Haye, Volume 77, 1950-II, pp. 481-597.

MORELLI, Gaetano. Cours général de droit international public. In: Recueil des Cours. Academie de Droit International de la Haye, Volume 89, 1956-I, pp. 437-604.

NEGRO, Sandra C. (Coord.). Lecturas sobre integración regional y comercio internacional. Buenos Aires: La Ley, 2012.

NEGRO, Sandra. Derecho de la integración. Buenos Aires: BDEF, 2013.

OLIVER, Covey T.. Historical development of international law : contemporary problems of treaty law. In: Recueil des Cours. Academie de Droit International de la Haye, Volume 88, 1955-II, pp. 417-508.

OREJA AGUIRRE, Marcelino. La révision institutionnelle de l'Union européenne. In: Recueil des Cours. Academie de Droit International de la Haye, Volume 267, 1997, pp. 345386.

PANHUYS, H.F. van. Relations and interactions between international and national scenes of law. In: Recueil des Cours. Academie de Droit International de la Haye, Volume 112, 1964-II, pp. 01-89.

PASTOR RIDRUEJO, José Antonio. Le droit international à la veille du vingt et unième siècle : normes, faits et valeurs : cours général de droit international public. In: Recueil des Cours. Academie de Droit International de la Haye, Volume 274, 1998, pp. 09-308.

PESCATORE, Pierre. Les relations extérieures des communautés européennes : contribution à la doctrine de la personnalité des organisations internationales. In: Recueil des Cours. Academie de Droit International de la Haye, Volume 103, 1961-II, pp. 01-244.

PILOTTI, Massimo. Les unions d'états. In: Recueil des Cours. Academie de Droit International de la Haye, Volume 24, 1928-IV, pp. 441-546.

PODESTÁ COSTA, L.A. Derecho internacional público - tomo I. Buenos Aires, Tipográfica Editora Argentina, 1955.

PODESTÁ COSTA, L.A. Derecho internacional público - tomo II. Buenos Aires, Tipográfica Editora Argentina, 1955.

QUADRI, Rolando. Le fondement du caractère obligatoire du droit international public. In: Recueil des Cours. Academie de Droit International de la Haye, Volume 80, 1952-I, pp. 579633.

QUADRI, Rolando. Cours général de droit international public. In: Recueil des Cours. Academie de Droit International de la Haye, Volume 113, 1964-III, pp. 237-483. 
RAWLS, John. A theory of justice. Cambridge: Harvard University Press, 1971.

REUTER, Paul. Principes de droit international public. In: Recueil des Cours. Academie de Droit International de la Haye, Volume 103, 1961-II, pp. 425-656.

RIVAROLA PAOLI, Juan Bautista. Derecho internacional público. Asunción: Ediciones y Arte, 2013.

ROBERTSON, Arthur Henry. Legal problems of European integration. In: Recueil des Cours. Academie de Droit International de la Haye, Volume 91, 1957-I, pp. 105-211.

ROLIN, Henri. Les principes de droit international public. In: Recueil des Cours. Academie de Droit International de la Haye, Volume 77, 1950-II, pp. 305-479.

ROSENNE, Shabtai. The perplexities of modern international law: general course on public international law. In: Recueil des Cours. Academie de Droit International de la Haye, Volume 291, 2001, pp. 09-471.

ROUSSEAU, Charles. L'indépendance de l'Etat dans l'ordre international. In: Recueil des Cours. Academie de Droit International de la Haye, Volume 73, 1948-II, pp. 167-253.

ROUSSEAU, Charles. Principes de droit international public. In: Recueil des Cours. Academie de Droit International de la Haye, Volume 93, 1958-I, pp. 369-550.

ROUSSEAU, Jean-jacques. Du contrat social. Paris: Union Générale d'Éditions, 1973.

RUNDSTEIN, Simon. La Cour permanente de justice internationale comme instance de recours. In: Recueil des Cours. Academie de Droit International de la Haye, Volume 43, 1933-I, pp. 01-113.

SABA, Hanna. Les accords régionaux dans la Charte de l'O.N.U. In: Recueil des Cours. Academie de Droit International de la Haye, Volume 80, 1952-I, pp. 635-720.

SALEM CAGGIANO, Monica Herman. Oposição na política. São Paulo: Angelotti, 1995

SALVIOLI, Gabariele. La règle de droit international. In: Recueil des Cours. Academie de Droit International de la Haye, Volume 73, 1948-II, pp. 369-405.

SANTOS, Boaventura de Souza. Uma concepção multicultural de direitos humanos. In: Lua Nova: Revista de Cultura e Política 39, 1997, pp. 105-124.

SCELLE, Georges. Théorie et pratique de la fonction exécutive en droit international. In: Recueil des Cours. Academie de Droit International de la Haye, Volume 55, 1936-I, pp. 87202.

SCHEUNER, Ulrich. L'influence du droit interne sur la formation du droit international. In: Recueil des Cours. Academie de Droit International de la Haye, Volume 68, 1939-II, pp. 95206. 
SCHINDLER, Diètrich. Les progrès de l'arbitrage obligatoire depuis la création de la Société des Nations. In: Recueil des Cours. Academie de Droit International de la Haye, Volume 25, 1928-V, pp. 233-364.

SCHWARZENBERGER, Georg. The fundamental principles of international law. In: Recueil des Cours. Academie de Droit International de la Haye, Volume 87, 1955-I, pp. 191-385.

SEFERIADES, Stelio. Le problème de l'accès des particuliers à des juridictions internationales. In: Recueil des Cours. Academie de Droit International de la Haye, Volume 51, 1935-I, pp. 01-120.

SEYERSTED, Finn. Applicable law in relations between intergovernmental organizations and private parties. In: Recueil des Cours. Academie de Droit International de la Haye, Volume 122, 1967-III, pp. 427-616.

SIMMA, Bruno. From bilateralism to community interest in international law. In: Recueil des Cours. Academie de Droit International de la Haye, Volume 250, 1994-VI, pp. 217-384.

SIOTTO PINTOR, Manfredi. Les sujets du droit international autres que les états. In: Recueil des Cours. Academie de Droit International de la Haye, Volume 41, 1932-III, pp. 245-361.

SLAUGHTER, Anne-Marie. International law and international relations. In: Recueil des Cours. Academie de Droit International de la Haye, Volume 285, 2000, pp. 09-249.

SOHN, Louis B.. The function of international arbitration today. In: Recueil des Cours. Academie de Droit International de la Haye, Volume 108, 1963-I, pp. 01-113.

SOHN, Louis B.. Settlement of disputes relating to the interpretation and application of treaties. In: Recueil des Cours. Academie de Droit International de la Haye, Volume 150, 1976-II, pp. 195-294.

SØRENSEN, Max. Principes de droit international public : cours général. In: Recueil des Cours. Academie de Droit International de la Haye, Volume 101, 1960-III, pp. 01-254.

SPERDUTI, Giuseppe. Le principe de souveraineté et le problème des rapports entre le droit international et le droit interne. In: Recueil des Cours. Academie de Droit International de la Haye, Volume 153, 1976-V, pp. 319-411.

SPIROPOULOS, J.. L'individu et le droit international. In: Recueil des Cours. Academie de Droit International de la Haye, Volume 30, 1929-V, pp. 191-270.

TAUBE, Michel de. Les origines de l'arbitrage international : antiquité et Moyen Age. In: Recueil des Cours. Academie de Droit International de la Haye, Volume 42, 1932-IV, pp. 01115 .

TEITGEN, Pierre-Henri. La décision dans la Communauté économique européenne. In: Recueil des Cours. Academie de Droit International de la Haye, Volume 134, 1971-III, pp. 589-689. 
TENEKIDES, Georges. Régimes internes et organisation internationale. In: Recueil des Cours. Academie de Droit International de la Haye, Volume 110, 1963-III, pp. 271-418.

THIERRY, Hubert. L'évolution du droit international : cours général de droit international public. In: Recueil des Cours. Academie de Droit International de la Haye, Volume 222, 1990-III, pp. 09-186.

THIRLWAY, Hugh. Concepts, principles, rules and analogies: international and municipal legal reasoning. In: Recueil des Cours. Academie de Droit International de la Haye, tomo 294, 2002, pp. 265-405.

TIBURCIO, Carmen; BARROSO, Luís Roberto. Direito constitucional internacional. Rio: Renovar, 2013.

TRINDADE, Antônio Augusto Cançado. International law for humankind : towards a new jus gentium (I): general course on public international law. In: Recueil des Cours. Academie de Droit International de la Haye, Volume 316, 2005, pp. 09-439.

TRUYOL Y SERRA, Antonio. Genèse et structure de la société internationale. In: Recueil des Cours. Academie de Droit International de la Haye, Volume 96, 1959-I, pp. 553-642.

TRUYOL Y SERRA, Antonio. Théorie du droit international public : cours général. In: Recueil des Cours. Academie de Droit International de la Haye, Volume 173, 1981-IV, pp. 09-443.

TUNKIN, Grigory. International law in the international system. In: Recueil des Cours. Academie de Droit International de la Haye, Volume 147, 1975-IV, pp. 01-218.

TUNKIN, Grigory. Politics, law and force in the interstate system. In: Recueil des Cours. Academie de Droit International de la Haye, Volume 219, 1989-VII, pp. 227-395.

VALLAT, Francis Aimé. The competence of the United Nations General Assembly. In: Recueil des Cours. Academie de Droit International de la Haye, Volume 97, 1959-II9I, pp. 203-292.

VASCONCELOS, Raphael Carvalho. O sistema de solução de controvérsias do MERCOSUL. Ética e Filosofia Política, v. jur., p. 01-30, 2009.

VELASCO, Manuel Diez de. Instituciones de derecho internacional público - Tomo I. Madrid: Editorial Tecnos, 1978.

VELASCO, Manuel Diez de. Instituciones de derecho internacional público - Tomo II. Madrid: Editorial Tecnos, 1977.

VERDROSS, Alfred. Le fondement du droit international. In: Recueil des Cours. Academie de Droit International de la Haye, Volume 16, 1927-I, pp. 247-323.

VERDROSS, Alfred von. Les principes généraux du droit dans la jurisprudence internationale. In: Recueil des Cours. Academie de Droit International de la Haye, Volume 52, 1935-II, pp. 191-251. 
VILLANI, Ugo. Les rapports entre l'ONU et les organisations régionales dans le domaine du maintien de la paix. In: Recueil des Cours. Academie de Droit International de la Haye, Volume 290, 2001, pp. 225-436.

VIRALLY, Michel. Panorama du droit international contemporain : cours général de droit international public. In: Recueil des Cours. Academie de Droit International de la Haye, Volume 183, 1983-V, pp. 09-382.

VISSCHER, Paul De. Les tendances internationales des constitutions modernes. In: Recueil des Cours. Academie de Droit International de la Haye, Volume 80, 1952-I, pp. 511-578.

VISSCHER, Charles de. Cours général de principes de droit international public. In: Recueil des Cours. Academie de Droit International de la Haye, Volume 86, 1954-II, pp. 445-556.

WALDOCK, Humphrey. General course on public international law. In: Recueil des Cours. Academie de Droit International de la Haye, Volume 106, 1962-II, pp. 01-251.

WALSH, Edmund A.. Les principes fondamentaux de la vie internationale. In: Recueil des Cours. Academie de Droit International de la Haye, Volume 53, 1935-III, pp. 97-175.

WALZER, Michael. Thick and thin, moral argument at home and abroad. Notre Dame: undp, 1994.

WEBER, Max. Politik als Beruf. Stuttgart: Reclam, 2008.

WEIL, Prosper. Le droit international en quete de son identité : cours général de droit international public. In: Recueil des Cours. Academie de Droit International de la Haye, Volume 237, 1992-VI, pp. 09-370.

WHITTON, John B.. La règle 'Pacta sunt servanda'. In: Recueil des Cours. Academie de Droit International de la Haye, Volume 49, 1934-III, pp. 147-276.

WOLFF, Karl. Les principes généraux du droit applicables dans les rapports internationaux. In: Recueil des Cours. Academie de Droit International de la Haye, Volume 36, 1931-II, pp. 479-553.

WRIGHT, Quincy. The strengthening of international law. In: Recueil des Cours. Academie de Droit International de la Haye, Volume 98, 1959-III, pp. 01-295.

YEPES, J.-M.. La contribution de l'Amérique latine au développement du droit international public et privé. In: Recueil des Cours. Academie de Droit International de la Haye, Volume 32, 1930-II, pp. 691-799.

YEPES, J.M.. Les accords régionaux et le droit international. In: Recueil des Cours. Academie de Droit International de la Haye, Volume 71, 1947-II, pp. 227-344.

ZEMANEK, Karl. The legal foundations of the international system : general course on public international law. In: Recueil des Cours. Academie de Droit International de la Haye, Volume 266, 1997, pp. 09-335. 
ZICCARDI, Piero. Les caractères de l'ordre juridique international. In: Recueil des Cours. Academie de Droit International de la Haye, Volume 95, 1958-III, pp. 263-407.

ZOLLER, Elisabeth. Aspects internationaux du droit constitutionnel: contribution à la théorie de la fédération d'Etats. In: Recueil des Cours. Academie de Droit International de la Haye, Volume 294, 2002, pp. 39-166. 